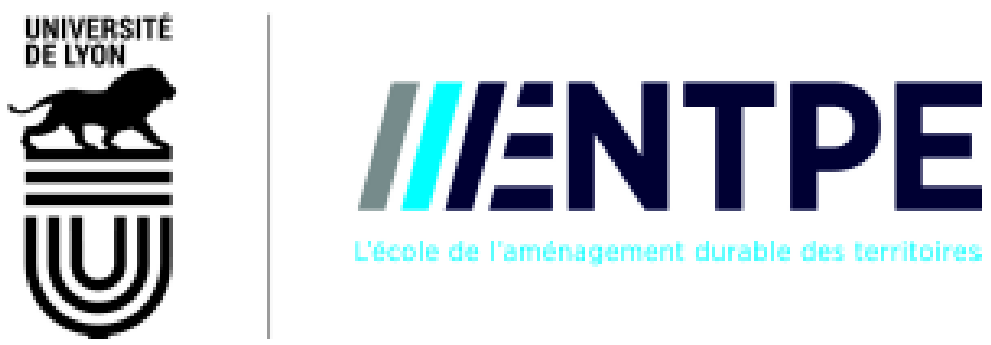

Nd'ordre NNT : 2018LYSET008

THESE de DOCTORAT DE L'UNIVERSITE DE LYON opérée au sein de

I'Ecole Nationale des Travaux Publics de I'Etat

Ecole Doctorale $N^{\circ}$ accréditation 162

MEGA (Mécanique, Energétique, Génie Civil, Acoustique)

Spécialité / discipline de doctorat : ENERGETIQUE

Soutenue publiquement le 05/11/2018, par :

José Carlos Frutos Dordelly

\title{
Active Solar Chimney (ASC): Numerical and experimental study of energy storage and evaporative cooling
}

Devant le jury composé de :

\begin{tabular}{|c|c|}
\hline Draoui, Abdeslam & Professeur \\
\hline Del Pero, Claudio & Professeur \\
\hline Salem, Talal & A.Professeur \\
\hline $\begin{array}{l}\text { Giroux-Julien, } \\
\text { Stéphanie }\end{array}$ & A.Professeur \\
\hline Roué, Magali & Docteur \\
\hline
\end{tabular}

Arce Landa, Jesus

Enriquez Miranda, Ricardo

El Mankibi, Mohamed

Professeur

Directeur de
Université Abdelmalek Essaadi

(UAE), Maroc

Politecnico di Milano (POLIMI), Italie

Notre Dame University (NDU), Liban

Faculté des sciences et

technologies, département de mécanique Villeurbanne (Lyon 1) Institut National de I'Energie Solaire

(INES)

Centro Nacional de Investigación y

Desarrollo Tecnológico (CENIDET), Mexique

Centro de Investigaciones

Energéticas, Medioambientales y Tecnológicas (CIEMAT), Espagne Recherche
Président du Jury

Rapporteur

Examinateur

Examinatrice Examinatrice Examinateur Tuteur

Directeur de Thèse 
Cheminée Solaire Active (CSA):

Étude numérique et expérimentale du stockage énergétique et du refroidissement par évaporation 


\section{Introduction - Motivation \& contexte}

L'année 1997 a marqué le début de la coopération internationale pour la lutte contre le réchauffement climatique à partir de la mise en place du protocole de Kyoto. Avant cet accord, les états concernés étaient responsables d'éviter des changements climatiques irréversibles, mais aucune action spécifique n'avait été déterminée. Le protocole de Kyoto, premier accord juridiquement contraignant et ambitieux, fixait les objectifs fondamentaux de maintenir les hausses de températures moyennes mondiales en dessous de $2{ }^{\circ} \mathrm{C}$ par rapport aux niveaux pré-industriels et de guider la communauté mondiale sur la voie du développement durable. Depuis, il a été soumis à des modifications et à l'ajout d'autres parties. La Conférence des Parties des Nations Unies (COP21), tenue en 2015 à Paris, a vu le règlement sans précédent de 195 pays en faveur du développement durable; promouvoir l'égalité entre les parties et encourager le soutien aux pays en développement.

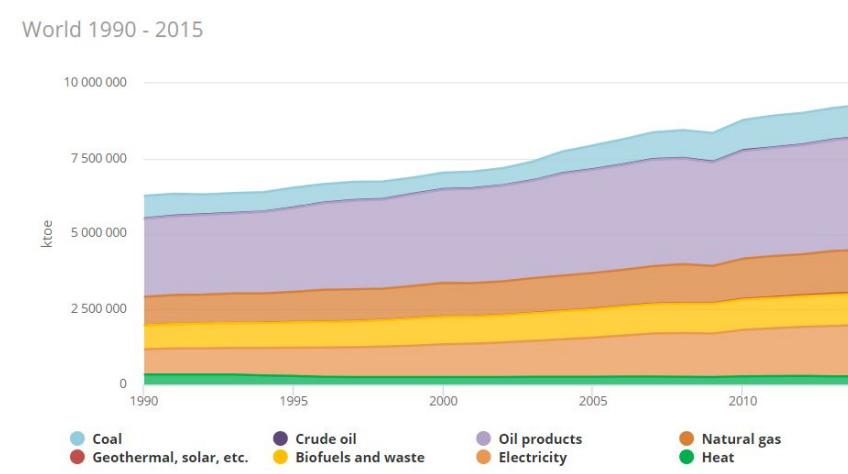

(a)

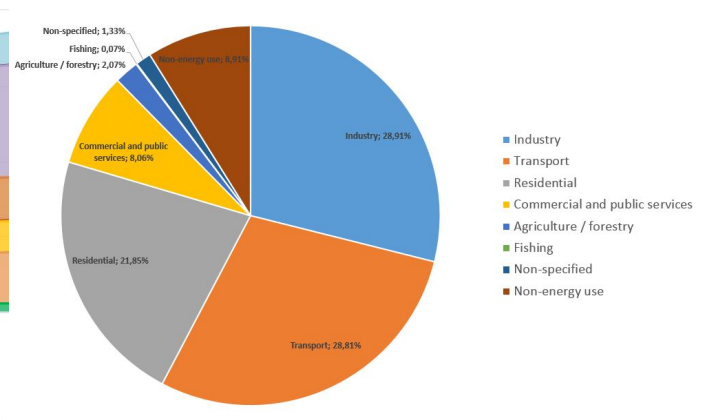

(b)

Figure 1: Consommation mondiale finale (CFT) totale par (a) source en ktoe et par (b) secteur. Source: IEA, Bilans énergétiques des pays de l'OCDE 2017, disponible sur: www.iea.org/statistics.

En raison de l'augmentation des préoccupations environnementales, la recherche prend de plus en plus en compte l'efficacité énergétique. L'Agence Européenne pour l'Environnement (AEE), le ministère français de l'Environnement, de l'Énergie et de la Mer, ainsi que le Secrétariat Mexicain à l'Énergie (SENER) reconnaissent les 
problèmes environnementaux actuels liés aux différents secteurs ainsi que la grande consommation énergétique et l'urgence d'encourager les institutions publiques et privées à agir sur le problème à partir du développement des solutions alternatives dans les différents domaines d'études. Ces agences considèrent l'industrie, les transports, le bâtiment, les services et l'agriculture comme les cinq principaux secteurs de consommation énergétique. La tendance globale (Figure 1) ainsi que les statistiques individuelles françaises, mexicaines et espagnoles (présentées ci-dessous) montrent que le secteur résidentiel est le troisième consommateur final d'énergie en importance après l'industrie et les transports.

Les cheminées solaires ont été conçues dans le but principal de réguler la sensation thermique d'un volume intérieur. Les éléments de construction tels que la cheminée solaire doivent respecter un certain nombre de réglementations en matière de santé et de sécurité, ainsi que d'être abordables sur le plan énergétique et économique. De plus, dans l'intérêt de réduire le réchauffement climatique d'environ $4,5{ }^{\circ} \mathrm{C}$ (d'ici 2100) à moins de $2,7{ }^{\circ} \mathrm{C}$ et de réduire les émissions de gaz à effet de serre de $9 \%$ par habitant d'ici à 2030 (UNFCCC, 2015), les cheminées solaires doivent prouver leur valeur potentielle par rapport à d'autres systèmes de ventilation passive plus réputés.

D’un point de vue technologique, les cheminées solaires ne représentent pas un élément structurel complexe, mais la configuration optimale dépend fortement de l'environnement. D'un point de vue scientifique, l'expertise de l'inertie thermique et le débit massique qui en résulte constituent encore des obstacles à relever. De la même manière, les Matériaux à Changement de Phase (MCPs) représentent une solution viable par rapport à d'autres options telles que le stockage thermique sensible. En revanche, l'incorporation aux composants de construction constitue un domaine relativement nouveau qui doit être étudié plus en profondeur selon différents scénarios.

Au niveau expérimental, les MCPs n'ont pas été caractérisés dans une cheminée solaire dans des conditions environnementales réelles. Les résultats de laboratoire, 
même s'ils sont prometteurs, ne représentent pas le phénomène global. Les cheminées solaires ont été utilisées en tant que systèmes couplés à d'autres éléments de ventilation. Cependant, la recherche du Bâtiments à Zéro Énergie (BZE) nécessite le développement et l'optimisation continue des systèmes. Enfin, les MCP représentent un investissement supplémentaire par rapport au prix de la construction. Afin que ce type de technologie soit viable, elle doit donner de meilleurs résultats que les matériaux de construction courants et/ou en simplifier la conception.

\section{I.1 Objectif de la thèse}

Afin de démontrer l'impact d'une cheminée solaire au regard des objectifs fixés dans les accords de Paris et Horizon 2020, le projet vise à améliorer les performances actuelles de la cheminée solaire classique. L'objectif est de réaliser l'activation de cette technologie pour une utilisation prolongée; en particulier, mais sans s'y limiter, après le coucher du soleil. Cet objectif doit être atteint en intégrant des composants passifs et actifs, l'appelant ainsi Cheminée Solaire Active (CSA). Pour ce faire, trois facteurs principaux doivent être pris en compte: la circulation de l'air, la conception et le stockage d'énergie.

La circulation de l'air concerne l'amélioration de la ventilation. Une ventilation optimisée se traduit par un débit d'air plus élevé, permettant ainsi une température stable. Les designs actuels conviennent principalement aux climats chauds. L'objectif de ce projet est la mise en œuvre de différentes technologies pour la capitalisation après le coucher du soleil et potentiellement, tout au long de l'année. Finalement, les cheminées solaires actuelles sont peu performantes par rapport à d'autres technologies vertes; surtout après le coucher du soleil. L'objectif de ce projet est d'intégrer des solutions de stockage d'énergie pour augmenter les performances du système en l'absence d'une source de chaleur. Ces travaux se servent des capacités de stockage d'énergie des MCP paraffiniques. 


\section{I.2 Démarche de la thèse}

L'approche scientifique utilisée tout au long de cette thèse peut être observée à la figure 2. Il explique la méthodologie suivie pour atteindre les objectifs susmentionnés. Le projet est divisé en deux étapes principales:

\section{Numérique:}

(a) Modélisation modèle réduit.

(b) Couplage et intégration à d'autres modèles de construction.

(c) Caractérisation: définition des paramètres et mesure de l'efficacité du système.

(d) Contrôle et optimisation du système.

\section{Expérimental:}

(a) Boîte Chaude Gardée (BCG): expérimentation en laboratoire d'un prototype de laboratoire innovant et original.

(b) Expérimentation in situ (Almeria, Espagne).

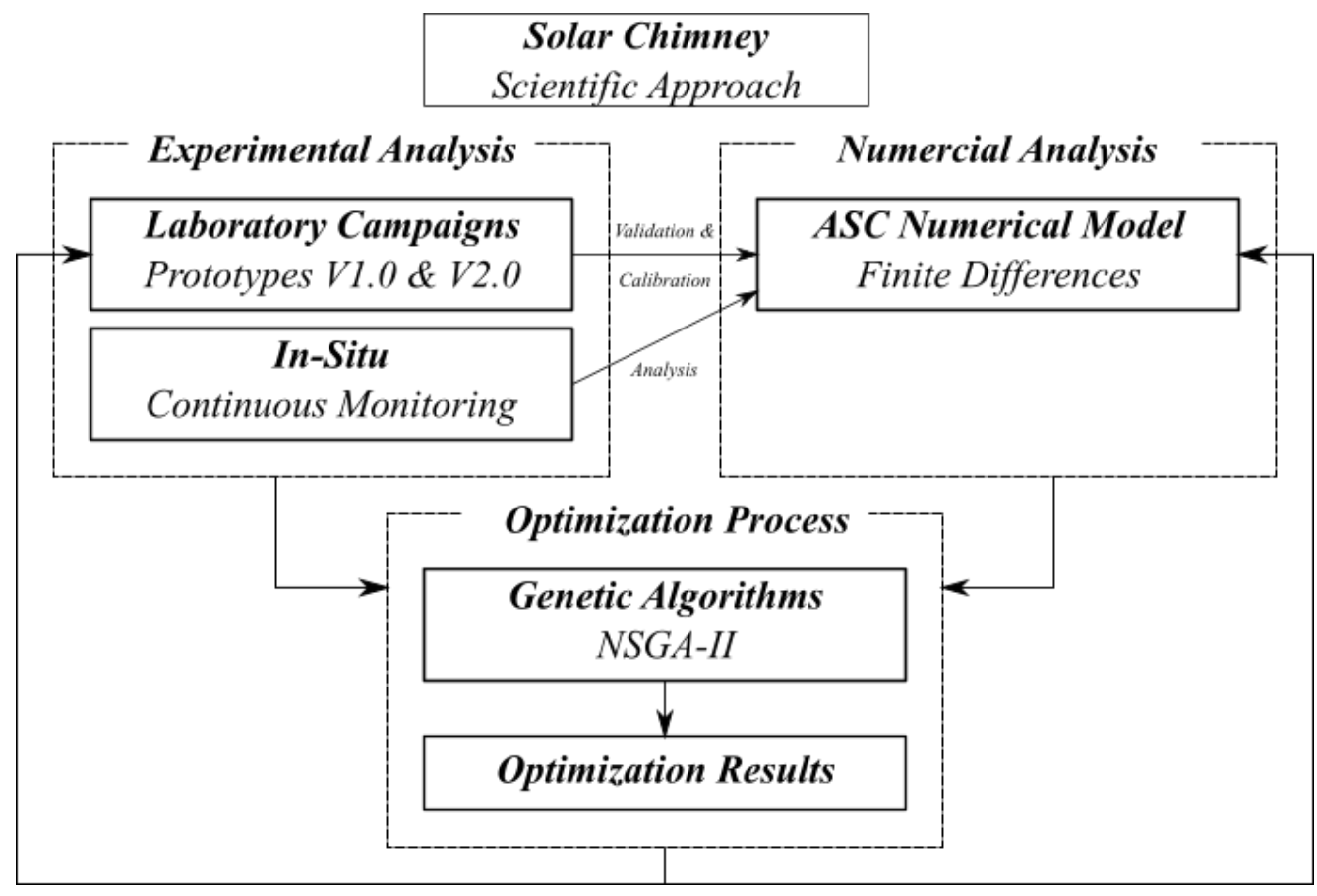

Figure 2: Approche scientifique utilisée lors de cette thèse. 


\section{Approche expérimentale}

Dans l'intérêt d'analyser, de valider et de calibrer le modèle numérique présenté par la suite; deux prototypes de cheminée ont été développés en laboratoire et une modification in situ a été effectuée. Bien que certaines configurations de cheminée ont montré une augmentation des performances de ventilation (par exemple: cheminée inclinée, double canal, etc), les prototypes développés au laboratoire de l'ENTPE sont basés sur les travaux de Arce et al. (2015); Arce, Jiménez, Guzmán, Heras, Alvarez and Xamán (2009); Arce et al. (2011); Arce, Xaman, Alvarez, Jiménez and Heras (2009); Arce et al. (2013). Les angles d'inclinaison et les combinaisons avec d'autres technologies passives ne sont pas abordés dans ce travail afin de comparer les résultats avec la cheminée solaire in situ. L'approche expérimental est organisé en trois sections principales:

1. L'étude préliminaire d'un panel MCP unique par la caractérisation du comportement de la cire de paraffine RT44 lorsqu'elle est soumise aux conditions expérimentales utilisées lors du montage expérimental en laboratoire. De plus, une brève explication du test DSC (calorimétrie différentielle à balayage) utilisé pour obtenir les caractéristiques thermiques de ce MCP est donnée dans cette sous-section.

2. L'expérimentation en laboratoire réalisée à l'ENTPE pour la caractérisation d'une cheminée solaire dans un environnement contrôlé. Deux prototypes de laboratoire ont été développés pour trois objectifs différents: premièrement, l'analyse de l'impact des panneaux de MCP sur le débit massique d'une cheminée solaire, l'évaluation de la répartition de la température sur toute la hauteur de la cheminée et enfin l'étude comparative avec le résultats in situ

3. Enfin, l'expérimentation in situ à Tabernas, en Espagne. La cheminée solaire autonome évoquée tout au long de cette section a été modifiée afin d'analyser le comportement de cette technologie dans des conditions environnementales réelles. 


\section{II.1 Choix du MCP}

Afin d'analyser les effets des MCP dans une technologie de ventilation passive telle que la cheminée solaire, une sélection des MCP optimaux a due être effectuée. Le choix du MCP était basé sur trois facteurs principaux. La disponibilité et le prix sur le marché sont primordiales. En fonction de la plage de température et du type de MCP, le prix du produit peut varier considérablement. Afin de faire d'une cheminée solaire une alternative viable, la sélection du MCP doit maintenir un prix relativement bas (par rapport aux autres MCP) et elle doit être d'un accès simple au grand public. De la même manière, la plage de température de stockage/déstockage est un élément à considérer. La ventilation dans les cheminées solaires est entraînée par la différence de température entre la température externe et la température à l'intérieur du conduit de la cheminée. La plage de température de fonctionnement du MCP doit maximiser le temps pendant lequel la cheminée est à une température élevée pour assurer la ventilation. La plage de température de 40 à $44{ }^{\circ} \mathrm{C}$ a été choisie sur la base des données disponibles de la cheminée solaire de la PSA (Plateforme Solaire d'Almeria) en Espagne, et du travail présenté par Liu and Li (2015). Finalement, les solutions d'encapsulation sont primordiales. Les cheminées solaires présentées tout au long de cette thèse considèrent une couche de MCP. Toutefois, d'un point de vue expérimental, la couche de MCP doit tenir compte des règles de sécurité, d'un conteneur léger et durable et enfin, en raison de l'incapacité de modifier l'architecture de la cheminée existante à Almeria, elle doit représenter une solution simple et adaptable.

\section{II.2 Protocole expérimental}

Afin de définir les performances d'une cheminée solaire avec et sans panneaux MCP, un protocole expérimental a été établi. Ce protocole a trois objectifs principaux:

1. Démontrer la différence entre la cheminée solaire actuelle et la cheminée solaire intégrée avec des panneaux MCP, dans des conditions de laboratoire.

2. Démontrer les capacités des MCPs pour prolonger l'utilisation d'une cheminée 
solaire en l'absence de source de chaleur.

3. La validation du modèle numérique présenté par la suite.

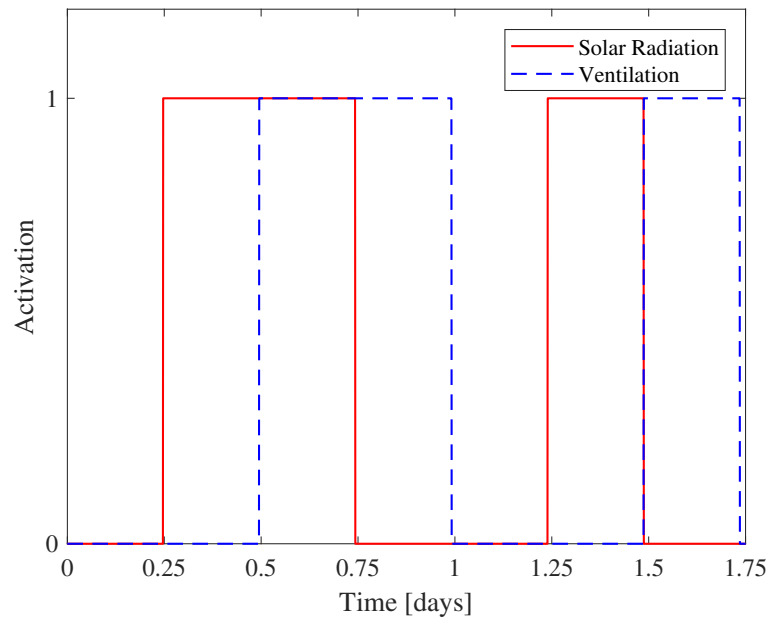

Figure 3: Protocole expérimental utilisé pour les deux prototypes montrant l'activation de la ventilation (sortie ouverte/fermée) en bleu et l'apport solaire (lampes halogènes allumées/éteintes) en rouge.

La Figure 3 ci-dessus montre le protocole utilisé pour l'expérimentation. Il est composé de sept phases consécutives de 6 heures chacune (0,25 jour), complétant un cycle d'environ 1,75 jour. Les phases dépendent de l'état de la sortie (ouvert/fermé), permettant ainsi le flux d'air pour la ventilation naturelle et l'échauffement fourni par les lampes halogènes (allumées/éteintes). Celles-ci simulent le rayonnement solaire. Les lampes sont uniformément réparties devant la surface vitrée tout au long de la hauteur de la cheminée et représentent un flux de chaleur maximal d'approximativement $600 \mathrm{~W} / \mathrm{m}^{2}$ au cours des phases de charge. Ce protocole a été utilisé pour les deux campagnes expérimentales.

\section{II.3 Première campagne expérimentale en laboratoire}

Le prototype V1.0 a eu pour objectif d'analyser le comportement des panneaux MCP sur une cheminée solaire de construction simple. Ce premier prototype de laboratoire a été construit avec des plaques de polystyrène de $5 \mathrm{~cm}$ de large, soutenues par une structure en aluminium (d'une section carrée de $3 \mathrm{~cm}$ de côté). Le prototype est connecté à l'une des sections de la boîte chaude gardée (illustrée 
Table 1: Dimensions de la cheminée solaire V1.0

\begin{tabular}{|c|c|c|c|}
\hline Volume & Hauteur $[\mathrm{m}]$ & $\begin{array}{c}\text { Longueur } \\
{[\mathrm{m}]}\end{array}$ & Largeur $[\mathrm{m}]$ \\
\hline \hline Volume de contrôle & 2.27 & 1.86 & 1.00 \\
\hline Cheminée solaire & 4.00 & 0.45 & 0.50 \\
\hline
\end{tabular}

à la Figure 4) afin d'établir une température contrôlée à l'entrée de la cheminée solaire. L'entrée rectangulaire de la cheminée a été fixée à $0,5 \times 0,075 \mathrm{~m}$, tandis que la sortie circulaire a un diamètre de 0,16 m. Les dimensions du prototype sont indiquées dans le tableau 1.

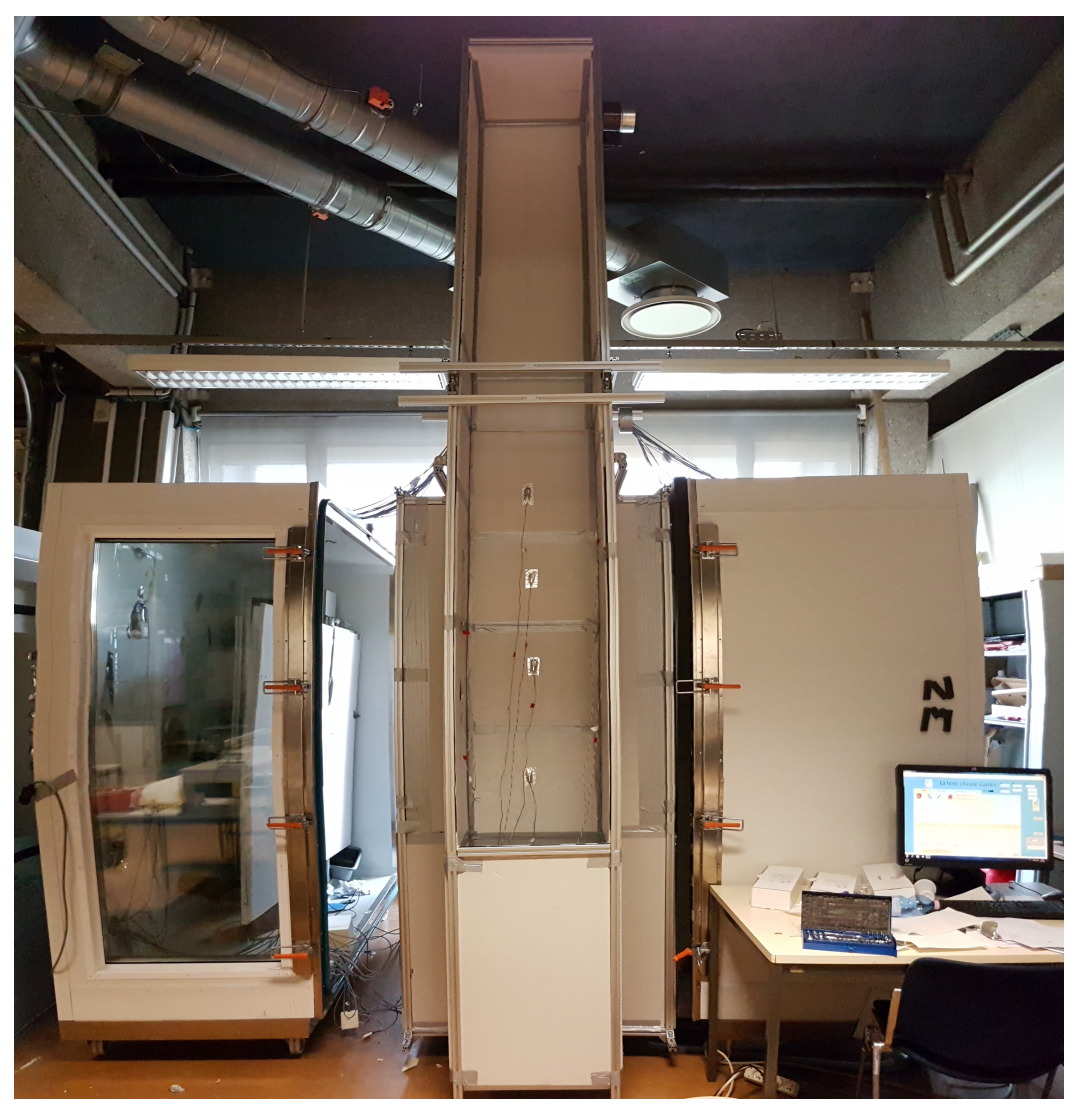

Figure 4: Premier prototype de laboratoire de cheminée solaire développé à l'ENTPE

Le prototype de cheminée solaire V1.0 (SCV1) peut intégrer 9 panneaux en position horizontale perpendiculaire à la source de chaleur et 6 panneaux en disposition verticale sur chacune des parois latérales de la cheminée, comme indiqué sur la Figure 5. Les douze panneaux trouvés sur les panneaux latéraux avaient pour objectif d'analyser les effets des panneaux MCP placés parallèlement à la source de 


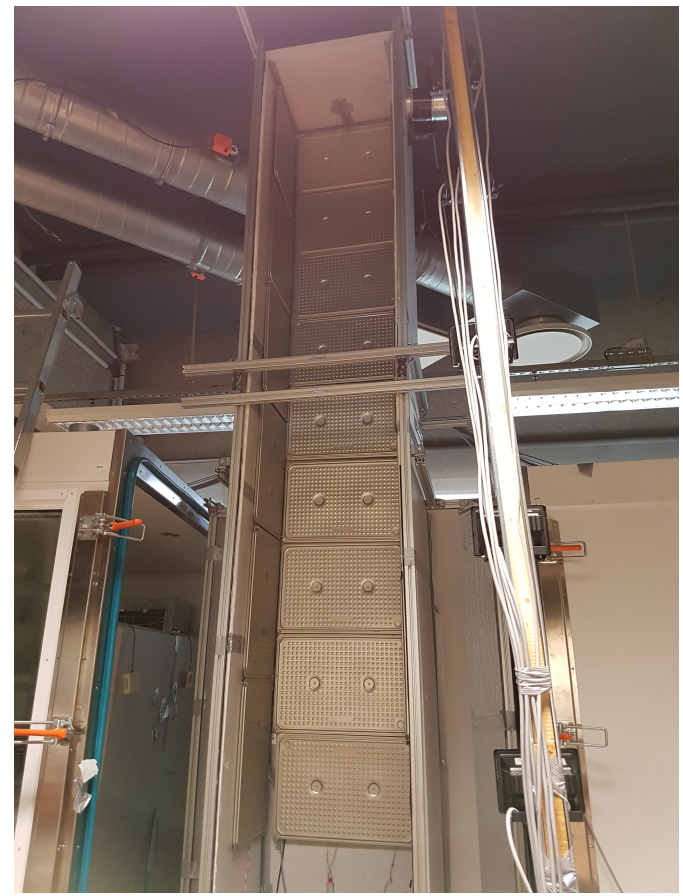

(a)

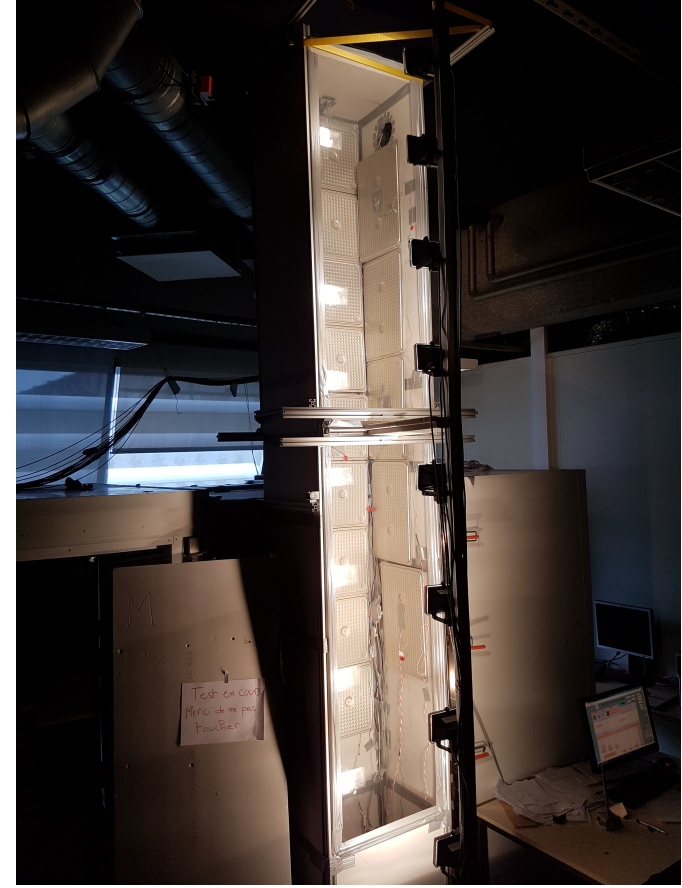

(b)

Figure 5: Prototype V1.0 de cheminée solaire, montrant la campagne expérimentale pendant (a) la ventilation uniquement et (b) la phase de charge du protocole expérimental avec des panneaux MCP

chaleur et leur capacité à effectuer un changement de phase complet.

\section{II.4 Expérimentation in situ}

L'expérimentation in situ est une collaboration avec le CIEMAT à Tabernas, en Espagne, et une continuité du travail effectué par Arce et al. (2015). La cheminée illustrée dans la Figure 6 a été développée dans le désert de Tabernas, en Espagne en 2003 à la "Plataforma Solar de Almeria" (PSA). La cheminée solaire de la PSA est située du côté sud de la plate-forme solaire dans le laboratoire d'essais énergétiques des composants du bâtiment (LECE).

La dernière version du système a une hauteur de 5,60 m, une largeur de 1,20 m et une profondeur de $0,52 \mathrm{~m}$. La cheminée est composée d'une plaque absorbante en béton armé de 4,5 m de haut, 1,0 $\mathrm{m}$ de large et 0,15 $\mathrm{m}$ d'épaisseur, une isolation thermique derrière la plaque en béton et un vitrage de $5 \mathrm{~mm}$ d'épaisseur qui sert à réduire les pertes convectives et radiatives vers l'environnement. De plus, la 


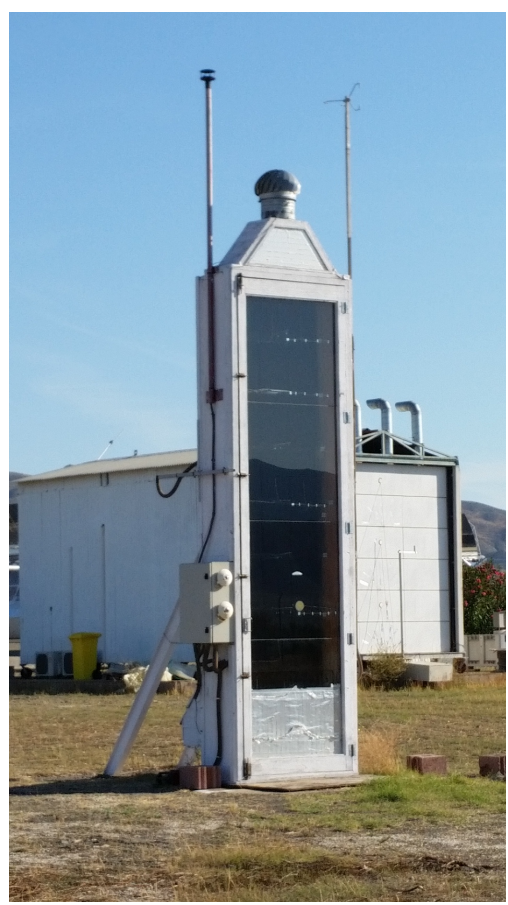

(a)

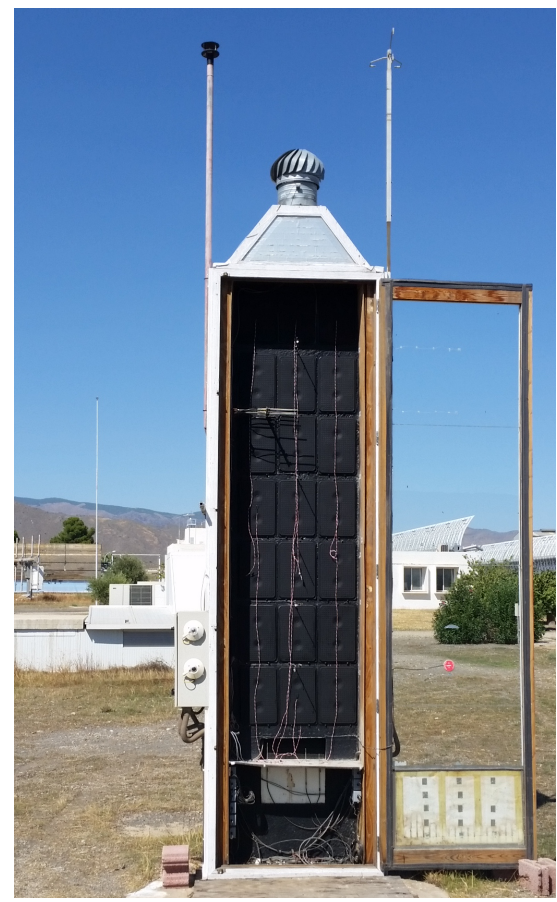

(b)

Figure 6: Cheminée solaire du CIEMAT à la PSA montrant (a) la cheminée en fonctionnement et (c) la cheminée ouverte pour l'installation de panneaux

cheminée est constituée d'un caisson en bois et la sortie, laquelle est entraînée par le vent, protège la cheminée de la circulation inverse et elle génère une chute de pression près de la sortie tout en facilitant l'extraction de l'air. Une image de la cheminée solaire, ainsi que ses caractéristiques, sont montrées dans la Figure 7.

La région de Tabernas, dans laquelle se trouve cette cheminée, à quelques kilomètres d'Almeria, est connue pour le rayonnement solaire moyen élevé qu'elle reçoit tout au long de l'année. Arce et al. (2015) a présenté différents scénarios tout au long de l'année. Trois dates différentes ont été sélectionnées afin d'analyser les performances de la cheminée solaire dans différentes conditions environnementales. Ces trois dates correspondent aux jours avec un ciel avec peu de nuages, vers le début de l'hiver, le printemps et l'été respectivement. Comme les cheminées solaires sont entraînées par l'énergie solaire, les effets du rayonnement solaire global vertical (VGSR) et du rayonnement solaire global horizontal (HGSR) peuvent être directement perçus sur la température de surface des panneaux de MCP, dans la température de l'air du canal et dans le débit de sortie du système. 


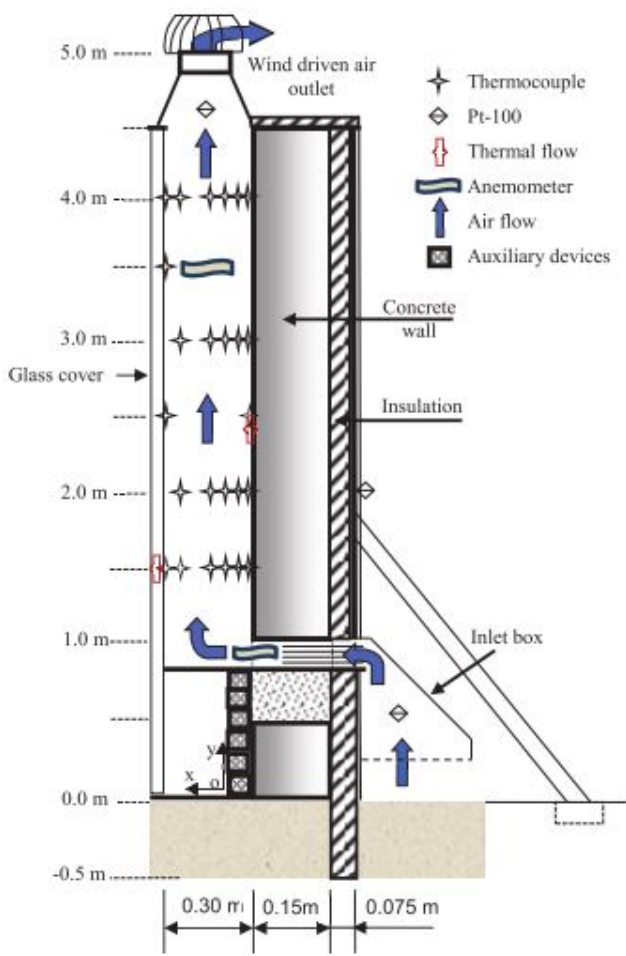

(a)

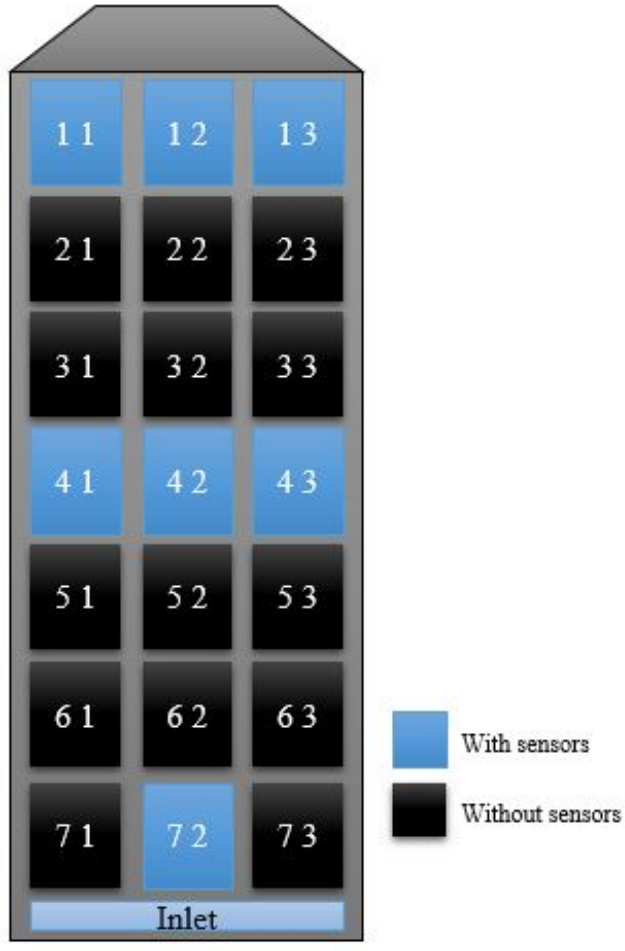

(b)

Figure 7: (a) Vue latérale de la cheminée solaire de la PSA et l'instrumentation selon (Arce et al., 2015) ainsi que (b) le placement des capteurs sur et sous les panneaux MCP à (72) 1,25 m, (41-43) 2,75 m et (11-13) 4,25m.

L'analyse des données environnementales est complexe en raison du nombre de variables, de leurs fluctuations et de la résolution de leur acquisition. Afin de exploiter des données, les informations disponibles et de l'impact des panneaux MCP, les données étudiées devraient idéalement être identiques. Les informations étudiées pour cette thèse correspondent aux années 2016 et 2018. L'analyse du système dépend de la similarité statistique des deux ensembles de données (avec et sans MCP).

La vitesse du vent, le rayonnement solaire (VGSR et HGSR) et la température extérieure ont été les variables prises en compte pour l'analyse statistique des conditions de fonctionnement de la cheminée. Cet ensemble des données a été choisi pour déterminer l'accord des conditions environnementales entre les deux années, dans la mesure où il représentait des variables non dépendantes de l'ajout des panneaux de MCP et qui décrivait les conditions auxquelles la cheminée était soumise. De plus, la température du vitrage a été ajoutée à cette étude statistique 
pour déterminer la différence de température de surface due au rayonnement solaire incident.

L'étude statistique a permis de déterminer le kurtosis et le coefficient d'asymétrie des ensembles de données. Ces valeurs sont des éléments statistiques qui définissent le "pic" ou "la planéité" et la symétrie d'une série de données. Ces deux valeurs mènent à la détermination de distributions normales, où si les deux valeurs sont proches de zéro, une distribution normale peut être attendue. En outre, la corrélation des données analysées permet de déterminer les couples de jours qui seraient utilisés pour l'analyse. Le choix d'un jour clair a été établi numériquement par l'écart type des données. L'écart type d'une journée claire pour l'hiver, le printemps et l'été doit être supérieur à 200, 300, 350 pour le HGSR et 350, 310, 150 pour le VGSR.

De plus, les séries de données ne possèdent pas de distributions normales et ne peuvent pas être normalisées par des méthodes logarithmiques ou de racine carrée. Une solution non paramétrique est donc nécessaire pour valider le choix des données. Le test de Wilcoxon (ou le test de Wilcoxon-Mann-Whitney ) représente la variante non paramétrique du test $t$-test, et il peut être utilisé de la même manière car ce dernier permet de comparer deux groupes d'échantillons indépendants pas normalement distribués.

\section{II.5 Deuxième campagne expérimentale en laboratoire}

Le premier prototype de cheminée solaire, ainsi que les premiers résultats obtenus à Almeria, Espagne, ont permis une première caractérisation du système. Le premier prototype a mis en évidence les avantages des panneaux MCP sur une structure sans inertie thermique. Cela démontre le comportement thermique et aérodynamique de la cheminée solaire lorsqu'elle est uniquement pilotée par les MCP. En effet, le développement du premier prototype a mis en évidence l'influence des MCP en tant que dispositif complémentaire de ce type de technologie. Cependant, les matériaux de construction de ce prototype n'étaient pas représentatifs d'un élément 
de construction réel. La deuxième version du prototype de cheminée solaire de laboratoire a été mise au point après l'analyse des premiers résultats de laboratoire et in situ. Le développement du deuxième prototype reposait sur deux raisons principales: la représentation et l'analyse d'un composant de bâtiment intégré avec des panneaux MCP et, principalement, l'étude comparative avec la cheminée solaire in situ de la PSA.

Le deuxième prototype de la cheminée solaire, appelé ci-après SCV2, a été développé conformément à la conception de la cheminée solaire in situ de la PSA à Almeria présentée précédemment. En raison de restrictions de taille du laboratoire, la SCV2 a été réduite de $0,50 m$ par rapport à la cheminée solaire de la PSA. En termes de placement de panneaux MCP, cette réduction représente une rangée de panneaux de moins par rapport à l'expérimentation de la cheminée solaire à Almeria. La figure 8 représente la SCV2 dans le laboratoire de l'ENTPE. Le deuxième prototype est composé de panneaux de contreplaqué de $2 \mathrm{~cm}$. La taille de l'entrée est de $0,8 \times 0,08 \mathrm{~m}$, tandis que la sortie a la même taille que le prototype V1.0 $\left(0,0201 \mathrm{~m}^{2}\right)$. Le vitrage a une épaisseur de $0,7 \mathrm{~cm}$ et il sert de porte vers l'intérieur de la cheminée.

Derrière la cheminée solaire, un volume de 4,68 $\mathrm{m}^{3}$ est connecté. Ce volume, comme celui du prototype V1.0, a pour but de définir un volume de contrôle à l'entrée de la cheminée où une température d'entrée peut être définie et/ou la vitesse n'est pas un facteur lors de l'expérimentation. Le volume a été construit avec trois entrées différentes: 1, $86 \times 1,86 \mathrm{~m}, 1,190 \times 0,94 \mathrm{~m}$ ou une entrée circulaire de 0,22 m de diamètre. Le volume est construit avec le même type de contreplaqué.

Afin de faciliter le changement de phase et de mieux exploiter la radiation incidente, les panneaux ont été peints en noir mat. Cette modification a été effectuée en relation avec la campagne expérimentale in situ, où les panneaux ont reçu le même traitement et après l'analyse des résultats de la température de surface de la SCV1. En effet, les résultats obtenus lors du premier prototype ont mis en évidence la fusion incomplète du MCP, nuisant ainsi à la performance 


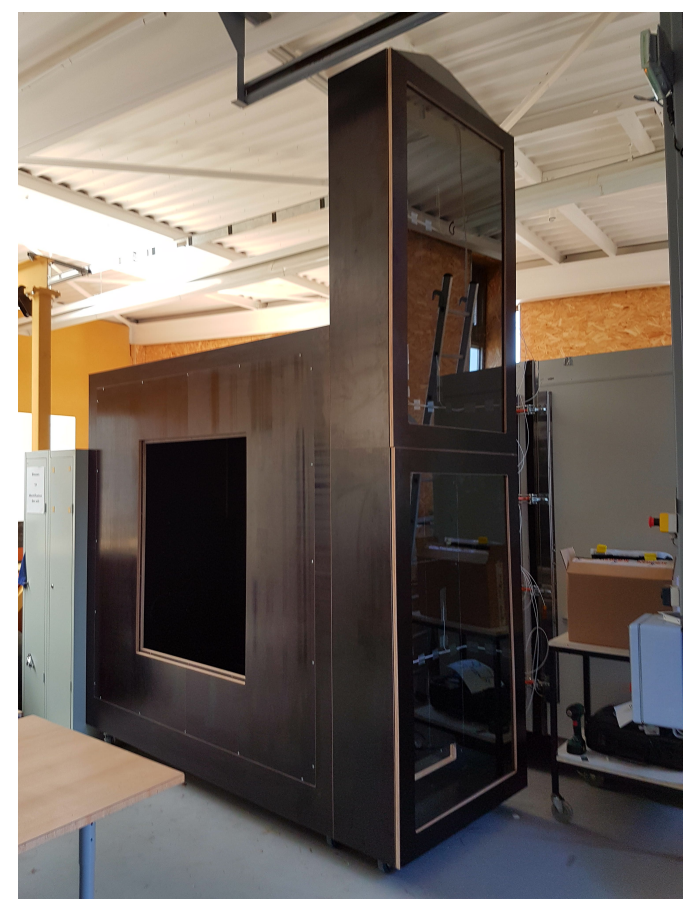

(a)

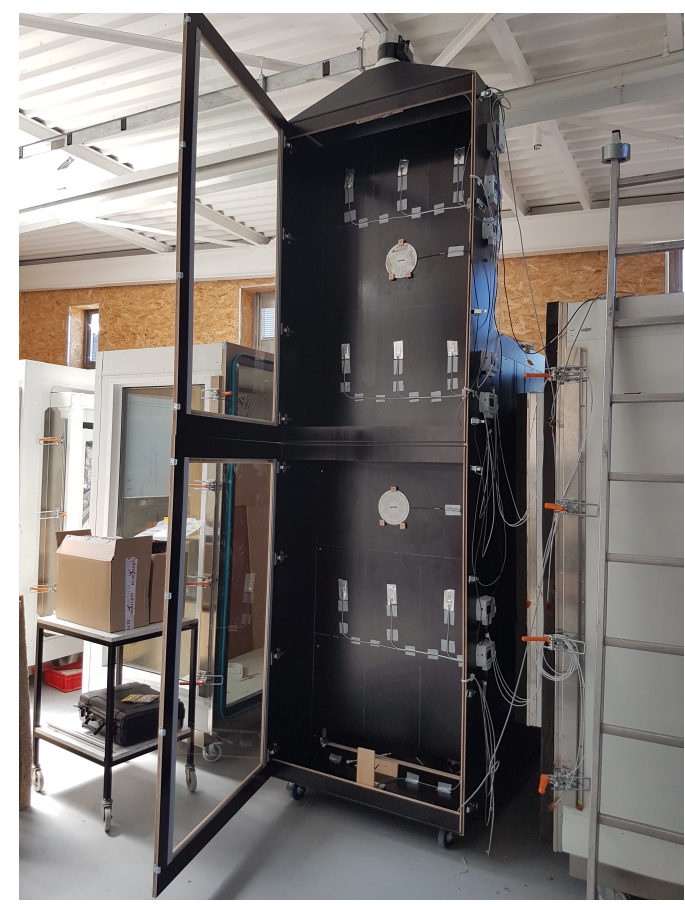

(b)

Figure 8: (a) Vue latérale de la SCV2 avant la mise en place des capteurs et (b) la SCV2 ouverte pour la configuration sans MCP.

du système. En plus de cette modification, une couche supplémentaire d'isolant a été ajoutée derrière la couche de contreplaqué où les panneaux ont été placés. Cette couche supplémentaire a été ajoutée pour éviter les pertes de chaleur du panneau vers l'extérieur et pour garantir une montée de la température du panneau au-dessus de la plage de fusion de $44^{\circ} \mathrm{C}$.

De plus, afin d'éviter les fuites observées lors du premier prototype expérimental, les panneaux du SCV2 ont été fixés à la surface avec une cale en bois au lieu d'être percés. En effet, la dilatation thermique constatée lorsque les panneaux montent en température a provoqué l'échappement du MCP du panneau.

\section{II.6 Résultats \& discussion}

Les résultats de laboratoire de la SCV1 ont montré l'intérêt des matériaux à changement de phase dans une cheminée solaire pour améliorer le taux de ventilation moyen lorsque le prototype est en présence d'une source de chaleur et une diminution progressive en l'absence de celle-ci. Ces résultats ont été obtenus 
malgré la fusion incomplète du matériau dans les panneaux. Ce phénomène suggère de meilleures performances lorsque le changement de phase complet est atteint. Les panneaux MCP fonctionnent comme prévu, absorbant l'énergie disponible à chaque phase de charge et libérant cette énergie une fois la source est éteinte. En général, les résultats avec les matériaux à changement de phase montrent un débit moyen plus élevé dans toutes les phases de l'expérience. Les résultats du premier prototype sont un exemple du potentiel des MCP en tant que composant séparé.

La différence majeure entre le débit d'air de sortie est observée pour les résultats SCV1. Les résultats démontrent que la fusion incomplète des panneaux MCP rend le système performant sans aucune amélioration. La principale différence se retrouve lors des phases de ventilation uniquement (4 et 7) lorsque l'inertie thermique des MCP augmente légèrement le débit d'air de $15,59 \mathrm{~m}^{3} / \mathrm{h}$ et de $18,92 \mathrm{~m}^{3} / \mathrm{h}$ à 17,25 $\mathrm{m}^{3} / \mathrm{h}$ et $26.64 \mathrm{~m}^{3} / \mathrm{h}$. Une fois que la température a augmenté et que les panneaux MCP ont fusionné, le prototype V1.0 intégré de MCP surpasse de 246,66\% son équivalent en phase 3 et affiche un taux de ventilation moyen de 110,04 $\mathrm{m}^{3} / \mathrm{h}$ et de $122,39 \mathrm{~m}^{3} / \mathrm{h}$ au cours des phases 4 et 7 où la version non MCP a un débit d'air proche de $0 \mathrm{~m}^{3} / \mathrm{h}$.

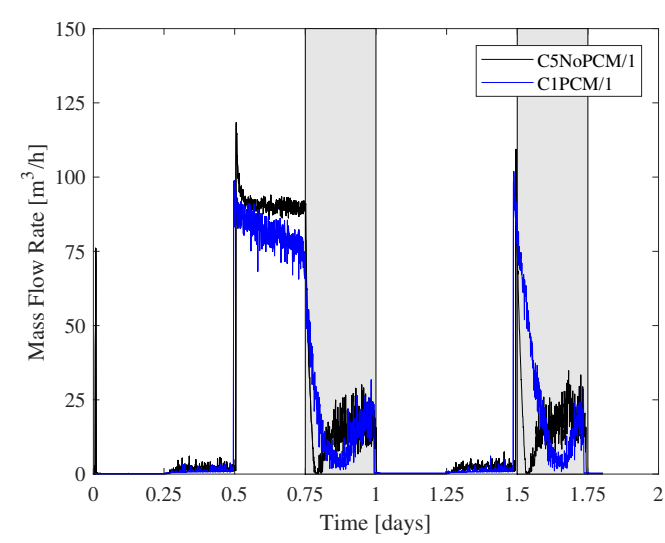

(a)

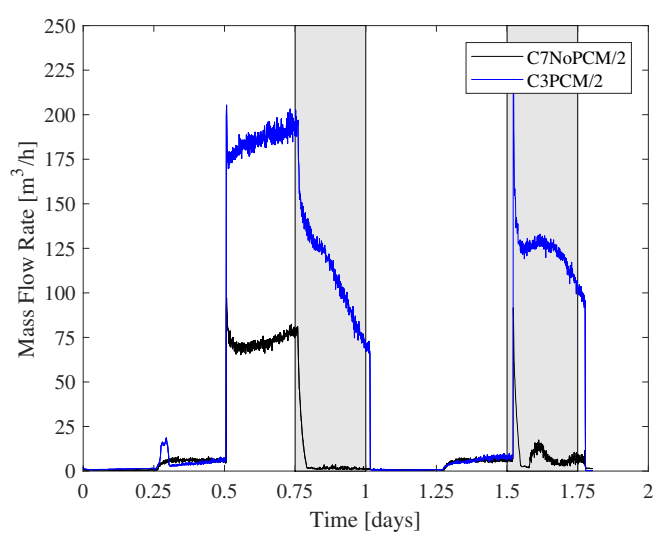

(b)

Figure 9: Débit massique dans des conditions de fonctionnement similaires pour la SCV1 (a) avec une température d'entrée définie et (b) suivant les conditions extérieures.

De même, les résultats de la SCV2 montrent une augmentation approximative 


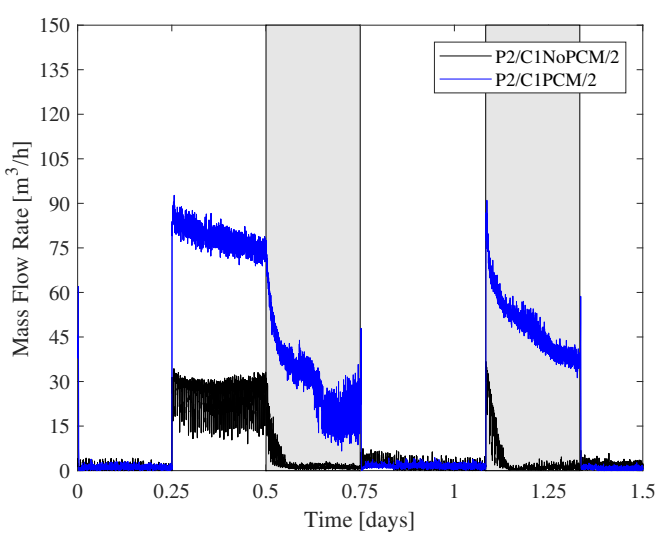

(a)

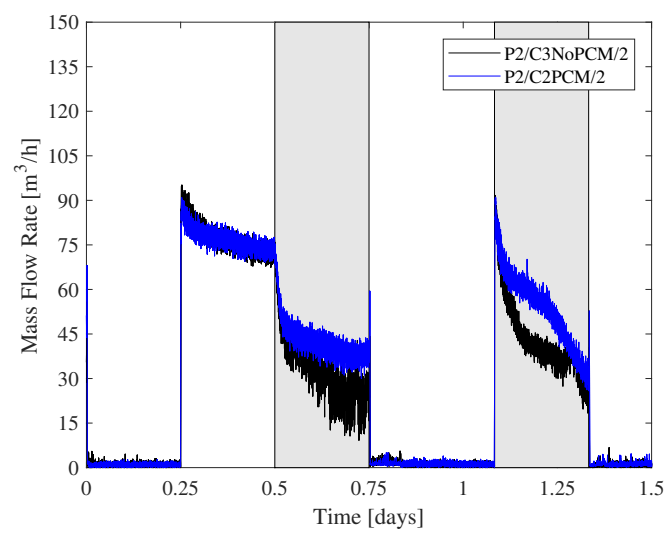

(b)

Figure 10: Débit massique dans des conditions de fonctionnement similaires pour la SCV2 (a) avec une température d'entrée définie et (b) suivant les conditions extérieures.

du débit d'air de $365 \%$ pendant la phase 3 lorsque le système n'est pas correctement isolé et que la cheminée subit une perte de chaleur importante. Une fois que cette perte est limitée par l'ajout d'isolant, les cycles avec et sans MCP atteignent des pics et des comportements similaires pendant la phase 3. En outre, la différence de débit d'air est appréciée pendant les phases de ventilation uniquement. La phase 4 semble se comporter d'une manière très similaire. La phase 7 montre toujours un taux de ventilation plus élevé. Lors du réglage d'une température d'entrée, en raison de la fusion incomplète de tous les panneaux MCP, le système n'augmente que de $43,03 \mathrm{~m}^{3} / \mathrm{h}$ à $53,51 \mathrm{~m}^{3} / \mathrm{h}$. D'autre part, lorsqu'il est soumis à des conditions extérieures, le système présente la plus grande augmentation de performances, passant de $34,93 \mathrm{~m}^{3} / \mathrm{h}$ à $60,82 \mathrm{~m}^{3} / \mathrm{h}$.

Globalement, les MCP entraînent une performance supérieure à celle des cycles sans MCP, même lors d'essais n'atteignant pas la plage de fusion. La cohérence des performances des cycles avec MCP suggère que l'ajout de panneaux MCP n'a pas d'impact négatif sur le système et peut s'améliorer en fonction des conditions externes, principalement une radiation incidente plus élevée et des températures externes plus élevées. Les séries de résultats de température et de débit massique sont obtenues avec un flux de chaleur incident maximal de $600 \mathrm{~W} / \mathrm{m}^{2}$. Plusieurs travaux montrent les conditions typiques de pays tels que le Mexique et l'Espagne (Arce et al., 2015; Matsumoto et al., 2014) où le rayonnement solaire peut atteindre 
des sommets supérieurs à ceux simulés lors des campagnes expérimentales. Un rayonnement plus élevé peut conduire à des températures de surface et d'air plus élevées, ce qui aiderait l'ensemble des panneaux à réaliser une transformation de phase complète. Dans l'ensemble, les résultats de la SCV1 et la SCV2 montrent une performance thermique supérieure de la cheminée solaire avec des panneaux MCP. En effet, les pics de température peuvent ne pas atteindre les mêmes maxima mais ils maintiennent une température élevée stable tout au long du protocole expérimental.

Les performances des MCPs intégré à une cheminée solaire ont été évaluées dans des conditions environnementales normales et ont des performances de ventilation similaires à celles de la cheminée solaire classique. Même si les résultats in situ n'ont pas donné de différences significatives en termes de débit, plusieurs conclusions peuvent être tirées: le mur en béton armé de $0,15 \mathrm{~m}$ (peint en noir pour une meilleure absorption de la chaleur solaire) influence clairement le comportement de la cheminée et fournit une bonne inertie thermique au système. Cette inertie est suffisamment importante pour générer des résultats similaires à ceux de la cheminée solaire avec MCPs. Il a été observé que le mur en béton a une capacité de chauffage limitée après le coucher du soleil au contraire des les panneaux de matériau à changement de phase. En outre, l'énergie du panneau de matériau à changement de phase peut être utilisée pour chauffer le mur en béton au lieu d'être exploitée pour créer une différence de température plus élevée dans le conduit, ce qui réduit l'impact des panneaux.

Il est important de mentionner que la plupart des rangées jusqu'à ceux à $3 \mathrm{~m}$ de hauteur, se comportent comme prévu et atteignent la plage de température de fonctionnement nécessaire. Cependant, la dernière rangée de panneaux n'atteint pas $40{ }^{\circ} \mathrm{C}$. Cette partie de la cheminée subit une chute de température, ce qui peut affecter le taux de ventilation général et particulièrement l'utilisation après le coucher du soleil. Ces températures plus basses s'expliquent par le manque de radiation solaire incidente. En effet, en raison de la géométrie de la cheminée, la dernière rangée de panneaux n'est pas exposée au soleil. Cette chute de température 
pourrait potentiellement limiter les performances globales de la cheminée.

De plus, l'ajout des panneaux MCP n'a pas d'incidence sur la répartition de la température de l'air dans la cheminée. Cependant, les résultats suggèrent que la taille du mur en béton pourrait être réduite ou complètement modifiée pour des panneaux MCP, simplifiant ainsi la construction et les dimensions du système. L'absence d'un taux de ventilation plus important pourrait être due à la chute de température à la sortie de la cheminée et devrait également être analysée dans des études ultérieures. Globalement, l'échappement rotatif de la cheminée solaire de la PSA, ainsi que la vitesse du vent semblent avoir un impact plus important sur les performances de ventilation. Les résultats démontrent que l'échappement de la cheminée solaire PSA crée une perte de charge suffisante pour augmenter le taux de ventilation au-dessus de $200 \mathrm{~m}^{3} / \mathrm{h}$, selon l'amplitude de la vitesse du vent supérieure à $6 \mathrm{~m} / \mathrm{s}$. Enfin, les résultats suggèrent que l'intégration des panneaux MCP sur une cheminée solaire in situ n'a pas d'impact négatif sur la performance du système, mais il peut aider à atteindre des taux de ventilation plus élevés en raison de la performance thermique supérieure. Les résultats obtenues (différence de température entre température extérieur et température de sortie, vitesse d'air et débit de sortie) pendant les périodes sélectionnées peuvent être observées dans les Figure 11 à 16. 


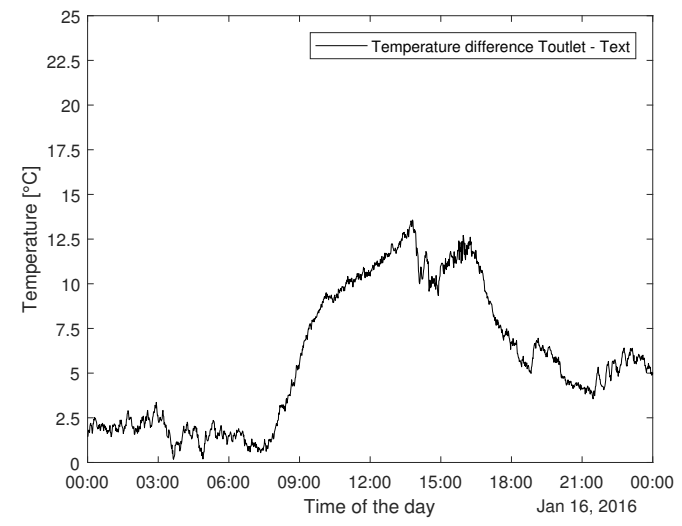

(a)

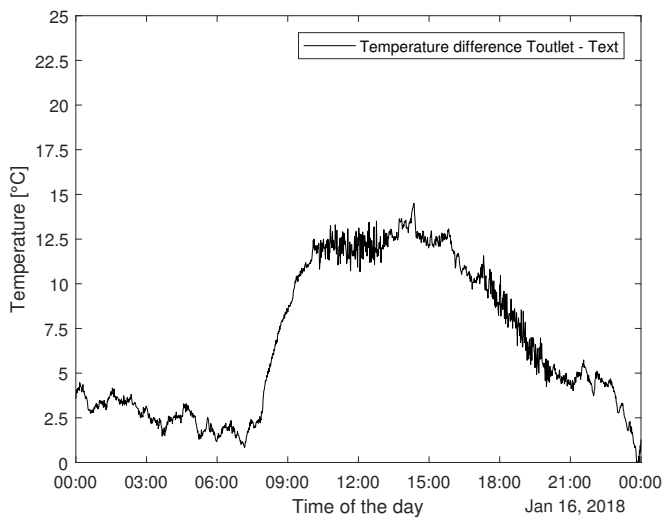

(b)

Figure 11: Différence de température d'air entre la température extérieure et la température à la sortie de la cheminée pour (a) le 16 janvier 2016 et (b) le 16 janvier 2018.

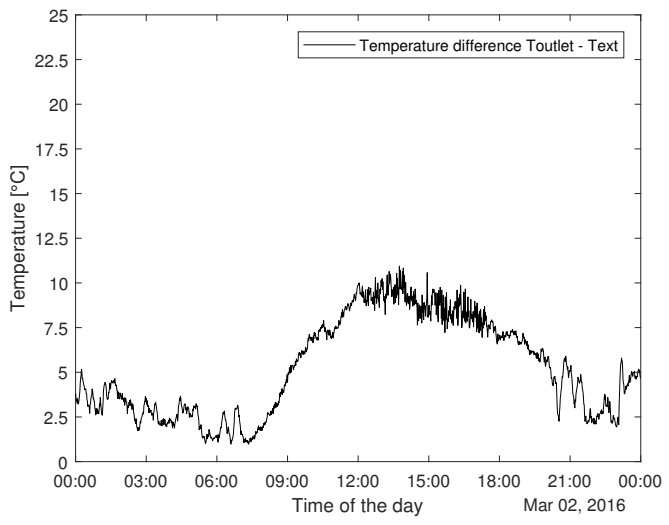

(a)

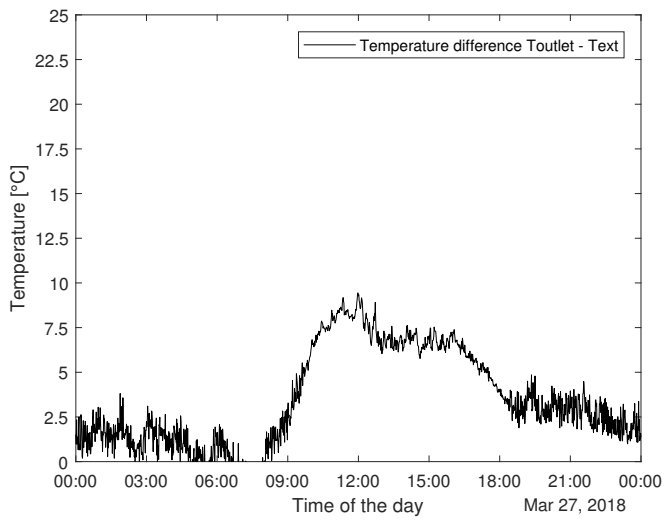

(b)

Figure 12: Différence de température d'air entre la température extérieure et la température à la sortie de la cheminée pour (a) le 2 mars 2016 et (b) le 27 mars 2018.

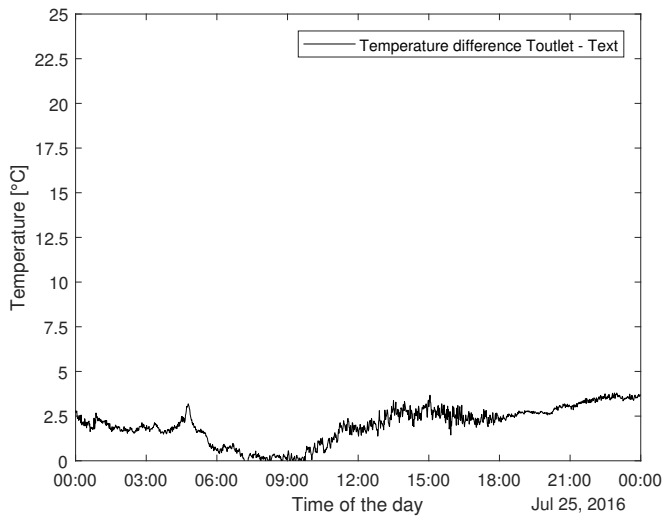

(a)

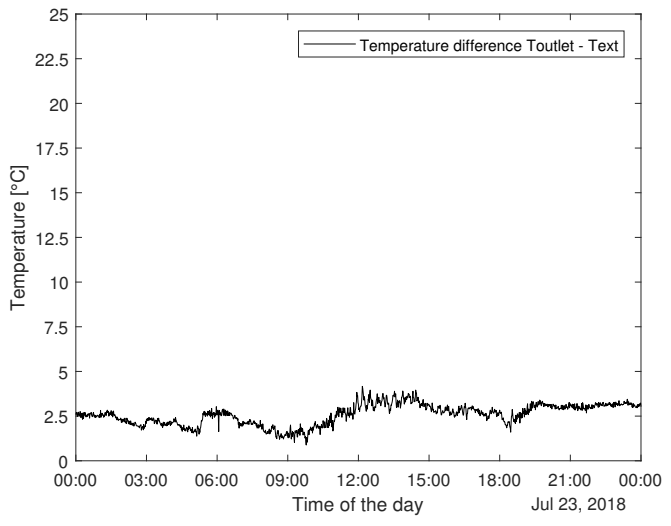

(b)

Figure 13: Différence de température d'air entre la température extérieure et la température à la sortie de la cheminée pour (a) 2 juillet 2016 et (b) le 17 juillet 2018. 


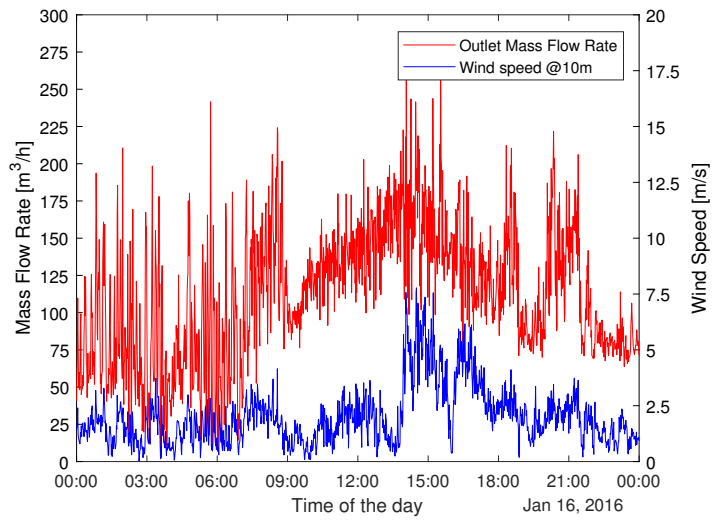

(a)

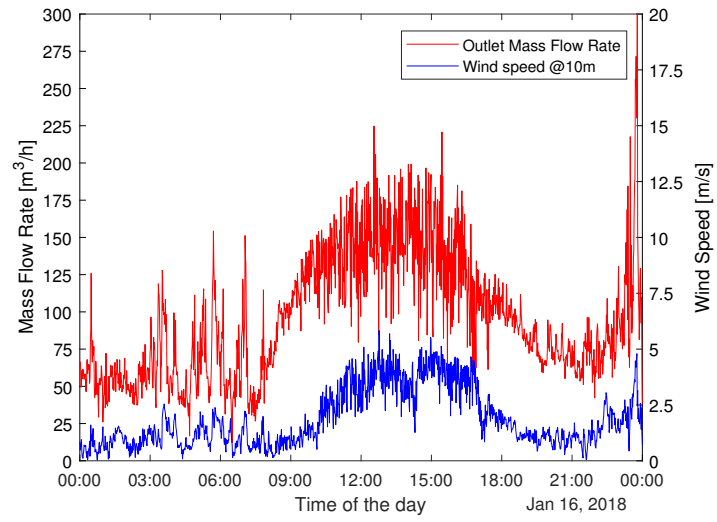

(b)

Figure 14: Débit d'air sortant et vitesse du vent pendant (a) le 16 janvier 2016 et (b) le 16 janvier 2018.

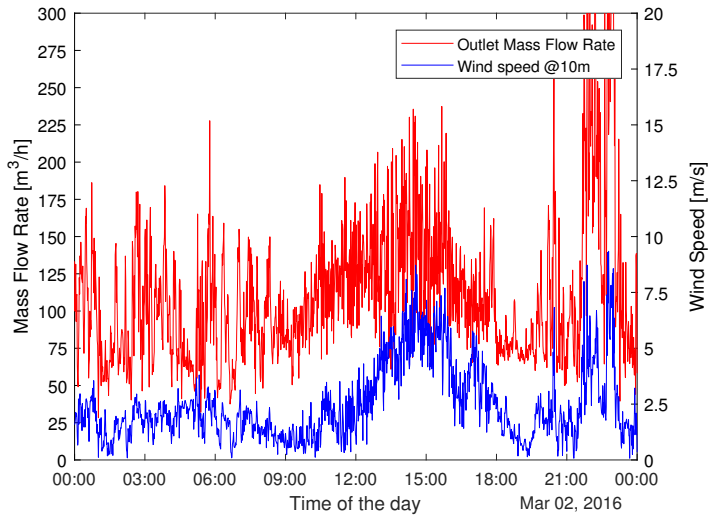

(a)

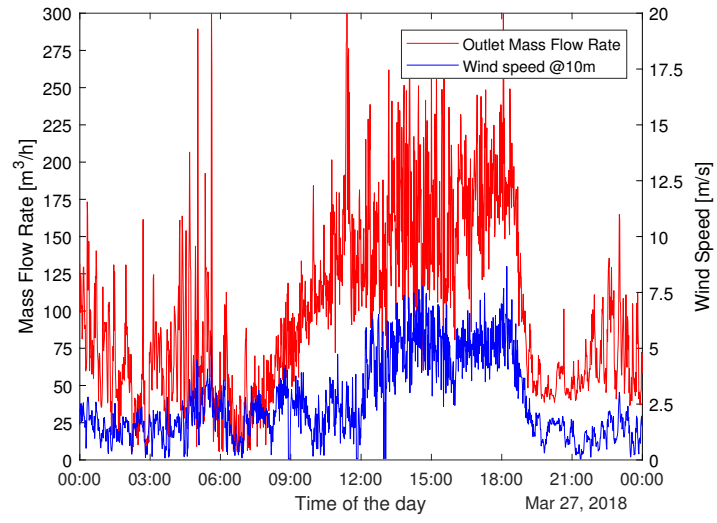

(b)

Figure 15: Débit d'air sortant et vitesse du vent pendant (a) le 2 mars 2016 et (b) le 27 mars 2018.

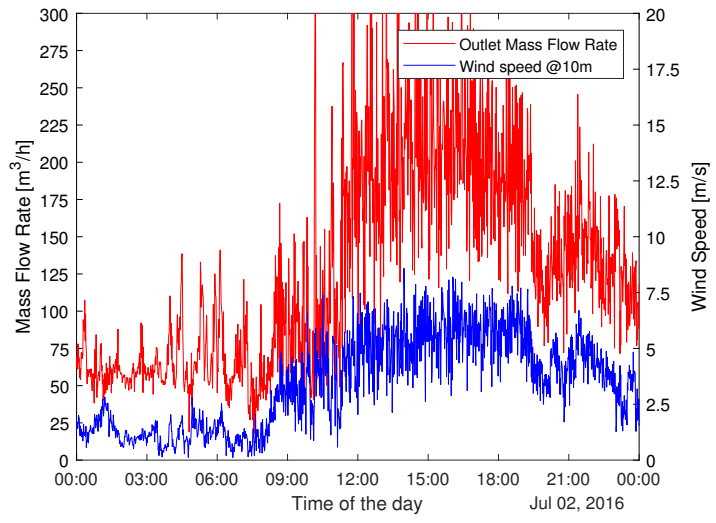

(a)

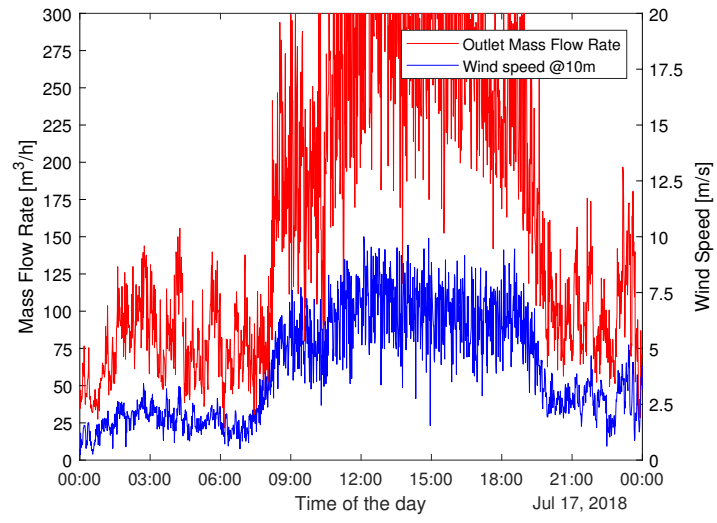

(b)

Figure 16: Débit d'air sortant et vitesse du vent pendant (a) le 2 juillet 2016 et (b) le 17 juillet 2018. 


\section{Modélisation numérique}

Le modèle est constitué de quatre sous-modèles couplés qui se complètent par le calcul de différentes variables. Le premier sous-modèle a été mis au point afin de prédire le transfert de chaleur à travers un mur multi-couche, constitué d'un nombre déterminé de couches de matériaux de construction et d'une couche de matériaux à changement de phase (dépendante de la température). Le modèle de transfert de chaleur est couplé à un code en pression permettant le calcul de l'écoulement d'air. Le code en pression détermine la répartition de la pression sur la longueur de la cheminée et permet de calculer les débits massiques d'entrée et de sortie. Enfin, les informations sont transmises au sous-modèle de convection qui calcule les échanges par convection présents dans le conduit et aide ensuite à recalculer la distribution de la température dans la cheminée solaire. L'approche logique utilisée peut être observée dans la figure 17 .

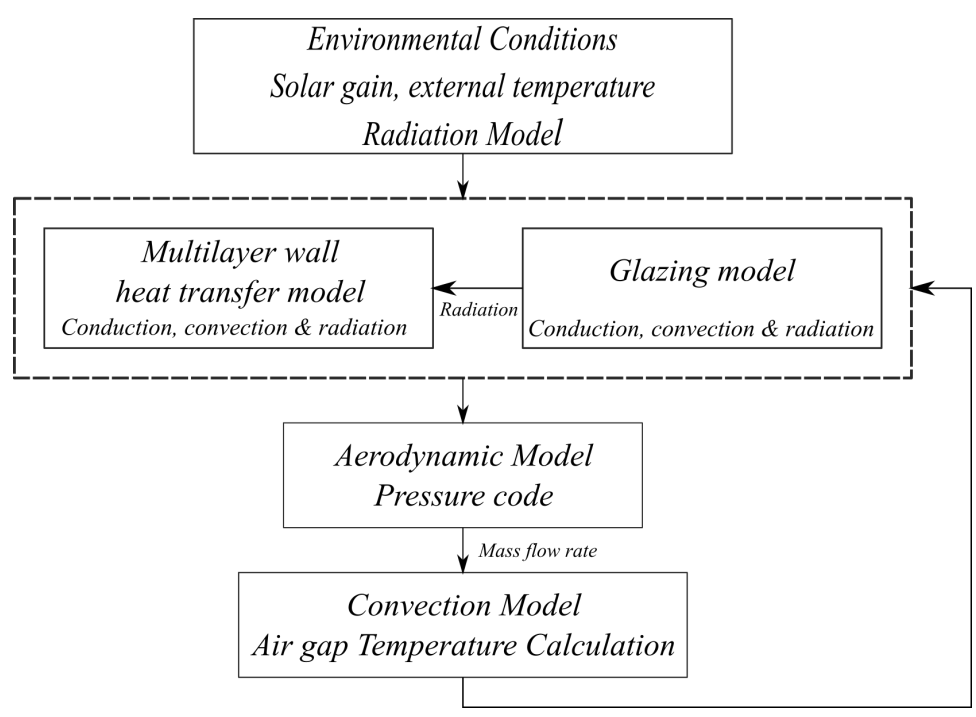

Figure 17: Diagramme du modèle numérique de cheminée solaire

Afin de simuler les performances d'une cheminée solaire, un programme Matlab Simulink a été développé. Matlab Simulink a été choisi comme outil de simulation dans l'intérêt de la poursuite de travaux antérieurs (El Mankibi et al., 2015; 
Mankibi et al., 2015) et afin de créer un outil numérique permettant d'intégrer différentes technologies à la représentation informatique d'un Bâtiment à Zéro Énergie (BZE). Plusieurs éléments d'un BZE ou un bâtiment à énergie verte, tels que le stockage d'énergie thermique à basses températures (Roccamena et al., 2018) ou des enveloppes de bâtiments multi-fonctionnelles (Bahrar et al., 2018) ont été développés par le laboratoire de l'ENTPE. Le modèle numérique de la cheminée solaire a été développé en tant qu'outil numérique pour déterminer l'impact de cette technologie sur un bâtiment dans l'intérêt des objectifs de l'Accord de Paris.

\section{III.1 Résultats}

Le modèle numérique développé décrit le comportement général de la cheminée solaire classique et de la cheminée solaire intégrée avec des panneaux MCP. L'analyse comparative entre les résultats expérimentaux et la simulation peut être observe dans les Figures 18 à 20 pour différents cycles expérimentaux. Des différences ont été constatées dans des configurations spécifiques. La différence de débit massique entre la simulation et les résultats expérimentaux peut également résulter des conditions expérimentales. Le rayonnement incident est considéré comme homogène à travers la cheminée et ne tient pas compte de la section de 0,28 $\mathrm{m}^{2}$ qui limite la contribution des lampes halogènes à mi-hauteur de la cheminée $(1,6 \mathrm{~m})$. La section peut affecter la distribution de la température de la cheminée solaire réelle et réduire la température au niveau de la sortie, comme indiqué dans la comparaison avec les résultats de la simulation. Une température de cheminée d'air inférieure affecterait directement les performances de ventilation du modèle numérique et pourrait décrire plus précisément le comportement réel de la cheminée.

La plus grande différence entre la simulation et les résultats expérimentaux réside dans la taille de l'entrée. Afin de représenter le comportement de la cheminée solaire au niveau de l'entrée, la taille numérique a du être modifié à $0,3 \mathrm{~m}$ pour assurer la convergence. Cette erreur pourrait être le résultat du rapport entre la taille de l'entrée et la hauteur de la cheminée. Les valeurs inférieures à cette taille d'entrée minimale font en sorte que la simulation sous-estime gravement les 
performances globales de la cheminée. Une optimisation numérique du calcul des flux entrants doit être effectuée afin d'établir la taille correcte de la cheminée. Il est clair que la loi des grandes ouvertures n'est pas bien adaptée à ce modèle numérique et devrait être modifiée pour un modèle plus raffiné.

Finalement, le modèle numérique représente le comportement de la cheminée solaire pour différents pas de temps. Le temps de simulation est inversement proportionnel à la taille du pas de temps, mais une simulation d'un jour avec un pas de temps de $60 \mathrm{~s}$ prend moins de 3 minutes. Le système peut représenter avec précision les résultats expérimentaux avec une confiance globale supérieure à $90 \%$. Toutefois, des études complémentaires devraient viser à réduire les écarts entre les deux séries de données à partir des optimisations suggérées précédemment. 


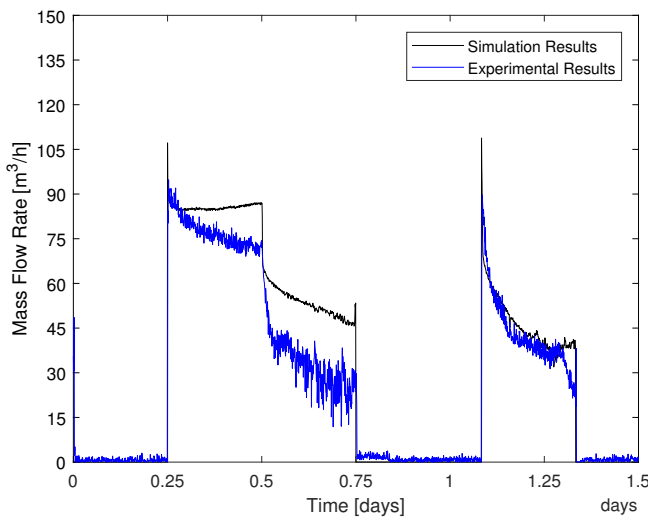

(a)

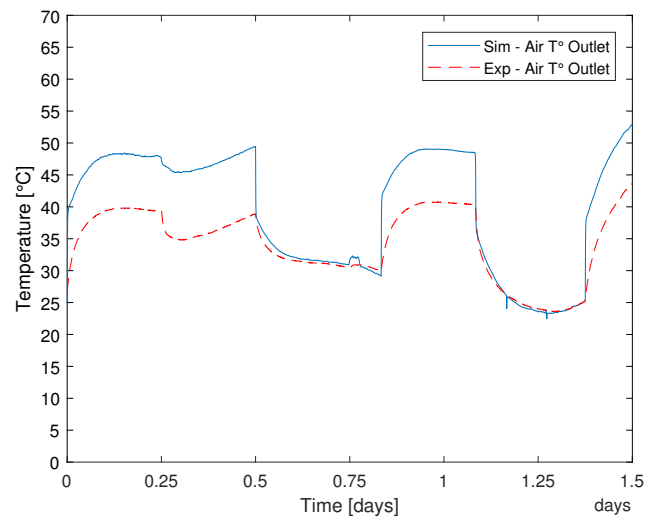

(b)

Figure 18: Résultats comparatifs pour (a) le débit massique et (b) la température de sortie entre la simulation et les premiers résultats expérimentaux.

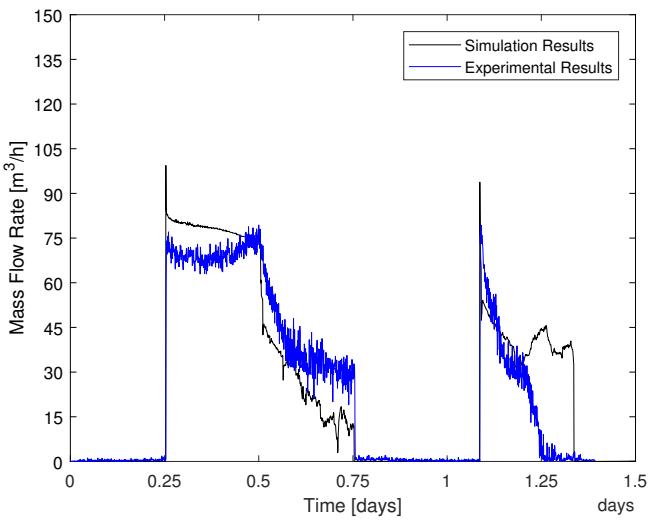

(a)

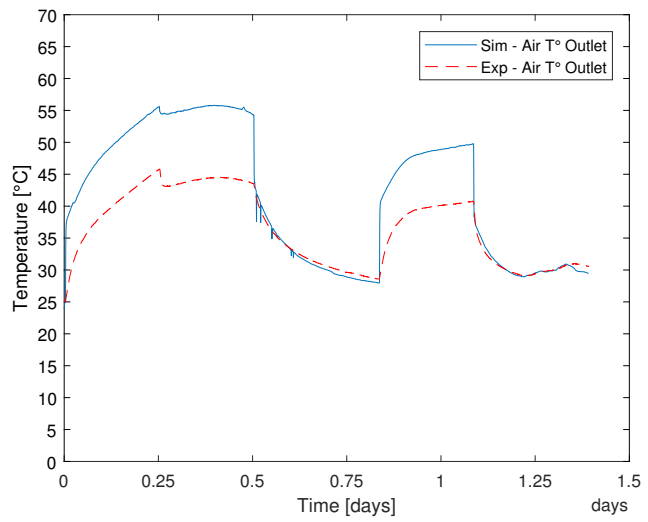

(b)

Figure 19: Résultats comparatifs pour (a) le débit massique et (b) la température de sortie entre la simulation et les deuxièmes résultats expérimentaux.

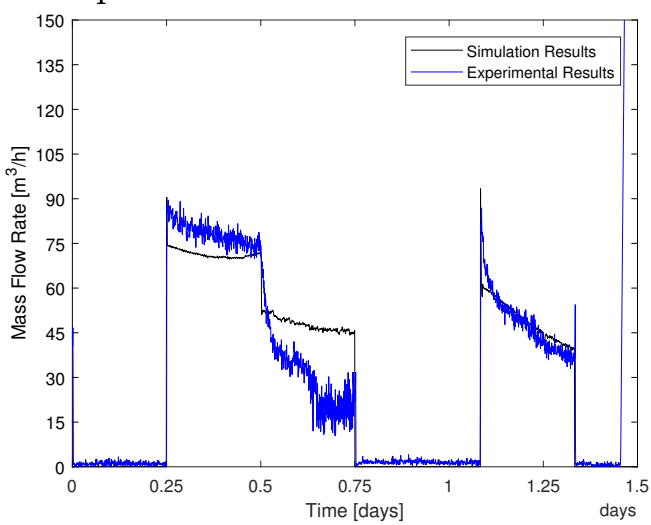

(a)

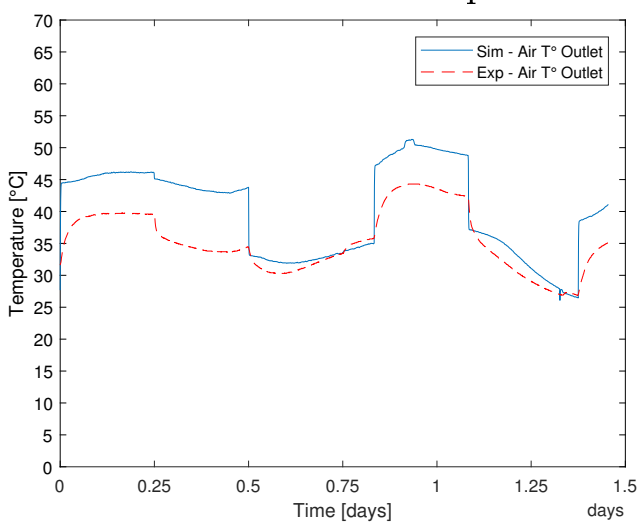

(b)

Figure 20: Résultats comparatifs pour (a) le débit massique et (b) la température de sortie entre la simulation et les troisièmes résultats expérimentaux. 


\section{Optimisation numérique}

Le développement d'un outil numérique fiable permet l'optimisation paramétrique du système grâce à la modification des paramètres de fonctionnement dans la simulation. Plusieurs méthodes d'optimisation peuvent être trouvées dans la littérature (Bassiouny and Koura, 2008; Chen and Qu, 2014; Harris and Helwig, 2007), ce qui implique généralement la modification de la configuration expérimentale ou la simulation extensive sous différents paramètres. Cependant, sur la base des travaux de Bahrar et al. (2018); Roccamena et al. (2018), les algorithmes génétiques ont été choisis en raison de leur capacité à fixer des paramètres de fonctionnement maximisant/minimisant une ou plusieurs fonctions objectives données.

Le but de cette optimisation est d'assurer la fusion complète des panneaux MCP et l'augmentation du débit d'air. Ces deux fonctions objectives ont été choisies principalement en raison de la nature contradictoire des deux valeurs. En effet, un débit massique plus élevé peut entraîner une diminution globale de la température de la cheminée. L'optimum entre les deux fonctions d'objectif représente la température de fonctionnement maximale permettant d'assurer la transformation de phase complète du MCP tout en maintenant un débit massique élevé.

1. OBJ1 - Maximiser le flux d'air sortant de la cheminée.

2. OBJ2 - Réduire le temps pendant lequel la cheminée solaire est en dessous de la plage de $44^{\circ} \mathrm{C}$.

\section{IV.1 Résultats}

L'optimisation présentée dans cette section a été réalisée avec différentes populations et pendant différentes génération. Le but de cette augmentation est de déterminer 
la taille optimale de la population et le nombre de générations nécessaires pour obtenir une solution. Premièrement, l'optimisation a été réalisée en prenant en compte un nombre réduit de variables. Les premières optimisations ont pris en compte la hauteur de la cheminée, la taille de l'entrefer (distance entre le mur absorbant et le vitrage) et la magnitude du rayonnement incident. Le modèle numérique est exécuté en continu pour différentes valeurs comprises dans les intervalles présentés dans le tableau 2. En conséquence, le temps de calcul est multiplié en fonction du nombre de générations et d'individus.

Table 2: Paramètres d'optimisation

\begin{tabular}{|c|c|c|}
\hline \hline Paramètre & État Actuel & Intervalle de variation \\
\hline Hauteur du volume de la & $0.5 \mathrm{~m}$ & {$\left[\begin{array}{ll}0.45 & 0.6\end{array}\right]$} \\
cheminée solaire & $0.3 \mathrm{~m}$ & {$\left[\begin{array}{ll}0.3 & 0.5\end{array}\right]$} \\
Largeur du conduit & $600 \mathrm{~W} / \mathrm{m} 2$ & $\phi+\left[\begin{array}{ll}0 & 400\end{array}\right]$ \\
Radiation incidente maximale & \\
\hline \hline
\end{tabular}

La première simulation réalisée sur 10 générations et 10 individus a accepté les intervalles des variables établies. L'ajout de générations et d'individus augment le nombre de valeurs à prendre en compte parmi la plage sélectionnée de la variable d'optimisation. En effet, certaines combinaisons variables conduisent le système à la divergence. Cette erreur est inhérente au code en pression et elle est directement liée au rapport entrée/hauteur du modèle numérique de la cheminée. Quelques combinaisons qui ont entraîné la divergence de la simulation peuvent être appréciées dans le tableau 3.

Bien que non concluant, l'utilisation des algorithmes génétiques affiche une augmentation de la performance grâce à la modification de certains paramètres. Comme prévu, l'augmentation du rayonnement incident diminue le temps accumulé pendant lequel la cheminée solaire se situe dans la plage de température de $44{ }^{\circ} \mathrm{C}$. De même, le débit d'air le plus élevé peut être obtenu en augmentant la hauteur de la cheminée solaire et en augmentant l'apport solaire simulé.

Les algorithmes génétiques ont montré un grand potentiel dans la littérature 
Table 3: Paramètres d'erreur dans la simulation

\begin{tabular}{|c|c|c|c|c|c|}
\hline \hline & Gen Error & Gen/Pop & H & w & phi \\
\hline 1 & 5 & $25 / 50$ & 0.6 & 0.24 & 351.15 \\
2 & 4 & $25 / 50$ & 0.52 & 0.28 & 400 \\
\hline 3 & 13 & $25 / 50$ & 0.47 & 0.31 & 390 \\
\hline 4 & 3 & $50 / 75$ & 0.54 & 0.25 & 250 \\
5 & 8 & $50 / 75$ & 0.52 & 0.28 & 400 \\
6 & 1 & $50 / 100$ & 0.61 & 0.42 & 350 \\
7 & 1 & $50 / 100$ & 0.54 & 0.41 & 187 \\
8 & 2 & $50 / 100$ & 0.48 & 0.34 & 206 \\
9 & 3 & $50 / 100$ & 0.46 & 0.37 & 281.3 \\
10 & 2 & $100 / 100$ & 0.45 & 0.28 & 214.10 \\
\hline \hline
\end{tabular}

et ils ont conduit à l'optimisation paramétrique de plusieurs modèles numériques, mais elle semble être peu adaptée pour le modèle numérique actuel de la cheminée solaire. Le modèle numérique développé tout au long de cette thèse dépend du calcul des pressions et du débit d'air. Le code de pression utilisé pour le calcul des variables utilisé dépend des caractéristiques de la cheminée solaire. L'entrée et la sortie de la cheminée sont maintenues à la même taille pour garder une certaine cohérence avec les caractéristiques actuelles du laboratoire de la cheminée; Les modifications de la hauteur et de la largeur peuvent entraîner une divergence du système en fonction de la combinaison et de la résolution du signal. Après un nombre exhaustif de simulations, les paramètres ont dus être sévèrement limités, car une valeur élevée entraînerait l'arrêt de l'optimisation paramétrique en raison de la divergence.

Globalement, la simulation met en évidence la définition progressive d'un front de Pareto (Figure 21 à 23), même si l'optimisation n'arrive pas à la fin. Les algorithmes génétiques ont un grand potentiel pour la détermination des conditions optimales de la cheminée, mais la détermination de ces variables de conception dépend du raffinement du modèle numérique développé. Le système devrait être testé plus profondément avec une variable plus grande. Il semble qu'il est possible d'obtenir de meilleurs résultats avec de plus grandes hauteurs et de plus petites entrées d'air. 


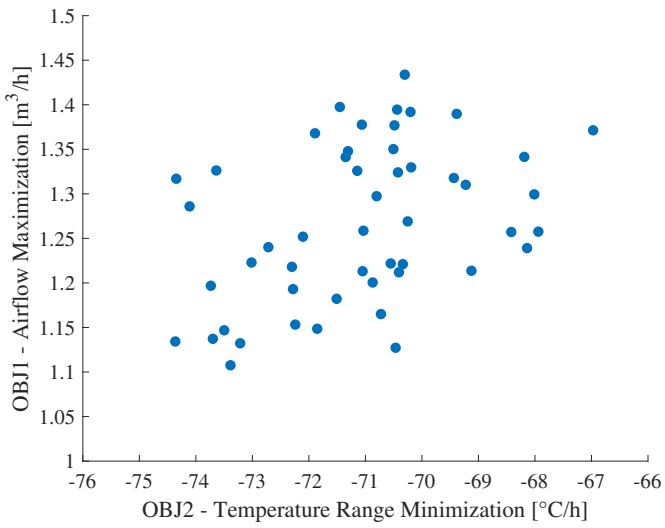

(a)

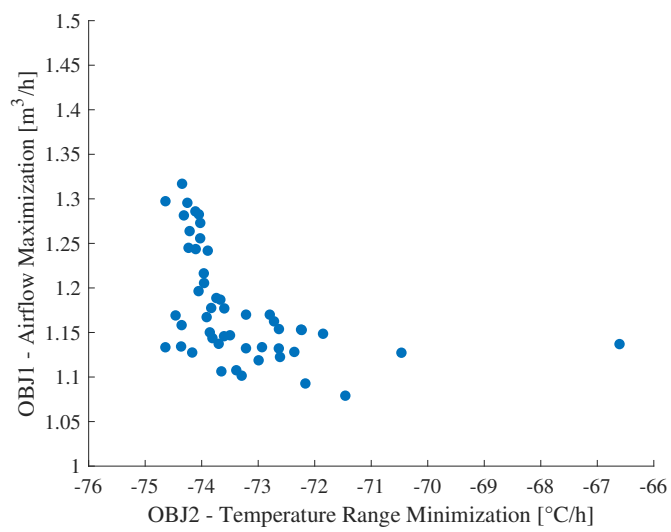

(b)

Figure 21: Résultats de (a) la première et (b) la troisième génération lors de l'application de la NSGA-II sur le modèle numérique de la cheminée solaire.

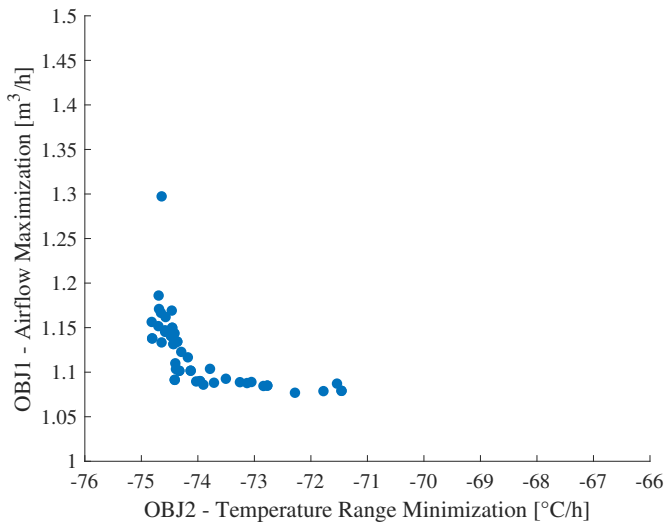

(a)

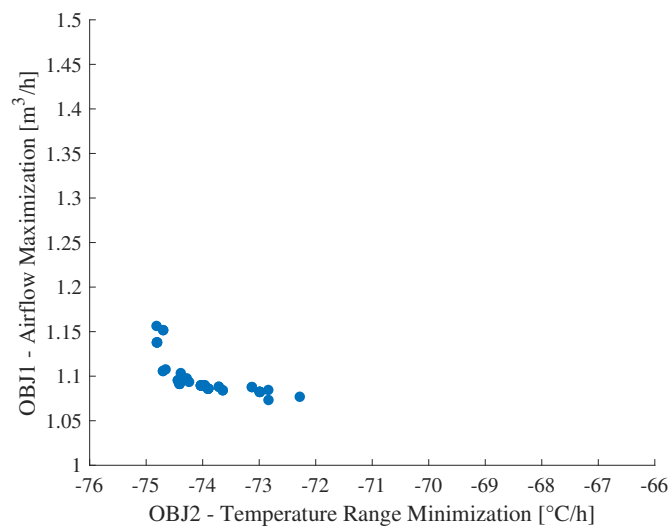

(b)

Figure 22: Résultats de (a) la sixième et (b) la neuvième génération lors de l'application de la NSGA-II sur le modèle numérique de la cheminée solaire.

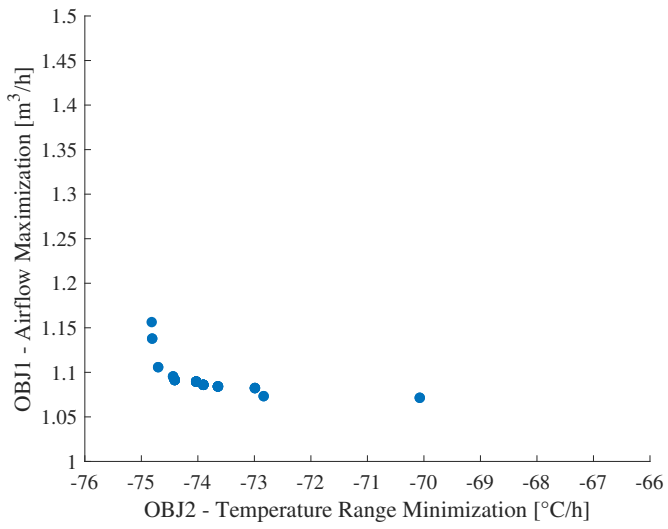

(a)

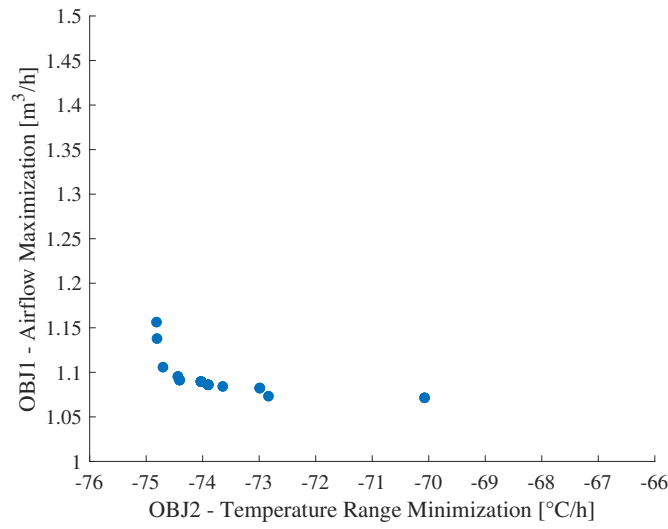

(b)

Figure 23: Résultats de (a) la douzième et (b) la treizième génération lors de l'application de la NSGA-II sur le modèle numérique de la cheminée solaire. 


\section{Conclusion}

Le travail présenté tout au long de cette thèse représente le travail collectif de trois laboratoires différents (ENTPE, CIEMAT et CENIDET) de trois pays investis dans les objectifs fixés lors de l'accord de Paris de 2015 sur l'efficacité énergétique. L'objectif de cette thèse était d'analyser numériquement et expérimentalement l'ajout de panneaux MCP sur une cheminée solaire en vue d'une utilisation prolongée de cette technologie verte. Les cheminées solaires ont déjà démontré un grand potentiel sans l'ajout de panneaux MCP, mais le système perd son potentiel sans énergie solaire. Afin de réaliser les objectifs de ce travail, la solution proposée consiste à incorporer des panneaux Rubitherm RT44 MCP qui sont intégrés à la surface de la cheminée.

Globalement, les deux campagnes expérimentales et celle in situ mènent aux conclusions suivantes:

1. L'ajout de panneaux MCP n'entrave pas les performances globales du système, mais il peut en résulter un débit massique plus élevé et une répartition de la température plus stable dans toute la cheminée. Cette température moyenne plus élevée peut être recirculée et utilisée pendant les saisons les plus froides. Une analyse de la qualité de cet air recyclé doit être effectuée s'il est utilisé à des fins de réutilisation à l'intérieur.

2. L'architecture de la cheminée semble nécessiter un certain nombre d'adaptations afin de capitaliser pleinement la mise en œuvre des panneaux MCP. Premièrement, la cheminée doit s'assurer que tous les panneaux reçoivent de l'énergie solaire incidente, soit en modifiant les parois de la cheminée, soit en faisant pivoter le système complet. Deuxièmement, le mur collecteur en béton de $0,15 \mathrm{~m}$ semble modifier les performances des résultats in situ en raison de la grande inertie thermique qu'il procure. Les travaux futurs devraient viser à modifier cet élément ou à ajouter une couche isolante entre les panneaux et le mur afin de réduire son impact. Il a été démontré qu'une 
cheminée solaire de construction simple peut fournir un débit d'air constant supérieur à $75 \mathrm{~m}^{3} / \mathrm{h}$ avec une énergie incidente relative faible de $600 \mathrm{~W} / \mathrm{m}^{2}$. Étant donné que les pays impliqués dans ce travail ont un rayonnement plus important, on peut en conclure que cette valeur peut atteindre des sommets plus élevés avec l'ajout de la vitesse du vent.

3. Afin de conclure sur les effets de la cheminée solaire intégrée MCP, une analyse plus complète doit être menée. Il a été prouvé que la vitesse du vent avait une grande influence sur la cheminée solaire PSA, mais cela pourrait être dû au rotatif utilisé pour créer un différentiel de pression supérieur. Une étude paramétrique de ces variables doit être réalisée afin de trouver l'élément le plus impactant.

Le modèle numérique a été calibré avec les données expérimentales, ce qui permet de définir une solution précise à un faible coût de calcul. L'utilisation d'algorithmes génétiques a permis de définir certains des paramètres de fonctionnement optimaux d'une cheminée solaire, mais des études supplémentaires devraient viser l'optimisation du modèle numérique dans des conditions environnementales. Ces outils sont limités par le modèle numérique qui peut diverger sous certains paramètres. L'optimisation continue de l'outil numérique est nécessaire pour les conclusions définitives fournies à la fois par le modèle numérique et la méthode d'optimisation. Néanmoins, les résultats de l'optimisation montrent les possibilités de cette méthode d'optimisation et le potentiel du modèle numérique de la cheminée solaire. 


\section{Abstract}

The current global warming conditions have led nations across the world to commit into energetic sustainability and greenhouse gas emission reduction. Being the third greatest energetic consumer, the building sector represents a major key towards energy efficiency and global temperature stabilization. Several solutions exist for the accomplishment of these goals, and the works presented throughout this dissertation concerns a particular external building solar-driven component known as solar chimney. This $\mathrm{PhD}$ thesis focuses on the experimental and numerical analysis of energy storage devices, in the form of Phase Changing Materials (PCMs), for the optimisation of the performance of this solar technology. The aim of this study is to characterize the impact of Rubitherm RT44 PCM panels on a solar chimney under laboratory and in-situ conditions to carry out a comparison against the classic version. Additionally, a numerical model was developed and tested in the interest of obtaining a numerical tool capable of representing the behaviour of a solar chimney. Finally a bi-objective optimization of the PCM integrated solar chimney numerical model was carried out in order to determine some of the optimal parameters of this type of technology to obtain the highest exiting air flow, all while maintaining a high enough temperature across the chimney to reach the fusion range of the PCMs. 


\section{Acknowledgements}

The work presented throughout this dissertation was carried out mostly at the "Laboratoire Génie Civil et Bâtiment" (LGCB/LTDS) as a member of the Geo-materials and Sustainable Constructions team. It represents the collaborative framework of three different countries and their respective laboratories towards energetic sustainability. I would like to start by thanking the "Centro de Investigaciones Energéticas, Medioambientales y Tecnológicas" (CIEMAT, Spain), the "Centro Nacional de Investigación y Desarrollo Tecnológico" (CENIDET, Mexico) and the ENTPE (France) for giving me the opportunity of meeting new colleagues and friends around the world, for all the teachings and good practices I learned and for helping me grow as an engineer, as a researcher and as a person throughout this three years.

My greatest gratitude is dedicated to Mohamed El Mankibi. His constant support and guidance allowed me to be a part of this great project and reach its completion. Through out this 3 years he became a pillar of my life whether it was as a thesis director or as a friend and colleague outside the laboratory, showing me that there is always a solution, and there is always a helping hand. I will forever be grateful for the trust he gave me and the constant encouragement in my everyday.

I would like to thank Ricardo Enriquez Miranda and Jesus Arce Landa for giving me the necessary support throughout my thesis work and always showing their availability and willingness to help. I am particularly grateful for setting the 
ground of the work I carried out and for letting me be a part of their group. Their kindness and friendliness will always be a part of my work and my life.

I would like to show my special appreciation to Professors Abdeslam Draoui and Claudio Del Pero for accepting to review this dissertation. In the same way, all my gratitude goes to Mrs. Stéphanie Giroux and Magali Roué, as well as Mr. Talal Salem for accepting to be members of the jury.

I thank CONACYT for giving me the opportunity of carrying out this $\mathrm{PhD}$ work. I thank their support and the financial help they gave me to accomplish this goal.

This achievement wouldn't be possible without the everlasting support of my family. I have no words to describe my gratitude for helping me in every step of this journey and for always being a part of every decision I have taken. Every stepping stone leading to this moment wouldn't have been possible without them.

Finally, I would like to show my appreciation to all the people from the LGCB/LTDS laboratory for the their friendship, their help and for welcoming me at this laboratory. I specially thank my fellow $\mathrm{PhD}$ students which whom I shared my everyday life, for they became my friends and a very important part of my life in Lyon. 


\section{Contents}

1 Introduction $\quad 65$

1.1 Motivation, Overview \& Context . . . . . . . . . . 66

1.1.1 French Context . . . . . . . . . . . 6 68

1.1.2 Mexican Context ................ 70

1.1.3 Spanish Context . . . . . . . . . . . . 71

1.2 Problematic and Scientific Challenges . . . . . . . . . . . 73

1.3 Research Objectives \& Scientific Approach . . . . . . . . . . . . 75

1.4 Dissertation Outline . . . . . . . . . . . . . 77

2 Literature Review - An Introduction to Passive Ventilation and $\begin{array}{ll}\text { Solar Chimneys } & 79\end{array}$

2.1 Introduction . . . . . . . . . . . . . . 80

2.2 Ventilation as a solution for Thermal Comfort . . . . . . . . . 80

2.3 Passive Ventilation . . . . . . . . . . . . . . 81

2.3.1 Trombe Walls and Ventilated Façades . . . . . . . . . . . 82

2.3.2 Wind Towers ................. 83

2.3.3 Solar Chimney . . . . . . . . . . . . . . 84

2.4 Thermal Energy Storage . . . . . . . . . . . . . . 96

2.4.1 Sensible Heat Storage . . . . . . . . . . . . . . . 96

2.4 .2 Chemical Heat Storage . . . . . . . . . . . . . 97

2.4 .3 Latent Heat Storage . . . . . . . . . . . . . . . . 97

2.4.4 Phase Changing Materials $(\mathrm{PCM}) \ldots . . . . . . . . . .999$

2.5 Active Solar Chimney (ASC): A PCM integrated Solar Chimney . . . 106

2.6 Conclusion . . . . . . . . . . . . . . . . . . 110 
3 Experimental Set-Up $\quad 111$

3.1 Introduction . . . . . . . . . . . . . . . . . . . 112

3.1 .1 PCM Selection ................... 113

3.2 Preliminary PCM Tests . . . . . . . . . . . . . . . . . 114

3.2.1 PCM Thermal Properties Determination . . . . . . . . 115

3.2 .2 Result Discussion . . . . . . . . . . . . . . 116

3.3 ENTPE Laboratory Experimentation . . . . . . . . . . . . . 118

3.3.1 Guarded Hot Box (GHB) . . . . . . . . . . . 118

3.3.2 Solar Chimney Prototype V1.0 . . . . . . . . . . . 119

3.3.3 Solar Chimney Prototype V2.0 . . . . . . . . . . . . 123

3.3.4 Experimental Protocol . . . . . . . . . . . . . 132

3.3.5 Results \& Discussion . . . . . . . . . . . . . . 133

3.4 PSA in-situ experimentation . . . . . . . . . . . . . . 150

3.4.1 PSA Solar Chimney Instrumentation . . . . . . . . . . . . 151

3.4 .2 PCM Implementation . . . . . . . . . . . . . 153

3.4.3 Analysis of Environmental Conditions . . . . . . . . . . . 154

3.4.4 Results \& Discussion . . . . . . . . . . . . . . 161

3.5 General Conclusion . . . . . . . . . . . . . . . . 174

4 Numerical Model for an Active Solar Chimney Simulation: Devel$\begin{array}{ll}\text { opment, Verification, Validation and Analysis } & 181\end{array}$

4.1 Introduction . . . . . . . . . . . . . . . . . . . . . 182

4.2 Application of the Finite Difference Method for a Multilayered wall . 183

4.2.1 Nodes in contact with the exterior . . . . . . . . . 185

4.2.2 Nodes within the inner layers . . . . . . . . . . . 187

4.2.3 Nodes in the interface between two solid materials . . . . . . . 189

4.2.4 Mathematical representation of a multilayer wall . . . . . . 189

4.2.5 Non-linearity modelization of PCM properties . . . . . . . . 191

4.2.6 Glazing Model . . . . . . . . . . . . . . 193

4.3 Modelization of radiative transfers . . . . . . . . . . . . . 194

4.3.1 Short wavelength radiative transfers . . . . . . . . . . 195

4.3.2 Long wavelength radiative transfers . . . . . . . . . . 196

4.4 Airflow Model - A zonal approach to the mass flow rate calculation . 197 
4.4 .1 Vertical Boundaries . . . . . . . . . . . . 199

4.4.2 Horizontal boundaries . . . . . . . . . . . . 200

4.4.3 Mathematical solution . . . . . . . . . . . 200

4.5 Convection Model and temperature correction . . . . . . . . . . . 202

4.6 Model coupling and Matlab Simulink Simulation . . . . . . . . . . . 204

4.6.1 The HYBCELL Model . . . . . . . . . . . . . . . . . 204

4.6.2 Active Solar Chimney Numerical Model . . . . . . . . . . . 205

4.6.3 Simulation parameters . . . . . . . . . . . 207

4.7 Results \& Discussion . . . . . . . . . . . . . . . . . 208

4.7.1 ASC Numerical Model Robustness and Correlation Validation 210

4.8 General Conclusion . . . . . . . . . . . . . . . . . . . 213

5 Numerical Optimization $\quad 215$

5.1 Introduction . . . . . . . . . . . . . . . . 216

5.1 .1 Principle of Genetic Algorithms . . . . . . . . . . . . 217

5.1.2 Non-dominated Sorting Genetic Algorithms II (NSGAs II) . 218

5.2 Optimization Procedure and Establishment of Objective Functions . . 220

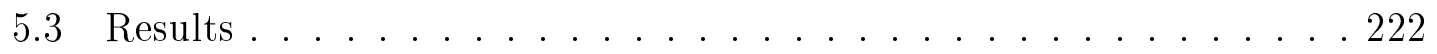

5.4 Conclusions . . . . . . . . . . . . . . . . 226

6 General Conclusion $\quad 229$

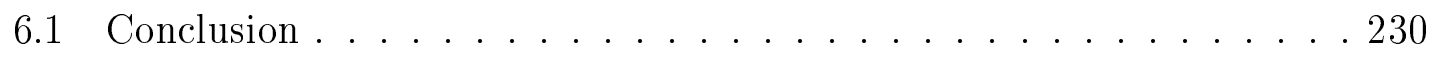

6.2 Outlook and Perspectives . . . . . . . . . . . . . 232

A Prototype V1 No PCM - Laboratory Results 235

A.1 C5NoPCM - Mass flow rate \& External and Surface Temperatures . . 236

A.2 C6NoPCM - Mass flow rate \& External and Internal Temperatures . 237

A.3 C7NoPCM - Mass flow rate \& External and Internal Temperatures . 239

B Prototype V1 PCM - Laboratory Results 241

B.1 C1PCM - Mass flow rate \& Surface Temperatures . . . . . . . . . . 242

B.2 C1PCM - Surface Temperature Behind PCM \& Surface Temperature

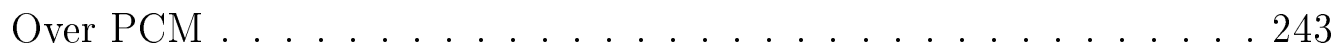

B.3 C3PCM - Mass flow rate \& Surface Temperatures . . . . . . . . . . 244 
B.4 C3PCM - Surface Temperature Behind PCM \& Surface Temperature

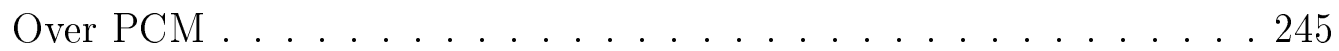

B.5 C4PCM - Mass flow rate \& Surface Temperatures . . . . . . . . . 246

B.6 C4PCM - Surface Temperature Behind PCM \& Surface Temperature Over PCM . . . . . . . . . . . . . . . . . . . 248

B.7 C5PCM - Mass flow rate \& Surface Temperatures . . . . . . . . . 250

B.8 C5PCM - Surface Temperature Behind PCM \& Surface Temperature

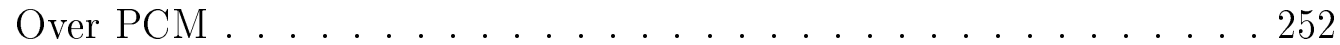

B.9 C6PCM - Mass flow rate \& Surface Temperatures . . . . . . . . . . 254

B.10 C6PCM - Surface Temperature Behind PCM \& Surface Temperature

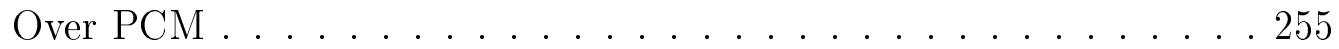

B.11 C7PCM - Mass flow rate \& Surface Temperatures . . . . . . . . . 256

B.12 C7PCM - Surface Temperature Behind PCM \& Surface Temperature

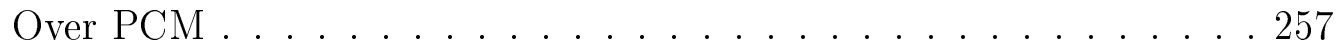

C Prototype V2 No PCM - Laboratory Results

C.1 P2C1NoPCM - Mass flow rate \& External and Internal Temperatures 260

C.2 P2C1NoPCM - Surface Temperatures \& Chimney air temperatures . 261

C.3 P2C2NoPCM - Mass flow rate \& External and Internal Temperatures 262

C.4 P2C2NoPCM - Surface Temperatures \& Chimney air temperatures . 262

C.5 P2C3NoPCM - Mass flow rate \& External and Internal Temperatures 263

C.6 P2C3NoPCM - Surface Temperatures \& Chimney air temperatures . 264

C.7 P2C4NoPCM - Mass flow rate \& External and Internal Temperatures 265

C.8 P2C4NoPCM - Surface Temperatures \& Chimney air temperatures . 266

$\begin{array}{ll}\text { D Prototype V2 PCM - Laboratory Results } & 267\end{array}$

D.1 P2C1PCM - Mass flow rate \& External and Internal Temperatures . 268

D.2 P2C1PCM - Surface Temperatures \& Chimney air temperatures . . . 269

D.3 P2C1PCM - Surface Temperature Behind PCM \& Surface Temperature Over PCM . . . . . . . . . . . . . . 270

D.4 P2C2PCM - Mass flow rate \& External and Internal Temperatures . 271

D.5 P2C2PCM - Surface Temperatures \& Chimney air temperatures . . . 272 
D.6 P2C2PCM - Surface Temperature Behind PCM \& Surface Temperature Over PCM . . . . . . . . . . . . . 273

D.7 P2C3PCM - Mass flow rate \& External and Internal Temperatures . 274

D.8 P2C3PCM - Surface Temperatures \& Chimney air temperatures . . . 275

D.9 P2C3PCM - Surface Temperature Behind PCM \& Surface Temperature Over PCM . . . . . . . . . . . . . 276

D.10 P2C5PCM - Mass flow rate \& External and Internal Temperatures . 277

D.11 P2C5PCM - Surface Temperatures \& Chimney air temperatures . . . 278

D.12 P2C5PCM - Surface Temperature Behind PCM \& Surface

Temperature Over PCM . . . . . . . . . . . . . 279

E Rubitherm RT44 Technical Data 281

F $\quad$ Statistical Selection of Seasonal Data 283 


\section{List of Figures}

1.1 World (a) Total Final Consumption (TFC) by source in ktoe and (b) of Total Final Consumption by sector. Source: IEA, Energy Balances of OECD Countries 2017, available at www.iea.org/statistics . . . . 66

1.2 World's Direct Normal Irradiance from 1983 to $2005 . \quad$. . . . . . . . . 67

1.3 French (a) Total Final Consumption (TFC) by source in ktoe and (b) of Total Final Consumption by sector. Source: IEA, Energy Balances of OECD Countries 2017, available at www.iea.org/statistics . . . . 69

1.4 Mexican (a) Total Final Consumption (TFC) by source in ktoe and (b) of Total Final Consumption by sector. Source: IEA, Energy Balances of OECD Countries 2017, available at www.iea.org/statistics 71

1.5 Spanish (a) Total Final Consumption (TFC) by source in ktoe and (b) of Total Final Consumption by sector. Source: IEA, Energy Balances of OECD Countries 2017, available at www.iea.org/statistics . . . . 72

1.6 Scientific approach employed during this dissertation. . . . . . . . . 76

2.1 Schematic diagram of classical Trombe wall (without dampers) presented by Chan et al. (2010) . . . . . . . . . . . 82

2.2 Ventilated façade presented by Ibañez-Puy et al. (2017) showing two different configurations. (left)Open joints, discontinuous skin and (right) closed joints, continues outer skin . . . . . . . . . 83

2.3 A two story wind tower along with the dome (Kolah-farangi) of the Aghazadeh mansion in Abarkuh city, Yazd, Iran (Dehghani-Sanij

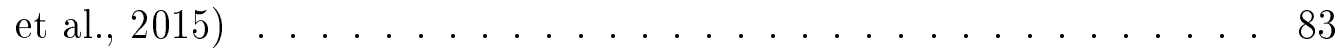

2.4 Schematic representation of air movement induced by a wind tower (Dehghani-Sanij et al., 2015) . . . . . . . . . . 84 
2.5 Schematic diagram of a simple solar chimney with vertical inlet subjected to environmental conditions. . . . . . . . . 86

2.6 Example of an existing solar chimney employed for the Manitoba Hydro Building in Winnipeg, Canada. (a) Photo available at http://manitobahydroplace.com and (b) description by Kuwabara et al. (2011) ......................... 87

2.7 System description used by Bansal et al. (1993) representing a Wall-Roof Inclined Solar Chimney . . . . . . . . . . . . . 88

2.8 Schematic of a two-dimensional solar chimney (IPWSC) attached to

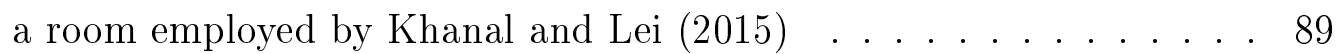

2.9 Location of Experimental (red), Numerical (blue) and Numerical \& Experimental (purple) SC studies . . . . . . . . . . . 93

2.10 Phase change diagram showing the theoretical transformation of a pure substance from solid state to liquid state. . . . . . . . . 98

2.11 Time evolution of the (a) temperature and (b) heat flux during the solidification of a pure body following a temperature drop (Kuznik et al., 2011) . . . . . . . . . . . . . . . 101

2.12 Phase Changing Material Classification (IEA,ECES Annex 23, 2013) 101

2.13 Phase Changing Material Classification depending on the melting temperature and enthalpy (Baetens et al., 2010) . . . . . . . . . . 102

2.14 PCM Macroencapsulation examples (Information from Rubitherm and Veerakumar and Sreekumar (2016)) . . . . . . . . . 104

2.15 Experimental set-up employed by Amori and Mohammed (2012) for the analysis of a PCM integrated $\mathrm{SC} \ldots \ldots 107$

2.16 Experimental set-up employed by Li and Liu $(2014 a, b)$; Li et al. (2016); Liu and $\operatorname{Li}(2015 a, b)$ for the analysis of a PCM integrated

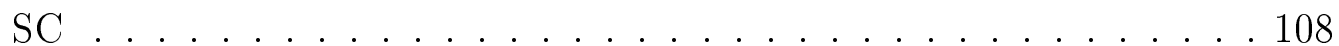

3.1 (a) RT44 panel subjected to a halogen lamp and (b) temperature evolution on an individual PCM panel . . . . . . . . . . 115

3.2 (a)-(c) DSC test machine and samples, and (d) DSC principle as shown by Borderon et al. (2017) . . . . . . . . . . . . . 116 
3.3 Isometric view of the Guarded Hot Box and its components: (from left to right) cold chamber, sample's case, hot chamber and protection case. . . . . . . . . . . . . . . . . . . 118

3.4 Blueprints of the cold chamber of the Guarded hot box employed in the solar chimney experimentations. . . . . . . . . . . . . 119

3.5 First solar chimney laboratory prototype developed at ENTPE . . . . 120

3.6 Sensors employed: (a) surface temperature, (b) air temperature, (c) air speed and $(\mathrm{d})$ heat flux . . . . . . . . . . . . . 121

3.7 Acquisition modules employed for the experimentation of the solar chimney prototype V1.0 . . . . . . . . . . . . . 122

3.8 Instrumentation employed for the solar chimney prototype V1.0 displaying (blue) surface temperature sensors, (green) air temperature sensors, (orange) Heat flux plate sensors and (red) wind speed sensors. 123

3.9 Solar chimney prototype V1.0 showing the experimental campaign during (a) ventilation only and (b) the charging phase of the experimental protocol without PCM panels . . . . . . . . . . 124

3.10 Solar chimney prototype V1.0 showing the experimental campaign during (a) ventilation only and (b) the charging phase of the experimental protocol with PCM panels . . . . . . . . . . . 124

3.11 (a) Lateral view of the SCV2 before sensor placement and (b) SCV2 open for no PCM set-up. . . . . . . . . . . . . . 125

3.12 Instrumentation changes for the SCV2 showing (a) surface temperature sensors and (b) the Delta Ohm wireless acquisition modules. . . . . . . . . . . . . . . . . 127

3.13 Instrumentation employed for the SCV2 displaying (green) surface temperature sensors on the chimney surface grid, (red) air temperature sensors, (blue) Heat flux plate sensors and (orange) wind speed sensors. . . . . . . . . . . . . . . . 127

3.14 SCV2 showing the experimental campaign during (a) ventilation only and (b) the charging phase of the experimental protocol without PCM128

3.15 SCV2 showing the experimental campaign during (a) ventilation only and (b) the charging phase of the experimental protocol with PCM . 128 
3.16 SCV2 with matte black PCM panels (a) during painting process and (b) completed work.

3.17 PCM panel leak after reaching maximum operating temperature $\left(70^{\circ} \mathrm{C}\right)$ and experiencing volume expansion. . . . . . . . . 130

3.18 Blueprints of the second solar chimney prototype et ENTPE . . . . . 131

3.19 Experimental protocol employed for both prototypes picturing the activation of ventilation (open/closed outlet) in blue and solar

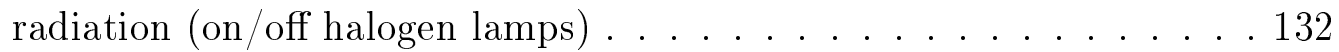

3.20 Incoming heat flux during the laboratory experiment . . . . . . . 133

3.21 Nomenclature of results for both (a) SCV1 and (b) SCV2. . . . . . 134

3.22 C5NoPCM-1 results showing (a) surface temperature and (b) experimental conditions. . . . . . . . . . . . . 135

3.23 C1PCM-1 results showing (a) surface temperature and (b) experimental conditions. . . . . . . . . . . . 136

$3.24 \mathrm{C} 7 \mathrm{NoPCM}-2$ results showing (a) surface temperature and (b) experimental conditions. . . . . . . . . . . . 136

3.25 C3PCM-2 results showing (a) surface temperature and (b) experimental conditions. . . . . . . . . . . . . 137

3.26 Mean surface temperature and surface temperature difference for (a) P2C1NoPCM-1 vs P2C2NoPCM-1 and (b) P2C1NoPCM-1 vs

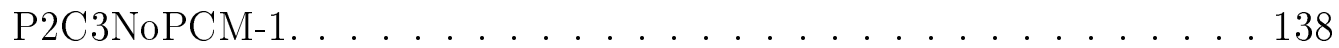

3.27 P2C1NoPCM-2 results of (a) surface temperature and (b) operating conditions (external and volume temperature). No insulation and cooler temperature set to $18{ }^{\circ} \mathrm{C} \ldots \ldots \ldots \ldots$. . . . . . . . . 139

3.28 P2C3NoPCM-2 results of (a) surface temperature and (b) operating conditions (external and volume temperature). With insulation and cooler temperature set to $18{ }^{\circ} \mathrm{C} \ldots \ldots \ldots \ldots$

3.29 P2C4NoPCM-3 results of (a) surface temperature and (b) operating conditions (external and volume temperature). With insulation and no cooler temperature support. . . . . . . . . . . . . 139 
3.30 P2C1PCM-2 results of (a) surface temperature and (b) operating conditions (external and volume temperature). No insulation and cooler temperature set to $18{ }^{\circ} \mathrm{C} \ldots \ldots \ldots$. . . . . . . . . . 141

3.31 P2C2PCM-2 results of (a) surface temperature and (b) operating conditions (external and volume temperature). With insulation and cooler temperature set to $18{ }^{\circ} \mathrm{C} \ldots \ldots \ldots 141$

3.32 P2C5PCM-2 results of (a) surface temperature and (b) operating conditions (external and volume temperature). With insulation and no cooler temperature support. . . . . . . . . . . . . . 141

3.33 Air temperature distribution showing inlet level, mid level $(1.6 \mathrm{~m})$ and outlet level $(3.2 \mathrm{~m})$ under similar operating conditions for (a) P2C1NoPCM-2 and (b) P2C1PCM-2. . . . . . . . . . . . . 144

3.34 Air temperature distribution showing inlet level, mid level $(1.6 \mathrm{~m})$ and outlet level $(3.2 \mathrm{~m})$ under similar operating conditions for (a) P2C3NoPCM-2 and (b) P2C2PCM-2. . . . . . . . . . . 144

3.35 Air temperature distribution showing inlet level, mid level $(1.6 \mathrm{~m})$ and outlet level $(3.2 m)$ under similar operating conditions for (a) P2C4NoPCM-3 and (b) P2C5PCM-2. . . . . . . . . . . . 144

3.36 Mass flow rate results under similar operating conditions for C5NoPCM-1 and C1PCM-1. . . . . . . . . . . . . 145

3.37 Mass flow rate results under similar operating conditions for C7NoPCM-1 and C3PCM-2. . . . . . . . . . . . 146

3.38 Mass flow rate results under similar operating conditions for P2C1NoPCM-2 and P2C1PCM-2. . . . . . . . . . 147

3.39 Mass flow rate results under similar operating conditions for P2C3NoPCM-2 and P2C2PCM-2. . . . . . . . . . 147

3.40 Mass flow rate results under similar operating conditions for (a) P2C4NoPCM-3 and (b) P2C5PCM-2. . . . . . . . . . . 149

3.41 Solar Chimney location on the PSA of the CIEMAT . . . . . . . . 150

3.42 Solar chimney of the CIEMAT at the PSA showing (a)the entrance of the PSA, (b) and (d) front and back images of the solar chimney and (c) the solar chimney opened for panel installation . . . . . . . 152 
3.43 (a) lateral view of the PSA solar chimney and the instrumentation according to (Arce et al., 2015) and (b)Sensor placement above and below the panels at (72) 1.25m, (41 - 43) 2.75m and (11 - 13) 4.25m. 153

3.44 Solar radiation (VGSR and HGSR) for the winter period on (a) January 16th, 2016 and (b) January 16th, 2018 . . . . . . . . . 157

3.45 Solar radiation (VGSR and HGSR) for the spring period on (a) March 4th, 2016 and (b) March 9th, $2018 \ldots \ldots$. . . . . . . . . . . . . . . . . .

3.46 Solar radiation (VGSR and HGSR) for the summer period on (a) July 2nd, 2016 and (b) July 17th, $2018 \ldots \ldots$. . . . . . . . . 159

3.47 Environmental conditions for the statistical data of the winter period of (a) January 16th, 2016 and (b) January 16th, 2018. . . . . . . . 160

3.48 Environmental conditions for the statistical data of the spring period of (a) March 2nd, 2016 and (b) March 27th, 2018. . . . . . . . 160

3.49 Environmental conditions for the statistical data of the summer period of (a) July 2nd, 2016 and (b) July 17th, 2018. . . . . . . . 160

3.50 Surface temperature at the different levels during the spring period on (a) January 16th, 2016 and (b) January 16th, 2018 . . . . . . . 164

3.51 Surface temperature at the different levels during the spring period on (a) March 2nd, 2016 and (b) March 27th, $2018 \ldots . . . . . . .164$

3.52 Surface temperature at the different levels during the Summer period on (a) July 2nd, 2016 and (b) July 17th, 2018. . . . . . . . . . 164

3.53 PCM surface temperature for rows (a) 7 (b) 4 and (c) 1 of January

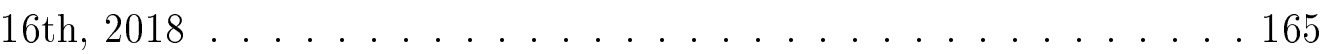

3.54 PCM surface temperature for rows (a) 7 (b) 4 and (c) 1 of March $27 \mathrm{th}, 2018 \ldots \ldots \ldots \ldots \ldots \ldots \ldots$

3.55 PCM surface temperature for rows (a) 7 (b) 4 and (c) 1 of July 17th,

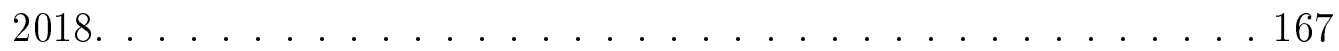

3.56 Air temperature for at different heights during (a) January 16th, 2016 and (b) January 16th, 2018. . . . . . . . . . . . . . 169

3.57 Air temperature for at different heights during (a) March 2nd, 2016 and (b) March 27th, 2018. . . . . . . . . . . 169 
3.58 Air temperature for at different heights during (a) July 2nd, 2016 and (b) July 17 th, 2018. . . . . . . . . . . . . . . . . 169

3.59 Air temperature difference between external temperature and outlet temperature during (a) January 16th, 2016 and (b) January 16th, 2018.170

3.60 Air temperature difference between external temperature and outlet temperature during (a) March 2nd, 2016 and (b) March 27th, 2018. . 170

3.61 Air temperature difference between external temperature and outlet temperature during (a) July 2nd, 2016 and (b) July 17th, 2018. . . . 170

3.62 Outlet air flow rate and wind speed during (a) January 16th, 2016 and (b) January 16th, 2018. . . . . . . . . . . . . . 173

3.63 Outlet air flow rate and wind speed during (a) March 2nd, 2016 and (b) March 27th, 2018.

3.64 Outlet air flow rate and wind speed during (a) July 2nd, 2016 and (b) July 17th, 2018 .

4.1 Spatial discretization of a $n$ layer multilayered wall . . . . . . 183

4.2 Schematic representation of a forward difference time $t$ and a second-order central difference for the space derivative at position $x_{i}$ of (a) an explicit scheme at (FTCS), a (b) in implicit backward difference at time $t+1$ and (c) a Crank-Nicholson scheme. . . . . 185

4.3 DSC results for the RT44 PCM showing the evolution of heat flux as function of temperature . . . . . . . . . . . . . 192

4.4 CLO radiation flux distribution in the simulated solar chimney . . . 195

4.5 Vertical discretization of the solar chimney . . . . . . . . . . 197

4.6 Airflow through a large vertical opening . . . . . . . . . . . 199

4.7 Matlab Simulink HYBCELL interface. . . . . . . . . . . . . . . . 204

4.8 Matlab Simulink HYBCELL volume characteristics. . . . . . . . . . 205

4.9 Solar chimney model calculation flow chart . . . . . . . . . 206

4.10 Comparative results for (a) mass flow rate and (b) outlet temperature between simulation and the P2C3NoPCM-2 experimental campaign. . 209

4.11 Comparative results for (a) mass flow rate and (b) outlet temperature between simulation and the P2C4NoPCM-3 experimental campaign. . 209 
4.12 Comparative results for (a) mass flow rate and (b) outlet temperature between simulation and the P2C1PCM-2 experimental campaign. . . 209

4.13 Comparative results for (a) mass flow rate and (b) outlet temperature between simulation and the P2C2PCM-2 experimental campaign. . . 210

4.14 Comparative results for (a) mass flow rate and (b) outlet temperature between simulation and the P2C5PCM-2 experimental campaign. . . 210

5.1 Genetic Algorithm field in the hierarchic structure of Knowledge Based Information Systems presented by Mukhopadhyay et al. (2009) 216

5.2 Pareto front for a bi-objective optimization function. . . . . . . . 218

5.3 Results of the (a) first and (b) third generations of the application of the NSGA-II on the ASC numerical model. . . . . . . . . . . . 225

5.4 Results of the (a) sixth and (b) ninth generations of the application of the NSGA-II on the ASC numerical model. . . . . . . . . . . . 225

5.5 Results of the (a) twelfth and (b) thirteenth generations of the application of the NSGA-II on the ASC numerical model. . . . . . . . 225

A.1 C5NoMCP-1 results of (a) mass flow rate and (b) external and volume temperatures. Cooler temperature $=18{ }^{\circ} \mathrm{C}$, unknown external

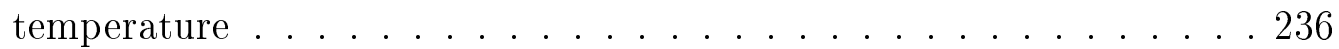

A.2 C5NoMCP-2 results of (a) mass flow rate and (b) external and volume temperatures. Cooler temperature $=18{ }^{\circ} \mathrm{C}$, unknown external

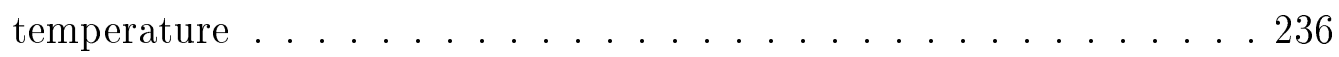

A.3 C6NoMCP-1 results of (a) mass flow rate and (b) external and volume temperatures. Cooler temperature $=19{ }^{\circ} \mathrm{C}$, unknown external

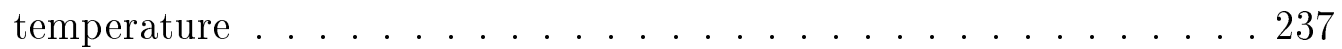

A.4 C6NoMCP-2 results of (a) mass flow rate and (b) external and volume temperatures. Cooler temperature $=19{ }^{\circ} \mathrm{C}$, unknown external

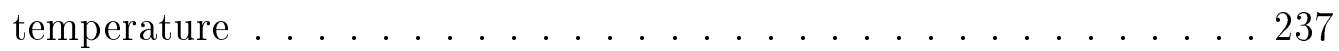

A.5 C6NoMCP-3 results of (a) mass flow rate and (b) external and volume temperatures. Cooler temperature $=19{ }^{\circ} \mathrm{C}$, unknown external

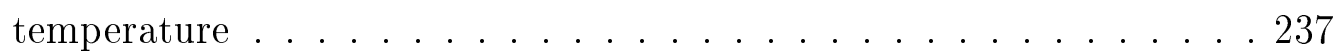


A.6 C6NoMCP-4 results of (a) mass flow rate and (b) external and volume temperatures. Cooler temperature $=19{ }^{\circ} \mathrm{C}$, unknown external

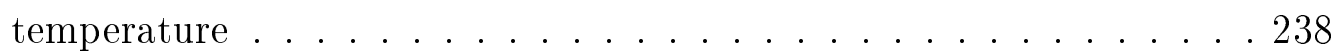

A.7 C7NoMCP-1 results of (a) mass flow rate and (b) external and volume temperatures. Cooler temperature $=18{ }^{\circ} \mathrm{C}$, unknown external

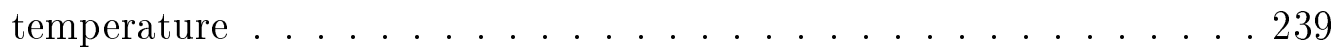

A.8 C7NoMCP-2 results of (a) mass flow rate and (b) external and volume temperatures. Cooler temperature $=18{ }^{\circ} \mathrm{C}$, unknown external

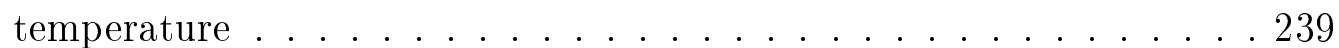

B.1 C1MCP-1 results of (a) mass flow rate and (b) external and volume temperatures. Cooler temperature $=18{ }^{\circ} \mathrm{C}$, unknown external

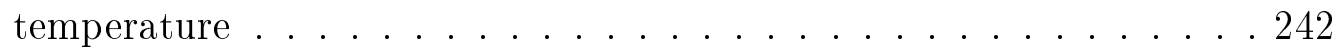

B.2 C1MCP-2 results of (a) mass flow rate and (b) external and volume temperatures. Cooler temperature $=18{ }^{\circ} \mathrm{C}$, unknown external

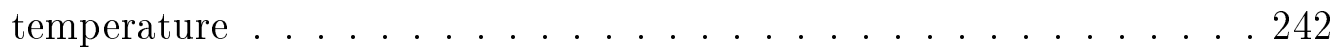

B.3 C1MCP-1 surface temperature results (a) behind and (b) in front the PCM panel at (blue) $1.0 \mathrm{~m}$, (black), $2.5 \mathrm{~m}$ and (red) $3.8 \mathrm{~m}$. . . . . . 243

B.4 C1MCP-2 surface temperature results (a) behind and (b) in front the PCM panel at (blue) $1.0 \mathrm{~m}$, (black), $2.5 \mathrm{~m}$ and (red) $3.8 \mathrm{~m} . . . .243$

B.5 C3MCP-1 results of (a) mass flow rate and (b) external and volume temperatures. No Cooler, prototype subjected to external temperature. 244

B.6 C3MCP-2 results of (a) mass flow rate and (b) external and volume temperatures. No Cooler, prototype subjected to external temperature. 244

B.7 C3MCP-3 results of (a) mass flow rate and (b) external and volume temperatures. No Cooler, prototype subjected to external temperature. 244

B.8 C3MCP-1 surface temperature results (a) behind and (b) in front the PCM panel at (blue) $1.0 \mathrm{~m}$, (black), $2.5 \mathrm{~m}$ and (red) $3.8 \mathrm{~m} . . . .245$

B.9 C3MCP-2 surface temperature results (a) behind and (b) in front the PCM panel at (blue) $1.0 \mathrm{~m}$, (black), $2.5 \mathrm{~m}$ and (red) $3.8 \mathrm{~m}$. . . . . . 245

B.10 C3MCP-3 surface temperature results (a) behind and (b) in front the PCM panel at (blue) $1.0 \mathrm{~m}$, (black), $2.5 \mathrm{~m}$ and (red) $3.8 \mathrm{~m}$. . . . . . 245 
B.11 C4MCP-1 results of (a) mass flow rate and (b) external and volume temperatures. Cooler temperature $=19{ }^{\circ} \mathrm{C}$, unknown external

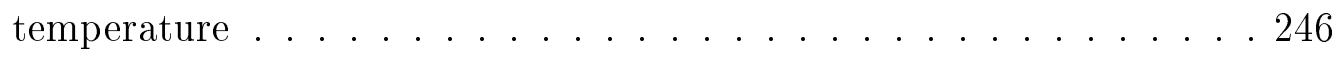

B.12 C4MCP-2 results of (a) mass flow rate and (b) external and volume temperatures. Cooler temperature $=19{ }^{\circ} \mathrm{C}$, unknown external

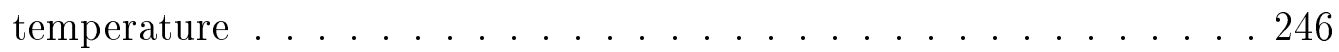

B.13 C4MCP-3 results of (a) mass flow rate and (b) external and volume temperatures. Cooler temperature $=19{ }^{\circ} \mathrm{C}$, unknown external

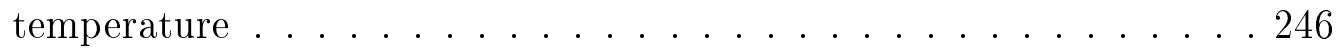

B.14 C4MCP-4 results of (a) mass flow rate and (b) external and volume temperatures. Cooler temperature $=19{ }^{\circ} \mathrm{C}$, unknown external

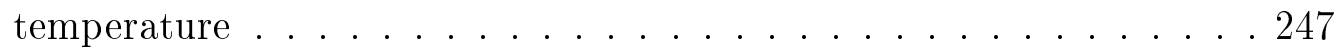

B.15 C4MCP-1 surface temperature results (a) behind and (b) in front the PCM panel at (blue) $1.0 \mathrm{~m}$, (black), $2.5 \mathrm{~m}$ and (red) $3.8 \mathrm{~m}$. . . . . . 248

B.16 C4MCP-2 surface temperature results (a) behind and (b) in front the PCM panel at (blue) $1.0 \mathrm{~m}$, (black), $2.5 \mathrm{~m}$ and (red) $3.8 \mathrm{~m}$. . . . . . 248

B.17 C4MCP-3 surface temperature results (a) behind and (b) in front the PCM panel at (blue) $1.0 \mathrm{~m}$, (black), $2.5 \mathrm{~m}$ and (red) $3.8 \mathrm{~m}$. . . . . 248

B.18 C4MCP-4 surface temperature results (a) behind and (b) in front the PCM panel at (blue) $1.0 \mathrm{~m}$, (black), $2.5 \mathrm{~m}$ and (red) $3.8 \mathrm{~m}$. . . . . . 249

B.19 C5MCP-1 results of (a) mass flow rate and (b) external and volume temperatures. Cooler temperature $=19{ }^{\circ} \mathrm{C}$, unknown external

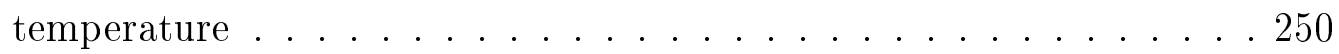

B.20 C5MCP-2 results of (a) mass flow rate and (b) external and volume temperatures. Cooler temperature $=19{ }^{\circ} \mathrm{C}$, unknown external

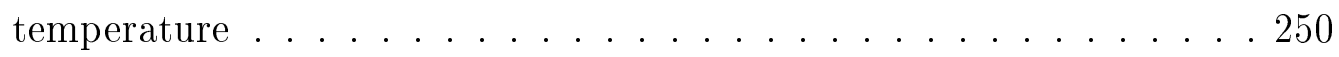

B.21 C5MCP-3 results of (a) mass flow rate and (b) external and volume temperatures. Cooler temperature $=19{ }^{\circ} \mathrm{C}$, unknown external

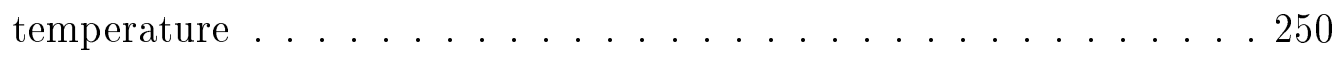

B.22 C5MCP-4 results of (a) mass flow rate and (b) external and volume temperatures. Cooler temperature $=19{ }^{\circ} \mathrm{C}$, unknown external

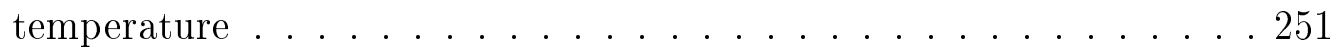


B.23 C5MCP-1 surface temperature results (a) behind and (b) in front the PCM panel at (blue) $1.0 \mathrm{~m}$, (black), $2.5 \mathrm{~m}$ and (red) $3.8 \mathrm{~m}$. . . . . . 252

B.24 C5MCP-2 surface temperature results (a) behind and (b) in front the PCM panel at (blue) $1.0 \mathrm{~m}$, (black), $2.5 \mathrm{~m}$ and (red) $3.8 \mathrm{~m}$. . . . . . 252

B.25 C5MCP-3 surface temperature results (a) behind and (b) in front the PCM panel at (blue) $1.0 \mathrm{~m}$, (black), $2.5 \mathrm{~m}$ and (red) $3.8 \mathrm{~m}$. . . . . . 252

B.26 C5MCP-4 surface temperature results (a) behind and (b) in front the PCM panel at (blue) $1.0 \mathrm{~m}$, (black), $2.5 \mathrm{~m}$ and (red) $3.8 \mathrm{~m}$. . . . . . 253

B.27 C6MCP-1 results of (a) mass flow rate and (b) external and volume temperatures. No Cooler, prototype subjected to external temperature. 254

B.28 C6MCP-2 results of (a) mass flow rate and (b) external and volume temperatures. No Cooler, prototype subjected to external temperature. 254

B.29 C6MCP-1 surface temperature results (a) behind and (b) in front the PCM panel at (blue) $1.0 \mathrm{~m}$, (black), $2.5 \mathrm{~m}$ and (red) $3.8 \mathrm{~m} . . .255$

B.30 C6MCP-2 surface temperature results (a) behind and (b) in front the PCM panel at (blue) $1.0 \mathrm{~m}$, (black), $2.5 \mathrm{~m}$ and (red) $3.8 \mathrm{~m}$. . . . . . 255

B.31 C1MCP-1 results of (a) mass flow rate and (b) external and volume temperatures. No Cooler, prototype subjected to external temperature. The time of each phase was extended to 8 hours to observe the behaviour of the PCM when exposed to a heat source for longer period. . . . . . . . . . . . . . . . 256

B.32 C7MCP-1 surface temperature results (a) behind and (b) in front the PCM panel at (blue) $1.0 \mathrm{~m}$, (black), $2.5 \mathrm{~m}$ and (red) $3.8 \mathrm{~m}$. The time of each phase was extended to 8 hours to observe the behaviour of the PCM when exposed to a heat source for longer period. . . . . . 257

C.1 P2C1NoPCM-1 results of (a) mass flow rate and (b) external and volume temperatures. Cooler set temperature $=18{ }^{\circ} \mathrm{C} \ldots 260$

C.2 P2C1NoPCM-2 results of (a) mass flow rate and (b) external and volume temperatures. Cooler set temperature $=18{ }^{\circ} \mathrm{C} \ldots 260$

C.3 P2C1NoPCM-1 results of (a) air temperature at inlet, mid and outlet level, and (b) surface temperature at $0.8,1.5$ and $3.0 \mathrm{~m} \ldots 261$ 
C.4 P2C1NoPCM-2 results of (a) air temperature at inlet, mid and outlet level, and (b) surface temperature at $0.8,1.5$ and $3.0 \mathrm{~m} \ldots 261$

C.5 P2C2NoPCM-1 results of (a) mass flow rate and (b) external and volume temperatures. Cooler set temperature $=18{ }^{\circ} \mathrm{C} \ldots 262$

C.6 P2C2NoPCM-1 results of (a) air temperature at inlet, mid and outlet level, and (b) surface temperature at $0.8,1.5$ and $3.0 \mathrm{~m}$. . . . . 262

C.7 P2C3NoPCM-1 results of (a) mass flow rate and (b) external and volume temperatures. Cooler set temperature $=18{ }^{\circ} \mathrm{C} \ldots 263$

C.8 P2C3NoPCM-2 results of (a) mass flow rate and (b) external and volume temperatures. Cooler set temperature $=18{ }^{\circ} \mathrm{C} \ldots 263$

C.9 P2C3NoPCM-3 results of (a) mass flow rate and (b) external and volume temperatures. Cooler set temperature $=18{ }^{\circ} \mathrm{C} \ldots 263$

C.10 P2C3NoPCM-1 results of (a) air temperature at inlet, mid and outlet level, and (b) surface temperature at $0.8,1.5$ and $3.0 \mathrm{~m} \ldots 264$

C.11 P2C3NoPCM-2 results of (a) air temperature at inlet, mid and outlet level, and (b) surface temperature at $0.8,1.5$ and $3.0 \mathrm{~m} \ldots . .264$

C.12 P2C3NoPCM-3 results of (a) air temperature at inlet, mid and outlet level, and (b) surface temperature at $0.8,1.5$ and $3.0 \mathrm{~m} \ldots 264$

C.13 P2C4NoPCM-1 results of (a) mass flow rate and (b) external and volume temperatures. Prototype subjected to external temperature. . 265

C.14 P2C4NoPCM-2 results of (a) mass flow rate and (b) external and volume temperatures. Prototype subjected to external temperature . 265

C.15 P2C4NoPCM-3 results of (a) mass flow rate and (b) external and volume temperatures. Prototype subjected to external temperature . 265

C.16 P2C4NoPCM-1 results of (a) air temperature at inlet, mid and outlet level, and (b) surface temperature at $0.8,1.5$ and $3.0 \mathrm{~m} \ldots 266$

C.17 P2C4NoPCM-2 results of (a) air temperature at inlet, mid and outlet level, and (b) surface temperature at $0.8,1.5$ and $3.0 \mathrm{~m} \ldots 266$

C.18 P2C4NoPCM-3 results of (a) air temperature at inlet, mid and outlet level, and (b) surface temperature at $0.8,1.5$ and $3.0 \mathrm{~m} \ldots 266$

D.1 P2C1PCM-1 results of (a) mass flow rate and (b) external and volume temperatures. Cooler set temperature $=18{ }^{\circ} \mathrm{C} \ldots \ldots 268$ 
D.2 P2C1PCM-2 results of (a) mass flow rate and (b) external and volume temperatures. Cooler set temperature $=18{ }^{\circ} \mathrm{C} \ldots$. . . . . . . 268

D.3 P2C1PCM-1 results of (a) air temperature at inlet, mid and outlet level, and (b) surface temperature at $0.8,1.5$ and $3.0 \mathrm{~m} \ldots 269$

D.4 P2C1PCM-2 results of (a) air temperature at inlet, mid and outlet level, and (b) surface temperature at $0.8,1.5$ and $3.0 \mathrm{~m} \ldots 269$

D.5 P2C1PCM-1 results of surface temperature (a) behind PCM and (b) over PCM at $0.8,1.5$ and $3.0 \mathrm{~m} \ldots \ldots . \ldots 270$

D.6 P2C1PCM-2 results of surface temperature (a) behind PCM and (b) over PCM at $0.8,1.5$ and $3.0 \mathrm{~m} \ldots \ldots . \ldots . \ldots . \ldots 270$

D.7 P2C2PCM-1 results of (a) mass flow rate and (b) external and volume temperatures. Cooler set temperature $=18{ }^{\circ} \mathrm{C}$. . . . . . . . . 271

D.8 P2C2PCM-2 results of (a) mass flow rate and (b) external and volume temperatures. Cooler set temperature $=18{ }^{\circ} \mathrm{C} \ldots \ldots . \ldots 271$

D.9 P2C2PCM-3 results of (a) mass flow rate and (b) external and volume temperatures. Cooler set temperature $=18{ }^{\circ} \mathrm{C} \ldots \ldots . \ldots 271$

D.10 P2C2PCM-1 results of (a) air temperature at inlet, mid and outlet level, and (b) surface temperature at $0.8,1.5$ and $3.0 \mathrm{~m} \ldots 272$

D.11 P2C2PCM-2 results of (a) air temperature at inlet, mid and outlet level, and (b) surface temperature at $0.8,1.5$ and $3.0 \mathrm{~m} \ldots 272$

D.12 P2C2PCM-3 results of (a) air temperature at inlet, mid and outlet level, and (b) surface temperature at $0.8,1.5$ and $3.0 \mathrm{~m} \ldots 272$

D.13 P2C2PCM-1 results of surface temperature (a) behind PCM and (b) over PCM at $0.8,1.5$ and $3.0 \mathrm{~m} \ldots \ldots . \ldots 273$

D.14 P2C2PCM-2 results of surface temperature (a) behind PCM and (b) over PCM at $0.8,1.5$ and $3.0 \mathrm{~m} \ldots \ldots . \ldots . \ldots . \ldots 273$

D.15 P2C2PCM-3 results of surface temperature (a) behind PCM and (b) over PCM at $0.8,1.5$ and $3.0 \mathrm{~m} \ldots \ldots . \ldots 273$

D.16 P2C3PCM-1 results of (a) mass flow rate and (b) external and volume temperatures. Cooler set temperature $=18{ }^{\circ} \mathrm{C} \ldots \ldots 274$

D.17 P2C3PCM-2 results of (a) mass flow rate and (b) external and volume temperatures. Cooler set temperature $=18{ }^{\circ} \mathrm{C} \ldots \ldots . \ldots . . .274$ 
D.18 P2C3PCM-1 results of (a) air temperature at inlet, mid and outlet level, and (b) surface temperature at $0.8,1.5$ and $3.0 \mathrm{~m} \ldots 275$

D.19 P2C3PCM-2 results of (a) air temperature at inlet, mid and outlet level, and (b) surface temperature at $0.8,1.5$ and $3.0 \mathrm{~m} \ldots 275$

D.20 P2C3PCM-1 results of surface temperature (a) behind PCM and (b) over PCM at $0.8,1.5$ and $3.0 \mathrm{~m} \ldots . . \ldots 276$

D.21 P2C3PCM-2 results of surface temperature (a) behind PCM and (b) over PCM at $0.8,1.5$ and $3.0 \mathrm{~m} \ldots \ldots . \ldots 276$

D.22 P2C5PCM-1 results of (a) mass flow rate and (b) external and volume temperatures. Cooler set temperature $=18{ }^{\circ} \mathrm{C} \ldots \ldots . \ldots 277$

D.23 P2C5PCM-2 results of (a) mass flow rate and (b) external and volume temperatures. Cooler set temperature $=18{ }^{\circ} \mathrm{C}$. . . . . . . . . 277

D.24 P2C5PCM-3 results of (a) mass flow rate and (b) external and volume temperatures. Cooler set temperature $=18^{\circ} \mathrm{C}$. . . . . . . . . 277

D.25 P2C5PCM-1 results of (a) air temperature at inlet, mid and outlet level, and (b) surface temperature at $0.8,1.5$ and $3.0 \mathrm{~m} \ldots 278$ D.26 P2C5PCM-2 results of (a) air temperature at inlet, mid and outlet level, and (b) surface temperature at $0.8,1.5$ and $3.0 \mathrm{~m} \ldots 278$

D.27 P2C5PCM-3 results of (a) air temperature at inlet, mid and outlet level, and (b) surface temperature at $0.8,1.5$ and $3.0 \mathrm{~m} \ldots 278$

D.28 P2C5PCM-1 results of surface temperature (a) behind PCM and (b) over PCM at $0.8,1.5$ and $3.0 \mathrm{~m} \ldots . . \ldots 279$

D.29 P2C5PCM-2 results of surface temperature (a) behind PCM and (b) over PCM at $0.8,1.5$ and $3.0 \mathrm{~m} \ldots . . \ldots 279$

D.30 P2C5PCM-3 results of surface temperature (a) behind PCM and (b) over PCM at $0.8,1.5$ and $3.0 \mathrm{~m} \ldots . . \ldots 279$ 


\section{List of Tables}

1.1 Goals set towards Energetic Sustainability and Climate Change for

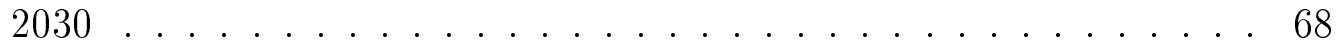

2.1 Comparison of typical storage densities of different energy storage methods presented by Cabeza and Mehling (2007) . . . . . . . . 99

2.2 Comparative table of TES technologies by Abedin and Rosen (2011) . 100

2.3 Characteristics of the solar chimneys presented in this section . . . 109

3.1 Technical data of the Rubitherm RT44 PCM and panel characteristics 114

3.2 Solar chimney V1.0 Dimensions . . . . . . . . . . . . . . . 120

3.3 National Instruments acquisition modules description . . . . . . . . . 122

3.4 Cycles discussed throughout this section for SCV1 and SCV2 . . . . . 134

3.5 Statistical analysis of the winter data . . . . . . . . . . 157

3.6 Statistical analysis of the spring data . . . . . . . . . . 158

3.7 Statistical analysis of the summer data . . . . . . . . . . . . 159

3.8 Outlet airflow mean values for each seasonal data for the whole day and after sundown $(16: 45 \mathrm{~h})$ in $\left[\mathrm{m}^{3} / \mathrm{h}\right] \ldots \ldots \ldots . \ldots \ldots$

3.9 Wind speed mean values for each seasonal data for the whole day and

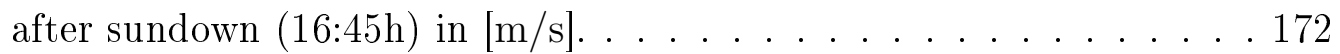

4.1 Components of the A matrix equation of the model . . . . . . . 190

4.2 Components of the B matrix equation of the model . . . . . . . . 190

4.3 Working parameters for the Heat Transfer Model . . . . . . . . . . 207

4.4 Working parameter for the Aerodynamic Model / Pressure Code . . . 207

4.5 Working parameters for the Convection Model . . . . . . . . . . . . 207

4.6 Correlation between simulation and experimental results. . . . . . . . 211 
4.7 Correlation between simulation and experimental results. . . . . . . . 212

5.1 Optimization parameters . . . . . . . . . . . . 220

5.2 Simulation Error Parameters . . . . . . . . . . . . . . . . 223

5.3 Optimization parameters . . . . . . . . . . . . . . . . 224

F.1 Statistical analysis of correlation and kurtosis based on standard deviation for Winter Data. . . . . . . . . . . . . . 284

F.2 Statistical analysis of correlation and kurtosis based on standard deviation for Spring Data. . . . . . . . . . . . . 285

F.3 Statistical analysis of correlation and kurtosis based on standard deviation for Summer Data. . . . . . . . . . . . . 286 


\section{Nomenclature}

\section{Abbreviations}

\begin{tabular}{|c|c|}
\hline Symbol & Description \\
\hline$A C H$ & Air Changes per Hour \\
\hline$A S C$ & Active Solar Chimney \\
\hline & American Society of Heating, \\
\hline$A S H R A E$ & Refrigerating and Air-Conditioning \\
\hline & Engineers \\
\hline atm & Atmospheric \\
\hline CHS & Chemical Heat Storage \\
\hline CIEMAT & Centro de Investigaciones Energéticas, \\
\hline & Medioambientales y Tecnologicas \\
\hline$C O P$ & United Nations Conference of Parties \\
\hline$E E A$ & European Environment Agency \\
\hline ENTPE & Ecole Nationale des Travaux Publics de \\
\hline & l'Etat \\
\hline$G A$ & Genetic Algorithm \\
\hline$G D P$ & Gross Domestic Product \\
\hline$G H B$ & Guarded Hot Box \\
\hline$H V A C$ & Heating, Ventilation, and Air \\
\hline & Conditioning \\
\hline$H Y B C E L L$ & Hybrid Cell \\
\hline
\end{tabular}


IPWSC

ktoe

$L H S$

LTECV

MOEA

$N S G A$

$P C M$

PEMEX

$P S A$

$P W S C$

RT44

$S C$

$S C V 2$

SENER

SHS

TES

$W R I S C$

$Z E B$

Greek Symbols

Symbol

$J_{j}$

$\alpha$
Inclined Passive Wall Solar Chimney

Kilo Tonnes of Oil Equivalent

Latent Heat Storage

French Energy Transition for Green

Growth Act

Multi-Objective

Evolutionary

Algorithms

Non-dominated Sorting Genetic

Algorithms

Phase Changing Materials

Mexican Petrols

Plataforma Solar de Almeria

Passive Wall Solar Chimney

Rubitherm Phase Changing Material

Current Solar Chimney

Second laboratory solar chimney prototype at ENTPE

Mexican Secretariat of Energy

Sensible Heat Storage

Thermal Energy Storage

Wall-Roof Inclined Solar Chimney

Zero Energy Building
Description

Radiosity of surface $j$

Absorption Coefficient
Unit

$\mathrm{W} / \mathrm{m}^{2}$ 


\begin{tabular}{|c|c|c|}
\hline$\alpha_{g}^{\prime}$ & Thermal diffusivity & $\mathrm{m}^{2} / \mathrm{s}$ \\
\hline$\beta^{\prime}$ & Coefficient of volumetric expansion & $1 / \mathrm{K}$ \\
\hline$\lambda$ & Thermal Conductivity & $\mathrm{W} / \mathrm{mK}$ \\
\hline$\nu$ & Kinematic viscosity & $\mathrm{m}^{2} / \mathrm{s}$ \\
\hline$\rho$ & Density & $\mathrm{kg} / \mathrm{m}^{3}$ \\
\hline$\varphi$ & Heat Flux & $\mathrm{W} / \mathrm{m}^{2}$ \\
\hline
\end{tabular}

\section{Roman Symbols}

\section{Symbol}

$C_{d}$

$C_{p}$

$e$

$g$

Gr

$H$

$h$

$H_{L}$

$h_{w-a i r}$

$k_{a i r}$

$L$

$L_{g-w}$

$m$

$\dot{m}$

\section{Description}

Discharge Coefficient

Specific Heat Capacity

Width of layer for heat transfer model

Gravitational Constant

Grashof number

Height of cell for pressure code

Convective Heat Transfer Coefficient

Latent Heat absorbed or released

during the phase change

Convective coefficient between wall and

collector wall

Thermal conductivity of air

Length of cell for pressure code

Distance between collector wall and glazing

Mass

Mass Flow Rate

\section{Unit}

$\mathrm{m}^{3} / \mathrm{sPa}^{2}$

$\mathrm{J} / \mathrm{kgK}$

$\mathrm{m}$

$\mathrm{m} / \mathrm{s}^{2}$

$\mathrm{m}$

$\mathrm{W} / \mathrm{m}^{2} \mathrm{~K}$

$\mathrm{J} / \mathrm{kg}$

$\mathrm{W} / \mathrm{m}^{2} \mathrm{~K}$

$\mathrm{W} / \mathrm{mK}$

$\mathrm{m}$

$\mathrm{m}$

$\mathrm{kg}$

$\mathrm{kg} / \mathrm{s}$ 
$n$

$N u$

$N y$

$P$

$\Delta P$

$\operatorname{Pr}$

$R a$

$S$

$T$

$t$

$\bar{T}$

$\Delta t$

$w$

$x$

$\Delta x$

$z$
Layer discretization size for heat

transfer model

Nusselt number

Discretization size for pressure code

$\mathrm{m}$

Pressure

$\mathrm{Pa}$

Pressure Differential

$\mathrm{Pa}$

Prandtl number

Rayleigh number

Surface

$\mathrm{m}^{2}$

Temperature

K

Time

S

Mean Temperature between the time $t$ and $t+\Delta t$

Time step

Width of cell for pressure code

Distance

Spacial step

Height
S

$\mathrm{m}$

$\mathrm{m}$

m

K

$\mathrm{m}$ 
Chapter 1

\section{Introduction}




\subsection{Motivation, Overview \& Context}

The year 1997 marked the beginning of international cooperation towards climate change through the settlement of the Kyoto Protocol. Before this moment, the states concerned were responsible of avoiding irreversible climate changes, but no specific actions were determined. The Kyoto Protocol, the first legally binding and ambitious agreement, established the fundamental goals to keep global average temperatures below $2^{\circ} \mathrm{C}$ above pre-industrial levels and to guide the global community towards the path of sustainable development. Since, it has been subjected to modifications and addition of new parties. The United Nations Conference of Parties (COP21), celebrated in the year 2015 in Paris, saw the ground-breaking settlement of 195 countries towards sustainable development; promoting equality between parties and encouraging the support for developing countries.

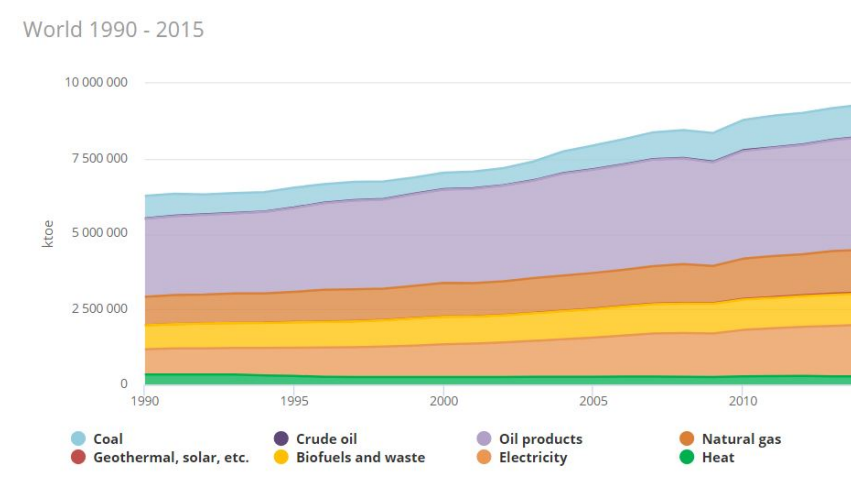

(a)

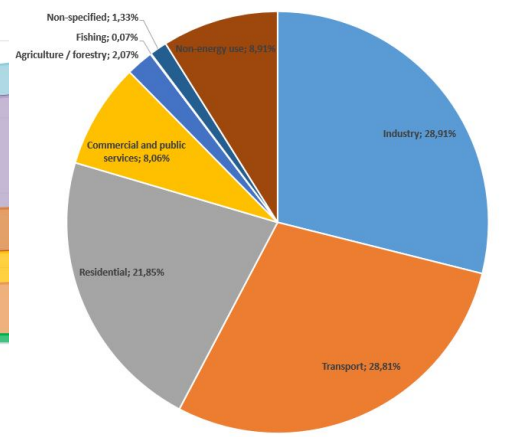

(b)
Industry
Iransport

- Residentia - Commercial and public services - Agriculture / forestry - Fishing - Non-specified

Figure 1.1: World (a) Total Final Consumption (TFC) by source in ktoe and (b) of Total Final Consumption by sector. Source: IEA, Energy Balances of OECD Countries 2017, available at www.iea.org/statistics

Due to the escalation of environmental concern, research has been increasingly taking energetic sustainability into consideration. The European Environment Agency (EEA), the French Ministry of Environment, Energy and Sea, as well as the Mexican Secretariat of Energy (SENER) recognize the current environmental 
problems associated with the great energetic consumption sectors and the urgency to encourage public and private institutions to develop alternative solutions in the different fields of study. These energy agencies consider industry, transport, households, services and agriculture as the five major energetic consumption sectors. The global trend (Figure 1.1) along with the French, Mexican and Spanish individual statistics (presented below) show the residential sector as the third most important final energy consumer after industry and transport.

The work presented in this $\mathrm{PhD}$ thesis focuses on the improvement of the

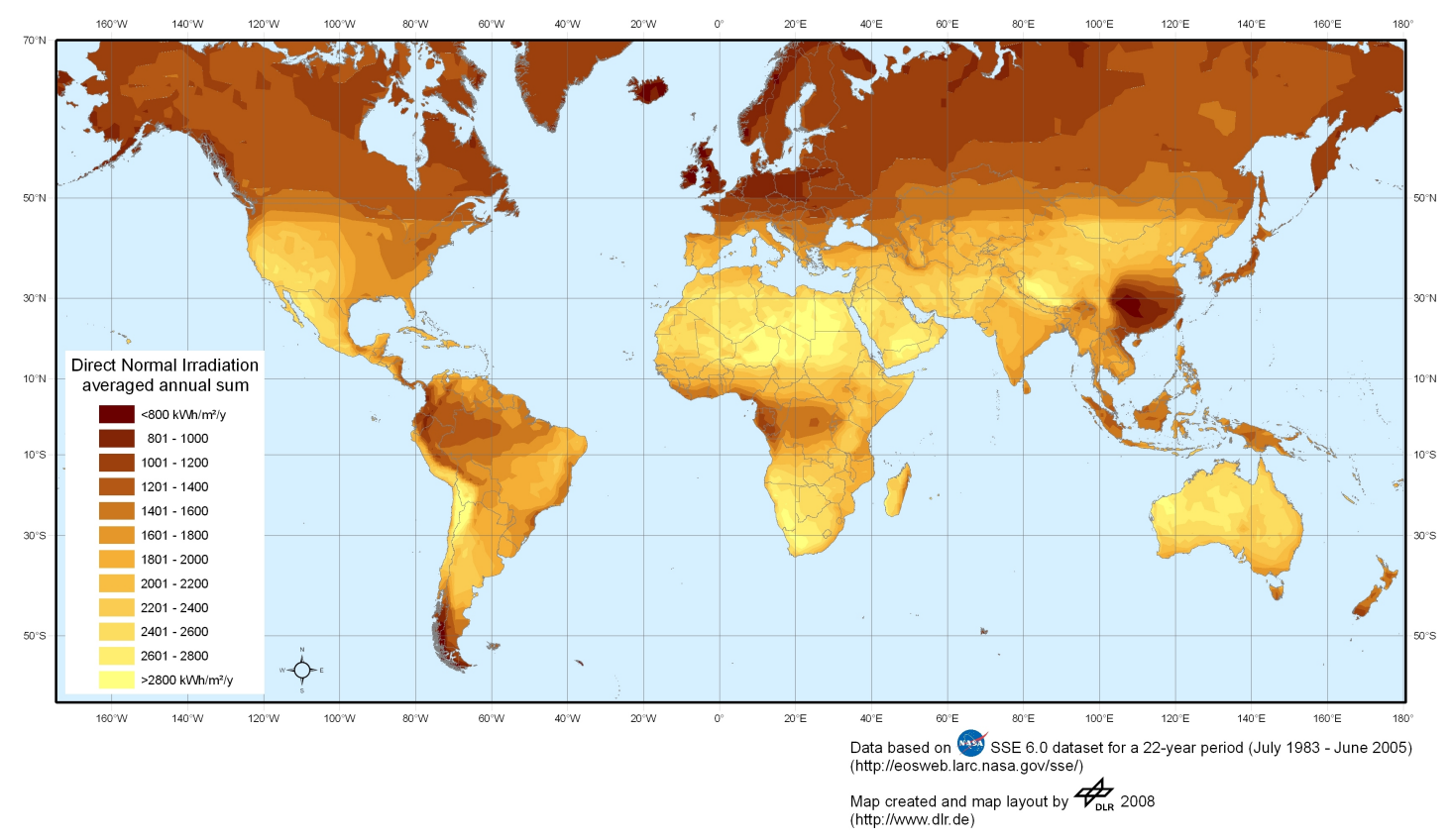

Figure 1.2: World's Direct Normal Irradiance from 1983 to 2005.

energetic efficiency of the building sector through the implementation of solar energy in ventilation. Concretely, three solutions can be active, passive and hybrid ventilation are viable solutions towards this goal. The first option, which depends mostly on mechanical elements, focuses on the optimization of energy consumption of the components and systems through technological breakthroughs, control techniques or regulations strategies. Passive solutions deal with the improvement or optimisation of the intrinsic qualities of the building, such as the choice of construction materials, the design of the building, the exploitation of natural resources for the building or through the utilization of renewables (eg.thermal storage). Figure 1.2 shows the Direct Normal Irradiance of the world for a period 
of 22 years. This image shows the solar potential of the countries concerned with the work of this project and the capacity to provide thermal comfort and air quality.

Table 1.1: Goals set towards Energetic Sustainability and Climate Change for 2030

\begin{tabular}{|c|c|c|c|}
\hline \multicolumn{3}{|c|}{2030 Objectives } \\
\hline \hline $\begin{array}{c}\mathrm{CO}_{2} \text { emission reduction (vs current } \\
\text { value) }\end{array}$ & France & Mexico & Spain \\
$\begin{array}{c}\text { Share of renewable energy } \\
\text { (consumption) }\end{array}$ & $30 \%$ & $22 \%^{*}$ & $43 \%$ \\
Reduction of fossil fuel consumption & $40 \%$ & $35 \% * *$ & $27 \%$ \\
\hline \hline
\end{tabular}

* and black carbon emissions by $51 \%$

** of total power generation using fossil fuels

As part of the green building architecture, natural ventilation can play an important role in providing a thermally suitable environment for human comfort in households and working complexes. Solar induced air ventilation can represent a viable alternative in the reduction of HVAC systems and thus, a reduction in energetic consumption. Different passive technologies have been developed over the years to in order to attain the aforementioned goals. These strategies based on passive ventilation have repeatedly demonstrated their potential. The project presented in this work represents a possible alternative towards the establishment of a Zero Energy Building (ZEB). The implementation of viable alternative solutions can boost the accomplishment of the goals set during the COP21 and by each government. This goals are presented in Table 1.1 (International Energy Agency (IEA), 2015, 2017a,b,c; International Renewable Energy Agency (IRENA), 2015, 2018).

\subsubsection{French Context}

After transitioning from coal and oil, the closure of more than $3 \mathrm{GW}$ of coal-fired capacity (International Energy Agency (IEA), 2017a), the progressive 
dismantlement of the remaining oil-fired power plants, and the reduction in fossil-fuel-based-energy adopted in the residential and industrial sectors, the energetic supply and consumption, as well as $\mathrm{CO}_{2}$ emissions in France have seen a substantial decline. Currently, the electric demand is met predominantly by nuclear power.

Nuclear energy has helped France establish itseld as one of the leading IEA countries in terms of low-carbon energy mix with only $47 \%$ coming from fossil fuels. Almost half of the energy mix and more than two thirds of electric generation are acquainted with nuclear power. Even though France has set up the groundwork towards energetic sustainability, in the long term energy security can become an issue due to the deterioration of the nuclear assets.

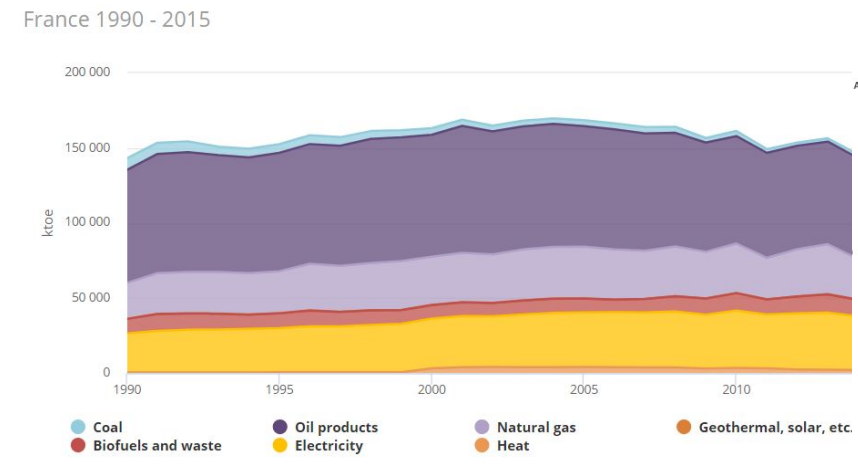

(a)

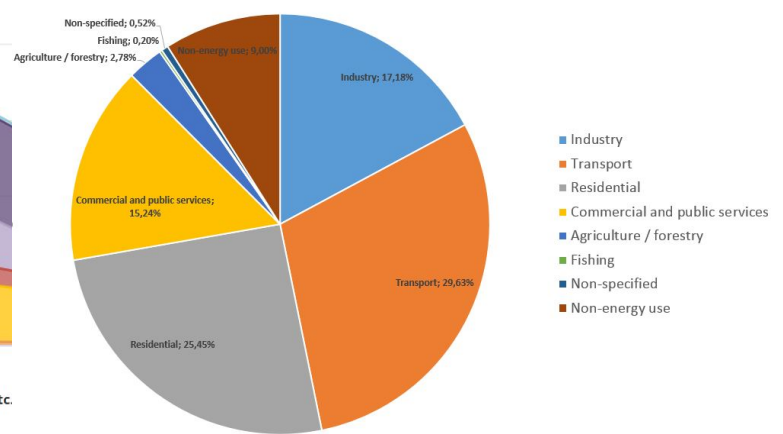

(b)

Figure 1.3: French (a) Total Final Consumption (TFC) by source in ktoe and (b) of Total Final Consumption by sector. Source: IEA, Energy Balances of OECD Countries 2017, available at www.iea.org/statistics

As stated before, France was the host of the $21^{\text {st }}$ United Nations Conference of Parties (COP21). During this assembly of countries, France reassured its commitment towards climate change mitigation and set the table for dialogue headed for cooperation. In preparation for this event and as the host of such, France adopted the Energy Transition for Green Growth Act (Loi relative à la Transition Energétique pour la Croissance Verte, LTECV). This legal framework establishes the progressive decarbonisation objectives up to 2030 and requires all economic agents to make sustainability a core element in their organization and businesses. In order to stimulate this transition significant new policies, such as tax incentives 
and public funding.

Thus far, the French government expects to reduce the nuclear energy share from $78 \%$ in 2015 to $50 \%$ by 2025 . As of $2014,15 \%$ of the total final consumption was attributed to renewable energies, however it is not yet on track towards the expected goal of $23 \%$ by 2020 . In order to accomplish the ambitious goals set by the French government, an greater focus needs to be turned towards renewables.

\subsubsection{Mexican Context}

Until recent years, the energy market in Mexico had been closed and monopolized by the Federal Electricity Commission (CFE). The latest energetic reform, first applied in December 2013, has progressively established an ideal ground for investors, energy security improvement and the reinforcement of environmental sustainability. The reform aimed to modernise the Mexican economy and society and bolster long-term growth through increased efficiency and productivity (International Energy Agency (IEA), 2017b).

The introduction of this reform halted the oil and gas monopoly over the country, while maintaining the national hydrocarbon resources' ownership. Being one of the world's major oil producer and exporter, Mexico's energetic supply relies largely on its fossil fuels. The environmental and health issues linked with fossil fuels have been widely discussed across the literature but most importantly, the effects can be appreciated in all major Mexican cities. Additionally, the fossil fuel dependency is incompatible with the country's climate policy ambitions. Figure 1.4 represents the energetic consumption of the Mexican case by source and sector.

In the past, the institution in charge with the extraction and management of petrol was PEMEX (Mexican Petrols). Until 2018, PEMEX did not have the technical capabilities to do deep sea extraction or the acquire shale resources, thus, it could not provide the country with the oil product needs. In recent years, the prices of petrol-derived products such as gasoline, have risen and have started to 


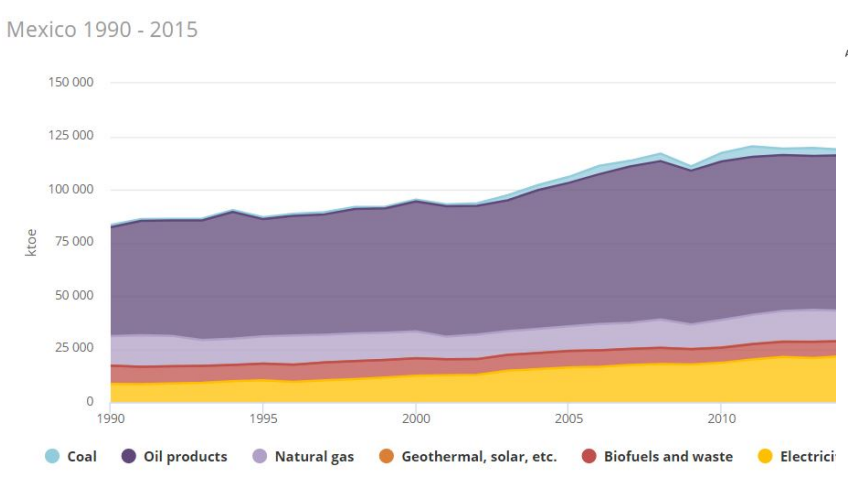

(a)

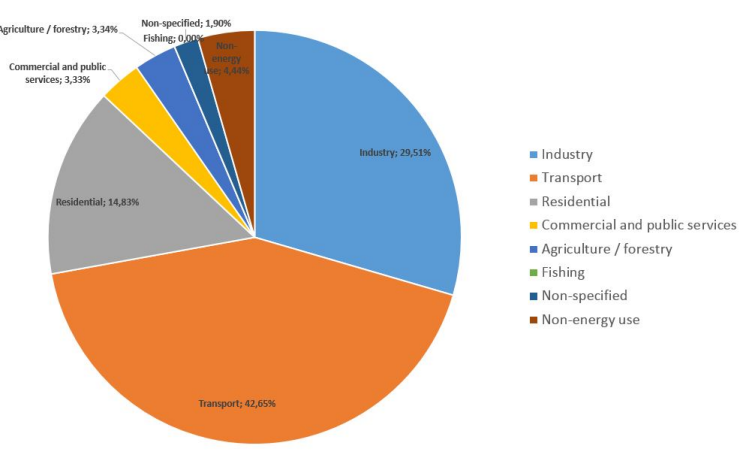

(b)

Figure 1.4: Mexican (a) Total Final Consumption (TFC) by source in ktoe and (b) of Total Final Consumption by sector. Source: IEA, Energy Balances of OECD Countries 2017, available at www.iea.org/statistics

catch up with international prices. Additionally, electricity in Mexico was subsided by between $60 \%$ and $70 \%$ of the total cost for households and farmers. This artificial low cost hinders the governmental efforts towards energetic efficiency, and prevents the population from being encouraged to adopt alternative solutions.

These obstacles increase the need of alternative technologies that can provide the necessary energy supply to the country. Currently, Mexico is providing a substantial boost to solar and wind energy, thriving on its large natural resources, and competing price-wise at an international level. Mexico has an immeasurable potential when it comes to alternative energies and the mastery of these technologies could boost Mexico's economy and solve the current pollution issues.

\subsubsection{Spanish Context}

Even though Spain posses one-third of the European Union's liquefied natural gas regasification capacity, until 2008, $80 \%$ of the Spanish energy supply was imported from other countries. This amount has seen a slow decrease mainly due to the introduction and development of renewable energies. This progress is mainly due to the energy policies established by the European directives and adopted by the Spanish government. Spain has successfully diversified its power generation sources by introducing wind power and taking advantage of its great solar potential, and has reliably connected it to its power system (International Energy Agency (IEA), 
2015).

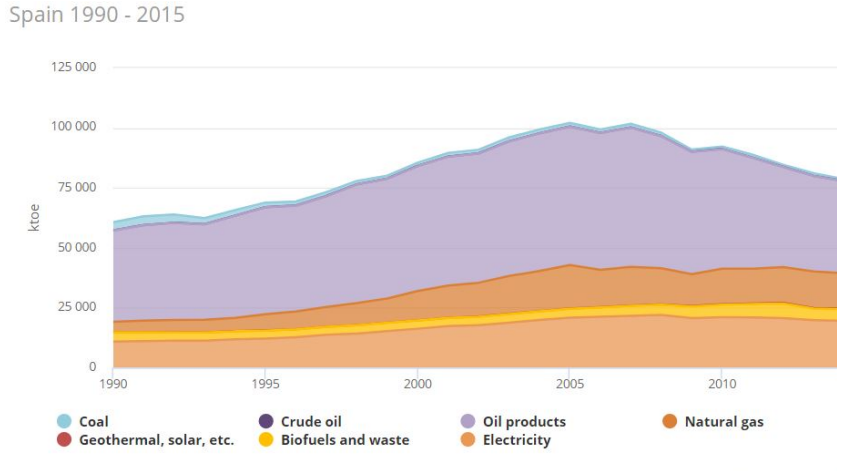

(a)

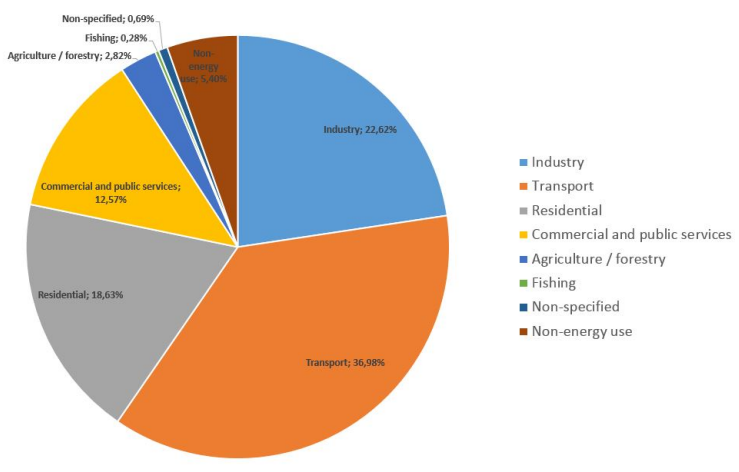

(b)

Figure 1.5: Spanish (a) Total Final Consumption (TFC) by source in ktoe and (b) of Total Final Consumption by sector. Source: IEA, Energy Balances of OECD Countries 2017, available at www.iea.org/statistics

In 2011, the Spanish public debt had reached $80 \%$ of the GDP and the energy system suffered from a asymmetry between the costs and revenues of the service. This tariff deficit became the main focus of the state's energy policy for the upcoming years in an effort to balance the level of costs of the electricity system. The need of alternative solutions and the reduction of energy consumption across Spain has to become a priority not only for the accomplishments of the EU directives, but to reduce the prices for consumers. 


\subsection{Problematic and Scientific Challenges}

Solar chimneys were conceived for the main purpose of regulating the thermal sensation of an indoor volume. Nowadays, construction elements such as the solar chimney, must attain to a number of health and safety regulations and must be affordable both energetically or economically. Additionally, in the interest of reducing global warming from an estimated $4.5^{\circ} \mathrm{C}$ (by 2100) to less than $2.7{ }^{\circ} \mathrm{C}$ and decreasing greenhouse gas emissions per capita by $9 \%$ by 2030 (UNFCCC, 2015), solar chimneys must prove its potential value against other more renown passive ventilation systems.

From a technological standpoint, solar chimneys do not represent a complex structural element, yet the optimal configuration is still environment dependent. From a scientific standpoint, the expertise of the thermal inertia and the resulting mass flow rate are still barriers to be raised. In the same way, PCMs represent a viable solution when compared to other options such as sensitive thermal storage, however the incorporation to building components rests a relatively new field which must be researched further under different scenarios.

Nowadays, several software are available for the calculation performance of the different building components and systems. Existing numerical tools such as Energy Plus and TRNSYS (to name a few) have been employed to carry out simplified models that can convey a general solution, however some of the exchanges of the system are lost in the process. Software with higher precision and accuracy, such as ANSYS Fluent, are also implemented for efficiency estimation, however they tend to come at a high computational cost, especially for simulations exceeding a day. Furthermore, building elements like the solar chimney, tend to be studied at a component level, yet they are always coupled to a building, thus the need of a reliable numerical tool which can connect different passive, active and hybrid solutions in a single model. 
At the experimental level, PCMs have not been characterised in a solar chimney under real environmental conditions. Laboratory results, even though promising, do not represent the phenomena. Solar chimneys have been employed as a coupled system of other ventilation systems, however the pursuit for Zero-Energy Buildings requires the continuous development and optimization of systems. Finally, PCMs represent an extra investment over the construction price. In order for this type of technology to be viable, it must yield better results than common construction materials and/or simplify its design. 


\subsection{Research Objectives \& Scientific Approach}

In order to demonstrate the impact of a solar chimney regarding the objectives set in the Paris Agreement and the Horizon 2020, the project aims to the improve the current performances of the classic Solar Chimney. The goal is to achieve the activation of this technology for a prolonged utilization; particularly, but not limited to, after sunset. This objective is to be achieved by integrating passive and active components therefore calling it ACTIVE Solar Chimney (ASC). In order to accomplish this, three main factors must be addressed: Air Circulation, Design \& Energy Storage.

Air Circulation: Relates to the improvement of ventilation. An optimized ventilation translates higher flow of air, thus allowing a stable temperature.

Design: Current designs are suited mainly for hot climates. The objective of this project is the implementation of different technologies for the capitalization throughout the year.

Energy Storage: The performance of the current Solar Chimney design is low in comparison with other green technologies; especially after sundown. This project's target is the integration of energy storage solutions to increase the performance of the system in the absence of a heat source. This work will take advantage of the energy storage capabilities of paraffinic Phase Changing Materials (PCM). The project is divided in two main stages:

\section{Numerical:}

(a) Modelization and Reduced Model.

(b) Coupling and integration to other building models.

(c) Characterization: Parameter definition and efficiency measurement of the system.

(d) System Control and Optimization. 


\section{Experimental:}

(a) Guarded Hot Box (GHB) laboratory experimentation with an innovative and original laboratory prototype.

(b) In-situ experimentation (Almeria, Spain).

The scientific approach employed throughout this dissertation can be observed in Figure 1.6. It explains the methodology followed in order to achieve the aforementioned objectives.

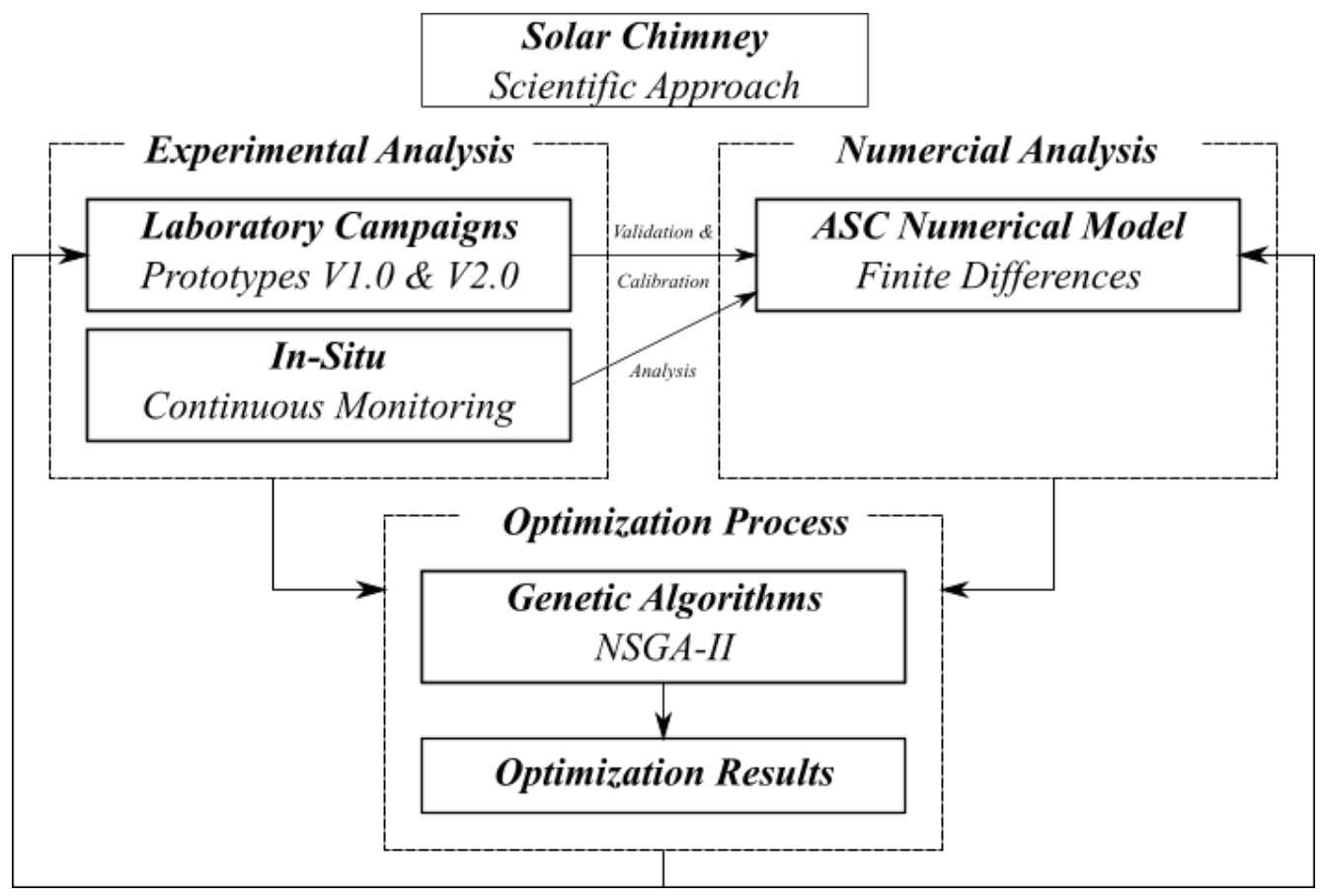

Figure 1.6: Scientific approach employed during this dissertation. 


\subsection{Dissertation Outline}

This thesis is divided into 4 main chapters. Each chapter describes a key component of the work done for the accomplishment of the goals set in this project.

The first chapter succinctly addresses the energetic context of France, Mexico and Spain, as well as the climate change objectives of these countries towards energetic sustainability set during the Paris Agreement of 2016. The chapter presents the thesis objectives, the research motivation and the problematic related to the work done. At the end of the chapter, the dissertation's outline is presented.

The second chapter is dedicated to the state of the art which presents the different ventilation configurations, some of the passive ventilation solutions, the introduction to the various thermal storage techniques, including thermal storage through Phase changing Materials (PCM), and finally, it presents the main axe of this PhD thesis: the solar chimney and the integration of PCM.

Subsequently, the third chapter introduces the experimental characteristics of PCMs for the further implementation in the solar chimney prototypes. The chapter continues with the description of the set-up employed for each experimental campaign. The two laboratory prototypes and the in-situ configurations, as well as the results obtained in the three cases are presented and discussed during this chapter.

Next, the fourth chapter presents the numerical method employed to characterise the behaviour of the solar chimney. The chapter describes each component of the numerical model and proceeds to illustrate coupling of each element. The results obtained through this numerical model, as well as the interpretation of these are addressed during this chapter.

To conclude, the fifth and final chapter is devoted to the optimisation of the 
presented solar chimney through the utilization of genetic algorithms. Different design parameters are studied in order to suggest the optimal configuration. The objective of this final chapter is to propose a viable solution which takes into consideration the results obtained throughout this work and the analysis of other current studies.

This dissertation ends with a general conclusion and offers a perspective towards the future of this technology. 
Chapter 2

Literature Review - An Introduction to Passive Ventilation and Solar

\section{Chimneys}




\section{$2.1 \quad$ Introduction}

Chapter 2 is dedicated to the fundamental concepts intrinsic to the nature of the Solar Chimney. The following sections overview the importance of ventilation systems in building designs through the comprehension of different ventilation alternatives and solutions. Ventilation allows for air quality control which favours thermal comfort in different seasons of the year which continues with the objectives and goals set during Paris Agreements explained during the previous chapter.

\subsection{Ventilation as a solution for Thermal Comfort}

Ventilation can serve several purposes (limit air pollutants, olfactory quality or degradation due tu humidity), however the work presented in this $\mathrm{PhD}$ thesis concerns primarily thermal comfort. Ventilation can lead (directly or indirectly) to the thermal comfort of occupants. Depending on the ventilation rate, temperature, humidity and air speed the thermal sensation of occupants can be impacted.

Ventilation is particularly important during hot seasons where the outside temperature is higher than the indoor temperature. In such cases, optimal ventilation strategies can release (or hamper) the energy stored by the building in order to bring down the temperature during occupancy periods. Studies such as the one carried out by Hassan Abdallah (2017) have shown the thermal potential of ventilation of up to $8 K$ through the implementation of a passive cooling system. This and other results encourage the further study optimization of ventilation strategies for the accomplishment of Zero Energy Buildings (ZEB). Alternative solutions are presented in the following sections. 


\subsection{Passive Ventilation}

Passive ventilation relates to natural ventilation systems which exploit natural resources such as wind or thermal buoyancy (which can be induced amongst other things through solar energy), to set off an air current to and from an indoor space. The goal of these type of systems is to control the temperature and the refreshment rate of the air of such area. In general, a building experiences passive ventilation through the opening and closing of windows, but other alternatives can achieve this same effect with a higher performance. Passive ventilation systems can be regrouped in three major categories:

1. Wind-driven ventilation: resulting from the wind currents surrounding the building.

2. Buoyancy-driven ventilation: derived from a temperature difference between the inside and the outside of the building.

3. Night Cooling: coming from the thermal mass of the building which charges during the day and is released during the night. During this type of passive ventilation method, the first two types of ventilation are involved since a temperature difference induces an air flow. Furthermore, the wind and lack of a heat source cools the thermal mass of the building.

Natural ventilation represents a viable alternative in the pursuit of green architecture, zero energy buildings as well as the goals discussed in section 1.1. Ventilated façades, trombe walls, wind towers and solar chimneys are some of the alternatives that have been recently seen an affluence in recent years. Some combinations of these elements, such as ventilated roofs and unglazed transpired solar façades, can be found in literature, however they are not discussed in this thesis. The work presented in this $\mathrm{PhD}$ thesis focuses on the latter of the alternatives, however a brief description of the rest is presented in this section. 


\subsubsection{Trombe Walls and Ventilated Façades}

The two elements presented in this sections work under the same principles but are used under different conditions. Trombe walls, also known as Passive walls, are generally used in cold weathers where the solar energy can be exploited to heat the air between the the actual wall of the building and an outer cover which can be replaced by a glazing. Several configurations exist for the Trombe wall such as the unventilated solar wall, insulated Trombe wall and composite solar wall (Sadineni et al., 2011). These configurations carry out a thermal exchange with the indoor volume by conductive transfers through the wall and/or convective transport through the circulating air. Even though Trombe walls have show promising results, they come with several limitations (Gan, 1998; Onbasioglu and Egrican, 2002; Shen et al., 2007). During night-time or low solar heat flux periods, the indoor can experience a heat loss with the environment. In some cases, when the external wall is colder than the inner wall, inverse circulation can have the opposite effect the to the one intended. Finally, as most of the solar driven technologies, the solar fluctuations can cause performance fluctuations on the system.

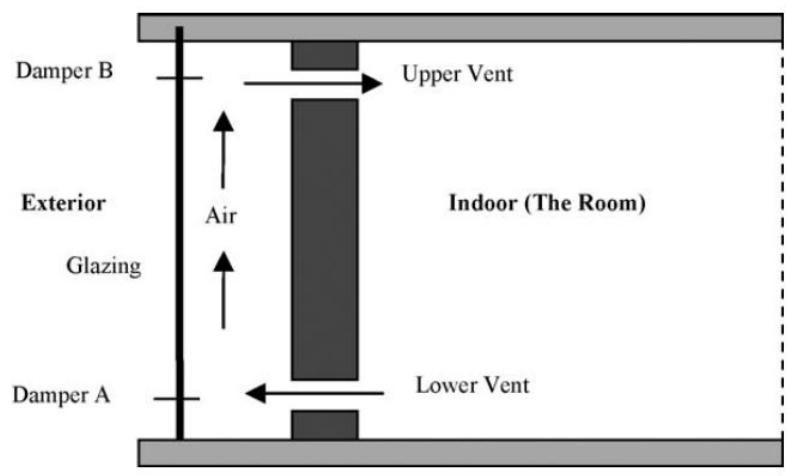

Figure 2.1: Schematic diagram of classical Trombe wall (without dampers) presented by Chan et al. (2010)

On the other hand, ventilated façades, while they are built in the same way as Trombe walls, are employed to improve the passive cooling of buildings. Ventilated façades, also known as cavity walls or double skin walls employ as well, solar energy to generate an up-draft. This stack effect depends on the incoming solar energy and has most of the limitations that Trombe walls have regarding solar energy(Sadineni et al., 2011). Works such as the one carried out by Ciampi et al. (2003) showed 
that for a typical summer, cooling energy can be reduced by $40 \%$ with a carefully designed ventilated wall. In the case of ventilated façades, poor quality materials or design can induce thermal bridge issues and reduced performance.

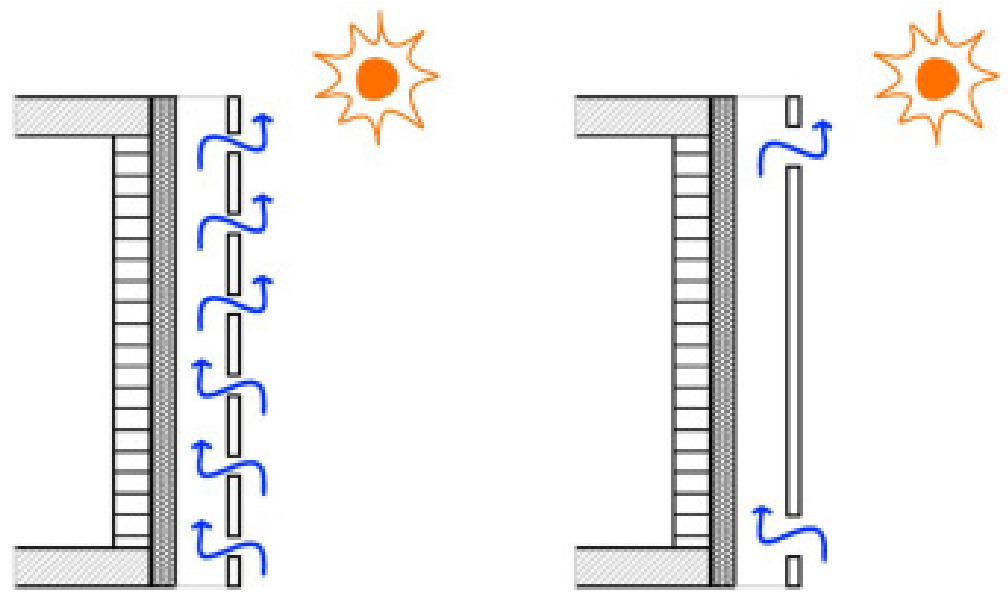

Figure 2.2: Ventilated façade presented by Ibañez-Puy et al. (2017) showing two different configurations. (left)Open joints, discontinuous skin and (right) closed joints, continues outer skin

\subsubsection{Wind Towers}

Wind towers are a well-known architectural element employed in the Middle Eastern or Persian architecture for more than three thousand years. In present day, wind towers have been modified in order to fully exploit the wind potential and maximizing the air flow traversing the inner environment.

Wind towers' performance relies entirely on the external velocity and direction of

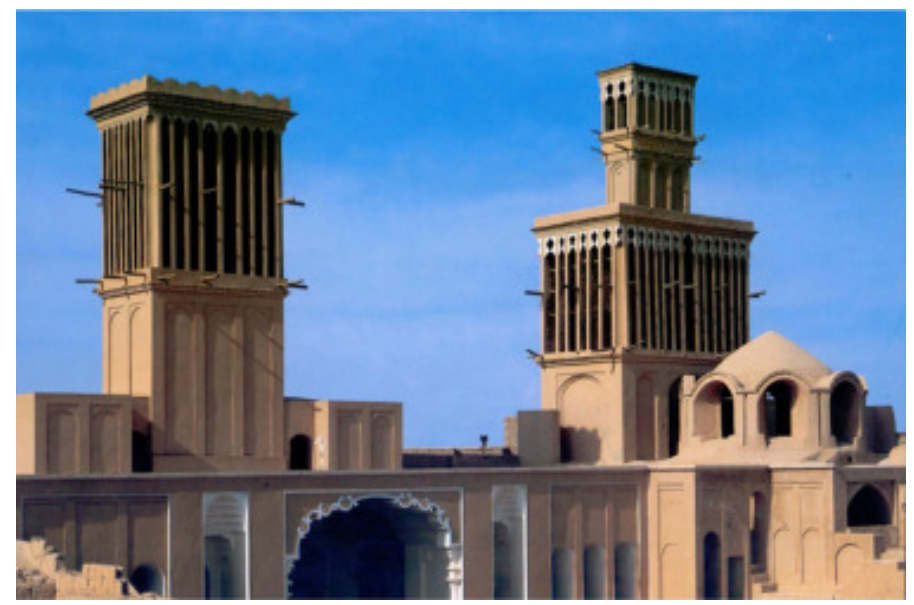

Figure 2.3: A two story wind tower along with the dome (Kolah-farangi) of the Aghazadeh mansion in Abarkuh city, Yazd, Iran (Dehghani-Sanij et al., 2015) 
the wind, which in turn affects the incoming air flow to the interior of the building. Since high wind speeds are vital for the optimal performance of a wind tower, regions with lower wind speeds can improve the efficiency of such systems by incorporating a solar chimney. Wind towers have two main driving forces. The first force employs wind pressure in order to provide fresh air and reject stale air from the indoor volume (Figure 2.4). The secondary force, depends on the air temperature difference between the indoor and outdoor temperature. This temperature difference induces warm air to rise and exit the tower (Dehghani-Sanij et al., 2015; Hughes et al., 2011). Overall, wind towers represent a viable alternative since they represent a simple architectural element, with an easy installation and a low maintenance cost.

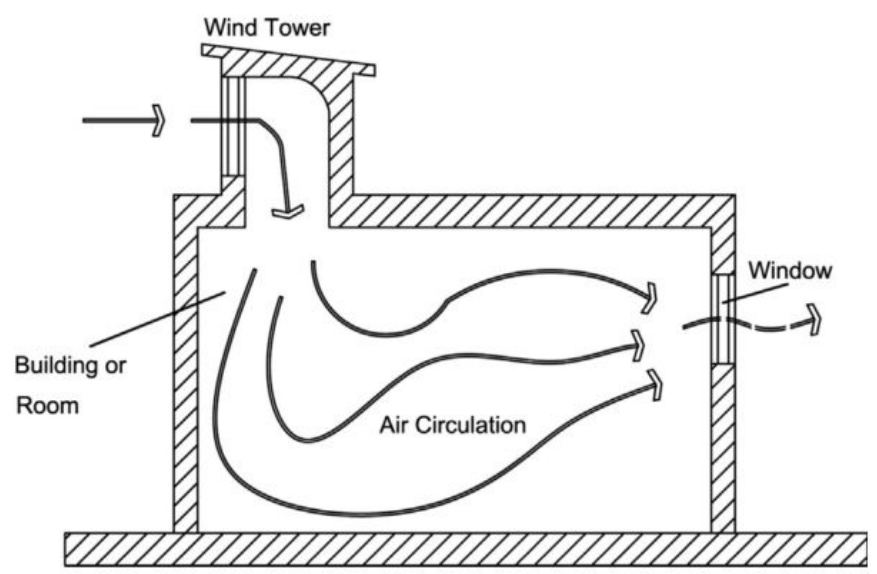

Figure 2.4: Schematic representation of air movement induced by a wind tower (Dehghani-Sanij et al., 2015)

\subsubsection{Solar Chimney}

A solar chimney (SC) is a technology that has existed for centuries, particularly useful in hot climates. In its simplest design, a Solar Chimney is a channel used to evacuate hot air from a building through a closed conduct at a higher elevation. By means of the greenhouse effect, temperature rises across the canal and induces a thermal up-draft. Most current designs (Arce, Jiménez, Guzmán, Heras, Alvarez and Xamán, 2009), have made modifications to the basic design to add elements 
such as a glazing or an opposite collector wall, both of which maximize the incoming solar energy and improve the chimney's performance. Solar chimneys are exclusively profitable during the day, as long as solar energy increases the temperature of chimney and the air inside it. Thus far, the induced up-draft produced by the solar chimney has been experimentally studied mostly in countries where there is a high and constant solar gain such as Egypt, Iran or Algeria to mention a few (Hosien and Selim, 2017; Saifi et al., 2012; Shahreza and Imani, 2015). It has been stated that temperature registered in the control volume can cool down faster and heat up slower with the addition of such technology (Tan and Wong, 2014).

The chimney acts like a heat engine converting heat generated by a collector into kinetic flow. The main task of the collector is to absorb solar energy for heating air and release it as solar radiation decreases. The difference between the indoors temperature and the conduit temperature is fundamental in order to generate an up-draft, which is the result of the density variation. Since warm air is lighter than cold air, lift force is arisen. In other words, a pressure difference between chimney outlet and the environment is generated. A schematic of a simple solar chimney can be observed in Figure 2.5.

Solar chimneys are commonly employed in the residential sector where this type of technology can generate a sufficient up-draft as to provide fresh air on its own, however solar chimneys are not exclusive to this sector. As designed by Kuwabara et al. (2009), the Manitoba Hydro Building located in Winnipeg, Canada can provide $100 \%$ fresh air every day throughout the year compared to the $80 \%$ recycled air of the average North American building, partly due to the implementation of a $115 \mathrm{~m}$ solar chimney. This feat is achieved through the combination of various green technologies and strategies. During spring, summer and fall, the Manitoba Hydro SC passively exhausts air. Throughout winter, the heated air is recirculated to the parking garage and some of the heat is recovered to pre-heat the incoming cold air from the south atrium. According to Kuwabara et al. (2011) the building reduces energy consumption by $60 \%$ over the Model National Energy Code of Canada without using on-site renewable energy. The Manitoba Hydro building can be observed in Figure 


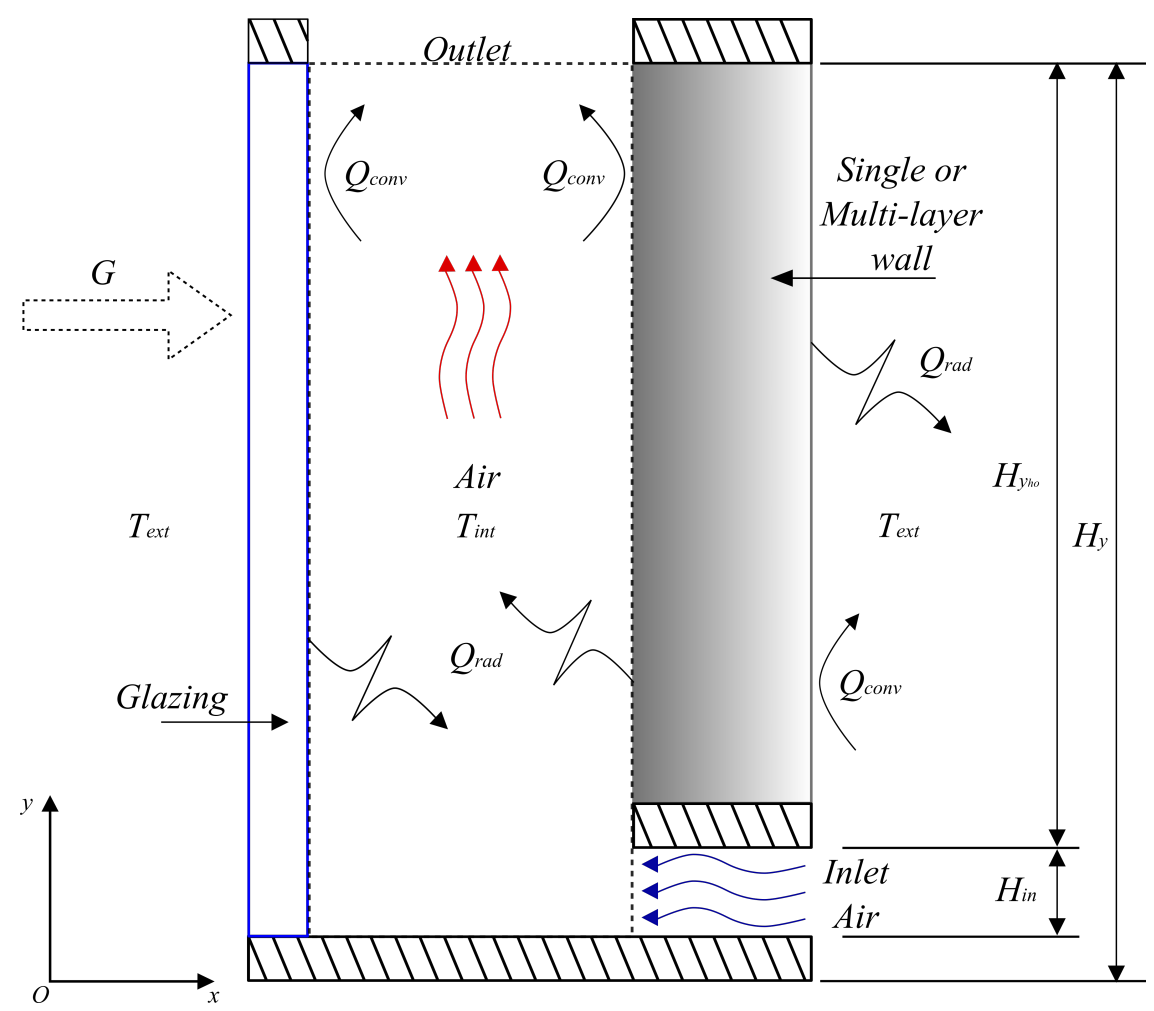

Figure 2.5: Schematic diagram of a simple solar chimney with vertical inlet subjected to environmental conditions.

2.6 .

According to Hassan Abdallah (2017) the inclusion of solar chimneys can lead to a room temperature reduction of up to $8^{\circ} \mathrm{C}$ with the implementation of a wet cellulose pad system made from expanded paper in an arid country like Egypt though, the design works almost exclusively under the arid day-time Egyptian climate. Nevertheless, solar chimneys represent no energetic consumption (in most cases) compared, for instance, to HVAC systems. Overall, the solar chimney represents a viable energy-saving technology that can reduce operation costs of buildings.

As stated by Asadi et al. (2016); compared to natural ventilation strategies, solar chimneys have the advantage of keeping the occupants privacy since they do not provide a view into the internal space of the building. They represent a silent technology due to the lack of mechanical components (in most cases) and the indirect effect of wind (direct wind above $1 \mathrm{~m} / \mathrm{s}$ can lead to occupant's discomfort). As a result of the nature and location of solar chimneys in the building, the 


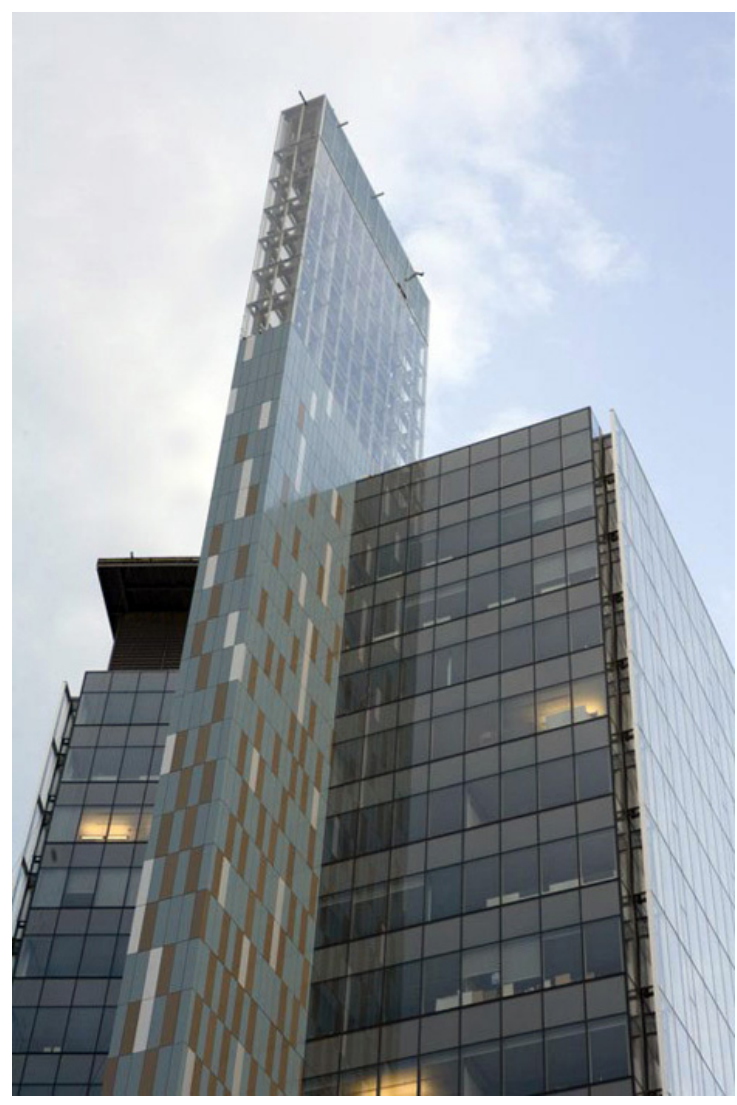

(a)

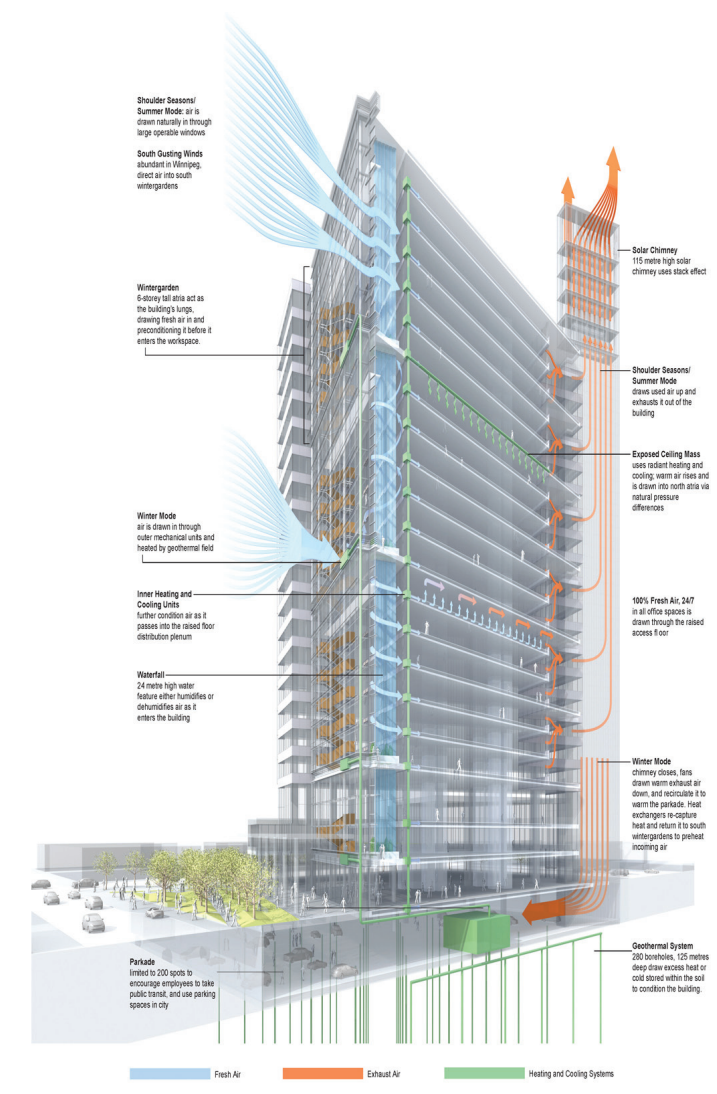

(b)

Figure 2.6: Example of an existing solar chimney employed for the Manitoba Hydro Building in Winnipeg, Canada. (a) Photo available at

http://manitobahydroplace.com and (b) description by Kuwabara et al. (2011)

prevention of dust and pollution can be attained and they can aid to increase the thermal comfort during cold dry nights of windless summers. Solar chimneys have the capacity to self regulate, the hotter the external temperature and the higher the solar irradiance, the greater the air flow will be.

\subsubsection{State of the Art: Analysis of a Solar Chimneys}

Solar chimneys' performance depend primarily on two parameters: structural and environmental. The first factor relates to the design of the chimney; this includes the size and geometry of the chimney, the tilt angle, the size of the inlet and outlet or the construction materials. Environmental parameters refer to the weather conditions as well as the location and orientation of the chimney (Kasaeian et al., 2014). 
The first studies and pioneering work for solar chimneys were carried out by Bansal et al. (1993). Their numerical analysis, carried out with a variety of radiation gains (between 100 and $1000 \mathrm{~W} / \mathrm{m}^{2}$ ), demonstrated that is possible to induce an airflow of $100-350 \mathrm{~m}^{3} / \mathrm{h}$ when the collector wall area is equal to 2.25 $m^{2}$ and a conduit width size (distance between collector wall and upper surface of the rear insulation) is $0.15 \mathrm{~m}$. Their results showed that the size of the chimney collector wall depends on the expected air circulation rate, however the efficiency of the chimney is proportional to the geometry of the collector wall, the cross-section of the duct and the thermal characteristics of the collector. It has also been established (AboulNaga and Abdrabboh, 2000) that an average irradiance of 850 $W / m^{2}$ can generate an average mass flow rate of $2-3 \mathrm{~m}^{3} / \mathrm{s}$ for a chimney stack height of $3.45 \mathrm{~m}$. It is also suggested that air speed can be further improved with an inlet lower from the ground; all this for a wall-roof inclined solar chimney (WRISC).

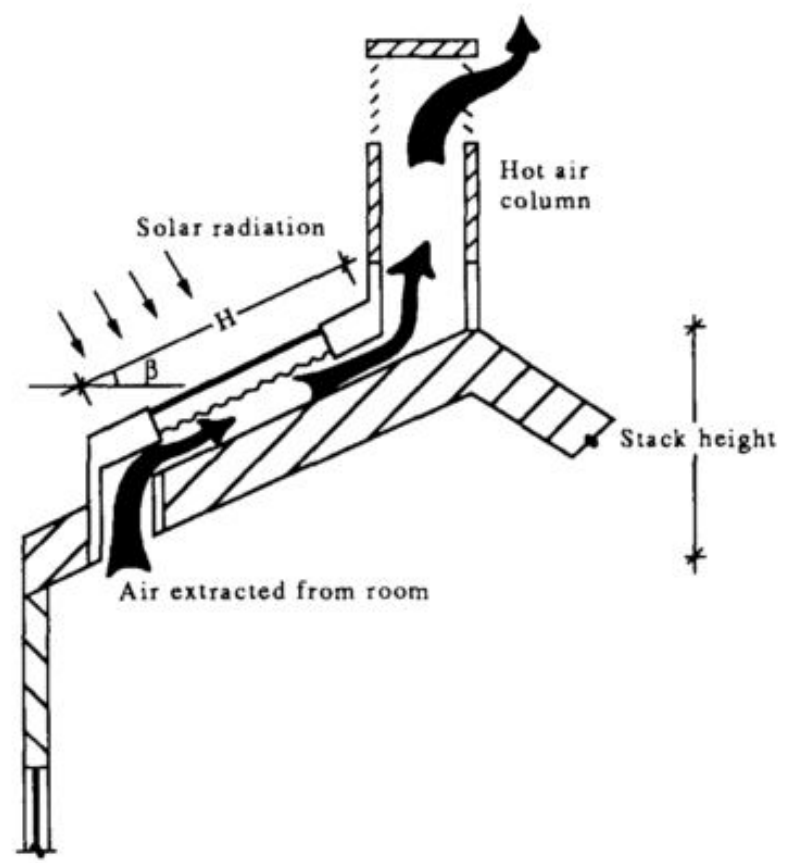

Figure 2.7: System description used by Bansal et al. (1993) representing a Wall-Roof Inclined Solar Chimney

Most articles focus in the design of the solar chimney. For the last couple of years, inclined solar chimneys have been the main focus of researchers. Mathur 
et al. (2006) carried out an analysis of nine different combinations of air gap and stack height in order obtain the maximum ventilation rate. For an average solar irradiance of $700 \mathrm{~W} / \mathrm{m}^{2}$ the best results were obtained with a $0.3 \mathrm{~m}$ air gap and a $0.85 \mathrm{~m}$ stack height, however other parameters such as the inlet/outlet area can modify the ventilation rate, therefore a stack height to air gap ratio can not be determined. Other studies have been conducted towards the establishment of this goal, for an inclined solar chimney (Chen et al., 2003). For a $45^{\circ}$ inclination with there seems to be no apparent optimum chimney gap, nonetheless, it is stated that for a fixed inlet size, the increase of the air gap can lead to the decrease of mass flow rate. According to the findings of this article, a $45^{\circ}$ tilt can lead to a $45 \%$ airflow increase. This improvement can be attributed to the increased stack pressure and reduced pressure losses across the chimney.

Khanal and Lei (2011) conducted as well a research on inclined solar chimneys, addressing the advantages in terms of operational cost, energy requirement and $\mathrm{CO}_{2}$ emissions. Their work mentions the possibility of passive heating and cooling through the implementation of a solar chimney for the reduction of HVAC loads.

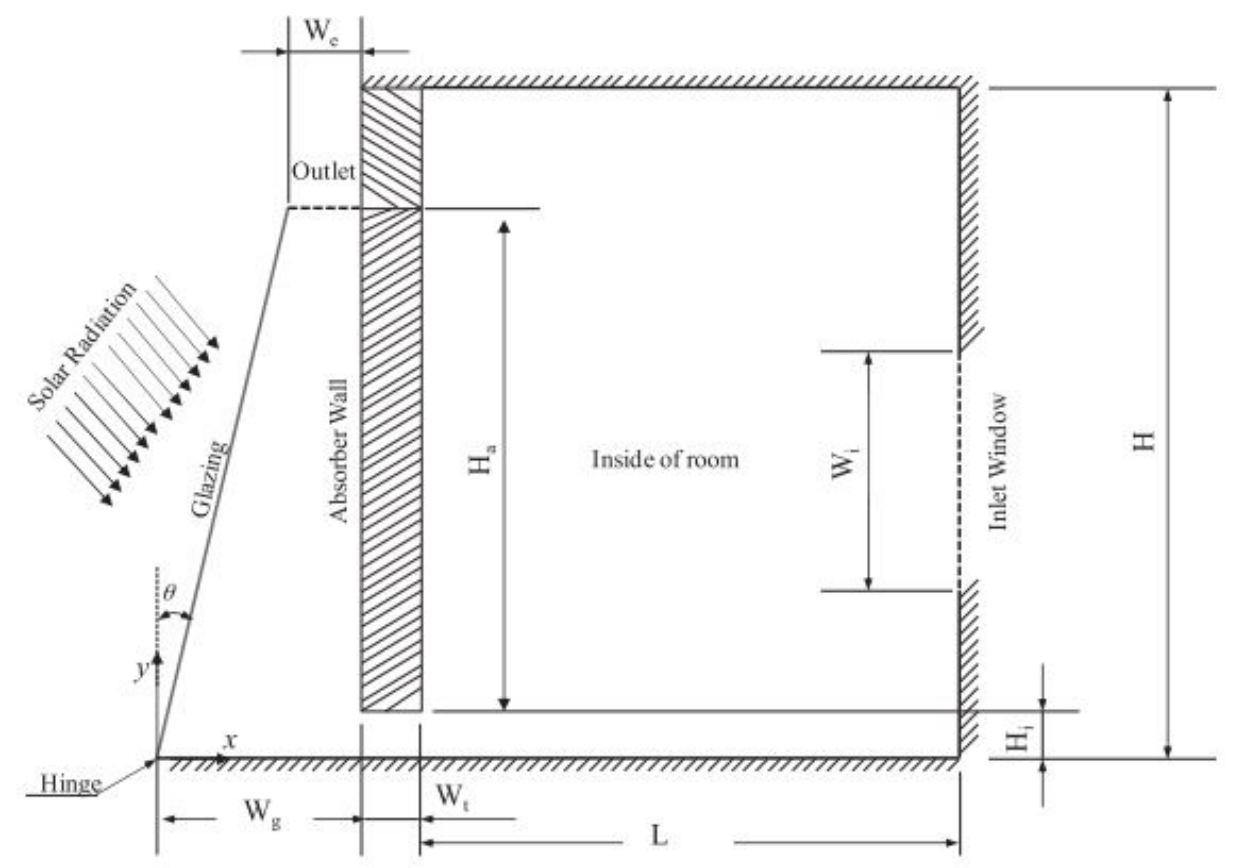

Figure 2.8: Schematic of a two-dimensional solar chimney (IPWSC) attached to a room employed by Khanal and Lei (2015) 
Furthermore, they (Khanal and Lei, 2014b, 2015) also analysed numerically and experimentally the performance of an inclined passive wall solar chimney (IPWSC), both stand-alone and building-coupled. Different from their laminar results for a vertical chimney, an IPWSC which accounts for turbulent flows has a better performance for an inclination of $4^{\circ}$. Their work show the clear influence on the mass flow rate of the Rayleigh number on both the conventional solar chimney and the IPWSC. It is reported that high Rayleigh $\left(R a \geq 10^{8}\right)$ numbers can significantly cutback the predicted mass flow rate growth due to a greater reverse flow. This effect is countered by the IPWSC which doesn't show signs of reverse flows and predicts a $17 \%$ mass flow rate increase for Rayleigh values of $10^{9}$ to $10^{11}$. It is worth noting that this increase is only observable for cases were a reverse flow is present. Moreover, a smoke flow and shadowgraph visualization was carried out to display the flow behaviour for the different inclination angles. Measurements of air temperature and velocity were carried out for a full scale model under steady-state conditions. The emphasis was placed on the effect of the cavity width (air gap width) and the inlet aperture area on the mass flow rate. Reverse flow was observed for a $0.5 \mathrm{~m}$ wide cavity. The experimental results show that the inclination angle of the passive wall has no significant effect on the temperature distribution across the air gap width and along the chimney height. On the other hand, the averaged air flow velocity across the air gap width is strongly affected by the inclination angle. The experimental results also show that the IPWSC with $0.7 \mathrm{~m}$ absorber height and $0.1 \mathrm{~m}$ air gap width at an inclination angle of $6^{\circ}$ and input heat flux of $500 \mathrm{~W} / \mathrm{m}^{2}$ can produce sufficient ventilation for a $27 \mathrm{~m}^{3}$ room based on ASHREA standards.

Efforts have been made to analyse different solar chimney configurations with different and improved numerical tools. Both Saleem et al. (2016) and Hosien and Selim (2017) developed a mathematical model dedicated to the analysis of different geometrical parameters of a solar chimney subjected to real meteorological data of a north-east Egyptian climate. Saleem et al. (2016) stated that the temperature varies between $33^{\circ}$ and $37^{\circ} \mathrm{C}$, with average winds of $3-8 \mathrm{~m} / \mathrm{s}$ and a mean global radiation of $850 \mathrm{~W} / \mathrm{m}^{2}$. Additionally, they conducted a series of quantitative comparison studies 
based on the previously mentioned work of Mathur et al. (2006) and Imran et al. (2015). Their results show an average deviation of $8.97 \%$ against the aforementioned experimental results. They state as well that for a $1.4 \mathrm{~m}$ long, $0.60 \mathrm{~m}$ wide, a 0.20 $m$ air gap and a $45^{\circ}$ inclination rooftop solar chimney, the flow rate is in accord with ASHRAE standard 62, capable of providing a compliant ventilation for $88.2 \%$ during day time. On the other hand, Hosien and Selim (2017) carried out a similar analysis for a passive wall solar chimney and compared it to the findings of Mathur et al. (2006). Their study elaborates on the influence of environmental conditions on a PWSC performance, which could be embedded to a window due to its reduced dimensions. Solar radiation, ACH and surface temperatures are discussed, however; most noticeable is the effect of wind speed on the mass flow rate. Indeed, mass flow rate reaches a maximum value of $0.12 \mathrm{~kg} / \mathrm{s}$ when wind speed reaches $5 \mathrm{~m} / \mathrm{s}$. It is established that solar effect has a lower impact on the chimney performance in regions with very high wind speeds.

Other articles describe a mathematical model adopted under the simplified Navier- Stokes energy and continuity equations through the Boussinesq approximation (Khanal and Lei, 2014a). The consideration of the thermal boundary layer of the chimney which allows a more detailed resolution of the flow behaviour. The comprehension and determination of the thermal boundary layer leads to the establishment of two main regimes dependant on the Rayleigh number. The first regime occurs when the thermal boundary layer is smaller than the air gap (high Rayleigh number) in which the air flow is mainly influenced by convection. The second regime (low Rayleigh number), where conduction dominates the air flow, is established for a thermal layer greater or comparable to the air gap size. They emphasize that in terms of ventilation performance, the Rayleigh number is the only controlling parameter for a set Prandtl number and a fixed aspect ratio.

Aerodynamic behaviour of the SC has also attracted some interest in recent years. Bassiouny and Koura (2008) developed a FORTRAN computer program and focused on the chimney's air velocity distribution, as well as the inner-flow for different inlet sizes and air gaps under various radiation values (300, 500 and 700 
$W / m^{2}$ ). Additionally, they represent the air flow pattern when subjected to several operating conditions. In their investigation, they considered a laminar flow under steady state conditions. They state that the maximum ACH is obtained for an inlet size of $0.2 \mathrm{~m}$ and thereupon; the size has no significant impact or has the opposite effect. In the same way, a greater gap size shows an increased ACH until the value of $0.25 \mathrm{~m}$. They conclude that the $\mathrm{ACH}$ is more dependant on the chimney width than on the inlet size. FORTRAN has also aided in the numerical investigation of different inclination angles and chimney air gaps. Imran et al. (2015) performed different simulations taking into consideration the Iraqi meteorological conditions. Their findings suggest an inclination angle of $60^{\circ}$. Subsequently, they analysed the results of an inclined chimney coupled to a $2 \times 3 \times 2 m$ room built on the fourth floor of a building in Baghdad for different thicknesses. A maximum air velocity was obtained for a solar radiation of $750 \mathrm{~W} / \mathrm{m}^{2}$ and an air gap of $50 \mathrm{~mm}$. In accordance with the results of Khanal and Lei (2015), no reverse flow is observed even at a maximum air gap of $150 \mathrm{~mm}$.

Similarly, EnergyPlus has been employed to calculate the maximum mass flow rate under Chinese summer conditions,in the Nanjing area (Jianliu and Weihua, 2013), were obtained with a tilt angle of $45^{\circ}$, concluding that ventilation rate increases as the ratio between the size of the absorber wall and the air gap increases. EnergyPlus has also been implemented to develop a model in order to simulate and determine the energy impact of this type of the solar chimney (Lee and Strand, 2009). They investigated the effect of three different weather conditions upon this technology. The results show that parameters such as chimney height as well as solar absorptance and transmittance of the collector wall have a greater impact in the air flow rate than the air gap size. They also suggest that the hot temperature air at the outlet could be used for heating purposes.

The findings obtained by Tan and Wong (2014) are noteworthy since, it states that for a tropical weather, wind speed has no significant impact on the air temperature of the chimney and the classroom temperature regardless of the incident solar radiation but they conclude that when under $2 \mathrm{~m} / \mathrm{s}$, it has barely 
any effect on the chimney airflow. Above this value, wind speed plays an important role in solar chimney induced ventilation. It has been demonstrated that when location-specific criteria such as wind speed are disregarded, numerical tools can show that the influence of internal heat load on air temperature and speed within the solar chimney ducts as well as within the classroom's interior are limited.

Shi and Zhang (2016) employed the Fire Dynamics Simulator to analyse the performance of a solar chimney for different cavity widths, surface temperatures and inlet heights. Experimental data was used to validate the numerical model under various conditions, disregarding location-specific criteria such as air speed. As stated previously, the size of the outlet can induce a reverse flow in the chimney.

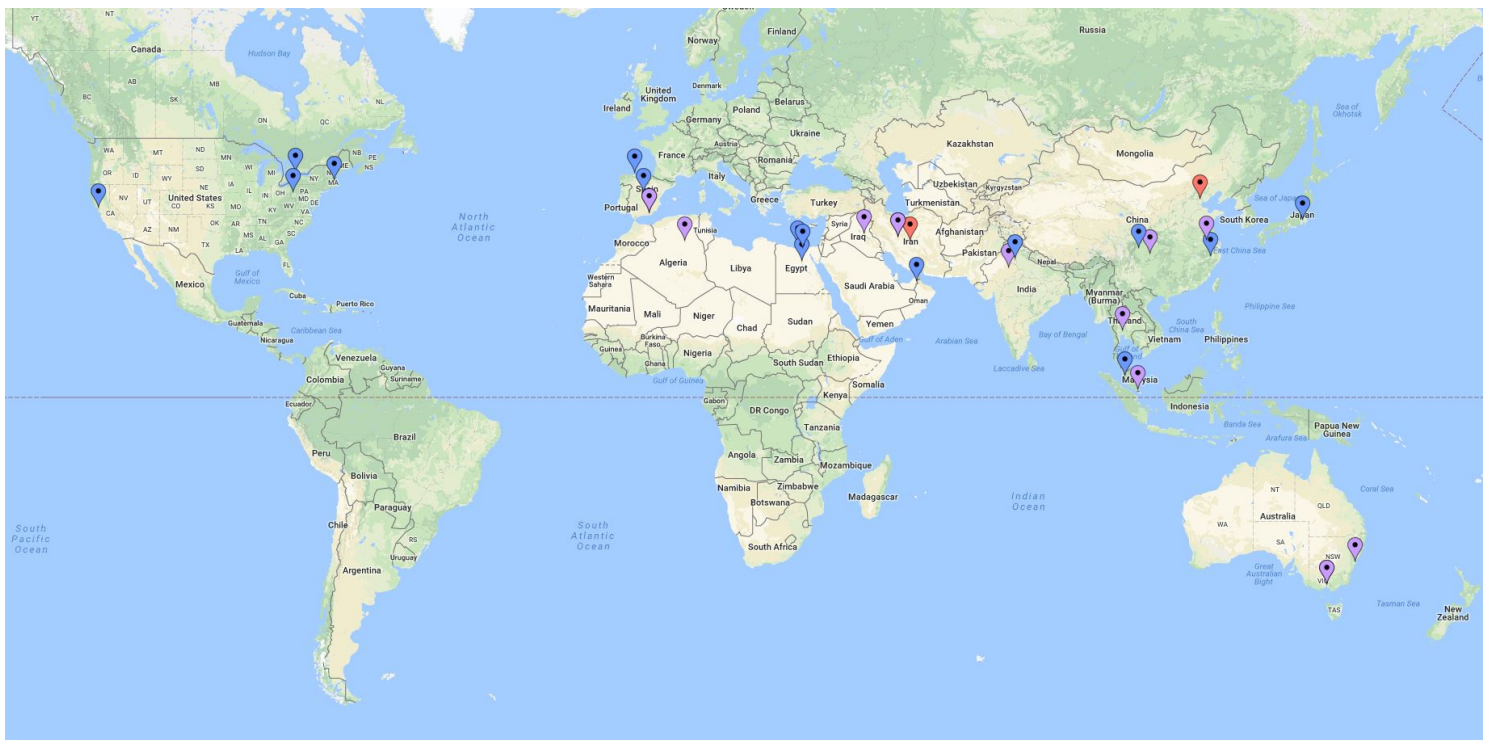

Figure 2.9: Location of Experimental (red), Numerical (blue) and Numerical \& Experimental (purple) SC studies

Overall, several conclusions can be drawn from the previous articles:

1. With increase in the gap between the absorber and glazing, air flow increases in all the cases since relatively less percentage of flow is restricted by the boundary layer resulting into higher values of air velocity.

2. There is no optimal gap size since the other factors affect the performance of the solar chimney, however air gaps above $0.3 \mathrm{~m}$ seem to hamper the mass flow rate.

3. Height is a varying factor across all the solar chimney studies. The cases presented can range from under $1 \mathrm{~m}$ to $3.5 \mathrm{~m}$, mostly relying on the thermal 
properties of the collector wall.

4. When subjected to environmental conditions, wind speed above $2 \mathrm{~m} / \mathrm{s}$ has a strong influence on the performance of the SC. Studies as the one carried out by Schwan et al. (2017) prove that ACH increases or decreases depending on the predominating wind direction and the inclusion of turbine vents can greatly improve the performance of this passive system.

These concepts need to be taken into consideration in the design and analysis of the performance of the solar chimney analysed in this $\mathrm{PhD}$ thesis. The location of the aforementioned articles are presented in Figure 2.9. The work presented throughout this dissertation mainly relates to the work done by Arce et al. (2015); Arce, Jiménez, Guzmán, Heras, Alvarez and Xamán (2009); Arce, Xaman, Alvarez, Jiménez and Heras (2009); Jiménez et al. (2007). The results obtained report an average mass flow rate of $100 \mathrm{~m}^{3} / \mathrm{h}$ during summer and $91.5 \mathrm{~m}^{3} / \mathrm{h}$ during winter. These values are a result of the chimney orientation (higher direct irradiance during winter) and the high wind speed. It is also reported that under higher wind speeds, mass flow rate can reach $374 \mathrm{~m}^{3} / h$, reasserting the influence of this environmental condition in the performance of SCs. A detailed description of the experimental set-up is presented in section 3.4. Finally, parallel studies (Arce et al., 2013; Tlatelpa et al., 2012) have been conducted at the CIEMAT where smaller solar chimneys are analysed through a mathematical model based on a thermal network. This SCs are installed in the bioclimatic building of the CIEMAT in Tabernas, Spain. The predicted value for a SC of this scale under summer conditions was of $147 \mathrm{~m}^{3} / \mathrm{h}$ under a solar irradiance of $700 \mathrm{~W} / \mathrm{m}^{2}$ with an absorber plate temperature of $91^{\circ} \mathrm{C}$.

\subsubsection{Solar Chimneys with Enhancers}

According to some of the previous studies presented in the section above, such as the work by (Martí-Herrero and Heras-Celemin, 2007), the implementation of enhancers can improve the performance of the solar chimney in different aspects and its recommended to further pursue the increase of the thermal inertia of 
solar chimneys. Suárez-López et al. (2015) suggested that from an energetic standpoint, the solar chimney could be more appropriate as a heating device than as a ventilation solution. Moreover, it is also stated that almost $2 / 3$ of the incoming solar energy is lost at or through the glass cover, which suggests optimization analysis for the incoming energy. Naraghi and Blanchard (2015) demonstrated that when increasing the thermal mass of the absorber plate, the mass flow rate during the evening and the early morning is as well increased.

Some of the simpler enhancement solutions are based on the addition of mechanical elements, for instance, a fan (Duan et al., 2015) yet, Even though it is stated that mechanical ventilation can increase the ventilation rate, it is demonstrated that it can lead to reverse flow scenarios, for high mechanical ventilation volumes due to the greater inflow pressure. Additional construction components can be coupled to the solar chimney for the same purpose. Solar chimneys have been coupled with solariums (Ravanfar, 2013) in order to increase the ventilation rate, to ensure the temperature difference and to allow energy saving potential to the adjacent room. Investigations such as the one carried out by Shahreza and Imani (2015) focused on the effect of solar radiation intensifiers. Other articles harness the potential of cool ceilings (Chungloo and Limmeechokchai, 2009) or Trombe walls (Rabani et al., 2015) in order to enhance the ventilation rate of the solar chimney, yet the main issue regarding the performance of solar chimneys is not addressed: the capitalization after sundown or the utilization in colder climates. The following sections present a viable alternative towards these goals. 


\subsection{Thermal Energy Storage}

As mentioned before, the energetic objectives established by the Paris Agreement and agreed by the three countries concerned with the works (France, Spain and Mexico) presented in this $\mathrm{PhD}$ thesis, reinforce the need of ventilation systems with a lower energetic consumption. This goal can be achieved, amongst other things, by the implementation of an efficient thermal energy storage system.

Thermal Energy Storage (TES), as it names states, allows the retention of thermal energy to be later released to the system (building, district, and town) with an hourly, daily or even seasonal delay. The utilization of TES can reduce the energetic demand of a certain system during peak hours, therefore reducing the costs of HVAC systems, and the lessening the greenhouse gas emissions resulting from fossil fuel energy sources. The three major TES solutions are presented in the following section.

\subsubsection{Sensible Heat Storage}

Sensible Heat Storage (SHS) is the result of the temperature variation of a solid or a liquid within a single phase, hence, without the phase transformation. The stored energy will be directly proportional to the mass of the sample, its thermodynamic properties (namely the specific heat coefficient) and the temperature difference between the initial and final states. This energy is calculated as follows:

$$
Q_{S H S}=m C_{p}\left(T_{2}-T_{1}\right)
$$

SHS applications are vastly used in construction for wall and can be found in wall insulation or solar or gas water heaters. Some of the most common storage mediums are water, oil, brick, concrete, sand, soil or even metals like aluminium, however, the simpler and cheaper design comes at a high efficiency cost. Since the stored energy depends on the mass and thermodynamic properties of the material, SHS systems tend to be voluminous and can lead to heat losses if not well insulated. 
This usually represents a much lower storage capacity.

\subsubsection{Chemical Heat Storage}

Chemical heat storage systems store thermal energy through stable chemical substances and converting heat energy into chemical potential energy. Chemical Heat Storage (CHS) depends on the reversible chemical reactions between two substances. When the first compound (A) is split though a dissociative endothermic reaction, energy absorption occurs through the chemical potential energy of elements $\mathrm{B}$ and $\mathrm{C}$. When the reverse reaction occurs, the stored thermal energy is recovered with a small loss (Yan et al., 2015). This chemical reaction is depicted in equation 2.2 .

$$
A+\text { heat } \Longleftrightarrow B+C
$$

Compared to other thermal energy storage methods, chemical heat storage exhibits high energy storage density as well as feasibility for long-duration energy storage however, this type of TES is not well suited for building applications concerning ventilation due to complexity of reaction processes, the particular consideration of safety and the large initial investment.

\subsubsection{Latent Heat Storage}

The third heat storage technique is called Latent Heat Storage $(L H S)$. In comparison to Sensible Heat Storage, LHS stores and releases energy during the phase change of a substance, which means energy storage at a constant temperature. Several state combinations are possible according to the working temperatures; some of these are presented below:

- Evaporation: usually involves large phase change enthalpy; however the process of evaporation strongly depends on the boundary conditions. This type of phase change may be carried out at a constant volume, constant pressure in a closed system or constant pressure in an open system.

- Melting: involves a solid to liquid phase change. Due to the low volume expansion (generally below 10\%) after the fusion of the material and the 
greater latent heat potential, this option is the most commonly used.

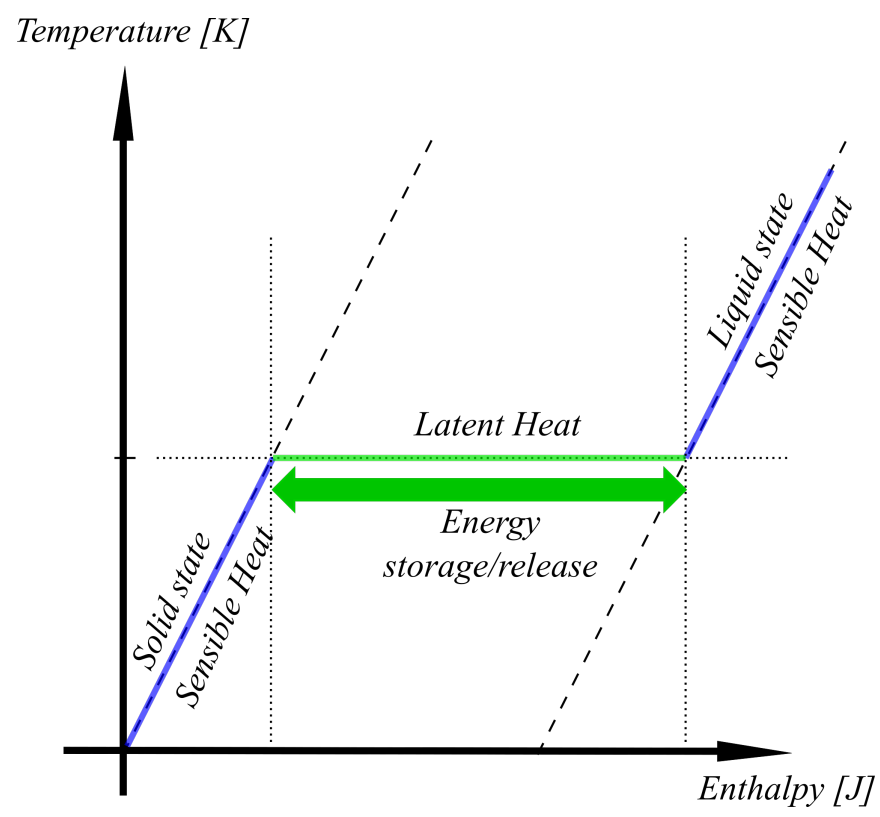

Figure 2.10: Phase change diagram showing the theoretical transformation of a pure substance from solid state to liquid state.

The energy stored during the latent phase is calculated by the following equation:

$$
Q_{L H S}=m H_{L}
$$

The phase change of a material is depicted in the phase change diagram in Figure 2.10. This diagram shows the theoretical temperature profile during a sensible heat to latent heat exchange process. The storage or release of energy will depend on the the temperature rise or drop. A brief comparison of of storage densities between common TES methods is presented below.

Tables 2.1 and 2.2 show the interest of LHS against the other TES methods and summarize the main topics discussed in the previous sections. The working temperature range of LHS allows the utilization under different conditions, whilst providing a higher storage density than SHS. CHS has a higher energetic potential but comes at a higher cost which makes it less convenient for ventilation purposes. LHS applications are usually used to enhance the cooling or heating performance of mechanical ventilation systems and for peak power reduction needs. 
Table 2.1: Comparison of typical storage densities of different energy storage methods presented by Cabeza and Mehling (2007)

\begin{tabular}{lcc}
\hline \hline & $k J / k g$ & Comment \\
\hline Sensible Heat & & \\
Granite & 17 & $\Delta T=20^{\circ} \mathrm{C}$ \\
Water & & $\Delta T=20^{\circ} \mathrm{C}$ \\
Latent Heat of Melting & 330 & \\
Water & 200 & $5-130^{\circ} \mathrm{C}$ \\
Paraffin & 200 & $5-130^{\circ} \mathrm{C}$ \\
Salthydrate & $300-700$ & $300-800^{\circ} \mathrm{C}$ \\
Salt & & \\
Latent Heat of Evaporation & 2450 & $\mathrm{Ambient} \mathrm{conditions}$ \\
Water & & \\
Chemical Energy & 120,000 & $300 \mathrm{~K}, 1 \mathrm{bar}$ \\
H gas & 120,000 & $20 \mathrm{~K}, 1 \mathrm{bar}$ \\
H liquid & 44,600 & $0{ }^{\circ} \mathrm{C}$ \\
Gas (Petroleum) &
\end{tabular}

\subsubsection{Phase Changing Materials (PCM)}

Phase Changing Materials (PCM) rely on the concept of Latent Heat Storage presented before. Through the process of energy storage and release, the indoor temperature can be modified depending on the PCM selection and employment method. (Baetens et al., 2010). The choice of PCM depends on multiple thermal, technological and economical factors. As stated by Cabeza et al. (2011) a suitable phase change temperature and a large melting enthalpy are two obvious requirements on a phase change material, however, PCM can come in a variety of prices and containers according to the melting range, the available applications and the quantity needed. An ideal pure substance carries out the transformation at a constant temperature. The impurity of the substances can modify the isothermal behaviour of the latent phase. Figure 2.11 represents the ideal transformation of a PCM following a temperature drop. It can be observed that during the phase transformation, a heat flux is released from the substance into the environment. (Kuznik et al., 2011). Since PCM can store about 3 to 4 times more energy per volume as sensible heat storage in solids or liquids in a temperature interval of 20 ${ }^{\circ} \mathrm{C}$, they are more interesting alternative. A detailed list of commercially available PCMs can be in the work of Kenisarin and Mahkamov (2007). 
Table 2.2: Comparative table of TES technologies by Abedin and Rosen (2011)

\begin{tabular}{|c|c|c|c|}
\hline \multirow[b]{2}{*}{ Performance Parameter } & \multicolumn{3}{|c|}{ Type of Thermal Energy Storage } \\
\hline & SHS & LHS & $\mathrm{CHS}$ \\
\hline Temperature Range & $\begin{array}{lr}\text { Up to: } & 110^{\circ} \mathrm{C} \\
\text { (water } & \text { tanks) } \\
50^{\circ} \mathrm{C} & \text { (aquifers } \\
\text { and } & \text { ground } \\
\text { storage) } & \end{array}$ & $\begin{array}{lr}20 \quad- & 40^{\circ} \mathrm{C} \\
\text { (paraffins) } & \& \\
30-80^{\circ} \mathrm{C} & \text { (salt } \\
\text { hydrates) } & \end{array}$ & $20-200^{\circ} \mathrm{C}$ \\
\hline Storage Density & $\begin{array}{l}\text { Low (with high } \\
\text { temperature } \\
\text { interval): } \\
0.2 G J / m^{3} \quad \text { (for } \\
\text { typical water } \\
\text { tanks) }\end{array}$ & $\begin{array}{l}\text { Moderate (with } \\
\text { low temperature } \\
\text { interval): } 0.3- \\
0.5 G J / m^{3}\end{array}$ & $\begin{array}{l}\text { Normally high: } \\
0.5-3 G J / m^{3}\end{array}$ \\
\hline Lifetime & Long & $\begin{array}{l}\text { Often limited } \\
\text { due to storage } \\
\text { material cycling }\end{array}$ & $\begin{array}{l}\text { Dependes } \\
\text { on reactant } \\
\text { degradation and } \\
\text { side reactions }\end{array}$ \\
\hline Technology Status & $\begin{array}{l}\text { Available } \\
\text { commercially }\end{array}$ & $\begin{array}{l}\text { Available } \\
\text { commercially } \\
\text { for some } \\
\text { temperatures } \\
\text { and materials }\end{array}$ & $\begin{array}{lr}\text { Generally } & \text { not } \\
\text { available, but } \\
\text { undergoing } \\
\text { research } \\
\text { pilot and } \\
\text { tests }\end{array}$ \\
\hline Advantages & $\begin{array}{l}\text { Low cost, } \\
\text { reliable, simple } \\
\text { application } \\
\text { with available } \\
\text { materials }\end{array}$ & $\begin{array}{l}\text { Medium storage } \\
\text { density, small } \\
\text { volumes and } \\
\text { short distance } \\
\text { transport } \\
\text { possibility }\end{array}$ & $\begin{array}{l}\text { High storage } \\
\text { density, low heat } \\
\text { losses (storage } \\
\text { at ambient } \\
\text { temperatures), } \\
\text { long storage } \\
\text { period, long } \\
\text { distance } \\
\text { transport } \\
\text { possibility and } \\
\text { high compact } \\
\text { energy storage }\end{array}$ \\
\hline Disadvantages & $\begin{array}{l}\text { Significant heat } \\
\text { loss over time } \\
\text { (depending on } \\
\text { level of Large } \\
\text { volume needed } \\
\text { insulation) }\end{array}$ & $\begin{array}{l}\text { Low heat } \\
\text { conductivity, } \\
\text { corrosivity } \\
\text { of materials, } \\
\text { significant } \\
\text { heat losses } \\
\text { (depending } \\
\text { on level of } \\
\text { insulation) }\end{array}$ & $\begin{array}{l}\text { High capital } \\
\text { costs and } \\
\text { technically } \\
\text { complex }\end{array}$ \\
\hline
\end{tabular}




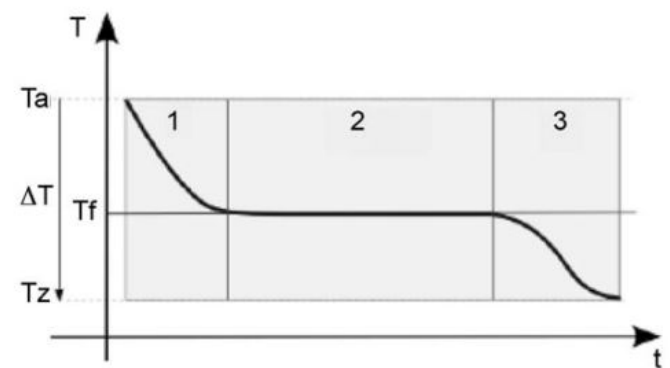

(a)

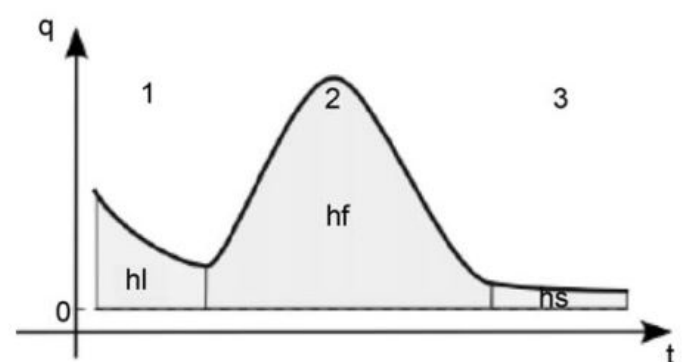

(b)

Figure 2.11: Time evolution of the (a) temperature and (b) heat flux during the solidification of a pure body following a temperature drop (Kuznik et al., 2011)

\subsubsection{PCM Classification}

The classification of PCMs is based on different thermodynamical factors such as the chemical composition of the PCM, melting temperature or the latent heat of fusion. According to the Annex 23, which focused on the application of energy storage to various types of low energy buildings, PCMs can be categorized in three different groups. This classification is presented in Figure 2.12.

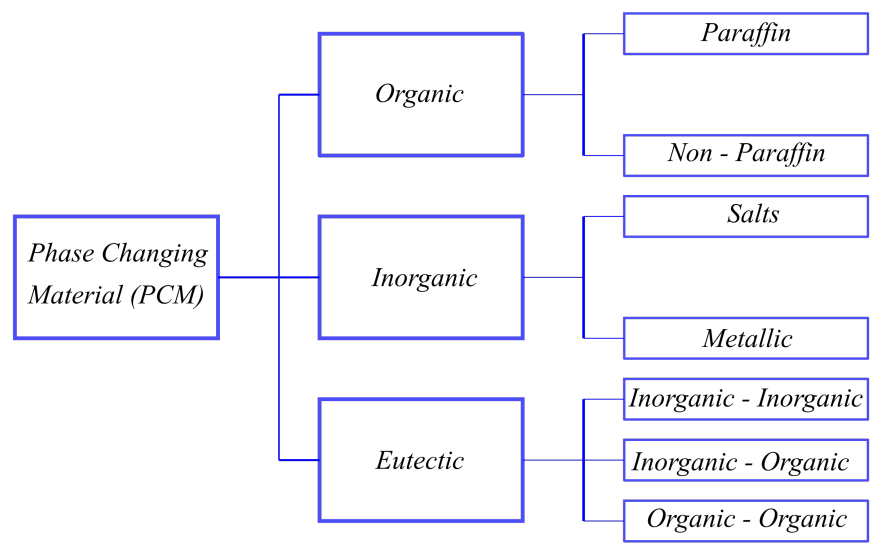

Figure 2.12: Phase Changing Material Classification (IEA,ECES Annex 23, 2013)

Inorganic PCMs are composed of salts, hydrated salts and metals. This materials have a particularly wide temperature range which extends from $-100^{\circ} \mathrm{C}$ to $1000^{\circ} \mathrm{C}$. Hydrated salts posses a notably high latent heat potential, good thermal conductivity and a small volumetric expansion, yet they must deal with problems such as (Haghighat et al., 2013):

- Supercooling: the substance remains in the liquid phase while its temperature is below the threshold of solidification which impacts the return 
of the energy stored during the melting.

- Segregation: the substance melts congruently with formation of lower salt hydrate. The process is irreversible and the storage density decreases with cycling.

Organic PCM include paraffins, fatty acids, easters, alcohols, or glycols. These substances have been successfully tested and implemented in many domestic and commercial applications, such as space heating in buildings, electronic devices, refrigeration and air-conditioning, solar air/water heating, textiles, cars, food and space industries (Alva et al., 2017). Organic PCMs posses a lower thermal conductivity and a lower storage potential than most salts however, they have a congruent melting without segregation or supercooling. Finally eutectic materials are a combination of the aforementioned two. A different classification based on the melting temperature and enthalpy of these materials can be observed in Figure 2.13.

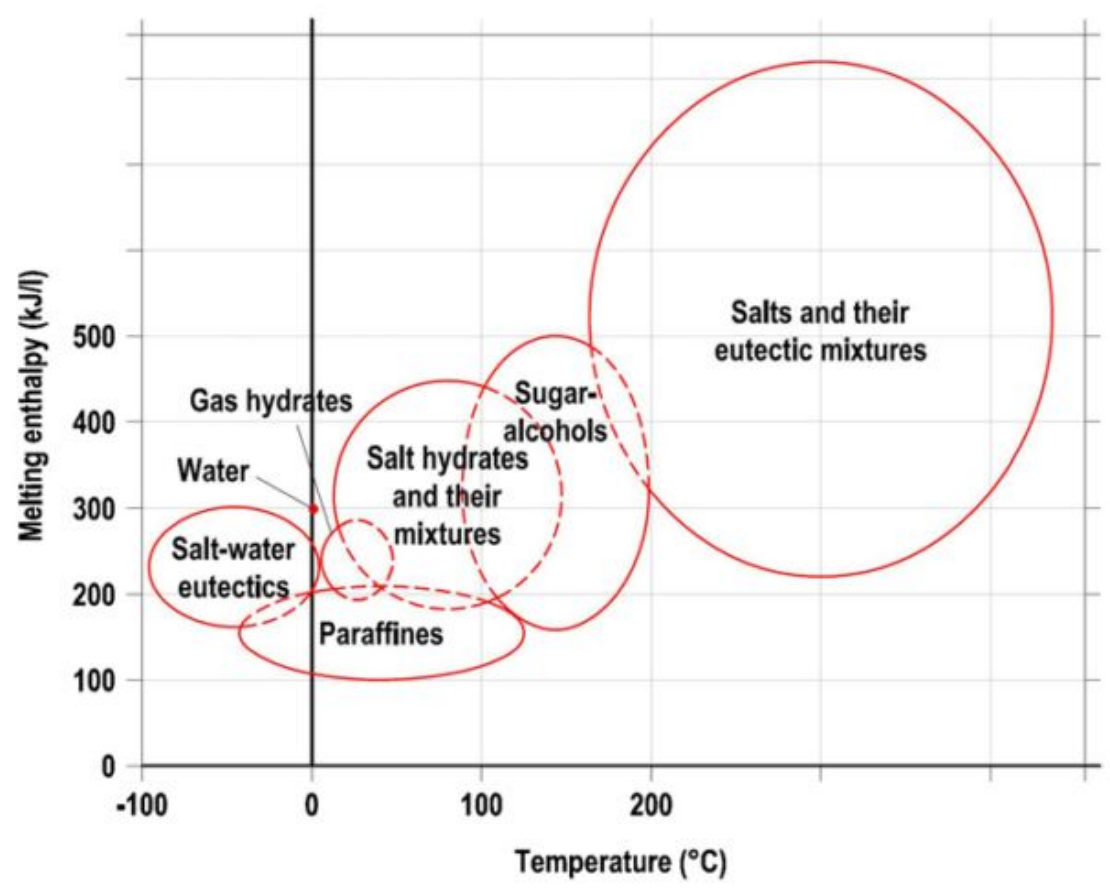

Figure 2.13: Phase Changing Material Classification depending on the melting temperature and enthalpy (Baetens et al., 2010) 


\subsubsection{PCM encapsulation}

The conditioning of PCMs depends on the aim of the system. PCMs may be embedded in building materials such as bricks, wall boards and flooring but they may be integrated to external components as well. This type of utilization can prevent temperature peaks during hot seasons and increase thermal comfort. Building applications usually focus on Micro and Macroencapsulated PCMs since the most common configuration is liquid-solid PCM. Both options prevent the liquid phase of the material to flow away however, the application is very different.

Microencapsulation consists of beads, spheres, rods or films usually varying form $1 \mu \mathrm{m}$ to $1000 \mu \mathrm{m}$, filled with PCM. The material is generally contained by a high molecular weight polymeric film. These PCM particles can be added to construction materials such as textile-reinforced concrete for the development of façade elements that can lead to a reduction of $2{ }^{\circ} \mathrm{C}$ of the inner temperature (Bahrar et al., 2018). In order for this type of application to work, the PCM particles must be compatible with the matrix it is incorporated to.

Macroencapsulation, on the other hand, consists on the containment of PCM in tubes, bags, sphere, panels or any other receptacle. These containers must have a good thermal conductivity and must prevent any leaks. Macroencapsulation is usually larger than $1 \mathrm{~cm}$ in diameter, and is the most common form of encapsulation.

\subsubsection{Advantages, Limitations and PCM Selection}

PCM are subjected to temperature cyclical variations. The normal PCM will maintain its thermal properties for multiple cycles before experiencing deterioration (reduction of thermal potential). The average lifespan of PCMs varies between 3000 and 10000 cycles (Hadjieva et al., 1992) before the properties start degrading and the optimal performance of the PCM is hampered.

Due to their composition and nature, PCM can also suffer from flammability and bad odor and, depending on the container, they might lead to corrosion. Degradation of the container may cause leakages, which would render the 


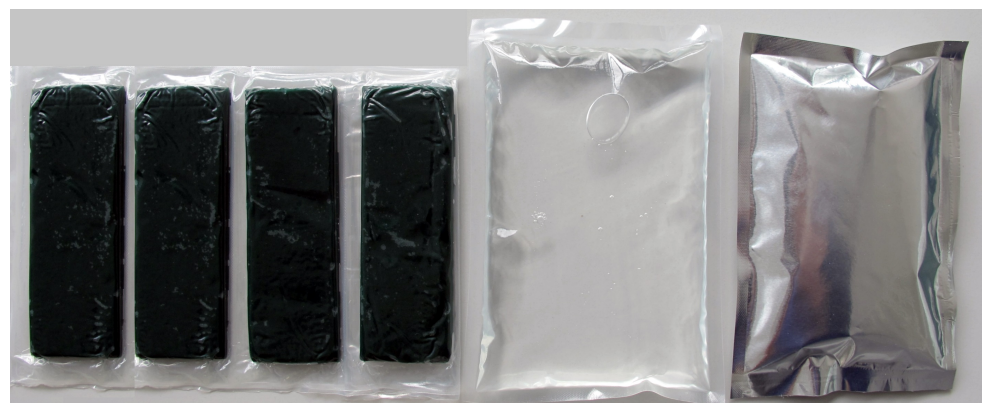

(a)

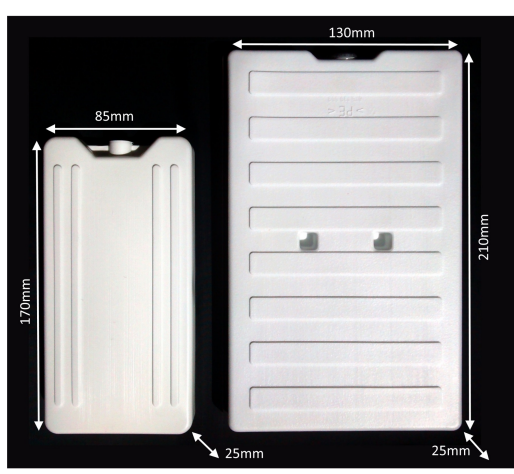

(b)

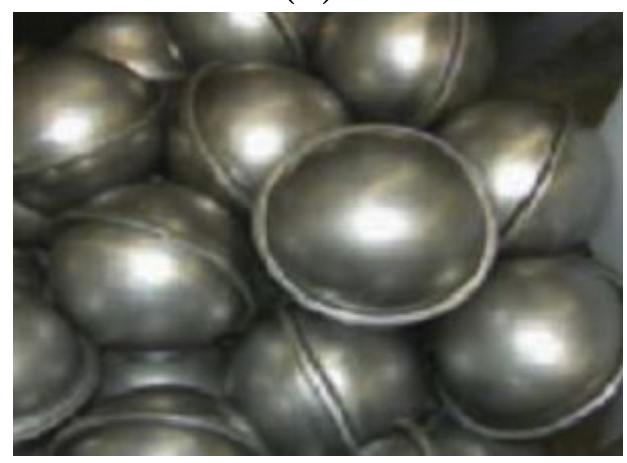

(d)

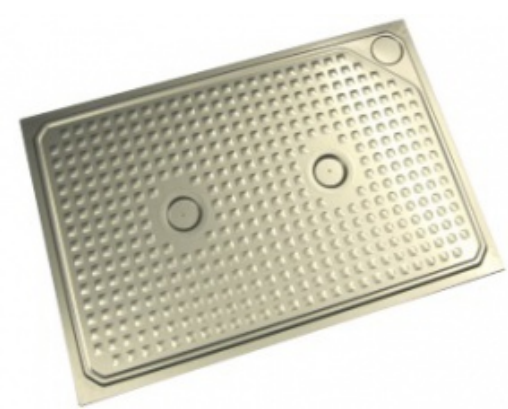

(c)

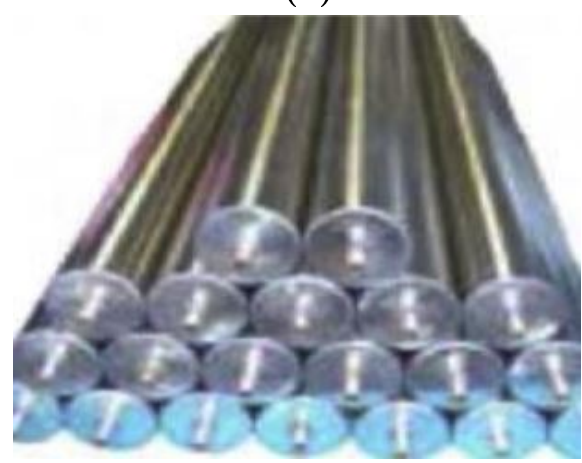

(e)

Figure 2.14: PCM Macroencapsulation examples (Information from Rubitherm and Veerakumar and Sreekumar (2016))

technology unusable. Furthermore, some of the aforementioned materials are composed of flammable substances. PCM applications dedicated to the building sector must respect the current building legislation related to fire risks and the occupants' olfactory comfort. Both of this problems can be overcome either by fire retardant additives, which show no modification of the performance of PCMs (Cai et al., 2007, 2006) or by the use of halogenous compounds (Haghighat et al., 2013) in order to increase the fire resistance, and/or by the correct choice of container.

The works presented in this thesis were carried out with paraffinic PCM. 
Paraffins are preferred over other options considering the price, the availability and the working temperature range. Moreover, they do not generally undergo subcooling and are chemically inert and stable with no phase segregation. Furthermore, paraffins are noncorrosive, odorless, long lasting, inexpensive, easily available, ecologically harmless and nontoxic (Alva et al., 2017).

Paraffin waxes consist of $n$ - alakanes chains $\left(\mathrm{CH}_{3}-\left(\mathrm{CH}_{2}\right)-\mathrm{CH}_{3}\right)$ as a product of the distillation of crude oil. The average length of the carbon chain is directly proportional to the increase in melting temperature range and heat of fusion. Paraffin PCMs tend to have a lifespan of 1000 to 2000 cycles, however, even after this limit is reached, they tend to present good thermal reliability. Finally, due to their composition, paraffinic PCM can be stored in aluminium containers since they do not contribute to corrosion. PCM aluminium panels as the ones in Figure were provided by the german societyRubitherm. This panels were selected due to the implementation simplicity and optimal temperature range, as well as the aforementioned characteristics. The thermal properties of this material are presented in the next Chapter, in Section 3.2. 


\subsection{Active Solar Chimney (ASC): A PCM inte- grated Solar Chimney}

The objective of this work is to analyse the effectiveness of energy storage devices, in particular organic phase changing materials (PCMs), on a laboratory and in-situ solar chimney. The activation of this technology is achieved through the implementation of these PCM panels. This study aims to provide an existing technology (Solar Chimney) with a different approach in means of improving the current performances, rendering it a viable option for year long use (Active Solar Chimney).

As presented in the section above, phase changing materials have been previously used with the intention of improving the occupants' thermal comfort during the different seasons. The incorporation of PCM in construction materials such as concrete, mortar or other porous materials has been characterized to a greater extent. Since PCM has been proven to provide a higher thermal storage density than sensible heat materials, the solar chimney's efficiency could be improved.

Thus far, the thermal performance of a solar chimney with PCM has been investigated by few researchers. To the author's knowledge, Amori and Mohammed (2012) began to lay the groundwork of the capabilities of PCM integrated solar chimneys. In their work, they investigate both numerically and experimentally the performance of said technology under Iraqi environmental conditions. In their studies, a paraffin wax (melting temperature of $65.16^{\circ} \mathrm{C}$ ) was employed and enclosed in a ductile steel plate. As with other PCM integrated passive systems, solar chimneys demonstrated a modification of the thermal performance of the chimney and further prolonged the ventilation hours in the absence of solar energy. The results obtained were compared to a vertical solar chimney with bottom, side, both bottom and side air entrances as well as tilt angle of $75^{\circ} \mathrm{C}$. They state that the system, when coupled with paraffin wax, is capable of storing 5016W from 8:00 AM to 13:00 PM (during 5 hours), discharging 4954.4W from 13:00 PM to 22:00 
PM (during 9 hours), however, even though air flow rate does not vary significantly, the PCM integrated case shows slightly lower values during day time due energy absorption phase of the paraffin wax which leads to lower overall temperatures and a reduced induced flow. This phenomena is also explained by the differences in weather conditions for each test.

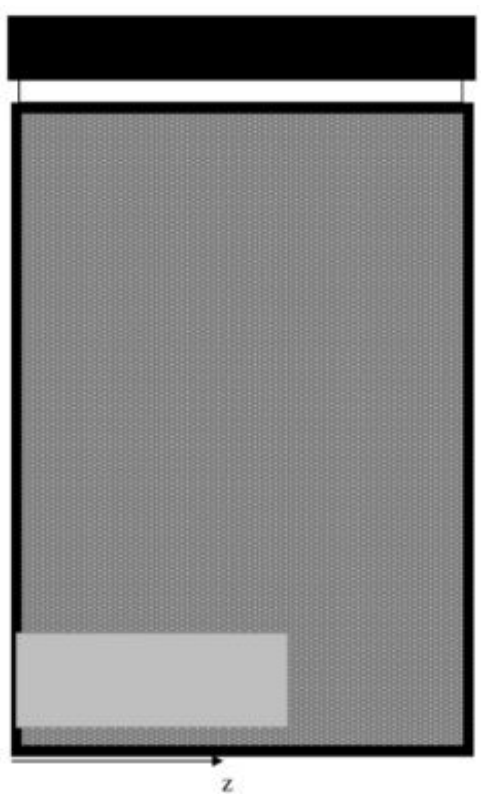

(a)

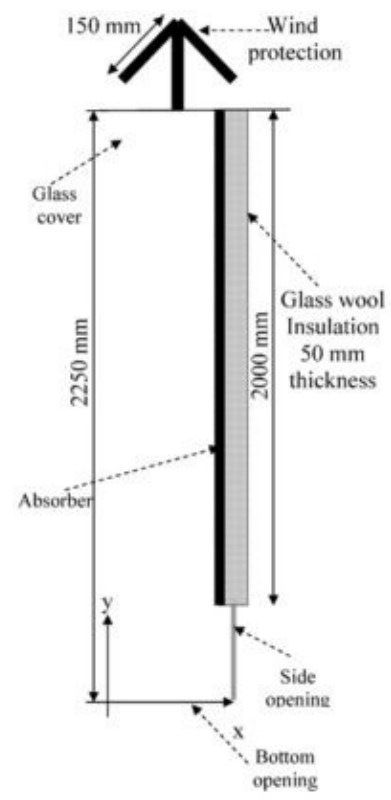

(b)

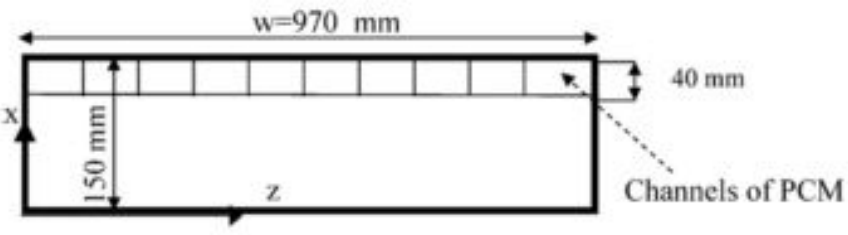

(c)

Figure 2.15: Experimental set-up employed by Amori and Mohammed (2012) for the analysis of a PCM integrated SC

Similarly, Li and Liu (2014a,b); Li et al. (2016); Liu and Li $(2015 a, b)$ experimentally and numerically analysed the effects of macro-encapsulated parrafin wax in a solar chimney. In order to analyse the capabilities of this solar chimney, three different modes (closed-fully charging mode, open-partly charging mode and open-fully charging mode) were developed. The closed mode was designed to maximize the use of the solar energy when the heating is not required, whilst the open mode was designed for delivering the heated air to the living space during charging period. The results showed that the inclusion of PCM to a solar chimney 

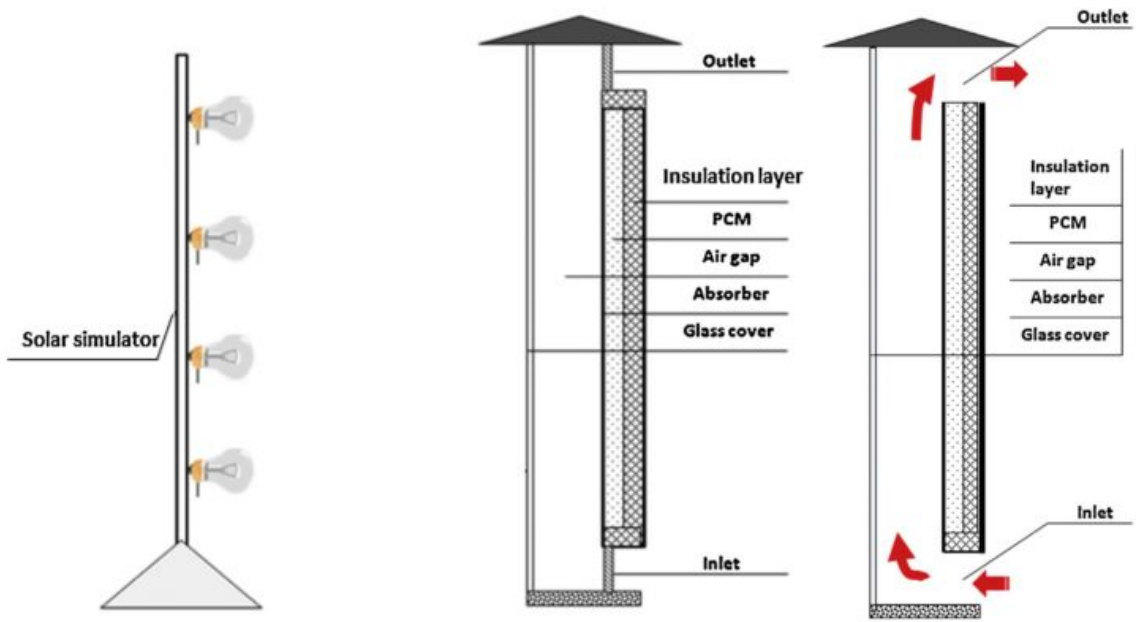

Figure 2.16: Experimental set-up employed by Li and Liu $(2014 a, b)$; Li et al. (2016); Liu and Li $(2015 a, b)$ for the analysis of a PCM integrated SC

can reduce the air flow and air temperature during charging period where sensible heat exchange is predominant, but increase it during discharging period compared with the solar chimney without PCM. For the open-partly mode, the mean air flow rate during phase change period was only $0.036 \mathrm{~kg} / \mathrm{s}$, which was lower than that for closed-fully charging mode $(0.041 \mathrm{~kg} / \mathrm{s})$. Regarding the open-fully charging mode, the melting time of the PCM was almost $11 \mathrm{~h}$, which was $57 \%$ longer than that for closed mode. The mean air flow rate during phase change period was $0.04 \mathrm{~kg} / \mathrm{s}$, which was higher than that for open-partly mode but lower than that for closed mode. The results show that the performance of the system drops once the heat flux decreases below $500 \mathrm{~W} / \mathrm{m}^{2}$, but no significant improvement is achieved above $700 \mathrm{~W} / \mathrm{m}^{2}$.

Overall, paraffinic phase change materials for implementation in solar chimneys could be an economically viable option for hybrid design solutions to create a healthy indoor environment within residential buildings through renewable solar energy. 
Table 2.3: Characteristics of the solar chimneys presented in this section

\begin{tabular}{|c|c|c|}
\hline Study & $\begin{array}{l}\text { Amori and Mohammed } \\
\qquad(2012)\end{array}$ & $\begin{array}{l}\mathrm{Li} \text { and } \mathrm{Liu}(2014 a, b) \text {; Li } \\
\text { et al. (2016); Liu and Li } \\
\qquad(2015 a, b)\end{array}$ \\
\hline Height $[\mathrm{m}]$ & 2.25 & 2.00 \\
\hline Large $[\mathrm{m}]$ & 0.97 & 1.00 \\
\hline Width $[\mathrm{m}]$ & 0.15 & 0.20 \\
\hline PCM choice & - & Rubitherm $R T 42$ \\
\hline $\begin{array}{l}\text { Absorber wall height } \\
\qquad[\mathrm{m}]\end{array}$ & 2.00 & 1.60 \\
\hline PCM Layer width [m] & 0.04 & 0.04 \\
\hline $\begin{array}{c}\text { PCM melting } \\
\text { temperature }\left[{ }^{\circ} \mathrm{C}\right]\end{array}$ & 56.16 & $38-43$ \\
\hline Heat Flux $\left[W / m^{2}\right]$ & $0-700$ & 500,600 and 700 \\
\hline $\begin{array}{l}\text { Inlet cross section } \\
\qquad\left[m^{2}\right]\end{array}$ & 0.2425 & 0.20 \\
\hline $\begin{array}{l}\text { Outlet cross section } \\
\qquad\left[\mathrm{m}^{2}\right]\end{array}$ & 0.1455 & 0.20 \\
\hline
\end{tabular}




\subsection{Conclusion}

This section was dedicated to the literature review of solar chimney and thermal energy storage systems. As stated throughout this section, most of the studies concerned with this type of technology have focused on the numerical characterization of its behaviour. There seems to be a great amount of information on the architectural characteristics of the solar chimney, however few experimental studies have been carried out. Furthermore, the impact of solar chimneys needs to be assessed under environmental conditions since it has been demonstrated that several environmental variables can severely impact the performance of a solar chimney.

The increase in the performance of the solar chimney has been mostly pursued through the modification of the inclination, the air gap size or the inlet/outlet modification however few studies have looked into energy storage devices. It has been stated that solar chimneys can provide constant ventilation and increase air quality in a building. TES can lead to the optimization of solar passive ventilation techniques. Particularly, the implementation of paraffinic PCMs can lead to a prolonged utilization of technologies such as the solar chimney and maintain a more stable performance throughout the day. TES can lead to the capitalization of solar technologies for different latitudes throughout the globe. 
Chapter 3

\section{Experimental Set-Up}




\subsection{Introduction}

The main characteristics of solar chimneys has been reviewed in section 2.5. As stated in Chapter 2, the objective of this study is to analyse the effectiveness of energy storage devices on a solar chimney for the prolongation of its utilization and to later develop a numerical model capable of representing the physical phenomena. In the interest of analysing, validating and calibrating the numerical model presented in chapter 4; two laboratory chimney prototypes were developed and an in-situ modification was carried out. Even though several chimney configurations have proven to improve the performance, the prototypes developed at the ENTPE laboratory are based on the works of Arce et al. (2015); Arce, Jiménez, Guzmán, Heras, Alvarez and Xamán (2009); Arce et al. (2011); Arce, Xaman, Alvarez, Jiménez and Heras (2009); Arce et al. (2013). Inclination angles and combinations with other passive technologies are not addressed in this work in order to compare the results with the in-situ solar chimney presented further in this chapter. This chapter is organized into three main sections:

1. The preliminary study of a single PCM panel through the characterization of the behaviour of RT44 paraffin wax when subjected to the experimental conditions used employed during the laboratory experimental set-up. Furthermore, a brief explanation of the DSC test employed to obtain the thermal characteristics of this PCM is given in this subsection.

2. The laboratory experimentation carried out at ENTPE for the characterization of a solar chimney under a controlled environment. Two laboratory prototypes were developed which served three different purposes: firstly the analysis of the impact of PCM panels on the mass flow rate of a solar chimney, the assessment of the temperature distribution throughout the height of the chimney and lastly the comparative study with the in-situ results.

3. Finally, the in-situ experimentation in Tabernas, Spain. The standalone solar chimney discussed throughout this section was modified in the interest of analysing the behaviour of such technology under real environmental conditions. 


\subsubsection{PCM Selection}

In order to analze the effects of PCMs in a passive ventilation technology such as the solar chimney a selection of the optimal PCM had to be carried out. The choice of PCM was based on three main factors:

- Availability and price in the market: Depending on the temperature range, and the type of PCM the price of the product can greatly vary. In order to make a solar chimney a viable alternative, the PCM selection must maintain a relative low price (compared to other PCMs) and must be of simple access to the general public.

- Storage/release temperature range: Solar chimneys are driven by the temperature difference between the external temperature and the temperature inside the chimney conduit. The working temperature range of the PCM must maximize the time the chimney is at a high temperature to ensure ventilation. The temperature range of 40 to $44^{\circ} \mathrm{C}$ was selected based on the available data of the standalone solar chimney of the PSA, and the work presented by Liu and $\operatorname{Li}(2015 a)$.

- Encapsulation solutions: The solar chimneys presented throughout this $\mathrm{PhD}$ thesis consider a PCM layer; however, from an experimental stand point, the PCM layer must consider safety regulations, a light durable container and finally, due to the incapability to modify the architecture of the existing chimney in Almeria, it must represent a simple adaptable solution.

Several options were taken into consideration for, however, the Rubitherm RT44 panel rose amongst other options due to their availability, fast delivery, aluminium encapsulation and the relative low cost of 30 euros per panel. 


\subsection{Preliminary PCM Tests}

The advantages of Phase Changing Materials have been studied across the literature for the past years and they were presented in section 2.4. In this way, a preliminary study was conducted on an individual panel to characterise the behaviour of the paraffinic material, macroencapsulated in the aluminium panels. This preliminary study was carried out in order to test the feasibility of RT44 panels for the subsequent laboratory and in-situ experiments. The overall characteristics of the RT44 paraffinic phase changing material can be found in Table 3.1.

The test consisted in subjecting an individual panel to a heat source in order to charge and discharge the paraffinic material and analyse the behaviour of such through the temperature evolution (Figure 3.1a). The obtained results produced by the individual panel displayed the behaviour of the material and exhibited the capacity for energy storage along with the change of phase. These characteristics are exemplified in Figure $3.1 \mathrm{~b}$ which represents the temperature evolution of an individual PCM panel when exposed to a $300 \mathrm{~W}$ halogen lamp. The ambient temperature registered during the test was approximately $30^{\circ} \mathrm{C}$. The panel reached a maximum temperature of $75^{\circ} \mathrm{C}$.

Table 3.1: Technical data of the Rubitherm RT44 PCM and panel characteristics

\begin{tabular}{|c|cc|}
\hline RT44 PCM Properties and characteristics & \\
\hline \hline Melting Area & $41-44$ & {$\left[{ }^{\circ} \mathrm{C}\right]$} \\
Congealing Area & $44-40$ & {$\left[{ }^{\circ} \mathrm{C}\right]$} \\
Heat Storage Capacity $\pm 7 \%$ & $250 *$ & {$\left[\frac{\mathrm{kJ}}{\mathrm{kg}}\right]$} \\
Specific Heat Capacity & 2 & {$\left[\frac{\mathrm{kJ}}{\mathrm{kgK}}\right]$} \\
Density (Liquid/Solid) & $700 / 800$ & {$\left[\frac{\mathrm{kg}}{\mathrm{m}^{3}}\right]$} \\
Panel Weight & 1 & {$[\mathrm{~kg}]$} \\
Panel Height & 0.45 & {$[\mathrm{~m}]$} \\
Panel Large & 0.20 & {$[\mathrm{~m}]$} \\
Panel Width & 0.025 & {$[\mathrm{~m}]$} \\
\hline \hline
\end{tabular}

${ }^{*}$ Combination of latent and sensible heat in a temperature range of $35^{\circ} \mathrm{C}$ to $50^{\circ} \mathrm{C}$. 


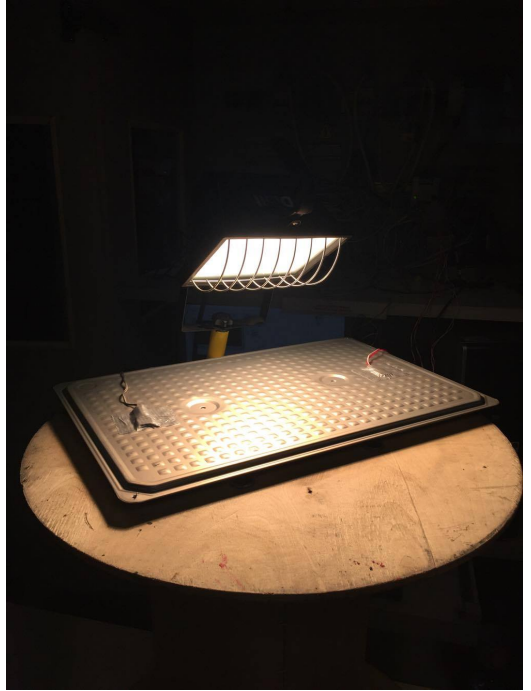

(a)

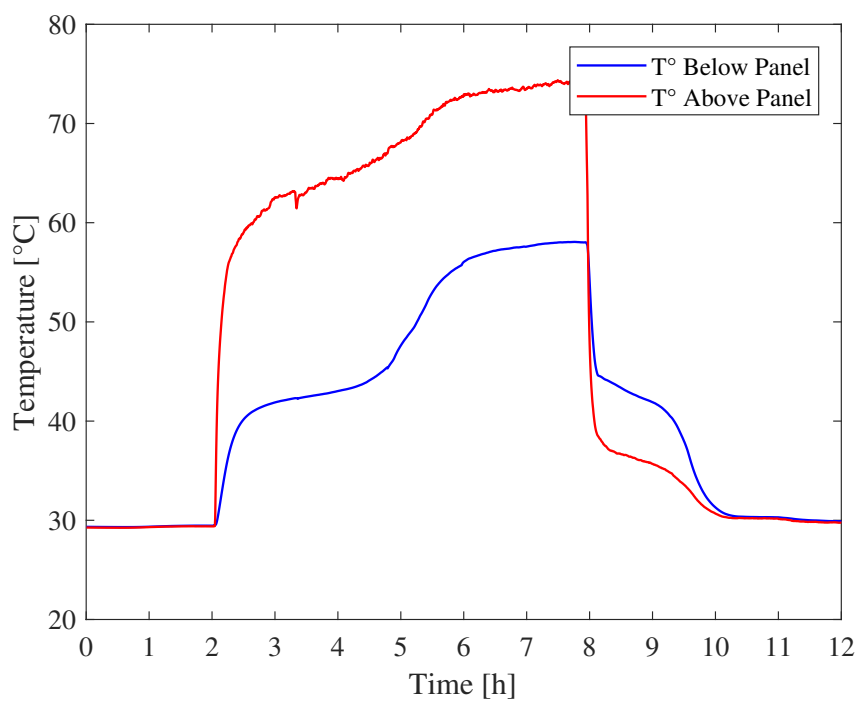

(b)

Figure 3.1: (a) RT44 panel subjected to a halogen lamp and (b) temperature evolution on an individual PCM panel

\subsubsection{PCM Thermal Properties Determination}

In order to input the thermal properties of Phase Changing Materials into the numerical model presented in the next chapter, several options were considered. Some articles have opted to work on approaches such as the Thermogravimetric Analysis (TGA), which analyses the mass variation for a certain period, for a specific temperature profile (Cai et al., 2007). Other methods such as the DTA (Differential Thermal Analysis) (Zhou et al., 2012) or the DSC (Differential Scanning Calorimetry) tests (Kheradmand et al., 2016) are techniques in which the difference in the amount of heat required to increase the temperature of a sample and its reference is measured as a function of temperature.

Specifically, the DSC is a thermo-physical method that enables the calculation of the specific heat capacity of a material through a small sample. After starting at an equilibrium temperature, both the test and reference sample (most commonly certified Indium metal) are slowly cooled/heated at a constant set rate. The excess heat absorbed or emitted by the test sample is recorded as a function of time (Baetens et al., 2010). Overall, the DSC methodology was retained over other options as it the results of the experimentation can be input into the model instead of using computational power in order to calculate the state of the PCM at each 


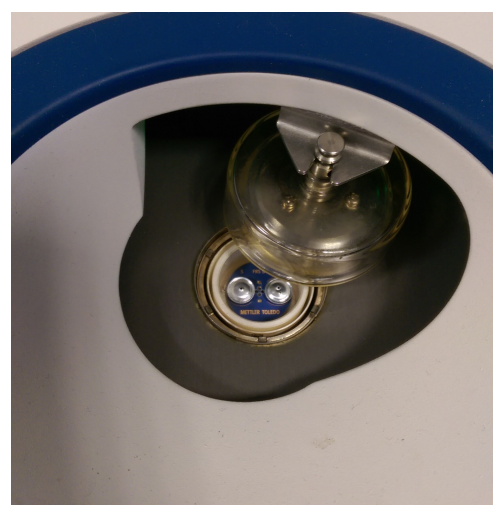

(a)

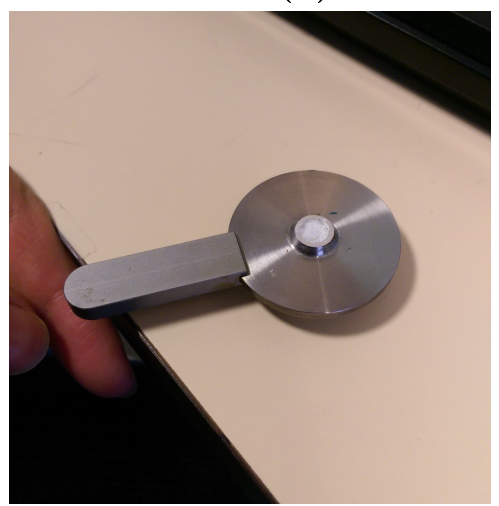

(c)

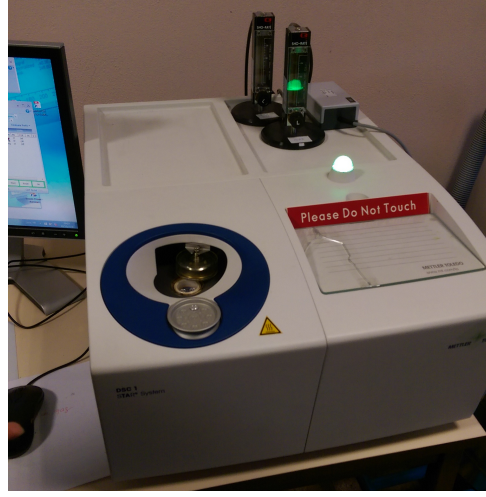

(b)

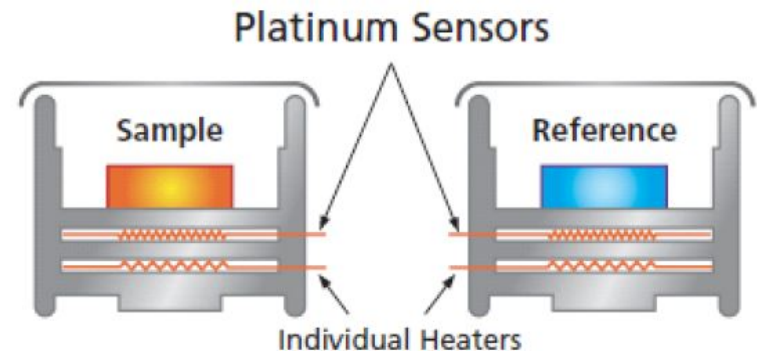

(d)

Figure 3.2: (a)-(c) DSC test machine and samples, and (d) DSC principle as shown by Borderon et al. (2017)

time step. Furthermore the DSC methodology has been employed to great success in different green technologies such as the ones presented by Bahrar et al. (2018); Mankibi et al. (2015); Roccamena et al. (2018); Stathopoulos et al. (2017).

\subsubsection{Result Discussion}

The approximate charge time of the panel when exposed to the aforementioned conditions is of 2 hours once it reaches $40^{\circ} \mathrm{C}$. When deprived of the heat source the panel returns to ambient temperature after 2 hours, however the panel releases the stored energy after approximately 1.5 hours. As shown by this test, PCM panels are implemented due to their capacity to release stored energy and extending the thermal inertia of a system. The performance of these materials is highly dependent on the incoming energy, the following sections are consecrated to the analysis of these panels on a laboratory and an in-situ solar chimney. The choice of 
macroencapsulated PCM panel is mainly due to the availability in the market and the facility of integration in a building component such as the solar chimney. It is important to take into consideration the limiting parameters of the PCM panels such as the volume expansion of $12.5 \%$ after fusion phase and the maximum operating temperature of $70{ }^{\circ} \mathrm{C}$. The preliminary test was carried out at room temperature, without any insulation covering the panel. Since the behaviour of the PCM is temperature dependant, the charging/discharging time can be modified according to the operating conditions, however, this test exemplifies the nature of the material under general conditions. 


\subsection{ENTPE Laboratory Experimentation}

\subsubsection{Guarded Hot Box (GHB)}

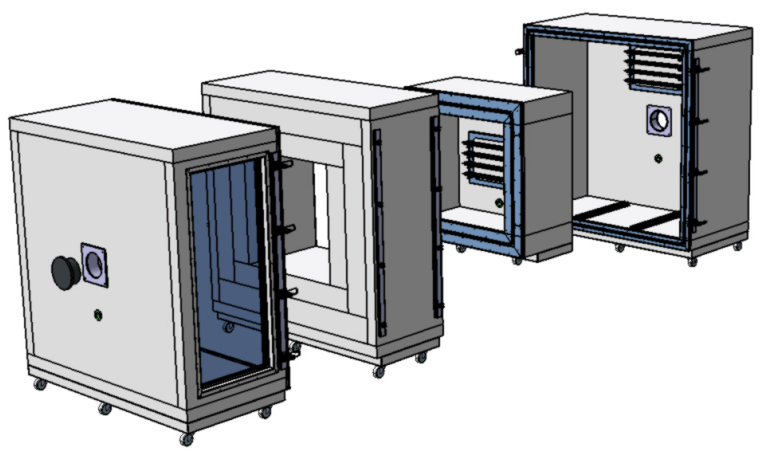

Figure 3.3: Isometric view of the Guarded Hot Box and its components: (from left to right) cold chamber, sample's case, hot chamber and protection case.

The Guarded Hot Box is an experimental device which allows the calculation of the thermal resistance of a material by setting two controlled temperatures. This type of testing equipment is employed for the characterization of construction materials with the aim of minimizing heat losses or gains. This device consists of two independent enclosures separated by the material that is tested. On the one side, a cold chamber with a cold unit establishes the cold temperature to one of the sides of the material. A case envelops the material that wants to be analysed, and limits the heat losses or gains with the exterior. Furthermore, the equipment includes a hot chamber composed of a measuring box surrounded by a protection case. Both the measuring box and case are equipped with heating resistors to increase temperature. Measurements of the air and surface temperatures in steady state are carried out, as well as the power supplied to the hot chamber. From these measurements, the heat transfer properties of the specimen are calculated. It is important to mention that for the purposes of the solar chimney. Both the sample's case as well as the hot chamber are not employed. Figure 3.3 shows the different sections of the BCG aforementioned. 


\subsubsection{GHB's Cold Chamber}

The dimensions of the cold box are presented in Figure 3.4. A cooling system can maintain a controlled atmosphere at a low temperature, up to a minimum temperature of $0^{\circ} \mathrm{C}$. A deflector is placed parallel to the entrance of the chimney volume, to ensure that the injected cooling flow does not influence the flow rate measured at the chimney. THE GHB's cold chamber is employed in order to carry out experiments with a controlled inlet temperature. Although the external temperature is an uncontrollable variable, the possibility of creating a $\Delta T$ allows for different experimental scenarios.

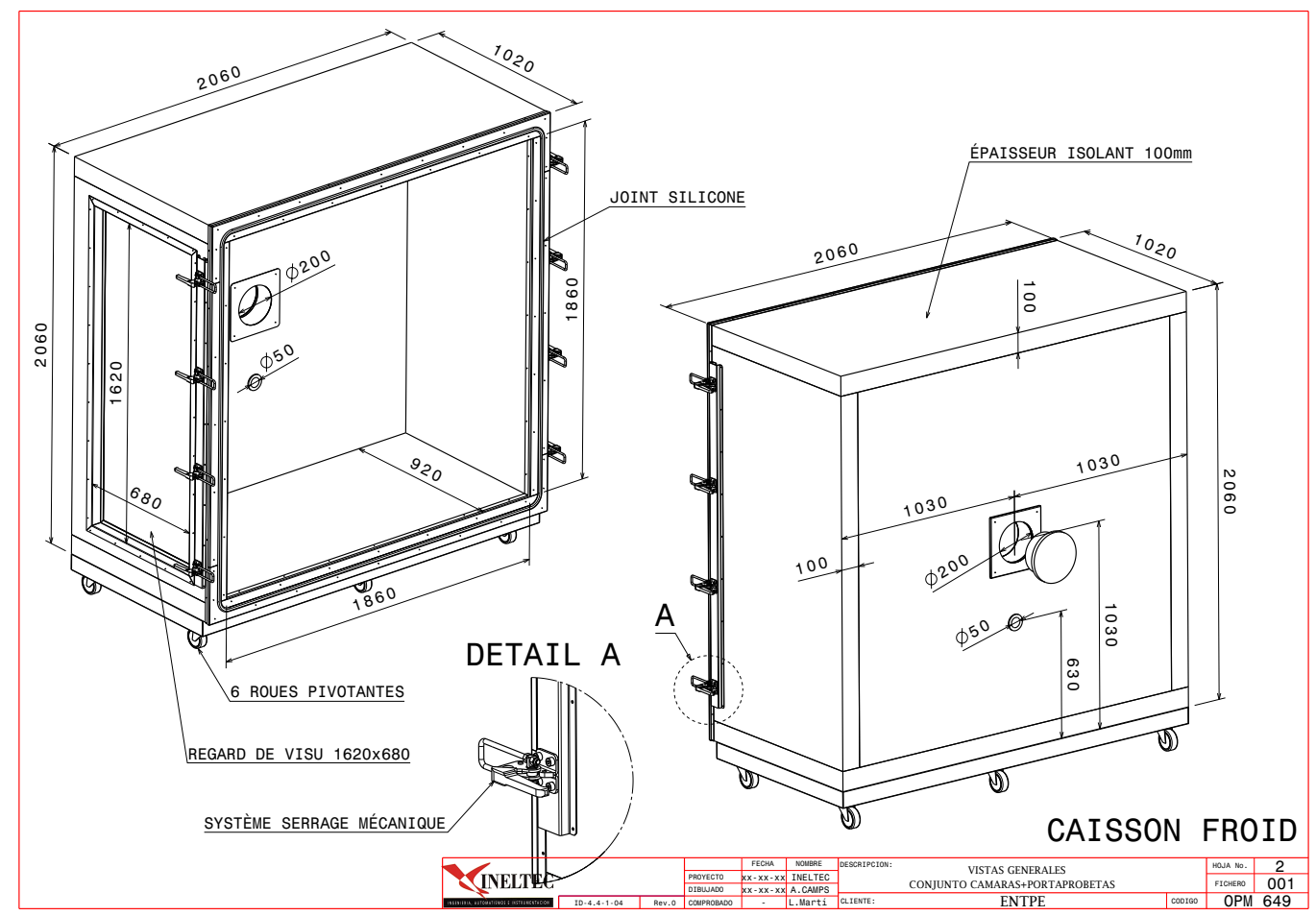

Figure 3.4: Blueprints of the cold chamber of the Guarded hot box employed in the solar chimney experimentations.

\subsubsection{Solar Chimney Prototype V1.0}

This section presents the experimental work carried out with the first prototype developed at the ENTPE laboratory. The prototype V1.0 served the purpose of analysing the behaviour of PCM panels on a simple-build solar chimney. This first laboratory prototype was built with $5 \mathrm{~cm}$-wide polystyrene plates, supported by an aluminium beam structure (3cm cross section). As mentioned in the previous 


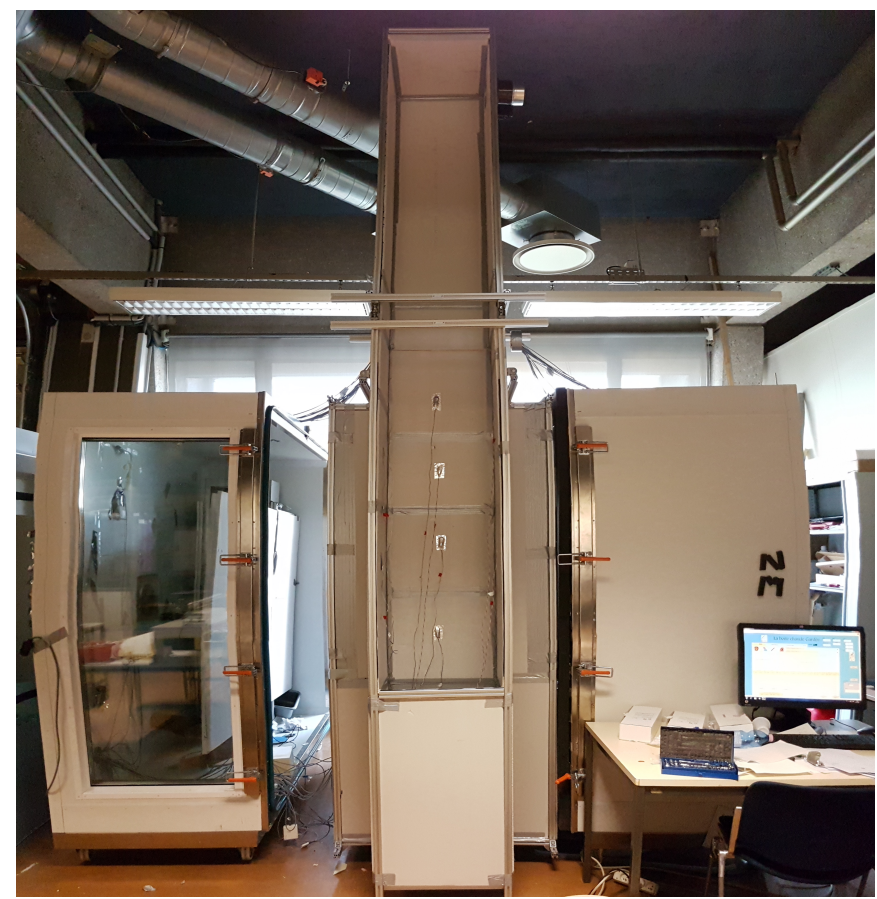

Figure 3.5: First solar chimney laboratory prototype developed at ENTPE

section, the prototype is connected to one of the sections of the Guarded Hot Box (shown in Figure 3.5) in order to establish a controlled temperature at the inlet of the solar chimney. The rectangular inlet of the chimney was fixed at $0.5 \times 0.075 \mathrm{~m}$, while the circular outlet has a diameter of $0.16 \mathrm{~m}$. The dimensions of the prototype are noted below in Table 3.2 .

Table 3.2: Solar chimney V1.0 Dimensions

\begin{tabular}{|c|c|c|c|}
\hline Volume & Height $[\mathrm{m}]$ & Length $[\mathrm{m}]$ & Width $[\mathrm{m}]$ \\
\hline \hline Control Volume & 2.27 & 1.86 & 1.00 \\
\hline Solar Chimney & 4.00 & 0.45 & 0.50 \\
\hline
\end{tabular}

\subsubsection{Prototype V1.0 Instrumentation}

The instrumentation on the first prototype was limited due to parallel ongoing experimentations with the GHB, however, 15 surface temperature sensors, 2 wind speed sensors, 2 air temperature sensors and 2 heat flux plate sensors were available for the experimentation. Platinum thermoresistance (PT100, 1/10 DIN) sensors are used to record surface temperature of the panels via a four-wire connection. These sensors consist of a very small sensing element embedded in a 

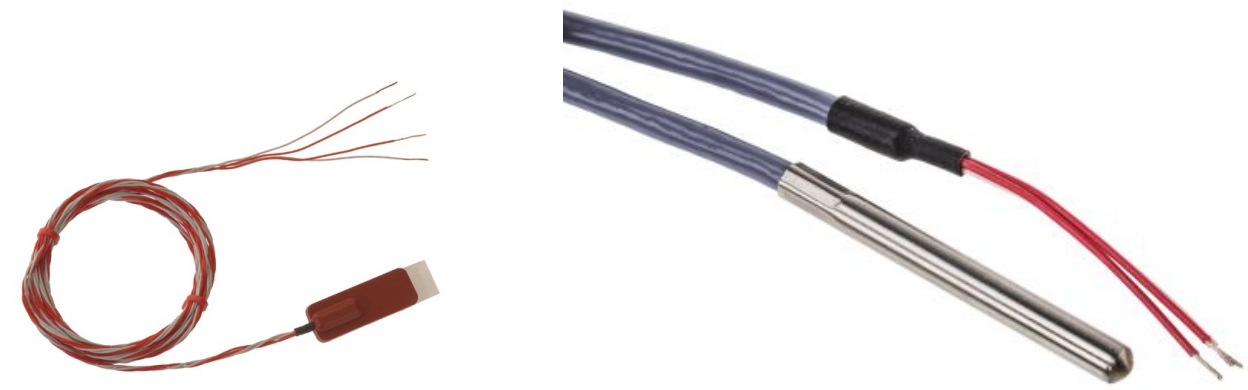

(a)

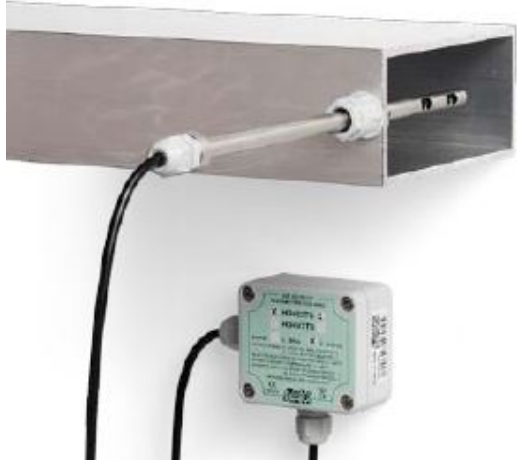

(c)

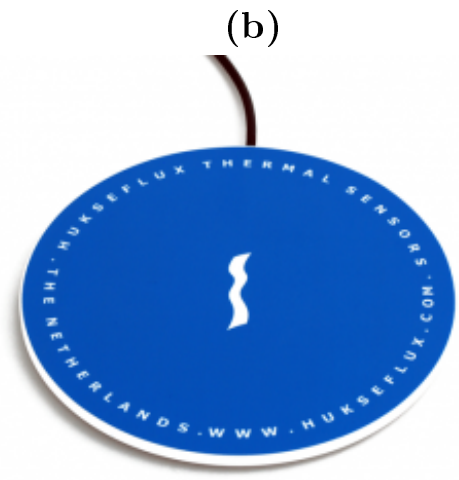

(d)

Figure 3.6: Sensors employed: (a) surface temperature, (b) air temperature, (c) air speed and $(\mathrm{d})$ heat flux

slim rubber substrate (Figure 3.6a). Likewise, air temperature measurements were carried out with PT100 sensors, however, the rubber protection is replaced with a stainless steel sheath(Figure $3.6 \mathrm{~b}$ ). The PT100 sensors have an uncertainty of $0.1^{\circ} \mathrm{C}$.

Delta Ohm hot wire transmitters (HD403TS series shown in Figure 3.6c) are employed for the continuous measurement of the inlet and outlet air speed. This type of sensors have a $4-20 \mathrm{~mA}$ output which is converted to $0.0-5.0 \mathrm{~m} / \mathrm{s}$. The speed measurements are precise up to $\pm 0.2 \mathrm{~m} / \mathrm{s}$ and requires a $24 \mathrm{~V}$ power supply.

Finally, HFP03 heat flux plate sensors (Figure 3.6d) from the company Hukseflux were selected to analyse the heat flux provided by the halogen lamps. This type of sensor estimates the heat flux of the surface it is mounted on, in $W / m^{2}$. This type of sensor has a $6 \%$ uncertainty linked to the calculation of the heat flux when dividing the plate's output voltage by the sensitivity of the thermopile (passive sensor). This heat flux plate does not require a power supply. 


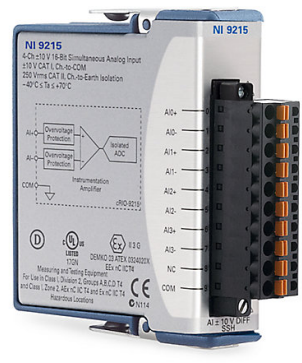

(a)

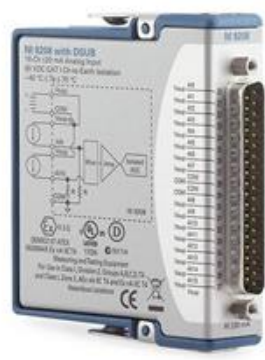

(c)

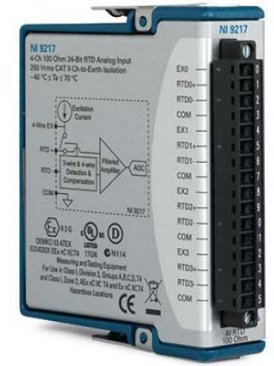

(b)

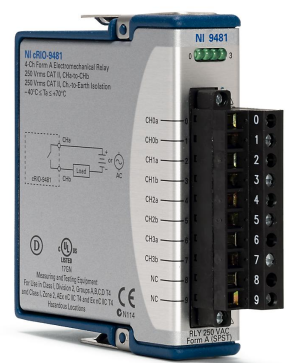

(d)

Figure 3.7: Acquisition modules employed for the experimentation of the solar chimney prototype V1.0

Table 3.3: National Instruments acquisition modules description

\begin{tabular}{|c|c|c|}
\hline Module & Description & Function \\
\hline \hline NI 9215 & $\begin{array}{c}\text { 4-Way, 16-Bit, Simultaneous } \\
\text { Input, 100 kS/s/channel, Module } \\
\text { Input Voltage } \pm 10 \mathrm{~V}\end{array}$ & $\begin{array}{c}\text { Acquisition of } 2 \text { heat flux } \\
\text { plate sensors }\end{array}$ \\
\hline NI 9217 & $\begin{array}{c}\text { Temperature input module for } \\
\text { RTD PT100, 4-way, 24-Bit }\end{array}$ & $\begin{array}{c}\text { Acquisition of 15 PT100 } \\
\text { surface temperature sensors }\end{array}$ \\
\hline NI 9208 & $\begin{array}{c}\text { 16 channels of } \pm 20 \mathrm{~mA} \text { input } \\
\text { with built-in } 50 / 60 \mathrm{~Hz} \text { rejection } \\
\text { for noise rejection. }\end{array}$ & $\begin{array}{c}\text { Acquisition of 2 DeltaOhm } \\
\text { wind speed sensors }\end{array}$ \\
\hline NI 9481 & $\begin{array}{c}\text { 4-way relay output module, } \\
\text { SPST relay, 60 Vdc }(1 \mathrm{~A}) / 250 \\
\text { Vrms }(2 \mathrm{~A})\end{array}$ & $\begin{array}{c}\text { Control of lamp (on/off) and } \\
\text { outlet states (open/closed) }\end{array}$ \\
\hline \hline
\end{tabular}

The acquisition system is composed of four different National Instruments acquisition modules. The information relative to the acquisition modules is presented in Table 3.3. The surface temperature acquisition modules have an approximate uncertainty of $\pm 0.2{ }^{\circ} \mathrm{C}$. 


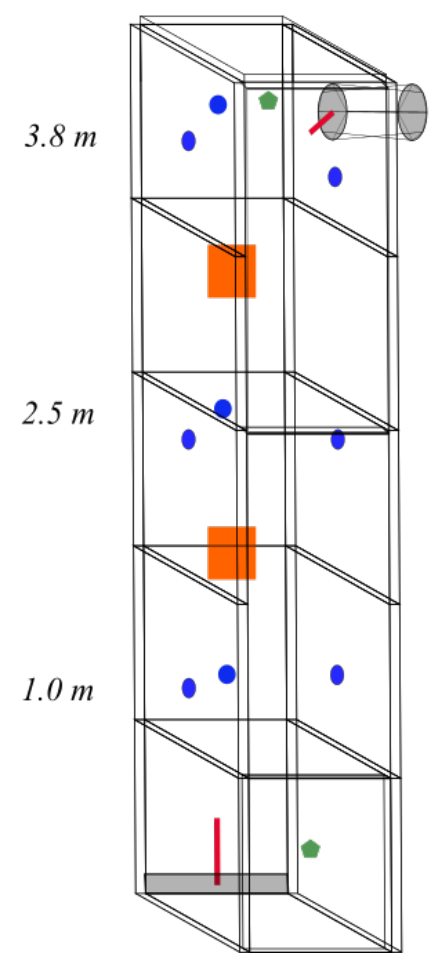

Figure 3.8: Instrumentation employed for the solar chimney prototype V1.0 displaying (blue) surface temperature sensors, (green) air temperature sensors, (orange) Heat flux plate sensors and (red) wind speed sensors.

The solar chimney prototype V1.0 (SCV1) can accommodate 9 panels in a horizontal position in the surface perpendicular to the heat source, and 6 panels in a vertical arrangement on each of the lateral walls of the chimney as seen in Figure 3.10. The twelve panels found on the lateral panels served the purpose of analysing the effects of PCM panels when placed parallel to the heat source and their capability to carry out a full phase change.

\subsubsection{Solar Chimney Prototype V2.0}

The first solar chimney prototype allowed an initial characterization of the system. The first prototype evidenced the advantages of PCM panels on a structure with no thermal inertia. This demonstrates the thermal and aerodynamic behaviour of the solar chimney when driven solely by the PCMs. Indeed, the development of the first prototype evidenced the influence of PCMs as a complementary device in this type of technology, however, the construction materials of this prototype were not 


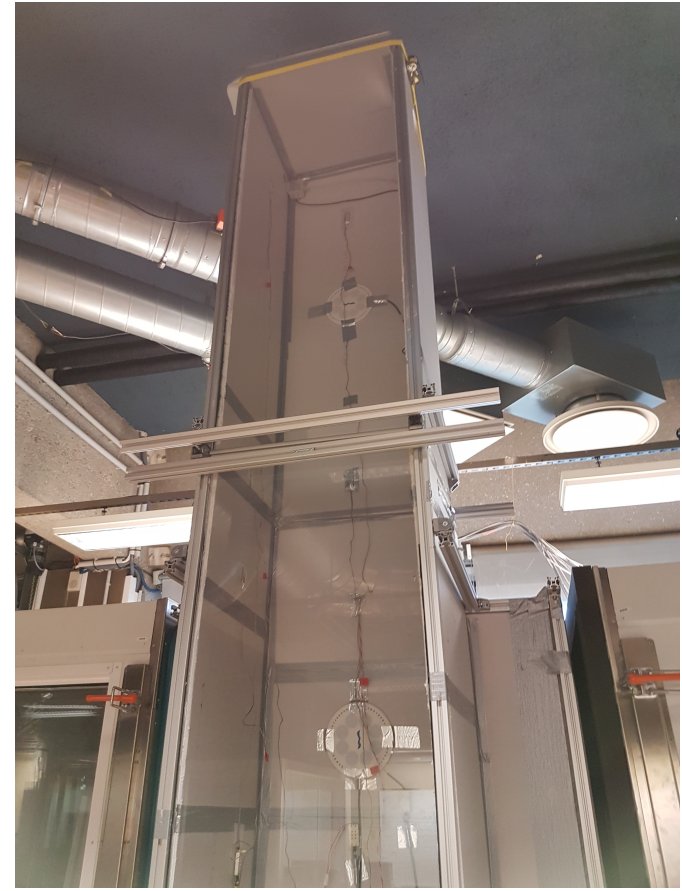

(a)

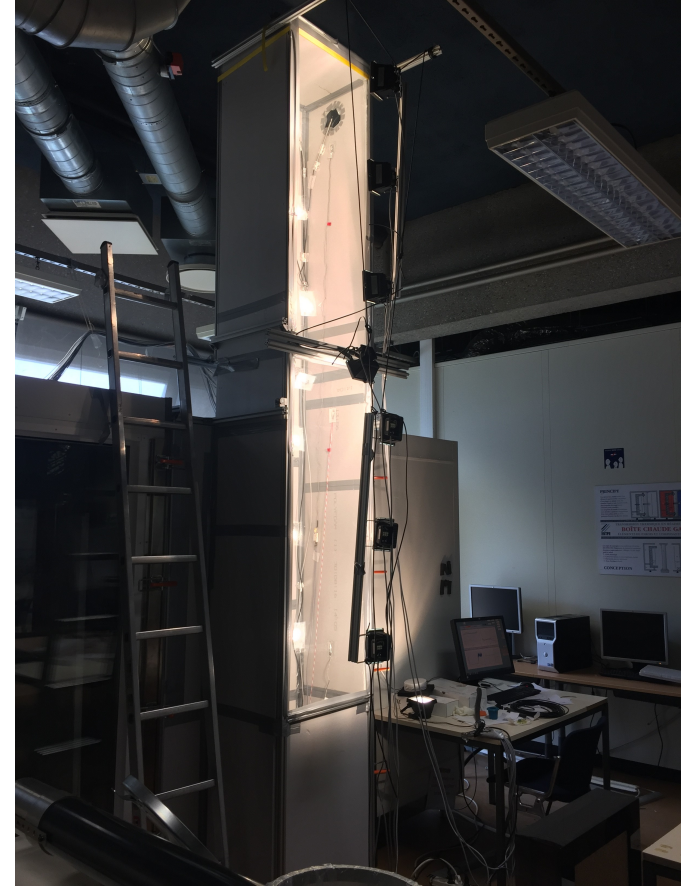

(b)

Figure 3.9: Solar chimney prototype V1.0 showing the experimental campaign during (a) ventilation only and (b) the charging phase of the experimental protocol without PCM panels

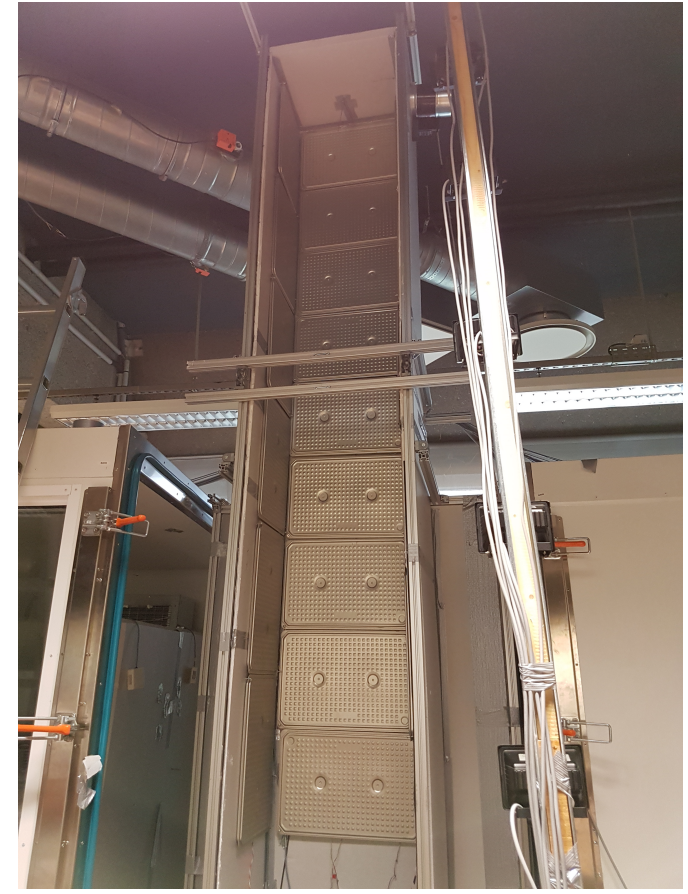

(a)

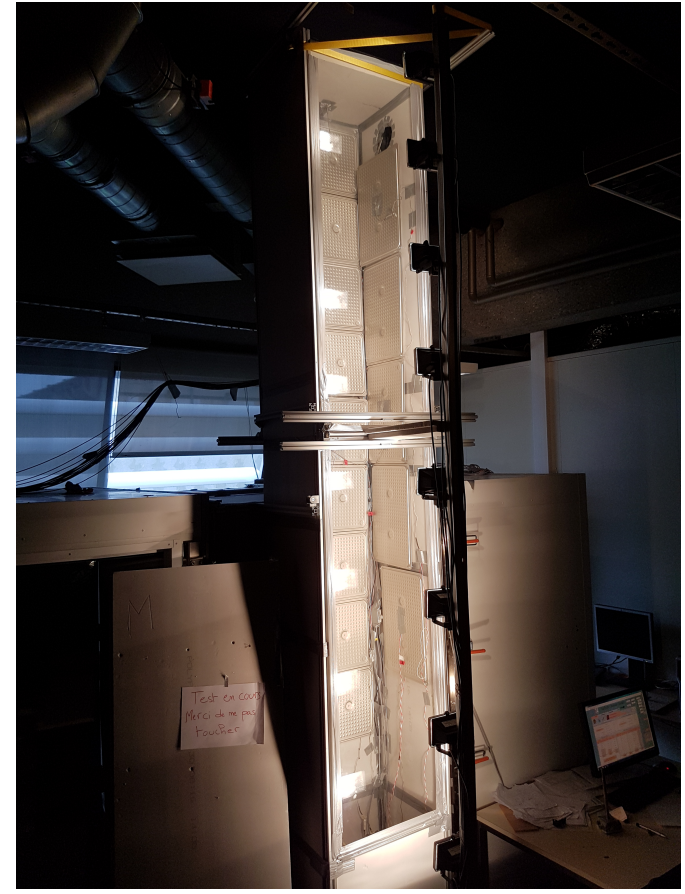

(b)

Figure 3.10: Solar chimney prototype V1.0 showing the experimental campaign during (a) ventilation only and (b) the charging phase of the experimental protocol with PCM panels 
representative of a real building component. The second version of the laboratory solar chimney prototype was developed after the analysis of the first laboratory and in-situ results. The development of the second prototype was based on two main reasons:

1. The representation and analysis of an actual building component integrated with PCM panels and,

2. mainly, the comparative study against the PSA in-situ solar chimney.

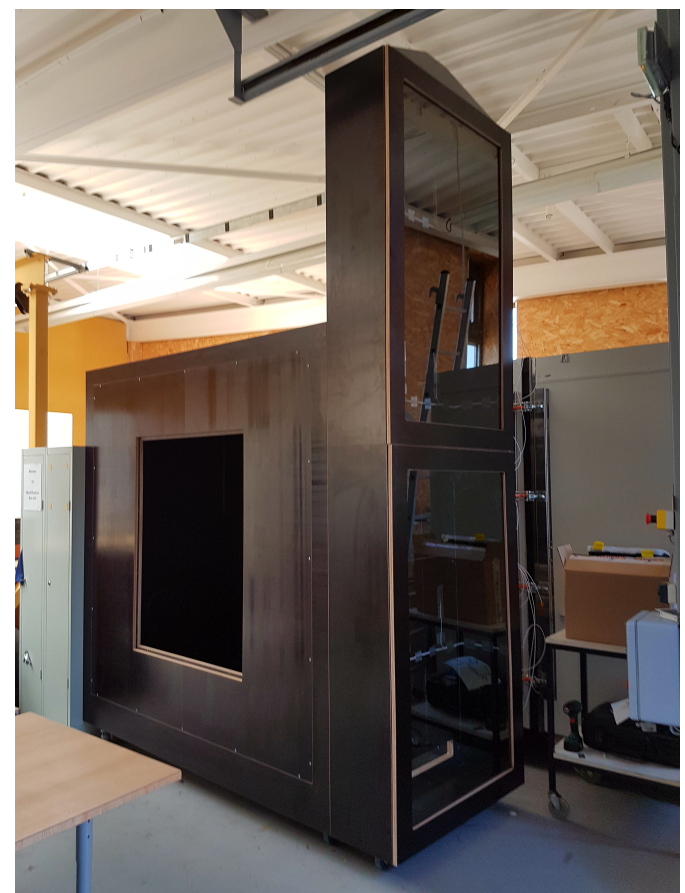

(a)

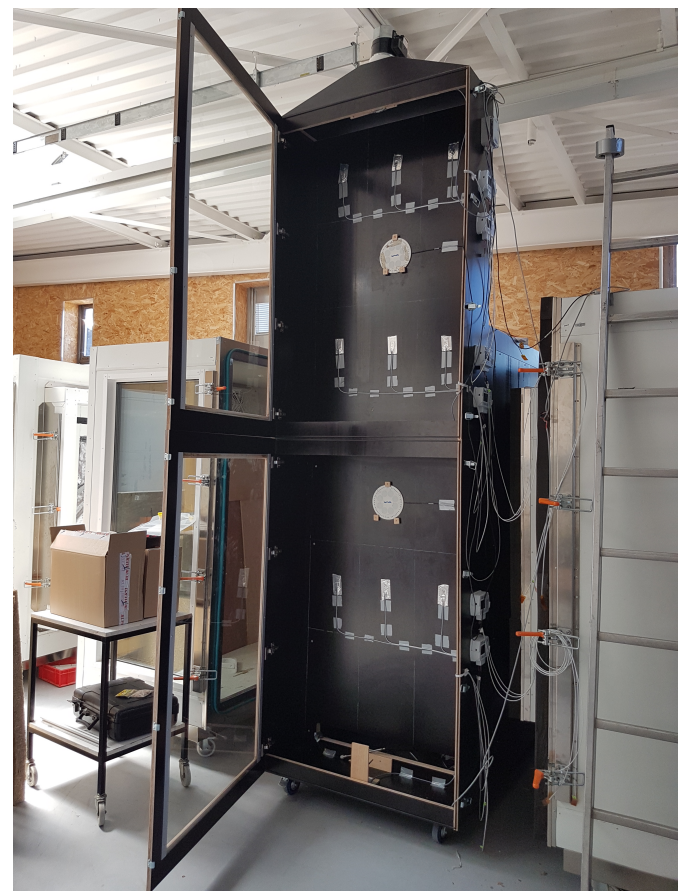

(b)

Figure 3.11: (a) Lateral view of the SCV2 before sensor placement and (b) SCV2 open for no PCM set-up.

The second prototype of the solar chimney, hereinafter called SCV2, was developed according to the design of the PSA in-situ solar chimney in Almeria presented in section 3.4. Due to laboratory size restrictions the SCV2 was shortened by $0.50 \mathrm{~m}$ in relation to the the solar chimney at the PSA. In terms of PCM panel placement, this reduction represents one less row of panels in comparison to the PSA solar chimney experimentation. Figure 3.11 displays the SCV2 at the ENTPE laboratory. The second prototype is built with $2 \mathrm{~cm}$ plywood boards. The size of the inlet is $0.8 \times 0.08$ while the outlet has the same size as the prototype V1.0 of $0.0201 \mathrm{~m}^{2}$. A $0.7 \mathrm{~cm}$ thick pane of glass covers the front of the chimney and works 
as a door to the inside of the chimney. The exact measures of the SCV2 can be observed in Figure 3.18 later in this section.

The volume behind the solar chimney is a cubic volume of $4.68 \mathrm{~m}^{3}$. This volume, just as the one of the prototype V1.0, serves the purpose of defining a control volume at the inlet of the chimney where an inlet temperature can be defined and wind speed is not a factor during the experimentation. The volume was built with three different entrances: $1.86 \times 1.86 \mathrm{~m}, 1.190 \times 0.94 \mathrm{~m}$ and a circular entrance with a diameter of $0.22 \mathrm{~m}$. The volume is built with the same type of plywood.

\subsubsection{Prototype V2.0 Instrumentation}

The equipment employed for the analysis of the SCV2 was mostly the same as the one used during the experimental campaign of the first prototype. Three air temperature PT100 sensors, both Hukseflux HFP03 heat flux plate sensors as well as both Delta Ohm hot wire transmitters to measure wind speed were used for the SCV2. The two main changes were the surface temperature sensors and the acquisition modules.

SFSC50 flexible temperature probe (Figure 3.12a) with resistive element from C2AI were employed to register surface temperatures across the chimney. These class A PT100 sensors have an uncertainty of $\pm 0.15^{\circ} \mathrm{C}+0.002|T|$. All sensors (air temperature, surface temperature, heat flux and air speed) relay information to a wireless acquisition module from Delta $\mathrm{Ohm}$ as the one seen in Figure 3.12b. These HD35ED wireless data logging systems allow the continuous monitoring of different physical quantities such as temperature, humidity, air speed, heat flux, $\mathrm{CO}_{2}$ levels, between others. The information is then sent to the nearby computer in order to be stored and displayed. 


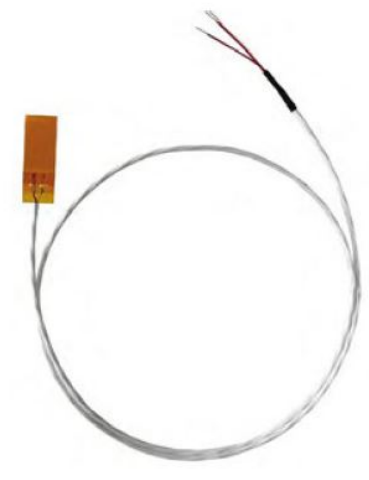

(a)

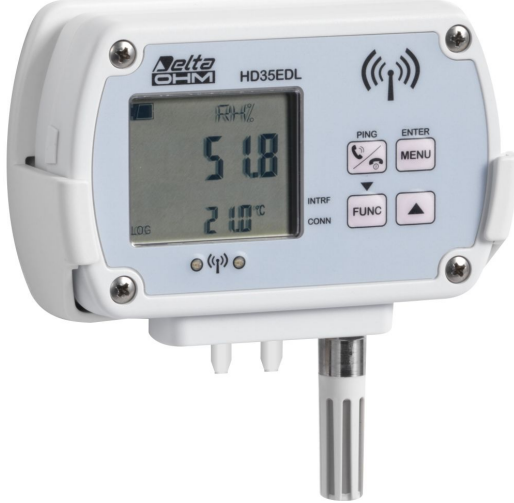

(b)

Figure 3.12: Instrumentation changes for the SCV2 showing (a) surface temperature sensors and (b) the Delta $\mathrm{Ohm}$ wireless acquisition modules.

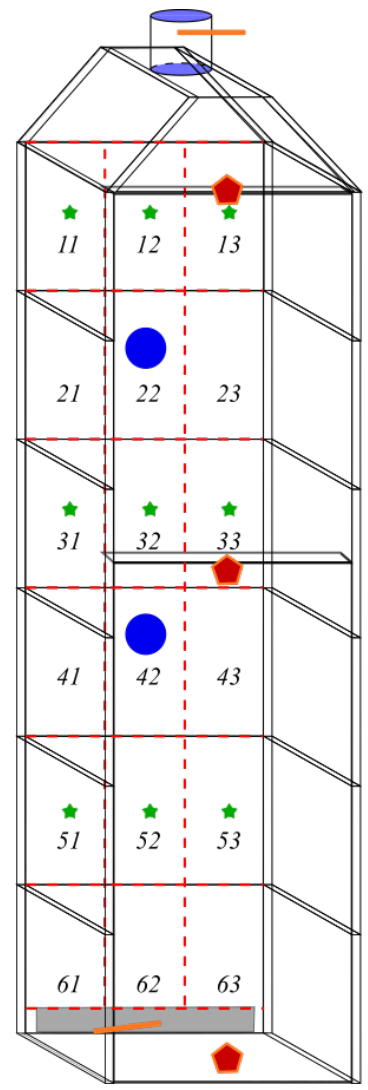

Figure 3.13: Instrumentation employed for the SCV2 displaying (green) surface temperature sensors on the chimney surface grid, (red) air temperature sensors, (blue) Heat flux plate sensors and (orange) wind speed sensors. 


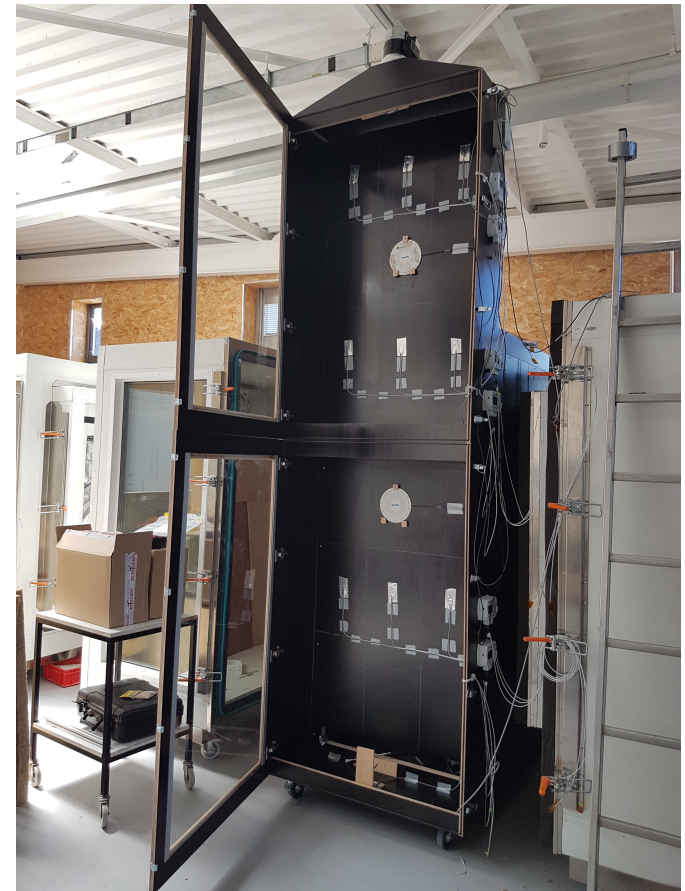

(a)

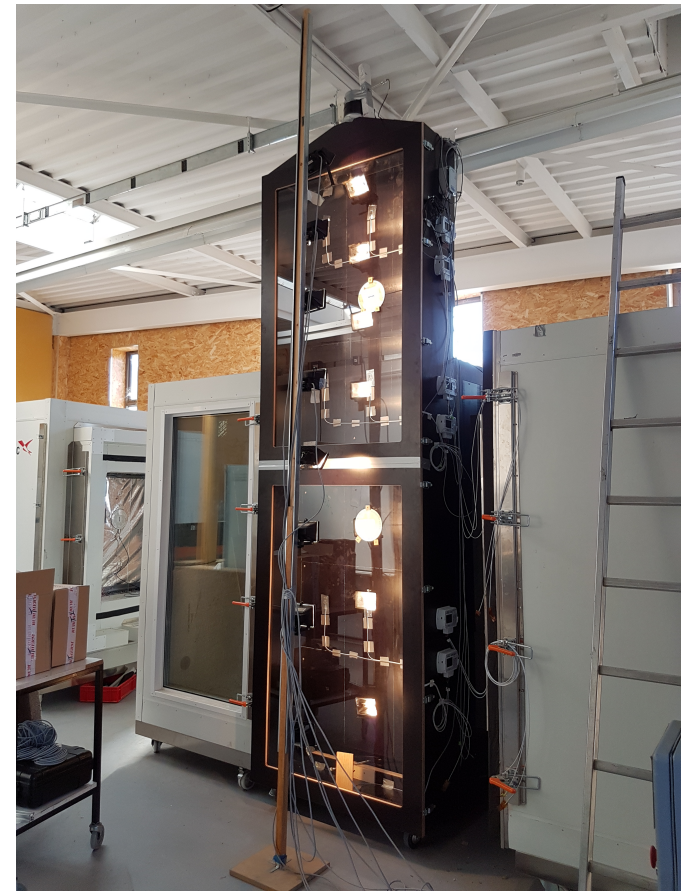

(b)

Figure 3.14: SCV2 showing the experimental campaign during (a) ventilation only and (b) the charging phase of the experimental protocol without PCM

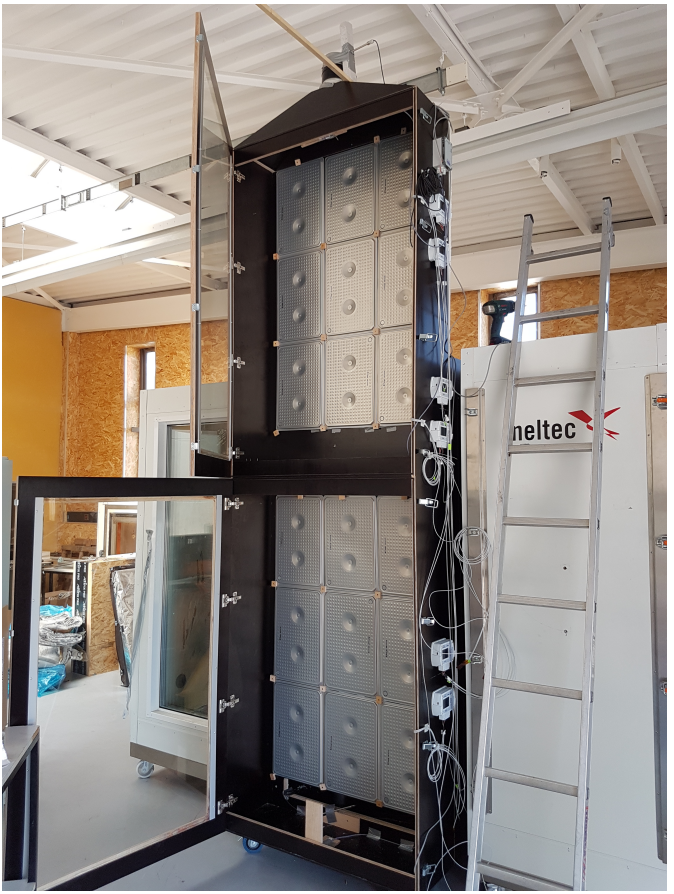

(a)

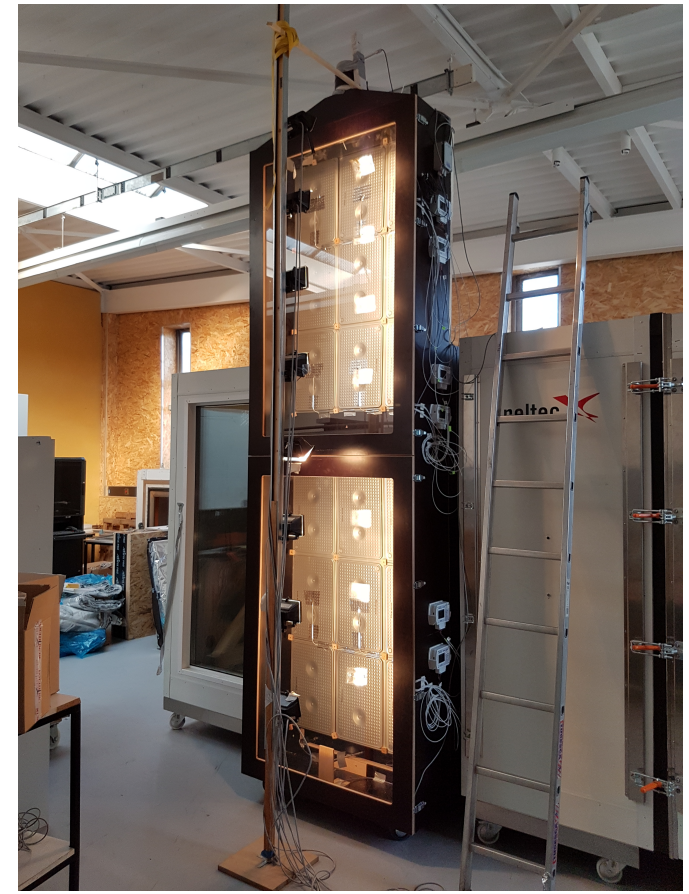

(b)

Figure 3.15: SCV2 showing the experimental campaign during (a) ventilation only and (b) the charging phase of the experimental protocol with PCM 


\subsubsection{Prototype Modifications}

The results obtained during the first laboratory experimental campaign and the first cycles with the second prototype, allowed the integration of some best-practices for the optimisation of the experimentation cycle. Naturally, these slight modifications were taken into consideration for further cycles.

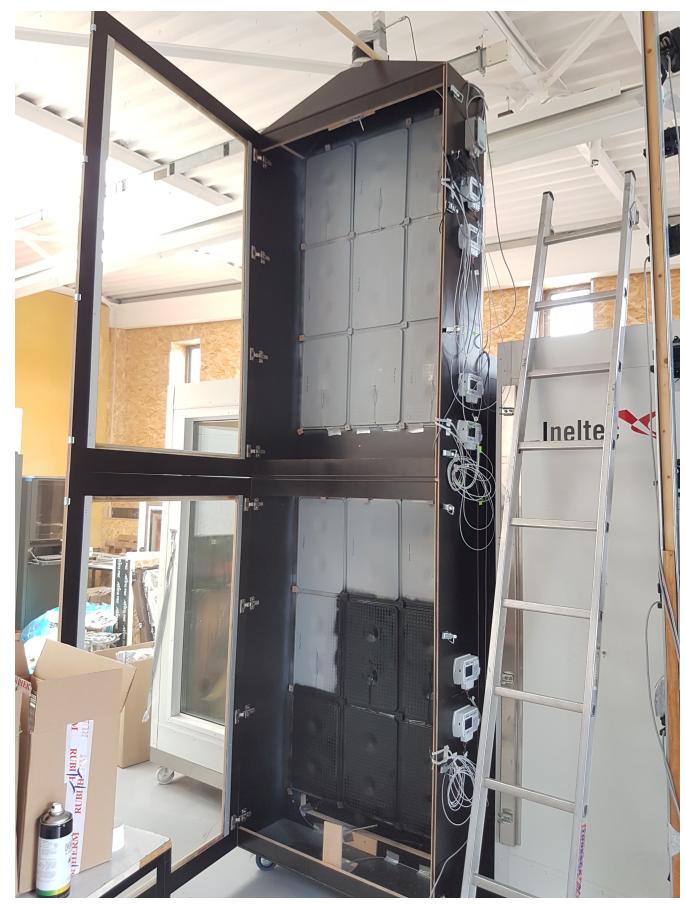

(a)

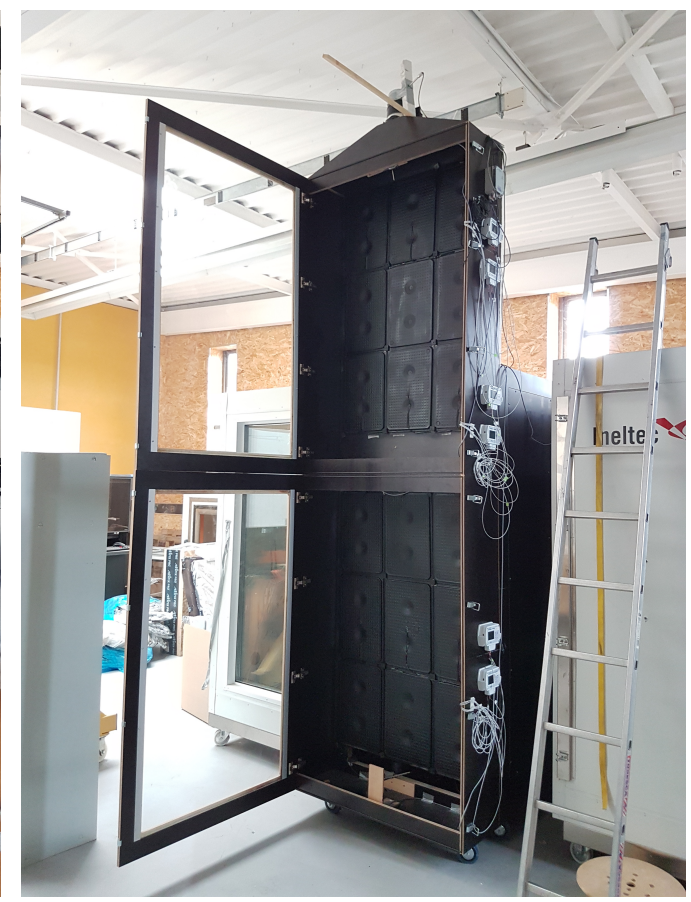

(b)

Figure 3.16: SCV2 with matte black PCM panels (a) during painting process and (b) completed work.

In order to propitiate the phase change and take better advantage of the incoming irradiance, the panels were painted matte black. This modification was carried out in relationship to the in-situ experimental campaign, where the panels received the same treatment and after the analysis of the surface temperature results of the SCV1 discussed later in this chapter. Indeed, the results obtained during with the first prototype evidenced the incomplete fusion of the PCM, thus hampering the performance of the system. In addition to this modification, an additional layer of insulation was added behind the plywood layer where the panels were placed. This additional layer, was summed to avoid panel heat loss to the exterior and to ensure the panel temperature rise above the fusion range of $44{ }^{\circ} \mathrm{C}$. 
Furthermore, in order to avoid leaks presented during the first laboratory experimental campaign, the panels in the SCV2 were fixed against the surface with a wooden hold instead of being drilled. Indeed, the thermal expansion experienced when the panels rise in temperature caused the PCM to exit the panel. An example of a leak panel can be observed in Figure 3.17.

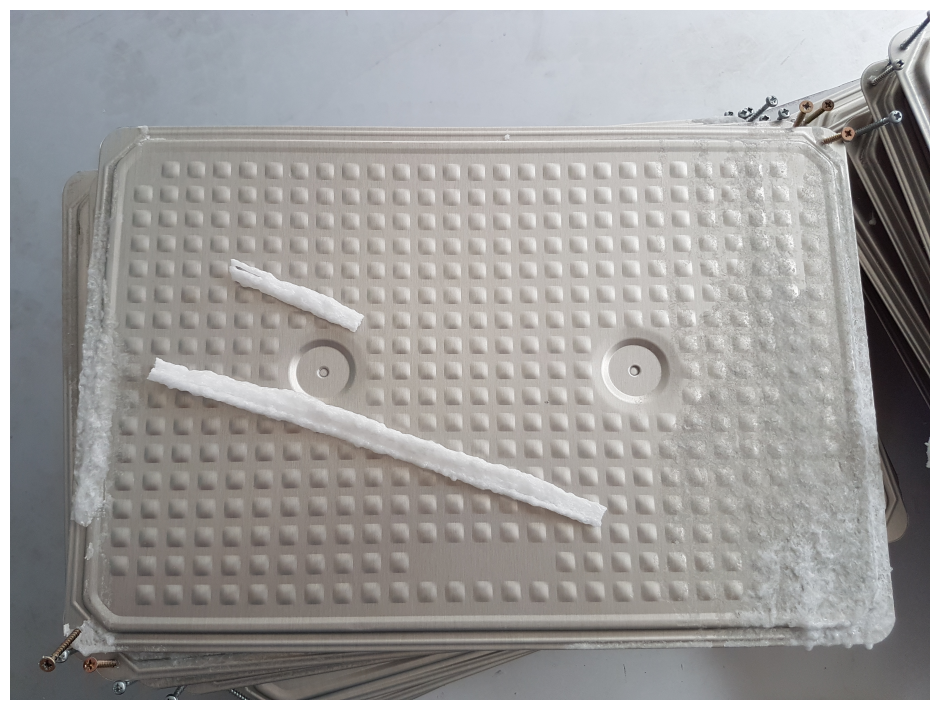

Figure 3.17: PCM panel leak after reaching maximum operating temperature $\left(70^{\circ} \mathrm{C}\right)$ and experiencing volume expansion. 


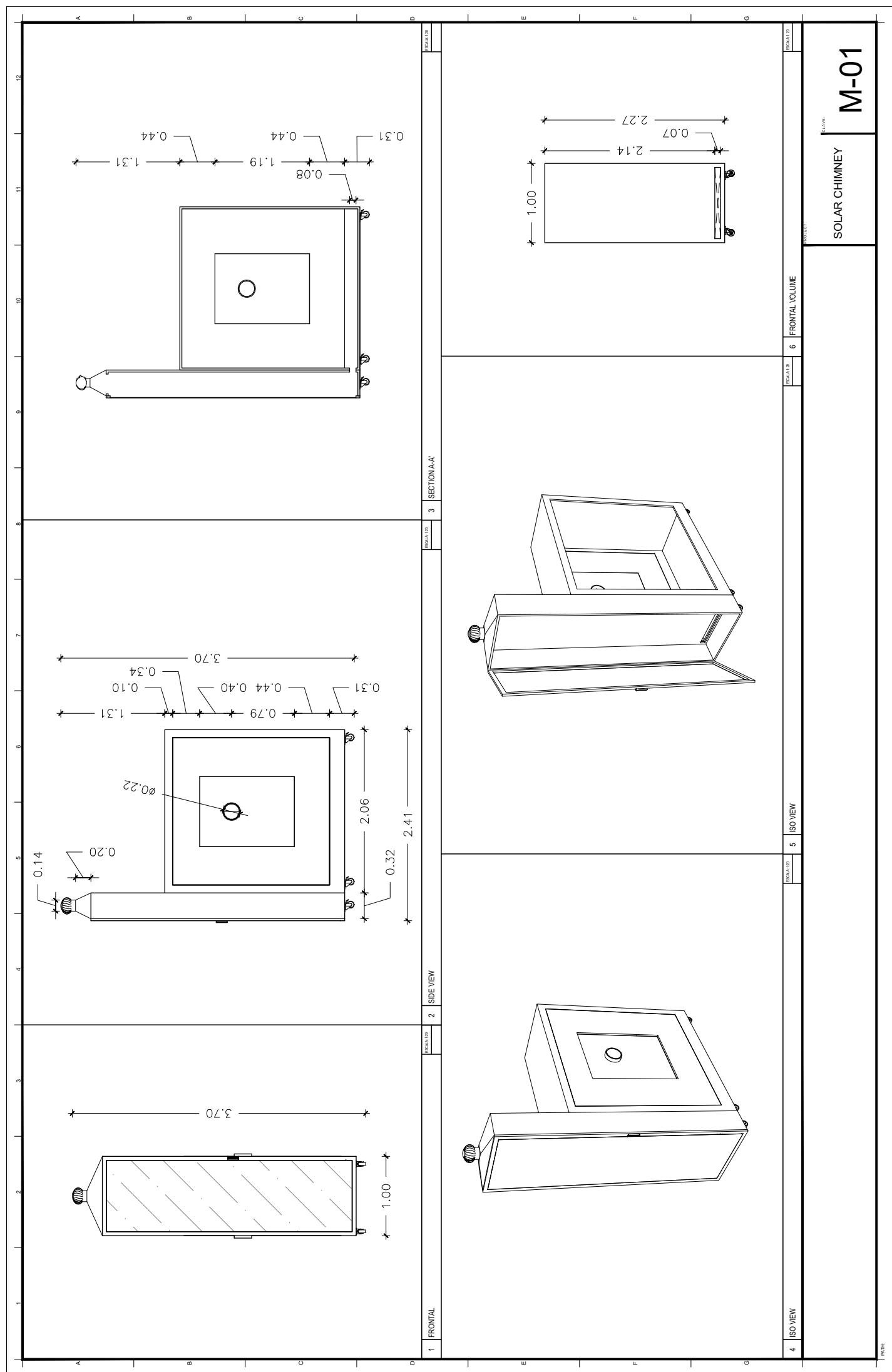

Figure 3.18: Blueprints of the second solar chimney prototype et ENTPE 


\subsubsection{Experimental Protocol}

In order to define the performance of a solar chimney with and without PCM panels, an experimental protocol was established. This protocol serves three main purposes:

1. To evidence the differences between the current solar chimney and the PCM integrates solar chimney, under laboratory conditions.

2. To demonstrate the capabilities of phase changing to materials to extend the use of a solar chimney in the absence of a heat source.

3. The validation of the numerical model presented in the following chapter.

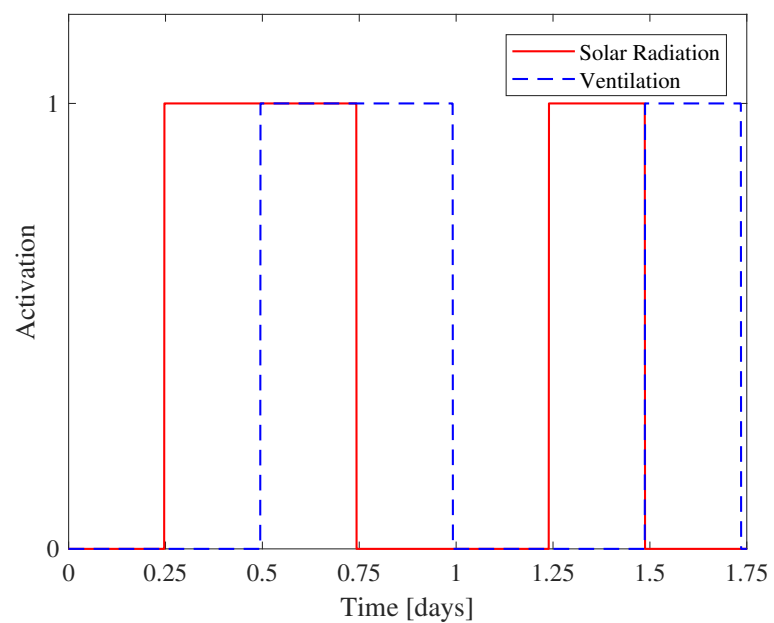

Figure 3.19: Experimental protocol employed for both prototypes picturing the activation of ventilation (open/closed outlet) in blue and solar radiation (on/off halogen lamps)

Figure 3.19 above shows the protocol used for the experimentation. The experimental protocol is composed of seven consecutive phases of 6 hours each (0.25 days), completing a full cycle in approximately 1.75 days. Phases depend on the state of the outlet (open/closed) thus allowing the flow of air for natural ventilation, and heating provided by the halogen lamps (on/off), which simulate solar radiation. The lamps are evenly distributed over the $3 \mathrm{~m}$ glass surface of the chimney and provide an approximate maximum heat flux of $600 \frac{\mathrm{W}}{\mathrm{m}^{2}}$ during the charging phases. The heat flux received by the chimney during an experimental cycle is shown in Figure 3.20. 


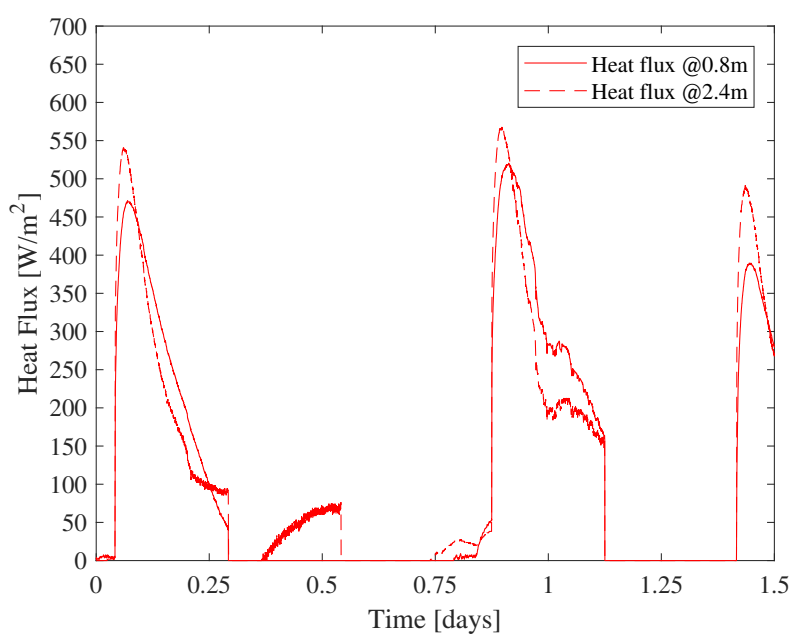

Figure 3.20: Incoming heat flux during the laboratory experiment

In a more detailed explanation, phase 1 corresponds to the initialization of the system. In this stage, the outlet is closed and there is no heat source present. Phase 2 was designed as a way to charge the PCM panels in order to guarantee the melting process of PCMs. Ventilation is neglected in this phase to assure the temperature raise. Phase 3 allows air circulation by opening the outlet and maintaining the heat source. This phase represents the normal utilization of a solar chimney. Phase 4 removes the heat source while allowing air circulation. This phase was designed to exemplify the behaviour of a solar chimney when solar radiation is hampered or for after sun-down hours. Phase 5 reinitializes the system and prepares it for the last two phases. Phases 6 and 7 work in the same way as phases 2 and 4 ; however, both conditions are not activated simultaneously.

\subsubsection{Results \& Discussion}

Outlet mass flow rate, air gap temperature and temperature difference between inlet and outlet, are some of the most important quantities for the design of a solar chimney. This variables allow the definition of the thermal and aerodynamic performance of the solar chimney. In order to profit the full potential of the ASC, the chimney surface temperature needs to surpass the temperature range of $40-44^{\circ} \mathrm{C}$.

This section presents the results obtained through out the different experimental cycles under different operating conditions. The results presented in this section 
adhere to the nomenclature presented in Figure 3.21. Results corresponding to the the SCV1, do not mention the prototype number, on the other hand; the SCV2 mention include the prefix $P$ 2. The second part of the nomenclature specifies the experimental cycle. The third part of the nomenclature specifies the addition of PCM. The number found at the end corresponds to the completed sequence of the experimental protocol for the same cycle. Finally, for every type of result, an extra section is added to specify the results presented (e.g. MFR - Mass Flow Rate). The results shown below were carried out under two different conditions: input temperature set by the Guarded Hot Box and no input temperature, thus following the exterior temperature. The difference between both set-ups is discussed in this section. The results presented in these sections correspond to the cycles presented in Table 3.4. The complete set of cycles and their results can found in Appendices A to D.

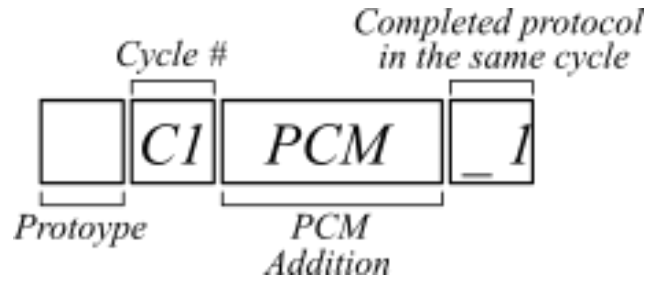

(a)

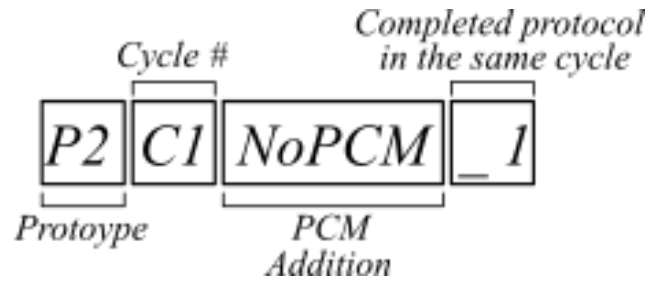

(b)

Figure 3.21: Nomenclature of results for both (a) SCV1 and (b) SCV2.

Table 3.4: Cycles discussed throughout this section for SCV1 and SCV2

\begin{tabular}{|c|c|c|}
\hline Cycle & Operating Conditions & Additional Information \\
\hline C5NoPCM-1 & GHB set inlet temperature & $\begin{array}{c}\text { Laboratory with HVAC } \\
\text { system }\end{array}$ \\
\hline C7NoPCM-2 & GHB set inlet temperature & $\begin{array}{c}\text { Laboratory without HVAC } \\
\text { system }\end{array}$ \\
\hline C1PCM-1 & GHB set inlet temperature & Laboratory with HVAC \\
\hline P2C1NoPCM-2 & GHB set inlet temperature & Extra insulation layer \\
\hline P2C3NoPCM-2 & GHB set inlet temperature & Extra insulation layer \\
\hline P2C4NoPCM-3 & External temperature & Extra insulation layer \\
\hline P2C1PCM-2 & GHB set inlet temperature & No insulation \\
\hline $\mathrm{P} 2 \mathrm{C} 2 \mathrm{PCM}-2$ & GHB set inlet temperature & Extra insulation layer \\
\hline P2C5PCM-2 & External temperature & Extra insulation layer \\
\hline
\end{tabular}




\subsubsection{Surface Temperature Results}

The effects of PCM panels on the surface temperature distribution is particularly noticeable in the results of the first prototype. In terms of surface temperature variations, there are two main modifying factors between the two prototypes: the material, and the insulation. Indeed the first prototype had only a single layer of polystyrene with limited thermal inertia while the second prototype was made of laminated plywood planks with an additional insulating polystyrene layer to reduce heat loss. The lack of thermal inertia of the first system evidences the potential of PCMs. The modifications and their impact on the prototype are discussed ahead.

Regarding the SCV1, the surface temperature results when not integrated with PCM, show a temperature distribution that reaches a difference of up to $30{ }^{\circ} \mathrm{C}$. Results with and without input temperature (from the GHB) show that temperature increases with height. For a set input temperature (Figure 3.22b), the surface temperature rises by approximately $25^{\circ} \mathrm{C}$ from the initial temperature, during charging only phases. When the prototype is subjected to the external temperature, between 25 and $35{ }^{\circ} \mathrm{C}$ (Figure 3.24), this difference can go up to $35^{\circ} \mathrm{C}$. The experimental conditions shown in Figure 3.22 were achieved when the prototype was placed in the first laboratory were the temperature was controlled by the HVAC system. The mean temperature registered during the experimental campaign for $\mathrm{C} 5 \mathrm{NoPCM}$ was of $19.5{ }^{\circ} \mathrm{C}$ with variations not exceeding $2.0{ }^{\circ} \mathrm{C}$.

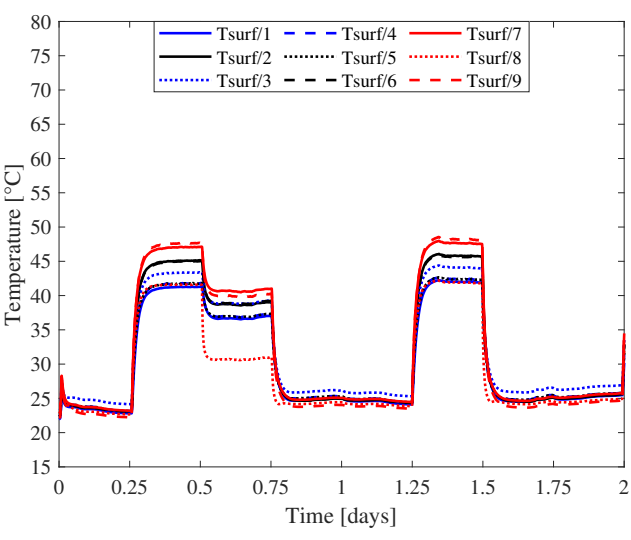

(a)

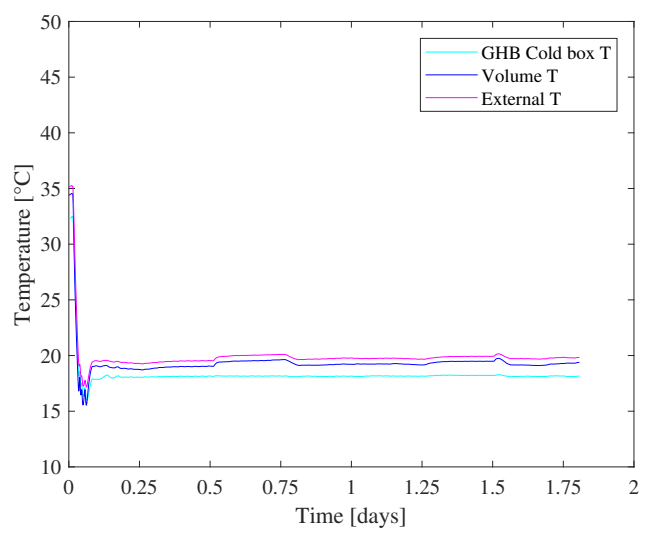

(b)

Figure 3.22: C5NoPCM-1 results showing (a) surface temperature and (b) experimental conditions. 


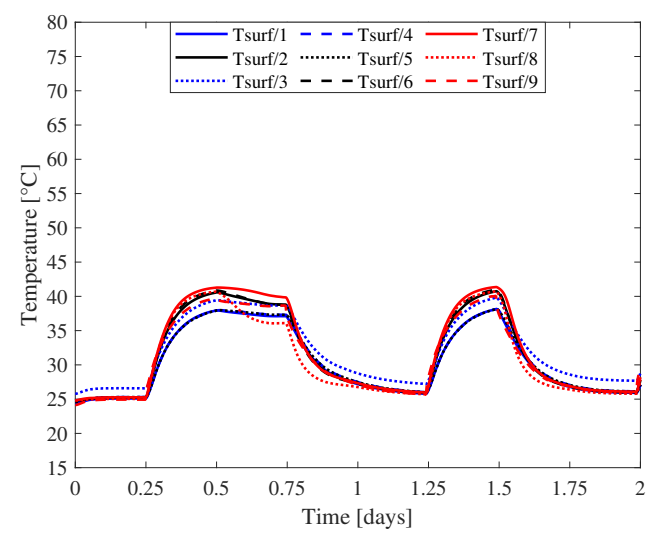

(a)

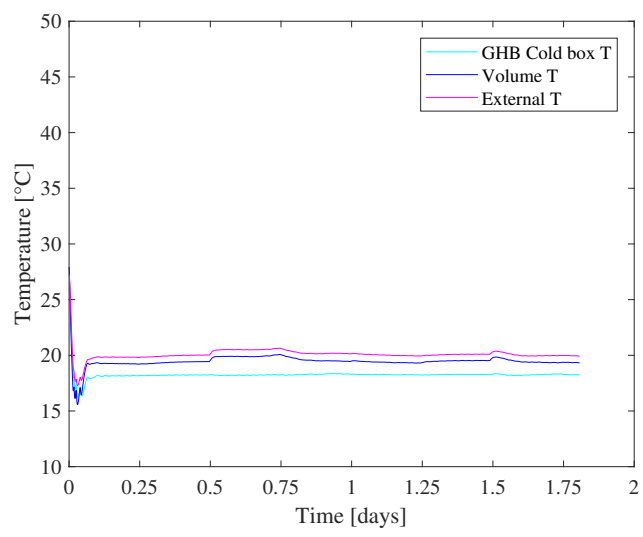

(b)

Figure 3.23: C1PCM-1 results showing (a) surface temperature and (b) experimental conditions.

On the other hand, the surface temperature results corresponding to C7NoPCM follow the behaviour of the external conditions which and show a dependence on external conditions. Indeed, the increase in external temperature leads to an increase of surface temperature. 3.24b). The surface temperature difference between the bottom and top sensors differs from cycle to cycle and the operating conditions but it is usually $10 \pm 2^{\circ} \mathrm{C}$.

When PCM panels are added to the polystyrene structure, this temperature difference is reduced and the overall surface temperature across the chimney is similar, only varying by approximately $5 \pm 2^{\circ} \mathrm{C}$ on the surface perpendicular to the heat source. The difference between surface temperature of the SC and the

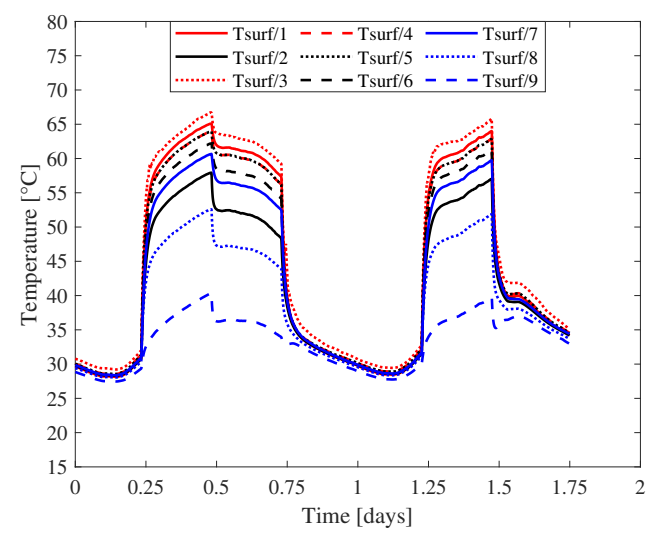

(a)

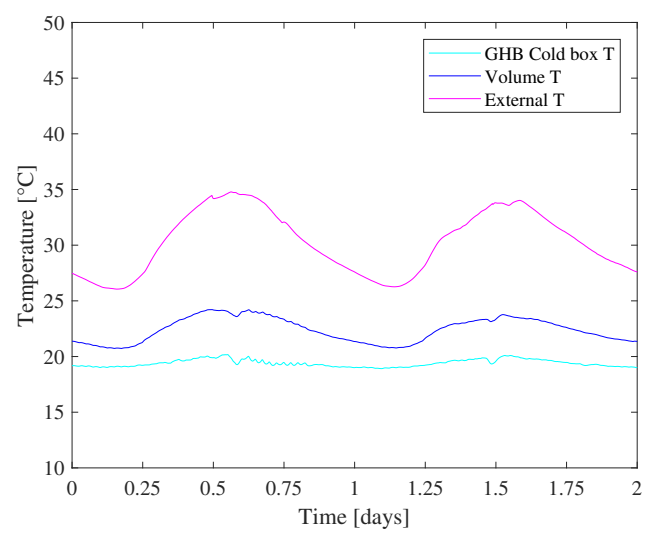

(b)

Figure 3.24: C7NoPCM-2 results showing (a) surface temperature and (b) experimental conditions. 


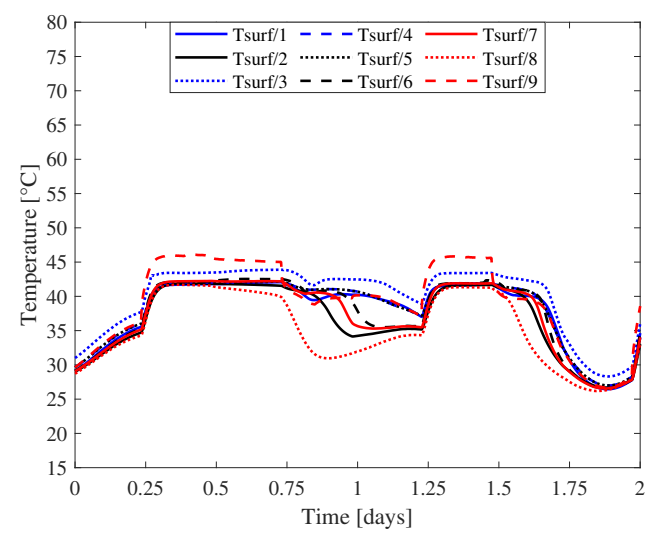

(a)

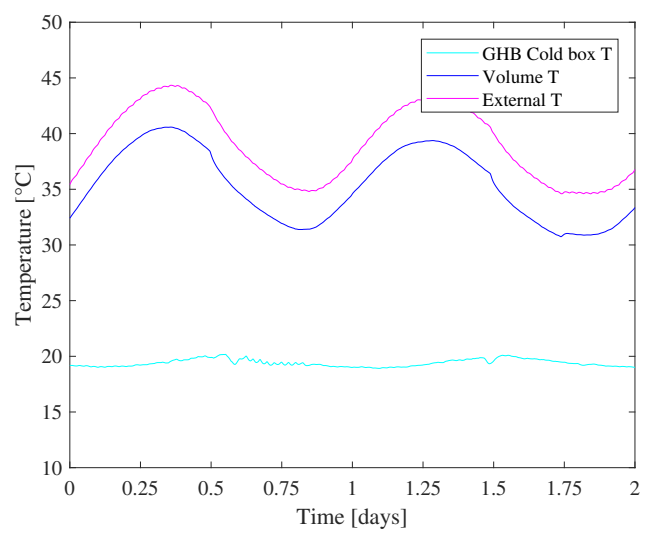

(b)

Figure 3.25: C3PCM-2 results showing (a) surface temperature and (b) experimental conditions.

ASC for prototype V1.0 is shown in Figures $3.22-3.25$, where the operating conditions, mainly the inlet temperature was controlled and set to $18{ }^{\circ} \mathrm{C}$ with the help of the GHB. The PCM panels allow the system to retain some of the thermal energy provided by the halogen lamps, however, due to the overall heat loss and the lack of proper insulation, the bottom panels in most of the cycles of the SCV1 do not surpass $44{ }^{\circ} \mathrm{C}$, therefore they do not achieve a complete fusion. This is further supported by the results of the second prototype (discussed ahead) where the surface temperatures do not drastically drop in the absence of a heat source. The surface temperature distribution difference between both cycles, where an important external temperature difference exists, indicates that a great part of the energy provided to the system escapes through the walls of the SCV1. The addition of PCM panels hampers the wall heat loss and enhances the system's performance regardless of the incomplete fusion. The thermal inertia provided by the PCMs to the system is represented in the dynamic of the surface temperature evolution of Figure 3.23a. Contrary to the NoPCM cycles, the surface temperature is maintained from Phase 3 of the experimental protocol (ventilation + heat source) to Phase 4 (ventilation only) in most PCM cycles. In general, temperature drops only occur once ventilation is neglected and the heat source is turned off.

Moreover, the surface temperature results of the second laboratory prototype were more consistent due to the modifications and best-practices mentioned in section 3.3.3. When comparing the operating conditions of P2C1NoPCM to both 


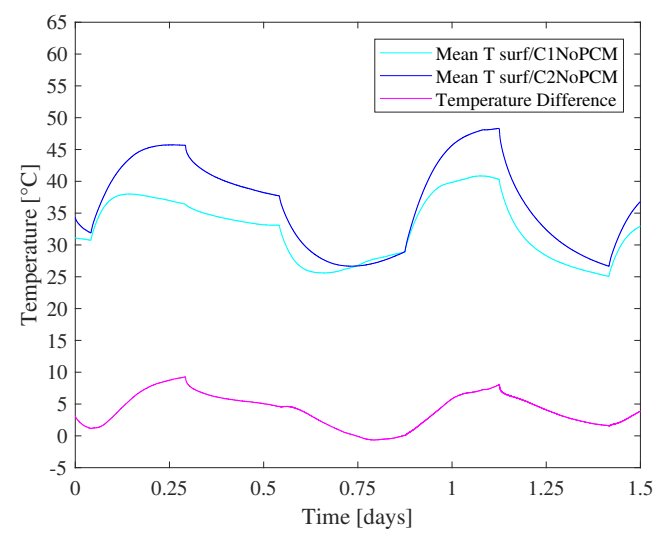

(a)

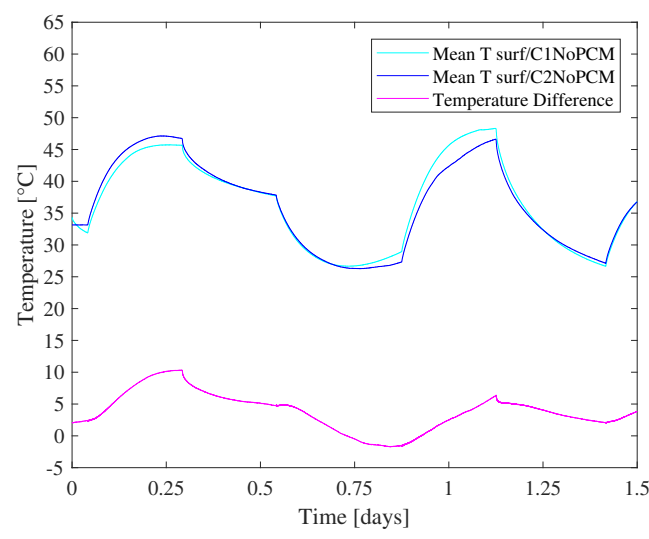

(b)

Figure 3.26: Mean surface temperature and surface temperature difference for (a) P2C1NoPCM-1 vs P2C2NoPCM-1 and (b) P2C1NoPCM-1 vs P2C3NoPCM-1.

P2C2NoPCM and P2C3NoPCM, the surface temperature results of the second prototype corroborate the assumption of the heat loss due to lack of insulation in the first cycle. Indeed the results shown in Figure 3.26, show an approximate temperature increase of up to $10{ }^{\circ} \mathrm{C}$ during the charging phases by the addition of insulation. Unlike the results obtained with the first prototype, the SCV2 shows a slower heat loss during ventilation only phases, compared to the abrupt temperature drops obtained with the SCV1 for NoPCM cycles. The influence of the experimental protocol is still well defined in the surface temperature evolution and the temperature difference between peak and summit can reach $30{ }^{\circ} \mathrm{C}$ when the inlet temperature is set to $18^{\circ} \mathrm{C}$, and the external conditions reach $37.5^{\circ} \mathrm{C}$.

During natural ventilation phases, where the halogen lamps provide energy to the system and the outlet allows the air to flow, the surface temperature does not drop in steps as observed for C5NoPCM in Figure 3.22a. Unlike the SCV1 results, the second prototype exhibits a less dispersed temperature distribution. Some cases, as the one shown in Figure 3.28a register a temperature decrease once the heat source is turned off, followed by minor temperature increase due to the rise of the external temperature. The greatest temperature drops occur during the final stages of the experimental protocol, where the binary behaviour of the experimental campaign subjects the system to a heat source only phase followed by a ventilation only phase. The thermal potential gained during the charging phase is lost in approximately 6 hours, with a temperature difference of $25 \pm 5^{\circ} \mathrm{C}$ according to the cycle. 


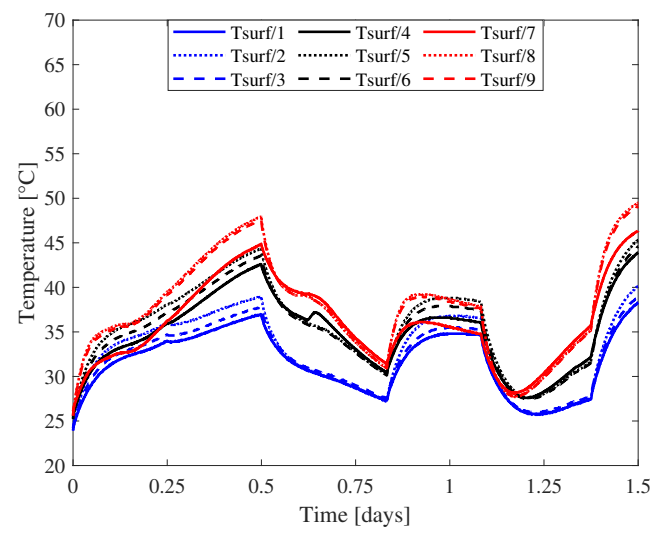

(a)

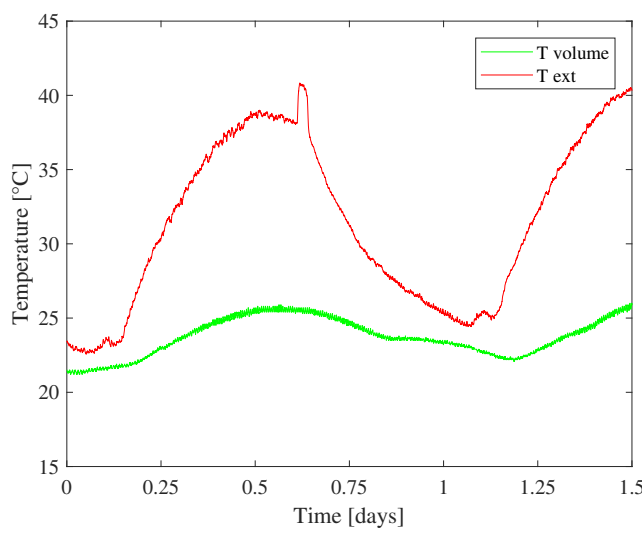

(b)

Figure 3.27: P2C1NoPCM-2 results of (a) surface temperature and (b) operating conditions (external and volume temperature). No insulation and cooler temperature set to $18{ }^{\circ} \mathrm{C}$.

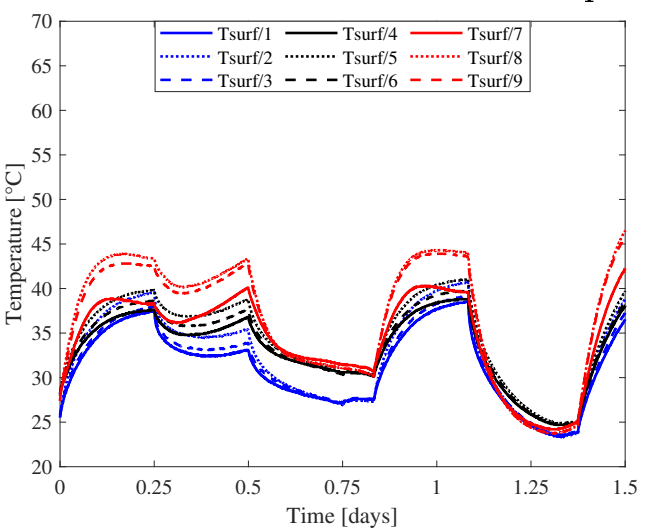

(a)

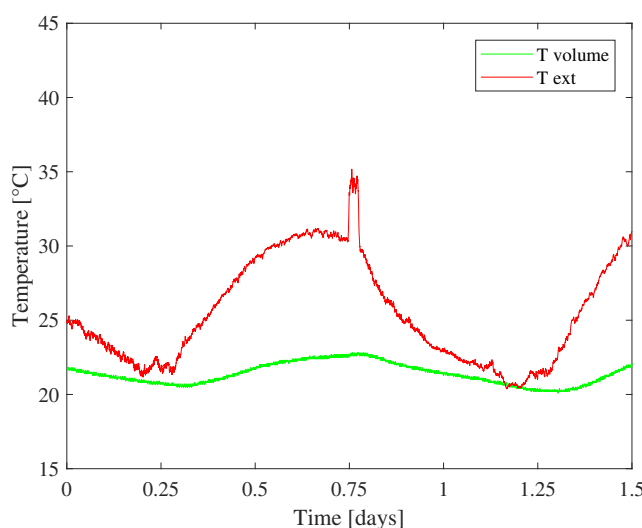

(b)

Figure 3.28: P2C3NoPCM-2 results of (a) surface temperature and (b) operating conditions (external and volume temperature). With insulation and cooler temperature set to $18{ }^{\circ} \mathrm{C}$.

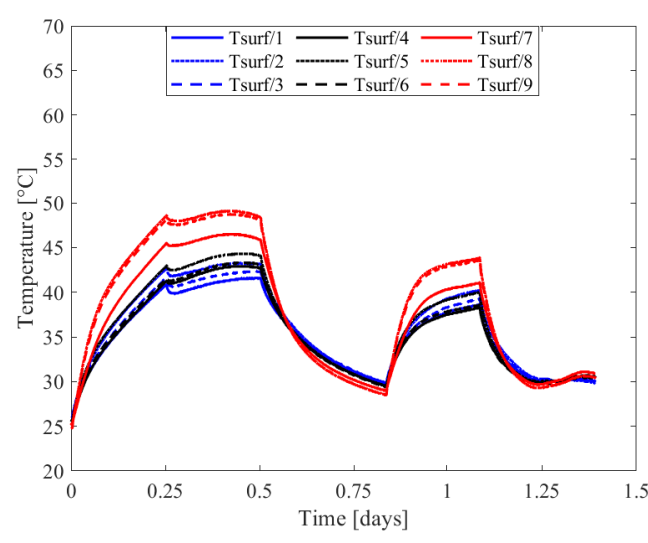

(a)

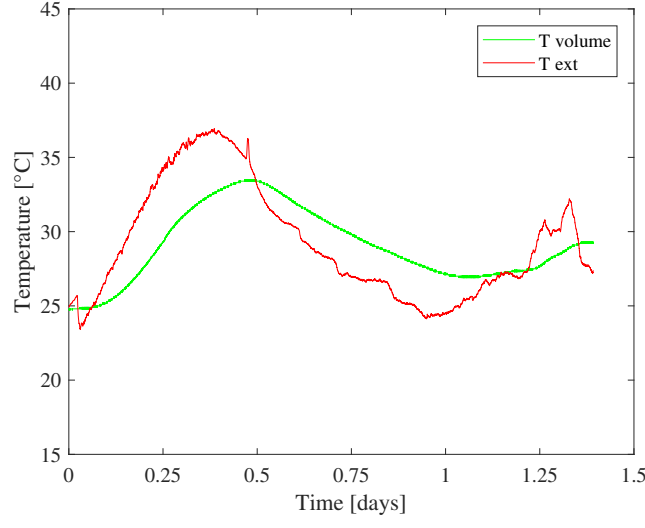

(b)

Figure 3.29: P2C4NoPCM-3 results of (a) surface temperature and (b) operating conditions (external and volume temperature). With insulation and no cooler temperature support. 
Finally, the PCM results of the SCV2 evidence two main points: firstly, the incomplete fusion of the PCM severely hampers the potential of phase changing materials in the overall performance of the chimney. Naturally, when the panels do not reach the fusion range, the system behaves as the NoPCM cycles, with a slight higher thermal inertia. In general, temperatures do not attain the same temperature peaks as the no-PCM solar chimney since some of the energy is employed for the phase transformation, however; they follow the experimental protocol in a similar fashion. The main difference is found after charging phases when the PCM releases the small amount of energy it stocked. The second point relates to the results obtained after the implementation of the additional insulation layer and the panel matte black paint coating. These modifications allowed higher temperature peaks and the conservation of higher temperatures across during the whole experimental protocol. Overall, the lower PCM panels, even though they reach the fusion temperature range, fail to surpass $44{ }^{\circ} \mathrm{C}$ which translates into an incomplete energy storage. These panels exhibit lower temperature drops similar to the results obtained without PCM. The rest of the system exceeds this temperature range and maintain a higher mean temperature throughout the test.

A significant difference can be appreciated for the PCM integrated solar chimney under the three different operating conditions of the experimental campaign (Figures $3.30-3.32)$. Indeed insulation allowed the system to surpass the melting range of the RT44 which enabled the full potential of the PCM panel. It can be appreciated between Figures 3.31a and 3.32a that inlet temperature has an important influence on the behaviour of the system's lower panels, however; temperature peaks for the top and middle rows of panels are similar regardless of this parameter. Due to the higher external temperature and the complete fusion of a larger number of PCM panels, the chimney is able to retain a quasi-constant surface temperature throughout the cycle. Moreover, it can be observed that once the PCM in the panels has achieved a complete fusion, the stored energy is enough to maintain the surface temperature on the PCM fusion range $\left(40-44^{\circ} \mathrm{C}\right)$ for the 6 hours of the ventilation-only phase. 


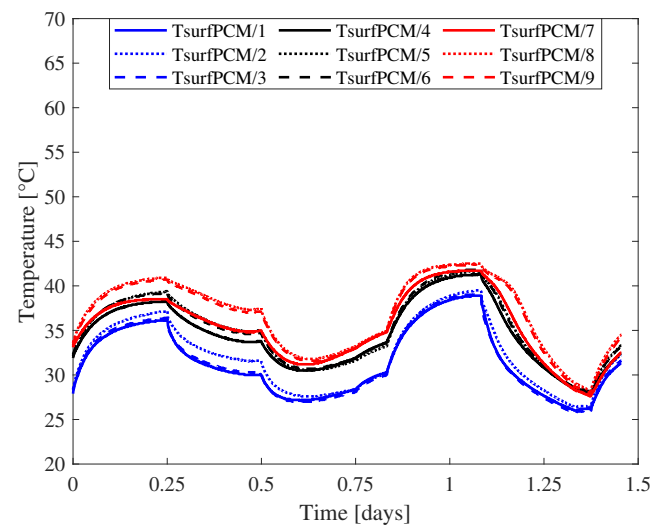

(a)

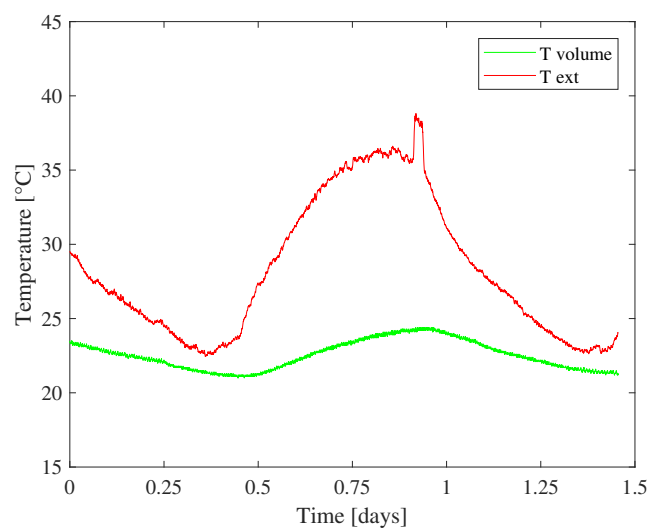

(b)

Figure 3.30: P2C1PCM-2 results of (a) surface temperature and (b) operating conditions (external and volume temperature). No insulation and cooler temperature set to $18{ }^{\circ} \mathrm{C}$.

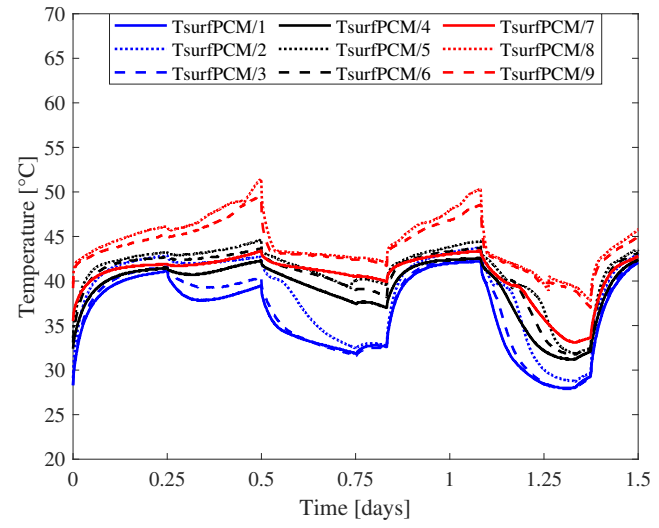

(a)

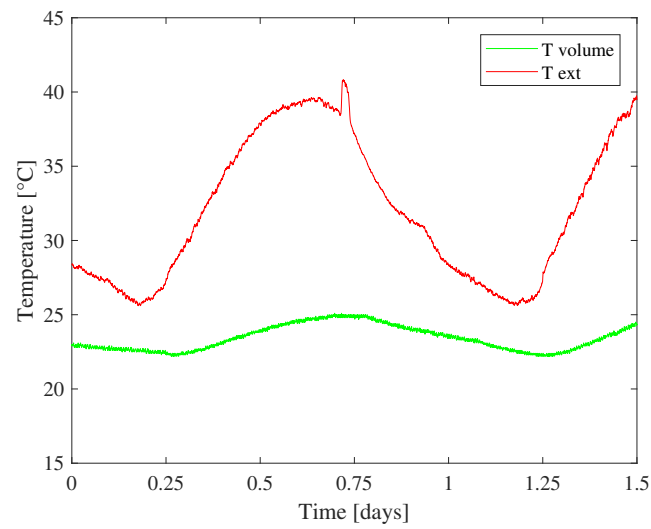

(b)

Figure 3.31: $\mathrm{P} 2 \mathrm{C} 2 \mathrm{PCM}-2$ results of (a) surface temperature and (b) operating conditions (external and volume temperature). With insulation and cooler temperature set to $18{ }^{\circ} \mathrm{C}$.

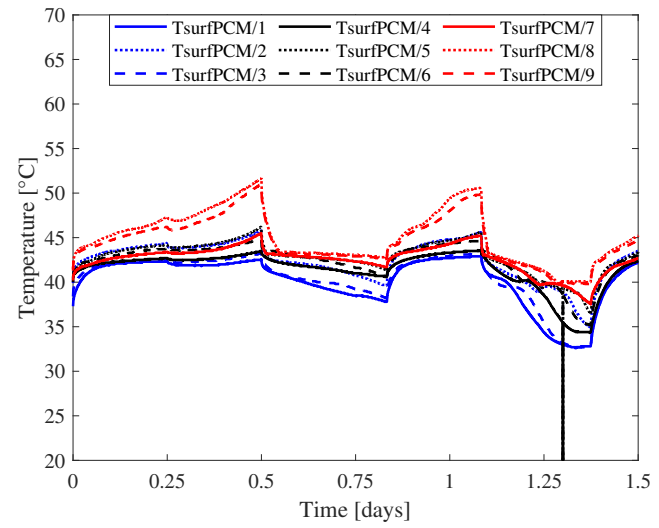

(a)

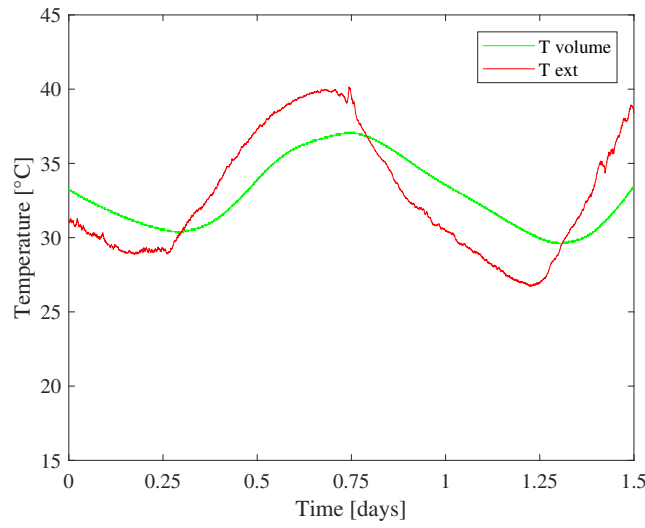

(b)

Figure 3.32: P2C5PCM-2 results of (a) surface temperature and (b) operating conditions (external and volume temperature). With insulation and no cooler temperature support. 


\subsubsection{Air Temperature Results}

The experimental protocol was ran under two different conditions. As explained in section 3.3.1, the GHB can set an operating temperature at the volume connected to the chimney and thus, at the inlet level. Through the establishment of an inlet temperature, a greater $\Delta T$ between inlet and outlet can be propitiated. In general, a greater $\Delta T$ will lead to a higher mass flow rate. Due to the nature of the first prototype, and the more consistent results obtained with the second prototype, this subsection mainly focuses on the latter.

The six cycles presented in this section are compared according to the operating and external conditions. Cycles P2C1NoPCM-2 and P2C1PCM-2 were carried out without the additional insulation layer and with a fixed GHB temperature. Cycles P2C3NoPCM-2 and P2C2PCM-2 were carried out with the additional insulation layer and with a fixed GHB temperature. Finally, cycles P2C4NoPCM-3 and P2C5PCM-2 were carried out with the additional insulation layer and without the GHB but following the external temperature. Overall, air temperatures tend to follow the behaviour and magnitude of surface temperatures. Inlet air temperature is dependent on the air drawn from the adjacent volume. When the GHB cold box modifies the volume temperature, the inlet temperature drops near to said setpoint temperature. The variation between the setpoint temperature and the inlet temperature depends on the external temperature, however for the cycles discussed in this section it is generally $5 \pm 1.5^{\circ} \mathrm{C}$. Once the charging phase starts, this temperature rises but never above $7.5^{\circ} \mathrm{C}$. When the $\mathrm{GHB}$ is not employed inlet temperature follows external temperature and the experimental protocol has little effect.

It is clear that the incomplete fusion of PCM panels makes the system behave in a similar fashion (Figures 3.33b and 3.34a), however; when PCM completes the phase change air temperatures present less variations and lesser drops. Cycles without insulation or without PCM panels register temperature decreases of up to $20^{\circ} \mathrm{C}$, while PCM cycles reduce this difference to approximately $12.5^{\circ} \mathrm{C}$ in the worst cases. PCM cycles, maintain a higher air temperature throughout the cycle compared to 
the NoPCM cycles. 


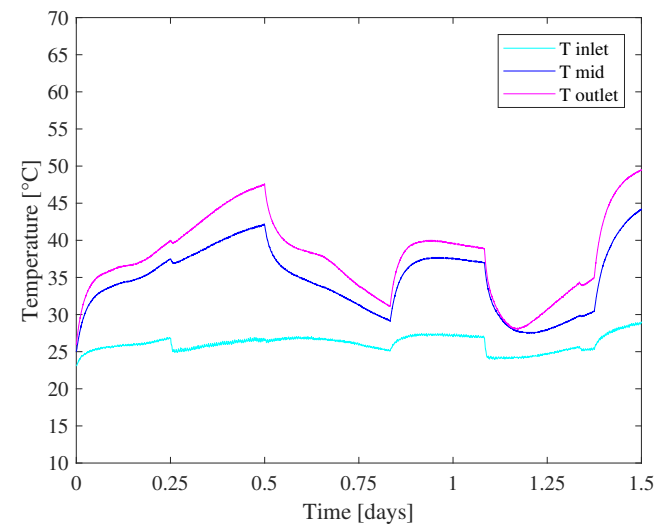

(a)

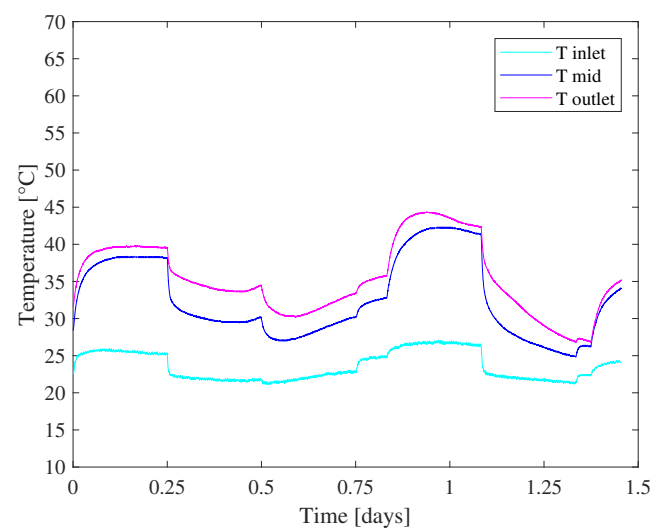

(b)

Figure 3.33: Air temperature distribution showing inlet level, mid level $(1.6 \mathrm{~m})$ and outlet level $(3.2 \mathrm{~m})$ under similar operating conditions for (a) P2C1NoPCM-2 and (b) P2C1PCM-2.

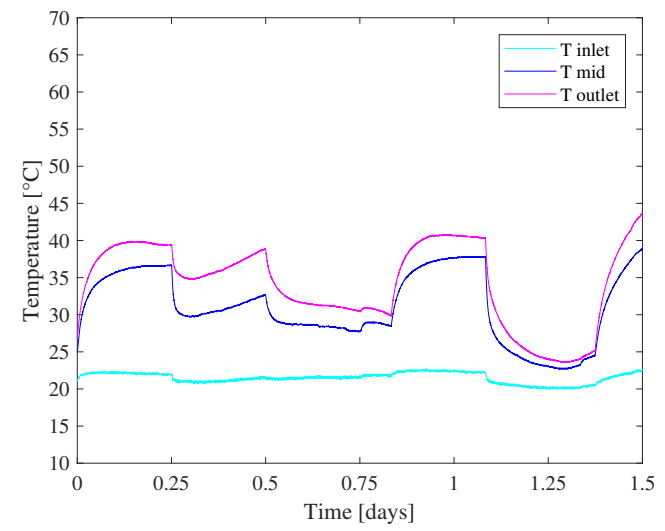

(a)

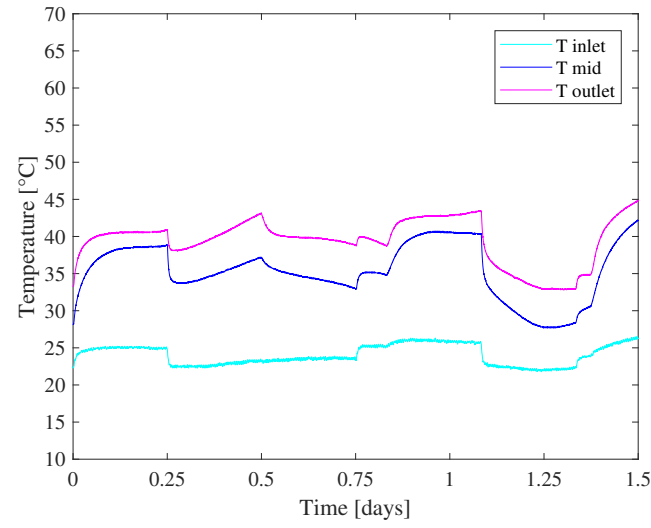

(b)

Figure 3.34: Air temperature distribution showing inlet level, mid level $(1.6 \mathrm{~m})$ and outlet level $(3.2 \mathrm{~m})$ under similar operating conditions for (a) P2C3NoPCM-2 and (b) P2C2PCM-2.

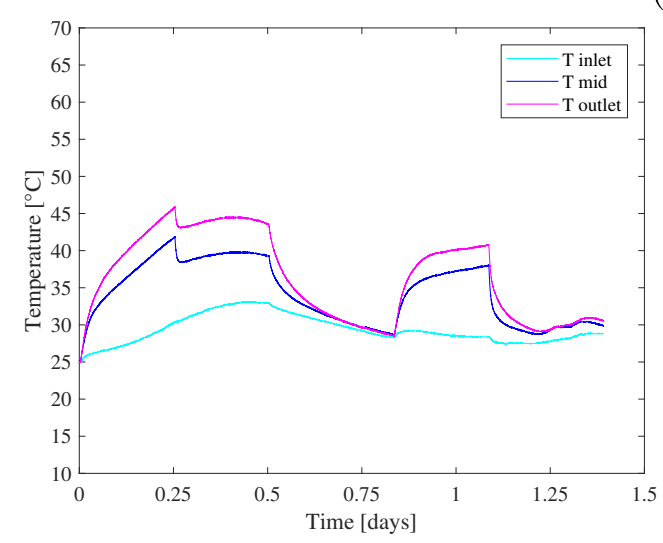

(a)

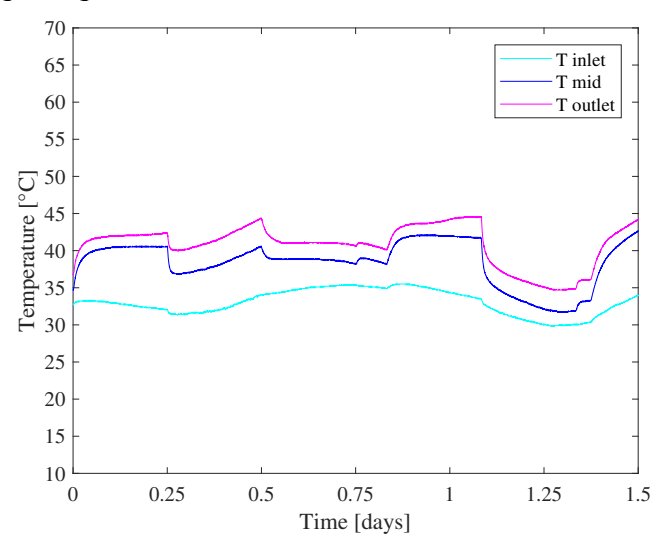

(b)

Figure 3.35: Air temperature distribution showing inlet level, mid level $(1.6 \mathrm{~m})$ and outlet level $(3.2 \mathrm{~m})$ under similar operating conditions for (a) P2C4NoPCM-3 and (b) P2C5PCM-2. 


\subsubsection{Mass Flow Rate Results}

The results shown in Figures 3.36 and 3.37 demonstrate the influence of the different stages of the experimental protocol on the outlet mass rate. For the following figures, the section highlighted in grey represents phases 4 and 7 of the experimental protocol. These phases show the impact of the PCMs since they correspond to ventilation only phases. Phase 4 comes after the charging phase (2) and the activation phase (3) where both the heat source and the ventilation are present. On the other hand, phase 7 comes after a charging only phase not going through an activation phase (3). The results shown in the following figures show the NoPCM cycles in black and the PCM cycles in blue.

The SCV1 without PCM panels shows dramatic mass flow rate drops as soon as the protocol enter phases 4 and 7 . The polystyrene structure provides no thermal inertia to the system, which causes a drop in outlet mass flow rate as soon as the heat source is withdrawn. The mass flow rate during phase 3 is very similar for the first set of results when the external temperature is below $25{ }^{\circ} \mathrm{C}$.

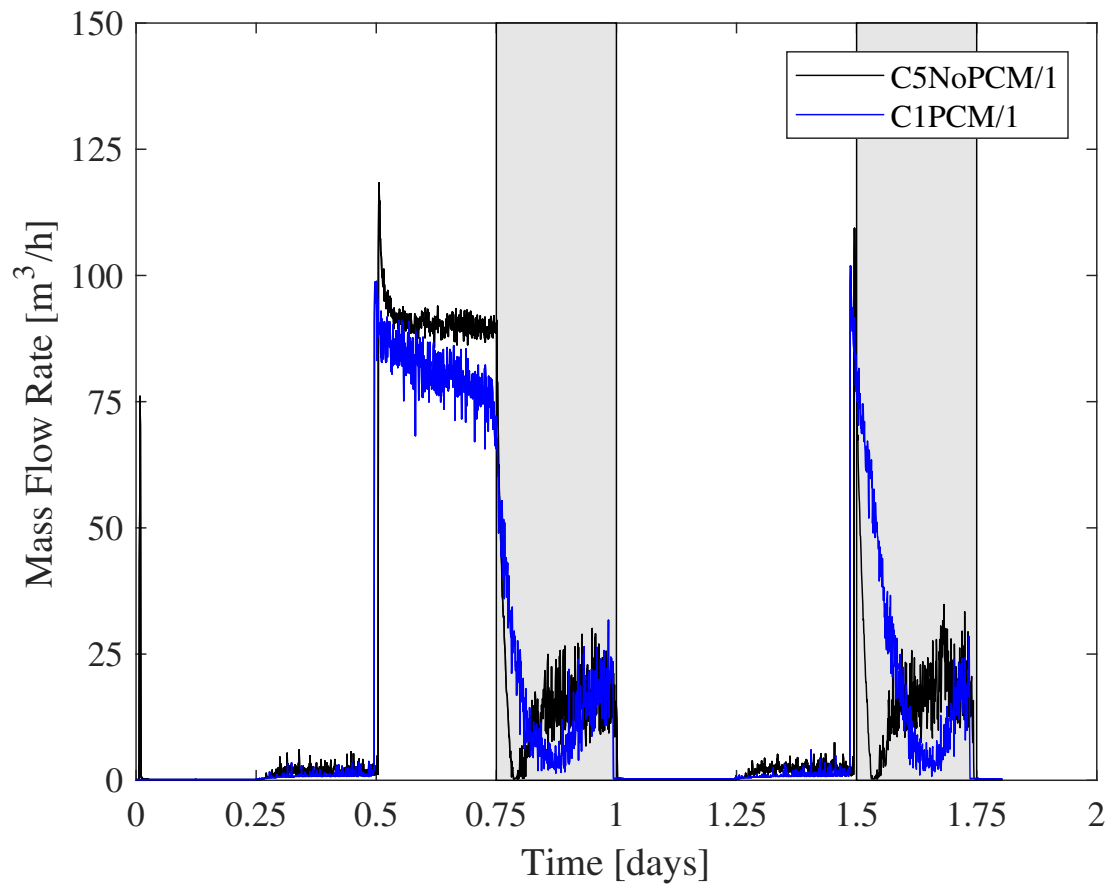

Figure 3.36: Mass flow rate results under similar operating conditions for C5NoPCM-1 and C1PCM-1.

In turn, SCV1 results with PCM panels display a slow decrease of mass flow rates between phases. This slow decrease depends on the complete fusion of the PCM. 


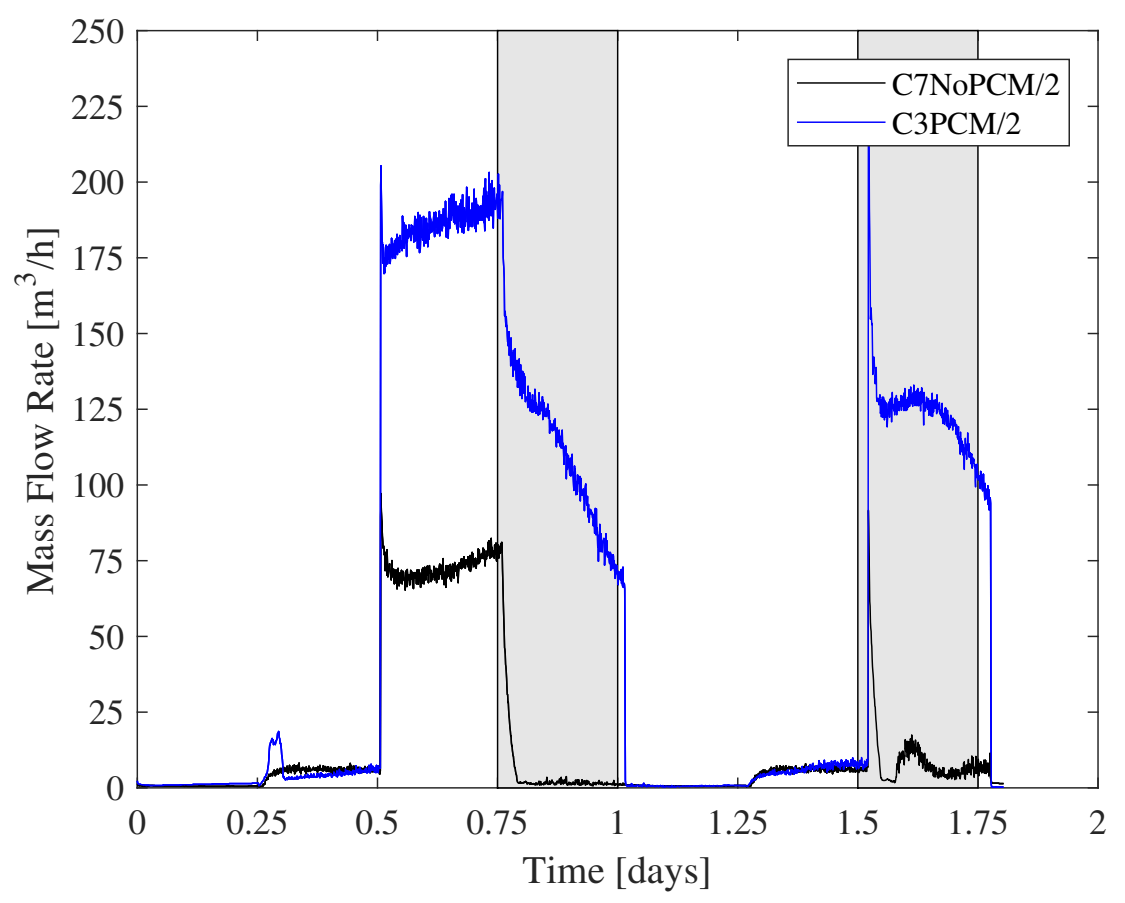

Figure 3.37: Mass flow rate results under similar operating conditions for C7NoPCM-1 and C3PCM-2.

The difference in mass flow rate, as well as the capitalization of these materials can be appreciated in the PCM Cycles of the figures presented in this subsection. Naturally, since a greater number of panels surpass the PCM fusion temperature range, the system exhibits a greater mass flow rate (Figure 3.37). This improvement is mainly due to the higher external temperature between cycles being compared. During phase 3 of the experimental protocol, when there is a heat source present and the outlet allows airflow, the chimney presents the highest values. C1PCM-1 achieves an approximate mean mass flow rate of $87.5 \mathrm{~m}^{3} / \mathrm{h}$, while C3PCM-2 reaches $187.5 \mathrm{~m}^{3} / \mathrm{h}$. As explained before, this is mainly due to the difference in operating conditions. Phases 4 and 7 which correspond to ventilation only phases, vary according to the percentage of RT44 in liquid state. The results from the latter figure demonstrate the potential of the PCM panels by maintaining a mean mass flow rate of $112.5 \mathrm{~m}^{3} / \mathrm{h}$. These results are obtained despite the incomplete fusion of several panels and the incapability of the rest to surpass the $44{ }^{\circ} \mathrm{C}$. The results obtained with the SCV1 evidence the potential of PCM panels, however; a more refined analysis was necessary in order to validate this assumption. The SCV2 was developed in order to analyse the true impact of PCM panels on a building component. 


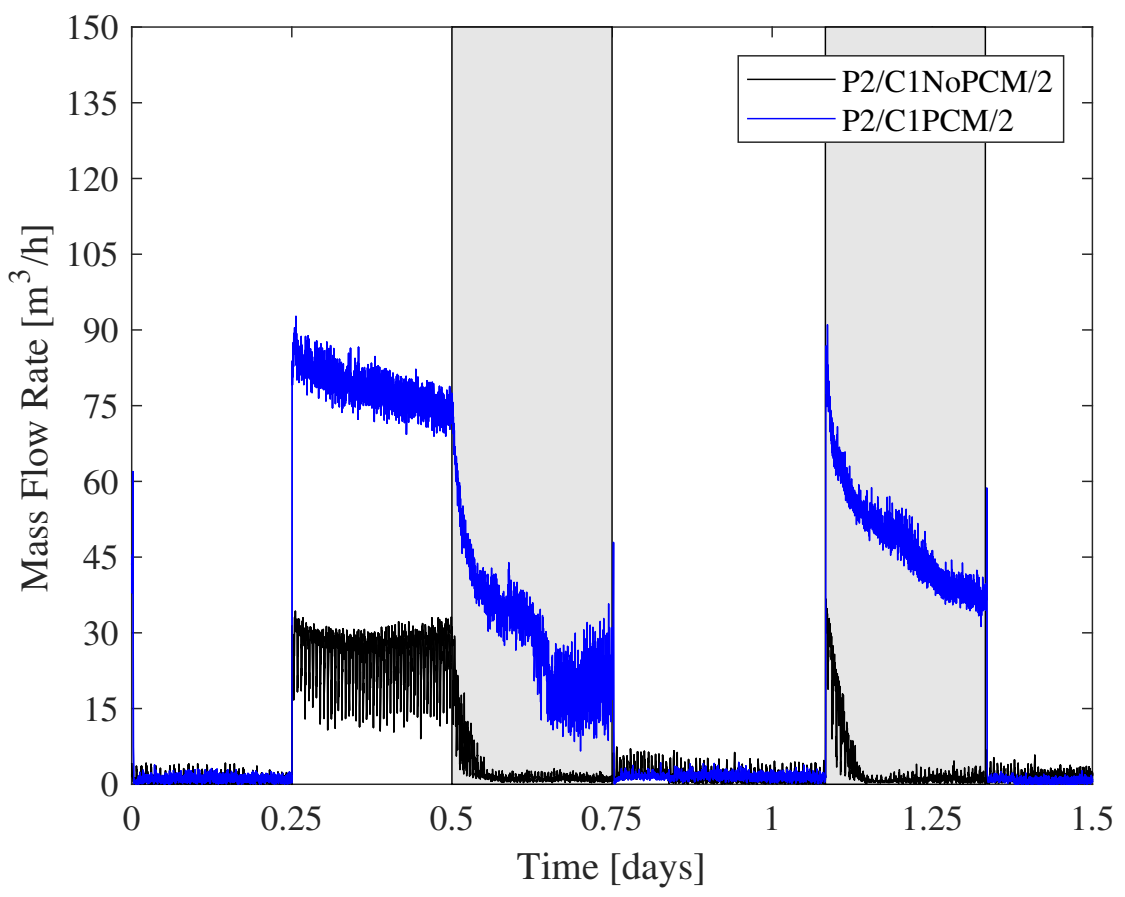

Figure 3.38: Mass flow rate results under similar operating conditions for P2C1NoPCM-2 and P2C1PCM-2.

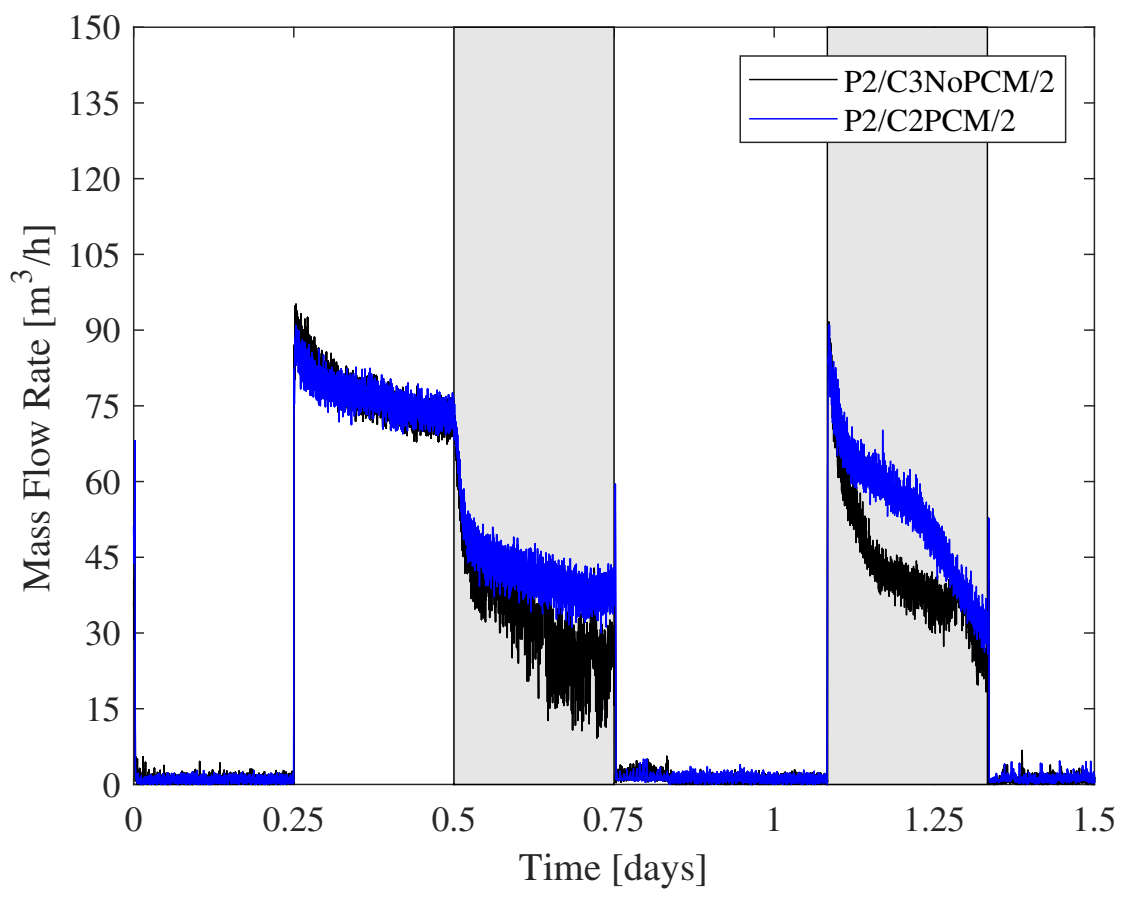

Figure 3.39: Mass flow rate results under similar operating conditions for P2C3NoPCM-2 and P2C2PCM-2. 


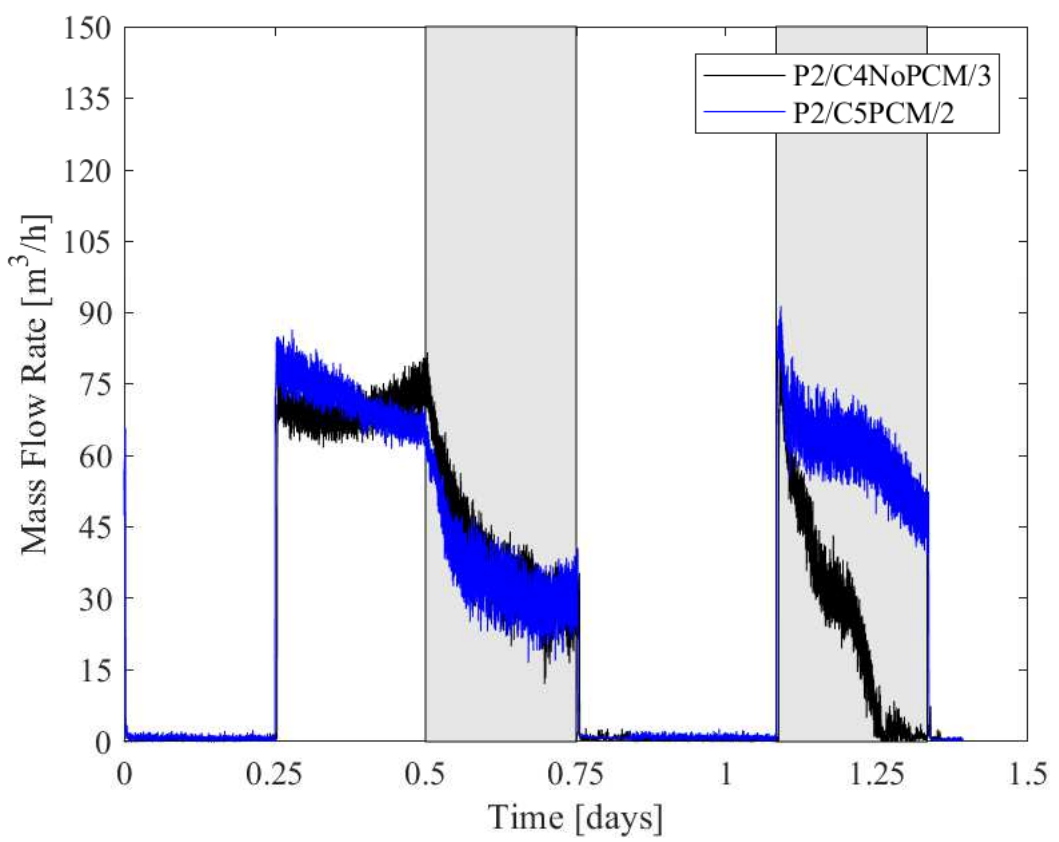

Figure 3.40: Mass flow rate results under similar operating conditions for (a) P2C4NoPCM-3 and (b) P2C5PCM-2.

The SCV2 mass flow rate results display a similar behaviour and magnitude during phase 3 (activation) for both NoPCM and PCM values (approximately 82.5 $\mathrm{m}^{3} / \mathrm{h}$ ). The differences in the mass flow rate during this phase for NoPCM and PCM cycles depend on the external temperature. Indeed, as temperature rises, the mass flow rate rises as well for cycles subjected to external temperature (Figure 3.40). The performance of the system during phases 4 and 7 of NoPCM cycles depends greatly on the temperature difference between inlet and outlet, as shown in the aforementioned figure, particularly noticeable in phase 7.

PCM cycles for the second prototype show a consistent performance of the system regardless of the operating conditions. Results demonstrate that the system is capable of maintaining an approximate mean ventilation rate of $60 \mathrm{~m}^{3} / \mathrm{h}$ during the 6 hours of the experimental protocol phase but the performance is halted as the phase reaches the end. A lower inlet temperature hampers the performance of the system, which translates to a reduction in the outlet mass flow rate (Figure 3.39). Furthermore, the when the system is exposed to the external temperature, the system displays an increased performance. This is mainly due to the higher surface temperatures and the greater number of PCM panels achieving fusion. 


\subsection{PSA in-situ experimentation}

The in-situ experimentation is a collaboration with the CIEMAT in Tabernas, Spain and a continuation of the work done by Arce et al. (2015). The stand-alone chimney depicted in Fig. 1 was developed in the dessert of Tabernas, Spain in 2003 at the "Plataforma Solar de Almeria" (PSA). The solar chimney at the PSA is located in the south side of the solar platform in the Laboratory of Energetic Tests for Building Components (Laboratorio de Ensayos Energéticos para Componentes de la Edificación - LECE).

The latest iteration of the system is $5.60 \mathrm{~m}$ tall, $1.20 \mathrm{~m}$ width and $0.52 \mathrm{~m}$ deep. The chimney is composed of a $4.5 \mathrm{~m}$ tall, $1.0 \mathrm{~m}$ width and $0.15 \mathrm{~m}$ thick, reinforced concrete absorbing plate, thermal insulation behind the concrete plate, a $5 \mathrm{~mm}$ thick glass cover to reduce convective and radiative losses to the environment, a wood casing, and a driving air protection, which generates a pressure drop near the exit, and at the same, time aids the extraction of air. An image of the solar chimney, as well as its characteristic are shown in Figure 3.42.

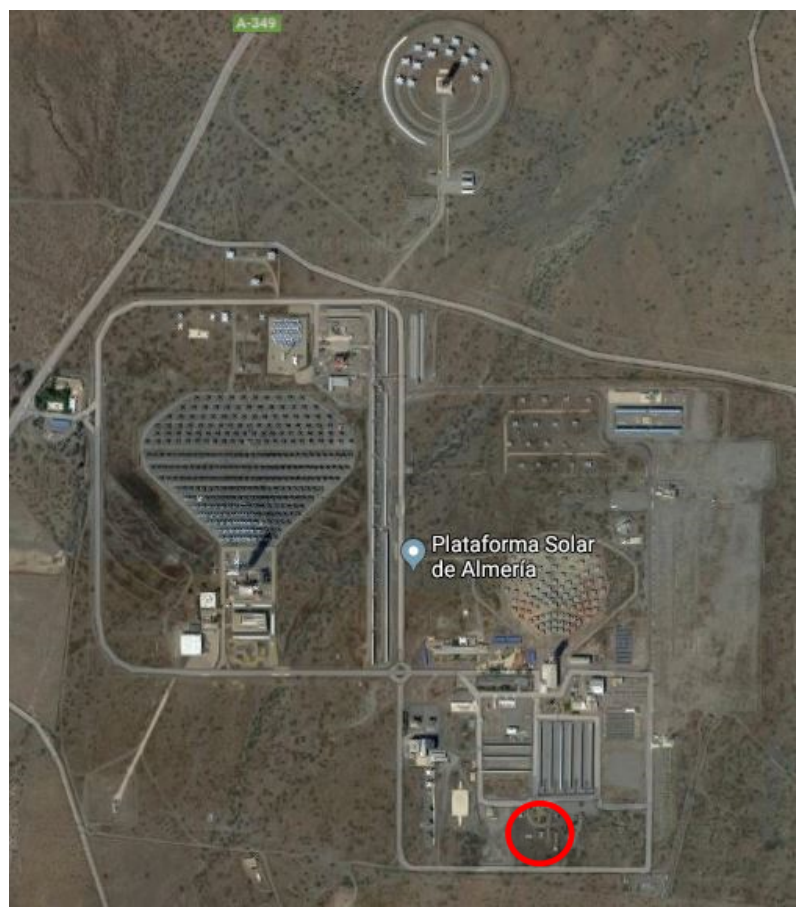

Figure 3.41: Solar Chimney location on the PSA of the CIEMAT 
The system is in vertical position and facing south. Thermal insulation was used to reduce heat losses from the absorber plate. Other accessories like wood around the lateral and back side, an air inlet in the low back side and an air exit at the top, are also included. In order to measure the main variables, such as air temperature and air velocity inside the channel, sensors and instruments were set up.

\subsubsection{PSA Solar Chimney Instrumentation}

The experimental instrumentation used for the different measurements of the SC is detailed in the technical note published by Arce, Xaman, Alvarez, Jiménez and Heras (2009). Additionally to the previously set thirty type "T" thermocouples, to measure temperature across the chimney's surfaces, 8 platinum thermoresistance (PT100, 1/10 DIN) sensors are used to record surface temperature of the panels via a four-wire connection. These sensors consist of a very small sensing element embedded in a slim rubber substrate. The sensors used to register the panel temperatures were glued to the centre of the panels as marked in Fig. 2 and painted black matte to integrate them as much as possible with the corresponding surface. Nine hot wire anemometers (Mod. TSI-8475) were used to measure the air velocity.

The data acquisition system has the following characteristics: 16-bit A/D resolution, range of measurements fitting sensor output, modules distributed to minimize wiring, based in Compact Field Point modules manufactured by NATIONAL INSTRUMENTS. Furthermore, in order to record environmental conditions, the PSA counts with its own meteorological station, which measures data ever second. Data are averaged and recorded every minute. Further details concerning the meteorological station can be found in the aforementioned article.

Finally, the chimney counts with a rotative driving air protection at the outlet in order to avoid any reverse flow to the chimney's channel. This exhaust is wind-driven which helps boost the systems ventilation potential through a pressure fall at the outlet. The inlet is protected with a wooden box to avoid air vortexes. 


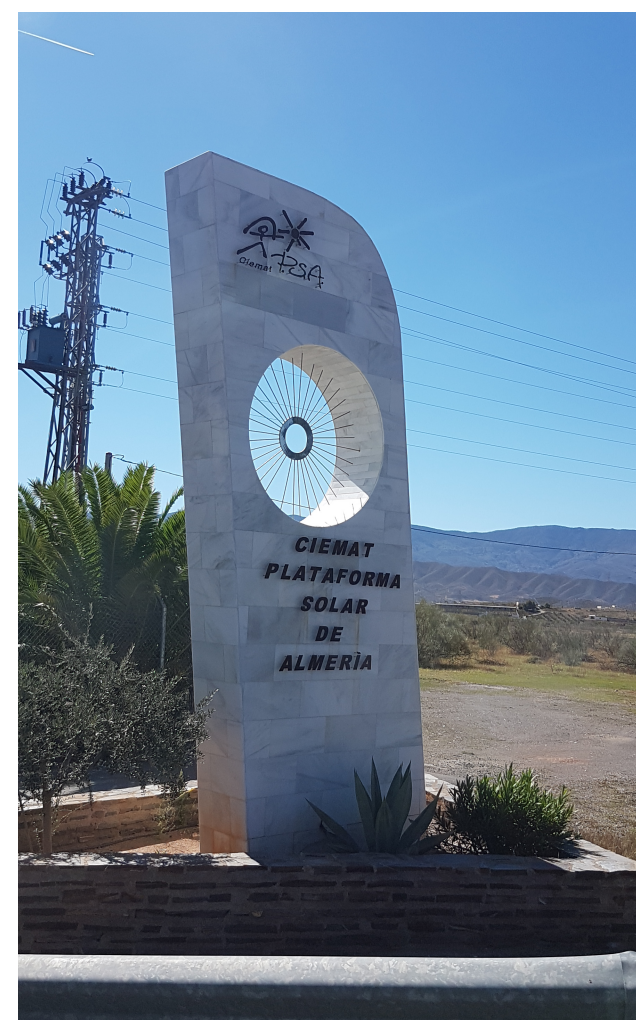

(a)

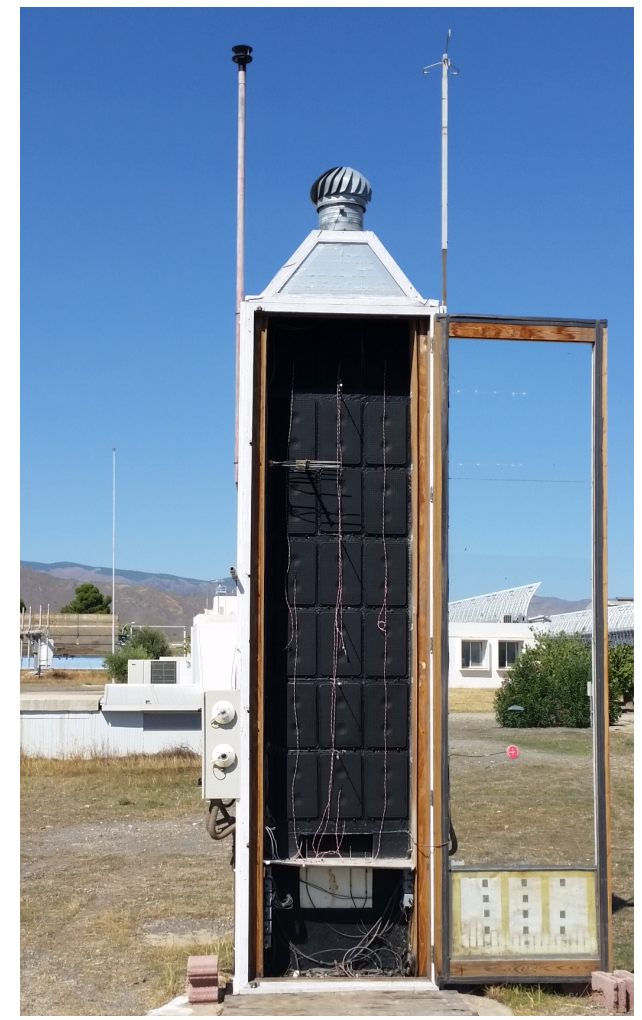

(c)

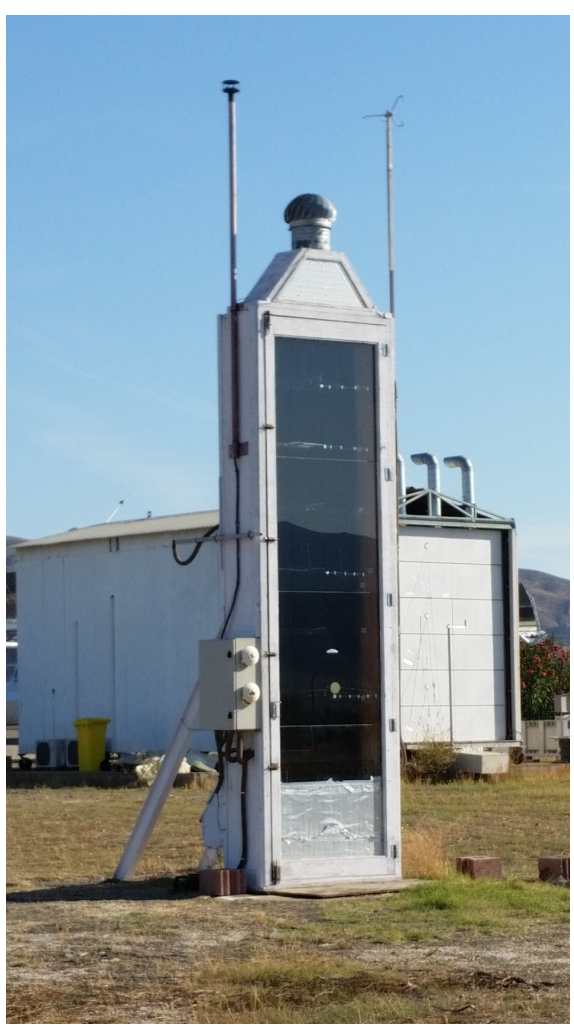

(b)

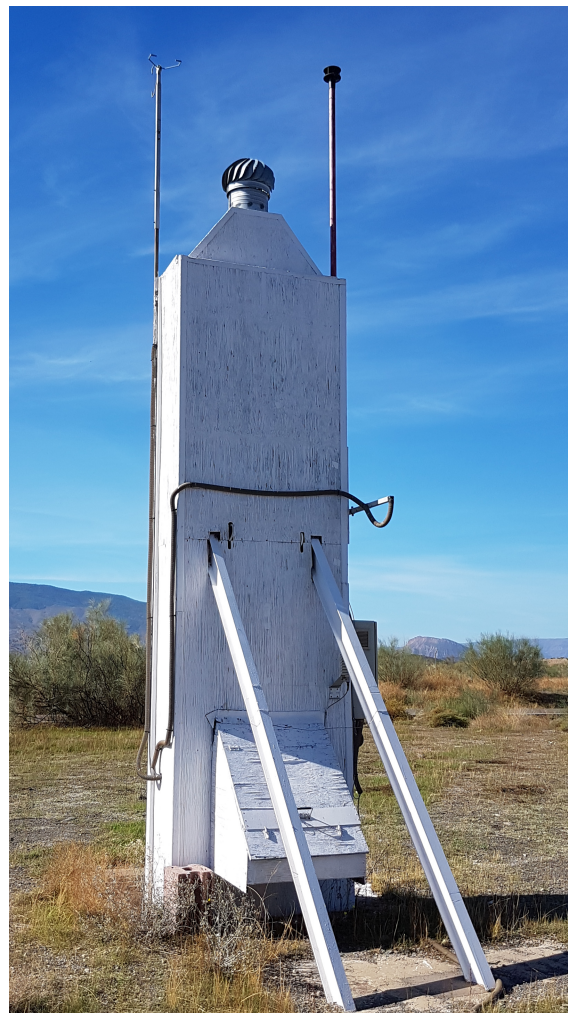

(d)

Figure 3.42: Solar chimney of the CIEMAT at the PSA showing (a)the entrance of the PSA, (b) and (d) front and back images of the solar chimney and (c) the solar chimney opened for panel installation 


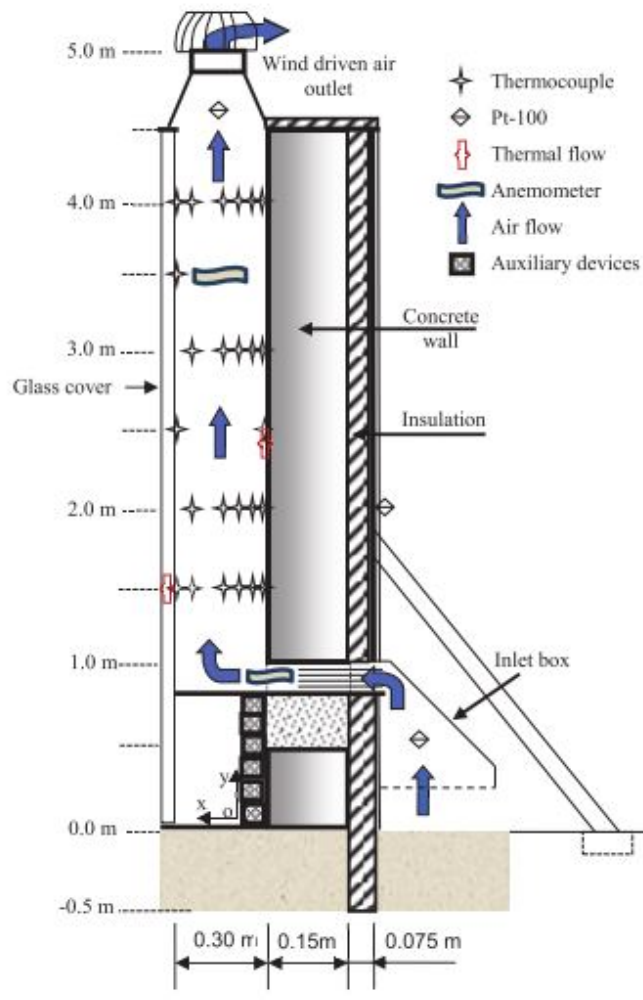

(a)

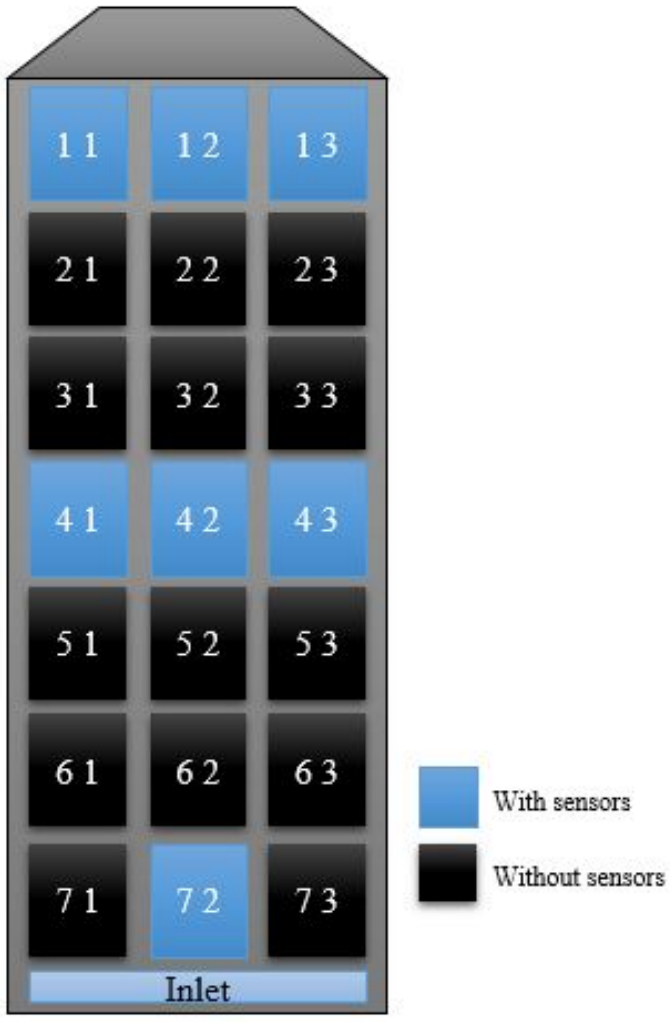

(b)

Figure 3.43: (a) lateral view of the PSA solar chimney and the instrumentation according to (Arce et al., 2015) and (b)Sensor placement above and below the panels at (72) 1.25m, (41 - 43) $2.75 \mathrm{~m}$ and (11 - 13) $4.25 \mathrm{~m}$.

\subsubsection{PCM Implementation}

The dimensions of the Almeria solar chimney, as well as the cable distribution do not allow the placement of PCM panels on the perpendicular sides to the glazing. The panels are distributed over the concrete collector wall as shown in Figure $3.43 \mathrm{~b}$ in a matrix manner. The sensors are placed in the centre of the panel, over and behind at three different levels: inlet panel (72) at $1,25 \mathrm{~m}$, centre of the solar chimney (41, 42 and 43$)$ at $2,75 \mathrm{~m}$ and the outlet panels $(11,12$ and 13$)$ at 4,25m. The panels' southern surfaces were painted matte black in order to maximize the absorption of solar radiation and to ensure the phase change. This approach was adopted as well for the concrete wall behind the panels since the first chimney iterations. The sensor distribution on the PCM panels was chosen according to the available channels in the acquisition modules. The PCM surface temperature analysis is carried out in three different levels just as the laboratory experimental campaigns. 


\subsubsection{Analysis of Environmental Conditions}

The Tabernas region, in which this chimney is located, a few kilometres from Almeria, is known for the high average solar radiation it receives throughout the year. Arce et al. (2015) presented different scenarios throughout the year. Three different dates were selected in order to analyse the performance of the solar chimney under different environmental conditions. These three dates correspond to days with a clear sky, near the beginning of winter, spring and summer respectively. Since solar chimneys are driven by solar energy, the effects of Vertical Global Solar Radiation (VGSR) and Horizontal Global Solar Radiation (HGSR)can be directly appreciated on the surface temperature of the PCM panels, in the air temperature of the channel and the mass flow rate of the system (Arce et al., 2015). Figures $3.44,3.45$ and 3.46 represent these variables for each one of the seasons studied.

The analysis of environmental data is complex due to the number of variables, the fluctuations of these and the resolution in their acquisition. In order to leverage the available data and information, and asses the impact of the PCM panels, the data studied should ideally be identical. The information treated in this section corresponds to the years 2016 and 2018, thus; the analysis of the system, depends on the statistical similarity of both sets of data (with and without PCMs). Big sets of data carry a considerable amount of fluctuations which can make this analysis non-conclusive. Variations in the sets of data can lead to biased or unfounded conclusions.

Wind speed, solar radiation (VGSR and HGSR), external temperature were the main variables taken into account for the statistical analysis of the chimney's operating conditions. These sets of data were chosen to determine the agreement of the environmental conditions since they represent variables which do not depend or are modified by the addition of the PCM panels and depict the conditions to which the chimney was subjected. Additionally, the glazing temperature was added to this statistical study to determine the surface temperature difference due to the incident solar radiation. 
The selection of the days corresponding to each one of the seasons was done through $R$ programming and the use of $R$-studio. This statistical software was employed for the calculation of different variables such as the the kurtosis and skewness of both daily sets of data. Kurtosis and skewness are statistical elements that define the "peakedness" or "flatness" and the symmetry of a series of data. This two values lead to the determination of normal distributions, where if the both values are near zero, a normal distribution can be expected. Furthermore, the correlation of the analysed data helped to determine the pairs of days that would be employed for the analysis. The choice of a clear day was established numerically by the standard deviation of the data. The standard deviation of a clear day for winter, spring and summer must be above 200, 300, 350 for HGSR and 350, 310, 150 for VGSR. The full analysis of the results can be seen on Annex F.

Once two days of each year have been chosen for each season, a further validation of the selected data was performed in order to outline the statistical difference between both sets. For each seasonal case, a statistical $t$-test could be carried out. This analysis, also referred to as two sample $t$-test, is a probabilistic statistical tool which allows the determination of the statistical difference between the means of two unrelated groups of data. This test must meet three assumptions :

1. The samples are independent. This is achieved by the selection of data in two different years.

2. Samples are drawn from populations with equal variances. If the $p$-value of a variance test is greater than 0.05 ( $95 \%$ confidence) then we can assume that the variances of both sets of data are the same.

3. Samples are drawn from populations with normal distributions.

In the case of the data analysed in this dissertation, the first two conditions are met, however; the samples are not drawn from normal distributions and cannot be normalized by logarithmic or squared-root methods. A non parametric solution is therefore needed. The unpaired two-sampled Wilcoxon test (or Mann-Whitney-Wilcoxon Test) which represents the non parametric alternative of the $t$-test can be used in the same manner, as the latter, to compare two independent 
groups of samples that are not normally distributed. In the same way as the $t$-test, this non parametric statistical tool relies on the definition of a null hypothesis which stipulates if two sets of data are identical populations (eqn. 3.1).

$$
H_{0}: \mu_{1}-\mu_{2}=0 \wedge H_{a}: \mu_{1}-\mu_{2} \neq 0
$$

If the null hypothesis is chosen, low $p$-values suggest that the null hypothesis is unlikely to be true, thus; the sets of data are non-identical populations. In general, $p$-values that are closer to 0 more strongly imply that the null hypothesis can be rejected. Inversely, a high $p$-value will reject the null hypothesis and suggest that the sets of data are drawn from identical populations.

For the data presented, the analysis must indicate that the actual difference in averages is approximately zero, which suggests that the environmental conditions for both data sets are statistically equivalent. The chosen data is selected due to similarities in external temperature and relative low mean wind speed under 3 $\mathrm{m} / \mathrm{s}$. In environmental data, obtaining the same results is practically impossible in all variables. The following results are a combination of the correlation, kurtosis, skewness and a Wilcoxon test. Even though the selected data cannot be taken as information from the exact same population, they can be analysed as statistic approximates with a high enough confidence value to draw conclusions. The statistical analysis performed with RStudio for each seasonal data is presented in Table 3.5, 3.6 and 3.7. 


\subsubsection{Winter Season (January 16th, 2016 and January 16th, 2018)}

Table 3.5: Statistical analysis of the winter data

\begin{tabular}{|c|c|c|c|}
\hline Variable & $\begin{array}{c}\text { Standard } \\
\text { Deviation } \\
\sigma\end{array}$ & $\begin{array}{c}\text { Sample } \\
\text { mean } \\
\bar{x}\end{array}$ & $\begin{array}{c}\text { Probability } \\
\text { value } \\
p \text {-value }\end{array}$ \\
\hline Wind speed SC & 1.5526 & 2.2865 & \multirow{2}{*}{$8.762 e^{-6}$} \\
\hline Wind Speed ASC & 1.5357 & 2.3340 & \\
\hline External temperature SC & 4.1737 & 10.578 & \multirow{2}{*}{0.1068} \\
\hline External temperature ASC & 4.9596 & 11.174 & \\
\hline Glazing temperature SC at $0.7 \mathrm{~m}$ & 8.3037 & 14.216 & \multirow{2}{*}{0.3846} \\
\hline Glazing temperature ASC at $0.7 \mathrm{~m}$ & 10.132 & 14.783 & \\
\hline Glazing temperature $\mathrm{SC}$ at $1.7 \mathrm{~m}$ & 7.9077 & 14.295 & \multirow{2}{*}{0.1386} \\
\hline Glazing temperature ASC at $1.7 \mathrm{~m}$ & 9.7526 & 14.848 & \\
\hline Glazing temperature $\mathrm{SC}$ at $2.7 \mathrm{~m}$ & 7.5666 & 14.878 & \multirow{2}{*}{0.001793} \\
\hline Glazing temperature ASC at $2.7 \mathrm{~m}$ & 9.7142 & 15.634 & \\
\hline Glazing temperature $\mathrm{SC}$ at $3.15 \mathrm{~m}$ & 7.3412 & 14.211 & \multirow{2}{*}{0.01556} \\
\hline Glazing temperature ASC at $3.15 \mathrm{~m}$ & 9.2205 & 14.807 & \\
\hline HGSR SC & 178.53 & 111.87 & \multirow{2}{*}{$2.508 e^{-14}$} \\
\hline HGSR ASC & 199.33 & 127.14 & \\
\hline VGSR SC & 306.91 & 194.25 & \multirow{2}{*}{$1.689 e^{-7}$} \\
\hline VGSR ASC & 333.62 & 216.32 & \\
\hline
\end{tabular}

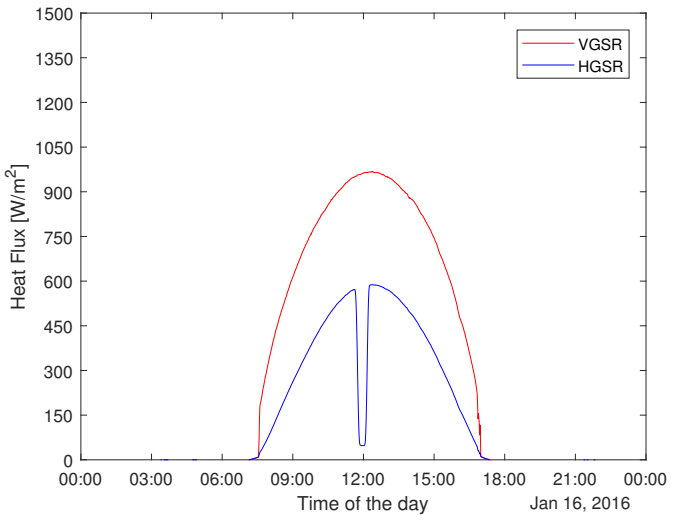

(a)

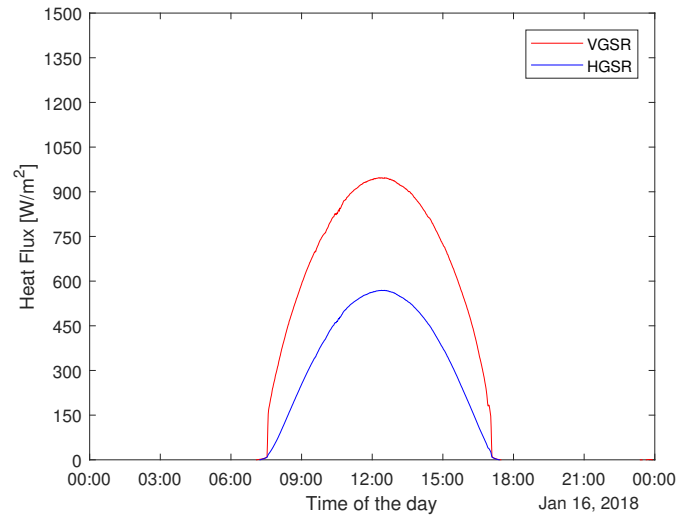

(b)

Figure 3.44: Solar radiation (VGSR and HGSR) for the winter period on (a) January 16th, 2016 and (b) January 16th, 2018 


\subsubsection{Spring Season (March 2nd, 2016 and March 27th, 2018)}

Table 3.6: Statistical analysis of the spring data

\begin{tabular}{cccc}
\hline \hline Variable & $\begin{array}{c}\text { Standard } \\
\text { Deviation } \\
\sigma\end{array}$ & $\begin{array}{c}\text { Sample } \\
\text { mean } \\
\bar{x}\end{array}$ & $\begin{array}{c}\text { Probability } \\
\text { value } \\
\text {-value }\end{array}$ \\
\hline Wind speed SC & 2.7999 & 3.8905 & 0.0035 \\
Wind Speed ASC & 2.8902 & 4.2017 & \\
External temperature SC & 4.3626 & 14.065 & $<2.2 e^{-16}$ \\
External temperature ASC & 4.1383 & 16.240 & \\
Glazing temperature SC at 0.7 m & 7.6528 & 18.474 & $<5.128 e e^{-14}$ \\
Glazing temperature ASC at 0.7 m & 8.0986 & 19.839 & \\
Glazing temperature SC at $1.7 \mathrm{~m}$ & 7.2261 & 17.599 & \multirow{2}{*}{$3.82 e^{-6}$} \\
Glazing temperature ASC at $1.7 \mathrm{~m}$ & 7.5169 & 18.906 & \\
Glazing temperature SC at $2.7 \mathrm{~m}$ & 8.1557 & 18.106 & $2.438 e^{-11}$ \\
Glazing temperature ASC at $2.7 \mathrm{~m}$ & 8.2939 & 19.430 & \\
Glazing temperature SC at $3.15 \mathrm{~m}$ & 8.7684 & 18.251 & \multirow{2}{*}{$1.458 e^{-12}$} \\
Glazing temperature ASC at $3.15 \mathrm{~m}$ & 8.9155 & 19.724 & \\
HGSR SC & 315.68 & 249.42 & \multirow{2}{*}{$6.576 e^{-10}$} \\
HGSR ASC & 310.59 & 234.92 & \\
VGSR SC & 300.73 & 228.18 & \multirow{2}{*}{0.337} \\
VGSR ASC & 315.46 & 232.85 & \\
\hline \hline
\end{tabular}

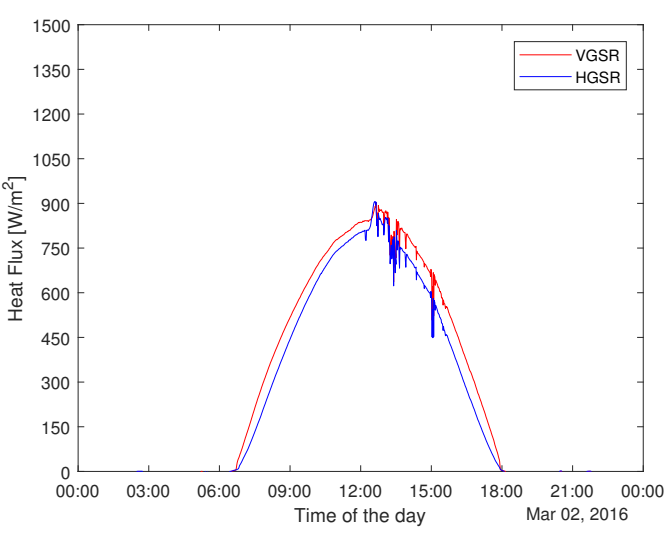

(a)

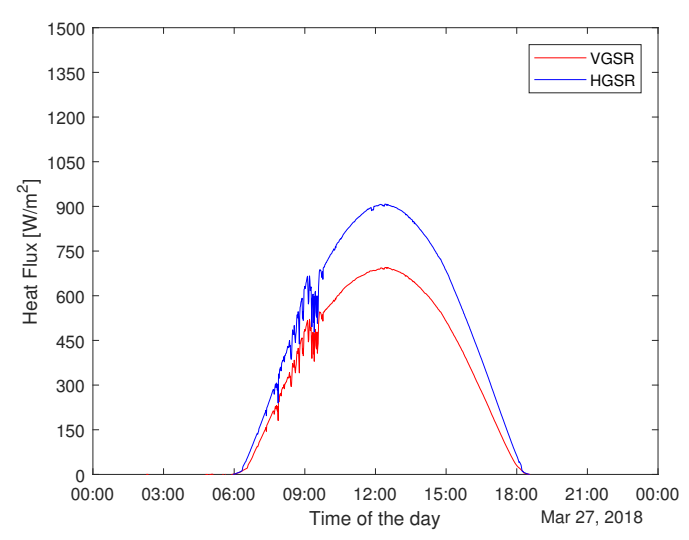

(b)

Figure 3.45: Solar radiation (VGSR and HGSR) for the spring period on (a) March 4th, 2016 and (b) March 9th, 2018 


\subsubsection{Summer Season (July 2nd, 2016 and July 17th, 2018)}

Table 3.7: Statistical analysis of the summer data

\begin{tabular}{cccc}
\hline \hline Variable & $\begin{array}{c}\text { Standard } \\
\text { Deviation } \\
\sigma\end{array}$ & $\begin{array}{c}\text { Sample } \\
\text { mean } \\
\bar{x}\end{array}$ & $\begin{array}{c}\text { Probability } \\
\text { value } \\
p \text {-value }\end{array}$ \\
\hline Wind speed SC & 2.0475 & 3.4224 & $2.947 e^{-15}$ \\
Wind Speed ASC & 2.3726 & 4.0964 & \\
External temperature SC & 4.9801 & 27.015 & $2.317 e^{-6}$ \\
External temperature ASC & 3.8334 & 27.535 & \\
Glazing temperature SC at 0.7 m & 5.9269 & 28.038 & $2.177 e^{-12}$ \\
Glazing temperature ASC at 0.7 m & 5.5128 & 29.346 & \\
Glazing temperature SC at $1.7 \mathrm{~m}$ & 5.8404 & 27.968 & \multirow{2}{*}{$7.266 e^{-13}$} \\
Glazing temperature ASC at $1.7 \mathrm{~m}$ & 5.4227 & 29.227 & \\
Glazing temperature SC at $2.7 \mathrm{~m}$ & 6.2641 & 28.181 & \multirow{2}{*}{$9.714 e^{-13}$} \\
Glazing temperature ASC at $2.7 \mathrm{~m}$ & 5.8507 & 29.328 & \\
Glazing temperature SC at $3.15 \mathrm{~m}$ & 6.5361 & 27.615 & \multirow{2}{*}{$1.598 e^{-14}$} \\
Glazing temperature ASC at $3.15 \mathrm{~m}$ & 6.0130 & 28.896 & \\
HGSR SC & 133.65 & 328.121 & \multirow{2}{*}{$3.296 e^{-14}$} \\
HGSR ASC & 146.20 & 323.231 & \\
VGSR SC & 360.24 & 123.211 & \multirow{2}{*}{0.1265} \\
\hline VGSR ASC & 369.54 & 114.591 & \\
\hline \hline
\end{tabular}

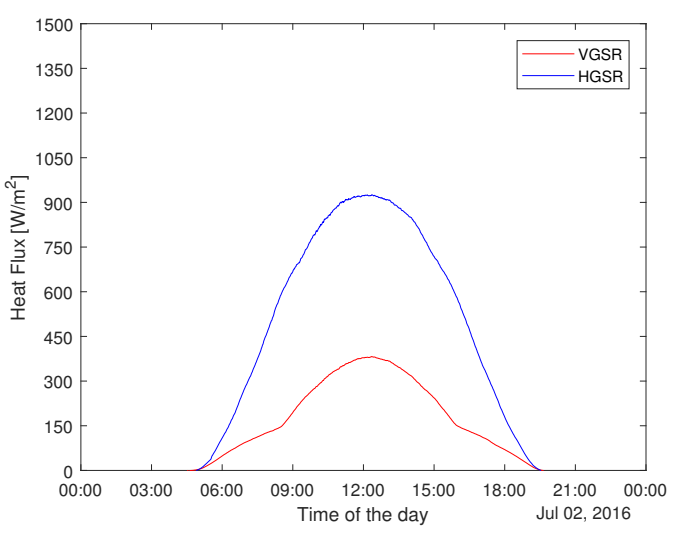

(a)

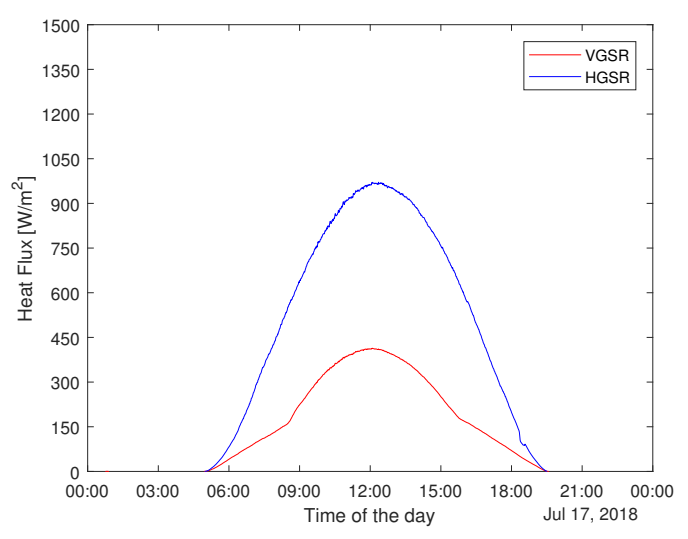

(b)

Figure 3.46: Solar radiation (VGSR and HGSR) for the summer period on (a) July 2nd, 2016 and (b) July 17th, 2018 


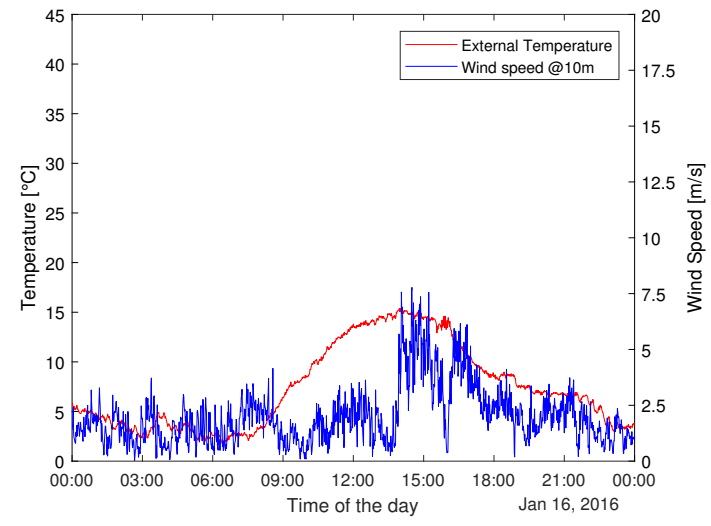

(a)

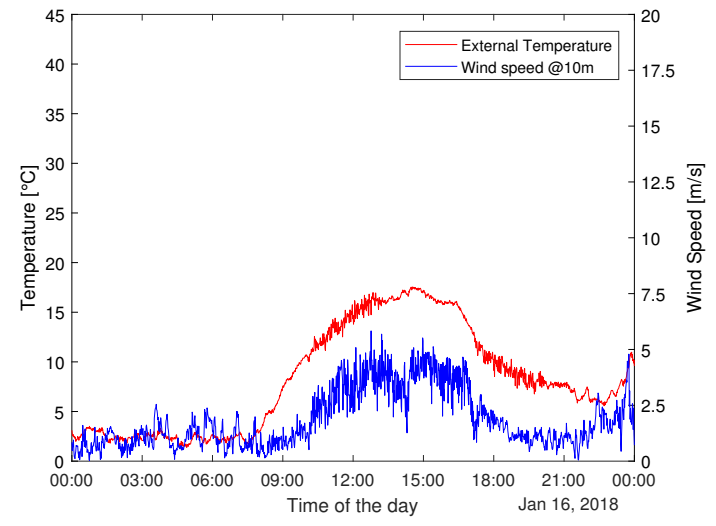

(b)

Figure 3.47: Environmental conditions for the statistical data of the winter period of (a) January 16th, 2016 and (b) January 16th, 2018.

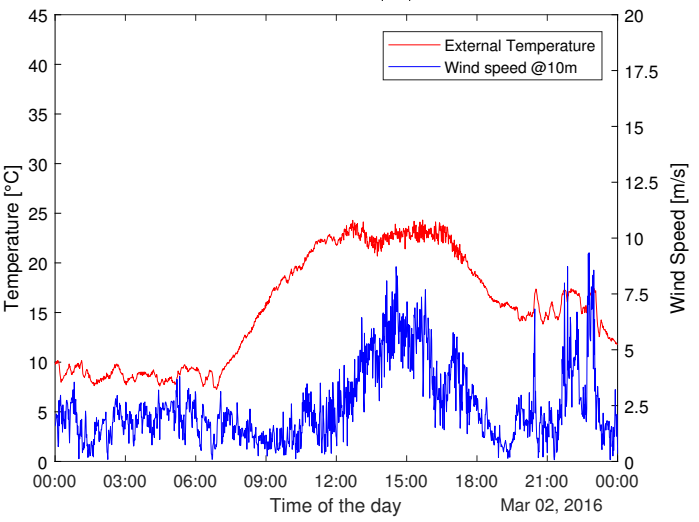

(a)

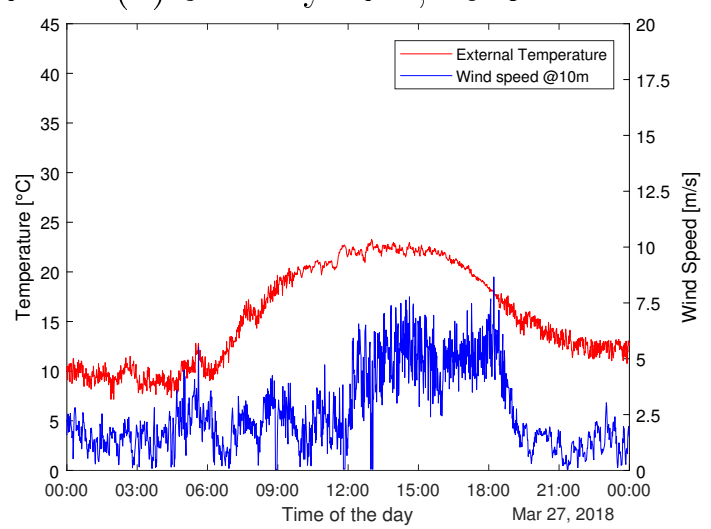

(b)

Figure 3.48: Environmental conditions for the statistical data of the spring period of (a) March 2nd, 2016 and (b) March 27th, 2018.

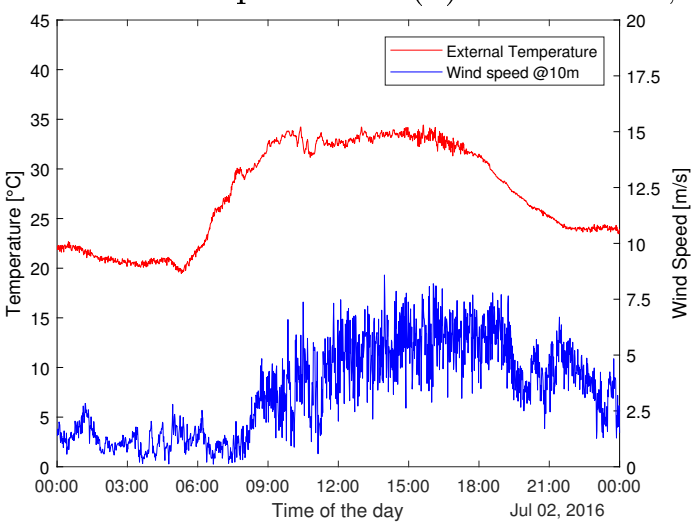

(a)

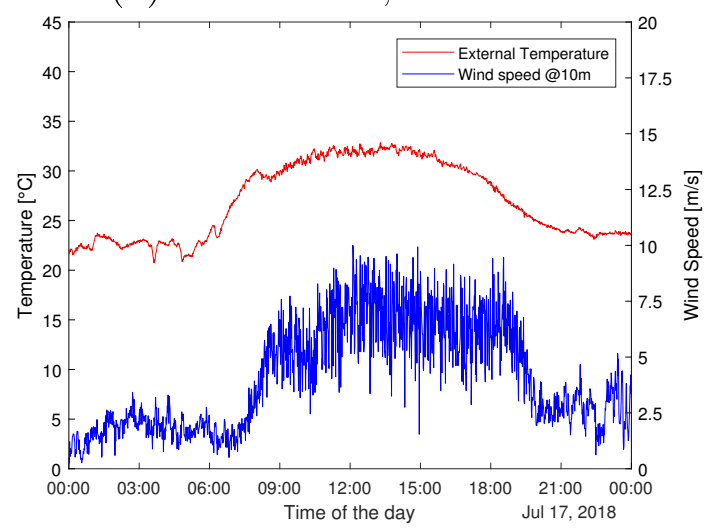

(b)

Figure 3.49: Environmental conditions for the statistical data of the summer period of (a) July 2nd, 2016 and (b) July 17th, 2018. 


\subsubsection{Results \& Discussion}

The results presented throughout this section represent the analysis of the sets of data selected for the winter, spring and summer periods. The data of the year 2016 is referred to as SC for classic Solar Chimney, and the data from 2018 is attributed the abbreviation ASC which designates the integration of PCM panels. The results mentioned in this section concern the same performance magnitudes reviewed for the laboratory results. A brief discussion of the effects of wind and the nature of the chimney is as well presented in this section.

\subsubsection{Surface Temperatures}

Surface temperatures are evaluated in two different ways. For the SC results of 2016 the analysis is based on three surface temperature sensors placed on the middle section of the concrete collector wall at $0.7,1.2,2.2$ and $3.2 \mathrm{~m}$. The ASC results of 2018 display this four variables plus the information provided by the sensors placed on the PCM panels and specified in Figure 3.43b. In order to ensure the activation (energy storage and release) of the PCM panels, the panel surface temperature must attain the temperature range of $40-44{ }^{\circ} \mathrm{C}$.

Firstly, the winter SC results of the concrete wall display a maximum temperature of $50{ }^{\circ} \mathrm{C}$. It is evident by the results showed in Figure 3.51a that the concrete wall provides enough energy to the system to maintain a similar temperature across the height of the chimney. The variation between the sensors at $0.7 \mathrm{~m}$ and the ones at $3.2 \mathrm{~m}$ at the hottest point is of only $3{ }^{\circ} \mathrm{C}$. The maximum surface temperature is reached approximately one hour after the external temperature has reached its peak and 3 hours after the maximum available solar irradiance. The sun during the winter period goes down around 17:00h. For the data of the 16 th of January of 2016 , the sun went down at $16: 48 \mathrm{~h}$. Once there is no more solar energy the surface temperature starts to drop until it reaches $20{ }^{\circ} \mathrm{C}$. The addition of PCM panels (Figure 3.51b) does not greatly modify the behaviour of the surface temperature. The maximum temperature reached with the ASC drops to $45{ }^{\circ} \mathrm{C}$ which is consistent with addition of PCM panels since part of the incoming energy is captured by the paraffin. The greatest difference is registered 
at $0.7 \mathrm{~m}$. The lowest section of the ASC takes a longer time to reach maximum temperature and falls $10{ }^{\circ} \mathrm{C}$ under the rest of the surface temperatures to a maximum of $35{ }^{\circ} \mathrm{C}$. Furthermore, the addition of PCM panels maintain the surface temperature of the concrete wall at a quasi stable temperature from 16:48h to 19:12h.

Furthermore, the panel surface temperature depends greatly on the incident solar radiation. Naturally, due to the architecture of the chimney and the sun path the panels experiment a different temperature evolution. For all the results the last row of panels never receives solar energy which hampers the temperature evolution of the last row. During the winter season, both panel rows $7(1.25 \mathrm{~m})$ and $4(2.75$ $\mathrm{m})$ surpass the melting range of the PCM. Results suggest that every $1.5 \mathrm{~m}$ the temperature rises by $6{ }^{\circ} \mathrm{C}$. The maximum surface temperature of rows 7 and 4 are 55 and $61{ }^{\circ} \mathrm{C}$. The phase transformation can be particularly appreciated in the surface temperature denominated "back" which represents the sensor between the concrete surface and the back surface of the panel. The last row (1) attains 32.5 ${ }^{\circ} \mathrm{C}$, thus not carrying out said phase transformation.

Spring data is very similar to the winter data even though there is a $10{ }^{\circ} \mathrm{C}$ difference between the external temperature of both SC series (Figure 3.51a). Contrarily to the winter $\mathrm{SC}$ results, the temperature registered at $3.2 \mathrm{~m}$ of the concrete collector wall experiences a different temperature evolution than the rest of the chimney. This can be attributed to two main things: firstly the sun path not directly hitting the surface. Secondly but related as well, due to the south orientation of the chimney. The first three levels register a maximum temperature of $51{ }^{\circ} \mathrm{C}$ while the last sensor registers only $41{ }^{\circ} \mathrm{C}$. This effect is more impactful with the addition of PCM panels since some of the incident solar energy is used to heat the PCM panel (3.51b). Just as the winter the results, the sensor closest to the inlet encounters a temperature drop, however; this effect extends to the rest of the chimney for during the spring season. The temperature concrete wall temperature during season reaches only a maximum of $37.5^{\circ} \mathrm{C}$ and there exists an approximate $5{ }^{\circ} \mathrm{C}$ difference between each level. 
Finally, the summer results present the differences between the SC and the ASC Figures(3.52a and 3.52b). The temperature difference is between the levels is almost non-existent and reach a maximum of $40{ }^{\circ} \mathrm{C}$. The main distinction of the ASC results can be appreciated after 17:00h were the registered temperature is maintained until approximately 19:12h.

For the series of ASC data of winter, spring and summer, the PCM surface temperatures were also analysed and they are presented in Figures 3.53, 3.54 and 3.55. The energy storage and release can be clearly observed in the plateau of the back-surface temperature of the panel. This behaviour is the result of the panel reaching its activation range $\left(40\right.$ to $\left.44^{\circ} \mathrm{C}\right)$. It can also be noticed that once the temperature drops to $44^{\circ} \mathrm{C}$, the energy release maintains a semi steady temperature for approximately 2.4 hours. The aforementioned figures show that the highest PCM surface temperatures are experienced during the winter season. Again, this is due to the incident solar chimney on the solar chimney during this season and the orientation of the latter. In every case, first two sensored rows reach the fusion range however, the last row fails to rise in temperature for the reasons explained above. 


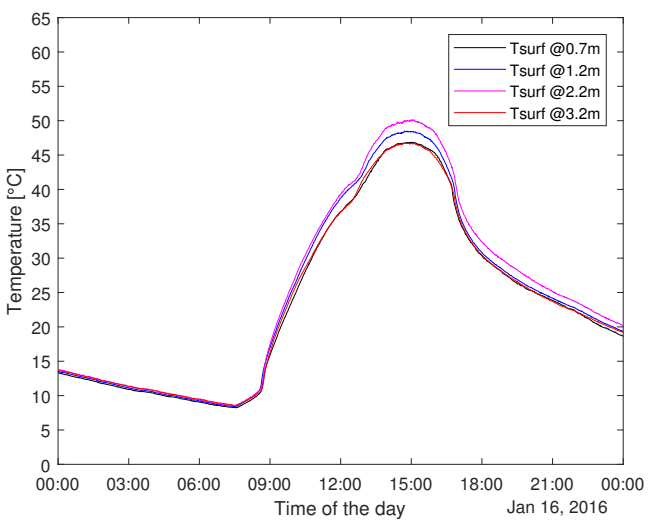

(a)

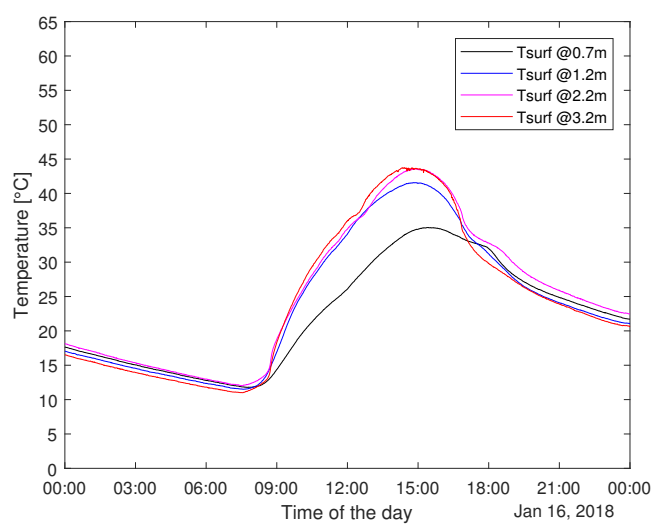

(b)

Figure 3.50: Surface temperature at the different levels during the spring period on (a) January 16th, 2016 and (b) January 16th, 2018

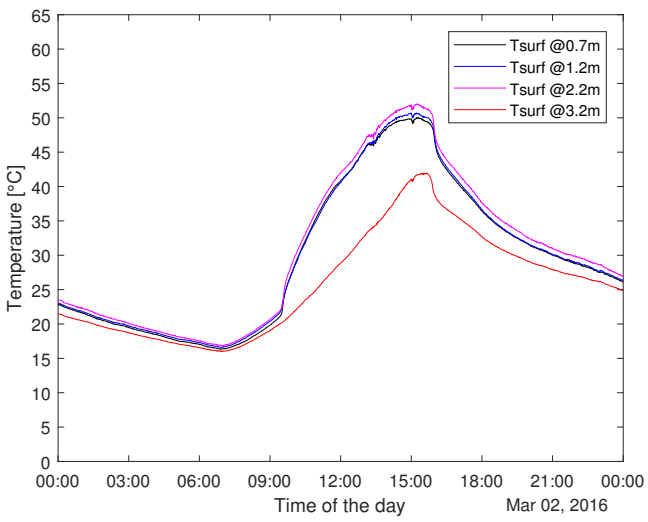

(a)

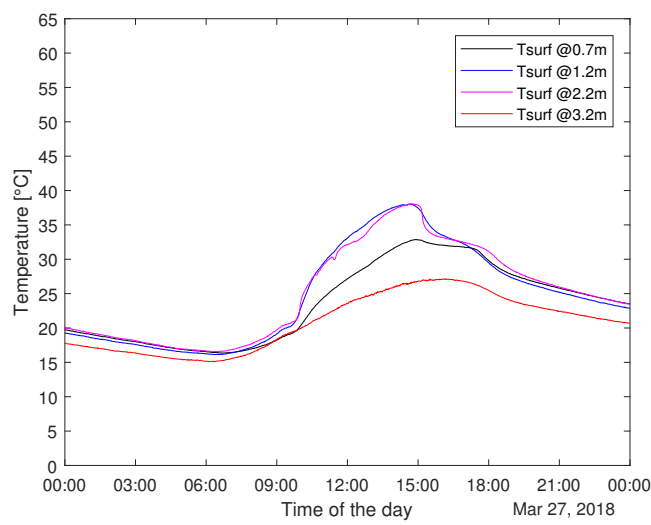

(b)

Figure 3.51: Surface temperature at the different levels during the spring period on (a) March 2nd, 2016 and (b) March 27th, 2018

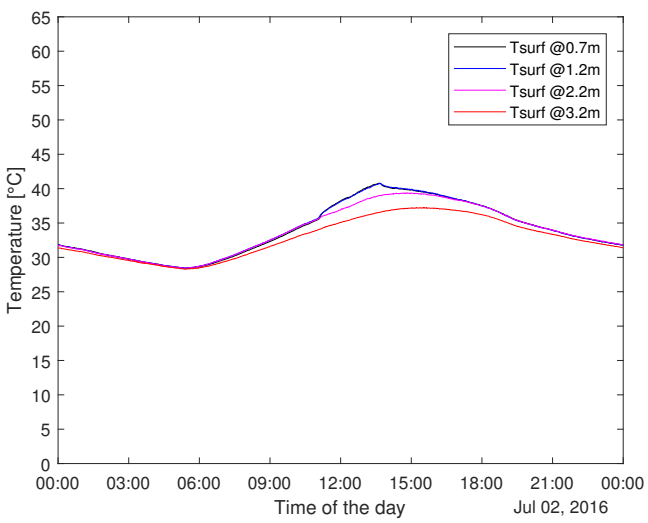

(a)

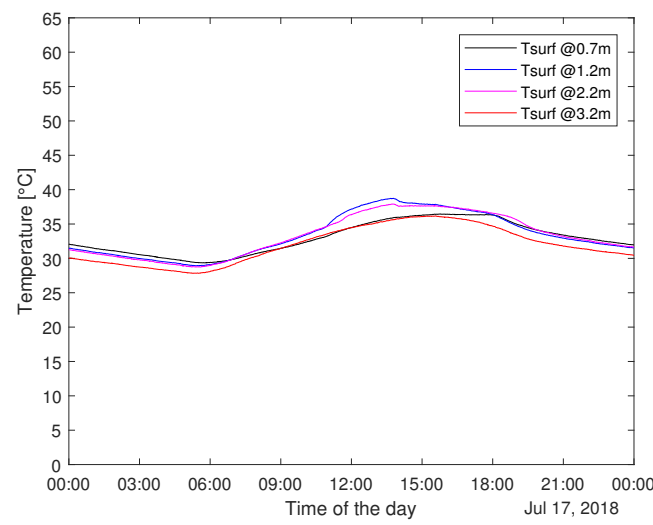

(b)

Figure 3.52: Surface temperature at the different levels during the Summer period on (a) July 2nd, 2016 and (b) July 17th, 2018. 


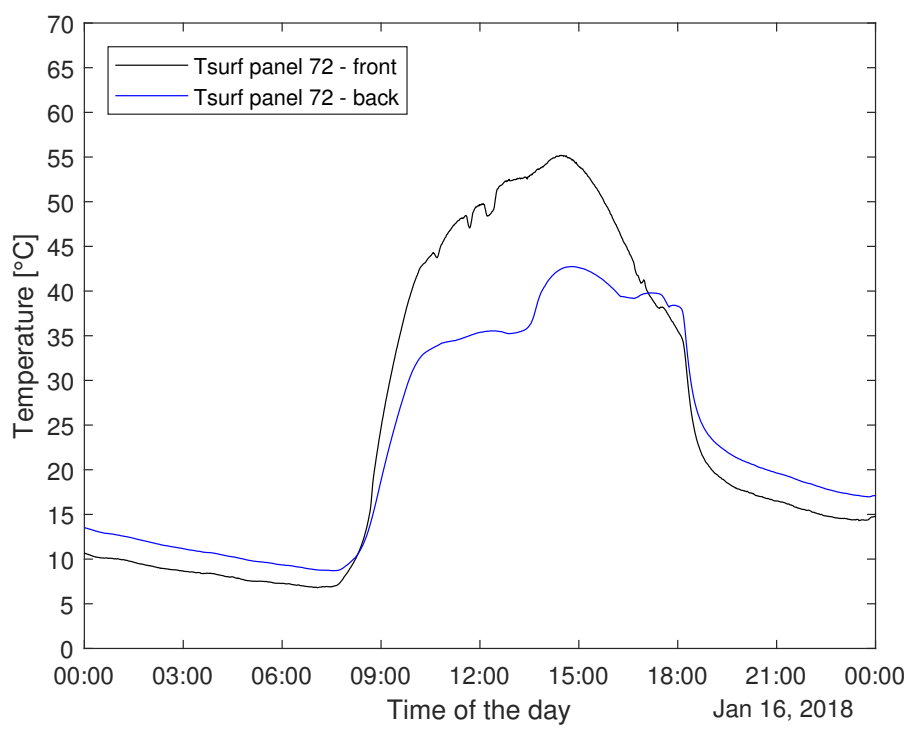

(a)

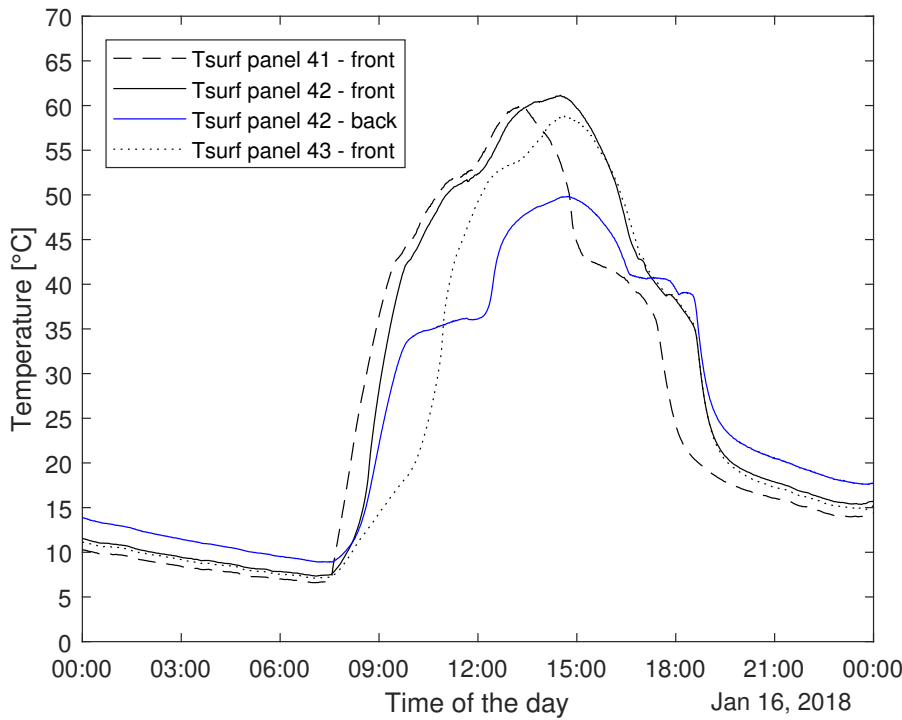

(b)

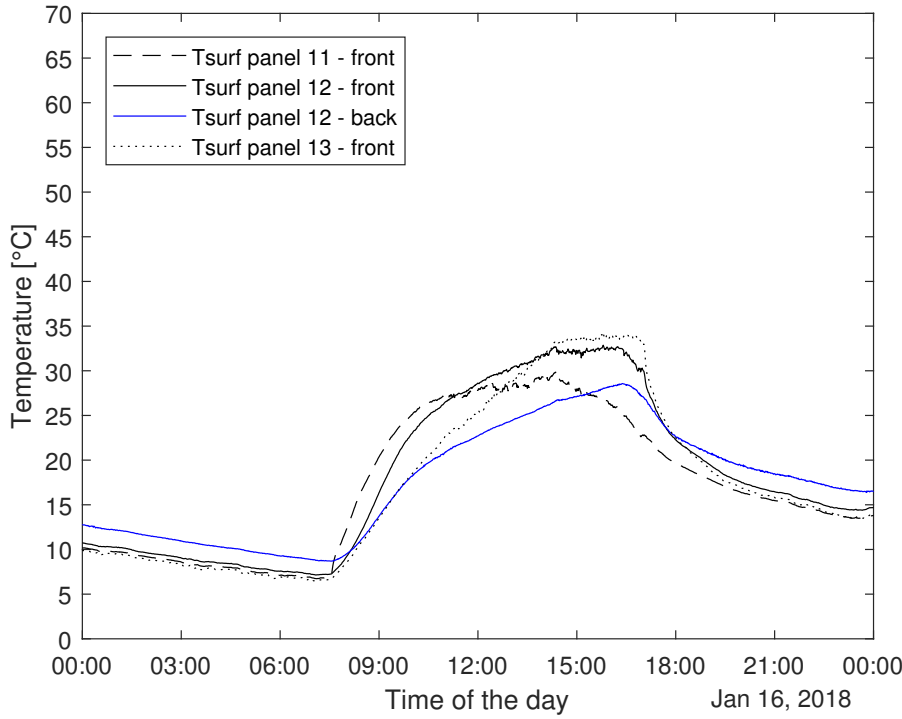

(c)

Figure 3.53: PCM surface temperature for rows (a) 7 (b) 4 and (c) 1 of January 16th, 2018 


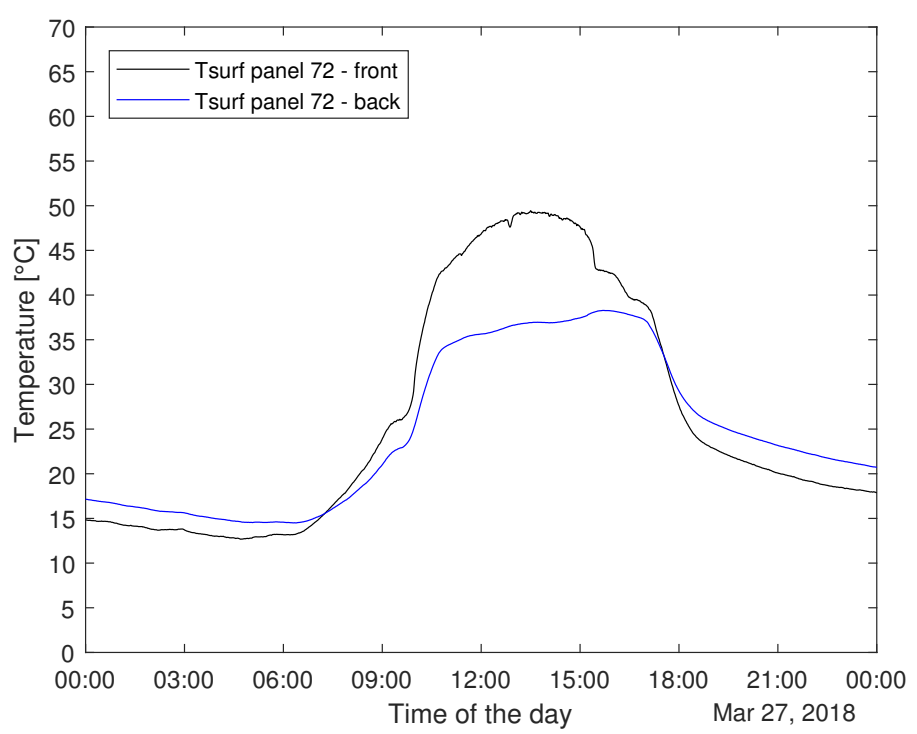

(a)

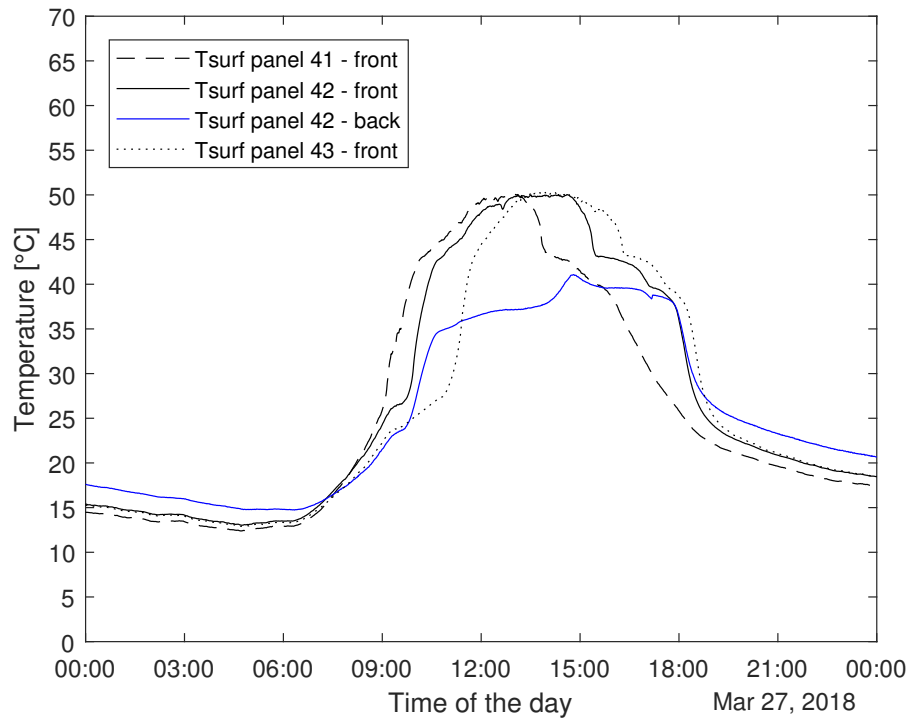

(b)

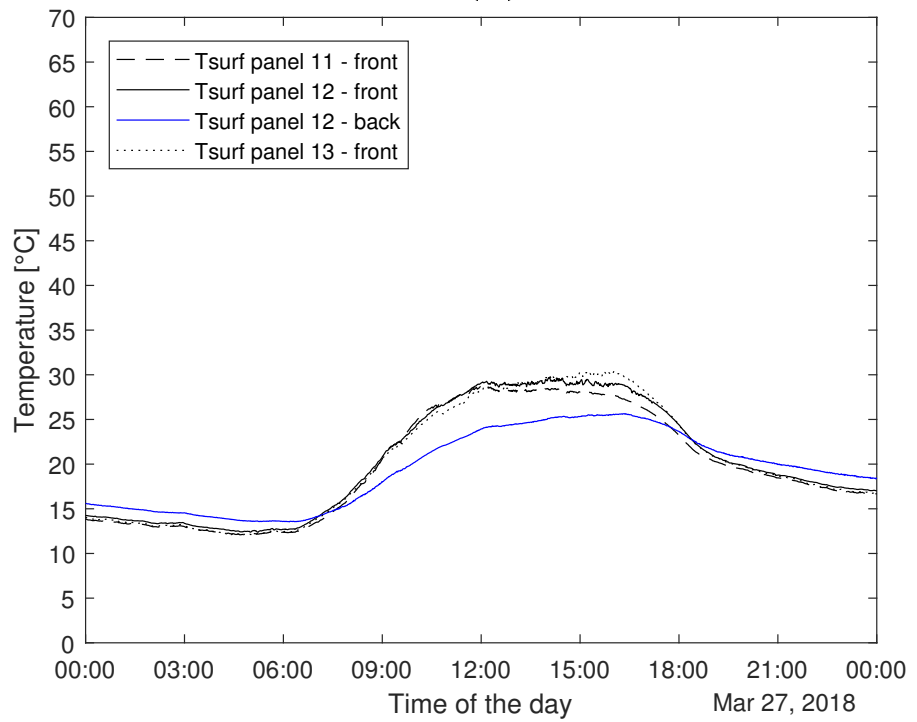

(c)

Figure 3.54: PCM surface temperature for rows (a) 7 (b) 4 and (c) 1 of March 27 th, 2018 


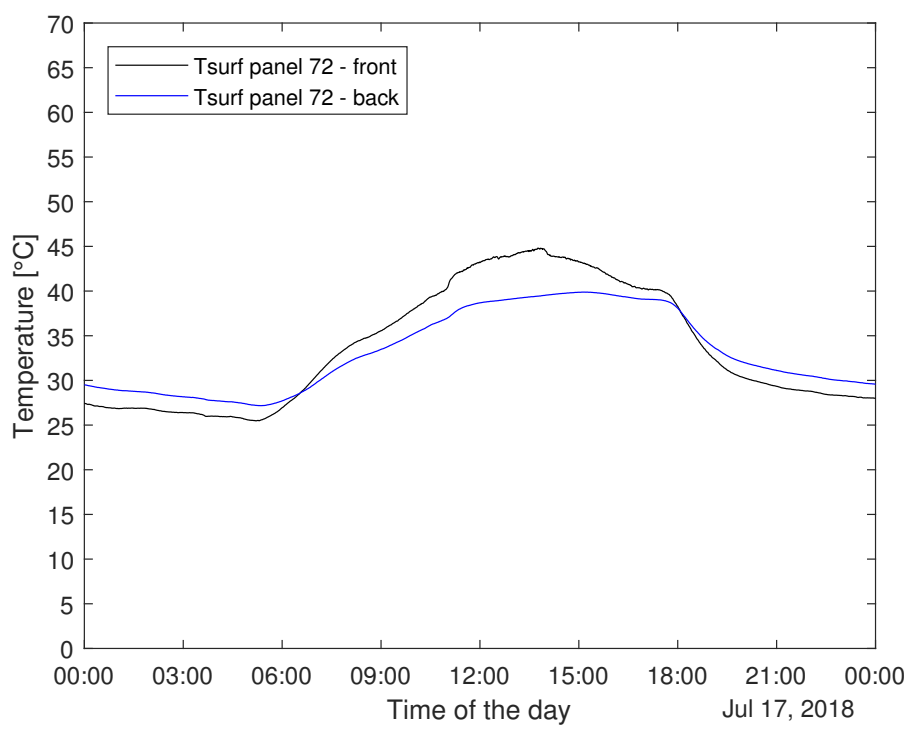

(a)

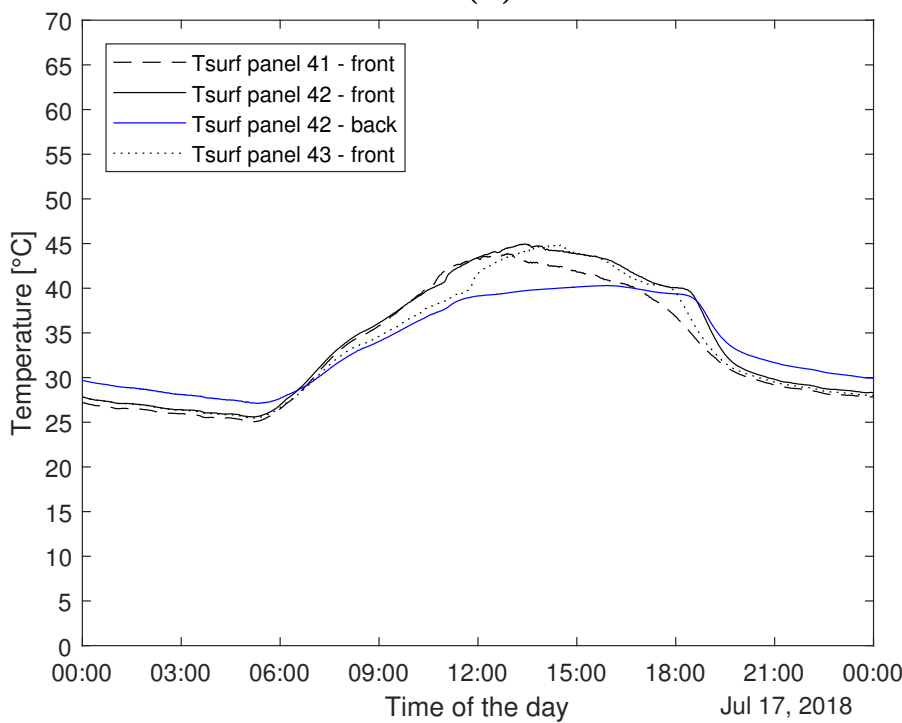

(b)

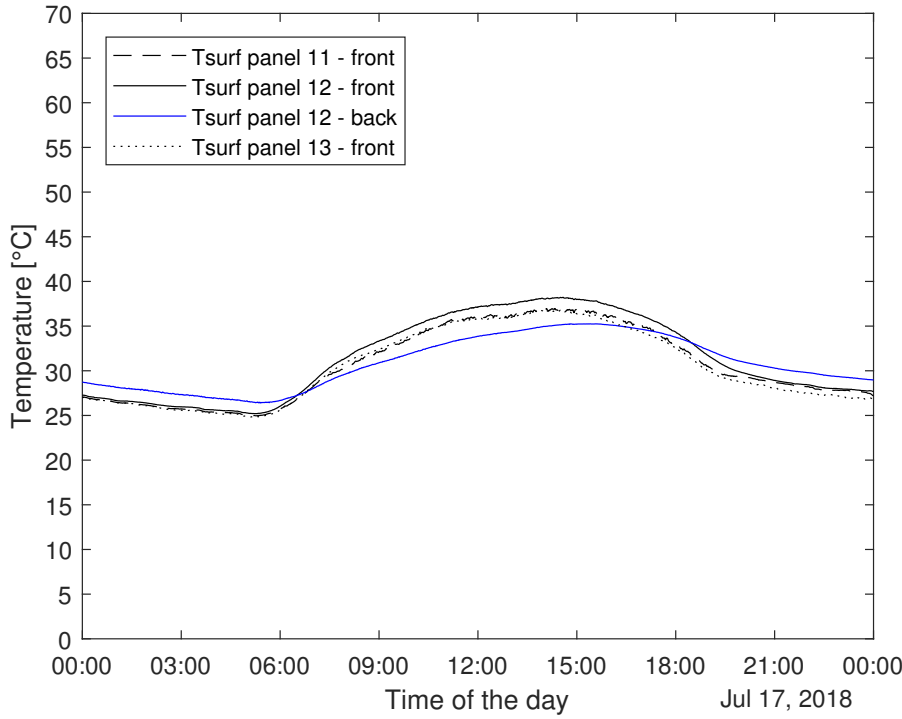

(c)

Figure 3.55: PCM surface temperature for rows (a) 7 (b) 4 and (c) 1 of July 17 th, 2018. 


\subsubsection{Chimney Air temperature}

When analysing a system such as the $\mathrm{SC}$, it is important to take into consideration the temperature difference between inlet and outlet and the temperature distribution across the height of the chimney. In the case of the PSA solar chimney, the external temperature and the inlet temperature are the same since the analysis is carried out in a stand-alone chimney. The results of each season for temperature distribution are presented in Figures 3.57 to 3.58 and temperature difference in Figures 3.60 to 3.61 .

As expected, winter results exhibit the greater temperature differences between external temperature and outlet temperature. For both SC and ASC results, the difference between the external temperature and the outlet temperature reaches an approximate peak value of $12.5^{\circ} \mathrm{C}$ and drops to $2{ }^{\circ} \mathrm{C}$ or below during night time. The effects of PCM can be slightly appreciated in in Figure 3.56b once the external temperature begins to decrease. In comparison with the results from 2016, the temperature difference does not drop abruptly as the sun starts to set. The PCM starts to release the stored energy once the panel reaches $44^{\circ} \mathrm{C}$. In comparison, the ASC maintains a higher temperature difference for the same period. In both cases, the temperature difference is negligible after 21:00.

The temperature difference reduces as the external temperature rises with each season. Summer results display the lowest temperature difference maintaining an average mean value of $2.5^{\circ} \mathrm{C}$ (Figure 3.58). This difference seems to be higher and more stable for the PCM results, however this could be the result of other environmental factors. Spring environmental data shows a drop in air temperature difference after 13:00h, however this could be explained by the higher wind speed condition registered during March 27th, 2018 (3.60b). In any case, the addition of PCM does not seem to affect negatively the performance of chimney.

As for the air temperature distribution, in every seasonal case, both results behave in a similar fashion regardless of the addition of PCM panels. 


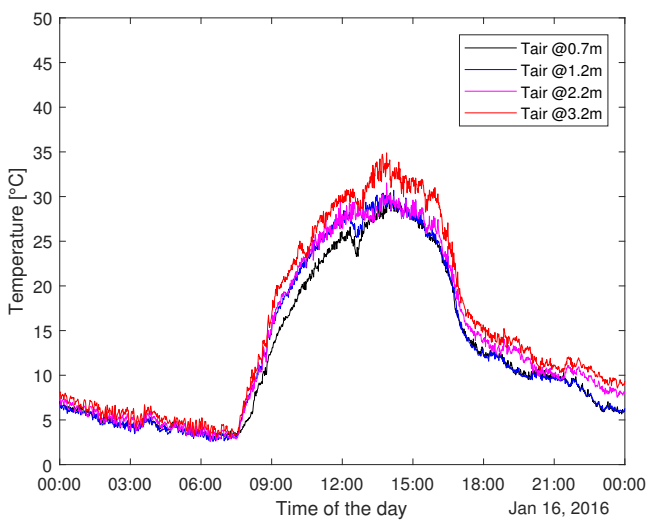

(a)

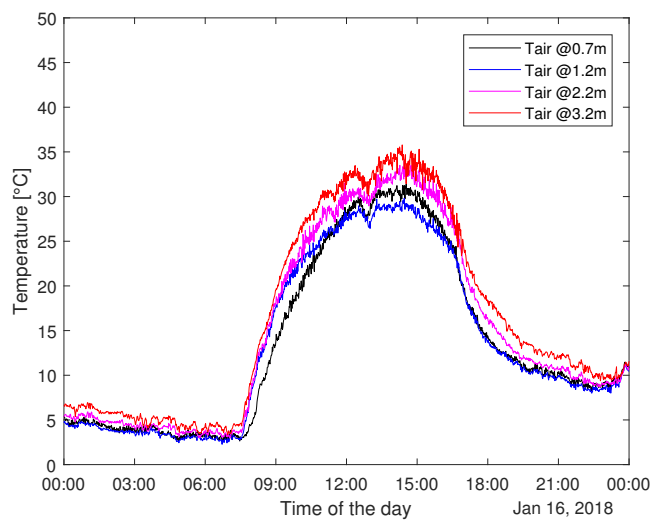

(b)

Figure 3.56: Air temperature for at different heights during (a) January 16th, 2016 and (b) January 16th, 2018.

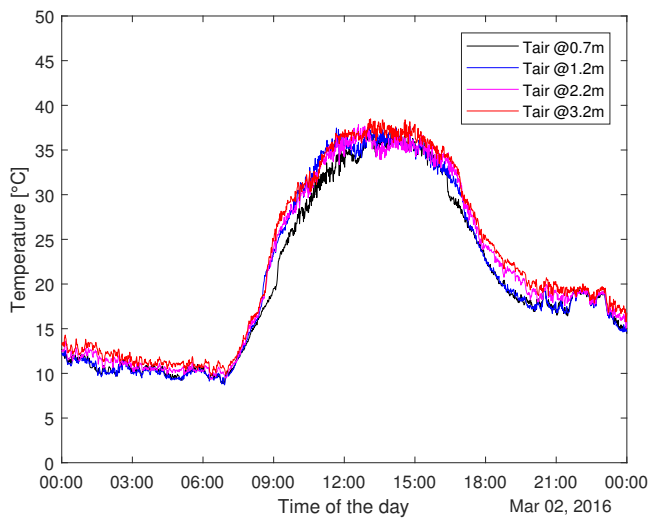

(a)

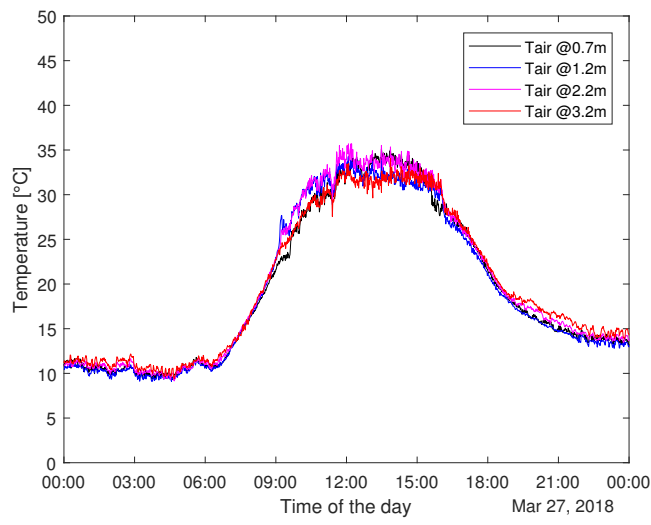

(b)

Figure 3.57: Air temperature for at different heights during (a) March 2nd, 2016 and (b) March 27th, 2018.

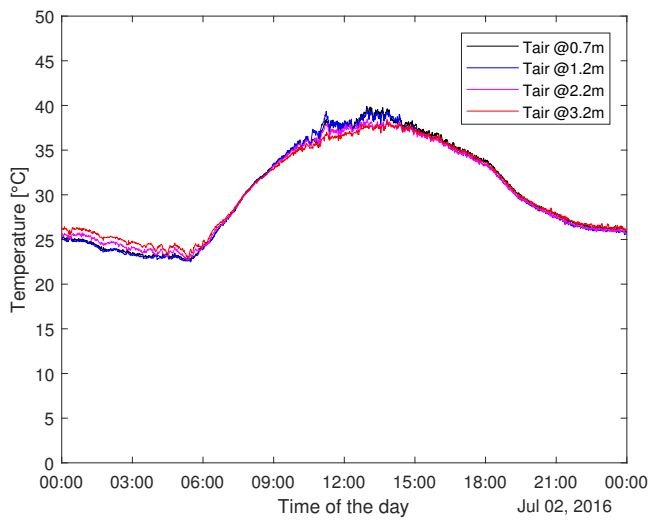

(a)

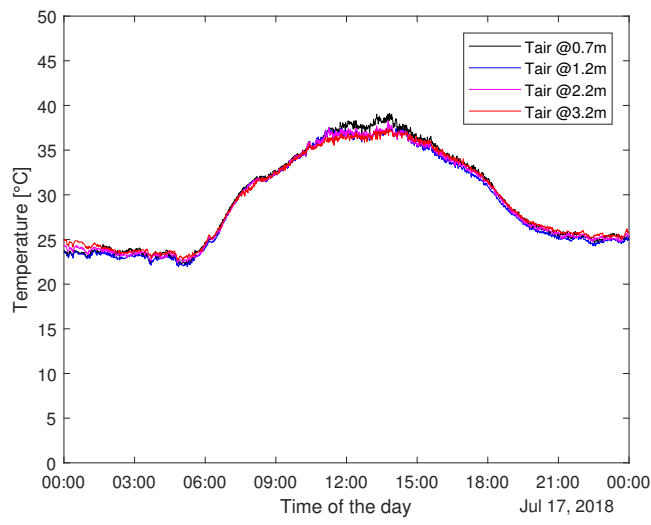

(b)

Figure 3.58: Air temperature for at different heights during (a) July 2nd, 2016 and (b) July 17th, 2018. 


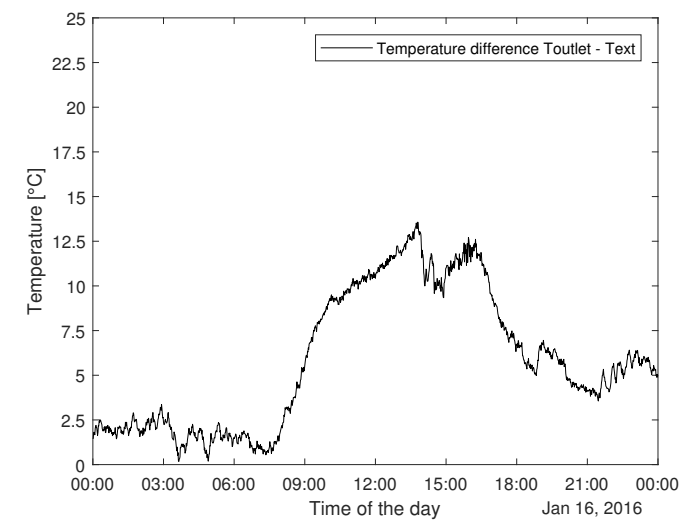

(a)

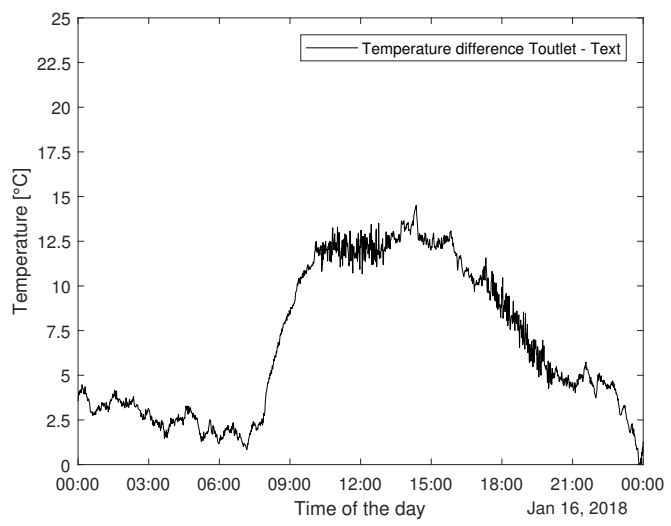

(b)

Figure 3.59: Air temperature difference between external temperature and outlet temperature during (a) January 16th, 2016 and (b) January 16th, 2018.

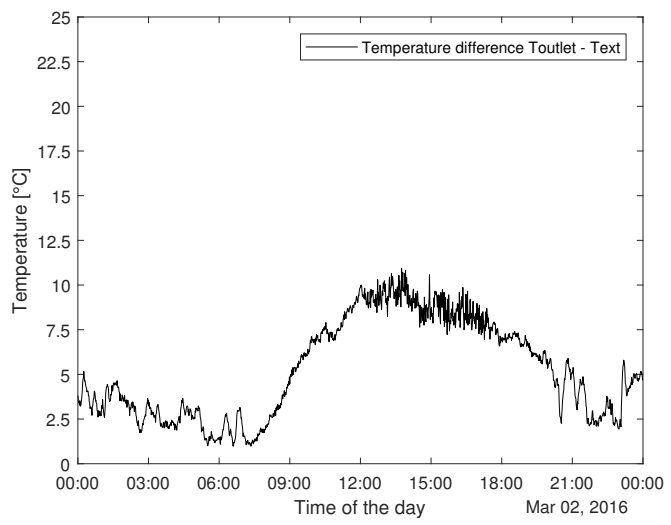

(a)

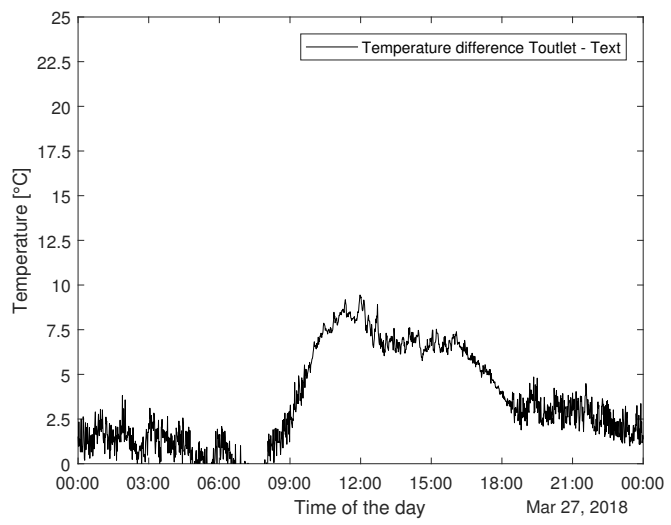

(b)

Figure 3.60: Air temperature difference between external temperature and outlet temperature during (a) March 2nd, 2016 and (b) March 27th, 2018.

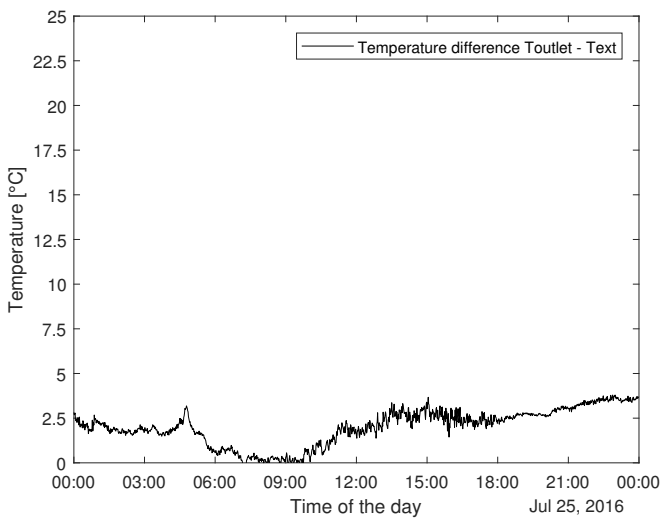

(a)

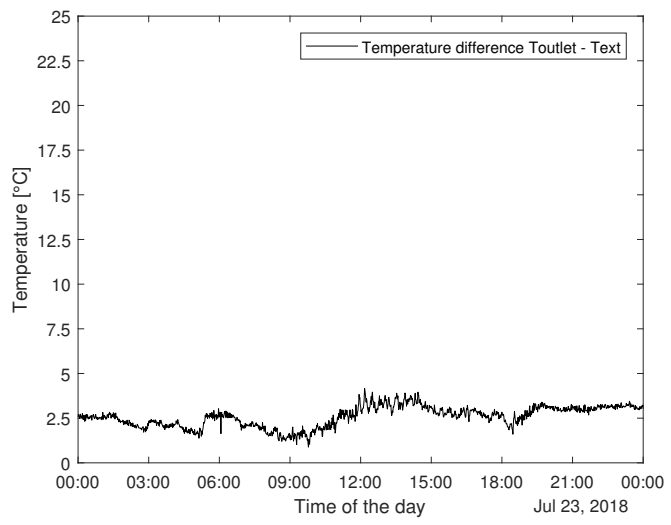

(b)

Figure 3.61: Air temperature difference between external temperature and outlet temperature during (a) July 2nd, 2016 and (b) July 17th, 2018. 


\subsubsection{Outlet Mass Flow Rate and Wind Speed}

Mass flow rate was analysed under low wind speed conditions for each set of data however, the presence of wind and its effects on the performance of the solar chimney are always present and non negligible. Figures 3.62 to 3.64 display the results of the stand alone solar chimney with and without PCM panels.

The mass flow rate was analysed during the entirety of the day, as well as after sundown. For each season, this moment of the day is different. The sundown hours for each season are 16:45h for winter, 18:00h for spring and 19:12h for summer. This results are displayed in Tables 3.8 and 3.9. Starting with the winter data, the mass flow rate of the ASC seems to have a decrease of $16.3301 \mathrm{~m}^{3} / \mathrm{h}$ for the overall sampled data with the integration of PCM panels and a decrease of $19.6845 \mathrm{~m}^{3} / \mathrm{h}$; however, this could be due to the higher mean wind speeds registered for the 2016 data. In the same way spring results display a higher air flow rate for the SC than that of the ASC but the chimney was subjected as well to a slightly higher wind speed. This is further supported by the summer season results where the mass flow rate is significantly higher for the ASC (difference of $37.538 \mathrm{~m}^{3} / \mathrm{h}$ ), under greater wind speeds $(4.0964 \mathrm{~m} / \mathrm{s})$. The differences in outlet air flow rate for the spring season is $11.7878 \mathrm{~m}^{3} / \mathrm{h}$ across the selected dates. When considering exclusively the mean mass flow rate after sundown, this value becomes $20.8134 \mathrm{~m}^{3} / \mathrm{h}$, where the greater results correspond to the 2016 data. It may seem that the SC displays a higher performance than the ASC but this may be biased by the higher wind speed.

The difference in performance regarding the outlet airflow rate between the solar chimney with and without PCM panels seems to be very similar. The addition of PCM panels seems the maintain air flow across the chimney. The slight decrease can be attributed to two main reasons. The first one, wind speed, was established before, the second one relates to the temperature distribution discussed in section 3.4.4.1. Indeed, the chimney experiences an important temperature drop near the outlet. The results show that temperature can decrease up to $30{ }^{\circ} \mathrm{C}$ in the last row of panels, which indicates that a part of the energy is being used to increase the panel temperature, thus hampering the exiting air flow. 
Table 3.8: Outlet airflow mean values for each seasonal data for the whole day and after sundown $(16: 45 \mathrm{~h})$ in $\left[\mathrm{m}^{3} / \mathrm{h}\right]$.

\begin{tabular}{|c|cc|cc|}
\hline & \multicolumn{2}{|c|}{ SC Data } & \multicolumn{2}{c|}{ ASC Data } \\
\hline & Overall & $\begin{array}{c}\text { After } \\
\text { Sundown }\end{array}$ & Overall & $\begin{array}{c}\text { After } \\
\text { Sundown }\end{array}$ \\
\hline Winter Data & 112.2879 & 109.6182 & 95.9578 & 89.9337 \\
Spring Data & 111.6576 & 121.2797 & 99.8698 & 80.1493 \\
Summer Data & 127.8526 & 135.0746 & 165.3906 & 105,9650 \\
\hline \hline
\end{tabular}

Table 3.9: Wind speed mean values for each seasonal data for the whole day and after sundown $(16: 45 \mathrm{~h})$ in $[\mathrm{m} / \mathrm{s}]$.

\begin{tabular}{|c|cc|cc|}
\hline & \multicolumn{2}{|c|}{ SC Data } & \multicolumn{2}{c|}{ ASC Data } \\
& Overall & $\begin{array}{c}\text { After } \\
\text { Sundown }\end{array}$ & Overall & $\begin{array}{c}\text { After } \\
\text { Sundown }\end{array}$ \\
\hline Winter Data & 1.9978 & 2.0127 & 1.8616 & 1.5712 \\
Spring Data & 2.4688 & 2.2760 & 3.2418 & 1.8758 \\
Summer Data & 3.4224 & 3.9808 & 4.0964 & 2.9564 \\
\hline \hline
\end{tabular}




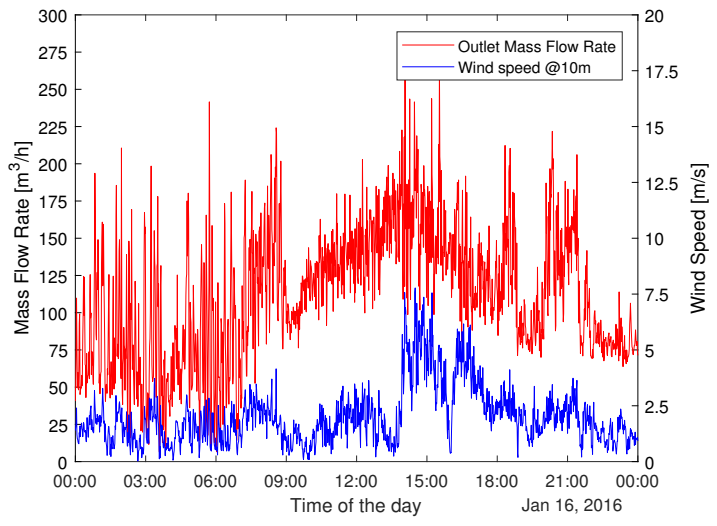

(a)

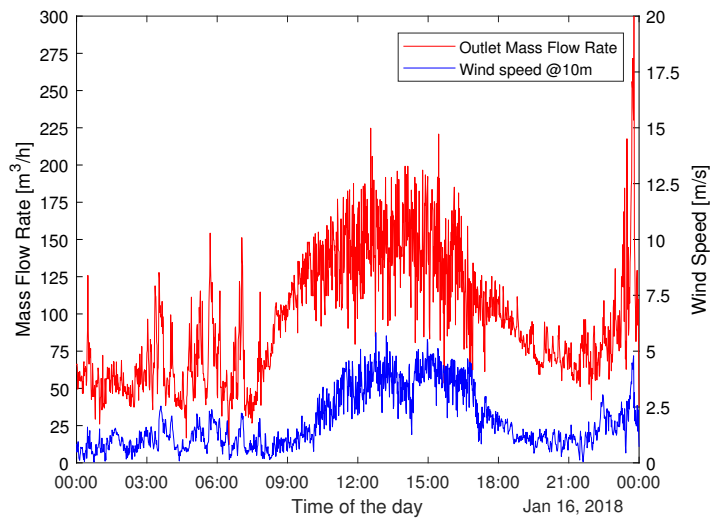

(b)

Figure 3.62: Outlet air flow rate and wind speed during (a) January 16th, 2016 and (b) January 16th, 2018.

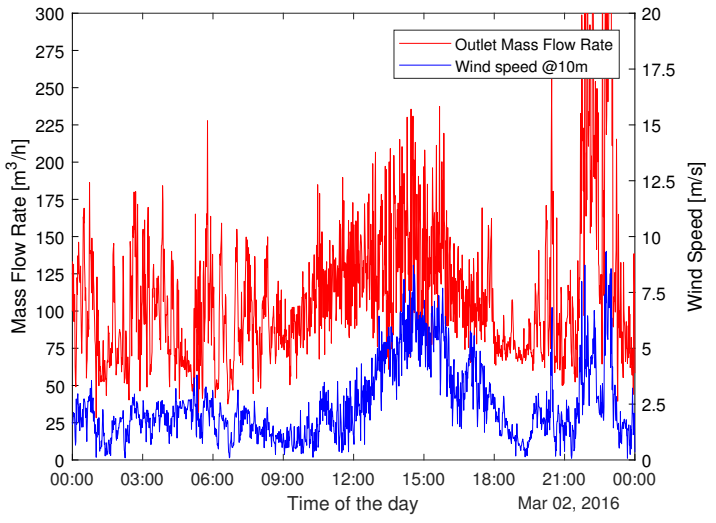

(a)

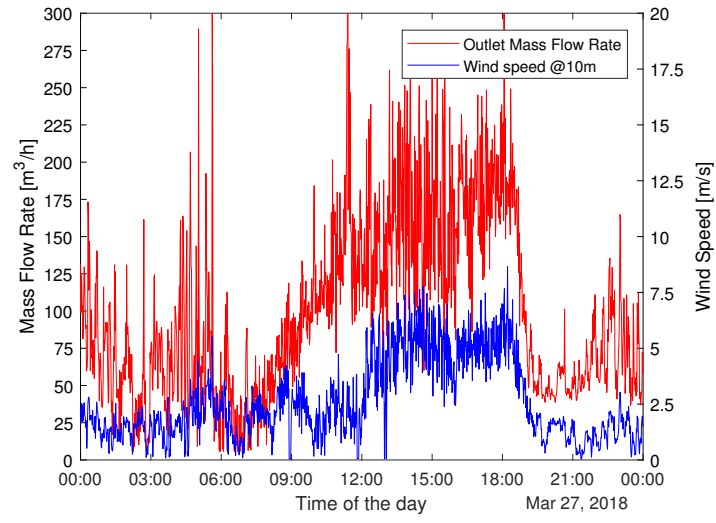

(b)

Figure 3.63: Outlet air flow rate and wind speed during (a) March 2nd, 2016 and (b) March 27th, 2018.

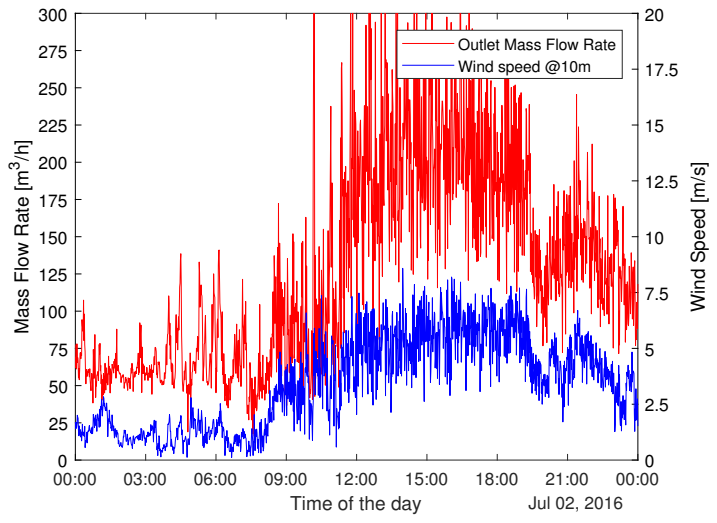

(a)

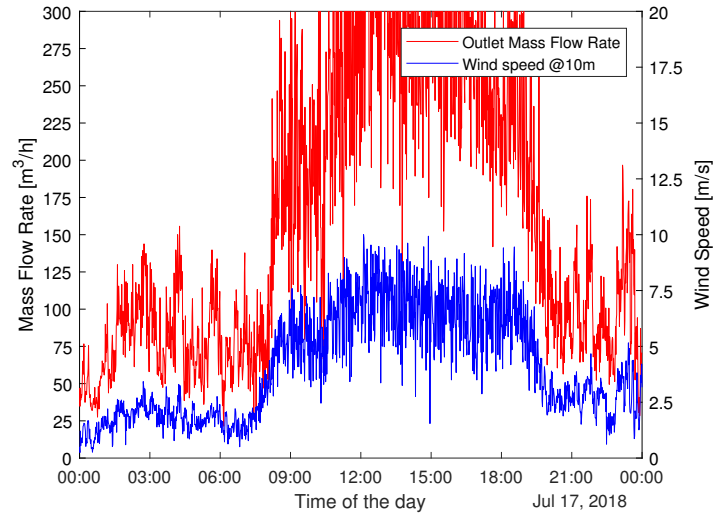

(b)

Figure 3.64: Outlet air flow rate and wind speed during (a) July 2nd, 2016 and (b) July 17th, 2018. 


\subsection{General Conclusion}

The assessment of the Rubitherm RT44 PCM panels was carried out under laboratory and in-situ conditions and review in this chapter. Laboratory results yielded promising results, demonstrating the thermal potential of the system and enhancing the ventilation of the system in the absence of a heat source. It was demonstrated that the performance of the system is highly dependent on the thermal properties of the walls of the chimney. Naturally a better insulation hampers the heat loss with the exterior. It is clear that by setting a lower temperature at the inlet compared to the external temperature, the system behaves in a similar fashion than the non-PCM version. This can be attributed to the temperature differential produced by the halogen lamps, however when the system is directly subjected to the external temperature, the influence of the PCM panels is more apparent.

The laboratory results of the SCV1 showed the interest of the phase change materials integrated into the solar chimney to improve the average ventilation rate when the prototype is in the presence of a heat source, and a progressive decrease in the absence of this. These results were obtained despite the incomplete fusion of the material within the panels, which suggests better performance when the complete phase change is achieved. The PCM panels work as expected, absorbing available energy during each charging phase and releasing once the source is withdrawn. In general, the results with phase change materials show a higher average flow rate in all phases of the experiment. It is important to mention that these results are achieved despite the incomplete fusion of the materials which means an increase in performance at higher temperatures for a simple build solar chimney with a low thermal inertia. The results of the first prototype are an example of the potential of PCMs as separate component.

The major difference between the exit airflow is observed for the SCV1 results. The results demonstrate that the incomplete fusion of the PCM panels make the 
system perform without any improvements. The main difference is found during the ventilation only phases (4 and 7 ) when the thermal inertia of the PCMs slightly increase the airflow from $15.59 \mathrm{~m}^{3} / \mathrm{h}$ and $18.92 \mathrm{~m}^{3} / \mathrm{h}$ to $17.25 \mathrm{~m}^{3} / \mathrm{h}$ and 26.64 $\mathrm{m}^{3} / \mathrm{h}$. Once the temperature increases and allows the fusion of the PCM panels, the PCM integrated prototype V1.0 outperforms its counterpart by $246.66 \%$ during phase 3 and display a mean ventilation rate of $110.04 \mathrm{~m}^{3} / \mathrm{h}$ and $122.39 \mathrm{~m}^{3} / \mathrm{h}$ during phases 4 and 7 where the non PCM version has a near $0 \mathrm{~m}^{3} / \mathrm{h}$ airflow. Similarly, the results SCV2 display an approximate airflow increase of $365 \%$ during phase 3 when the system is not properly insulated and the chimney suffers a great heat loss. Once the heat loss is limited through the addition of insulation, both NoPCM and PCM cycles reach similar peaks and behaviours during phase 3 and the airflow difference is appreciated during ventilation only phases. Phase 4 seems to behave in a very similar manner however, phase 7 always displays a higher ventilation rate. When setting an inlet temperature, due to the incomplete fusion of all the PCM panels, the system only experiences an increase from $43.03 \mathrm{~m}^{3} / \mathrm{h}$ to $53.51 \mathrm{~m}^{3} / \mathrm{h}$. On the other hand, when subjected to external conditions, the system exhibits the greatest performance increase going from $60.82 \mathrm{~m}^{3} / \mathrm{h}$ to $34.93 \mathrm{~m}^{3} / \mathrm{h}$.

Overall, PCMs exhibit a greater performance compared to NoPCM cycles, even during tests which do not reach the fusion range. The consistency in performance of PCM cycles suggest that the addition of PCM panels has no negative impact on the system and can improve according to external conditions, mainly higher irradiance and higher external temperatures. The series of temperature and mass flow rate results are obtained with a maximum incoming heat flux of $600 \mathrm{~W} / \mathrm{m}^{2}$. Several works demonstrate the typical weather conditions of countries such as Mexico and Spain (Arce et al., 2015; Matsumoto et al., 2014) where the incoming solar radiation can reach higher peaks than the ones simulated in these experimental campaigns. Higher radiation can lead to higher surface temperatures and higher air temperatures which would aid the whole group panels to achieve a full phase transformation. Overall the results of both the SCV1 and the SCV2 exhibit a greater thermal performance of the PCM integrated solar chimney. Indeed the temperature peaks might not reach the same highs but they maintain a stable high 
temperature across the experimental cycle.

The temperature difference achieved with the solar chimney as well as the consistent results throughout the experimental campaigns, suggests that the system has a great potential to use the heated air inside the chimney to be recirculated in order to reduce heating loads in a building. No air quality study was carried out during the experimental campaigns, however, the air inside of the chimney can be classified as class 2 according to the ASHRAE standard 62.1 (ASHRAE, 2010), where the air contains a moderate amount of contaminants, a mild sensory-irritation intensity or mildly offensive odours. This type of air is is not necessarily harmful but since the chimney does not receive constant maintenance, dust and other particles could be found in the air. Nevertheless, the temperature potential could be coupled with other systems.

The laboratory results presented in this section indicate the following:

1. The system's overall performance is highly dependent on the thermal characteristics of the chimney walls. Indeed, heat loss can reduce not only surface temperatures, but airflow for NoPCM and PCM cycles. The influence of the construction materials on the solar chimney's performance cannot be neglected.

2. The addition of PCM panels gives consistency to the system despite the operating conditions. PCM panels provide thermal inertia, and the additional layer avoids heat loss across the chimney.

3. PCMs provide ventilation throughout the 6 hours of ventilation only phases after the panels have been charged. This period is limited due to the nature of the experimental protocol, however, it could be extended according to the external conditions, or through the extension of ventilation phases.

The performance of a phase change material integrated a solar chimney was evaluated under normal environmental conditions has a similar ventilation performance than that of the regular solar chimney. Even though on-site results did not yield significant results in terms of flow, several conclusions can be drawn: the $0.15 \mathrm{~m}$ concrete wall (painted black for a better absorption of solar heat) clearly 
influences the behaviour of the chimney and provides a good thermal inertia to the system. This inertia is significant enough to generate results similar to those of the solar chimney integrated with phase change material. It was noted that the concrete wall has a limited heating capacity after sunset against the phase change material panels. In addition, the energy of the phase change material panel can be wasted by heating the concrete wall instead of being exploited to create a higher temperature difference in the conduit, which reduces the impact of the exchange material panels phase.

It is important to mention that from the first row to the mid-level panels, up to a $3 \mathrm{~m}$ height, behave as expected and reach the necessary operating temperature range, however; the last row of panels does not reach $40{ }^{\circ} \mathrm{C}$. As this section of the chimney experiences a temperature drop, it may affect the overall ventilation rate and may particularly affect utilization after sunset. These lower temperatures are explained by the lack of incident solar energy. Indeed, due to the geometry of the chimney, the last row of panels has no direct sunlight. This temperature drop could be potentially limiting the overall performance of the ASC.

In addition, the distribution of air temperature through the chimney is not affected by the addition of panels of phase change material; however, the results suggest that the concrete wall with panels of phase change material could be reduced in size or changed completely, thus simplifying the construction and the dimensions of the system. The lack of a more important ventilation rate could be due to the temperature drop at the outlet level of the chimney and should be analysed in further studies as well. Overall, the rotative exhaust of the PSA solar chimney as well as the wind speed seem to have a greater impact on the ventilation performance.

The results demonstrate that the exhaust outlet of the PSA solar chimney, creates a high enough pressure drop to increase the ventilation rate above 200 $\mathrm{m}^{3} / \mathrm{h}$ depending on the wind speed magnitude is higher than $6 \mathrm{~m} / \mathrm{s}$. Finally, the results suggest that the in-situ ASC does not negatively impact the solar chimney's performance but can help reach higher ventilation rates due to the higher thermal 
performance.

The in-situ results, although inconclusive, evidence a number of factors. The wind and the exhaust chosen for the chimney have a greater influence on the airflow than the addition of the PCM panels. The continuous monitoring of the chimney performance displays a greater air flow rate under higher wind speeds. This results are in accordance with the results presented by Arce et al. (2015). Indeed the rotative exhaust creates a large enough pressure differential to induce a flow of air. It is clear that the sun path and incident solar energy also have a greater influence on the solar chimney integrated with PCM panels than the classic version. The lack of incident solar energy on the last row of panels creates a temperature drop at the outlet of the chimney. This problem affects specially the ASC since the panels lose heat while transferring energy to the concrete wall behind.

Overall both experimental campaigns help determine the following conclusions:

1. The addition of PCM panels do not hamper the overall performance of the system, however it can lead to a higher mass flow rate and a more stable temperature distribution across the chimney. This higher mean temperatures can be used for recirculation purposes during colder seasons. An analysis of the quality of this recirculated air must be carried out if it is to be used for indoor re-purposes.

2. The architecture of the chimney seems to require a number of adaptations in order to fully capitalize the implementation of PCM panels. Primarily, the chimney must ensure that all the panels receive incident solar energy either by the modification of the walls of the chimney, or by the rotation of the full system. Secondly, the $0.15 \mathrm{~m}$ concrete collector wall seems to be modifying the performance of the in-situ results due to the high thermal inertia it provides. Future works should aim to modify this element or add an insulation layer between the panels and the wall in order to reduce its impact. It was demonstrated that a simple-build solar chimney can provide a constant air flow rate above $75 \mathrm{~m}^{3} / \mathrm{h}$ with low relative incident energy of $600 \mathrm{~W} / \mathrm{m}^{2}$. Since the countries involved in this work have a greater irradiance, it can be 
concluded that this value can reach higher peaks with the addition of wind speed.

3. In order to conclude on the effects of the PCM integrated solar chimney, further analysis on the exhaust need to be carried out. Wind speed has been proven to have a great influence on the PSA solar chimney, however this could be due to the rotative exhaust employed to create a greater pressure differential. A parametric study of these variables must be performed in order to find the most impactful element. 
Chapter 4

Numerical Model for an Active Solar

Chimney Simulation: Development,

Verification, Validation and Analysis 


\subsection{Introduction}

Solar chimneys have been demonstrated to be a suitable technology for the reduction of energetic consumption and green-house gas emissions (Khedari et al., 2000, 2003; Kuwabara et al., 2011; Miyazaki et al., 2006). The previous chapters analysed the capabilities of Phase Changing Materials and the potential in the building sector. In order to leverage the capabilities of an ASC, it is fundamental to analyse the system coupled with PCMs. This chapter is dedicated to the development of a numerical model capable of predicting the behaviour of such technology when coupled to the non-linear nature of PCMs. In this chapter, the numerical model will be assessed against the experimental results obtained.

The model is constituted of four coupled sub-models which complement each other through the calculation of different variables. The first sub-model has been developed in order to predict the heat transfer through a multilayered wall, constituted of a determined number of layers of construction materials and a temperature-dependant layer of Phase Changing Materials. The heat transfer model is coupled to an air flow pressure code model using the ping pong principle. The pressure code determines the pressure distribution across the length of the chimney and allows the calculation of the inlet and outlet mass flow rates. Finally, information is relayed to the convection sub-model which calculates the convective exchanges present in the air gap and subsequently help to recalculate the temperature distribution across the solar chimney. The logical approach employed can be observed in Figure 4.9 in section 4.6. 


\subsection{Application of the Finite Difference Method for a Multilayered wall}

The heat transfer model presented in this section is executed through the discretization of a multilayered wall. The sub-model only considers unidirectional heat transfer. Exchanges along the stack height of the chimney are neglected on account of the vertical discretization employed for the pressure code presented in section 4.4. The characteristics of this wall are employed both during the experimentation and the simulation. The model calculates the spatial time steps through the definition of the thickness of the layer and the size of the discretization. The discretization can be modified to have a more refined representation the temperature evolution across a certain layer. For a wall with $N$ nodes, the following convention is adopted:

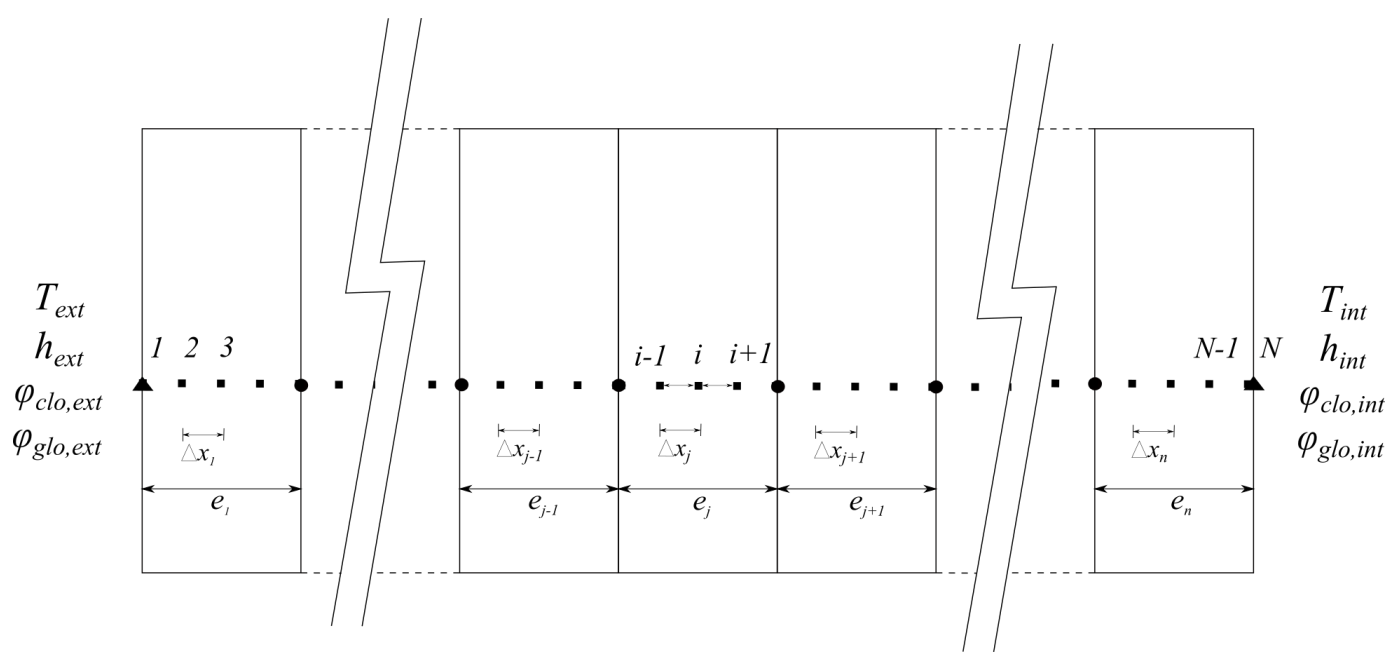

Figure 4.1: Spatial discretization of a $n$ layer multilayered wall

1. Subindex 1 is attributed to the node in contact with the environment.

2. Subindex $i$ is attributed to the current node within the material.

3. Subindex $N$ is attributed to the node in contact with the internal channel of the chimney.

4. Subindex $j$ relates to the wall layer.

5. Subindex $n$ is attributed to the layer in contact with the internal channel of 
the chimney.

6. e represents the thickness of the layer.

7. $\Delta x$ represents the spatial discretization size.

Different methods are available for the calculation of heat transfer across a wall. Among the different numeric schemes employed throughout the literature, explicit are the most common (El Mankibi et al. (2006); Farid et al. (2004); Naraghi and Blanchard (2015); Paksoy (2007); Tan and Wong (2014) to name a few) due to the low computational power required compared to other methods. Explicit solutions for a single node at a time $t+\Delta t$, are the product of a single equation containing the information of neighbouring nodes at the current time step (Figure 4.2a). Explicit Schemes are an easier programming alternative, however, they must meet a stability condition to avoid divergence from the solution. Time steps in explicit methods tend to be small. The stability condition of explicit methods is calculated with the following equation:

$$
\frac{\Delta t \lambda}{\Delta x^{2} \rho C_{p}} \leq \frac{1}{2}
$$

On the other hand, the implicit difference method solution is obtained through a simultaneous system of equations from the neighbouring nodes at each time step. This type of finite difference method, evaluates the spatial derivatives at a new time step, which means that the system's future state is calculated taking into consideration the system status at times $t$ and $t+\Delta t$ (Figure 4.2b). Implicit schemes tend to be more computationally costly due to the size of the matrix system and the algorithms used to convey a solution, however, they are unconditionally numerically stable even at greater time steps. The Crank-Nicholson method is a type of implicit scheme which consists in calculating the mean value by a quadrature formula of a certain node. The resolution is carried out through a trapezoidal rule which is technique for approximating a definite integral. The method consists relies on the supposition of a function between two existing nodes 4.2c. Mathematically, the Crank-Nicholson scheme is described as follows:

$$
\frac{1}{\Delta t}\left(u^{t+1}-u^{t}\right)=\frac{1}{2}\left[f\left(u^{t}\right)+f\left(u^{t+1}\right)\right]
$$

This scheme was preferred over the other alternatives for two main reasons. The 
numerical simulation and the experimental set-up are analysed over long duration (generally longer than a day). The analysis of the system in very small time steps is not suitable due to the long simulation times related to it. The second reason is associated with the PCM nature. Indeed, the Crank-Nicholson scheme allows for the definition of the PCM temperature according to the current and future states, as well as the neighbouring nodes, which translates to a better characterization of the PCM during the simulation.

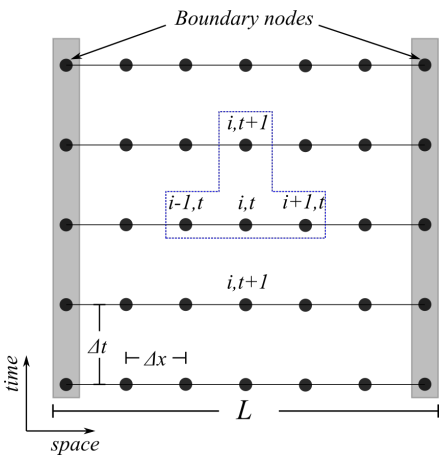

(a)

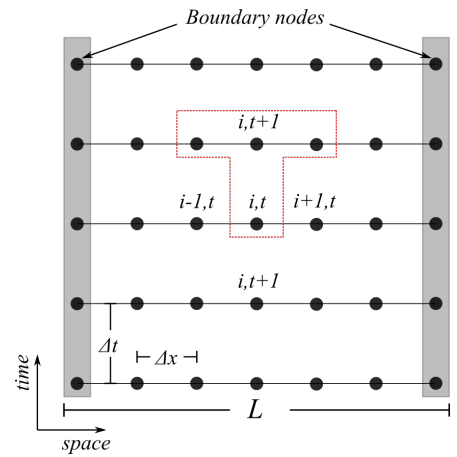

(b)

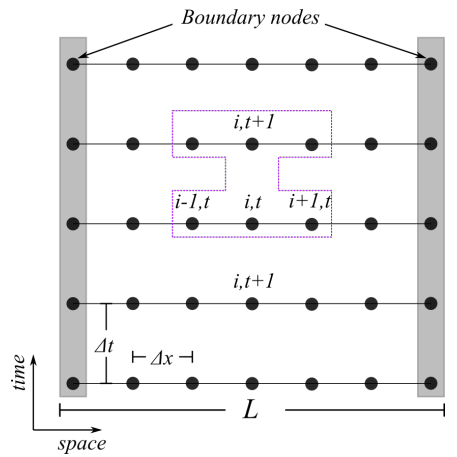

(c)

Figure 4.2: Schematic representation of a forward difference time $t$ and a second-order central difference for the space derivative at position $x_{i}$ of (a) an explicit scheme at (FTCS), a (b) in implicit backward difference at time $t+1$ and (c) a Crank-Nicholson scheme.

Figure 4.1 represents the general case of a multilayered wall subjected to two different environments. The definition of the discrete mathematical equations relies on the definition of three types of nodes presented in the following sections. A simple glazing model is as well presented in this section.

\subsubsection{Nodes in contact with the exterior}

Nodes in contact with the exterior are subjected to the environmental conditions which are imposed to the system. Since the values of the radiative and convective heat transfers are given on the boundary. For the nodes on the exterior of the chimney $(e x t)$ : 


$$
m_{n} C_{n}(T)\left(\frac{\partial T}{\partial t}\right)=-\lambda_{n} S_{n}\left(\frac{\partial T}{\partial x}\right)+h_{e x t_{2}} S_{n}\left(T_{e x t_{2}}^{t}-T_{n}^{t}\right)+\alpha_{C L O} S_{n} \varphi_{C L O}+S_{n} \varphi_{G L O}
$$

By replacing the mass in Eq 4.3 for the expression $m_{i}=\rho_{i} s_{i} \frac{\Delta x_{i}}{2}$ and simplifying we obtain the following equation:

$$
\rho_{n} \frac{\Delta x_{n}}{2} C_{n}(T)\left(\frac{\partial T}{\partial t}\right)=-\lambda_{n}\left(\frac{\partial T}{\partial x}\right)+h_{e x t_{2}}\left(T_{e x t_{2}}^{t}-T_{n}^{t}\right)+\alpha_{C L O} \varphi_{C L O}+\varphi_{G L O}
$$

After the discretisation in Eq 4.4 is now expressed as follows:

$\rho_{n} \frac{\Delta x_{n}}{2} C_{n}(T)\left(\frac{T_{n}^{t+\Delta t}-T_{n}^{t}}{\Delta t}\right)=-\lambda_{n}\left(\frac{T_{n}^{t}-T_{n-1}^{t}}{\Delta x}\right)+h_{i n t}\left(T_{i n t}^{t}-T_{n}^{t}\right)+\alpha_{C L O} \varphi_{C L O}+\varphi_{G L O}$

In order to analyze in an implicit method an intermediate point in time is set and a new variable $\bar{T}$ is defined:

$$
\bar{T}_{i}=\frac{T_{i}^{t+\Delta t}+T_{i}^{t}}{2}
$$

Therefore;

$$
T_{i}^{t+\Delta t}=2 \bar{T}_{i}-T_{i}^{t}
$$

Equation 4.5 is then rewritten as following:

$$
\rho_{n} \Delta x_{n} C_{n}(T)\left(\frac{\bar{T}_{n}-T_{n}^{t}}{\Delta t}\right)=-\lambda_{n}\left(\frac{\bar{T}_{n}^{t}-\bar{T}_{n-1}^{t}}{\Delta x}\right)+h_{i n t}\left(T_{i n t}^{t}-\bar{T}_{n}\right)+\alpha_{C L O} \varphi_{C L O}+\varphi_{G L O}
$$

By introducing $\gamma=\frac{1}{\rho_{i} C_{i}(T)}$, the equation is then expressed in terms of $T_{n}^{t}$ : 
$T_{n}^{t}=-\frac{\lambda_{n} \gamma_{n} \Delta t_{n}}{\Delta x_{n}^{2}} \bar{T}_{n-1}+\left(1+\frac{\lambda_{n} \gamma_{n} \Delta t_{n}}{\Delta x_{n}^{2}}-\frac{\gamma h_{i n t} \Delta t_{n}}{\Delta x_{n}}\right) \bar{T}_{n}-\frac{\gamma h_{i n t} \Delta t_{n}}{\Delta x_{n}} T_{i n t}-\frac{\gamma_{n} \Delta t_{n}}{\Delta x_{n}}\left(\alpha_{C L O} \varphi_{C L O}+\varphi_{G L O}\right)$

Similarly to Eq 4.3, for the nodes of the side ext the characteristic equation is:

$$
m_{1} C_{1}(T)\left(\frac{\partial T}{\partial t}\right)=-\lambda_{1} S_{1}\left(\frac{\partial T}{\partial x}\right)+h_{e x t} S_{1}\left(T_{e x t}^{t}-T_{1}^{t}\right)+\alpha S_{1} \varphi_{C L O}+S_{1} \varphi_{G L O}
$$

Following the same approach as before; Eq. 4.8 leads to the expression:

$$
T_{1}^{t}=\left(1+\frac{\lambda_{1} \gamma_{1} \Delta t_{1}}{\Delta x_{1}^{2}}+\frac{\gamma_{1} h_{e x t} \Delta t_{1}}{\Delta x_{1}}\right) \bar{T}_{1}+\frac{\lambda_{1} \gamma_{1} \Delta t_{1}}{\Delta x_{1}^{2}} \bar{T}_{2}-\frac{\gamma_{1} h_{e x t} \Delta t_{1}}{\Delta x_{1}} T_{e x t}-\frac{\gamma_{1} \Delta t_{1}}{\Delta x_{1}}\left(\alpha_{C L O} \varphi_{C L O}+\varphi_{G L O}\right)
$$

\subsubsection{Nodes within the inner layers}

For the interior nodes of the same material we write the heat equation for one-dimensional medium without internal heat source as a combination of the adjacent nodes to node $i$ :

$$
\left\{\begin{array}{l}
\rho_{i-1} \frac{\Delta x_{i-1}}{2} C_{i-1}(T)\left(\frac{\partial T}{\partial t}\right)=-\lambda_{j-1}\left(\frac{\partial T}{\partial x}\right) \\
\left.\rho_{i+1} \frac{\Delta x_{i+1}}{2} C_{i+1}(T)\left(\frac{\partial T}{\partial t}\right)=\lambda_{j+1}\left(\frac{\partial T}{\partial x}\right)\right)
\end{array}\right.
$$

As shown in the previous section, and taking into account constant thermal characteristics the previous heat equations can be rewritten as follows:

$$
\rho_{i} C_{i}(T) \Delta x_{i}\left(\frac{\partial T}{\partial t}\right)=\lambda_{j}\left(\frac{\partial T}{\partial x}\right)_{x}^{x+\Delta x}
$$


By means of a Taylor expansion of second order:

$$
\left(\frac{d T}{d x}\right)_{x+\Delta x} \simeq\left(\frac{d T}{d x}\right)_{x}+\Delta x\left(\frac{d^{2} T}{d x^{2}}\right)_{x}
$$

Eq 4.10 can then expressed:

$$
\rho_{i} C_{i}(T)\left(\frac{\partial T}{\partial t}\right)=\lambda_{j}\left(\frac{\partial^{2} T}{\partial x^{2}}\right)
$$

Following a Crank Nicholoson implicit methdod:

$$
\begin{gathered}
\lambda_{j}\left(\frac{\partial^{2} T}{\partial x^{2}}\right)=\lambda_{j}\left(\frac{T_{i+1}^{t+\frac{1}{2}}+T_{i-1}^{t+\frac{1}{2}}-2 T_{i}^{t+\frac{1}{2}}}{\Delta x^{2}}\right) \\
\lambda_{j}\left(\frac{\partial^{2} T}{\partial x^{2}}\right)=\frac{\lambda_{j}}{2}\left(\frac{T_{i+1}^{t+1}+T_{i-1}^{t+1}-2 T_{i}^{t+1}}{\Delta x^{2}}+\frac{T_{i+1}^{t}+T_{i-1}^{t}-2 T_{i}^{t}}{\Delta x^{2}}\right)
\end{gathered}
$$

We introduce the previous expression into equation Eq 4.11 and we obtain:

$$
\rho_{i} C_{i}(T)\left(\frac{T_{i}^{t+1}-T_{i}^{t}}{\Delta t}\right)=\frac{\lambda_{j}}{2}\left(\frac{T_{i+1}^{t+1}+T_{i-1}^{t+1}-2 T_{i}^{t+1}}{\Delta x^{2}}+\frac{T_{i+1}^{t}+T_{i-1}^{t}-2 T_{i}^{t}}{\Delta x^{2}}\right)
$$

We reintroduce the variable $\gamma$ to group and simplify $\gamma=\frac{1}{\rho_{i} C_{i}(T)}$ and we obtain the following equation:

$$
2\left(T_{i}^{t+\Delta t}-T_{i}^{t}\right)=\frac{\lambda_{j} \gamma_{i} \Delta t_{i}}{2 \Delta x_{i}^{2}}\left(T_{i-1}^{t+\Delta t}+T_{i-1}^{t}\right)+\frac{\lambda_{i} \gamma_{i} \Delta t_{i}}{2 \Delta x_{i}^{2}}\left(T_{i+1}^{t+\Delta t}-T_{i+1}^{t}\right)+\frac{\lambda_{i} \gamma_{i} \Delta t_{i}}{\Delta x_{i}^{2}}\left(T_{i}^{t+\Delta t}-T_{i}^{t}\right)
$$

Using the previous relationship from $\mathrm{Eq} 4.6$ we can rewritte the previous expression to leave it in terms of $\bar{T}$ :

$$
T_{i}^{t}=-\frac{\lambda_{i} \gamma_{i} \Delta t_{i}}{2 \Delta x_{i}^{2}} \bar{T}_{i-1}+\left(1+\frac{\lambda_{i} \gamma_{i} \Delta t_{i}}{\Delta x_{i}^{2}}\right) \bar{T}_{i}-\frac{\lambda_{i} \gamma_{i} \Delta t_{i}}{2 \Delta x_{i}^{2}} \bar{T}_{i+1}
$$




\subsubsection{Nodes in the interface between two solid materials}

The interface between two materials will usually represent different thermal characteristics at the node $j$, simillarly as in the previous section, the the heat balance equation of the interface can be expressed by taking the adjecent elementary volumes $j-1$ and $j+1$ :

$$
\begin{gathered}
\left\{\begin{array}{l}
\rho_{i-1} \frac{\Delta x_{i-1}}{2} C_{i-1}(T)\left(\frac{\partial T}{\partial t}\right)=\lambda_{j-1}\left(\frac{\partial T}{\partial x}\right) \\
\left.\rho_{i+1} \frac{\Delta x_{i+1}}{2} C_{i+1}(T)\left(\frac{\partial T}{\partial t}\right)=-\lambda_{j+1}\left(\frac{\partial T}{\partial x}\right)\right)
\end{array}\right. \\
\frac{\Delta x_{i-1}}{2} \rho_{i-1} C_{i-1}(T)\left(\frac{\partial T}{\partial t}\right)+\frac{\Delta x_{i+1}}{2} \rho_{i+1} C_{i+1}(T)\left(\frac{\partial T}{\partial t}\right)=\lambda_{j-1}\left(\frac{\partial \bar{T}}{\partial x}\right)_{i-1}-\lambda_{j+1}\left(\frac{\partial \bar{T}}{\partial x}\right)_{i+1}
\end{gathered}
$$

The relationship from equation $\mathrm{Eq} 4.6$ is added to the heat balance equation 4.14 to follow the same approach as before:

$$
\left(\rho_{i-1} C_{i-1}(T) \frac{\Delta x_{i-1}}{2}+\rho_{i} C_{i}(T) \frac{\Delta x_{i}}{2}\right)\left(\frac{\bar{T}_{i}-\bar{T}_{i-1}}{\Delta t}\right)=\left(\frac{\lambda_{j-1}}{\Delta x_{i-1}}\right)\left(\bar{T}_{i}-\bar{T}_{i-1}\right)-\left(\frac{\lambda_{j}}{\Delta x_{i}}\right)\left(\bar{T}_{i+1}-\bar{T}_{i}\right)
$$

By defining the variable $\vartheta=\rho_{i-1} C_{i-1}(T) \frac{\Delta x_{i-1}}{2}+\rho_{i+1} C_{i+1}(T) \frac{\Delta x_{i+1}}{2}$ and rearranging the previous expression in terms of $T_{i}^{t}$, we obtain:

$$
T_{i}^{t}=-\frac{\lambda_{j-1} \Delta t}{\vartheta \Delta x_{i-1}} \bar{T}_{i-1}+\left(1+\frac{\lambda_{j-1} \Delta t}{\vartheta \Delta x_{i-1}}+\frac{\lambda_{j+1} \Delta t}{\vartheta \Delta x_{i+1}}\right) \bar{T}_{i}-\frac{\lambda_{j+1} \Delta t}{\vartheta \Delta x_{i+1}} \bar{T}_{i+1}
$$

\subsubsection{Mathematical representation of a multilayer wall}

The solution of the multilayer wall model is carried out through a matrix system if equations. Equations 4.7, 4.9, 4.13 and 4.15, summarized below are employed for the representation of said matrix. 


$$
\left\{\begin{array}{l}
T_{1}^{t}=\left(1+\frac{\lambda_{1} \gamma_{1} \Delta t_{1}}{\Delta x_{1}^{2}}+\frac{\gamma_{1} h_{e x t} \Delta t_{1}}{\Delta x_{1}}\right) \bar{T}_{1}+\frac{\lambda_{1} \gamma_{1} \Delta t_{1}}{\Delta x_{1}^{2}} \bar{T}_{2}-\frac{\gamma_{1} h_{e x t} \Delta t_{1}}{\Delta x_{1}} T_{e x t}-\frac{\gamma_{1} \Delta t_{1}}{\Delta x_{1}}\left(\alpha_{C L O} \varphi_{C L O}+\varphi_{G L O}\right) \\
T_{i}^{t}=-\frac{\lambda_{i} \gamma_{i} \Delta t_{i}}{2 \Delta x_{i}^{2}} \bar{T}_{i-1}+\left(1+\frac{\lambda_{i} \gamma_{i} \Delta t_{i}}{\Delta x_{i}^{2}}\right) \bar{T}_{i}-\frac{\lambda_{i} \gamma_{i} \Delta t_{i}}{2 \Delta x_{i}^{2}} \bar{T}_{i+1} \\
T_{i}^{t}=-\frac{\lambda_{j-1} \Delta t}{\vartheta \Delta x_{i-1}} \bar{T}_{i-1}+\left(1+\frac{\lambda_{j-1} \Delta t}{\vartheta \Delta x_{i-1}}+\frac{\lambda_{j+1} \Delta t}{\vartheta \Delta x_{i+1}}\right) \bar{T}_{i}-\frac{\lambda_{j+1} \Delta t}{\vartheta \Delta x_{i+1}} \bar{T}_{i+1} \\
T_{n}^{t}=-\frac{\lambda_{n} \gamma_{n} \Delta t_{n}}{\Delta x_{n}^{2}} \bar{T}_{n-1}+\left(1+\frac{\lambda_{n} \gamma_{n} \Delta t_{n}}{\Delta x_{n}^{2}}-\frac{\gamma h_{i n t} \Delta t_{n}}{\Delta x_{n}}\right) \bar{T}_{n}-\frac{\gamma h_{i n t} \Delta t_{n}}{\Delta x_{n}} T_{i n t}-\frac{\gamma_{n} \Delta t_{n}}{\Delta x_{n}}\left(\alpha_{C L O} \varphi_{C L O}+\varphi_{G L O}\right.
\end{array}\right.
$$

The construction of the matrix is based on the previous equations and the following tables:

Table 4.1: Components of the A matrix equation of the model

\begin{tabular}{|c|c|c|}
\hline \multicolumn{3}{|c|}{ Nodes $(1, n)$ in contact with the exterior (From Eqs $4.7 \& 4.9$ ) } \\
\hline$a_{1,1}=1+\frac{\lambda_{1} \gamma_{1} \Delta t_{1}}{\Delta x_{1}^{2}}+\frac{\gamma_{1} h_{e x t} \Delta t_{1}}{\Delta x_{1}}$ & $a_{1,2}=\frac{\lambda_{1} \gamma_{1} \Delta t_{1}}{\Delta x_{1}^{2}}$ & $a_{2,1}=-\frac{\lambda_{i} \gamma_{i} \Delta t_{i}}{2 \Delta x_{i}^{2}}$ \\
\hline$a_{n, n}=1+\frac{\lambda_{n} \gamma_{n} \Delta t_{n}}{\Delta x_{n}^{2}}-\frac{\gamma h_{i n t} \Delta t_{n}}{\Delta x_{n}}$ & $a_{n-1, n}=-\frac{\lambda_{n} \gamma_{n} \Delta t_{n}}{\Delta x_{n}^{2}}$ & $a_{n, n-1}=-\frac{\lambda_{i} \gamma_{i} \Delta t_{i}}{2 \Delta x_{i}^{2}}$ \\
\hline \multicolumn{3}{|c|}{ Interior nodes $(i)$ within a solid (From Eqs 4.13$)$} \\
\hline$a_{i, i-1}=-\frac{\lambda_{i} \gamma_{i} \Delta t_{i}}{2 \Delta x_{i}^{2}}$ & $a_{i, i}=1+\frac{\lambda_{i} \gamma_{i} \Delta t_{i}}{\Delta x_{i}^{2}}$ & $a_{i, i+1}=-\frac{\lambda_{i} \gamma_{i} \Delta t_{i}}{2 \Delta x_{i}^{2}}$ \\
\hline \multicolumn{3}{|c|}{ Nodes $(j)$ between two solid interfaces (From Eq 4.15) } \\
\hline$a_{j, j-1}=-\frac{\lambda_{j-1} \Delta t}{\vartheta \Delta x_{i-1}}$ & $a_{j, j}=1+\frac{\lambda_{j-1} \Delta t}{\vartheta \Delta x_{i-1}}+\frac{\lambda_{j+1} \Delta t}{\vartheta \Delta x_{i+1}}$ & $a_{j, j+1}=-\frac{\lambda_{j+1} \Delta t}{\vartheta \Delta x_{i+1}}$ \\
\hline
\end{tabular}

Table 4.2: Components of the B matrix equation of the model

\begin{tabular}{|c|c|c|}
\hline \hline \multicolumn{2}{|c|}{ Nodes in contact with the exterior and interior ambiances (From Eqs 4.7 \& 4.9) } \\
\hline$b_{1,1}=\frac{\gamma_{1} h_{e x t} \Delta t_{1}}{\Delta x_{1}}$ & $b_{1,3}=\frac{\gamma_{1} \alpha_{C L O_{e x t}} \Delta t_{1}}{\Delta x_{1}}$ & $b_{1,4}=\frac{\gamma_{1} \alpha_{G L O_{e x t}} \Delta t_{1}}{\Delta x_{1}}$ \\
\hline$b_{n, n-5}=\frac{\gamma h_{i n t} \Delta t_{n}}{\Delta x_{n}}$ & $b_{n, n-2}=\frac{\gamma \alpha_{C L O} O_{\text {int }} \Delta t_{n}}{\Delta}$ & $b_{n, n-1}=\frac{\gamma \alpha_{G L O} O_{\text {int }} \Delta t_{n}}{\Delta x_{n}}$ \\
\hline \multicolumn{3}{|c}{ For all other nodes, the value is 0.} \\
\hline
\end{tabular}

$$
\left(\begin{array}{c}
T_{1}^{t} \\
\vdots \\
\vdots \\
\vdots \\
\vdots \\
\vdots \\
\vdots \\
\vdots \\
T_{n}^{t}
\end{array}\right)=\left(\begin{array}{cccccccc}
a_{1,1} & a_{1,2} & 0 & \ldots & \ldots & \ldots & \ldots & 0 \\
a_{2,1} & \ddots & \ddots & & & & & \vdots \\
0 & \ddots & \ddots & \ddots & & & & \vdots \\
\vdots & & a_{i, i-1} & a_{i, i} & a_{i, i+1} & & & \vdots \\
\vdots & & & \ddots & \ddots & \ddots & & \vdots \\
\vdots & & & a_{j, j-1} & a_{j, j} & a_{j, j+1} & & \vdots \\
\vdots & & & & \ddots & \ddots & \ddots & \vdots \\
\vdots & & & & & \ddots & \ddots & a_{n, n-1} \\
0 & \ldots & \ldots & \ldots & \ldots & \ldots & a_{n-1, n} & a_{n, n}
\end{array}\right)\left(\begin{array}{c}
\bar{T}_{1} \\
\vdots \\
\vdots \\
\bar{T}_{i} \\
\vdots \\
\bar{T}_{n}
\end{array}\right)
$$




$$
+\left(\begin{array}{cccccccc}
b_{1,1} & b_{1,2} & 0 & \ldots & \ldots & \ldots & \ldots & 0 \\
b_{2,1} & \ddots & \ddots & & & & & \vdots \\
0 & \ddots & \ddots & \ddots & & & & \vdots \\
\vdots & & b_{i, i-1} & b_{i, i} & b_{i, i+1} & & & \vdots \\
\vdots & & & \ddots & \ddots & \ddots & & \vdots \\
\vdots & & & b_{j, j-1} & b_{j, j} & b_{j, j+1} & & \vdots \\
\vdots & & & & \ddots & \ddots & \ddots & \vdots \\
\vdots & & & & & \ddots & \ddots & b_{n, n-1} \\
0 & \ldots & \ldots & \ldots & \ldots & \ldots & b_{n-1, n} & b_{n, n}
\end{array}\right)\left(\begin{array}{c}
T_{e x t}^{t} \\
T_{i n t}^{t} \\
\varphi_{C L O_{e x t}} \\
\varphi_{G L O_{e x t}} \\
\varphi_{C L O_{i n t}} \\
\varphi_{G L O_{i n t}} \\
T_{\text {air }}^{t}
\end{array}\right)
$$

\subsubsection{Non-linearity modelization of PCM properties}

Studies such as the one carried out by Mirzaei et al. (2012) have modelled the behaviour in similar ways, adding a discretization along the PCM layer to simulate the progressive phase change of the material.

As stated in the previous subsection, the heat transfer model takes into consideration several wall layers. The model is solved with fixed physical properties on walls without a PCM layer, however; the properties of phase changing materials depend on the temperature distribution. In order to account for the non-linear behaviour of phase changing materials, several options were considered. Some studies have explained the behaviour of phase changing materials by setting three different working phases: solid, liquid and transitory state (Li and Liu, 2014b). These studies, consider that once a certain temperature has been reached, the assumption of phase change can be made. Two main methodologies can be used for the characterization of PCM.

The first method, known as the Enthalpy Method, includes this quantity $H$ in the heat transfer equation, in order to take into consideration both the sensible and latent heat in the calculation of heat transfer.

$$
\rho \frac{\partial H}{\partial t}=\frac{\partial}{\partial x}\left(\lambda \frac{\partial T}{\partial x}\right)
$$

The DSC test presented in section 3.2.1 allows the calculation of the $C_{p}$ through two main variables: the heat rate at which the test was carried out and the 
released/stored latent heat:

$$
C_{p}(T)=\frac{D S C(T)_{s}}{\phi}
$$

where $D S C(T)_{s}$ is the heat flow across the sample at temperature $T$ from the thermogram $\frac{W}{g}$, and $\phi$ is the heating/cooling rate $\frac{{ }^{\circ} C}{s}$.

These results were employed in order to input the $C_{p}$ values of the PCMs into the numerical model as a function of temperature. This methodology was employed in other green technology studies such as the ones carried out by Bahrar et al. (2018); Roccamena et al. (2018); Stathopoulos et al. (2017). The results of the DSC test for the Rubitherm RT44 phase changing material are shown in 4.3. This test was carried out at a cooling/heating speed of $0.05{ }^{\circ} \mathrm{C} / \mathrm{min}$, according to the expected charge/discharge speed of the panels in the chimney. The double peak experienced during heating can be due to the impurity of the material. The specific heat of the RT44 material is input to each node of the discretization as a function of temperature $C_{p}(T)$, allowing a more specific evolution along the PCM layer. Specific heat is calculated using the following expression:

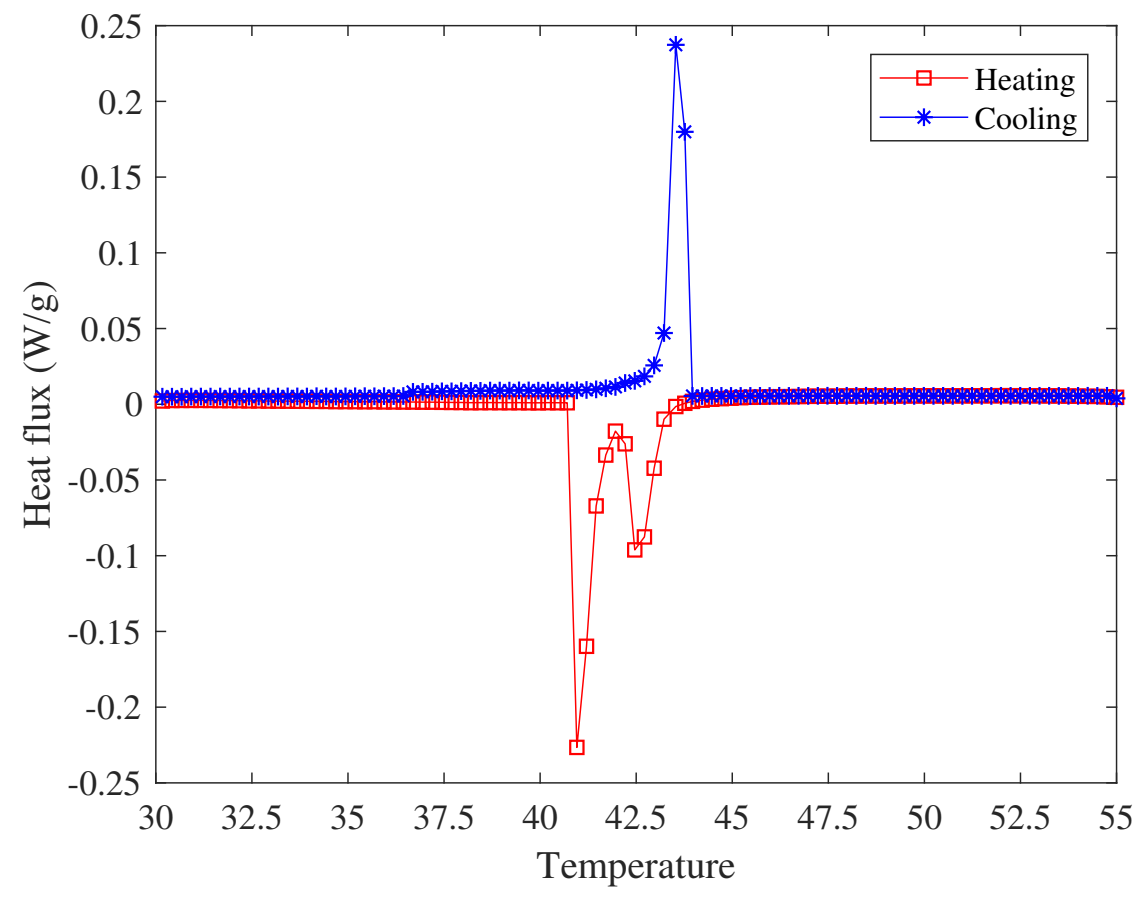

Figure 4.3: DSC results for the RT44 PCM showing the evolution of heat flux as function of temperature 
The calculation of the thermal properties are input into each one of the nodes of the discretization. Three different intervals are settled in order to set the said thermal properties: liquid, solid and transitory. Properties such as density are given by the supplier however, a linear regression is employed in order to determine the values during the transitory state.

\subsubsection{Glazing Model}

The glazing is a fundamental element of the solar chimney since it allows solar radiation to directly influence the energy gains and losses of the air inside the chimney. The glazing model treats this chimney element as a transparent wall which favours the transmission of CLO radiation. The surface overheat of the interior walls of the chimney establishes temperature profiles due to convective exchanges. This changes greatly influence the performance of the chimney.

For the direct CLO radiation, the transmission properties such as reflection and absorption for a single glazing are taken into account. For diffuse radiation, a predominant angle of incidence can not be defined. Absorption, transmission and reflection coefficients are supposed constant regardless of the angle of incidence to simplify the numerical model (El Mankibi, 2003). The characteristic coefficients of the glazing relating to direct radiation are therefore used with an angle of incidence of $60^{\circ}$.

The simple glazing has two main surfaces, one in contact with the external conditions and the other facing the interior of the chimney. The equilibrium equations for both surfaces are expressed as follows:

$$
\begin{gathered}
\alpha_{1} \varphi_{C L O_{\text {ext }}}+h_{\text {ext }}\left(T_{\text {ext }}-T_{1}\right)=\frac{\lambda_{\text {glazing }}}{e_{\text {glazing }}}\left(T_{1}-T_{2}\right) \\
\alpha_{2} \varphi_{G L O_{\text {int }}}+h_{\text {int }}\left(T_{\text {int }}-T_{2}\right)=\frac{\lambda_{\text {glazing }}}{e_{\text {glazing }}}\left(T_{2}-T_{1}\right)
\end{gathered}
$$




\subsection{Modelization of radiative transfers}

As stated in Chapter 2.3.3 the work carried out by Bansal et al. (1993) stated that it is possible to induce an airflow of 100 up to $350 \mathrm{~m}^{3 / h}$, however the efficiency of the chimney depends, among other things, on the characteristics of the collector. In other words, one of the essential design element depends on the optimization of the incoming solar radiation. Other works (Al-Kayiem et al., 2014; Mathur et al., 2006) show the system under performs for solar radiation under $300-400$ $W / \mathrm{m}^{2}$ and a maximum ventilation rate of $5.6 \mathrm{ACH}$ can be achieved at $700 \mathrm{~W} / \mathrm{m}^{2}$. Furthermore, it is also stated that at high solar radiations, a greater wind speed can be detrimental for the performance of the solar chimney as much as $25 \%$. Moreover Suárez-López et al. (2015), established that almost 2/3 of the incoming solar energy is lost at or through the glass cover, which outlines the need of an accurate radiative model. Accordingly, the radiative model employed for the simulation of a solar chimney was developed taking this information into consideration.

Solely diffuse and opaque grey bodies were considered, aside from the transparent glazing. The main exchanges correspond to short and long wavelengths. The surface conditions are treated in the same manner.Firstly, short wavelengths (CLO) belong to the visible range between 380 and $780 \mathrm{~nm}$ and they are characteristic of radiative exchanges involving solar inputs. On the other hand, long wavelengths (GLO) exchanges are considered to be characteristic of low-temperature transfers between the walls of the solar chimney. This involves wavelengths greater than $780 \mathrm{~nm}$. The objective of the model, is to obtain through the wall temperatures and solar gains, the net radiative flux of each surface. This flux is equal to the difference between the flux emitted and absorbed. The model is based on the calculation of the incident CLO (short wavelength) and GLO radiations. The calculation is then coupled with the multi-layered wall code. The radiative heat transfer is expressed as follows:

$$
\phi_{\text {absorbed }}=\alpha \sigma T^{4}
$$




$$
\begin{gathered}
\phi_{\text {emitted }}=\alpha_{G L O} \varphi_{G L O}=\alpha_{C L O} \varphi_{C L O} \\
\phi_{\text {net }}=\phi_{\text {emitted }}-\phi_{\text {absorbed }}
\end{gathered}
$$

\subsubsection{Short wavelength radiative transfers}

The incoming CLO flux on each surface is categorized in either diffuse or reflected Figure 4.4. The model does not consider any flux coming from a surface of the solar chimney as a part of the CLOs.

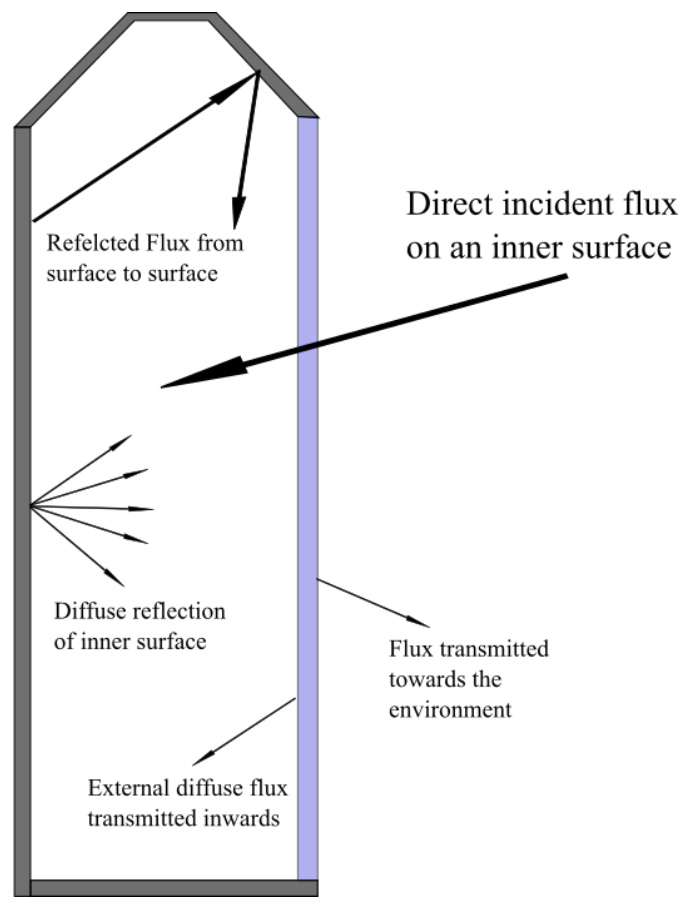

Figure 4.4: CLO radiation flux distribution in the simulated solar chimney

Direct flux depends on the solar intake and the incident solar flux of each surface. This incident flow depends on the weather data as well as the geographical location of the solar chimney. The determination of this flow is mentioned in the following section. Similarly, the diffuse flux corresponds to the amount of heat radiated by the environment on the surfaces of the solar chimney. This type of flow can come from the sky, the surroundings (e.g. buildings) or the ground. Finally, the reflected flux corresponds to all the CLO flows reflected between the surfaces of the solar chimney arriving on the other surfaces. Each surface reflects a part of the direct flux and a 
part of the diffuse flux but also a part of these flux previously reflected by another surface, thus, it involves several reflections between same surfaces.

\subsubsection{Long wavelength radiative transfers}

The long wavelength radiative transfers are hereinafter referred to as GLO. The GLO transfers received by a surface $i$ corresponds to the sum of the radiosities of the other surfaces. The radiosity is defined as the sum of flows that are released from a surface. It is composed of emitted and reflected flows. Several reflections can occur between two same surfaces. The following expressions help define the GLO transfers:

$$
\begin{gathered}
\varphi_{G L O, i}=\sum_{j=1}^{n} F_{i, j} \times J_{j} \\
J_{j}=M_{j}+\sum_{i=1}^{n} \rho_{i} F_{i, j} J_{i} \\
M_{j}=J_{j}-\sum_{i=1}^{n} \rho_{i} F_{i, j} J_{i} \\
M_{j}=\sum_{i=1}^{n}\left(\partial_{i j}-\rho_{i} F_{i, j}\right) J_{i}
\end{gathered}
$$

Where $M_{j}$ corresponds to the emittance and is defined as:

$$
\begin{aligned}
& M_{j}=\epsilon \sigma T^{4} \\
& {[B]=[A][J]}
\end{aligned}
$$

where:

$$
A=\sum_{i=1}^{n}\left(\partial_{i j}-\rho_{i} F_{i, j}\right)
$$

and

$$
B=\epsilon_{j} M_{j}
$$




\subsection{Airflow Model - A zonal approach to the mass flow rate calculation}

The following section illustrates the numerical model employed for the calculation of mass flow rate and the pressure distribution in a multi-zone solar chimney. The pressure code employed, simulates a two-dimensional, flat rectangular duct where the temperature and velocity develop simultaneously. Pressure codes compute the conditions of a determined volume to provide information on the inlet and outlet boundaries. Previous works have employed different software such as ANSYS Fluent (Suárez-López et al., 2015; Tan and Wong, 2014), FORTRAN (Bassiouny and Koura, 2008; Imran et al., 2015) or EnergyPlus (Asadi et al., 2016; Lee and Strand, 2009) to characterize the behaviour of the chimney, however; these set ups tend to represent a great computational cost. The pressure code approach was chosen over these methods, firstly due to the coupling potential with existing building models and because of the reduced computational power required to obtain a valid solution. These advantages come at the cost of information loss through out the chimney, which does not hamper the solution but fails to represent with precision the interactions through out the system.

The performance of the solar chimney is assessed through the mass flow rate

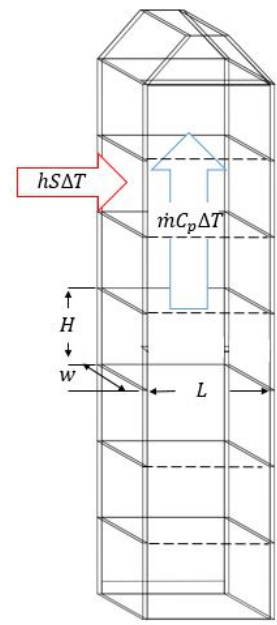

Figure 4.5: Vertical discretization of the solar chimney 
of air exiting the chimney. The calculation of this physical quantity requires the definition of an initial pressure and temperature distribution, as well as the boundary conditions that will modify the chimney's state. Each volume must respect the mass balance equation for a given pressure and a defined temperature (4.20). Simultaneously; each volume must agree with the calculation of the adjacent volumes. The calculations from volume $i$ are communicated to neighbouring volumes through the boundaries $k$ for several iterations until the system arrives to a solution at each time step. The model iterates until the pressure values attain a convergence factor of $1 e^{-6}$.

$$
\sum_{k=1}^{j} \rho_{i} \dot{m}_{i k}=0
$$

The mass flow rate depends on the pressure of neighbouring cells. The mass exchange between common interfaces will serve to calculate the new pressure distribution through several iterations which will lead to a pressure differential. Density fluctuates due to temperature differences between adjacent zones, which induces the buoyancy driven flow. This phenomenon is known as thermal up-draft. The effect of temperature on the mass flow rate is depicted within the density variable. Indeed, the Boussinesq approximation was employed to define density as a function of temperature $(\mathrm{Eq} 4.21)$. The system is solved through the combination of the mass balance equation introduced before (Eq 4.20) and Bernoulli's principle. The rearranged equation is shown in equation 4.22 .

$$
\begin{gathered}
\rho_{i}=\rho_{0}\left[\frac{T_{0}}{T_{0}+T_{i}}\right] \\
\sum_{k=1}^{j} C_{d} S_{i} \rho_{i} \sqrt{\frac{2 \Delta P_{i k}}{\rho_{\text {mean }}}}=0
\end{gathered}
$$

Figure 4.5 represents the system analysed, where the reference pressure on the lower boundary of the cell corresponds to $P_{0}$ the pressure due to stack effect at height $z$ is $P_{i}$. The chimney takes into consideration two types of boundaries for the calculation of airflows: horizontal frontiers and vertical frontiers. 


$$
\Delta P_{i j}=P_{i}-P_{j}-\left(\rho_{i}-\rho_{j}\right) g z
$$

$$
\Delta P_{i j}=\Delta P_{0_{i j}}-\Delta \rho_{i j} g z
$$

\subsubsection{Vertical Boundaries}

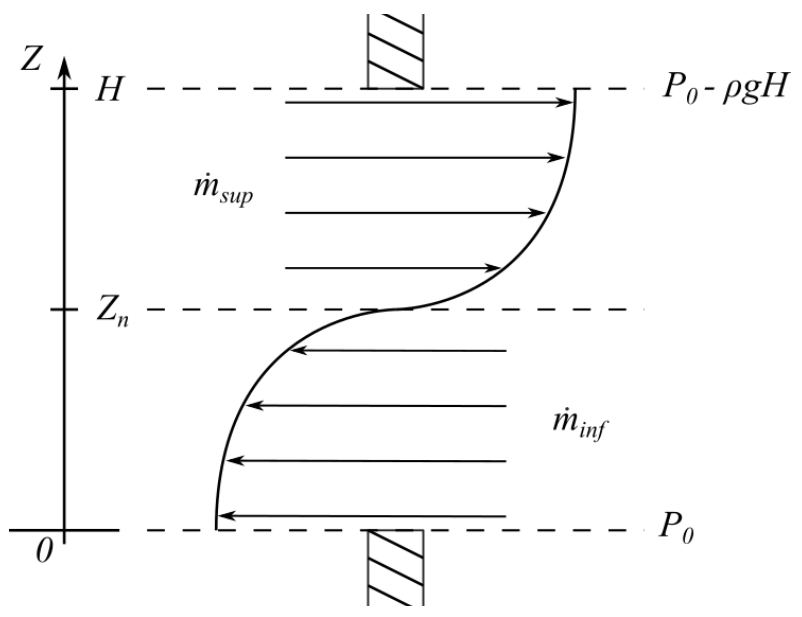

Figure 4.6: Airflow through a large vertical opening

The chimney consists of a single vertical opening at the inlet level. This vertical boundary is considered to have a bidirectional airflow, divided by a neutral level named $z_{n}$. The airflow distribution can be appreciated in Figure 4.6. Equation 4.22 is then integrated upon the two sections of the opening as stated below:

$$
\left\{\begin{array}{l}
\dot{m}_{\text {inf }}=C_{d} S \sqrt{\frac{2}{\rho_{\text {mean }}}} \int_{0}^{z_{n}} \sqrt{\Delta P_{0}-\Delta \rho g z} d z \\
\dot{m}_{\text {sup }}=C_{d} S \sqrt{\frac{2}{\rho_{\text {mean }}}} \int_{z_{n}}^{H} \sqrt{\Delta P_{0}-\Delta \rho g z} d z
\end{array}\right.
$$

Therefore:

$$
\left\{\begin{array}{l}
\dot{m}_{\text {inf }}=-A \sqrt{\left(\Delta P_{0}-\Delta \rho g z_{n}\right)^{3 / 2}-\Delta P_{0}^{3 / 2}} \\
\dot{m}_{\text {sup }}=-A \sqrt{\left(\Delta P_{0}-\Delta \rho g H\right)^{3 / 2}-\left(\Delta P_{0}-\Delta \rho g z_{n}\right)^{3 / 2}}
\end{array}\right.
$$

Where the value of $z_{n}$ and $A$ are calculated through the following expressions:

$$
z_{n}=\frac{\Delta P_{0}}{\Delta \rho g}
$$




$$
A=\frac{C_{d} H w \sqrt{\frac{4}{\rho_{i}+\rho_{i+1}}}}{\frac{3}{2}\left(\rho_{i}-\rho_{i+1}\right) g}
$$

\subsubsection{Horizontal boundaries}

The airflow through horizontal boundaries is considered unidirectional. The airflow is considered to enter or leave the volume $i$ at each time step. By applying equation 4.22 to a horizontal boundary we obtain:

$$
\sum_{k=1}^{j} B \rho_{i} \sqrt{\frac{2 \Delta P_{i k}}{\rho_{\text {mean }}}}=0
$$

Where $B$ is equal to:

$$
B=C_{d} L w \sqrt{\frac{4}{\rho_{i}+\rho_{i+1}}}
$$

Two cases can be set:

$$
\begin{aligned}
& \left\{\begin{array}{l}
P_{\text {inf }}-\rho_{\text {inf }} g \frac{H_{\text {inf }}}{2} \geq P_{\text {sup }}-\rho_{\text {sup }} g \frac{H_{\text {sup }}}{2} \\
\dot{m}=B \rho_{\text {inf }} \sqrt{P_{\text {inf }}+\rho_{\text {inf }} g \frac{H_{\text {inf }}}{2}-P_{\text {sup }}-\rho_{\text {sup }} g \frac{H_{\text {sup }}}{2}}
\end{array}\right. \\
& \left\{\begin{array}{l}
P_{\text {inf }}-\rho_{\text {inf }} g \frac{H_{\text {inf }}}{2} \leq P_{\text {sup }}-\rho_{\text {sup }} g \frac{H_{\text {sup }}}{2} \\
\dot{m}=B \rho_{\text {sup }} \sqrt{P_{\text {sup }}-\rho_{\text {sup }} g \frac{H_{\text {sup }}}{2}-P_{\text {inf }}+\rho_{\text {inf }} g \frac{H_{\text {inf }}}{2}}
\end{array}\right.
\end{aligned}
$$

\subsubsection{Mathematical solution}

By applying Eq 4.20 to each node, a non-linear system of $\mathrm{N}$ equations can be formed. The solution method is based on a Newton-Raphson iterative method, where an initial pressure is attribute to each node. For the general case of $N$ unknown pressures, an initial pressure is assigned to each pressure node. Each iteration calculates a new pressure estimate in order to minimize the residue of equation 4.33. The jacobian matrix is built with the following expressions:

$$
f\left(P_{i}\right)=\sum_{j=1}^{N} \rho_{i} \dot{m}_{i j}
$$


Diagonal elements :

$$
J(i, i)=\frac{\partial f\left(P_{i}\right)}{\partial P_{i}}
$$

Off-diagonal elements :

$$
J(i, j)=\frac{\partial f\left(P_{i}\right)}{\partial P_{j}}
$$

The new pressure distribution is computed through the pressure states of the previous time step and the corrections $X^{t}$. The $X$ matrix is defined through a Jacobian matrix $J(N \times N)$ and the $F(N \times N)$ matrix containing the residues of equation 4.22 for each of the pressure nodes. The $F$ matrix is constructed with the diagonal and off diagonal elements resulting of equations 4.41 and 4.42. The system is expressed as follows:

$$
\begin{gathered}
P^{t+1}=P^{t}-X^{t} \\
{[F]=[J][X]}
\end{gathered}
$$

In the Matlab Simulink interface, this process is carried out by the fsolve function which solves a system of non-linear equations for a problem specified as $F(x)=0$. The function includes a termination tolerance on the function value set to $1^{-6}$ as default. 


\subsection{Convection Model and temperature correction}

The natural convection phenomena is a result of the temperature rise of the interior walls of the solar chimney. This temperature difference between the walls and the air, induces the air to flow in the chimney. The following section presents the numerical model employed for the calculation of the convective heat transfer between the walls and the air inside the solar chimney. This model allows the later recalculation of the air temperature for subsequent time steps.

The temperature correction is carried out through an implicit finite difference method which determines the temperature of volume $i$ according to the temperature of the neighbouring volumes at the previous time step. The system is defined as follows:

$\rho_{i} C_{p} V_{i} \frac{d T}{d t}=\sum_{i=1}^{N} h_{i} S_{i}\left(T_{\text {surf }_{i}}-T_{a i r_{i}}\right)+\dot{m}_{i} C_{p}\left(T_{a i r_{i-1}}-T_{a i r_{i}}\right)+\dot{m}_{i+1} C_{p}\left(T_{a i r_{i+1}}-T_{a i r_{i}}\right)$

Solving for the temperature for volume $i$ at time step $t+\Delta t$ the previous equation can be rewritten as:

$$
T_{a i r_{i}}^{t+\Delta t}=\frac{\beta_{i} T_{a i r_{i}}^{t}+\dot{m}_{i} C_{p} T_{i-1}^{t}+\dot{m}_{i+1} C_{p} T_{i+1}^{t}+Q_{\text {conv }_{i}}}{\beta_{i}+\dot{m}_{i} C_{p}+\dot{m}_{i+1} C_{p}+\sum_{i=1}^{N} h_{i} S_{i}}
$$

where,

$$
Q_{\text {conv }_{i}}=\sum_{i=1}^{N} h i S_{i}\left(T_{\text {surf }_{i}}\right)
$$

The new temperature value is then re-input into the previous numerical models in order reiterate the state of the system. The convective coefficient has a great impact on the performance of the system. Indeed, once the temperature rises, the airflow starts inducing a heat transfer by convection. The calculation of the convective coefficient has been presented in literature by (Al-Kayiem et al., 2014; Bassiouny and Koura, 2008; Harris and Helwig, 2007; Mathur et al., 2006). In this work it was calculated as follows: 


$$
\begin{gathered}
h_{w-a i r}=\frac{N u_{w-a i r} k_{a i r}}{L_{g-w}} \\
N u_{w-a i r}=0.68+\frac{0.67 R a^{1 / 4}}{\left[1+(0.492 / P r)^{9 / 16}\right]^{4 / 9}} \\
R a=G r P r=\frac{g \beta_{a i r-w}^{\prime} \Delta T L_{g-w}^{3}}{\nu \alpha_{g}^{\prime}} \\
\alpha_{g}^{\prime}=\frac{\lambda}{\rho C_{p}}
\end{gathered}
$$




\subsection{Model coupling and Matlab Simulink Simula- tion}

\subsubsection{The HYBCELL Model}

As stated by M. El Mankibi in the work entitled "Developpement et evaluation numerique et experimentale de strategies de regulation de la ventilation hybride" El Mankibi (2003), HYBCELL is an experimental tool developed at the Laboratoire des Sciences de l'Habitat of the ENTPE. HYBCELL is a tool that simulates the behaviour and air quality of a mono-zone room. In comparison with the experimental approach, this tool was developed as a faster and cheaper alternative to test, parametrize and/or optimize on a theoretical level. This thermo-aerodynamic model served as the basis of the Active Solar Chimney numerical model. The interface was modified with the aforementioned modules in order to fit the geometry, conditions and performance parameters of a PCM integrated solar chimney.

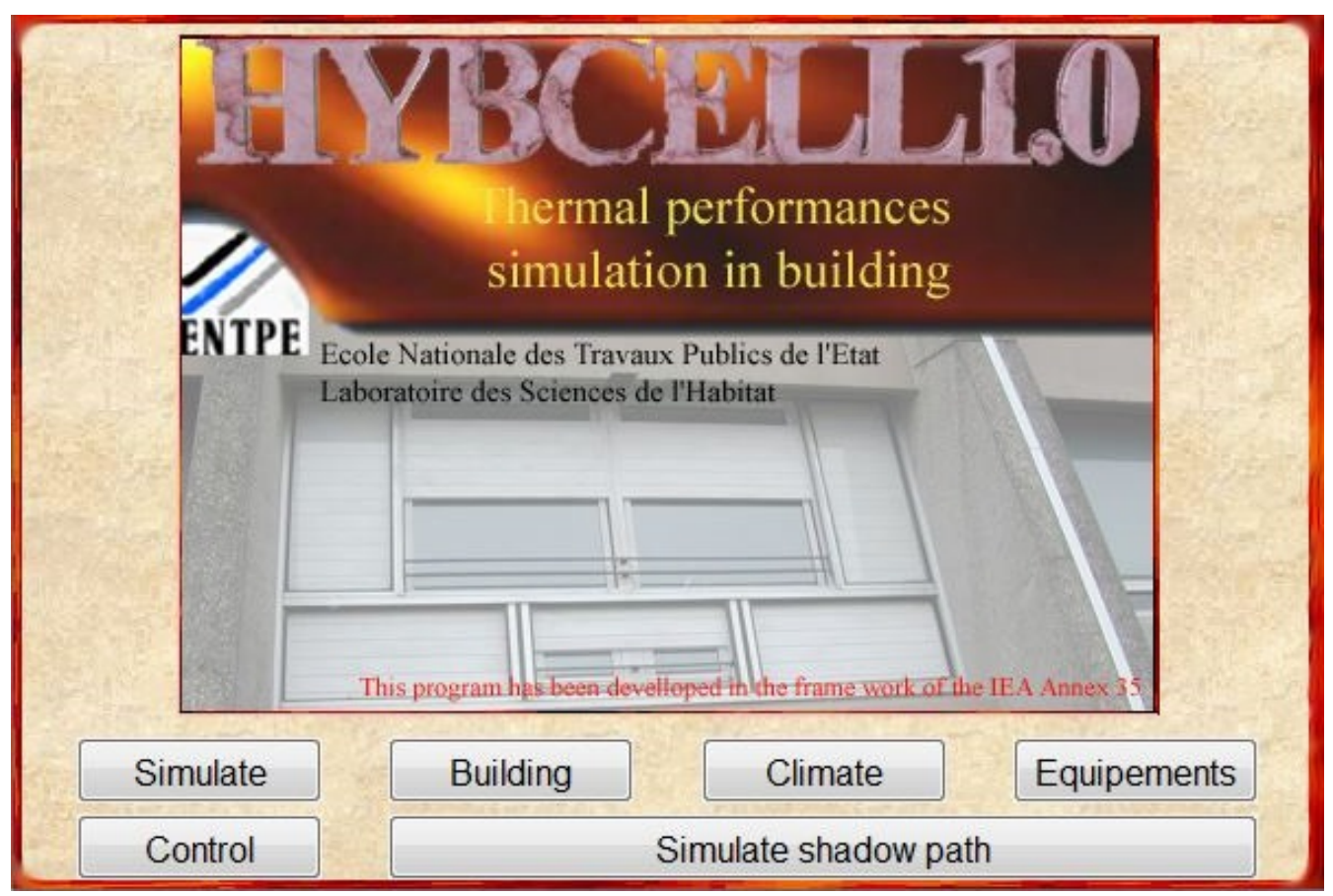

Figure 4.7: Matlab Simulink HYBCELL interface. 


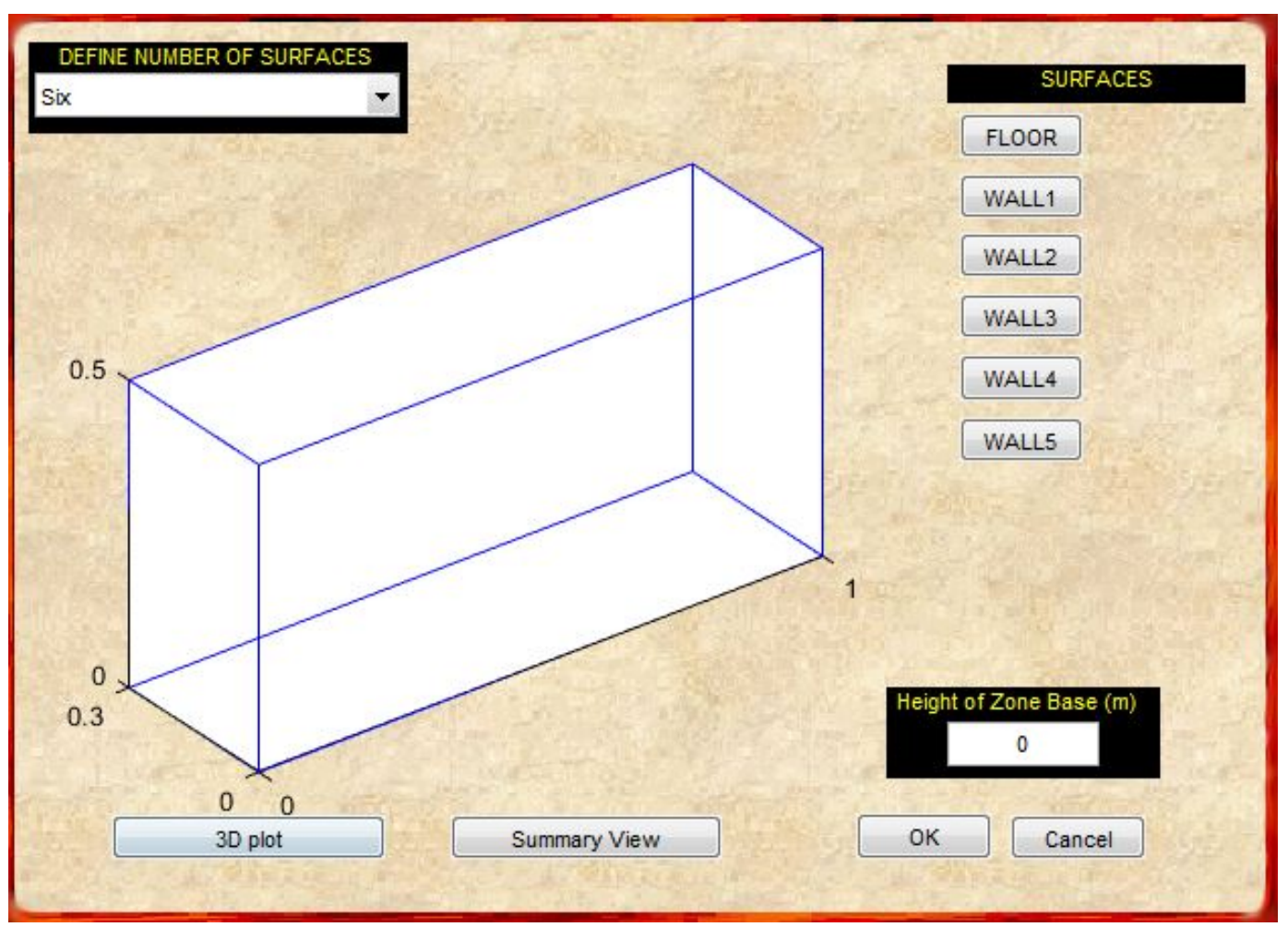

Figure 4.8: Matlab Simulink HYBCELL volume characteristics.

\subsubsection{Active Solar Chimney Numerical Model}

As stated previously, in order to simulate the performance of a solar chimney, a Matlab Simulink program was developed. Matlab Simulink was selected as the simulation tool in the interest of continuing previous works (El Mankibi et al., 2015; Mankibi et al., 2015) and in order to create a numerical tool able to integrate different alternative technologies into the computational representation of a ZEB. Several elements of a ZEB or green energy buildings such as thermal energy storage technology at low temperatures (Roccamena et al., 2018) or multifunctional building envelopes (Bahrar et al., 2018) have been developed by the group at the ENTPE in the search of these goals. The ASC numerical model was developed as a numerical tool able to determine the impact of such technology on a building in the interests of the Paris Agreements goals.

The combination of the modules presented across this section were regrouped in a Simulink interface which determines the performance of the solar chimney. Each level of the chimney ( 7 in total) provides constant information that is exchanged 
between the adjacent volumes. As reported previously, the heat exchange and the airflow phenomena across the chimney influence each other. In order to analyse and solve each system, the model regroups the surface temperatures for the inner and outer wall across the height of the chimney, and the overall pressure distribution from the pressure code discretization which allows the determination of the exit mass flow rate. The radiative model conveys the information concerning the incident energy of each surface. This information is then used to calculate the conductive heat transfer across the multi-layered wall. The temperature across the channel, as well as the newly acquired wall temperature help to define the corresponding pressure distribution. The conduit experiences a pressure drop due to the height of the system and the stack effect induced by the temperature difference. Finally, the information of the three previous models is used to calculate the convective transfers across the chimney and calculate the new channel air temperature distribution. The chimney is initialized to atmospheric conditions with a density and pressure drop depending on the elevation. The solar chimneys presented throughout Chapter 3 are subjected to different environmental and experimental conditions. These different conditions and inputs modify the initial and operational conditions of each simulation. The validation of the numerical tool is assessed against the experimental results. The general structure of the Simulink program can be appreciated in Figure 4.9.

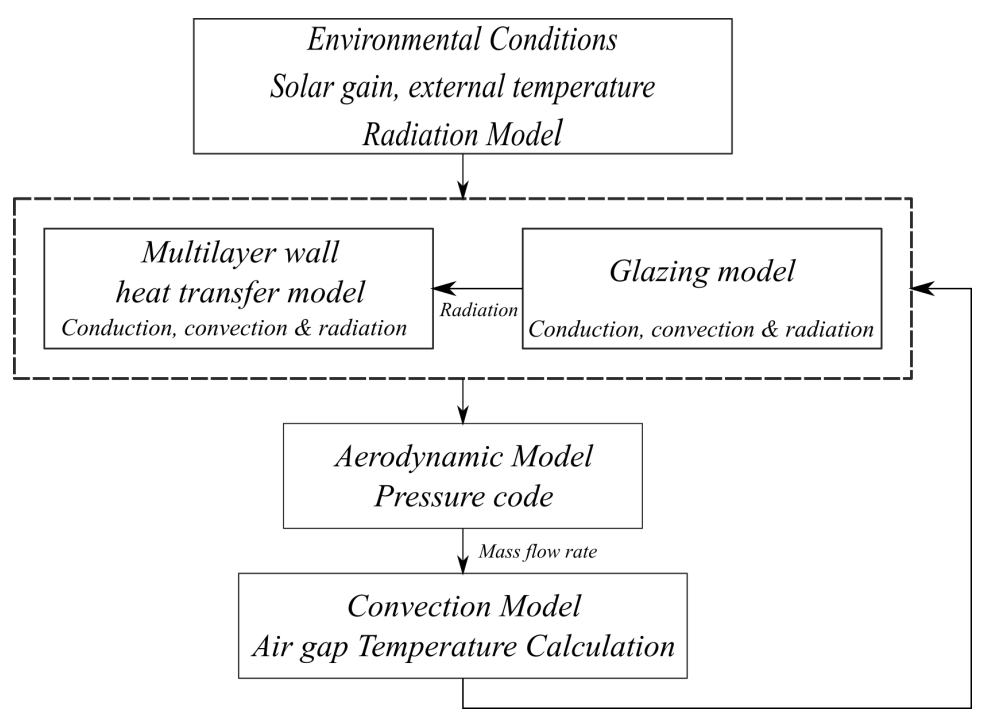

Figure 4.9: Solar chimney model calculation flow chart 


\subsubsection{Simulation parameters}

In order to run the numerical models on the Matlab Simulink interface, the system requires the initial physical information of each one of the systems. The working parameters for the simulation are presented in the following tables.

Table 4.3: Working parameters for the Heat Transfer Model

\begin{tabular}{|c|c|c|c|c|}
\hline \multicolumn{5}{|c|}{ Heat Transfer Model } \\
\hline \hline Layer discretization size & Layer 1 & Layer 2 & Layer 3 & MCP layer \\
$(n)$ & 4 & 10 & 4 & 10 \\
$\rho\left[\mathrm{kg} / \mathrm{m}^{3}\right]$ & 2640 & 30 & 450 & 800 \\
$C_{p}[\mathrm{KJ} / \mathrm{kgK}]$ & 800 & 1400 & 1215 & $250^{*}$ \\
$\lambda[\mathrm{W} / \mathrm{mK}]$ & 1.14 & 0.035 & 0.135 & 0.2 \\
Layer width $(e)$ & 0.025 & 0.025 & 0.025 & 0.015 \\
\hline MCP Panel location & \multicolumn{4}{|c|}{ North wall } \\
\hline \hline
\end{tabular}

*Combination of latent and sensible heat in a temperature range of 35 to $50{ }^{\circ} \mathrm{C}$.

Table 4.4: Working parameter for the Aerodynamic Model / Pressure Code

\begin{tabular}{|c|c|}
\hline \multicolumn{2}{|c|}{ Pressure Code } \\
\hline \hline Chimney Discretization $(N y)$ & 7 \\
Height of cell $(H)$ & 0.5 \\
Length of cell $(L)$ & 1 \\
Width of cell $(w)$ & 0.3 \\
Specific Air Heat Capacity $\left(C_{p}\right)$ & 1006 \\
Atmospheric pressure $\left(P_{a t m}\right)$ & 101325 \\
Discharge Coefficient $\left(C_{d}\right)$ & 0.70 \\
\hline
\end{tabular}

Table 4.5: Working parameters for the Convection Model

\begin{tabular}{|c|c|}
\hline \multicolumn{2}{|c|}{ Convection Model } \\
\hline \hline Glass convection coefficient $\left(h_{\text {glass }}\right)$ & 15 \\
Wall convection coefficient $\left(h_{\text {wall }}\right)$ & 4 \\
\hline Glazing Location & South wall \\
\hline \hline
\end{tabular}

The multi-layered wall is not composed of all the layers depicted in Table 4.3, but the values were modified according to the prototype in use. The layers correspond to (1) glazing, (2) extruded polystyrene and (3) plywood. 


\subsection{Results \& Discussion}

In order to compare and validate the numerical model presented throughout this section, the solar chimney model was assessed against the results of the second prototype. The experimental cycles employed for this analysis have already been established (see Table 3.4 in section 3.3.5). The choice is based on the consistency of the second prototype results. The validation of the the numerical model consists on the analysis of the mass flow rate and the temperature at the outlet of the chimney. The comparative study of the simulation results are presented in Figures 4.10 to 4.14. As stated through out the aforementioned section, the difference between the experimental cycles are mainly the insulation layer and the inlet temperature of the solar chimney. The ASC numerical model shows the capability of following the real behaviour of the experimental campaigns regardless of the chimney configuration.

In terms of exiting mass flow rate, the NoPCM cycles show a discrepancy specially during charging phases. During this part of the experimental protocol, the simulation shows a quasi constant behaviour. The chimney's experimental data shows a clear dependency in external temperature. This impact is evidenced in the increase of mass flow rate in Figure 4.11a compared to Figure 4.10a. When setting an inlet temperature of $18{ }^{\circ} \mathrm{C}$ (P2C3NoPCM-3 case) the numerical model seems to over estimate the mass flow rate during the ventilation phase (3) which is followed by the activation phase (open outlet and incoming radiation) but decreases slightly from the real data when subjected to the external temperature. The second ventilation phase (7) seems to show a high correlation to the experimental data, however, the ASC model seems to maintain a certain inertia, thus deviating from reality. PCM cycles, on the other hand, seem to replicate to a good degree the aforementioned phase (7). Phases (3) and (4) behave in the same way as NoPCM cycles; which means that the numerical model over estimates the mass flow rate. This over estimation is particularly noticeable for cycle P2C2PCM-2 (Figure 4.13a) where the inlet temperature was set to $18{ }^{\circ} \mathrm{C}$ with the help of the GHB. 


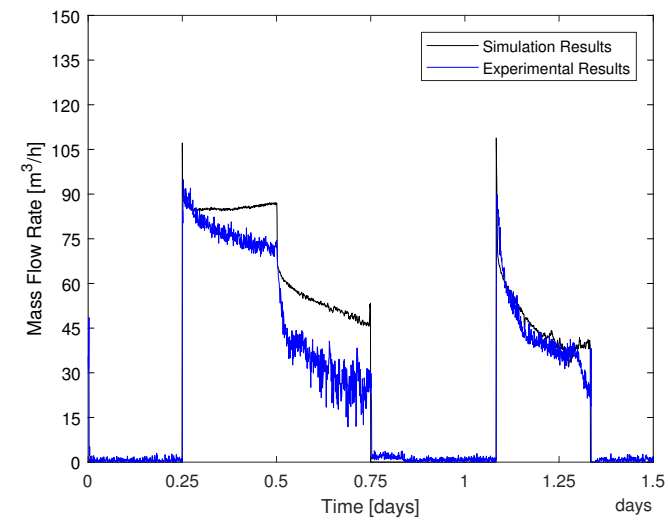

(a)

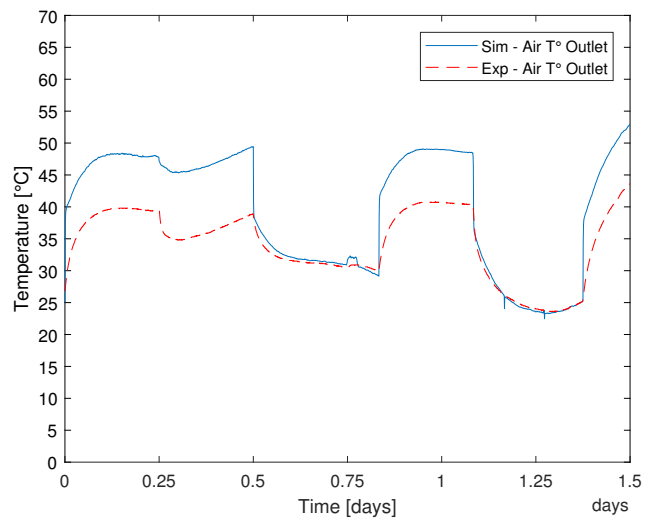

(b)

Figure 4.10: Comparative results for (a) mass flow rate and (b) outlet temperature between simulation and the P2C3NoPCM-2 experimental campaign.

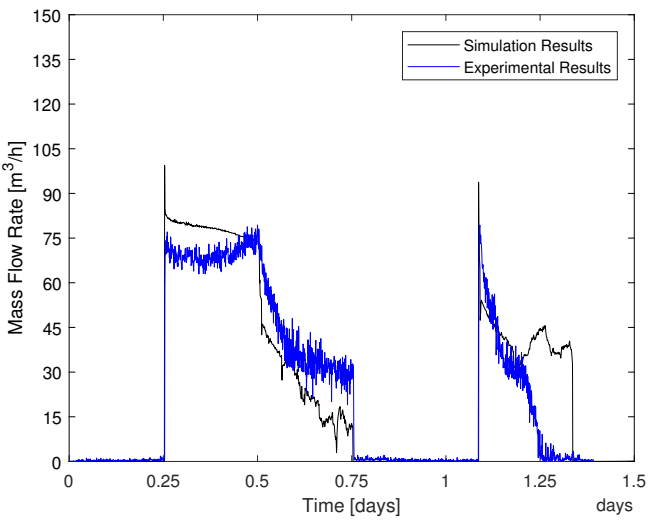

(a)

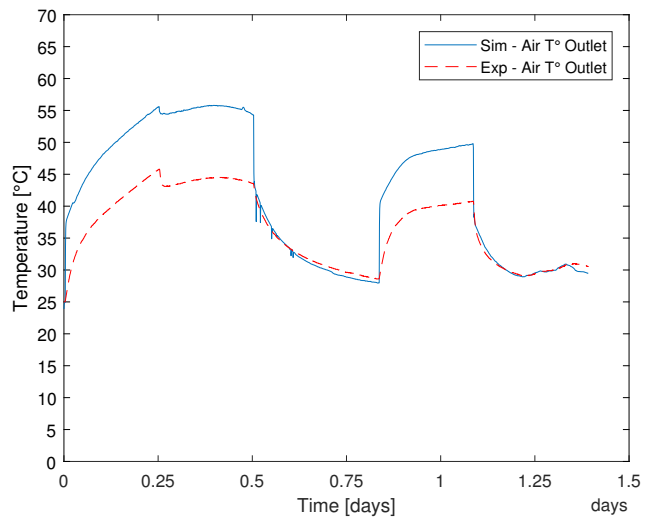

(b)

Figure 4.11: Comparative results for (a) mass flow rate and (b) outlet temperature between simulation and the P2C4NoPCM-3 experimental campaign.

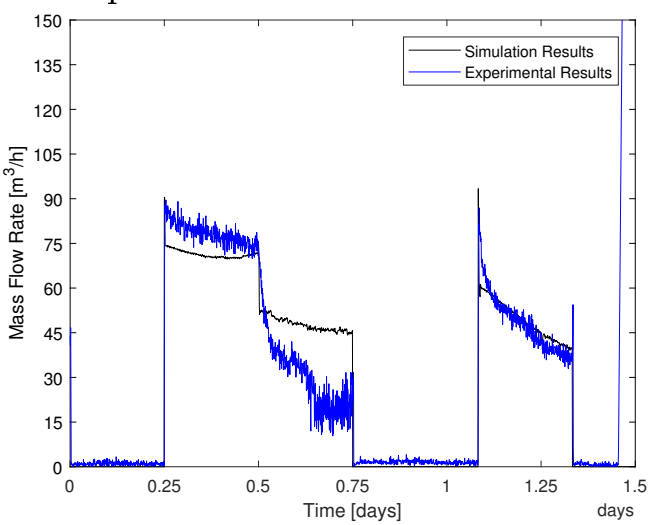

(a)

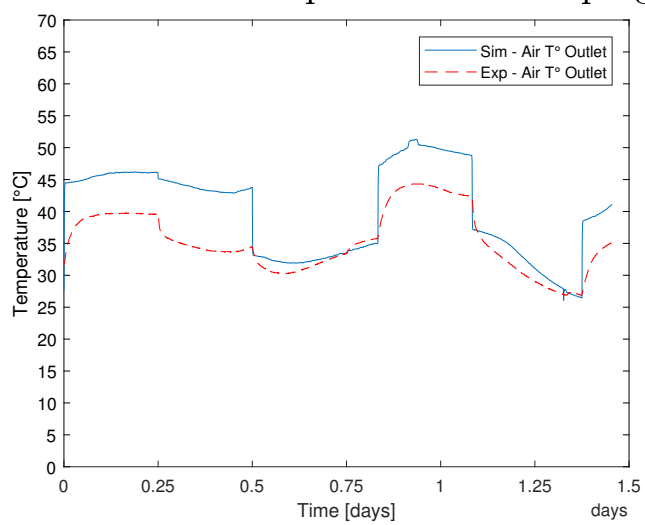

(b)

Figure 4.12: Comparative results for (a) mass flow rate and (b) outlet temperature between simulation and the $\mathrm{P} 2 \mathrm{C} 1 \mathrm{PCM}-2$ experimental campaign. 
The over estimation of the numerical model could be attributed to different factors, however it is important to notice that the overall outlet temperature calculated by the ASC numerical model presented in this section is approximately $7.5{ }^{\circ} \mathrm{C} \pm 2{ }^{\circ} \mathrm{C}$ during phases 3,4 and 7 . Otherwise, the temperature calculation shows good agreement during the rest of the experimental protocol.

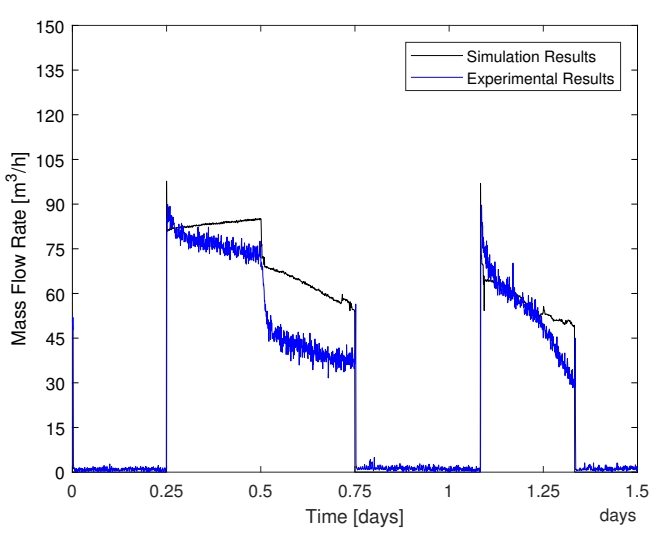

(a)

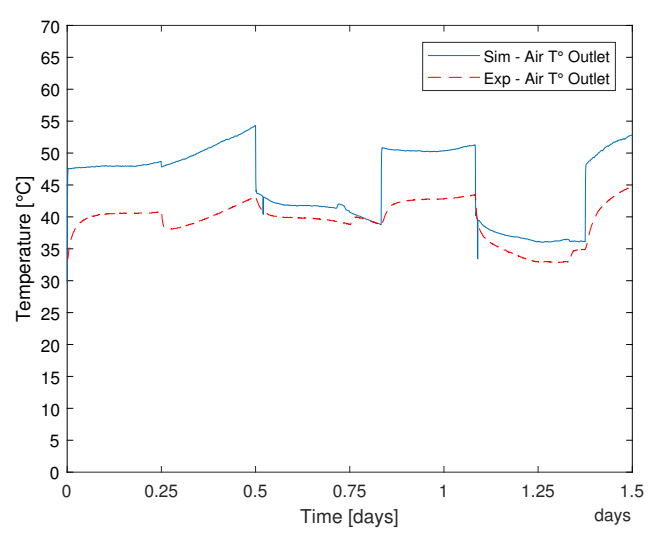

(b)

Figure 4.13: Comparative results for (a) mass flow rate and (b) outlet temperature between simulation and the P2C2PCM-2 experimental campaign.

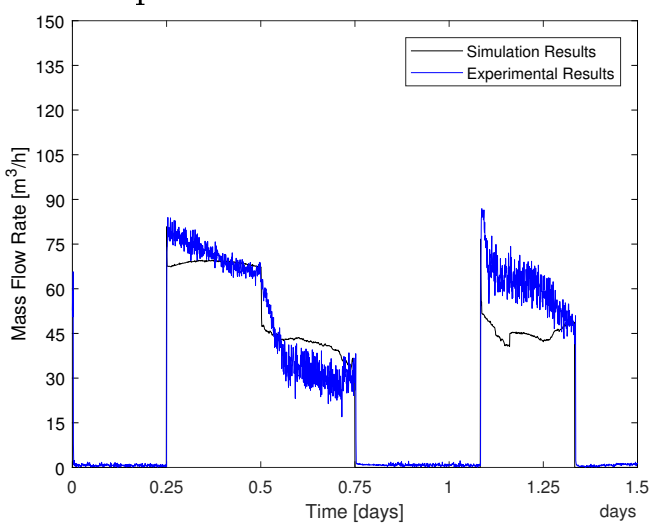

(a)

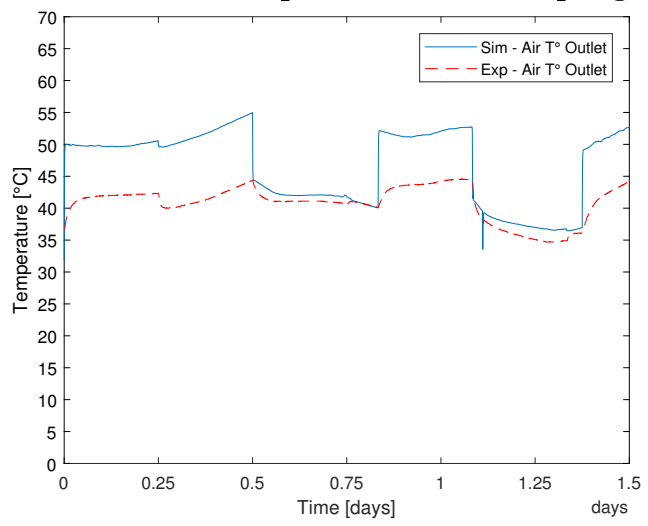

(b)

Figure 4.14: Comparative results for (a) mass flow rate and (b) outlet temperature between simulation and the P2C5PCM-2 experimental campaign.

\subsubsection{ASC Numerical Model Robustness and Correlation Validation}

The numerical simulations were carried out with the data captured during each experimental cycle, hence why the statistical analysis of the operating conditions was not performed, however; in order to determine the reliability of the numerical 
model, the correlation between the simulation and the experimental results must be determined. Just as the statistical analysis carried out in section 3.4 .3 both sets of data were compared through $R$ programming. According to ASHRAE guideline 14 (Measurement of Energy and Demand Savings) the Normalized Mean Bias Error (NMBE) and the Coefficient of Variation of the Root Mean Square Error $(\mathrm{CV}(\mathrm{RMSE}))$ can help calibrate a model if the respective values are $\pm 10 \%$ and $\pm 30 \%$. Usually the value of $p$ is considered 0 which leads to equation 4.53 .

$$
\begin{gathered}
N M B E=\frac{1}{\bar{y}_{\text {measured }}} \frac{\sum_{n}^{i=1}\left(y_{\text {simulated }}-y_{\text {measured }}\right)}{n-p} \times 100(\%) \\
N M B E=\frac{\sum_{n}^{i=1}\left(y_{\text {simulated }}-y_{\text {measured }}\right)}{\bar{y}_{\text {measured }} n} \times 100(\%) \\
C V(R M S E)=\frac{1}{\bar{y}_{\text {measured }}} \sqrt{\frac{\sum_{n}^{i=1}\left(y_{\text {simulated }}-y_{\text {measured }}\right)^{2}}{n-p-1}} \times 100(\%)
\end{gathered}
$$

Table 4.6: Correlation between simulation and experimental results.

\begin{tabular}{|c|c|c|c|c|}
\hline \hline & \multicolumn{2}{|c|}{ Mass Flow Rate } & \multicolumn{2}{c|}{ Air Temperature } \\
\hline Cycle & NMBE [\%] & $\begin{array}{c}\text { CV(RMSE) } \\
{[\%]}\end{array}$ & NMBE [\%] & $\begin{array}{c}\text { CV(RMSE) } \\
{[\%]}\end{array}$ \\
\hline P2C1NoPCM-2 & 384.74 & 583.24 & 12.312 & 16.177 \\
P2C3NoPCM-2 & 5.3456 & 32.764 & 13.476 & 19.987 \\
P2C4NoPCM-3 & -8.2523 & 44.306 & 13.089 & 20.004 \\
P2C1PCM-2 & 3.7202 & 32.971 & 13.261 & 17.613 \\
P2C2PCM-2 & 13.273 & 33.985 & 15.237 & 18.968 \\
P2C5PCM-2 & -8.2515 & 31.456 & 13.885 & 18.392 \\
\hline \hline
\end{tabular}

The results presented in Table 4.6 demonstrate that the system is capable of recreating the behaviour of the system with a slight error. The error can be attributed, as shown in the values for the outlet temperature, by the over calculation of the air temperature across the chimney. In the case of the first cycle (first row of Table 4.6) the great difference is attributed to the results affected by the lack of insulation. This heat loss was not considered during the simulation, thus the greater difference. The calibration of the model to better represent the temperature distribution could bring the error of the mass flow rate even lower. The 
cycle P2C1NoPCM-2 shows the greatest error but this is due to the experimental conditions mentioned throughout this section.

Additionally and in order to further support the results obtained through the simulation, the correlation between both sets of data was calculated. The results of this analysis are presented in the table below (Table 4.7). It can be observed that for most of the results, there exits a very high correlation between the simulation and the experimental data. The smaller correlation in mass flow rate for the first NoPCM cycle is a result of the low performance of the system during the experimental campaign where the chimney suffered a great heat loss and the exiting air flow was severely hampered. Moreover, the system seems to under estimate the outlet temperature of the PCM cycles for the reasons stated before.

Table 4.7: Correlation between simulation and experimental results.

\begin{tabular}{|c|c|c|}
\hline \hline Cycle & Mass Flow Rate & Air Temperature \\
\hline P2C1NoPCM-2 & 0.7599 & 0.9411 \\
P2C3NoPCM-2 & 0.9881 & 0.9243 \\
P2C4NoPCM-3 & 0.9123 & 0.9527 \\
P2C1PCM-2 & 0.9463 & 0.9086 \\
P2C2PCM-2 & 0.9656 & 0.8091 \\
P2C5PCM-2 & 0.9539 & 0.7545 \\
\hline
\end{tabular}




\subsection{General Conclusion}

The developed numerical model describes to good agreement the overall behaviour of both the classic solar chimney and the PCM integrated solar chimney, however some discrepancies have been noticed in specific configurations. The discrepancy in mass flow rates between the simulation and the experimental results can also be a result of the experimental conditions. The incident radiation is considered homogeneous across the chimney and does not take into consideration the $0.28 \mathrm{~m}$ section that limits the contribution of the halogen lamps at the middle level of the chimney $(1.6 \mathrm{~m})$. The section can affect the temperature distribution of the real solar chimney and thus reducing the outlet temperature at the outlet level, as seen in the comparison with the simulation results. A lower air chimney temperature would directly impact the ventilation performance of the numerical model and could more precisely depict the real behaviour of the chimney.

The major difference between the simulation and the experimental results was in the size of the inlet. In order to represent the behaviour of the solar chimney a numerical inlet of $0.3 \mathrm{~m}$ had to be established to ensure convergence. This error might be the result of the ratio between the size of the inlet and the size of the chimney. Values under this minimum inlet size cause the simulation to severely under estimate the overall performance of the chimney. A numerical optimisation of the calculation of entering flows must be carried out in order to establish the correct inlet size of the chimney. It is clear that the law of big openings employed is not well adapted for this numerical model and should be changed for a more refined model.

Overall the numerical model represents the behaviour of the solar chimney for large or small time steps. The simulation time is inversely proportional to the size of the time step, however the simulation of a day with a time step of $60 \mathrm{~s}$ takes under 3 minutes. The system can accurately represent the experimental results 
with an overall confidence greater than $90 \%$, however further studies should aim at reducing the discrepancies between both sets of data through the optimisations suggested previously. The system is overall $3 \%$ above the accepted values of NMBE and $\mathrm{CV}(\mathrm{RMSE})$ which suggests that even though it can demonstrate the behaviour of both a classic solar chimney and a PCM integrated solar chimney, there is still a necessary improvement to make. 
Chapter 5

Numerical Optimization 


\subsection{Introduction}

Chapter 4 was consecrated to the development of a numerical program capable of representing the phenomena produced by the temperature difference in a Solar Chimney. It was demonstrated that the numerical model is capable of predicting the behaviour of the SC and the ASC under laboratory conditions with great accuracy without the need of extended experimental campaigns.

The definition of a reliable numerical tool allows the parametric optimization of the system through the modification of operating parameters in the simulation. Several optimization methods can be found in literature (Bassiouny and Koura, 2008; Chen and Qu, 2014; Harris and Helwig, 2007) which involve usually involve the modification of experimental set-up or the extensive simulation under different parameters; however, based on the works of Bahrar et al. (2018); Roccamena et al. (2018) Genetic Algorithms (GAs) were chosen due to their capability to fix operating parameters that maximize/minimize a given objective function. This chapter is dedicated to the presentation of GAs, the definition of the optimization parameters and objective functions as well as the results obtained after the simulation.

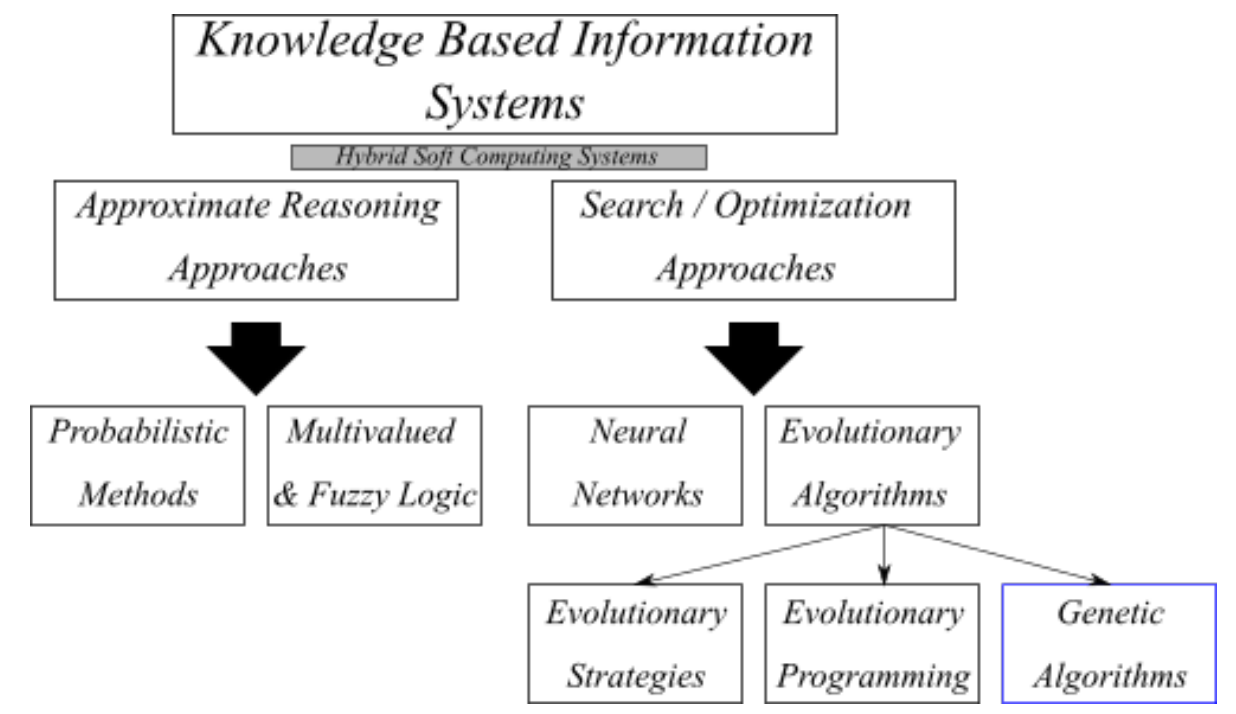

Figure 5.1: Genetic Algorithm field in the hierarchic structure of Knowledge Based Information Systems presented by Mukhopadhyay et al. (2009) 


\subsubsection{Principle of Genetic Algorithms}

Genetic Algorithms are a heuristic optimization technique first introduced in 1975 by John Holland in his book "Adaptation in Natural and Artificial Systems". The method is based on the principle of natural selection and genetics, where the permutation of genes in chromosomes (properties of a system within a given interval for each individual) leads to the establishment of a population. In term, this population is analysed for a given number of generations (iterations) until a set of optimal solutions is defined. This solution is based on the probabilistic selection of chromosomes throughout each generation according to a certain fitness value. This process is repeated until the end condition is met, which can be the number of generations or the solution is found. The solution met by the implementation of these stochastic algorithms is "approximately optimal" since it depends on the number of variables and the selection of objective functions. The random selection of individuals in a population and the number of individuals selected, reduce the error in the solution. According to Coley (1999), the definition of the further populations depend on three main factors:

- Selection: individuals with a higher fit have a greater probability of being chosen over weaker or less optimal options for next generations

- Crossover: the solutions exchange "genes" randomly resulting in individuals permutations

- Mutation: the random modification of single information "genes" in an individual.

Chromosomes are made of units - genes (features or characters), arranged in a linear succession. Every gene controls the inheritance of one or several characteristics (Michalewicz, 1996). The algorithm searches the balance between the size of the population and a potential solution, thus the Darwinian analogy. As stated before, several solutions may be found depending in the population size and number of generations, however, GAs objective is to find the global maximum or global optimum. Several types of genetic algorithms are available for the optimization of numerical models, however; the work presented in this $\mathrm{PhD}$ thesis must ensure the ideal combination of parameters which lead to an optimal solution. Multi-Objective Evolutionary Algorithms (MOEAs) were chosen for this purpose. 


\subsubsection{Non-dominated Sorting Genetic Algorithms II (NSGAs} II)

Non-dominated Sorting Genetic Algorithms (NSGAs) are preferred over other available options because the optimization of the population depends on the Pareto-optimal solution. Pareto-optimal solutions, which correspond to non-dominated solutions, convey results for the combination of the objective functions.

According to Deb et al. (2002), NSGAs come with disadvantages such as the numerical complexity related to the number of objective functions and the population size, the non-elitistic approach (therefore a lack computational speed and the prevention of the loss of optimal solutions) and the need of a specific sharing parameter, which ensures the diversity of the population. The first population towards the solution is arbitrarily chosen from the pool of chromosomes of the system. The evolution of the system is defined and sampled through performance or objective functions. For a given bi-objective optimization, the set of solutions allows the best compromise between the conflicting objectives. The combination of points form what is called a Pareto front.

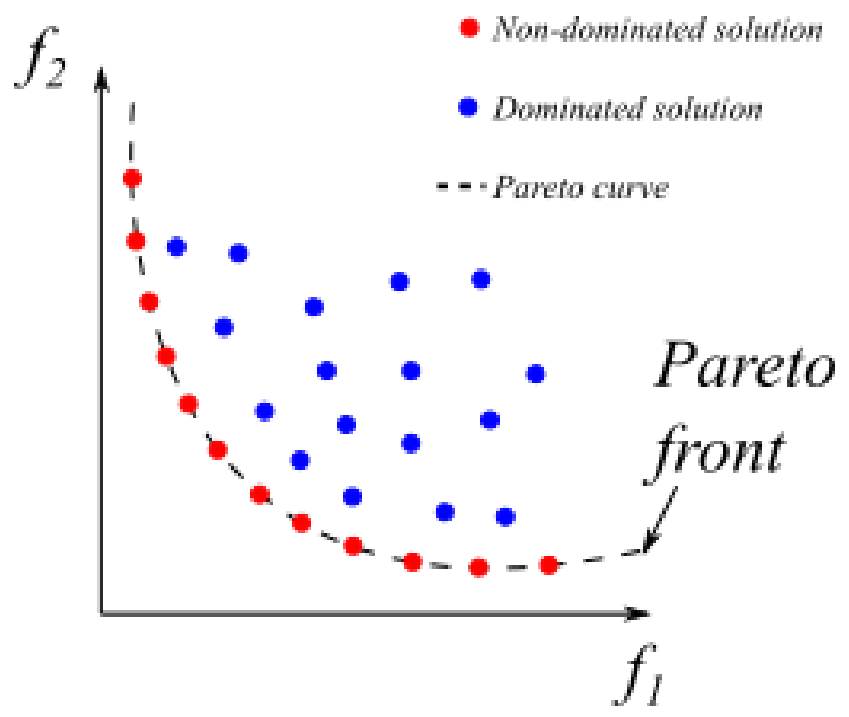

Figure 5.2: Pareto front for a bi-objective optimization function.

The optimisation of the ASC numerical model was based on the NSGA II toolbox 
developed and thoroughly explained by Lin (2011). It has been stated that through the simulation of diverse complex test problems, the NSGA-II has demonstrated its capability to outperform other contemporary MOEAs the Pareto-Archived Evolution Strategy (PAES) Knowles and Corne (1999) or the Strength-Pareto Evolution Strategy (SPEA) (Zitzler, 1999) in the diversity of the solutions and in the convergence towards the true optimum. 


\subsection{Optimization Procedure and Establishment of Objective Functions}

As stated in previous chapters, the solar chimney's performance depends on several factors such as the wall insulation, the incident solar energy or, in the case of the in-situ solar chimney, the wind speed. The optimisation presented in this section concerns the laboratory results and simulation, particularly the experimental campaigns with PCM panels for the second solar chimney prototype. This choice is based on the control of the operating parameters as well as the immediate experimental application. The problem considered seeks to establish a compromise between exiting mass flow rate and temperature differential between the fusion range and the chimney temperature, thus defining the objective functions of the system. In order to maximize both functions several parameters were considered. They concern both modifiable and non-modifiable parameters of the laboratory experimentation. This parameter modification is carried out on the P2C5PCM-2 laboratory results which are subjected to ambient temperature.

Table 5.1: Optimization parameters

\begin{tabular}{|c|c|c|}
\hline \hline Parameter & Current state & Variation range \\
\hline Solar chimney volume height & $0.5 \mathrm{~m}$ & {$\left[\begin{array}{ll}0.4 & 0.7\end{array}\right]$} \\
PCM layer width & $0.015 \mathrm{~m}$ & {$\left[\begin{array}{ll}0.01 & 0.05\end{array}\right]$} \\
PCM fusion range & $40-44^{\circ} \mathrm{C}$ & $40-44 \pm 5^{\circ} \mathrm{C}$ \\
Air gap width & $0.3 \mathrm{~m}$ & {$[0.20 .5]$} \\
Incoming maximum radiation & $600 \mathrm{~W} / \mathrm{m} 2$ & $\phi+\left[\begin{array}{lll}-100 & 400\end{array}\right]$ \\
\hline
\end{tabular}

Laboratory results demonstrated the same peak air flow values during the SC and ASC experimental campaigns. The greatest difference between both results was displayed during phases 4 and 7 of (see section 3.3.5). The goal of this optimization is to ensure the complete fusion of the PCM panels and the air flow increase. The two aforementioned objective functions were chosen primarily due to 
the contradictory nature of both values. Indeed, a higher mass flow rate can lead to the overall decrease of the chimney temperature. The optimum between both objective functions represents the maximum operating temperature to ensure the full PCM phase transformation while maintaining a high mass flow rate.

The results presented throughout section 3 showed the severe negative impact of a partial phase transformation during the ASC experimental cycles. An ideal operating temperature range can be defined from these results. It is considered that any temperature under $44{ }^{\circ} \mathrm{C}$ hampers the ventilation of the chimney and the fusion of the PCM panels, therefore; the longer the system is above this range, the higher the performance of the solar chimney will be. The system therefore looks to:

1. OBJ1 - Maximize the exiting air flow of the solar chimney.

2. OBJ2 - Minimize the the time the solar chimney is below the $44{ }^{\circ} \mathrm{C}$ range. 


\subsection{Results}

The optimisation presented in this section was run under different population sizes and different generation values. The purpose of this increment is to determine the optimal size of the population and the number of generations necessary to obtain a solution. Firstly the optimisation was carried out taking into consideration a reduced number of variables. The first optimisations took into consideration the height of the chimney, the size of the air gap (distance between absorber wall and glazing) and the incident radiation magnitude. The numerical tool is ran continuously for different values comprised between the intervals presented in Table 5.1, as a result, the computational time is multiplied according to number of generation and individuals. The elapsed time for the three aforementioned design variables was of 2.2297 hours on the bi-objective function for 10 generations and 10 individuals.

The first simulation carried out for 10 generations and 10 individuals accepted the established variable ranges. The addition of generations and individuals makes the NSGA-II choose between a greater number of design variables amid the selected range. Some of the ranges had to be modified in order to ensure the completion of the optimisation. Indeed, certain variable combinations lead the system towards divergence. This error is inherent to the pressure code and is directly related to the inlet to height/width ratio of the chimney's numerical model. Some of the combinations that caused the simulation to diverge can be appreciated in Table 5.2.

Several assumptions can be made through the analysis of these results. Mainly 2 major modifications had to be made in the interest of reaching convergence through out the series of generations. It can be observed that the big differences between $H$ and $w$ can lead to divergence. Furthermore, it was observed that radiation values with significant figures, or not multiples of 10 , cause the system the stop prematurely. The first modification relates to the architectural characteristics of the 
Table 5.2: Simulation Error Parameters

\begin{tabular}{|c|c|c|c|c|c|}
\hline \hline & Gen Error & Gen/Pop & H & w & phi \\
\hline 1 & 5 & $25 / 50$ & 0.6 & 0.24 & 351.15 \\
2 & 4 & $25 / 50$ & 0.52 & 0.28 & 400 \\
\hline 3 & 13 & $25 / 50$ & 0.47 & 0.31 & 390 \\
\hline 4 & 3 & $50 / 75$ & 0.54 & 0.25 & 250 \\
5 & 8 & $50 / 75$ & 0.52 & 0.28 & 400 \\
6 & 1 & $50 / 100$ & 0.61 & 0.42 & 350 \\
7 & 1 & $50 / 100$ & 0.54 & 0.41 & 187 \\
8 & 2 & $50 / 100$ & 0.48 & 0.34 & 206 \\
9 & 3 & $50 / 100$ & 0.46 & 0.37 & 281.3 \\
10 & 2 & $100 / 100$ & 0.45 & 0.28 & 214.10 \\
\hline
\end{tabular}

solar chimney. These values were constrained to two significant figures in order to maintain a physical logic and to ensure the convergence of the system. In the same way the value $\phi$, which helped to modify the radiation input to the system, was bound to multiples of ten. The system seems reject values between this multiples.

Even though the system consistently stopped due to convergence issues, the results highlighted on Table 5.2 corresponding to a population of 50 for 25 generations, displayed the capabilities and the first possible combination of parameters towards the optimisation of a PCM integrated solar chimney. Figures 5.5 to 5.5 show the formation of the aforementioned Pareto front.

Although inconclusive, the employment of Genetic Algorithms displays a performance increase through the modification of certain parameters. As expected, the increase in incident radiation, decreases the time accumulated time that the solar chimney is under the $44{ }^{\circ} \mathrm{C}$ temperature range. Similarly, the highest air flow rate can be obtained by increasing the height of the solar chimney and increasing the simulated solar gain. During the simulation, it was considered that the width of the panels cannot be modified (Rubitherm's size format). The fusion range of the PCM was also neglected in order to limit the variables that could cause the system to diverge.

The new values employed for this optimization can be appreciated in Table 5.3. The results of the optimisation after the thirteenth generation selects systematically 
air gap widths close to $0.3 \mathrm{~m}$. Similarly, the system tends to choose values for the incoming radiation above $250 \mathrm{~W} / \mathrm{m}^{2}$ which is consistent with the studies review through Chapter 2. The height of the chimney seems to affect as well the performance of the solar chimney. Indeed an increase can be appreciated for values an overall height above $3.5 \mathrm{~m}$, however this values also correspond to a higher incoming irradiance.

Table 5.3: Optimization parameters

\begin{tabular}{|c|c|c|}
\hline \hline Parameter & Current state & Variation range \\
\hline Solar chimney volume height & $0.5 \mathrm{~m}$ & {$\left[\begin{array}{ll}0.45 & 0.6\end{array}\right]$} \\
Air gap width & $0.3 \mathrm{~m}$ & {$\left[\begin{array}{ll}0.3 & 0.5\end{array}\right]$} \\
Incoming maximum radiation & $600 \mathrm{~W} / \mathrm{m} 2$ & $\phi+\left[\begin{array}{ll}0 & 400\end{array}\right]$ \\
\hline \hline
\end{tabular}




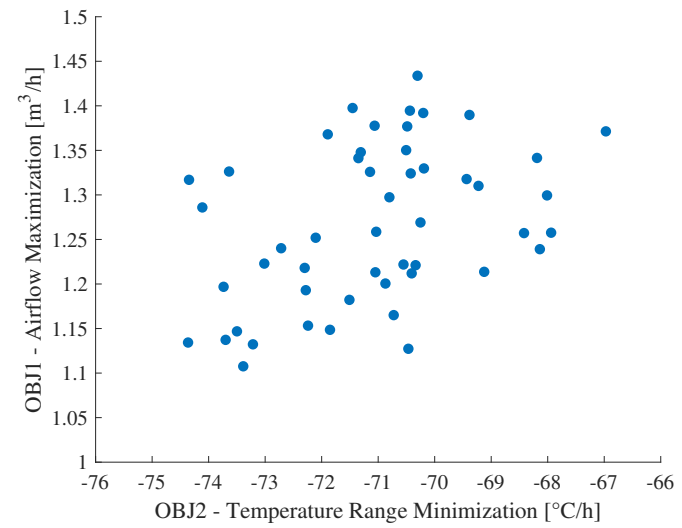

(a)

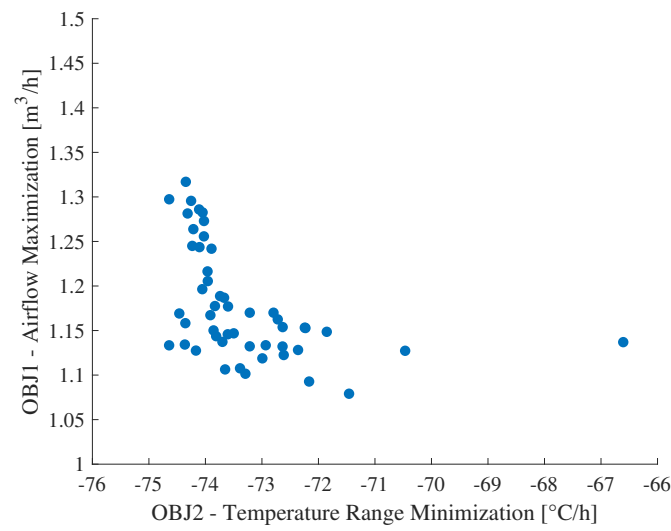

(b)

Figure 5.3: Results of the (a) first and (b) third generations of the application of the NSGA-II on the ASC numerical model.

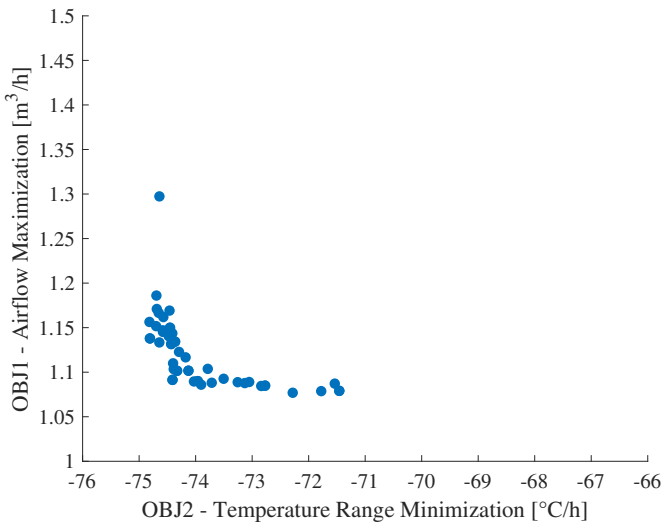

(a)

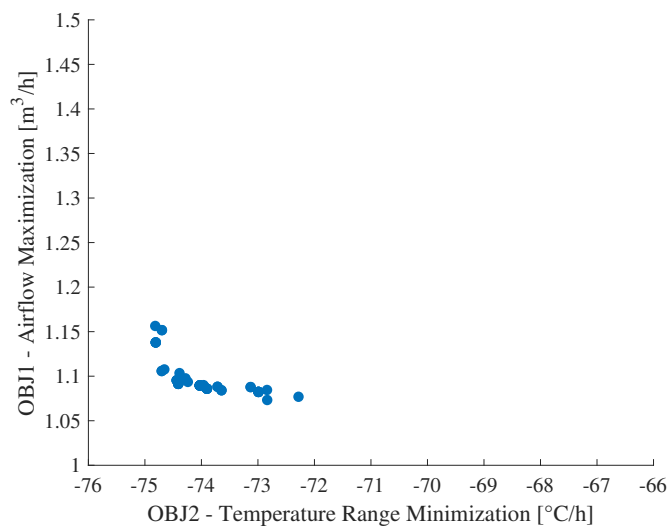

(b)

Figure 5.4: Results of the (a) sixth and (b) ninth generations of the application of the NSGA-II on the ASC numerical model.

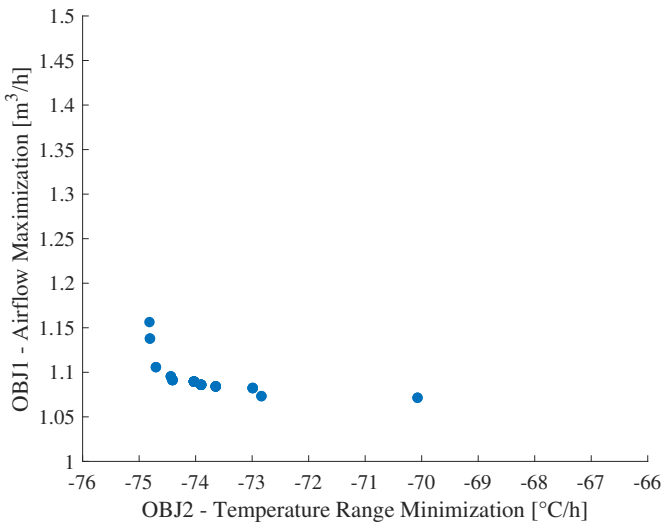

(a)

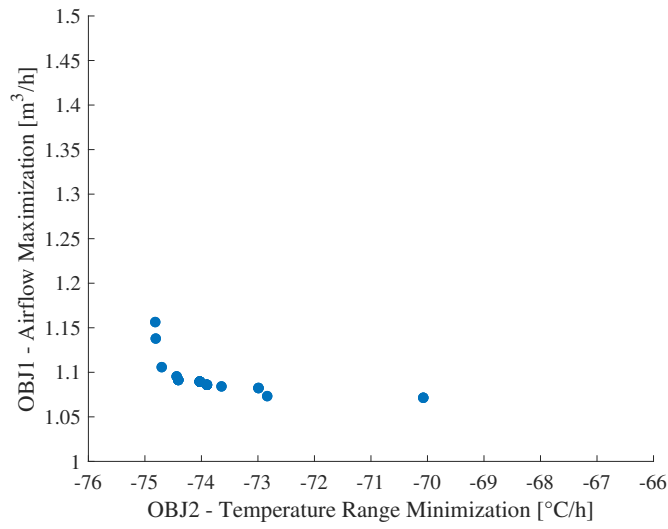

(b)

Figure 5.5: Results of the (a) twelfth and (b) thirteenth generations of the application of the NSGA-II on the ASC numerical model. 


\subsection{Conclusions}

The optimization study conducted in this chapter aimed to determine if the modification of certain operating parameters of the laboratory solar chimney, minimizing the time the chimney is below the fusion temperature range of the PCM panels while increasing the mass flow rate across the chimney. More parameters could be added to this optimisation study, however the greater the number of variables, the number of generations and the size of the population have a great impact on the simulation time.

The NSGA-II has shown great potential throughout the literature and has led to the parametric optimization of several numerical models, however it seems to be ill adapted for the ASC numerical model. The numerical tool developed throughout this dissertation depends on the calculation of pressure distribution and airflow of the pressure code. The pressure code employed for the calculation of the aforementioned variables, depends on the characteristics of the solar chimney. The inlet and outlet of the chimney are kept at the same size to maintain some coherence with the actual characteristics of the laboratory chimney, however; the modifications to the height and width can lead to the divergence of the system depending on the combination and resolution of the signal. After an exhaustive number of simulations, the parameters had to be severely constrained since large value ranges would lead the NSGA-II to stop due to divergence.

Overall, the simulation highlights the progressive definition of a Pareto front even though the optimization is not carried out until the end. As it is, the NSGA-II shows great potential for the determination of the optimal chimney conditions, yet as it has been stated in the previous chapter, the determination of these design variables depends on refinement of the developed numerical model. The system should be further tested under larger variable ranges seems the results display possibility of obtaining better results under bigger heights and smaller air gaps. 
Chapter 6

General Conclusion 


\subsection{Conclusion}

The work presented throughout this thesis represents the collective work of three different laboratories (ENTPE, CIEMAT and CENIDET) from three countries invested in the goals set during the 2016 Paris Agreement towards energetic sustainability. The goal of this PhD was to analyse experimentally and numerically the addition of PCM panels on a solar chimney for the prolonged utilization of this green technology. Solar chimneys have already demonstrated a great potential without the addition of the PCM panels, however the system stops performing without solar energy. In order to achieve the goals of this work, the proposed solution consisted in the incorporation of Rubitherm RT44 PCM panels thorough out the surface of the chimney.

Laboratory experimental campaigns carried out in the laboratories of the ENTPE allowed the characterization of PCM panels on a simple-build solar chimney for two different configurations. These experimental cycles evidenced the potential of PCM panels and the importance of insulation in this type of solar technology. By increasing the thermal inertia of the system, the laboratory results displayed greater ventilation and thermal results than the NoPCM cycles. Furthermore, the panels maintain both a more stable temperature and air flow in the absence of a heat source. It was demonstrated that the ventilation rate of the solar chimney under laboratory conditions could be extended for ventilation only phases and could maintain a stable airflow of $60.82 \mathrm{~m}^{3} / \mathrm{h}$ without any heat source present. Overall the laboratory prototypes achieved a regular exit airflow of approximately $82 \mathrm{~m}^{3} / \mathrm{h}$ during activation phases regardless of the addition of PCMs. Furthermore it was demonstrated that the surface temperature during the complete experimental cycle is sustained at a slightly lower temperature during charging phases (approximatey $2{ }^{\circ} \mathrm{C}$ ), however, they are kept at a higher temperature during the whole cycle. 
The in-situ experimental study allowed the continuous monitoring of a $4 \mathrm{~m}$ PCM integrated solar chimney and the effect of these energy storage devices on its performance. It is clear that wind speed has a great influence on the ventilation performance of this green technology and this is further amplified by the exhaust characteristics. The PSA solar chimney displays design flaws that affect the performance of the PCM panels. In order to conclude on the effects of the RT44 panels on this SC, the chimney might need to be slightly modified. It is also very likely that the $0.15 \mathrm{~m}$ wall is hampering the PCM performance, thus an additional insulation layer between the concrete wall and the PCM panels could better help characterize a PCM integrated solar chimney under environmental conditions. It was concluded that wind speeds above $4 \mathrm{~m} / \mathrm{s}$ increase the ventilation performance of the solar chimney and the addition of PCMs has a lower effect than the effects of wind.

A numerical model was developed for the determination of the ideal parameters of a PCM integrated solar chimney. The ASC model can reliably represent the behaviour of the laboratory operating conditions but loses accuracy with the addition of additional environmental variables such as the pressure loss generated by wind speed. The numerical model was not coupled to another building model for this reason, since it does not depict entirely the behaviour of the solar chimney under the influence of wind speed. This tool, however; can help as a first version for a future coupled model. The numerical model can reliably replicate the behaviour of the solar chimney up to a $90 \%$ confidence, however a continuous optimisation is necessary in order to increase the reliability of the model.

The numerical model was calibrated with the experimental data, which allows the definition of an accurate solution at a low computational cost. The employment of genetic algorithms helped define some of the optimal operating parameters of a solar chimney, however further studies should aim at the optimization of the numerical model under environmental conditions. These tools are limited by the numerical model which can diverge under certain parameters. The continuous optimization of the numerical tool is necessary for the definitive conclusions 
provided by both the numerical model and the optimization method. Nonetheless, the optimization results show the capabilities of both this optimization method and the potential of the ASC numerical tool.

\subsection{Outlook and Perspectives}

Throughout this dissertation, a broad study of the performance of a PCM integrated solar chimney (ASC) was carried out towards the definition of the optimal working parameters both numerically and experimentally. Several experimental campaigns were performed in order to analyse the behaviour of this energy storage devices under different operating conditions. The previous works mentioned during the literature review as well as the laboratory campaigns carried out at ENTPE demonstrated that PCMs increase the thermal performance of the system and the energy stored by the solar chimney can be redistributed to other sections of the building. In addition, an optimization of the solar chimney walls should be carried out in order to avoid any heat loss that might hamper the performance of the PCM panels. Furthermore, in-situ results displayed the capabilities of the solar chimney of reaching high air temperatures regardless of low external temperature, which also supports this point.

Subsequent studies should focus on the optimisation of these parameters for the determination of the ideal PCM quantity. Moreover, it was demonstrated that the PCM integrated chimney suffers a noticeable performance decrease due to the incomplete fusion of the PCM, thus the need of further investigation on the optimisation of the incident solar energy. The simulated solar radiation employed during the laboratory experimental campaigns was limited to approximately $600 \mathrm{~W} / \mathrm{m}^{2}$ on a $90{ }^{\circ}$ angle. Further studies should focus on the magnitude and angle of the heat source in order to establish the individual performance of each panel on the solar chimney, and the optimal quantity of panels. In any case, the 
PCM panels displayed the ability of maintaining or increasing the performance of a solar chimney without any negative effects and demonstrate a higher thermal inertia.

The numerical model requires calibration since the size of the inlet had to be numerically modified in order to ensure convergence. Nevertheless, the statistical analysis carried out demonstrates that the model can predict the behaviour of the solar chimney with a minimum confidence of $88 \%$. Even though this confidence value is high, it is not sufficiently elevated to properly couple to a building model. Further works should aim at the calibration of the ASC numerical model before any integration to other models. 


\title{
Appendix A
}

\section{Prototype V1 No PCM - Laboratory}

\author{
Results
}




\section{A.1 C5NoPCM - Mass flow rate \& External and Surface Temperatures}

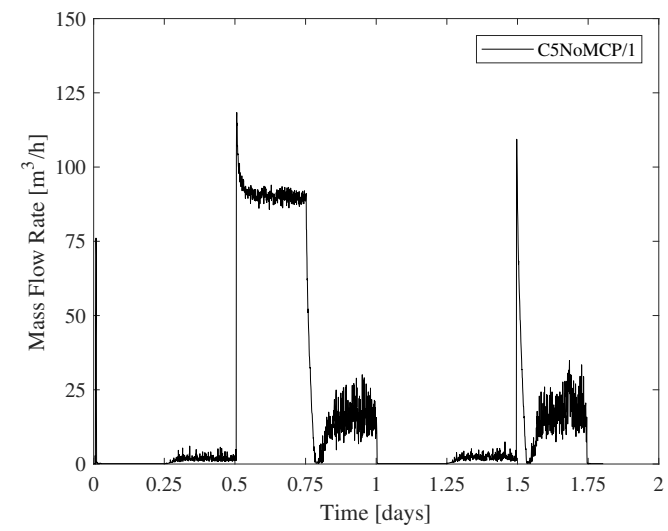

(a)

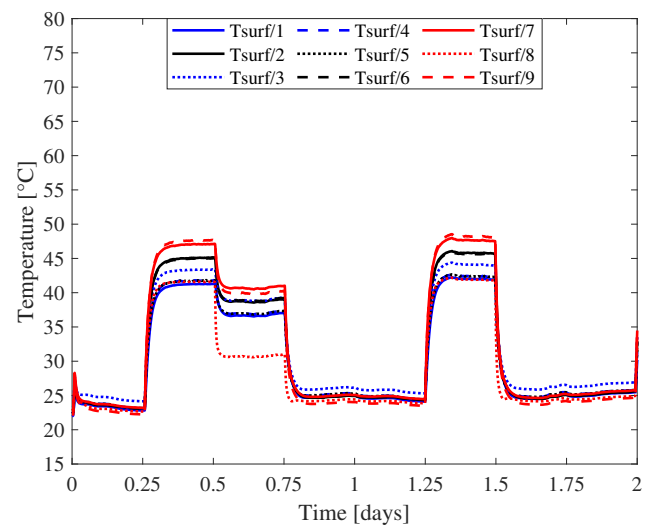

(b)

Figure A.1: C5NoMCP-1 results of (a) mass flow rate and (b) external and volume temperatures. Cooler temperature $=18^{\circ} \mathrm{C}$, unknown external temperature

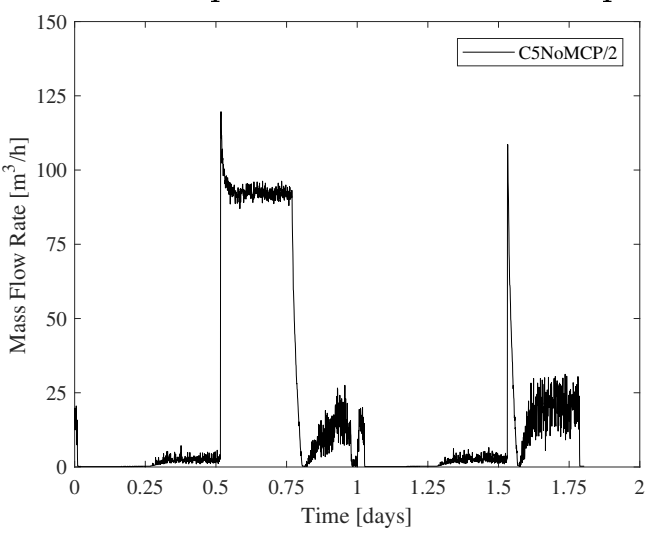

(a)

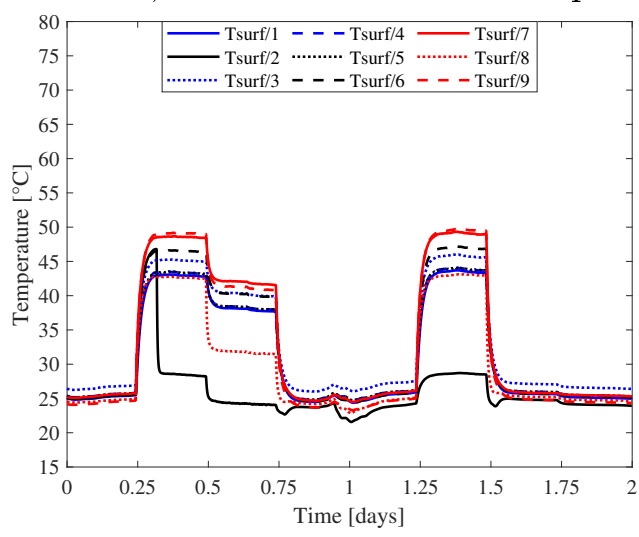

(b)

Figure A.2: C5NoMCP-2 results of (a) mass flow rate and (b) external and volume temperatures. Cooler temperature $=18^{\circ} \mathrm{C}$, unknown external temperature 


\section{A.2 C6NoPCM - Mass flow rate \& External and Internal Temperatures}

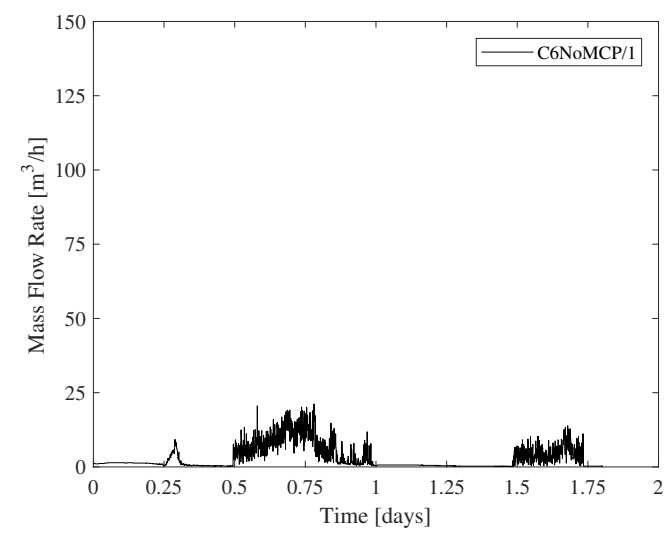

(a)

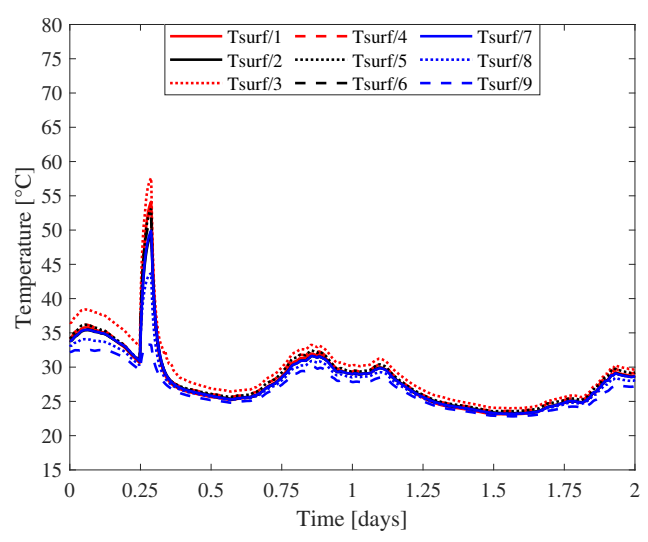

(b)

Figure A.3: C6NoMCP-1 results of (a) mass flow rate and (b) external and volume temperatures. Cooler temperature $=19^{\circ} \mathrm{C}$, unknown external temperature

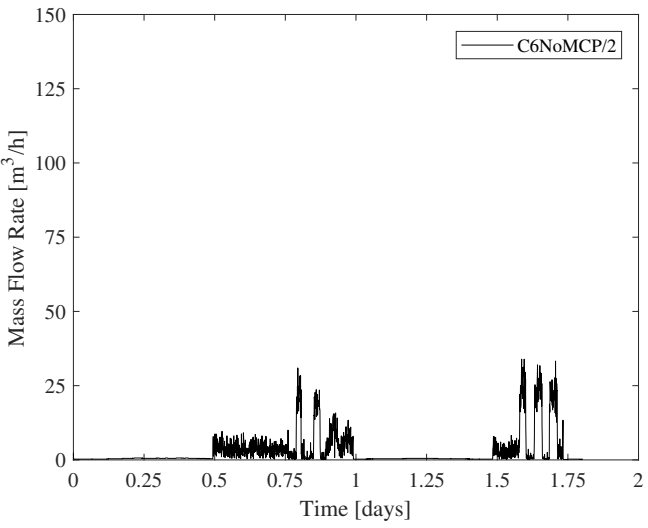

(a)

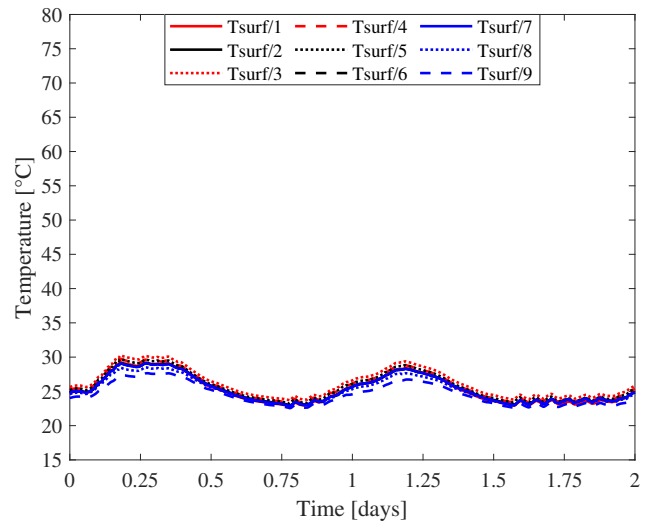

(b)

Figure A.4: C6NoMCP-2 results of (a) mass flow rate and (b) external and volume temperatures. Cooler temperature $=19^{\circ} \mathrm{C}$, unknown external temperature

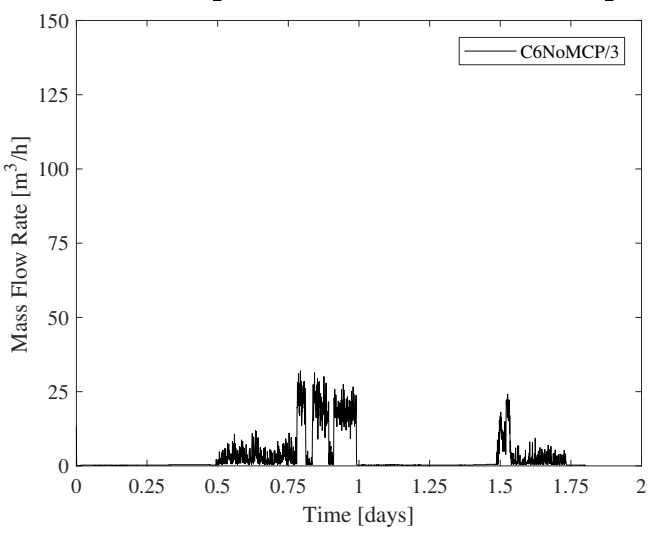

(a)

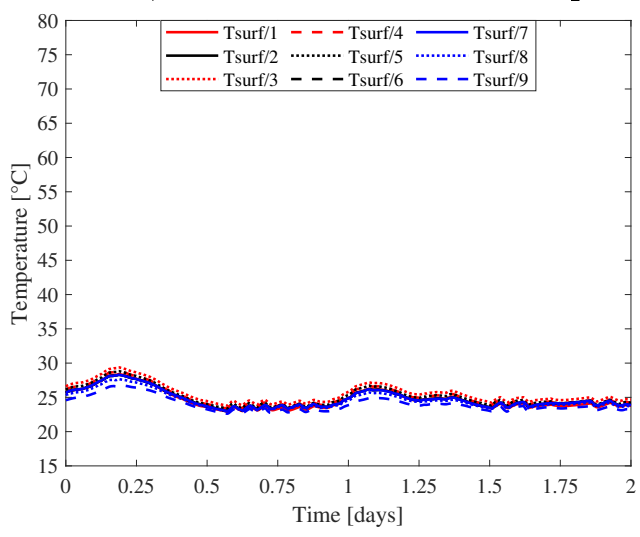

(b)

Figure A.5: C6NoMCP-3 results of (a) mass flow rate and (b) external and volume temperatures. Cooler temperature $=19^{\circ} \mathrm{C}$, unknown external temperature 


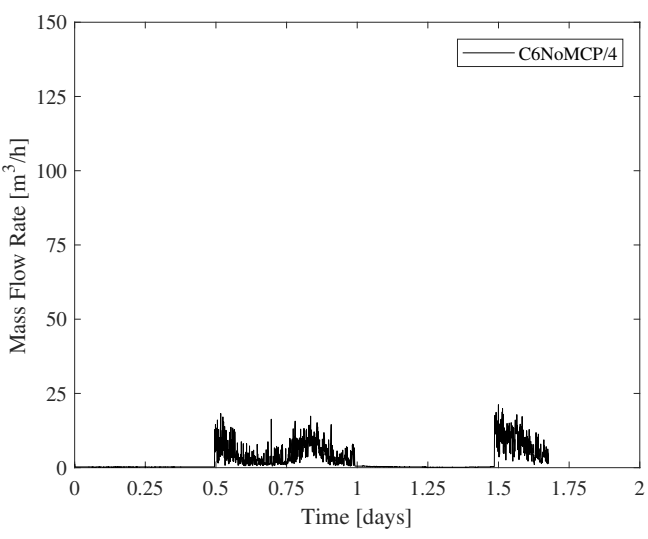

(a)

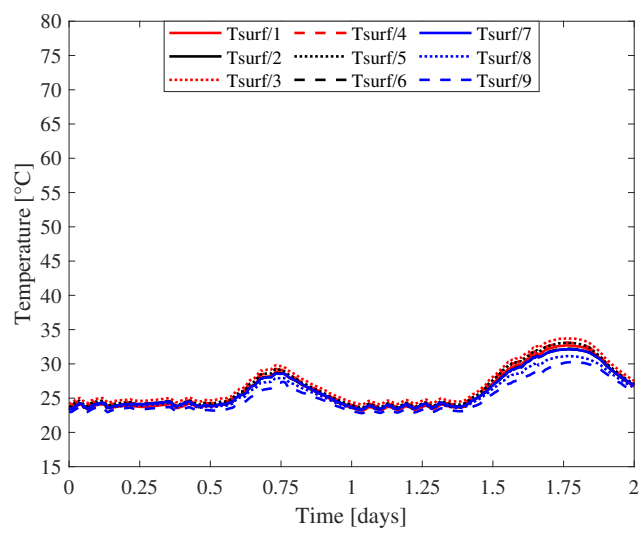

(b)

Figure A.6: C6NoMCP-4 results of (a) mass flow rate and (b) external and volume temperatures. Cooler temperature $=19^{\circ} \mathrm{C}$, unknown external temperature 


\section{A.3 C7NoPCM - Mass flow rate \& External and Internal Temperatures}

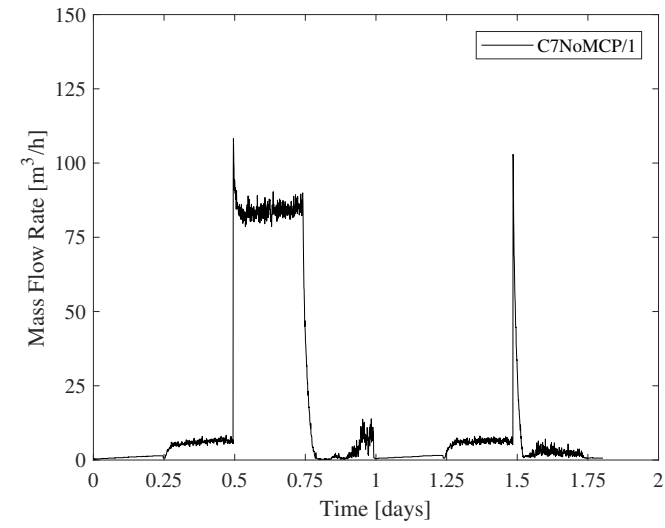

(a)

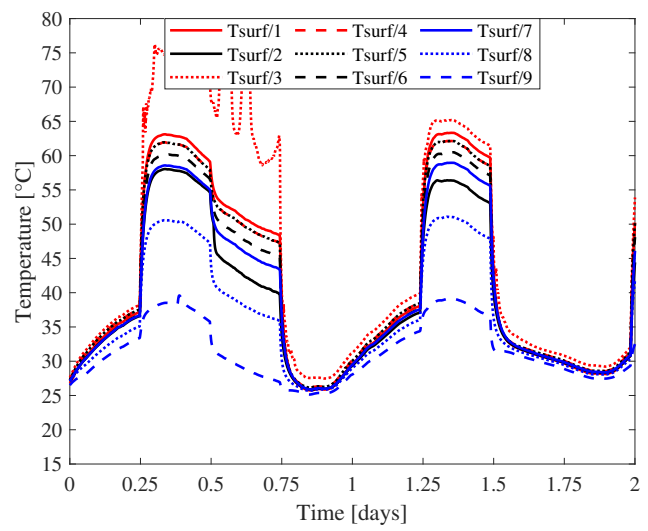

(b)

Figure A.7: C7NoMCP-1 results of (a) mass flow rate and (b) external and volume temperatures. Cooler temperature $=18^{\circ} \mathrm{C}$, unknown external temperature

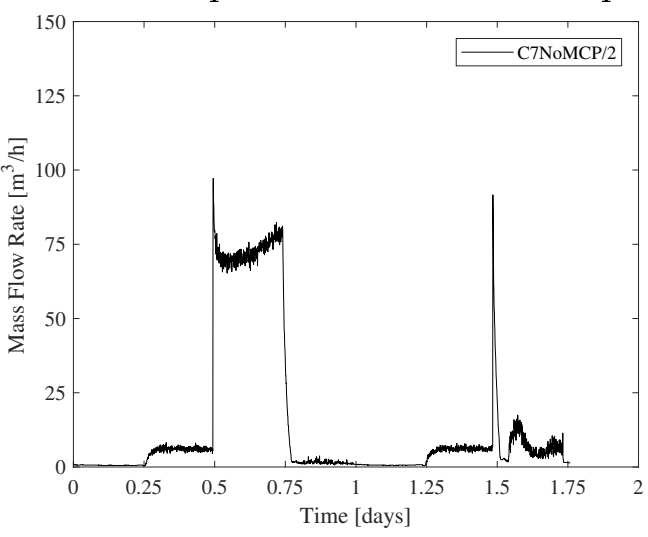

(a)

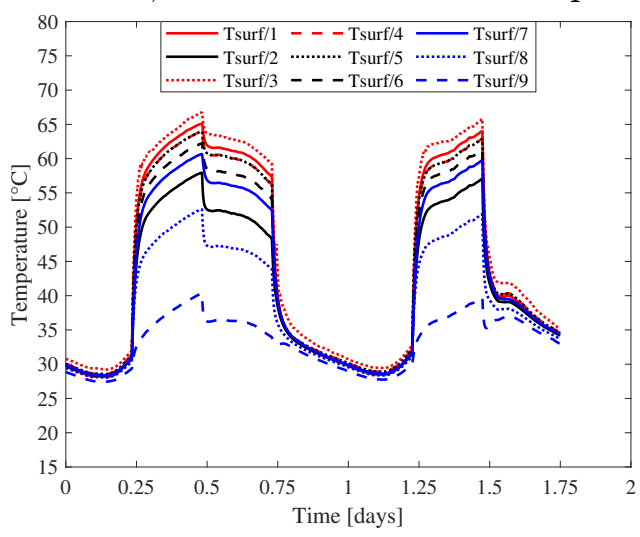

(b)

Figure A.8: C7NoMCP-2 results of (a) mass flow rate and (b) external and volume temperatures. Cooler temperature $=18{ }^{\circ} \mathrm{C}$, unknown external temperature 


\title{
Appendix B
}

\section{Prototype V1 PCM - Laboratory}

\author{
Results
}




\section{B.1 C1PCM - Mass flow rate \& Surface Tempera- tures}

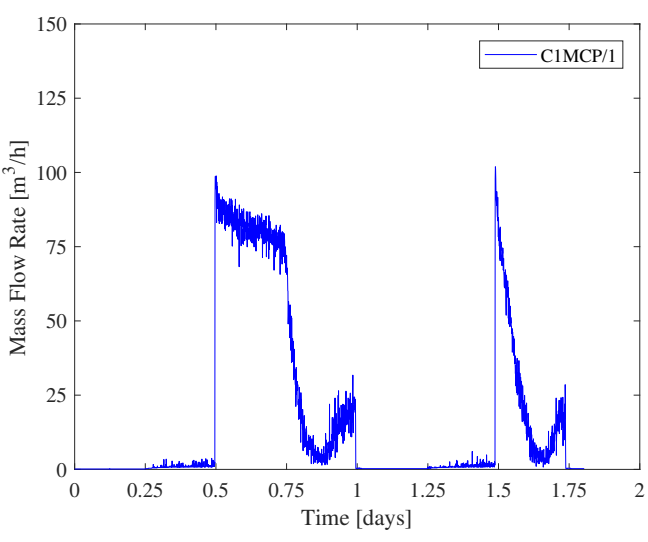

(a)

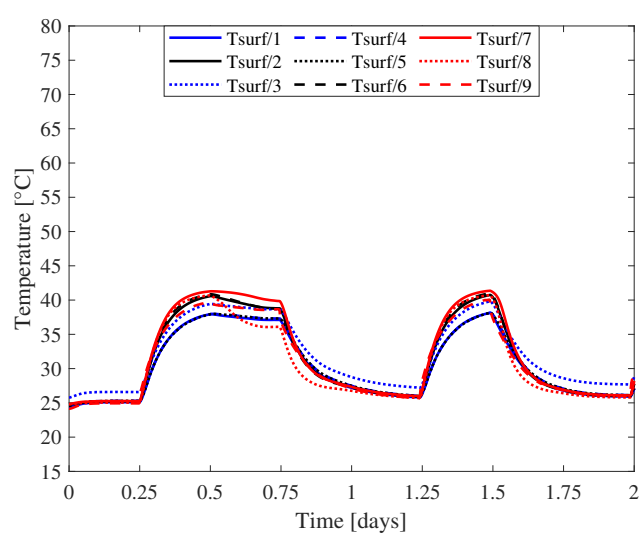

(b)

Figure B.1: C1MCP-1 results of (a) mass flow rate and (b) external and volume temperatures. Cooler temperature $=18{ }^{\circ} \mathrm{C}$, unknown external temperature

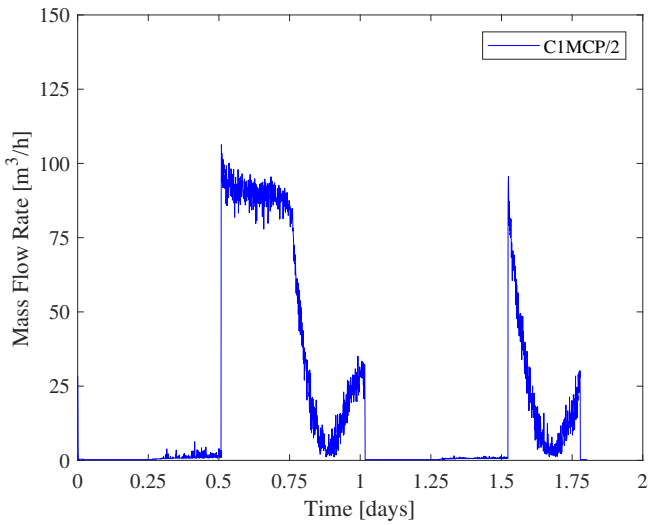

(a)

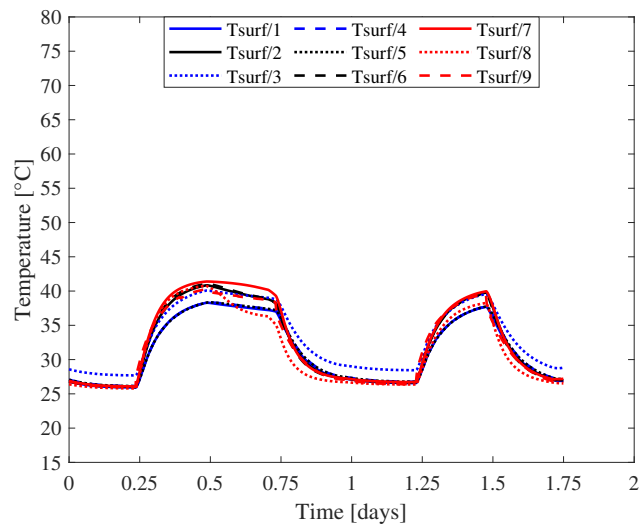

(b)

Figure B.2: C1MCP-2 results of (a) mass flow rate and (b) external and volume temperatures. Cooler temperature $=18{ }^{\circ} \mathrm{C}$, unknown external temperature 


\section{B.2 C1PCM - Surface Temperature Behind PCM \& Surface Temperature Over PCM}

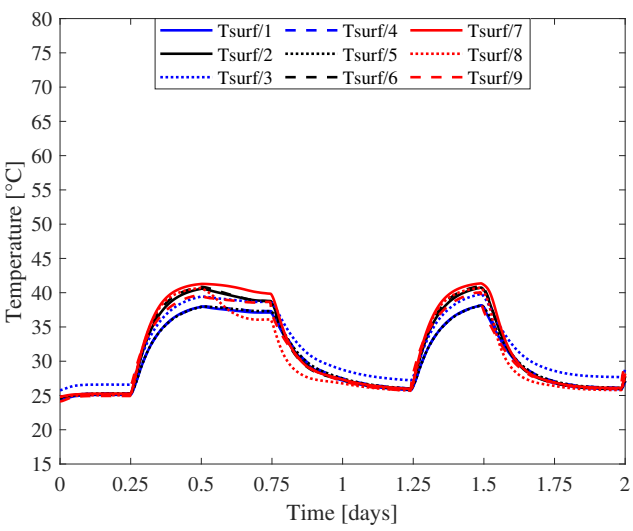

(a)

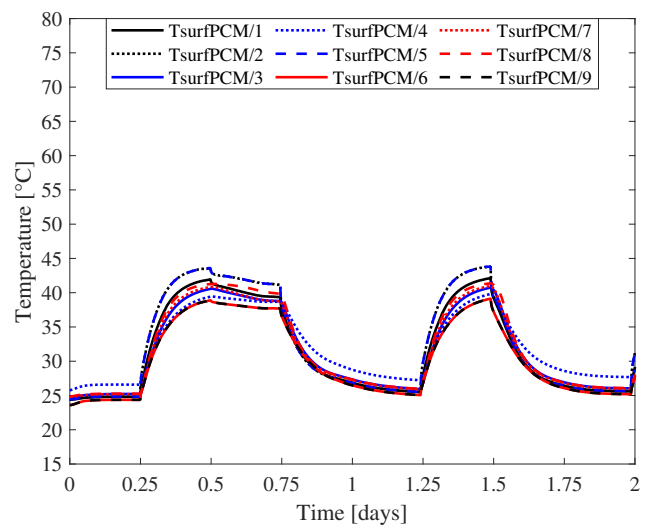

(b)

Figure B.3: C1MCP-1 surface temperature results (a) behind and (b) in front the PCM panel at (blue) $1.0 \mathrm{~m}$, (black), $2.5 \mathrm{~m}$ and (red) $3.8 \mathrm{~m}$.

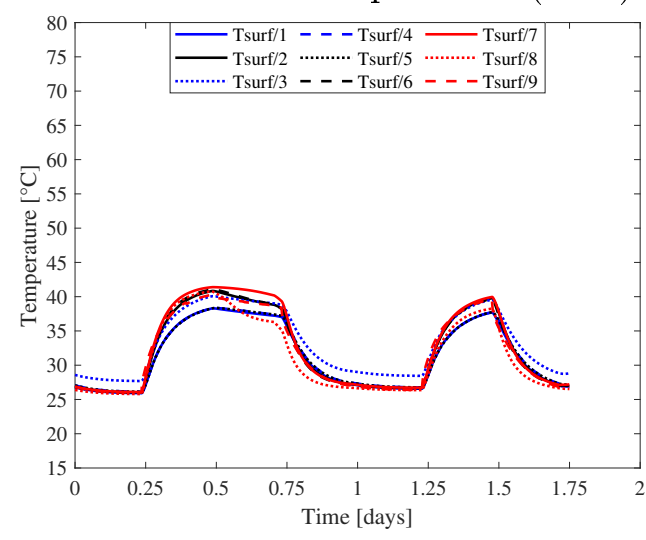

(a)

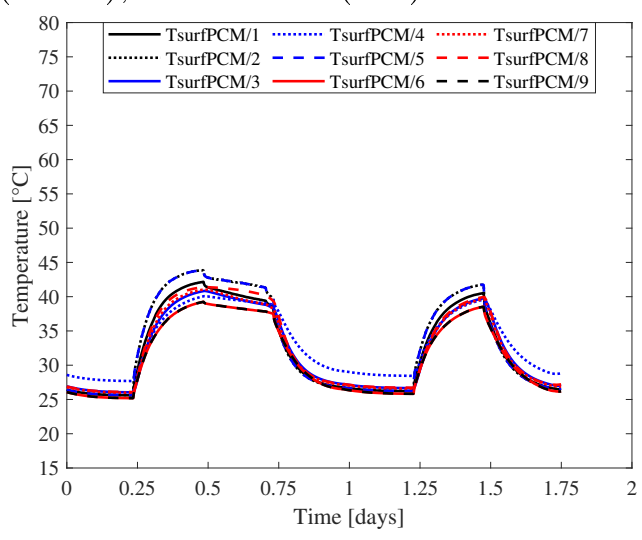

(b)

Figure B.4: C1MCP-2 surface temperature results (a) behind and (b) in front the PCM panel at (blue) $1.0 \mathrm{~m}$, (black), $2.5 \mathrm{~m}$ and (red) $3.8 \mathrm{~m}$. 


\section{B.3 C3PCM - Mass flow rate \& Surface Tempera-}

\section{tures}

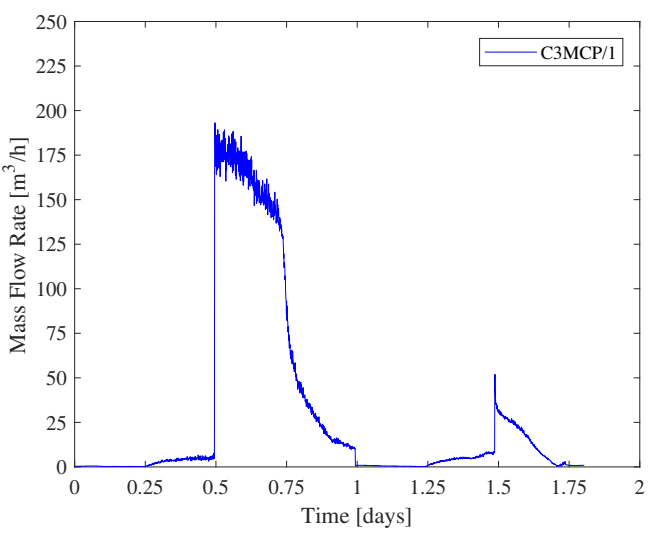

(a)

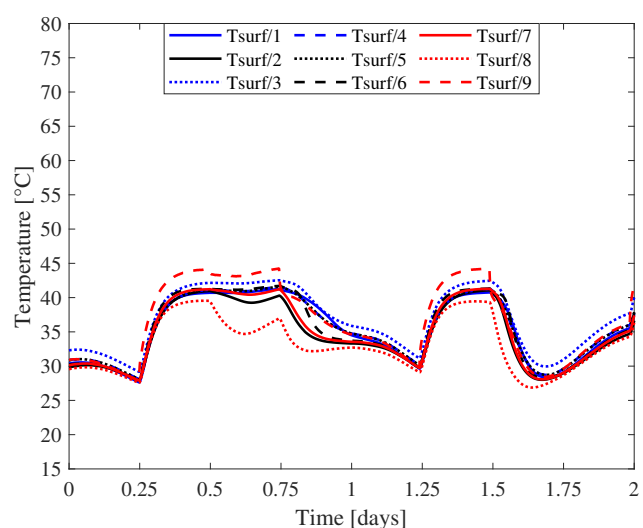

(b)

Figure B.5: C3MCP-1 results of (a) mass flow rate and (b) external and volume temperatures. No Cooler, prototype subjected to external temperature.

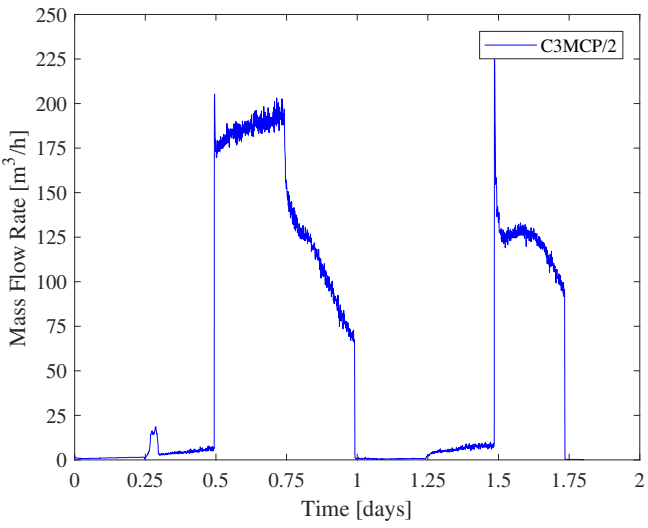

(a)

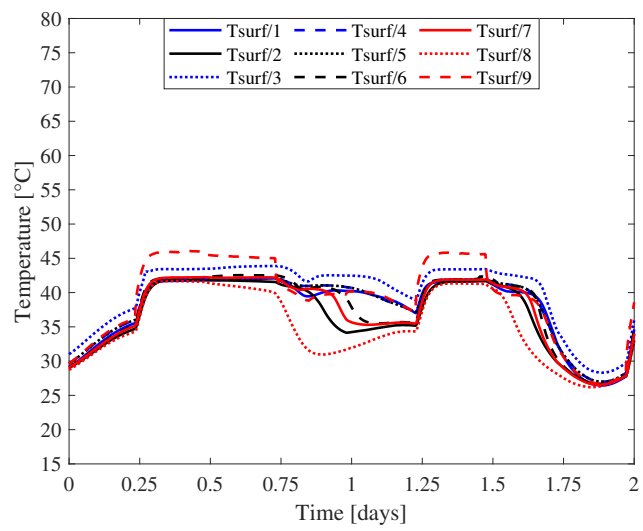

(b)

Figure B.6: C3MCP-2 results of (a) mass flow rate and (b) external and volume temperatures. No Cooler, prototype subjected to external temperature.

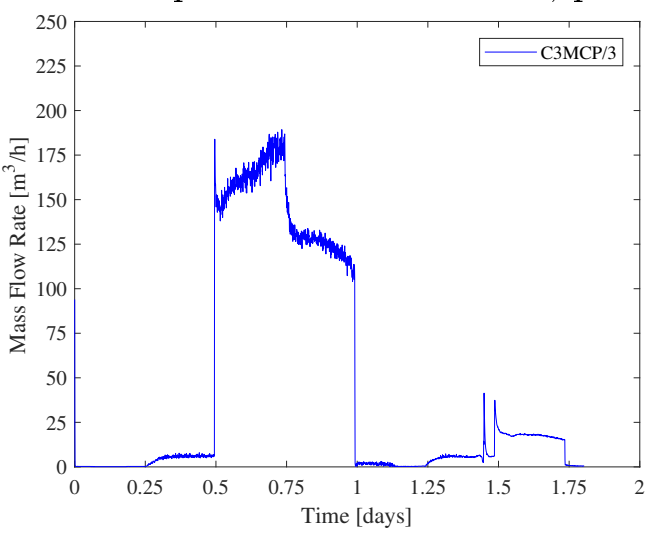

(a)

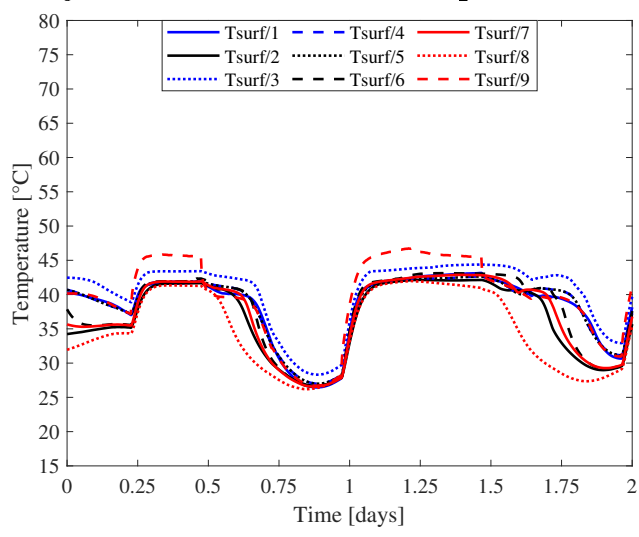

(b)

Figure B.7: C3MCP-3 results of (a) mass flow rate and (b) external and volume temperatures. No Cooler, prototype subjected to external temperature. 


\section{B.4 C3PCM - Surface Temperature Behind PCM \& Surface Temperature Over PCM}

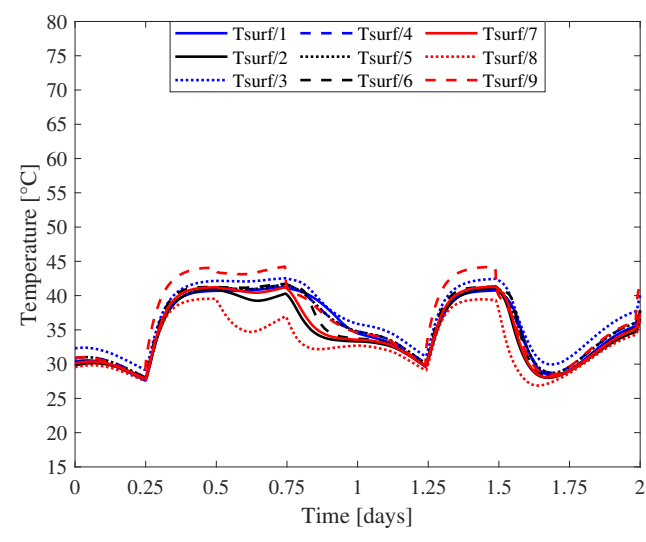

(a)

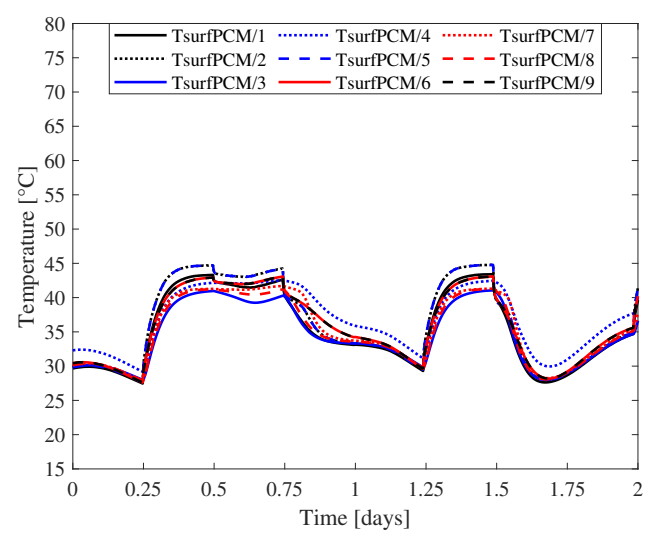

(b)

Figure B.8: C3MCP-1 surface temperature results (a) behind and (b) in front the PCM panel at (blue) $1.0 \mathrm{~m}$, (black), $2.5 \mathrm{~m}$ and (red) $3.8 \mathrm{~m}$.

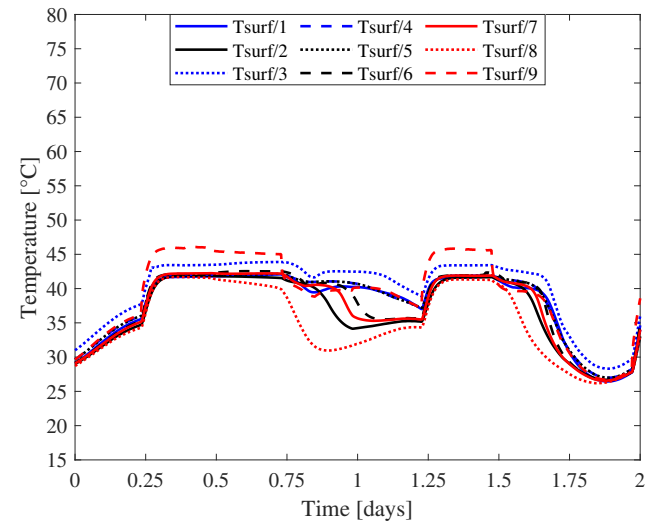

(a)

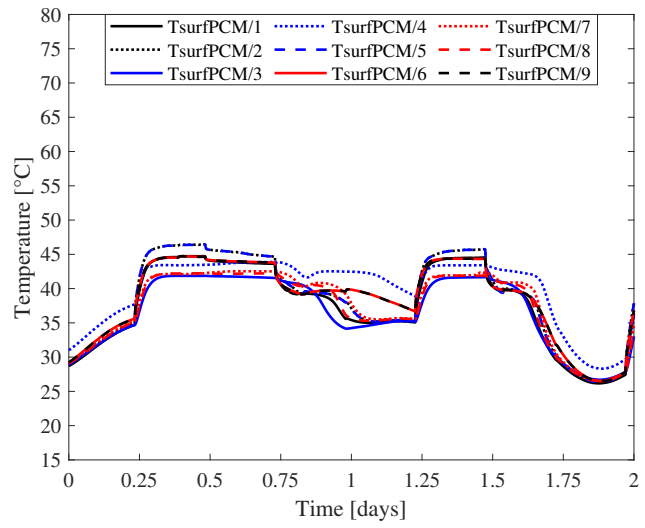

(b)

Figure B.9: C3MCP-2 surface temperature results (a) behind and (b) in front the PCM panel at (blue) $1.0 \mathrm{~m}$, (black), $2.5 \mathrm{~m}$ and (red) $3.8 \mathrm{~m}$.

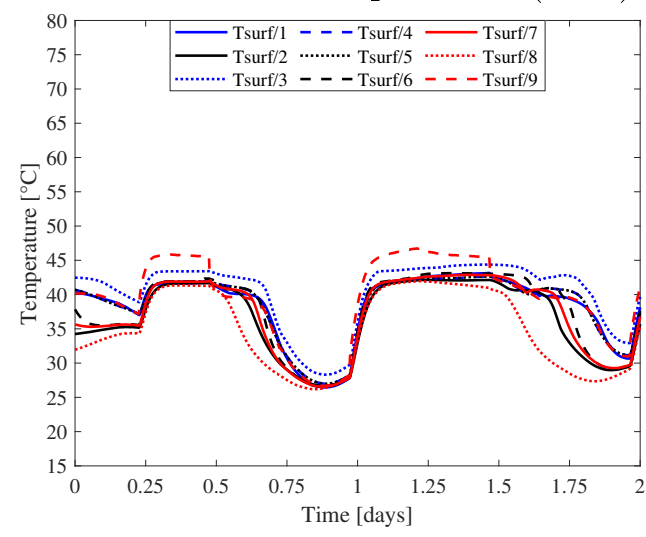

(a)

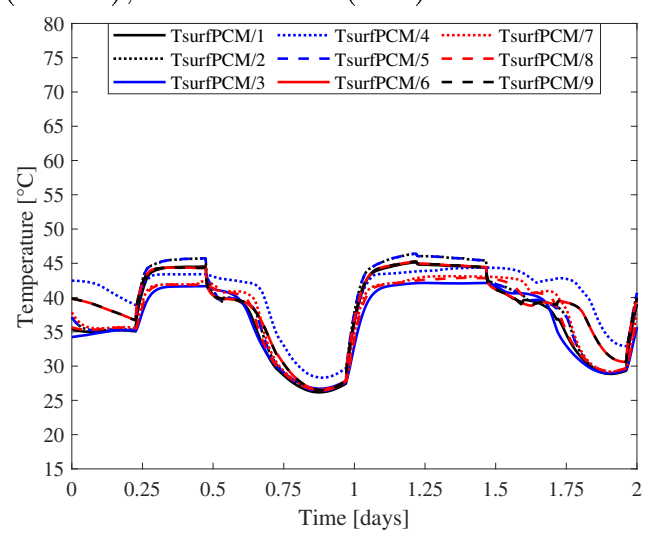

(b)

Figure B.10: C3MCP-3 surface temperature results (a) behind and (b) in front the PCM panel at (blue) $1.0 \mathrm{~m}$, (black), $2.5 \mathrm{~m}$ and (red) $3.8 \mathrm{~m}$. 


\section{B.5 C4PCM - Mass flow rate \& Surface Tempera-}

\section{tures}

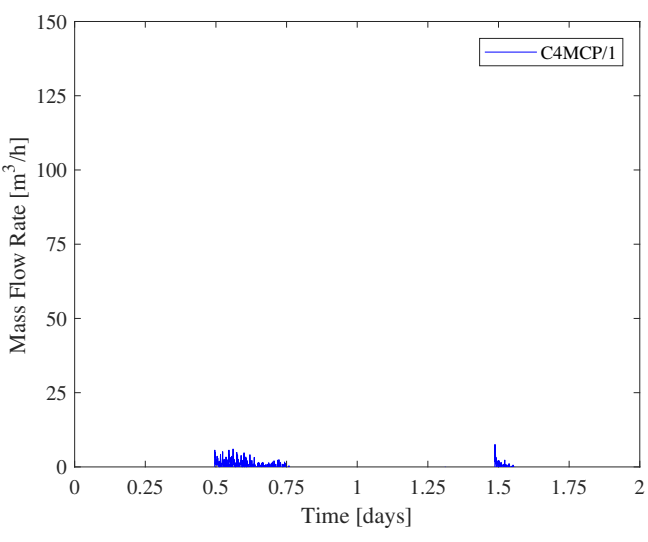

(a)

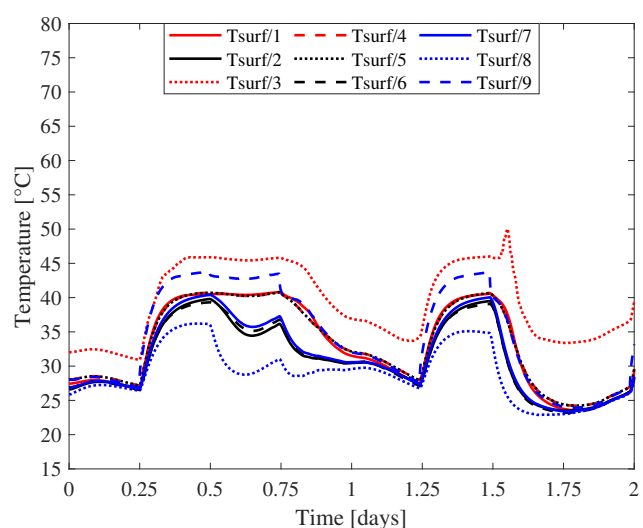

(b)

Figure B.11: C4MCP-1 results of (a) mass flow rate and (b) external and volume temperatures. Cooler temperature $=19{ }^{\circ} \mathrm{C}$, unknown external temperature

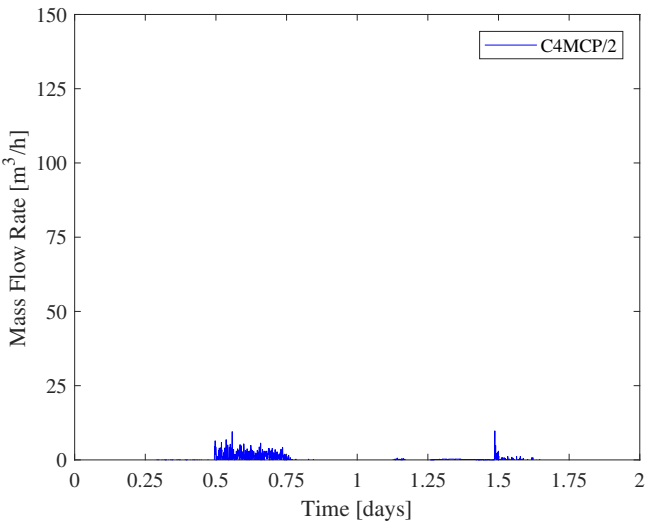

(a)

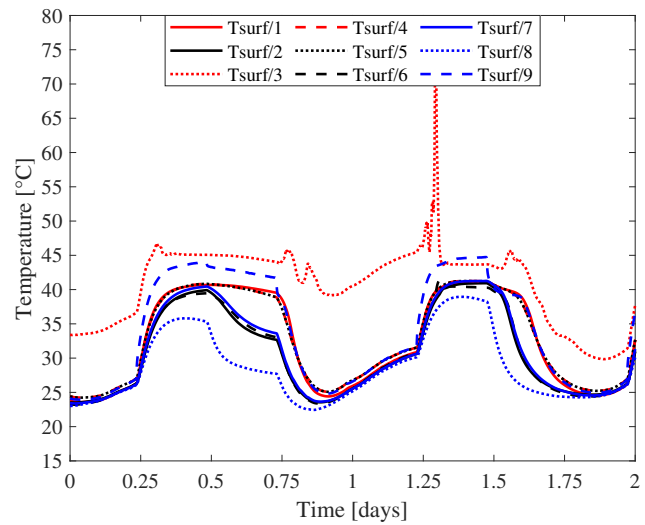

(b)

Figure B.12: C4MCP-2 results of (a) mass flow rate and (b) external and volume temperatures. Cooler temperature $=19{ }^{\circ} \mathrm{C}$, unknown external temperature

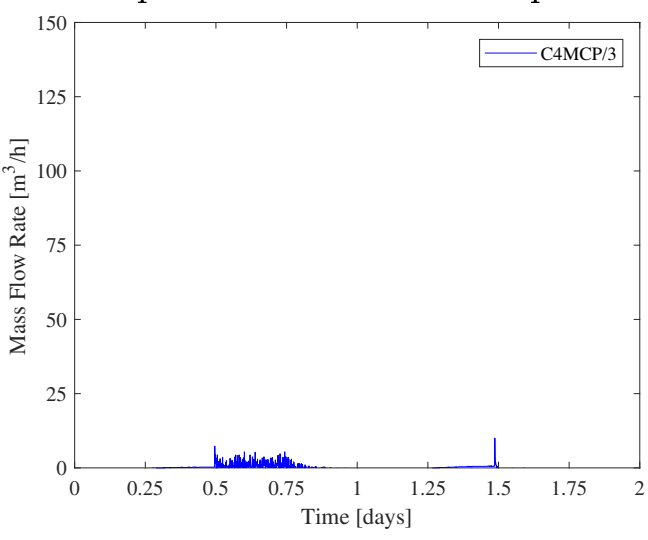

(a)

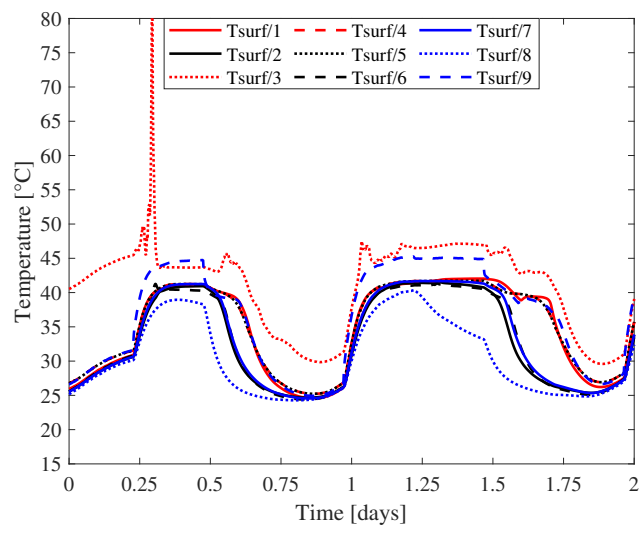

(b)

Figure B.13: C4MCP-3 results of (a) mass flow rate and (b) external and volume temperatures. Cooler temperature $=19{ }^{\circ} \mathrm{C}$, unknown external temperature 


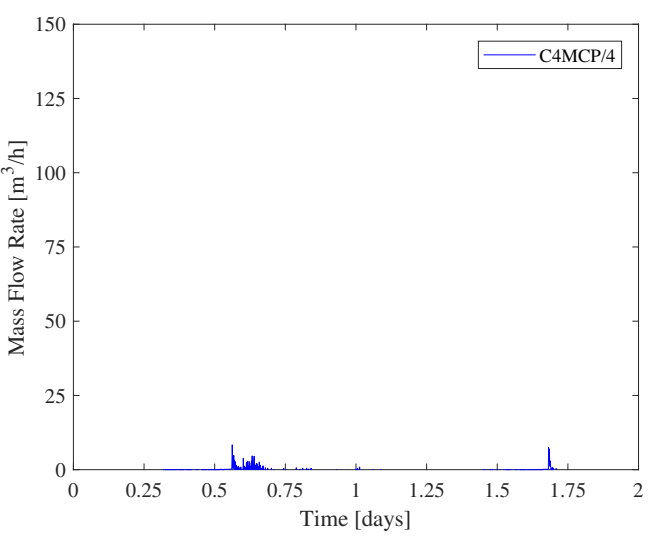

(a)

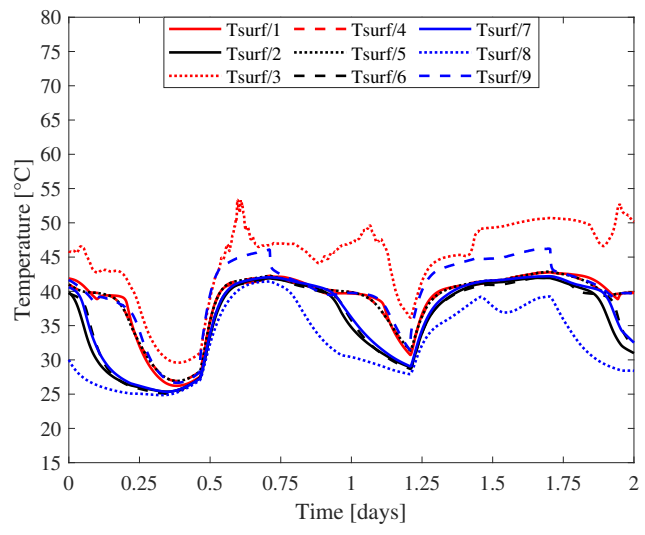

(b)

Figure B.14: C4MCP-4 results of (a) mass flow rate and (b) external and volume temperatures. Cooler temperature $=19^{\circ} \mathrm{C}$, unknown external temperature 


\section{B.6 C4PCM - Surface Temperature Behind PCM \& Surface Temperature Over PCM}

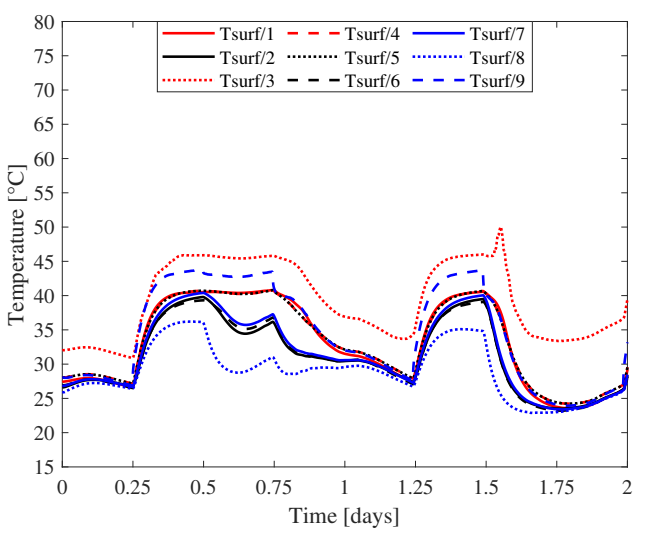

(a)

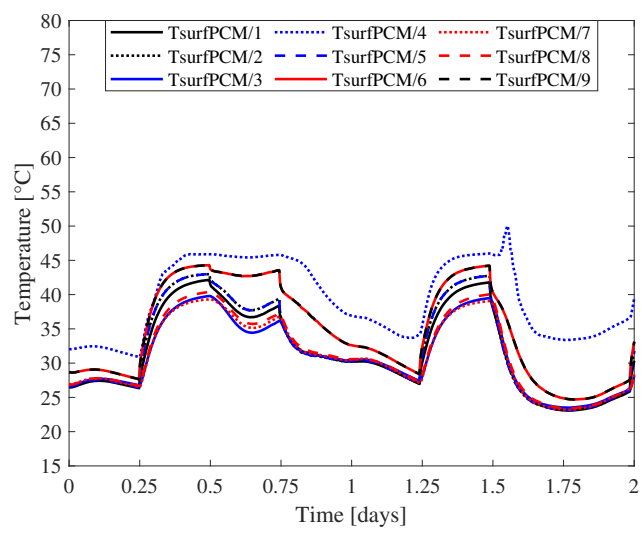

(b)

Figure B.15: C4MCP-1 surface temperature results (a) behind and (b) in front the PCM panel at (blue) $1.0 \mathrm{~m}$, (black), $2.5 \mathrm{~m}$ and (red) $3.8 \mathrm{~m}$.

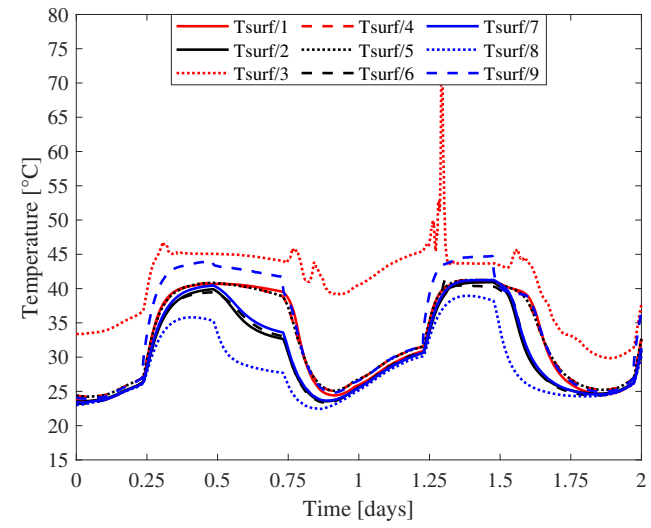

(a)

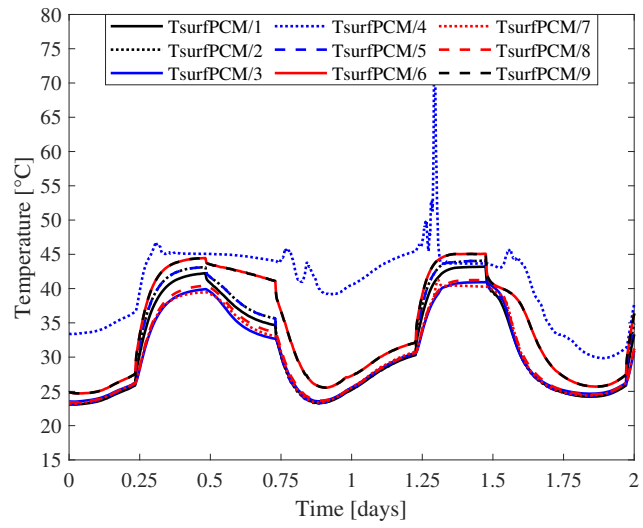

(b)

Figure B.16: C4MCP-2 surface temperature results (a) behind and (b) in front the PCM panel at (blue) $1.0 \mathrm{~m}$, (black), $2.5 \mathrm{~m}$ and (red) $3.8 \mathrm{~m}$.

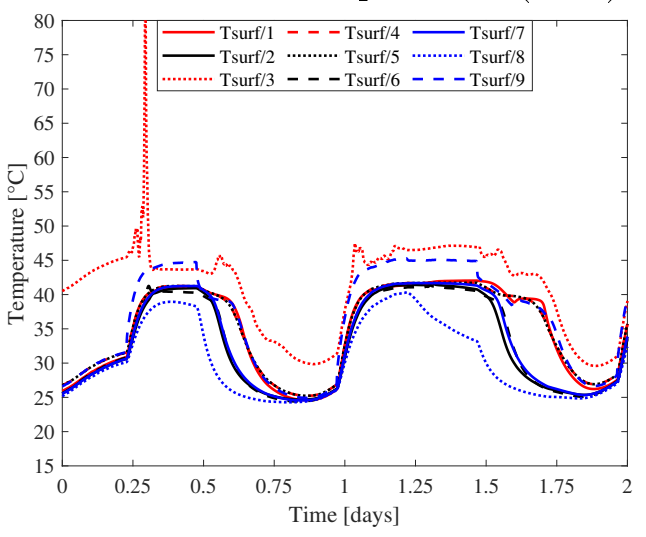

(a)

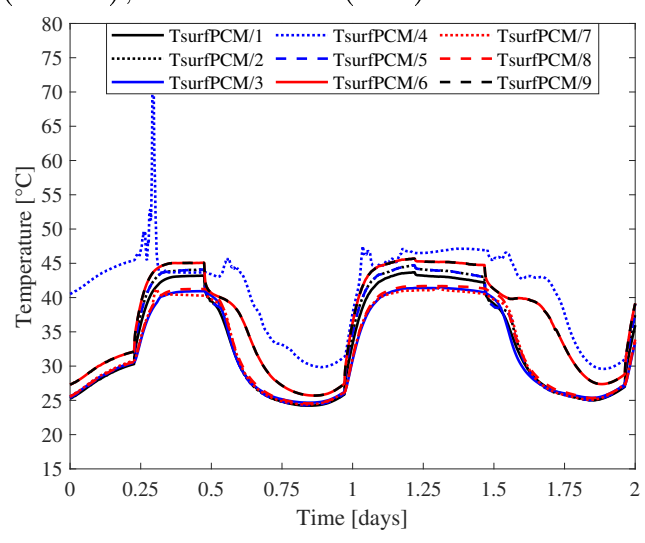

(b)

Figure B.17: C4MCP-3 surface temperature results (a) behind and (b) in front the PCM panel at (blue) $1.0 \mathrm{~m}$, (black), $2.5 \mathrm{~m}$ and (red) $3.8 \mathrm{~m}$. 


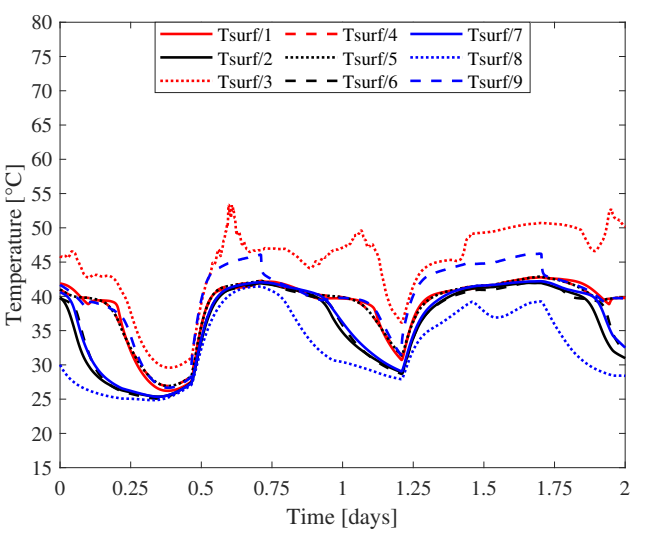

(a)

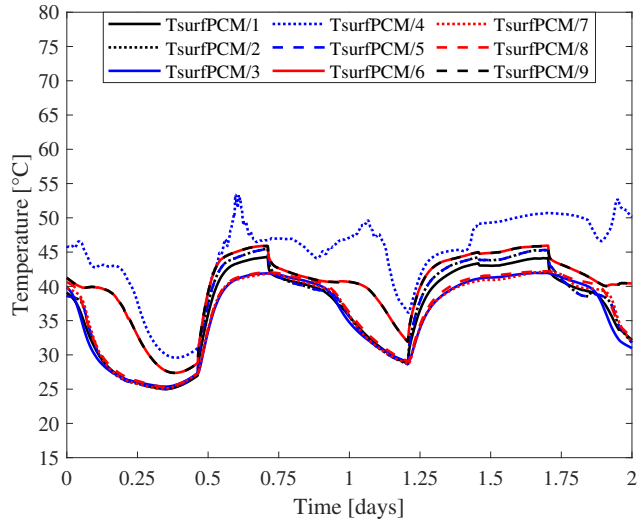

(b)

Figure B.18: C4MCP-4 surface temperature results (a) behind and (b) in front the PCM panel at (blue) $1.0 \mathrm{~m}$, (black), $2.5 \mathrm{~m}$ and (red) $3.8 \mathrm{~m}$. 


\section{B.7 C5PCM - Mass flow rate \& Surface Tempera-}

\section{tures}

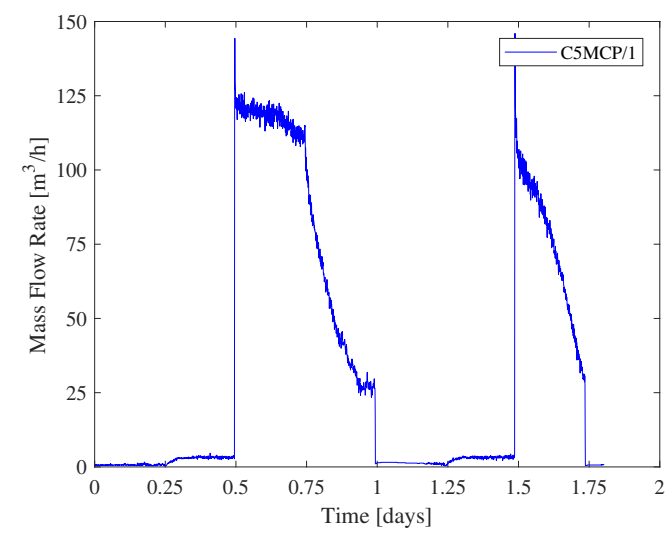

(a)

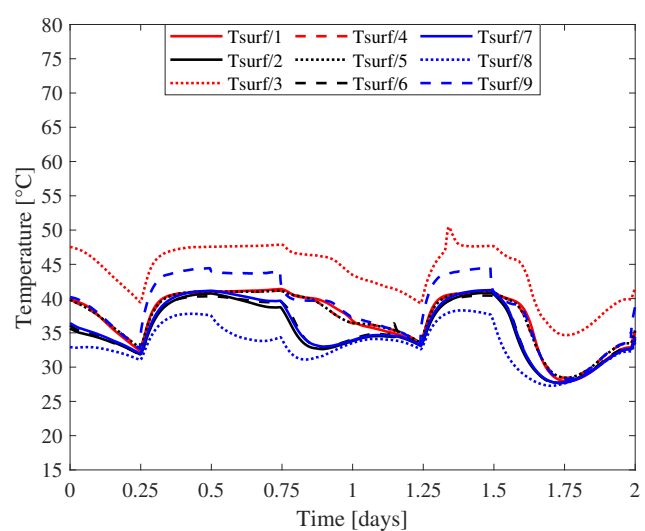

(b)

Figure B.19: C5MCP-1 results of (a) mass flow rate and (b) external and volume temperatures. Cooler temperature $=19{ }^{\circ} \mathrm{C}$, unknown external temperature

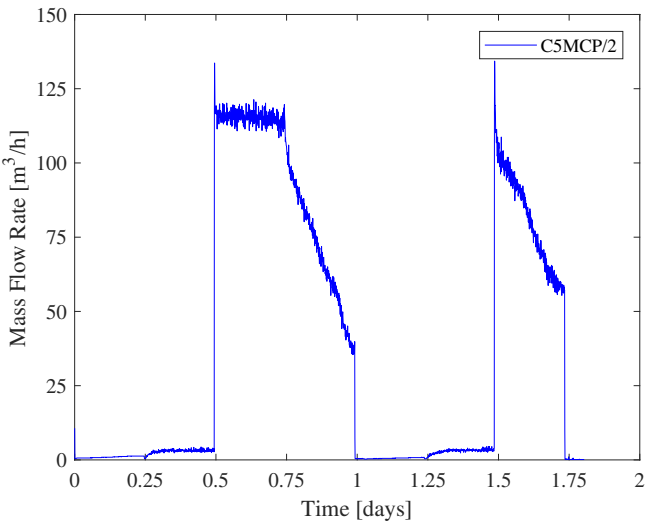

(a)

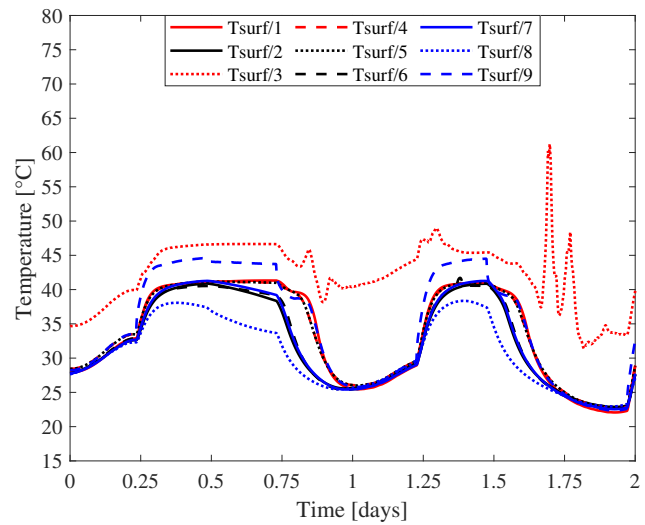

(b)

Figure B.20: C5MCP-2 results of (a) mass flow rate and (b) external and volume temperatures. Cooler temperature $=19{ }^{\circ} \mathrm{C}$, unknown external temperature

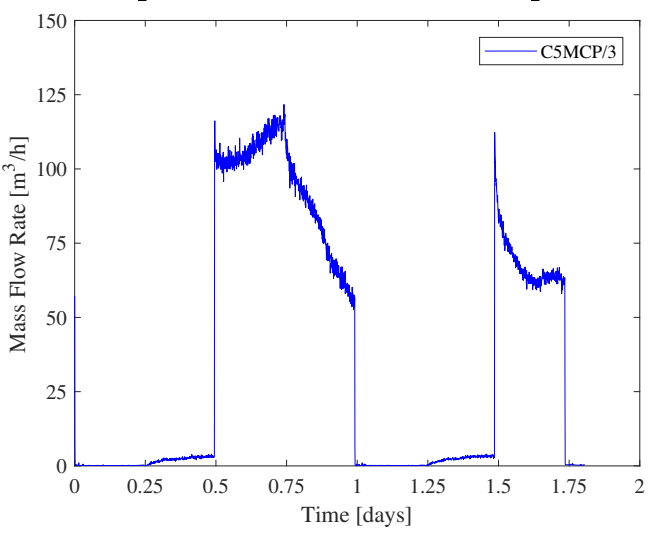

(a)

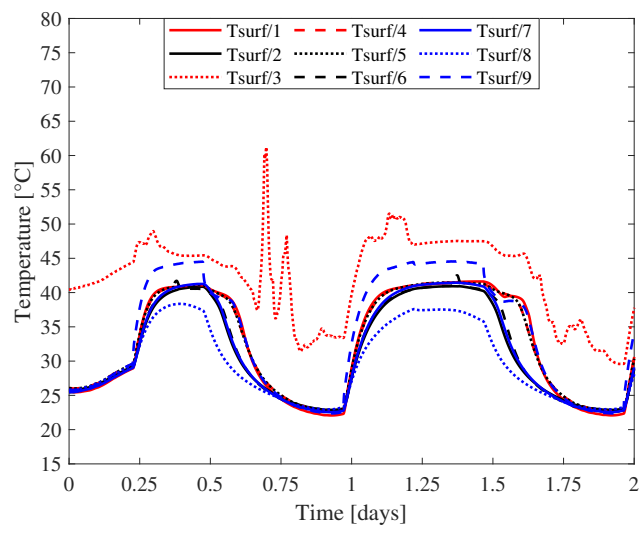

(b)

Figure B.21: C5MCP-3 results of (a) mass flow rate and (b) external and volume temperatures. Cooler temperature $=19{ }^{\circ} \mathrm{C}$, unknown external temperature 


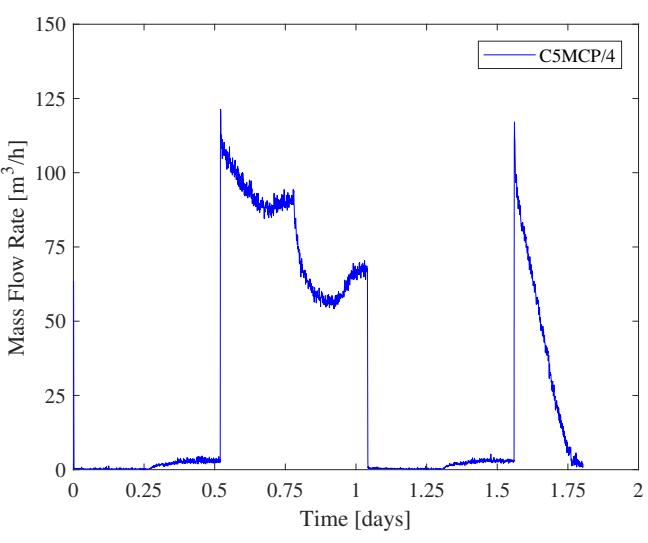

(a)

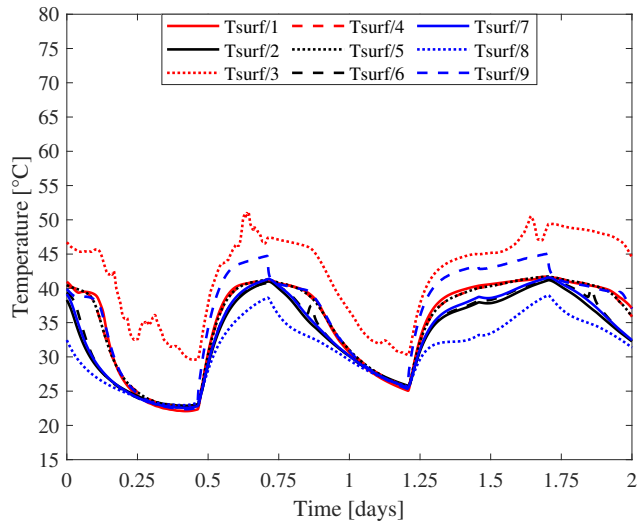

(b)

Figure B.22: C5MCP-4 results of (a) mass flow rate and (b) external and volume temperatures. Cooler temperature $=19^{\circ} \mathrm{C}$, unknown external temperature 


\section{B.8 C5PCM - Surface Temperature Behind PCM \& Surface Temperature Over PCM}

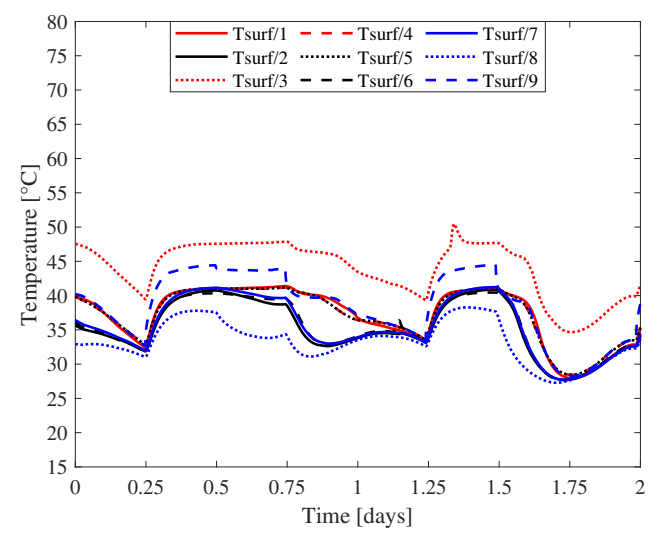

(a)

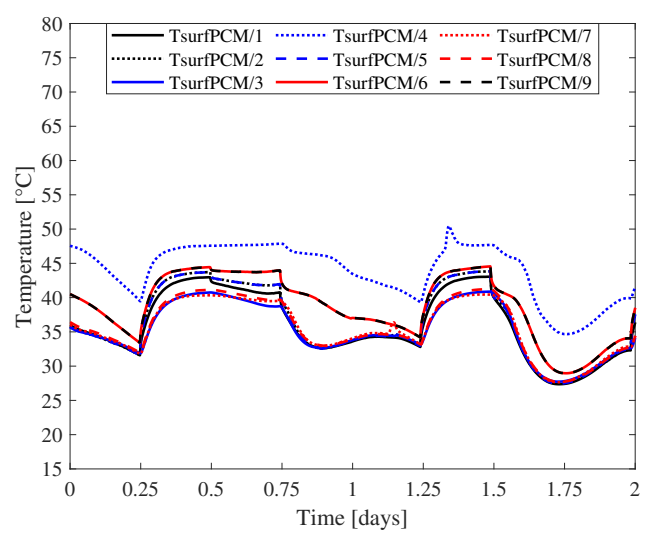

(b)

Figure B.23: C5MCP-1 surface temperature results (a) behind and (b) in front the PCM panel at (blue) $1.0 \mathrm{~m}$, (black), $2.5 \mathrm{~m}$ and (red) $3.8 \mathrm{~m}$.

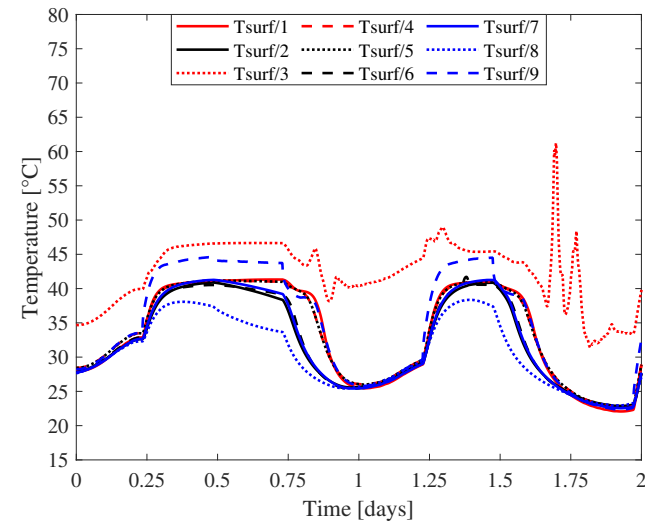

(a)

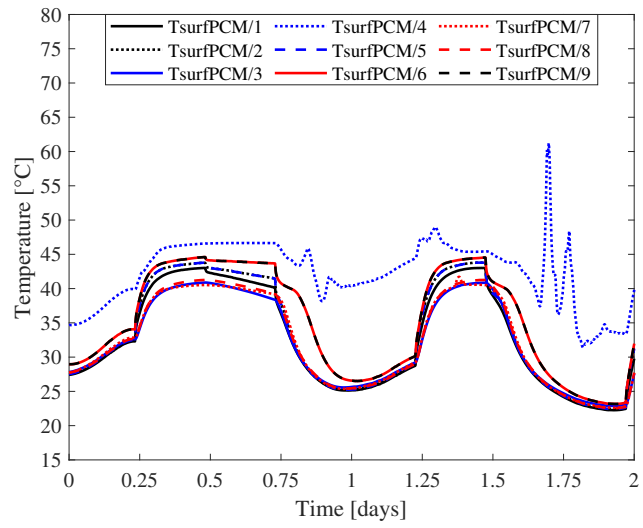

(b)

Figure B.24: C5MCP-2 surface temperature results (a) behind and (b) in front the PCM panel at (blue) $1.0 \mathrm{~m}$, (black), $2.5 \mathrm{~m}$ and (red) $3.8 \mathrm{~m}$.

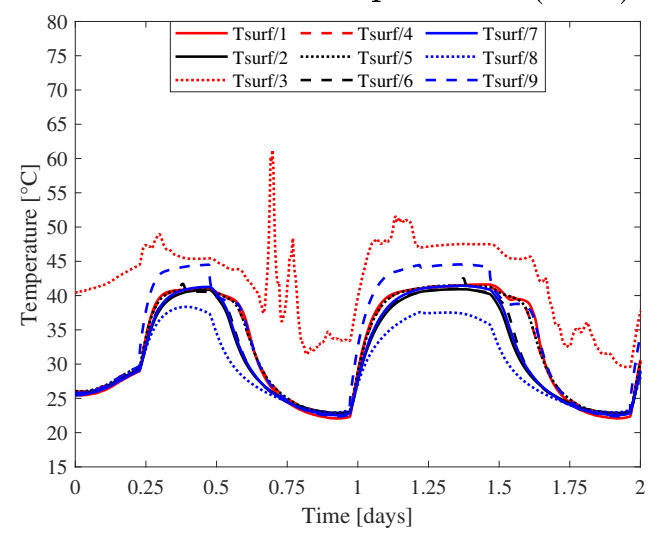

(a)

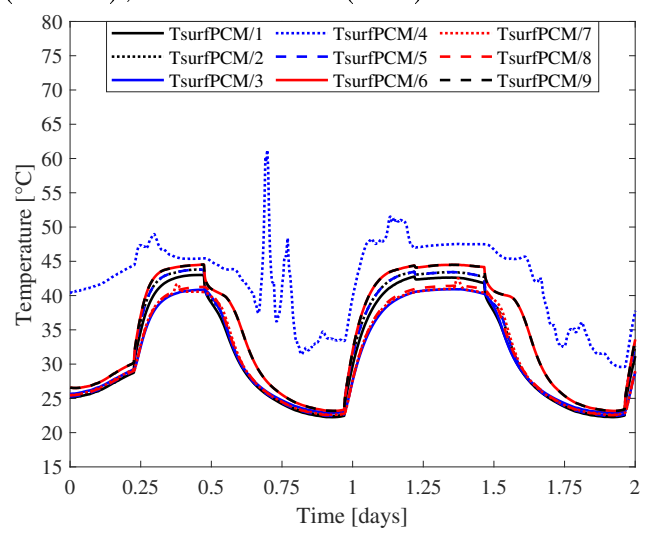

(b)

Figure B.25: C5MCP-3 surface temperature results (a) behind and (b) in front the PCM panel at (blue) $1.0 \mathrm{~m}$, (black), $2.5 \mathrm{~m}$ and (red) $3.8 \mathrm{~m}$. 


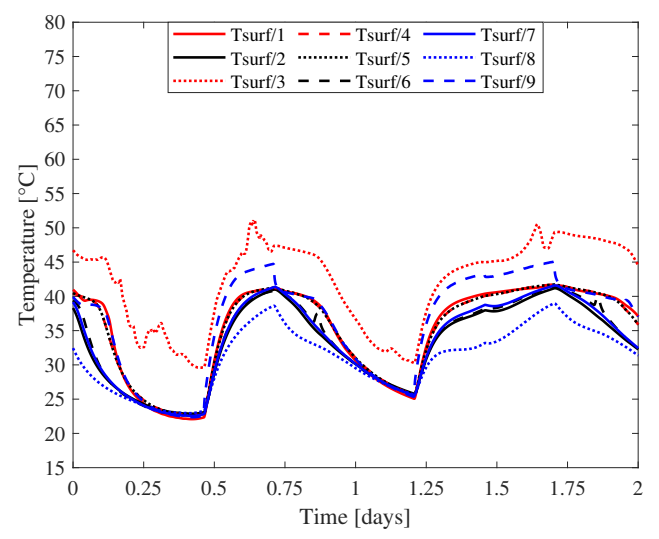

(a)

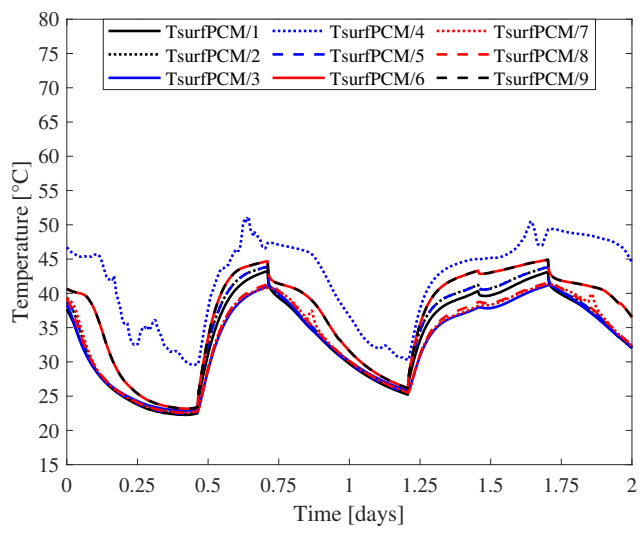

(b)

Figure B.26: C5MCP-4 surface temperature results (a) behind and (b) in front the PCM panel at (blue) $1.0 \mathrm{~m}$, (black), $2.5 \mathrm{~m}$ and (red) $3.8 \mathrm{~m}$. 


\section{B.9 C6PCM - Mass flow rate \& Surface Tempera-}

\section{tures}

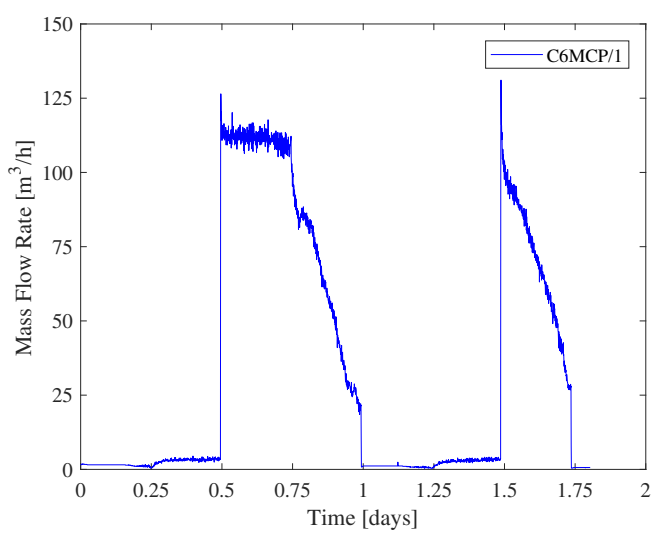

(a)

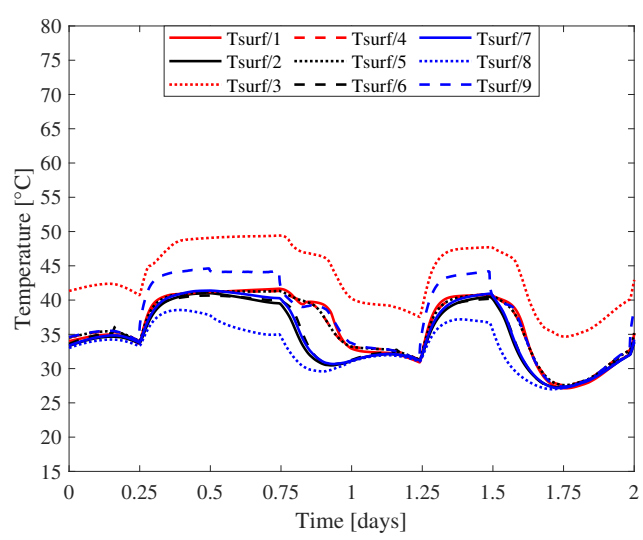

(b)

Figure B.27: C6MCP-1 results of (a) mass flow rate and (b) external and volume

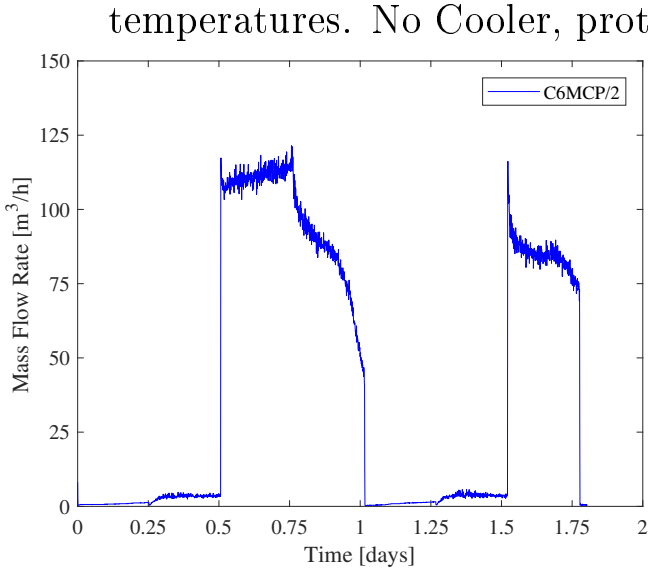

(a)

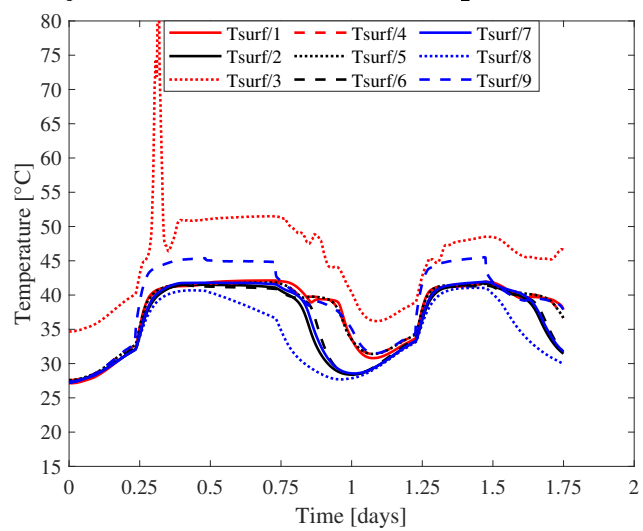

(b)

Figure B.28: C6MCP-2 results of (a) mass flow rate and (b) external and volume temperatures. No Cooler, prototype subjected to external temperature. 


\section{B.10 C6PCM - Surface Temperature Behind PCM \& Surface Temperature Over PCM}

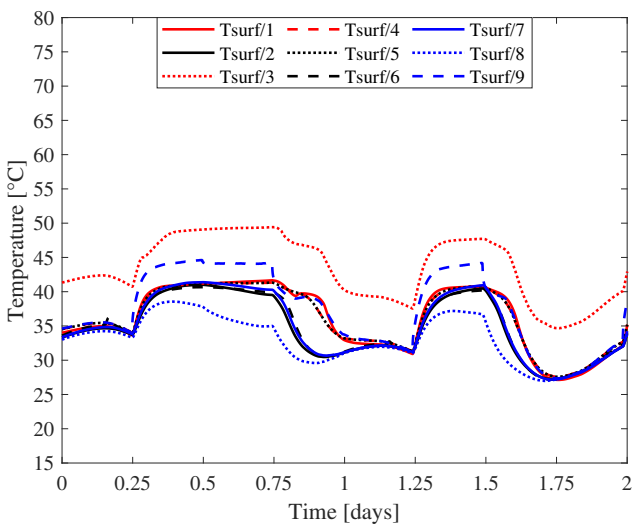

(a)

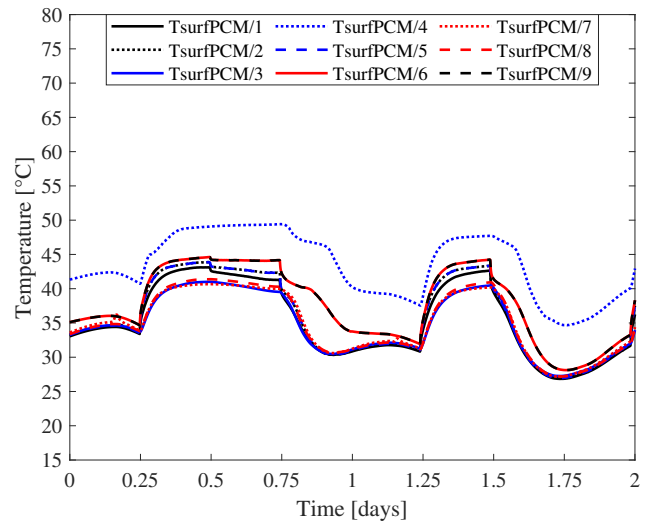

(b)

Figure B.29: C6MCP-1 surface temperature results (a) behind and (b) in front the PCM panel at (blue) $1.0 \mathrm{~m}$, (black), $2.5 \mathrm{~m}$ and (red) $3.8 \mathrm{~m}$.

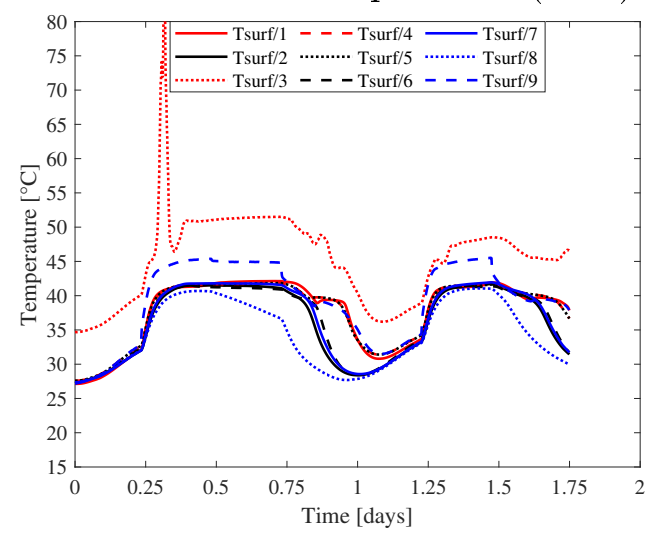

(a)

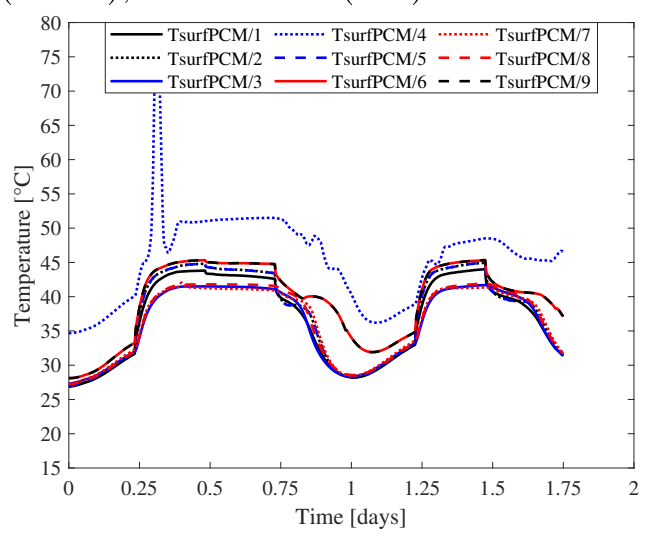

(b)

Figure B.30: C6MCP-2 surface temperature results (a) behind and (b) in front the PCM panel at (blue) $1.0 \mathrm{~m}$, (black), $2.5 \mathrm{~m}$ and (red) $3.8 \mathrm{~m}$. 


\section{B.11 C7PCM - Mass flow rate \& Surface Temper- atures}

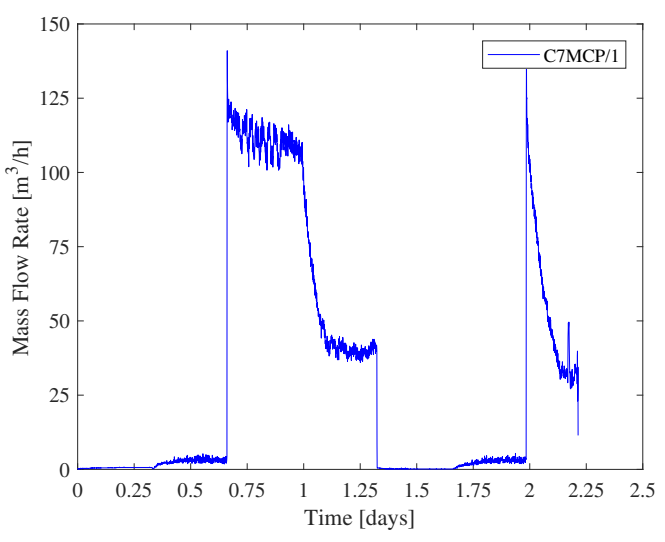

(a)

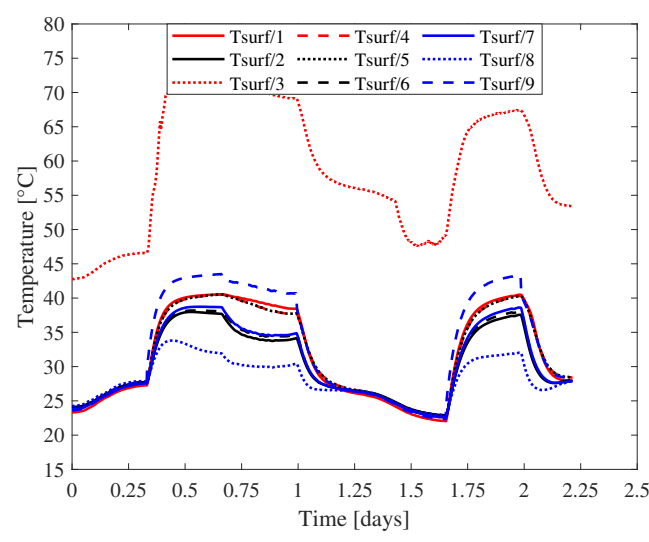

(b)

Figure B.31: C1MCP-1 results of (a) mass flow rate and (b) external and volume temperatures. No Cooler, prototype subjected to external temperature. The time of each phase was extended to 8 hours to observe the behaviour of the PCM when exposed to a heat source for longer period. 


\section{B.12 C7PCM - Surface Temperature Behind PCM \& Surface Temperature Over PCM}

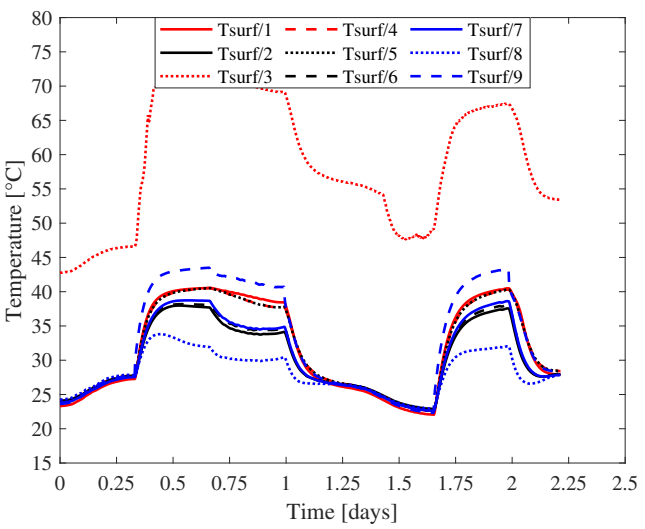

(a)

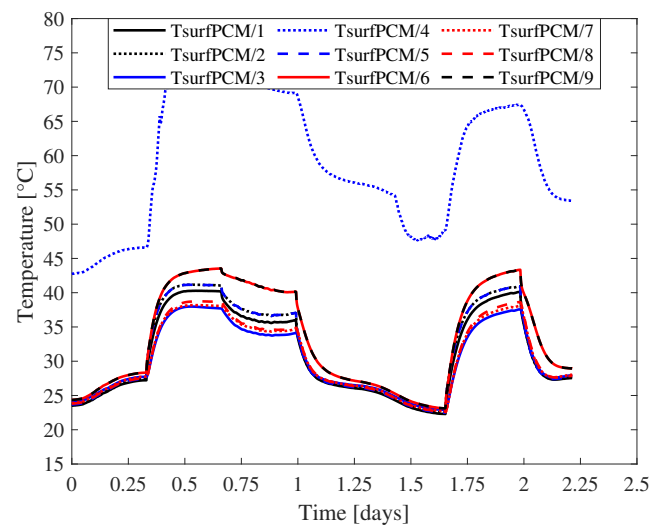

(b)

Figure B.32: C7MCP-1 surface temperature results (a) behind and (b) in front the PCM panel at (blue) $1.0 \mathrm{~m}$, (black), $2.5 \mathrm{~m}$ and (red) $3.8 \mathrm{~m}$. The time of each phase was extended to 8 hours to observe the behaviour of the PCM when exposed to a heat source for longer period. 


\title{
Appendix C
}

\section{Prototype V2 No PCM - Laboratory}

\author{
Results
}




\section{C.1 P2C1NoPCM - Mass flow rate \& External and Internal Temperatures}

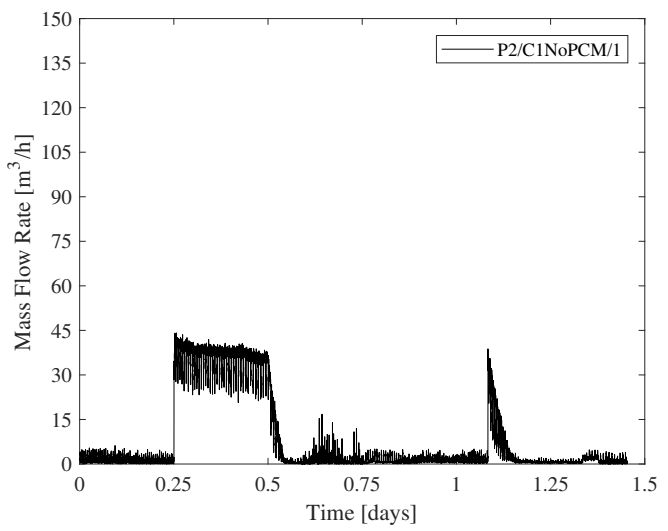

(a)

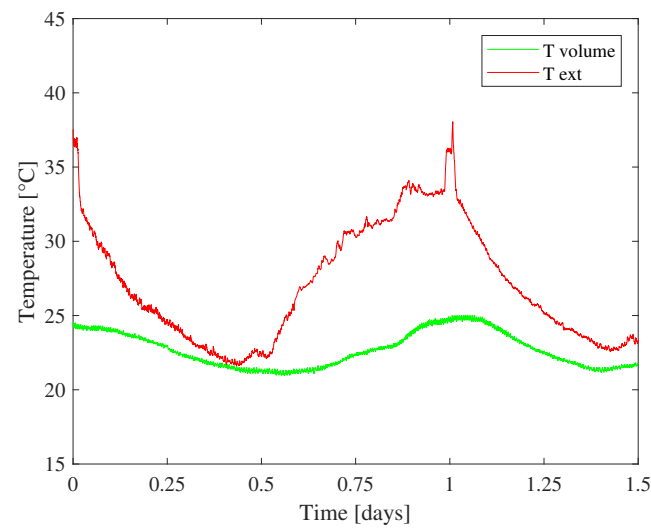

(b)

Figure C.1: P2C1NoPCM-1 results of (a) mass flow rate and (b) external and volume temperatures. Cooler set temperature $=18{ }^{\circ} \mathrm{C}$

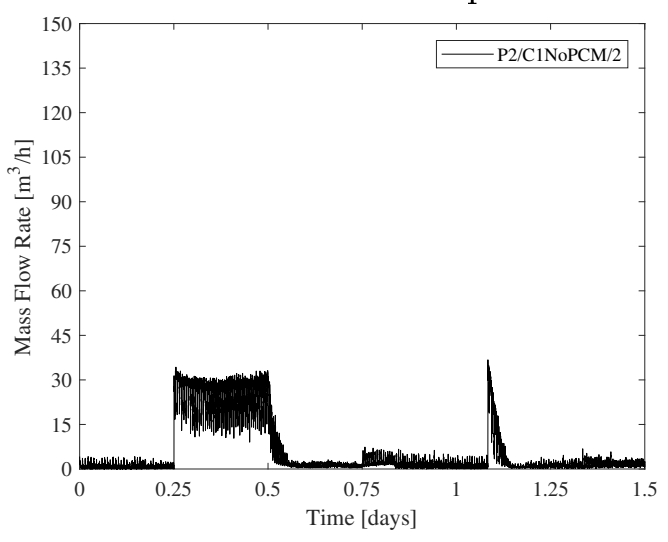

(a)

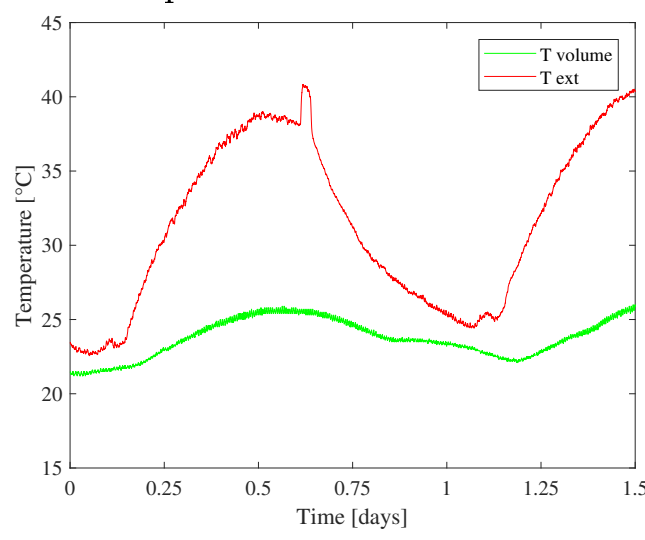

(b)

Figure C.2: P2C1NoPCM-2 results of (a) mass flow rate and (b) external and volume temperatures. Cooler set temperature $=18{ }^{\circ} \mathrm{C}$ 


\section{C.2 P2C1NoPCM - Surface Temperatures \& Chim- ney air temperatures}

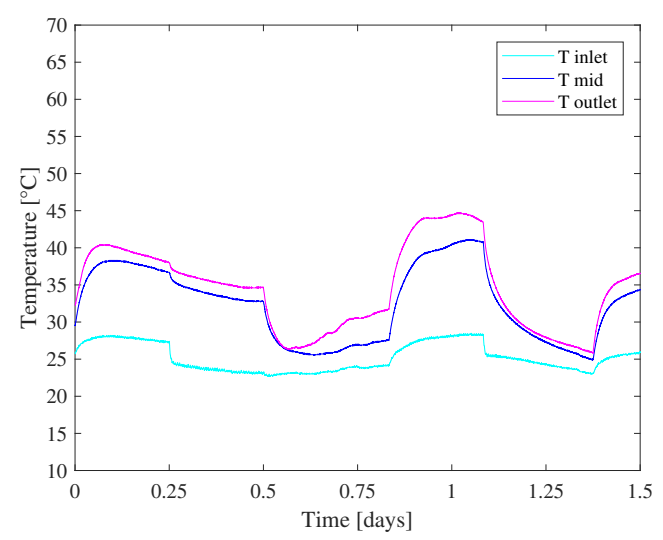

(a)

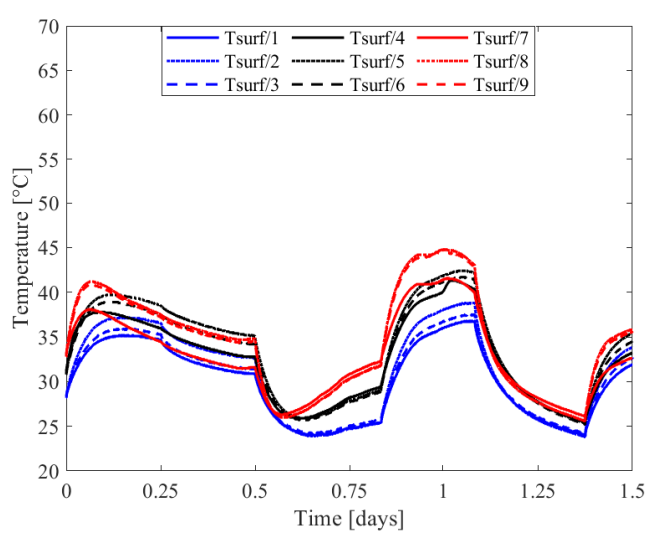

(b)

Figure C.3: P2C1NoPCM-1 results of (a) air temperature at inlet, mid and outlet level, and (b) surface temperature at $0.8,1.5$ and $3.0 \mathrm{~m}$

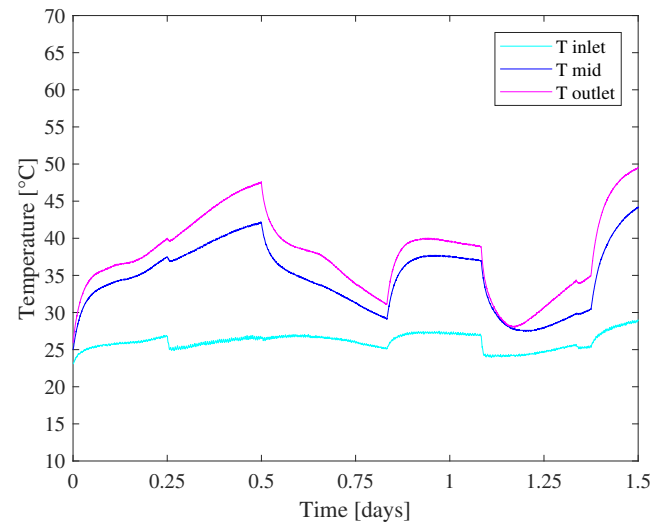

(a)

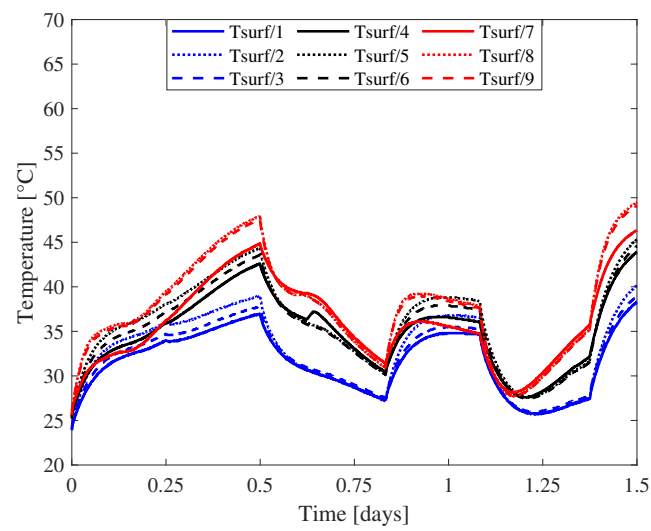

(b)

Figure C.4: P2C1NoPCM-2 results of (a) air temperature at inlet, mid and outlet level, and (b) surface temperature at $0.8,1.5$ and $3.0 \mathrm{~m}$ 


\section{C.3 P2C2NoPCM - Mass flow rate \& External and Internal Temperatures}

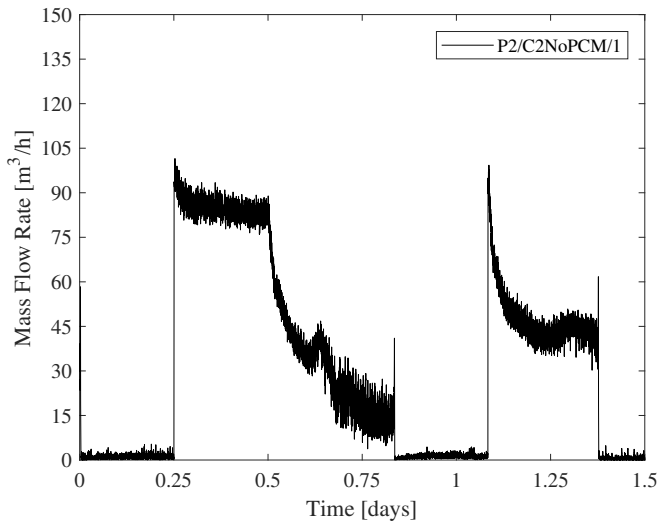

(a)

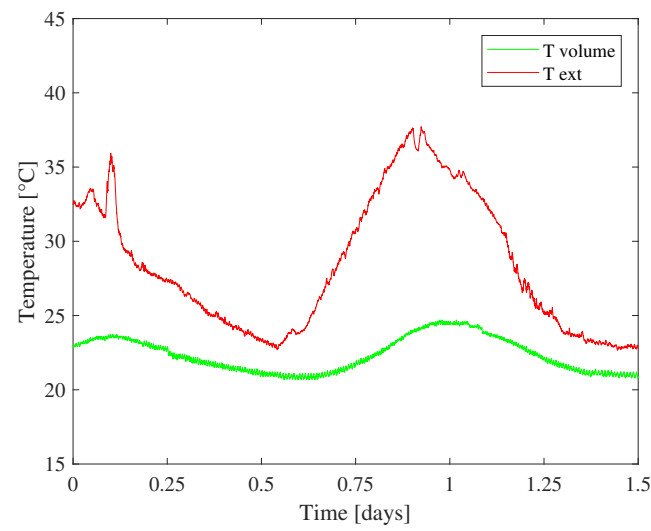

(b)

Figure C.5: P2C2NoPCM-1 results of (a) mass flow rate and (b) external and volume temperatures. Cooler set temperature $=18^{\circ} \mathrm{C}$

\section{C.4 P2C2NoPCM - Surface Temperatures \& Chim- ney air temperatures}

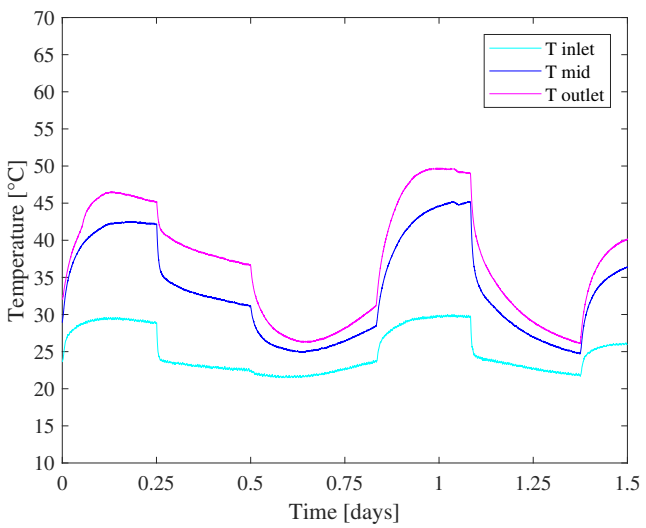

(a)

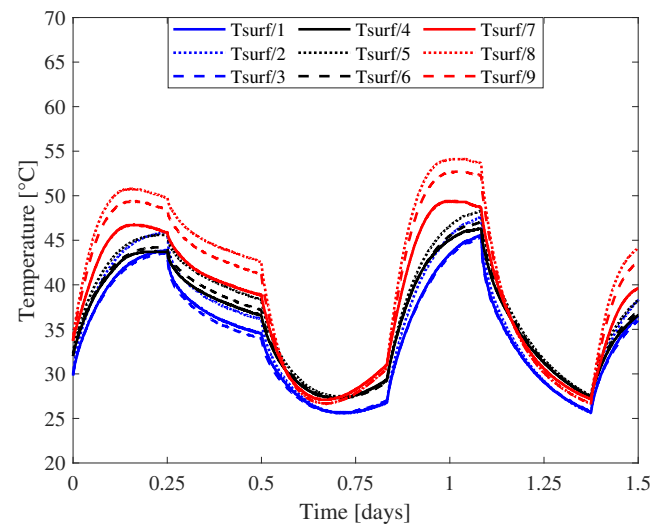

(b)

Figure C.6: P2C2NoPCM-1 results of (a) air temperature at inlet, mid and outlet level, and (b) surface temperature at $0.8,1.5$ and $3.0 \mathrm{~m}$ 


\section{C.5 P2C3NoPCM - Mass flow rate \& External and Internal Temperatures}

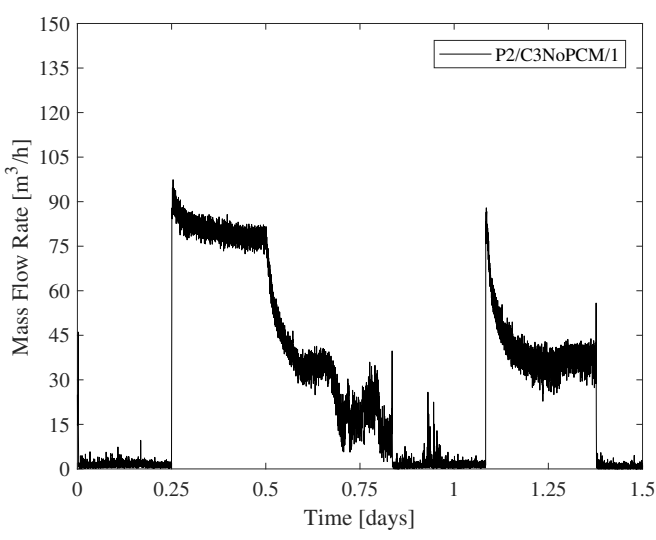

(a)

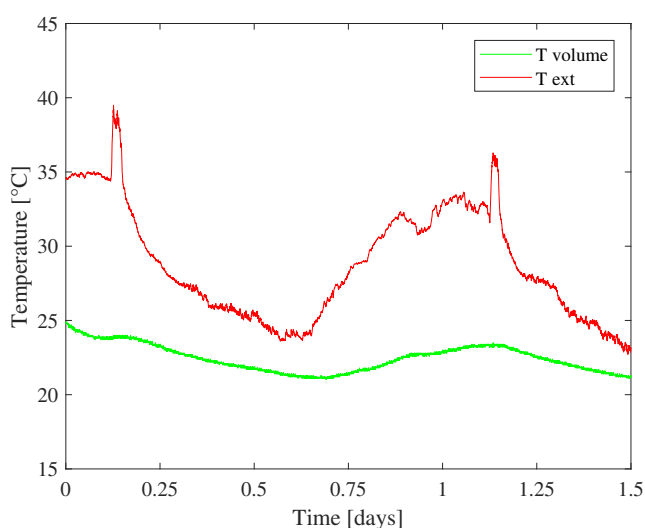

(b)

Figure C.7: P2C3NoPCM-1 results of (a) mass flow rate and (b) external and volume temperatures. Cooler set temperature $=18{ }^{\circ} \mathrm{C}$

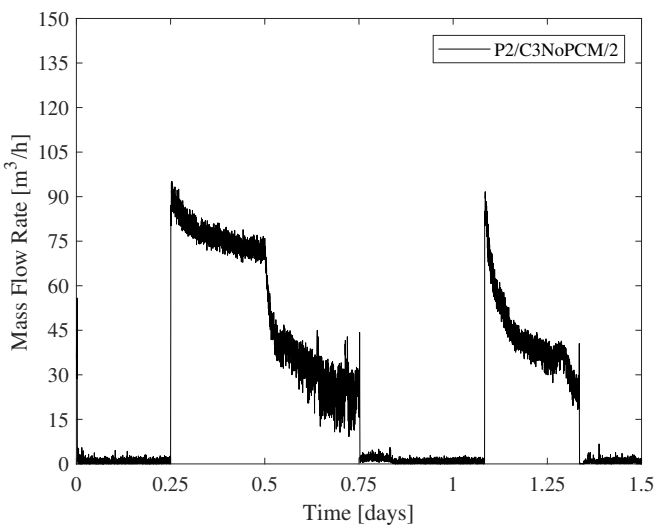

(a)

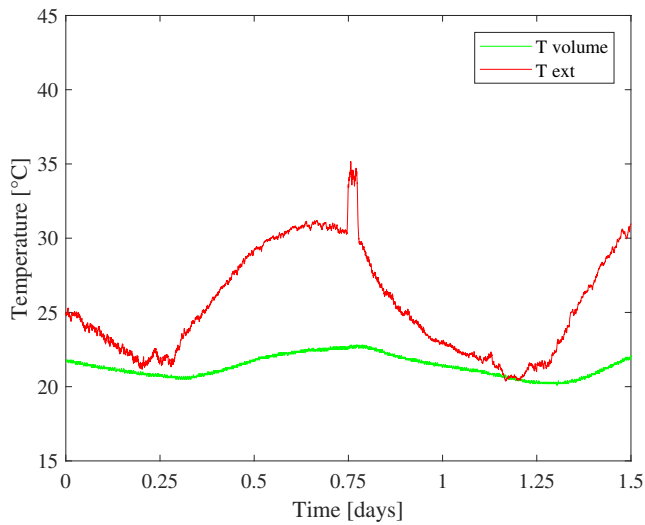

(b)

Figure C.8: P2C3NoPCM-2 results of (a) mass flow rate and (b) external and volume temperatures. Cooler set temperature $=18^{\circ} \mathrm{C}$

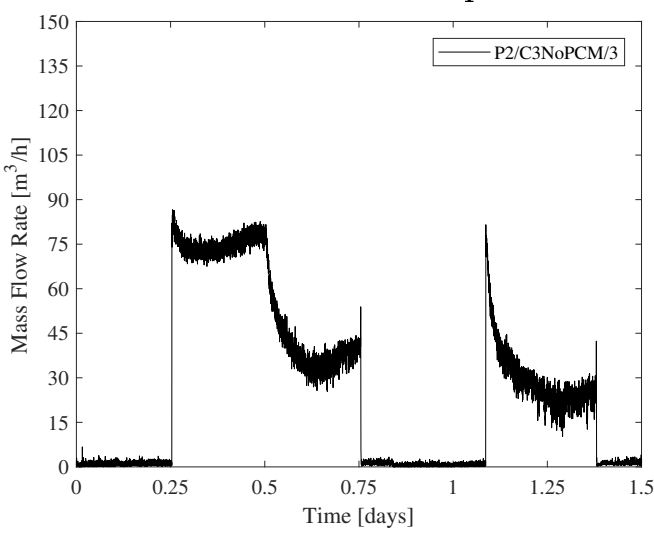

(a)

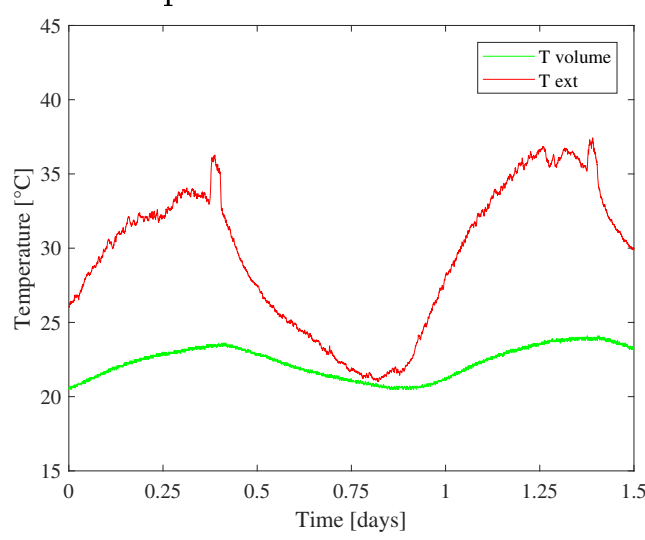

(b)

Figure C.9: P2C3NoPCM-3 results of (a) mass flow rate and (b) external and volume temperatures. Cooler set temperature $=18{ }^{\circ} \mathrm{C}$ 


\section{C.6 P2C3NoPCM - Surface Temperatures \& Chim- ney air temperatures}

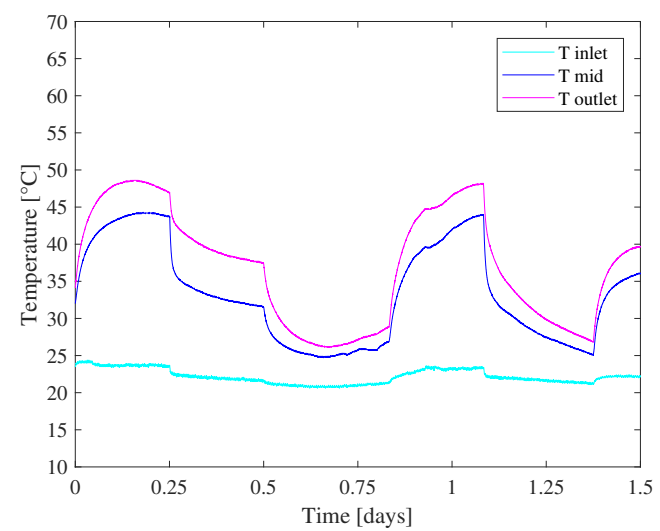

(a)

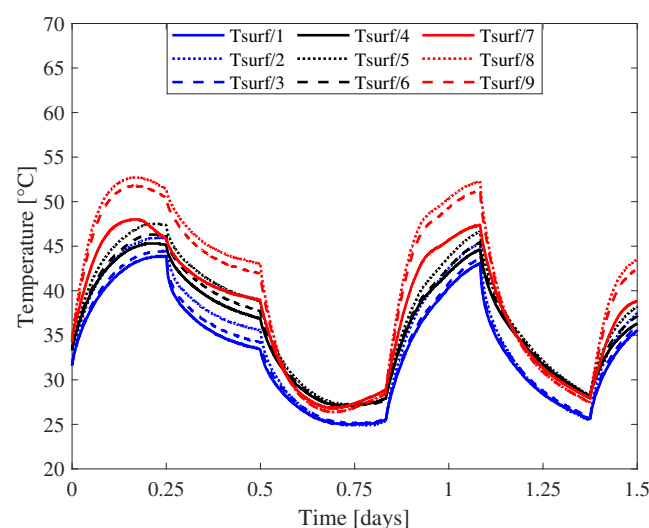

(b)

Figure C.10: P2C3NoPCM-1 results of (a) air temperature at inlet, mid and outlet level, and (b) surface temperature at $0.8,1.5$ and $3.0 \mathrm{~m}$

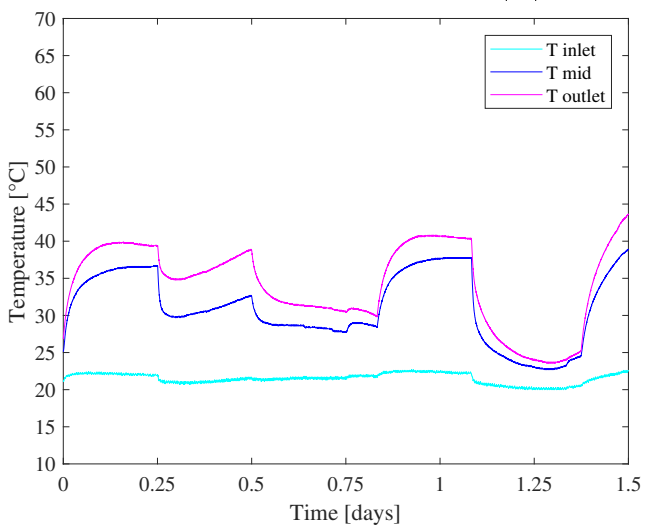

(a)

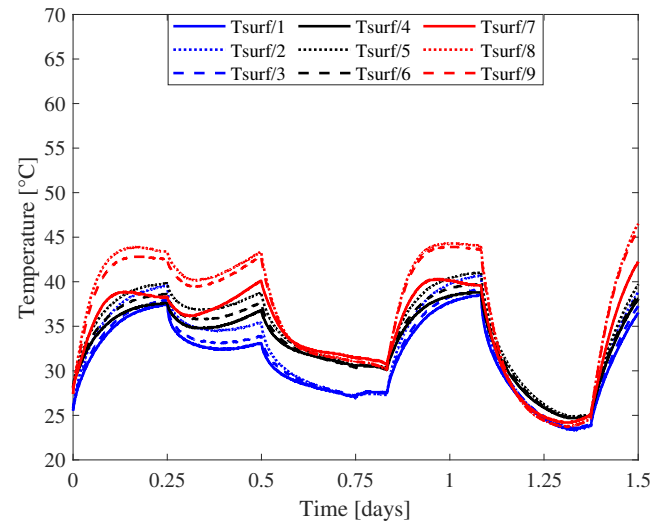

(b)

Figure C.11: P2C3NoPCM-2 results of (a) air temperature at inlet, mid and outlet level, and (b) surface temperature at $0.8,1.5$ and $3.0 \mathrm{~m}$

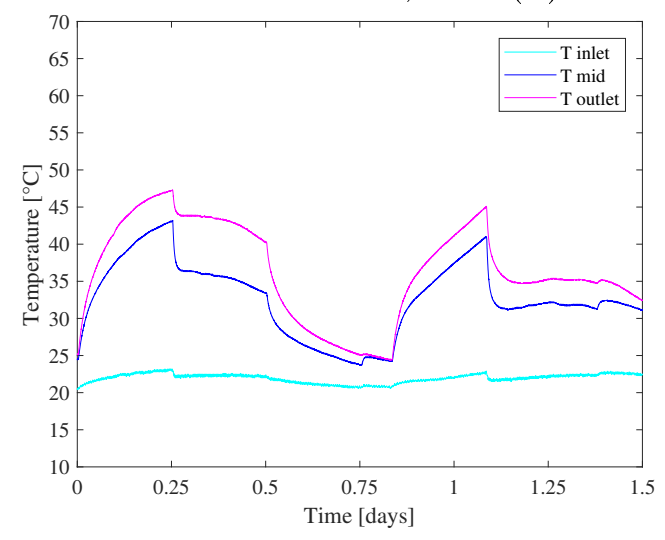

(a)

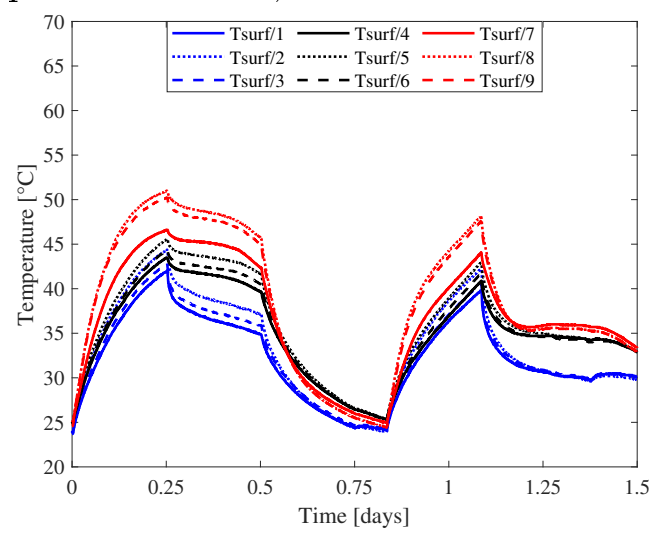

(b)

Figure C.12: P2C3NoPCM-3 results of (a) air temperature at inlet, mid and outlet level, and (b) surface temperature at $0.8,1.5$ and $3.0 \mathrm{~m}$ 


\section{C.7 P2C4NoPCM - Mass flow rate \& External and Internal Temperatures}

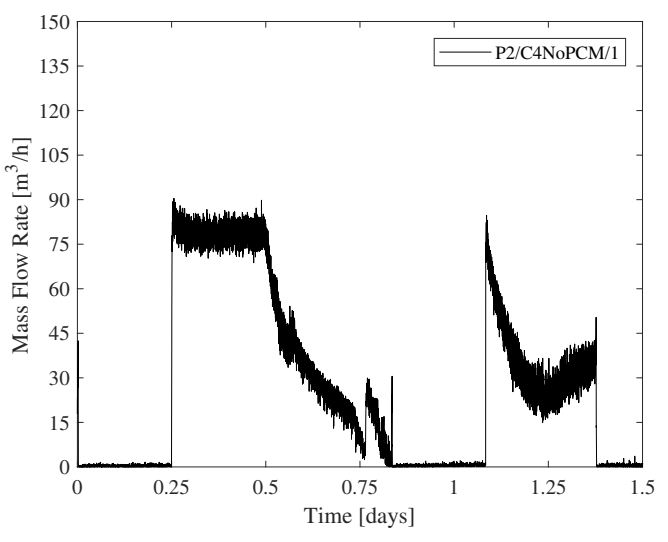

(a)

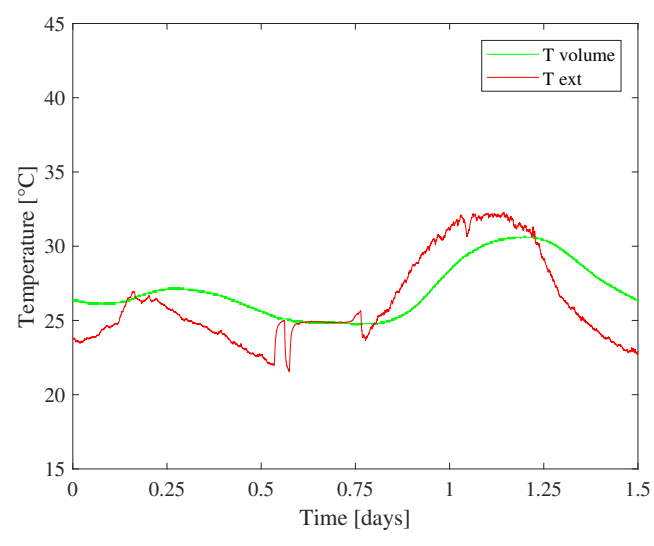

(b)

Figure C.13: P2C4NoPCM-1 results of (a) mass flow rate and (b) external and volume temperatures. Prototype subjected to external temperature.

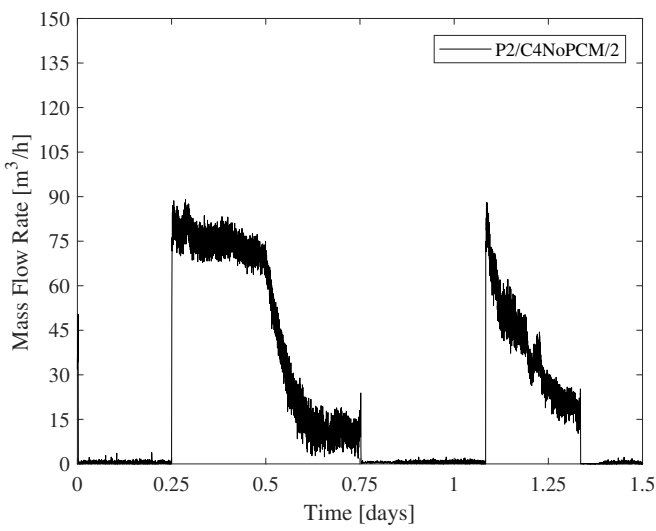

(a)

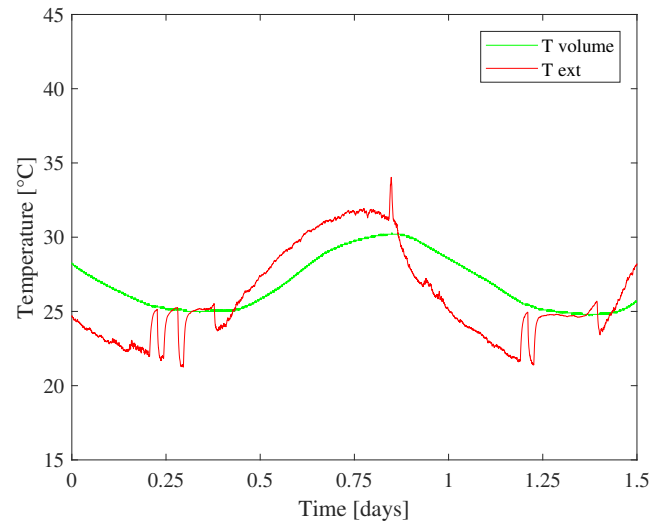

(b)

Figure C.14: P2C4NoPCM-2 results of (a) mass flow rate and (b) external and volume temperatures. Prototype subjected to external temperature

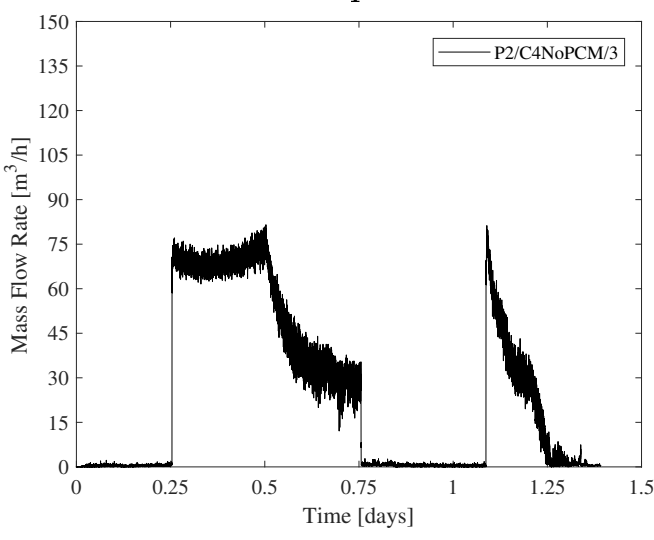

(a)

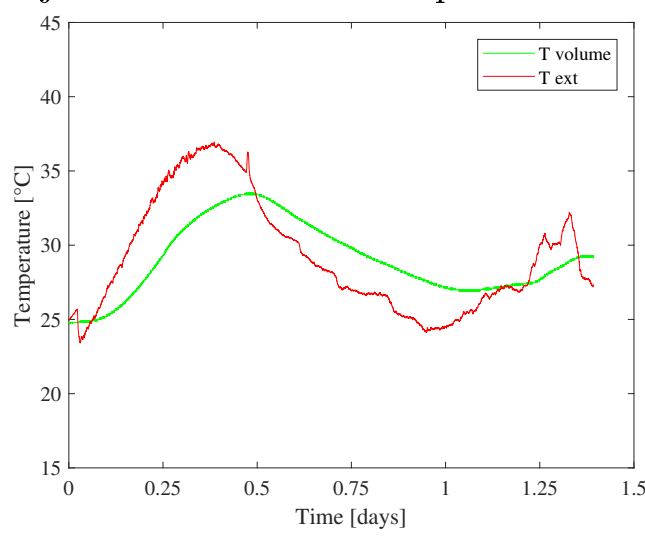

(b)

Figure C.15: P2C4NoPCM-3 results of (a) mass flow rate and (b) external and volume temperatures. Prototype subjected to external temperature 


\section{C.8 P2C4NoPCM - Surface Temperatures \& Chim- ney air temperatures}

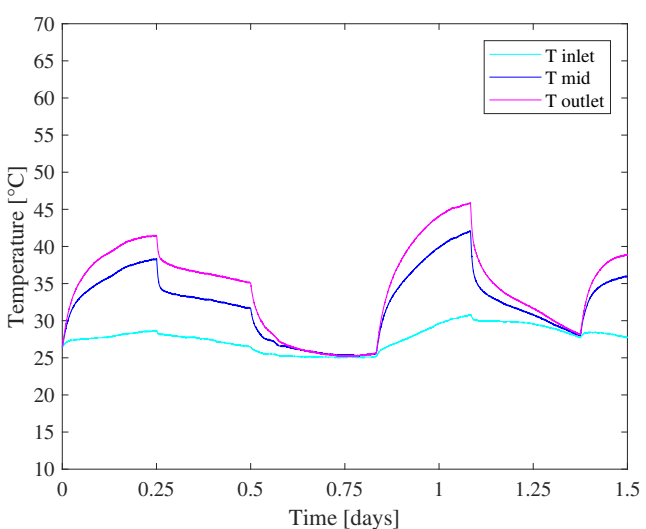

(a)

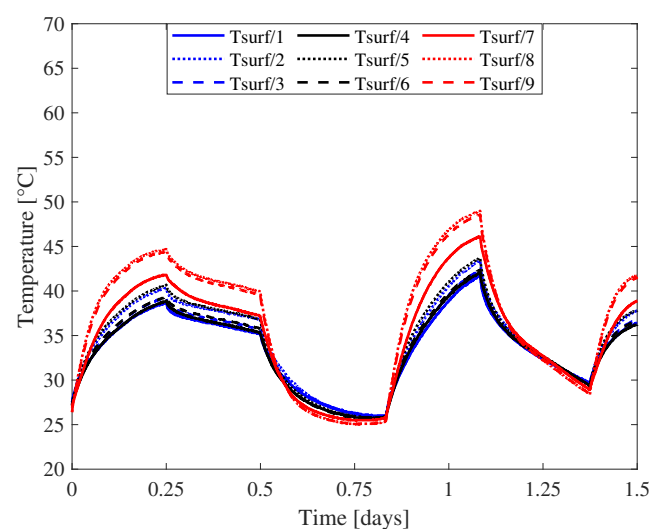

(b)

Figure C.16: P2C4NoPCM-1 results of (a) air temperature at inlet, mid and outlet level, and (b) surface temperature at $0.8,1.5$ and $3.0 \mathrm{~m}$

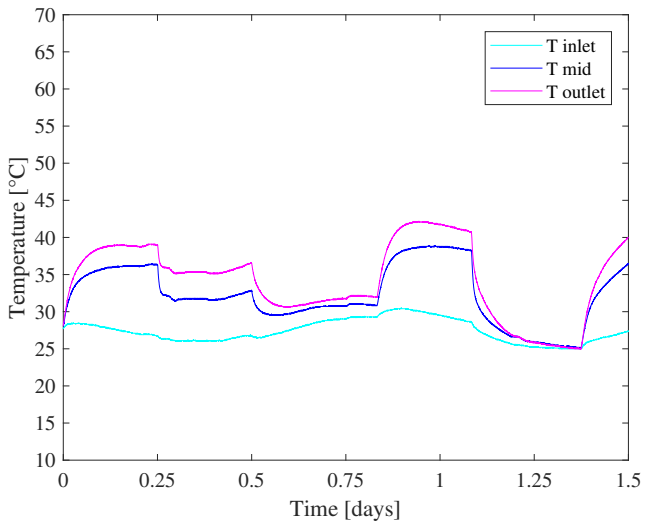

(a)

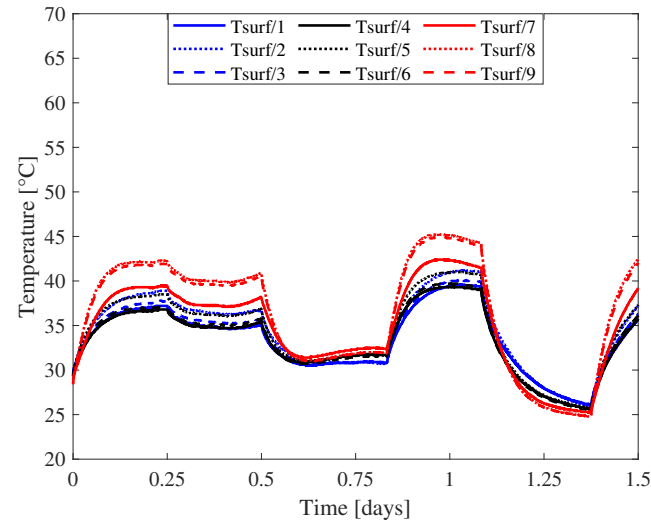

(b)

Figure C.17: P2C4NoPCM-2 results of (a) air temperature at inlet, mid and outlet level, and (b) surface temperature at $0.8,1.5$ and $3.0 \mathrm{~m}$

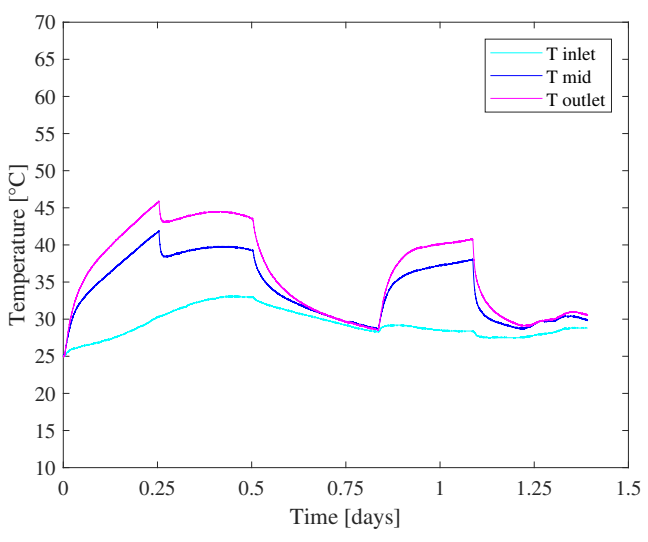

(a)

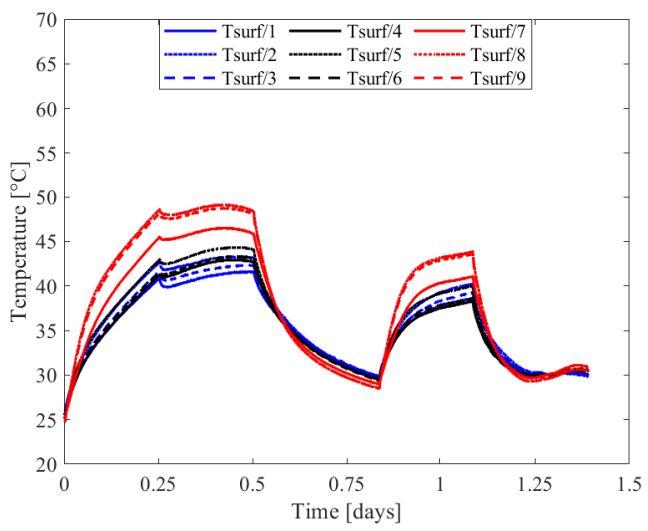

(b)

Figure C.18: P2C4NoPCM-3 results of (a) air temperature at inlet, mid and outlet level, and (b) surface temperature at $0.8,1.5$ and $3.0 \mathrm{~m}$ 


\section{Appendix D}

\section{Prototype V2 PCM - Laboratory \\ Results}




\section{D.1 P2C1PCM - Mass flow rate \& External and Internal Temperatures}

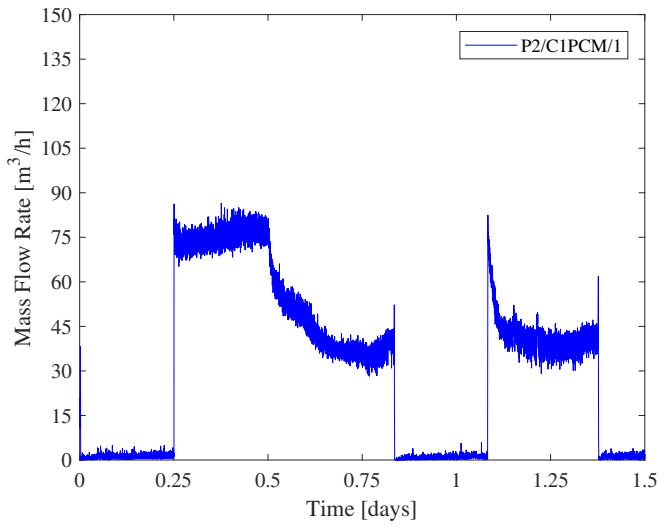

(a)

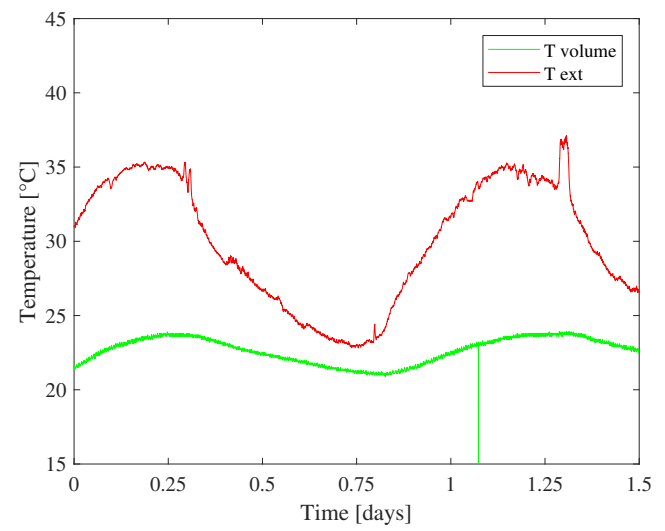

(b)

Figure D.1: P2C1PCM-1 results of (a) mass flow rate and (b) external and volume temperatures. Cooler set temperature $=18^{\circ} \mathrm{C}$

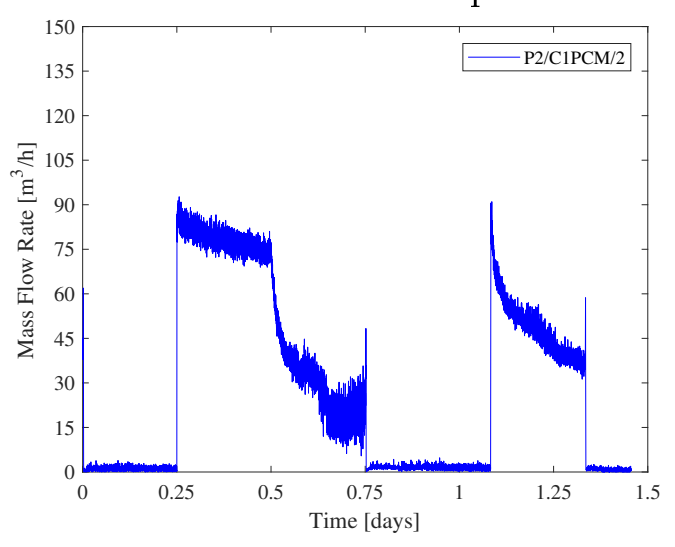

(a)

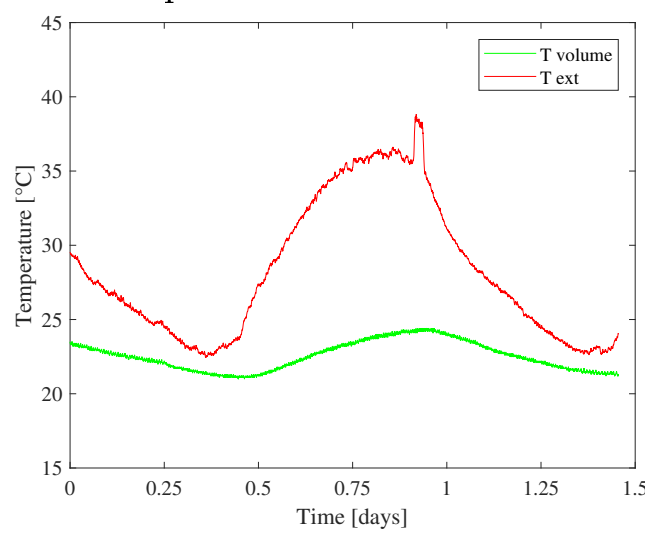

(b)

Figure D.2: P2C1PCM-2 results of (a) mass flow rate and (b) external and volume temperatures. Cooler set temperature $=18{ }^{\circ} \mathrm{C}$ 


\section{D.2 P2C1PCM - Surface Temperatures \& Chimney air temperatures}

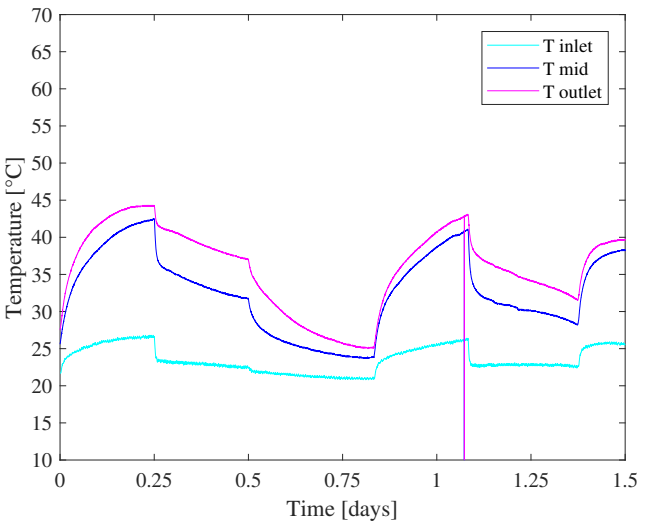

(a)

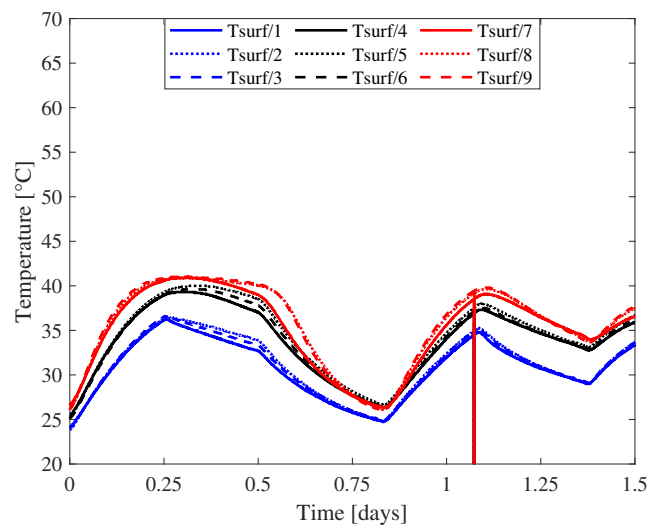

(b)

Figure D.3: P2C1PCM-1 results of (a) air temperature at inlet, mid and outlet level, and (b) surface temperature at $0.8,1.5$ and $3.0 \mathrm{~m}$

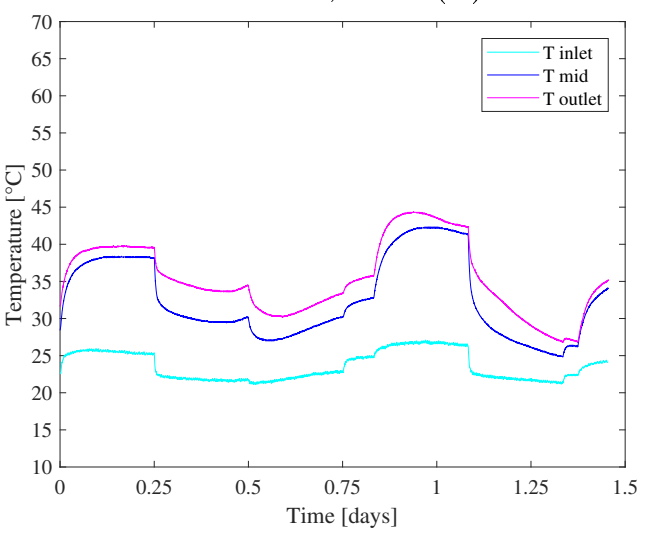

(a)

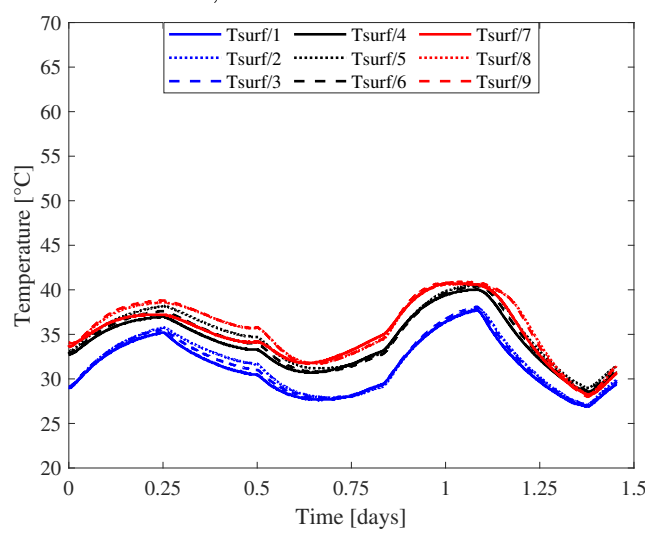

(b)

Figure D.4: P2C1PCM-2 results of (a) air temperature at inlet, mid and outlet level, and (b) surface temperature at $0.8,1.5$ and $3.0 \mathrm{~m}$ 


\section{D.3 P2C1PCM - Surface Temperature Behind PCM \& Surface Temperature Over PCM}

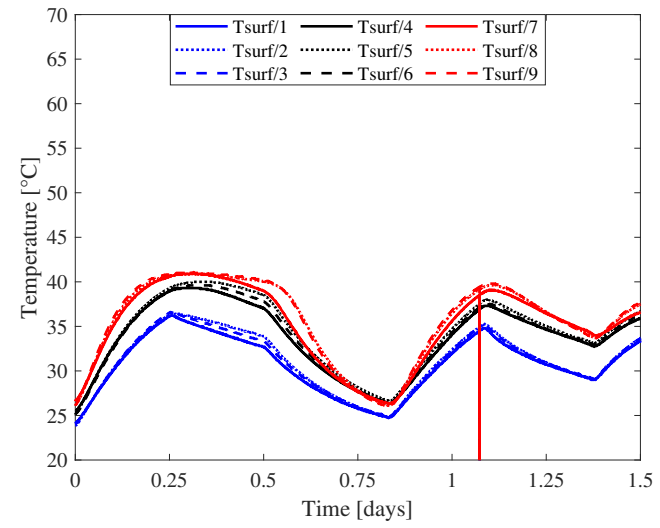

(a)

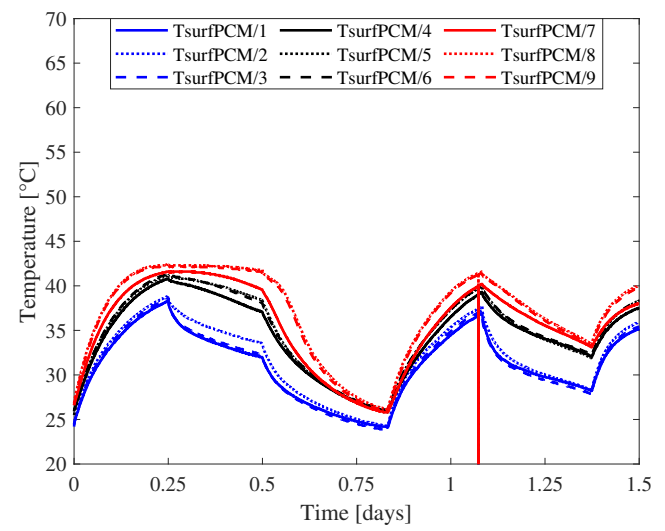

(b)

Figure D.5: P2C1PCM-1 results of surface temperature (a) behind PCM and (b) over PCM at $0.8,1.5$ and $3.0 \mathrm{~m}$

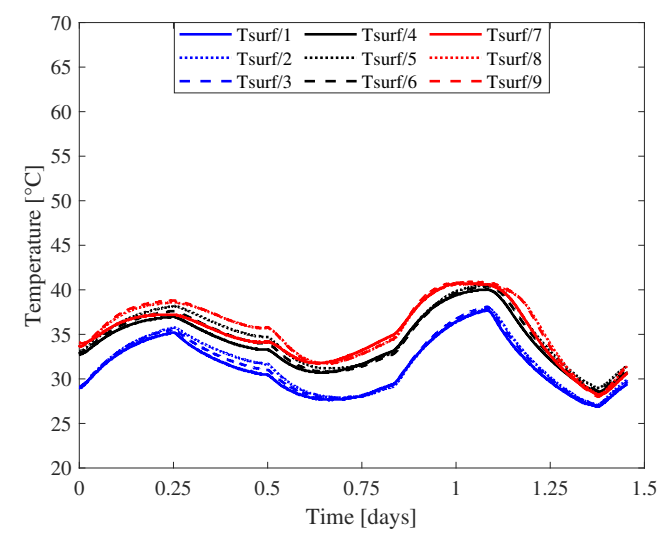

(a)

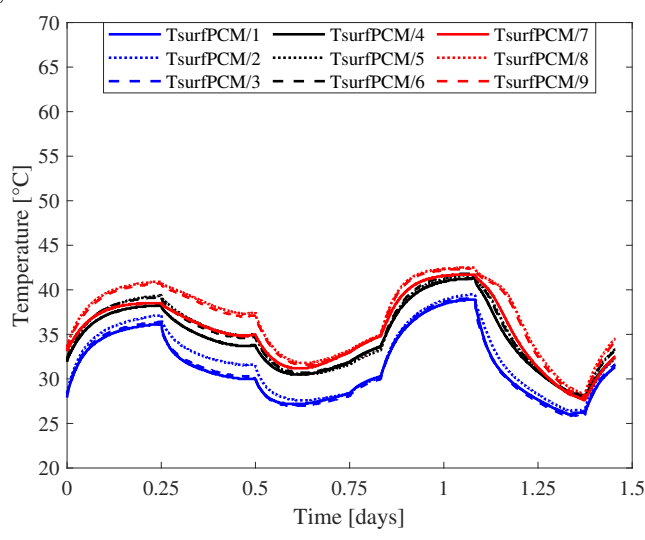

(b)

Figure D.6: P2C1PCM-2 results of surface temperature (a) behind PCM and (b) over PCM at $0.8,1.5$ and $3.0 \mathrm{~m}$ 


\section{D.4 P2C2PCM - Mass flow rate \& External and Internal Temperatures}

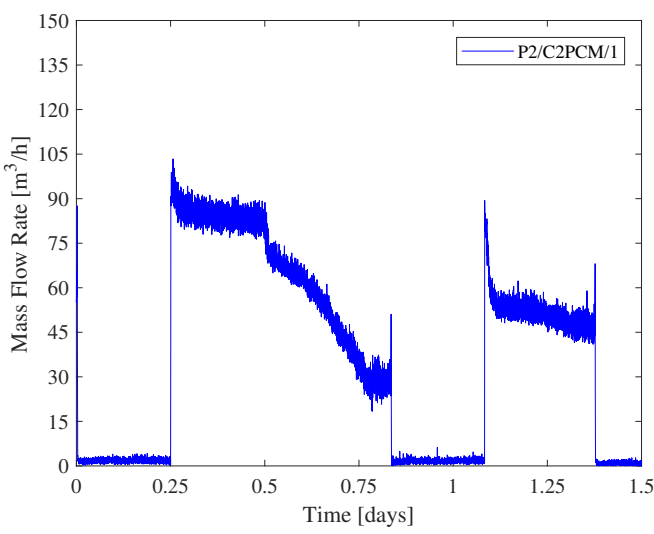

(a)

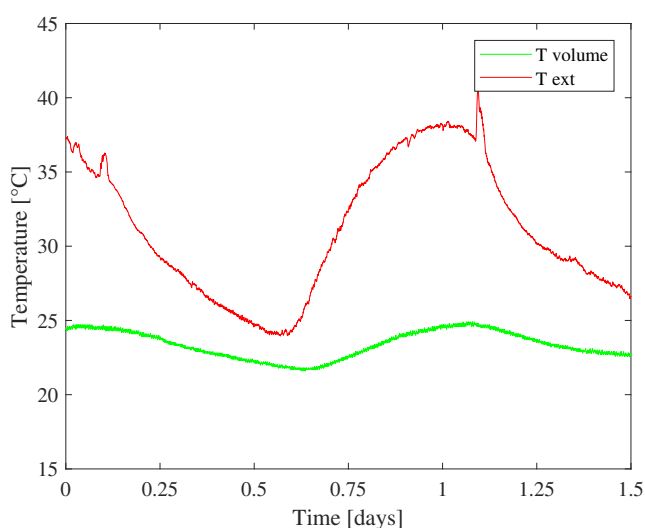

(b)

Figure D.7: P2C2PCM-1 results of (a) mass flow rate and (b) external and volume temperatures. Cooler set temperature $=18{ }^{\circ} \mathrm{C}$

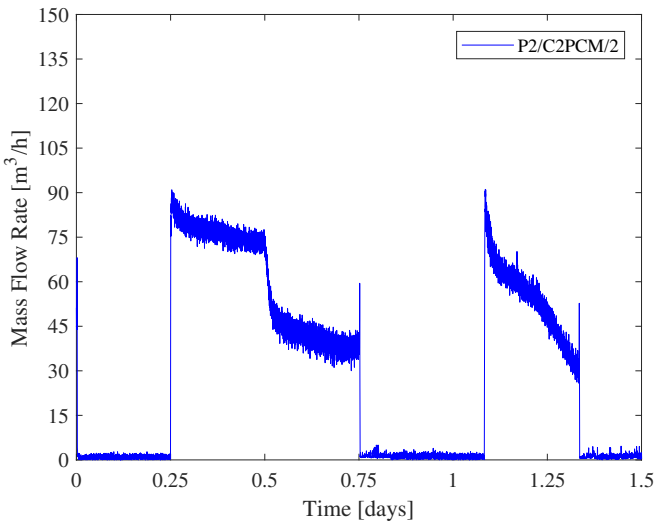

(a)

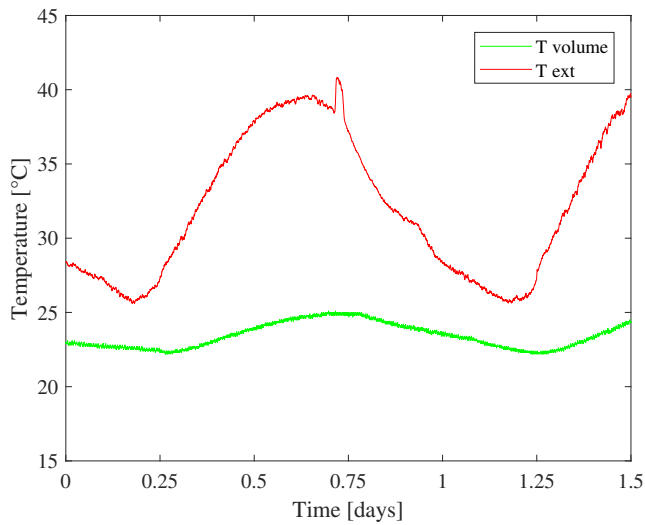

(b)

Figure D.8: P2C2PCM-2 results of (a) mass flow rate and (b) external and volume temperatures. Cooler set temperature $=18{ }^{\circ} \mathrm{C}$

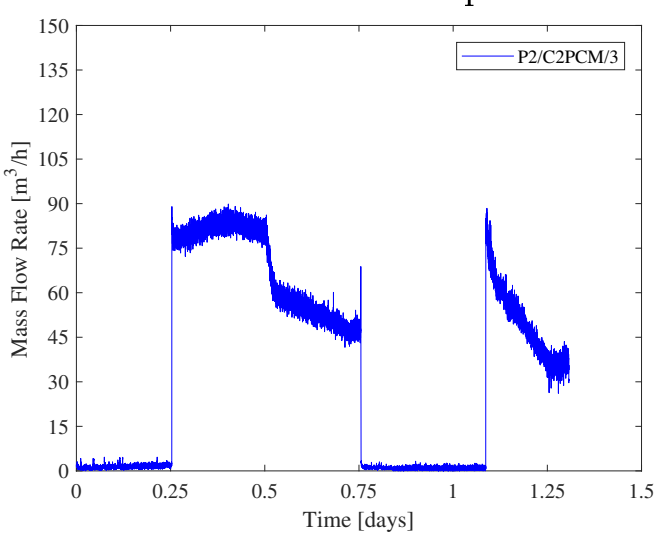

(a)

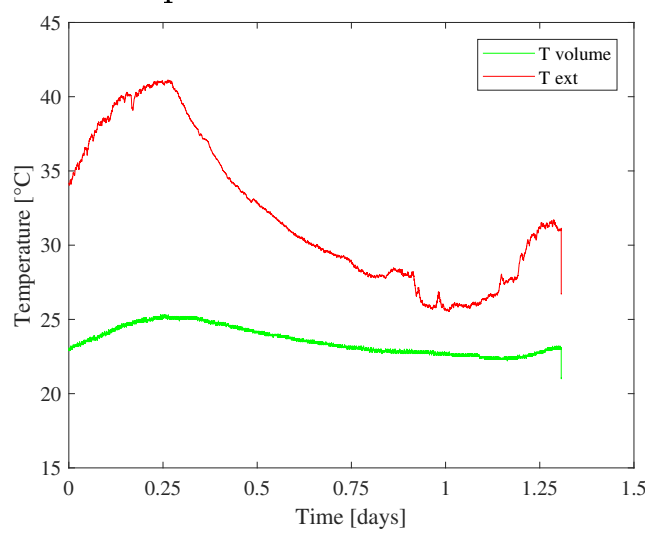

(b)

Figure D.9: P2C2PCM-3 results of (a) mass flow rate and (b) external and volume temperatures. Cooler set temperature $=18{ }^{\circ} \mathrm{C}$ 


\section{D.5 P2C2PCM - Surface Temperatures \& Chimney air temperatures}

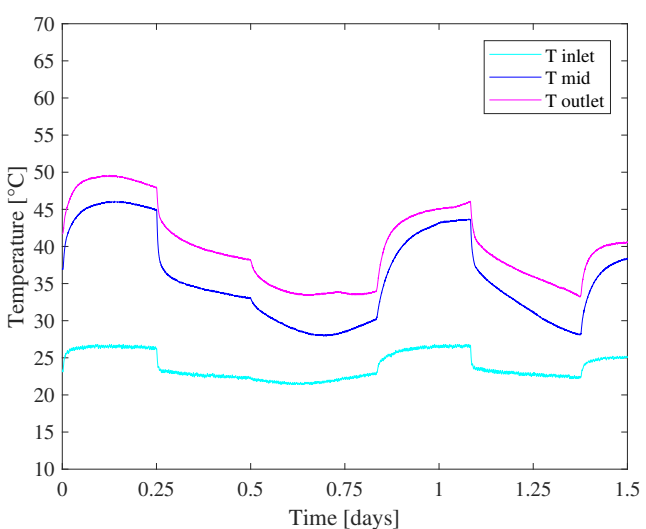

(a)

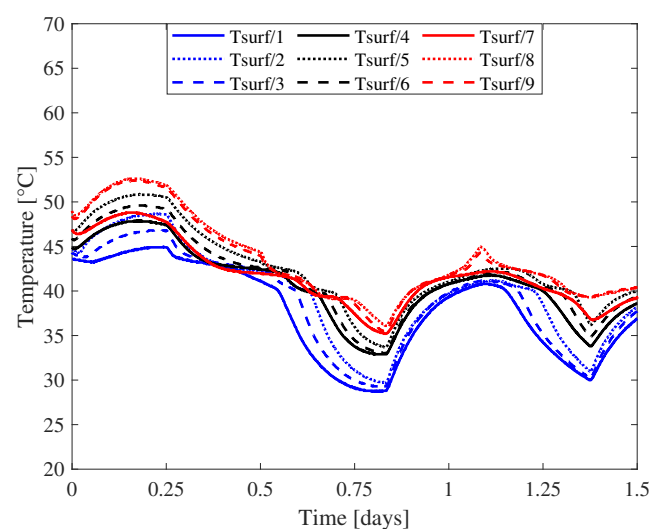

(b)

Figure D.10: P2C2PCM-1 results of (a) air temperature at inlet, mid and outlet level, and (b) surface temperature at $0.8,1.5$ and $3.0 \mathrm{~m}$

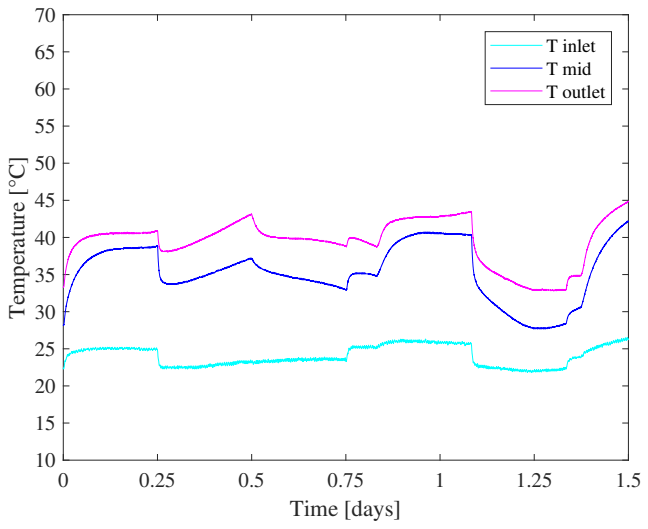

(a)

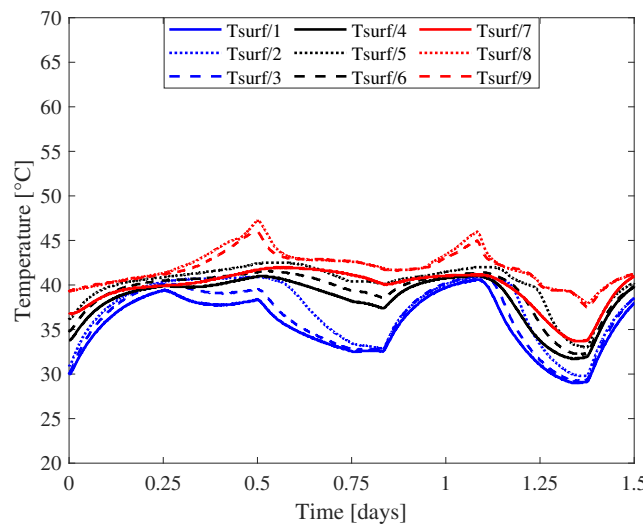

(b)

Figure D.11: P2C2PCM-2 results of (a) air temperature at inlet, mid and outlet level, and (b) surface temperature at $0.8,1.5$ and $3.0 \mathrm{~m}$

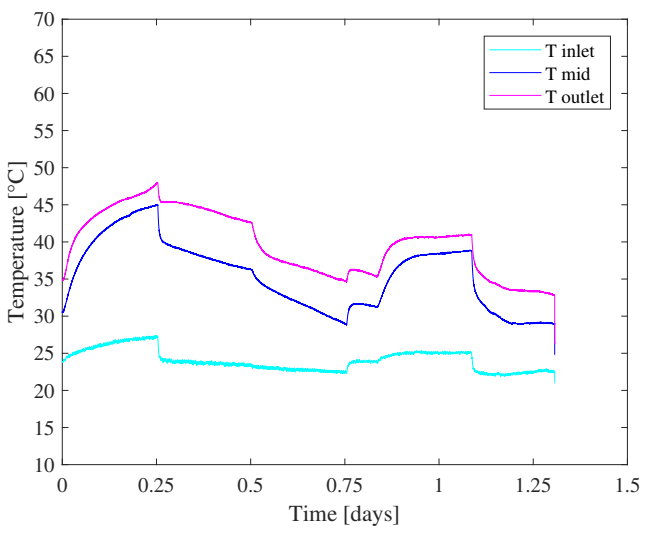

(a)

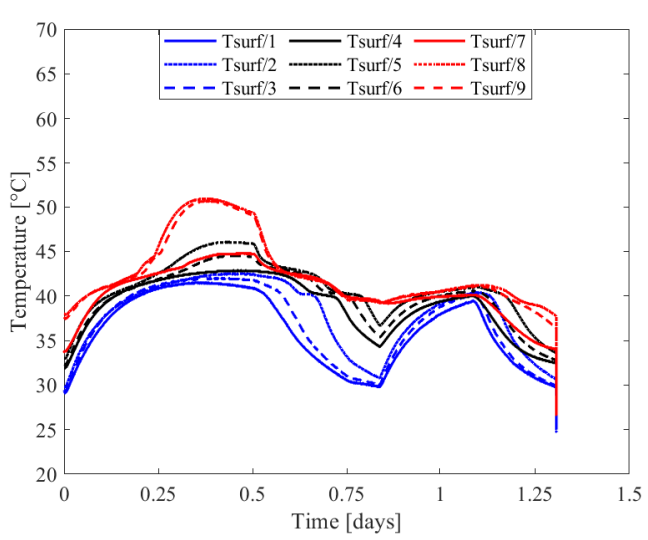

(b)

Figure D.12: $\mathrm{P} 2 \mathrm{C} 2 \mathrm{PCM}-3$ results of (a) air temperature at inlet, mid and outlet level, and (b) surface temperature at $0.8,1.5$ and $3.0 \mathrm{~m}$ 


\section{D.6 P2C2PCM - Surface Temperature Behind PCM \& Surface Temperature Over PCM}

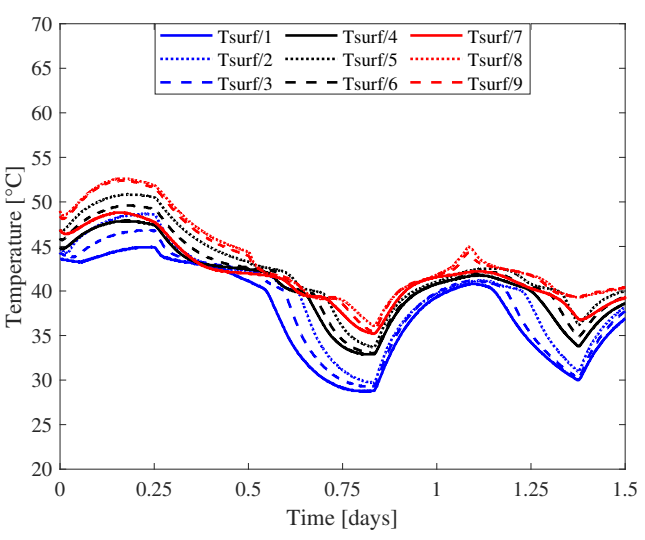

(a)

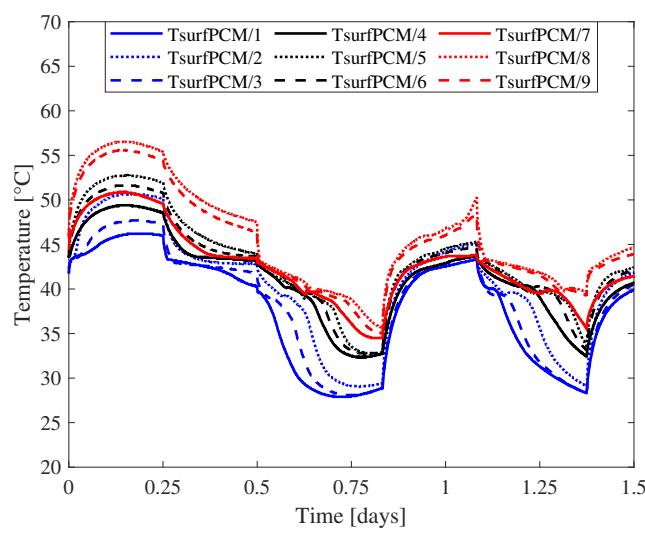

(b)

Figure D.13: P2C2PCM-1 results of surface temperature (a) behind PCM and (b) over PCM at $0.8,1.5$ and $3.0 \mathrm{~m}$

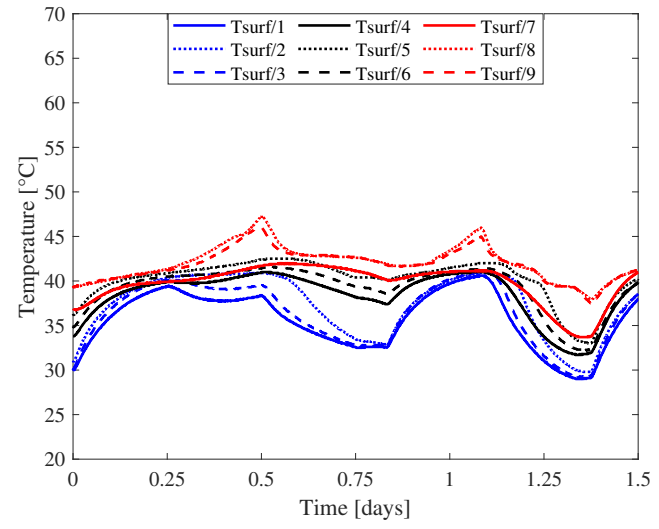

(a)

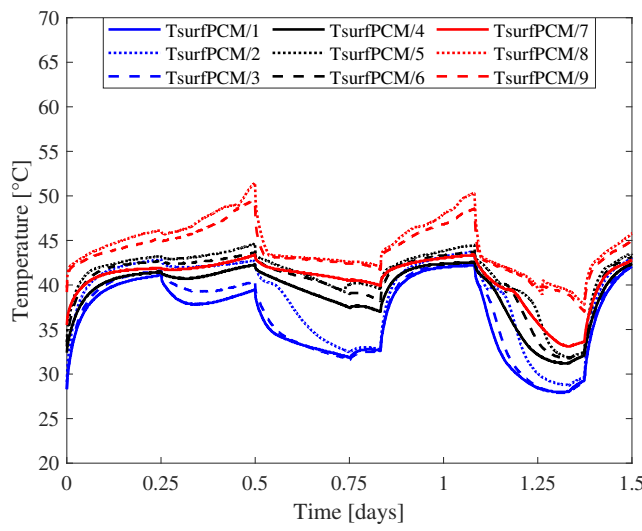

(b)

Figure D.14: $\mathrm{P} 2 \mathrm{C} 2 \mathrm{PCM}-2$ results of surface temperature (a) behind $\mathrm{PCM}$ and (b) over PCM at $0.8,1.5$ and $3.0 \mathrm{~m}$

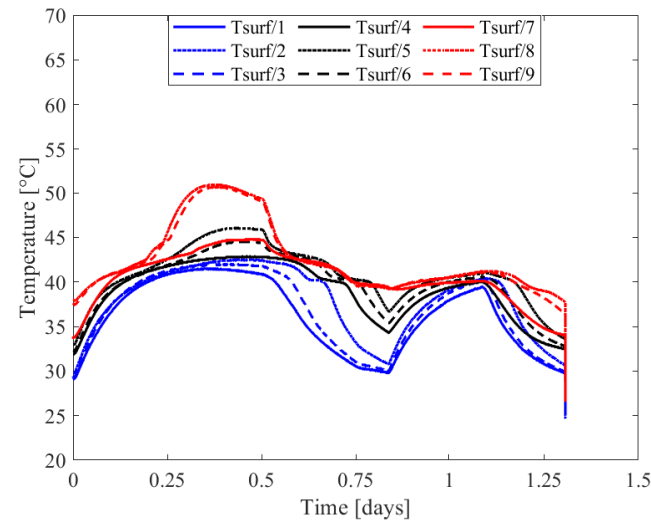

(a)

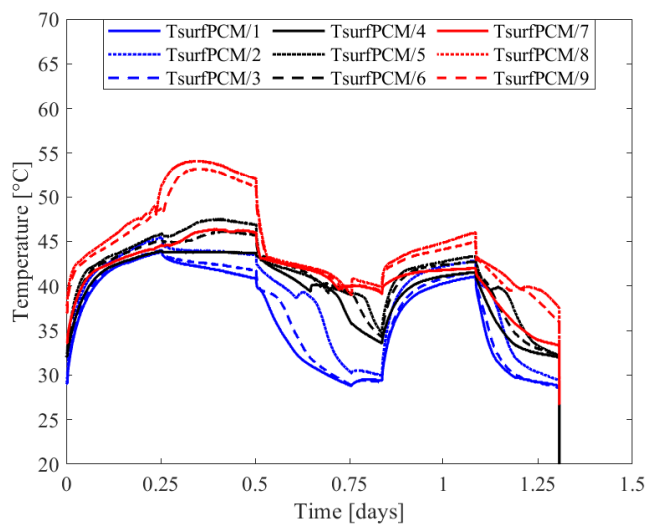

(b)

Figure D.15: P2C2PCM-3 results of surface temperature (a) behind PCM and (b) over PCM at $0.8,1.5$ and $3.0 \mathrm{~m}$ 


\section{D.7 P2C3PCM - Mass flow rate \& External and Internal Temperatures}

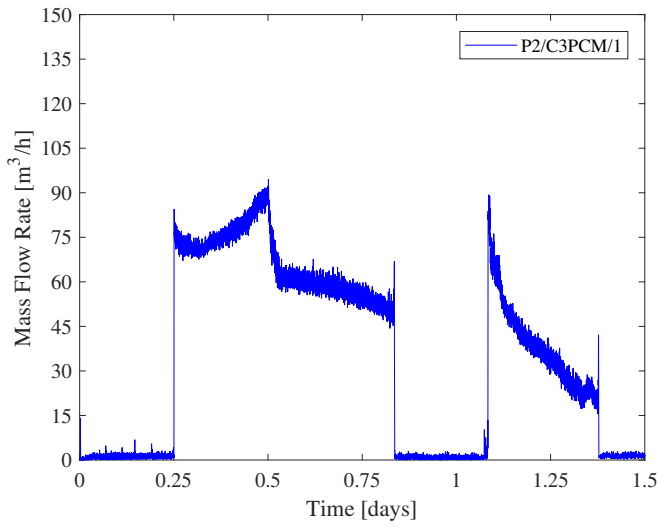

(a)

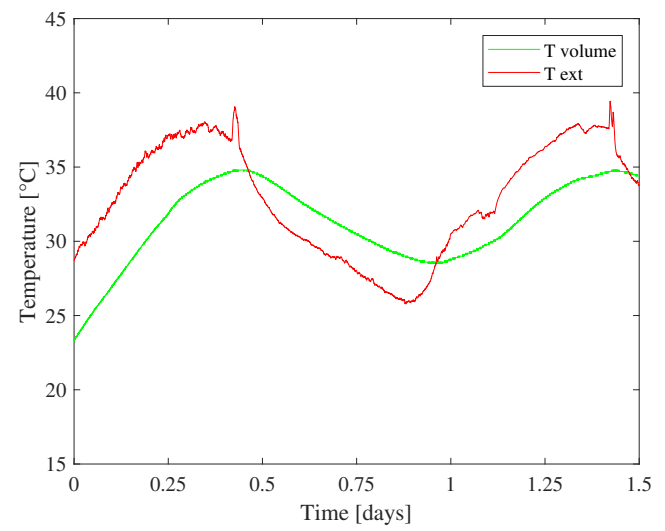

(b)

Figure D.16: P2C3PCM-1 results of (a) mass flow rate and (b) external and volume temperatures. Cooler set temperature $=18^{\circ} \mathrm{C}$

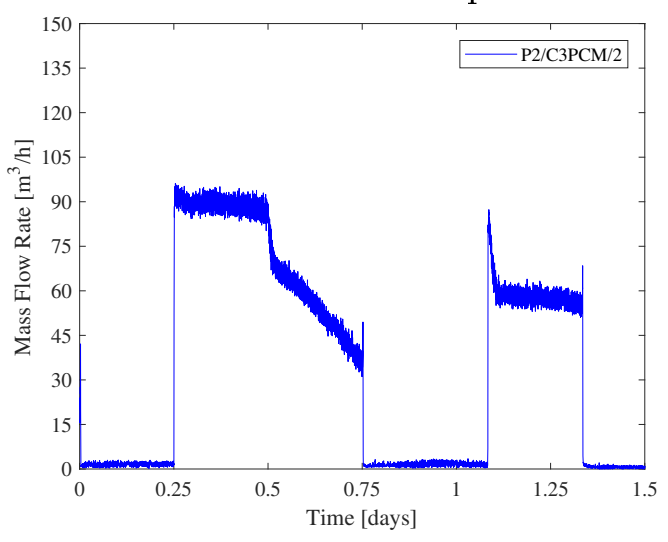

(a)

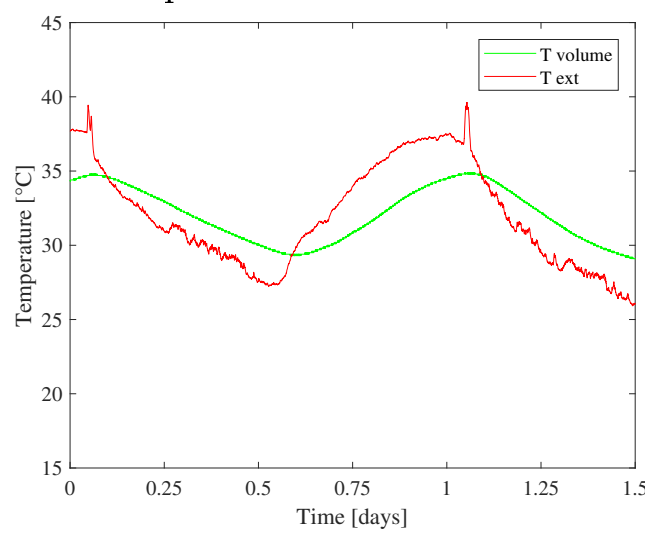

(b)

Figure D.17: P2C3PCM-2 results of (a) mass flow rate and (b) external and volume temperatures. Cooler set temperature $=18{ }^{\circ} \mathrm{C}$ 


\section{D.8 P2C3PCM - Surface Temperatures \& Chimney}

\section{air temperatures}

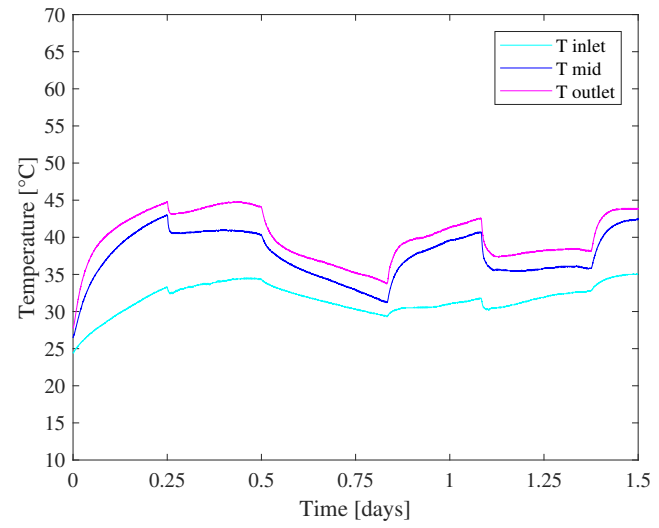

(a)

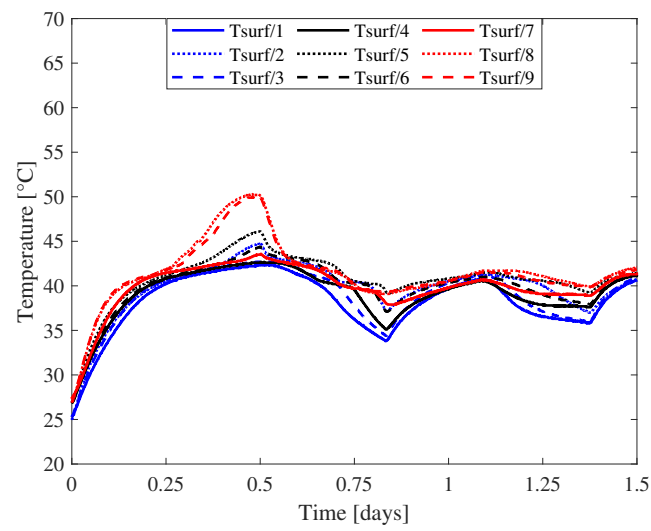

(b)

Figure D.18: P2C3PCM-1 results of (a) air temperature at inlet, mid and outlet level, and (b) surface temperature at $0.8,1.5$ and $3.0 \mathrm{~m}$

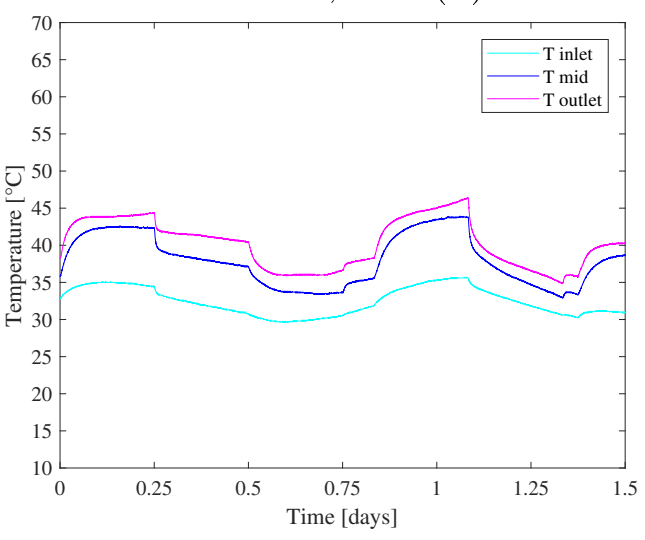

(a)

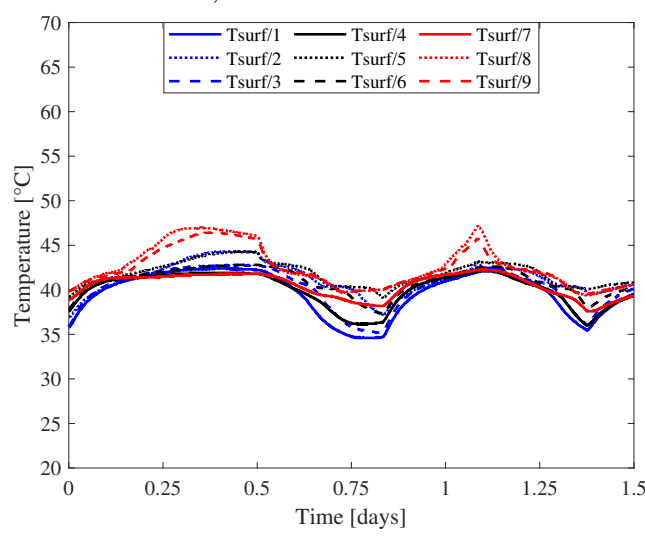

(b)

Figure D.19: P2C3PCM-2 results of (a) air temperature at inlet, mid and outlet level, and (b) surface temperature at $0.8,1.5$ and $3.0 \mathrm{~m}$ 


\section{D.9 P2C3PCM - Surface Temperature Behind PCM \& Surface Temperature Over PCM}

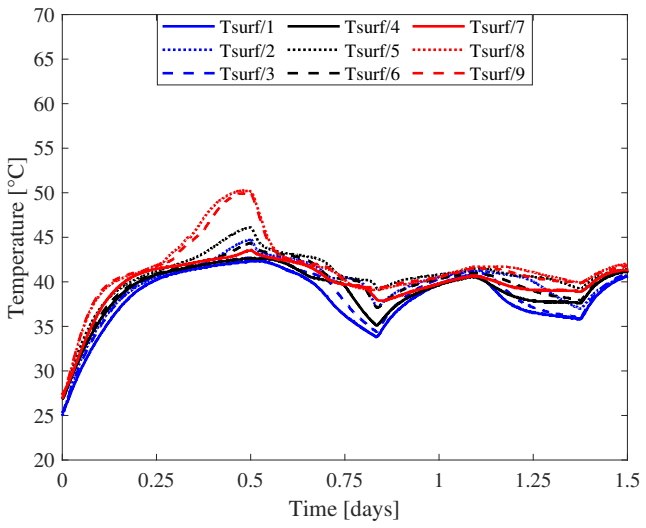

(a)

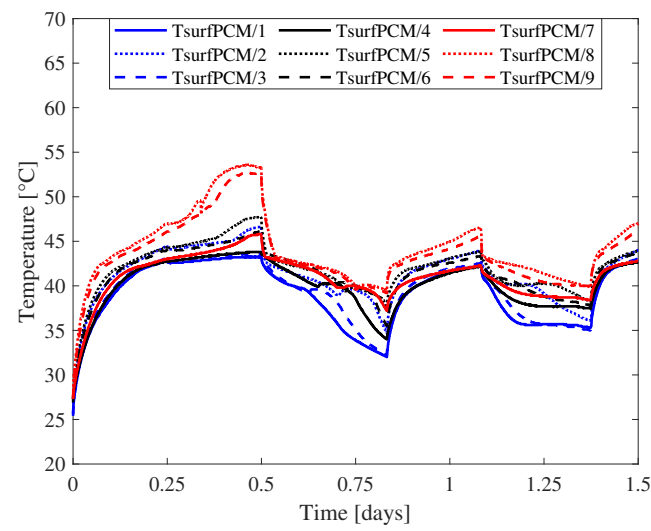

(b)

Figure D.20: P2C3PCM-1 results of surface temperature (a) behind PCM and (b) over PCM at $0.8,1.5$ and $3.0 \mathrm{~m}$

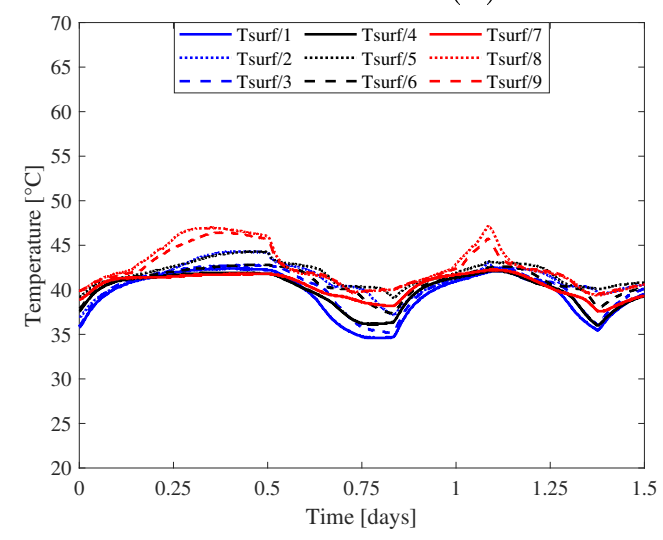

(a)

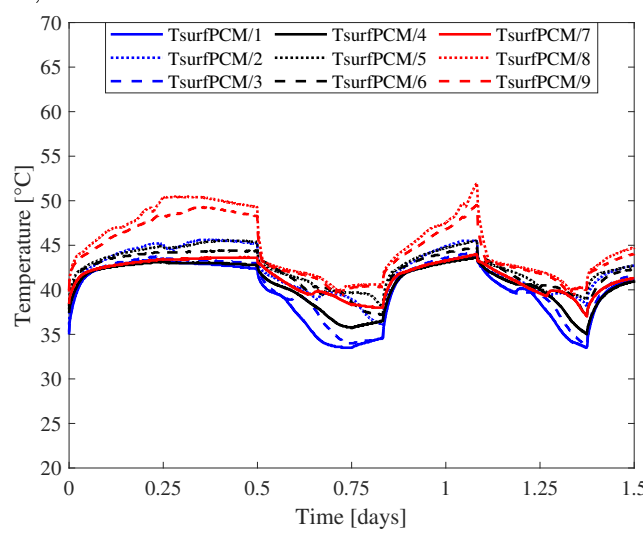

(b)

Figure D.21: P2C3PCM-2 results of surface temperature (a) behind PCM and (b) over PCM at $0.8,1.5$ and $3.0 \mathrm{~m}$ 


\section{D.10 P2C5PCM - Mass flow rate \& External and Internal Temperatures}

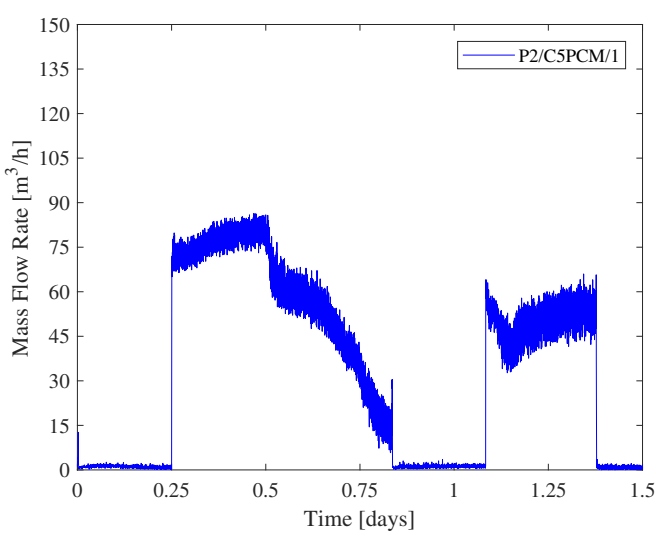

(a)

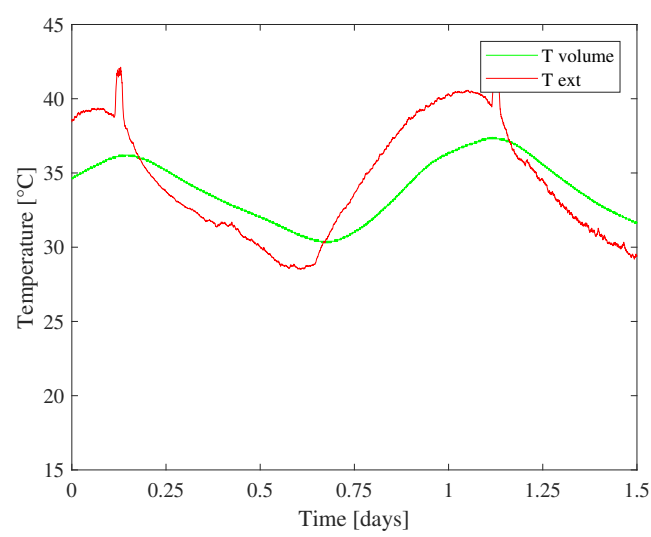

(b)

Figure D.22: P2C5PCM-1 results of (a) mass flow rate and (b) external and volume temperatures. Cooler set temperature $=18{ }^{\circ} \mathrm{C}$

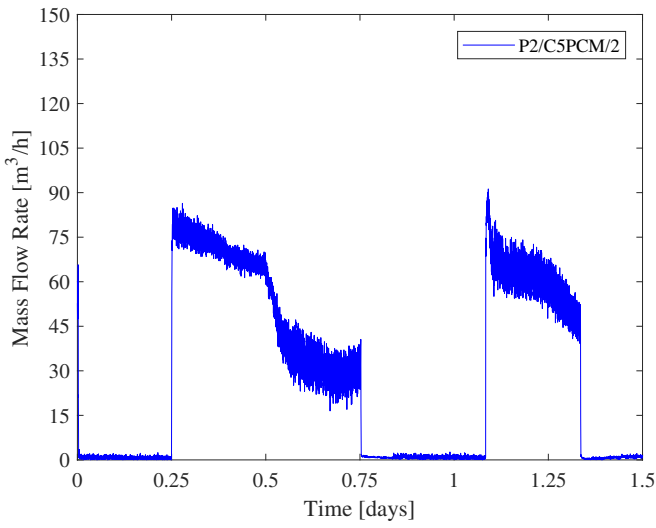

(a)

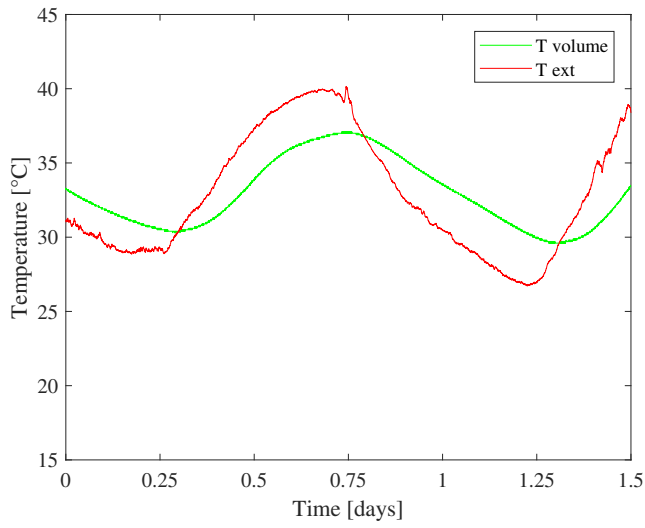

(b)

Figure D.23: P2C5PCM-2 results of (a) mass flow rate and (b) external and volume temperatures. Cooler set temperature $=18{ }^{\circ} \mathrm{C}$

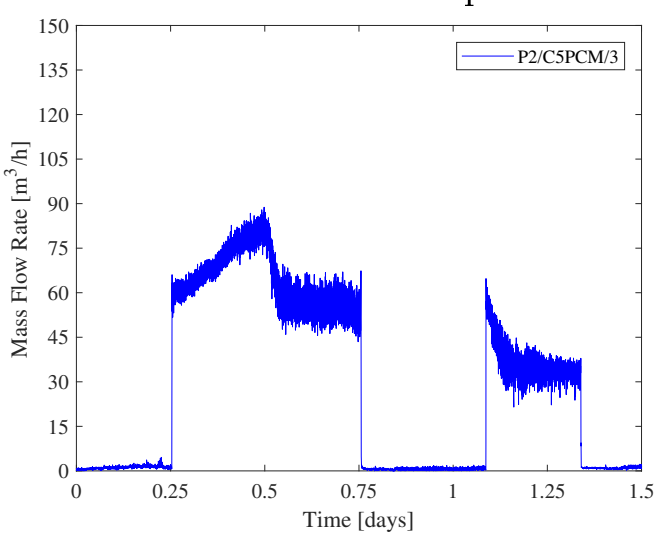

(a)

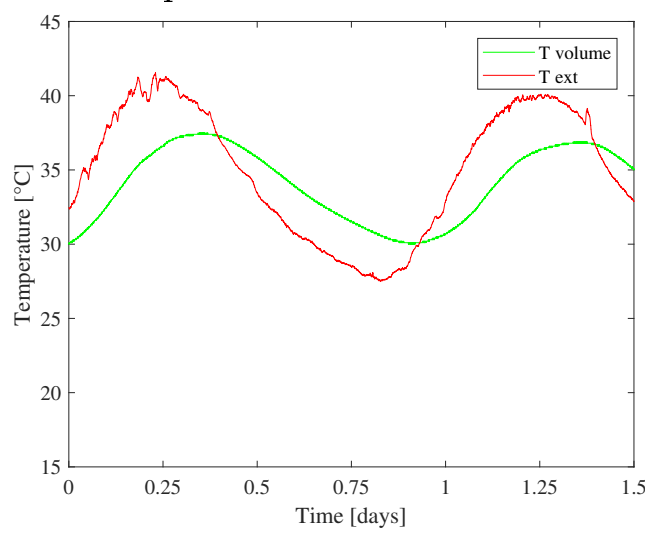

(b)

Figure D.24: P2C5PCM-3 results of (a) mass flow rate and (b) external and volume temperatures. Cooler set temperature $=18{ }^{\circ} \mathrm{C}$ 


\section{D.11 P2C5PCM - Surface Temperatures \& Chim- ney air temperatures}

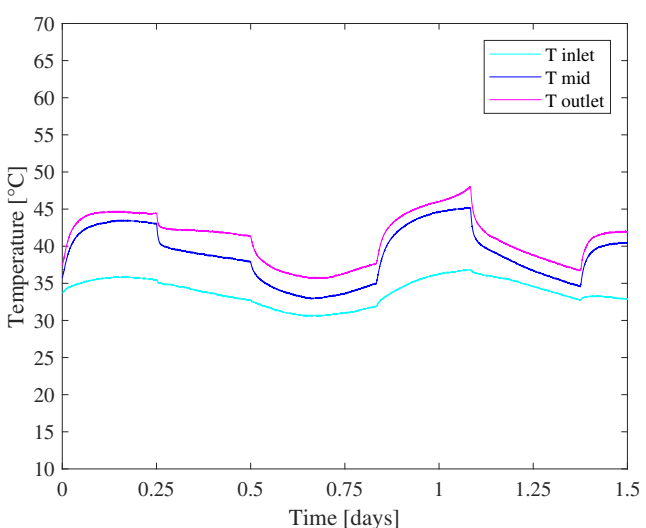

(a)

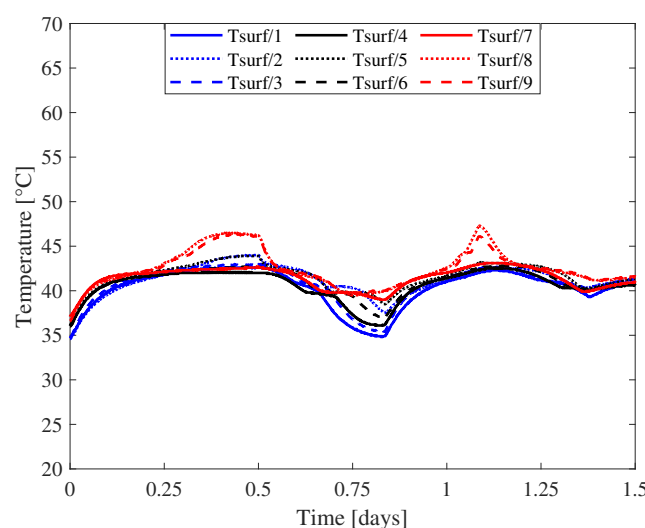

(b)

Figure D.25: P2C5PCM-1 results of (a) air temperature at inlet, mid and outlet level, and (b) surface temperature at $0.8,1.5$ and $3.0 \mathrm{~m}$

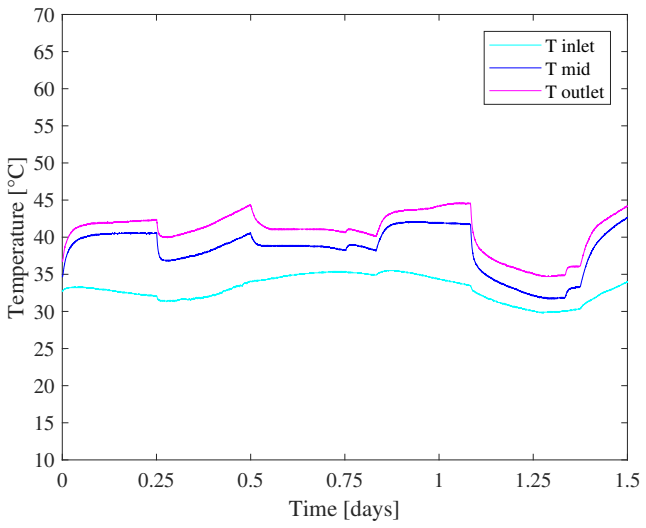

(a)

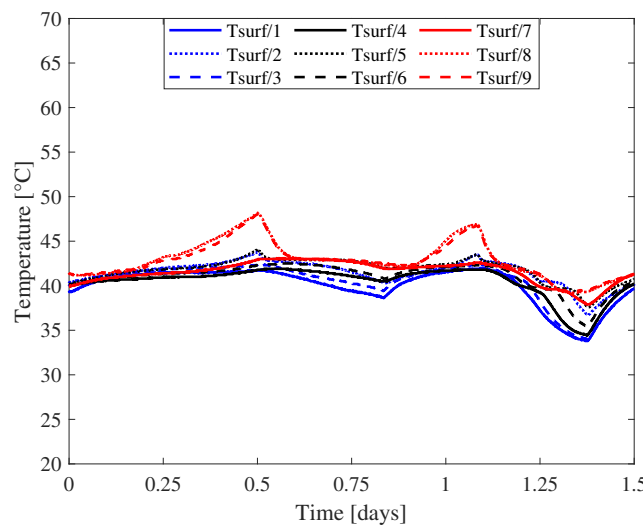

(b)

Figure D.26: P2C5PCM-2 results of (a) air temperature at inlet, mid and outlet level, and (b) surface temperature at $0.8,1.5$ and $3.0 \mathrm{~m}$

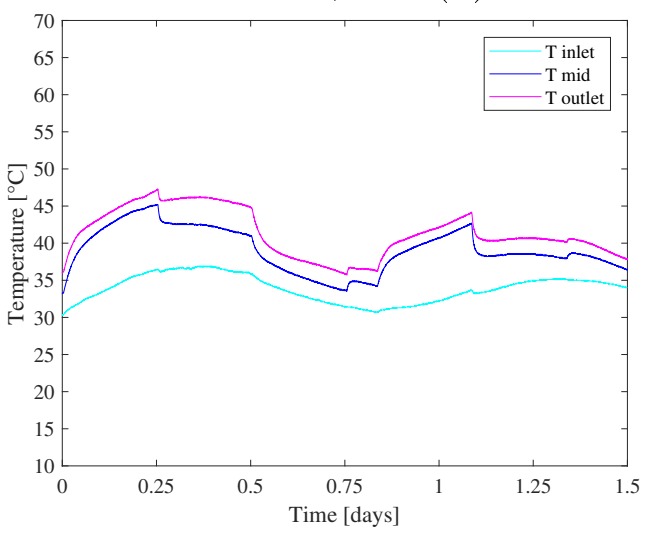

(a)

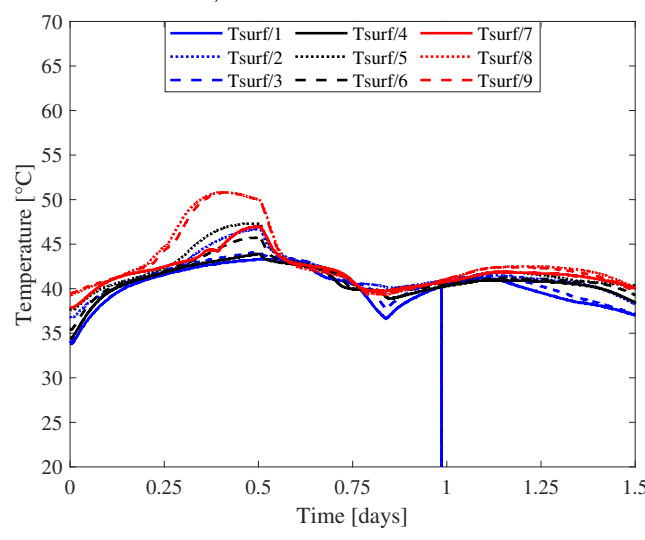

(b)

Figure D.27: P2C5PCM-3 results of (a) air temperature at inlet, mid and outlet level, and (b) surface temperature at $0.8,1.5$ and $3.0 \mathrm{~m}$ 


\section{D.12 P2C5PCM - Surface Temperature Behind PCM \& Surface Temperature Over PCM}

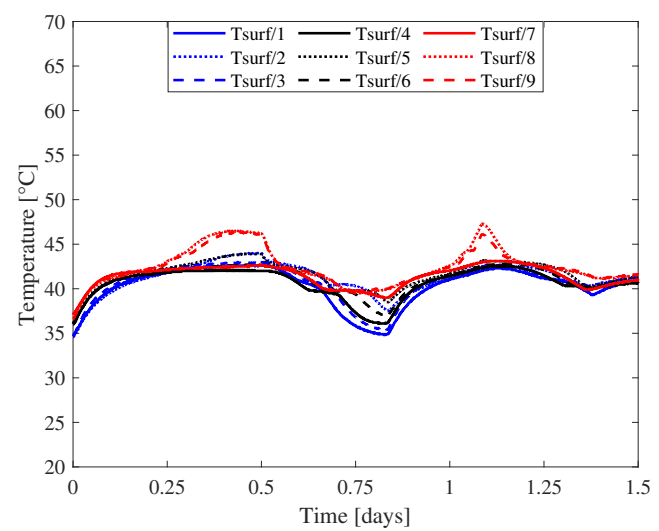

(a)

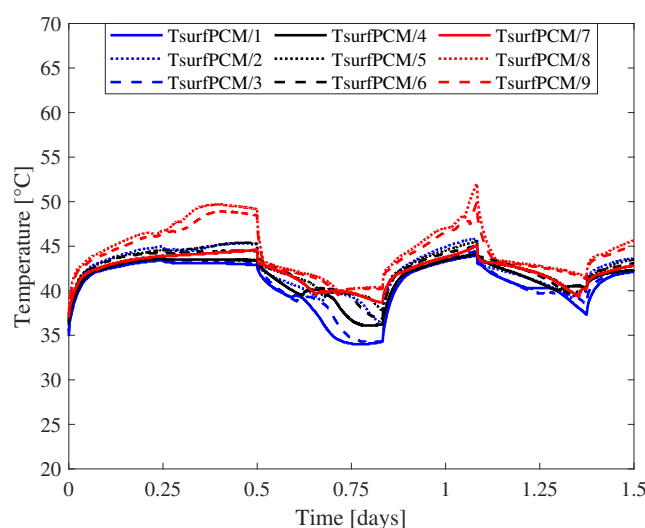

(b)

Figure D.28: P2C5PCM-1 results of surface temperature (a) behind PCM and (b) over PCM at $0.8,1.5$ and $3.0 \mathrm{~m}$

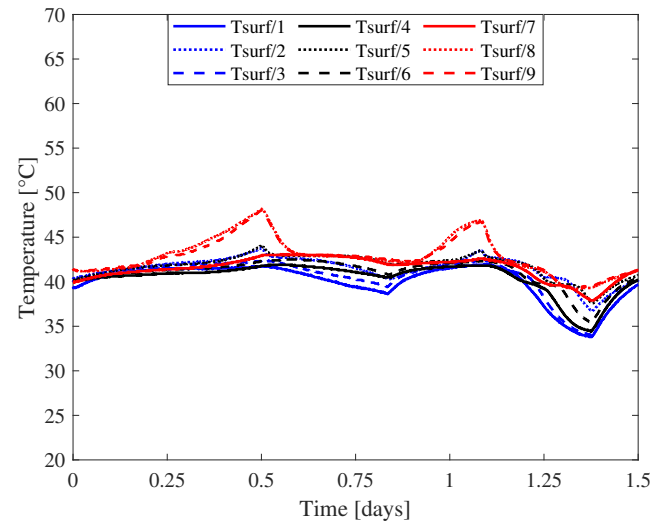

(a)

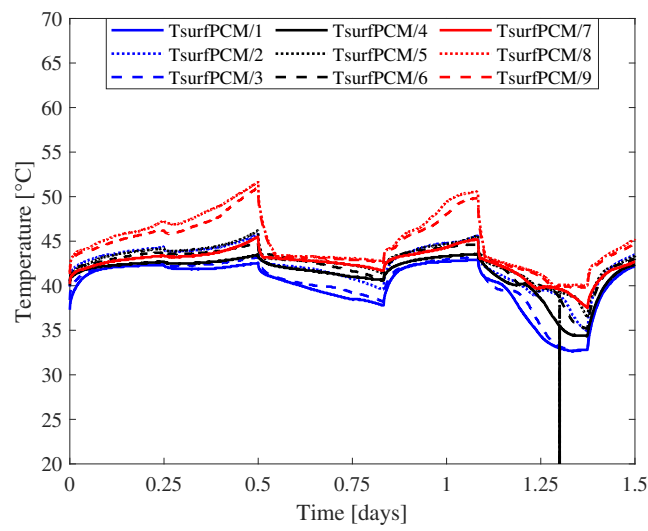

(b)

Figure D.29: P2C5PCM-2 results of surface temperature (a) behind PCM and (b) over PCM at $0.8,1.5$ and $3.0 \mathrm{~m}$

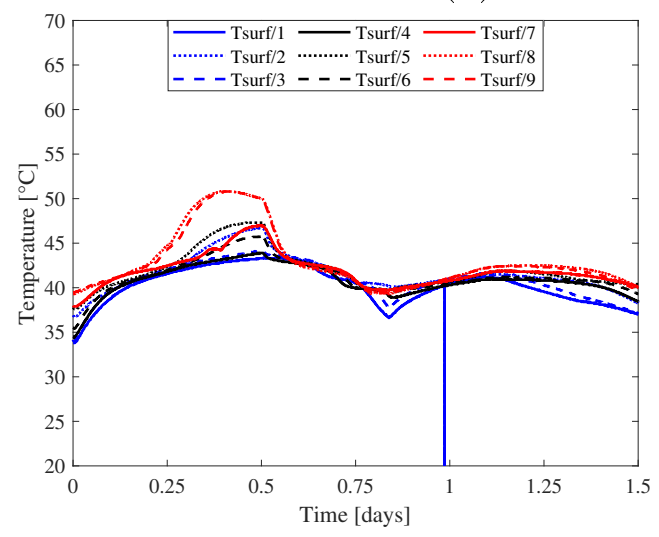

(a)

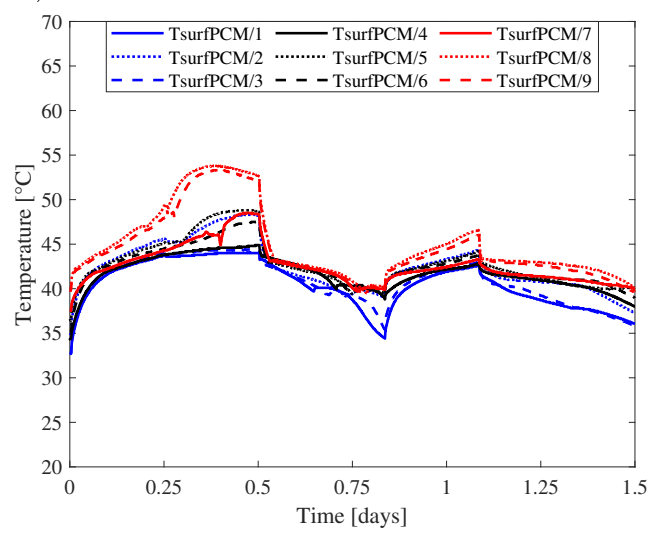

(b)

Figure D.30: P2C5PCM-3 results of surface temperature (a) behind PCM and (b) over PCM at $0.8,1.5$ and $3.0 \mathrm{~m}$ 


\section{Appendix E}

\section{Rubitherm RT44 Technical Data}


RUBITHERM ${ }^{\circledR} R T$ is a pure PCM, this heat storage material utilising the processes of phase change between solid and liquid (melting and congealing) to store and release large quantities of thermal energy at nearly constant temperature. The RUBITHERM ${ }^{\circledR}$ phase change materials (PCM's) provide a very effective means for storing heat and cold, even when limited volumes and low differences in operating temperature are applicable.

We look forward to discussing your particular questions, needs and interests with you.

Properties:

- high thermal energy storage capacity

- heat storage and release take place at relatively constant temperatures - no supercooling effect, chemically inert

- long life product, with stable performance through the phase change cycles

- melting temperature range between $-4{ }^{\circ} \mathrm{C}$ and $100^{\circ} \mathrm{C}$

\section{The most important data:}

\section{Melting area}

\section{Congealing area}

Heat storage capacity $\pm 7,5 \%$ in a temperatur range of $35^{\circ} \mathrm{C}$ to $50^{\circ} \mathrm{C}$.

Specific heat capacity

Density solid

at $25^{\circ} \mathrm{C}$

Density liquid

at $80^{\circ} \mathrm{C}$

Heat conductivity (both phases)

\section{Volume expansion}

Flash point

\section{Max. operation temperature}

Combination of latent and sensible heat

$\begin{array}{ll}\begin{array}{l}\text { Typical Values } \\ \text { 41-44 } \\ \text { main peak:43 }\end{array} & {\left[{ }^{\circ} \mathrm{C}\right]} \\ \begin{array}{l}\text { 44-40 } \\ \text { main peak:43 }\end{array} & {\left[{ }^{\circ} \mathrm{C}\right]} \\ 250 & {[\mathrm{~kJ} / \mathrm{kg}]^{*}} \\ 70 & {[\mathrm{Wh} / \mathrm{kg}]^{*}} \\ 2 & {[\mathrm{~kJ} / \mathrm{kg} \cdot \mathrm{K}]} \\ 0,8 & {[\mathrm{~kg} / \mathrm{l}]} \\ 0,7 & {[\mathrm{~kg} / \mathrm{l}]} \\ 0,2 & {\left[\mathrm{~W} /\left(\mathrm{m}^{\circ} \cdot \mathrm{K}\right)\right]} \\ 12,5 & {[\%]} \\ >180 & {\left[{ }^{\circ} \mathrm{C}\right]} \\ 70 & {\left[{ }^{\circ} \mathrm{C}\right]}\end{array}$

Typical Values

41-44

44-40

main peak: 43

$[\mathrm{Wh} / \mathrm{kg}]^{*}$

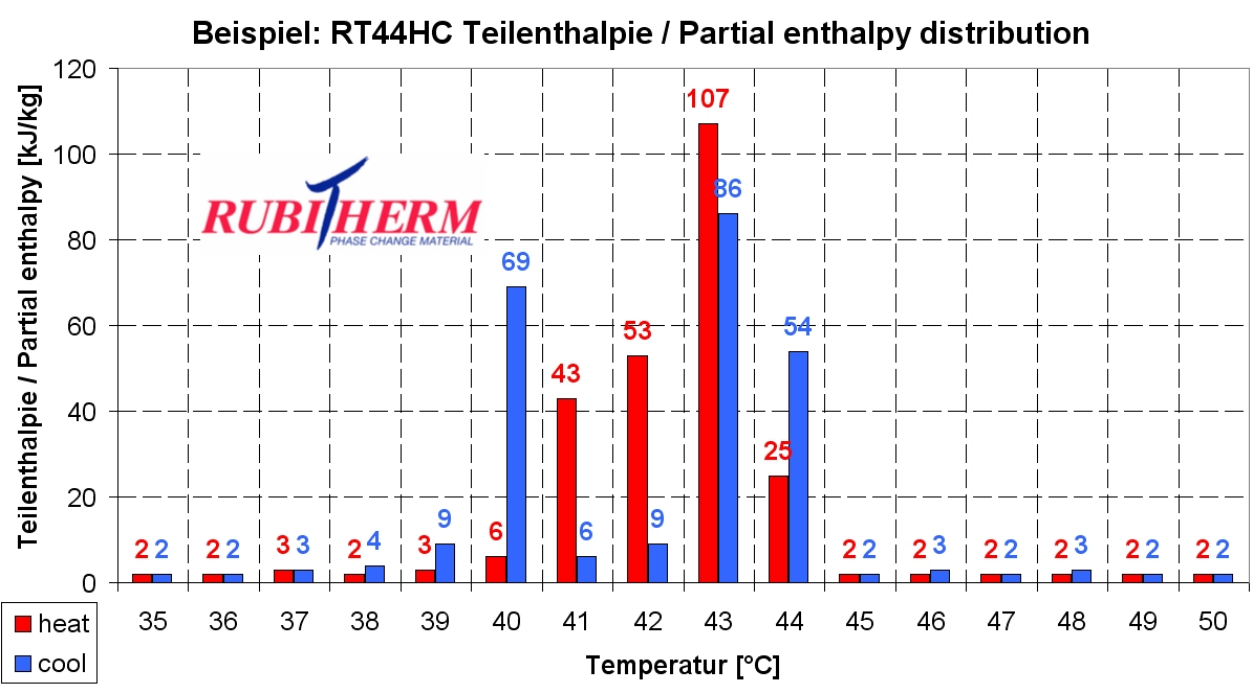

Temperatur $\left[{ }^{\circ} \mathrm{C}\right]$
Rubitherm Technologies GmbH Sperenberger Str. 5a D-12277 Berlin

Tel: +49 $30720004-62$

Fax: +49 $30720004-99$

E-Mail: info@rubitherm.com Internet: www.rubitherm.com

The product information given is a nonbinding planning aid, subject to technical changes without notice. Version:

31.05.2016

*Measured with 3-layer-calorimeter. 


\section{Appendix F}

Statistical Selection of Seasonal Data 


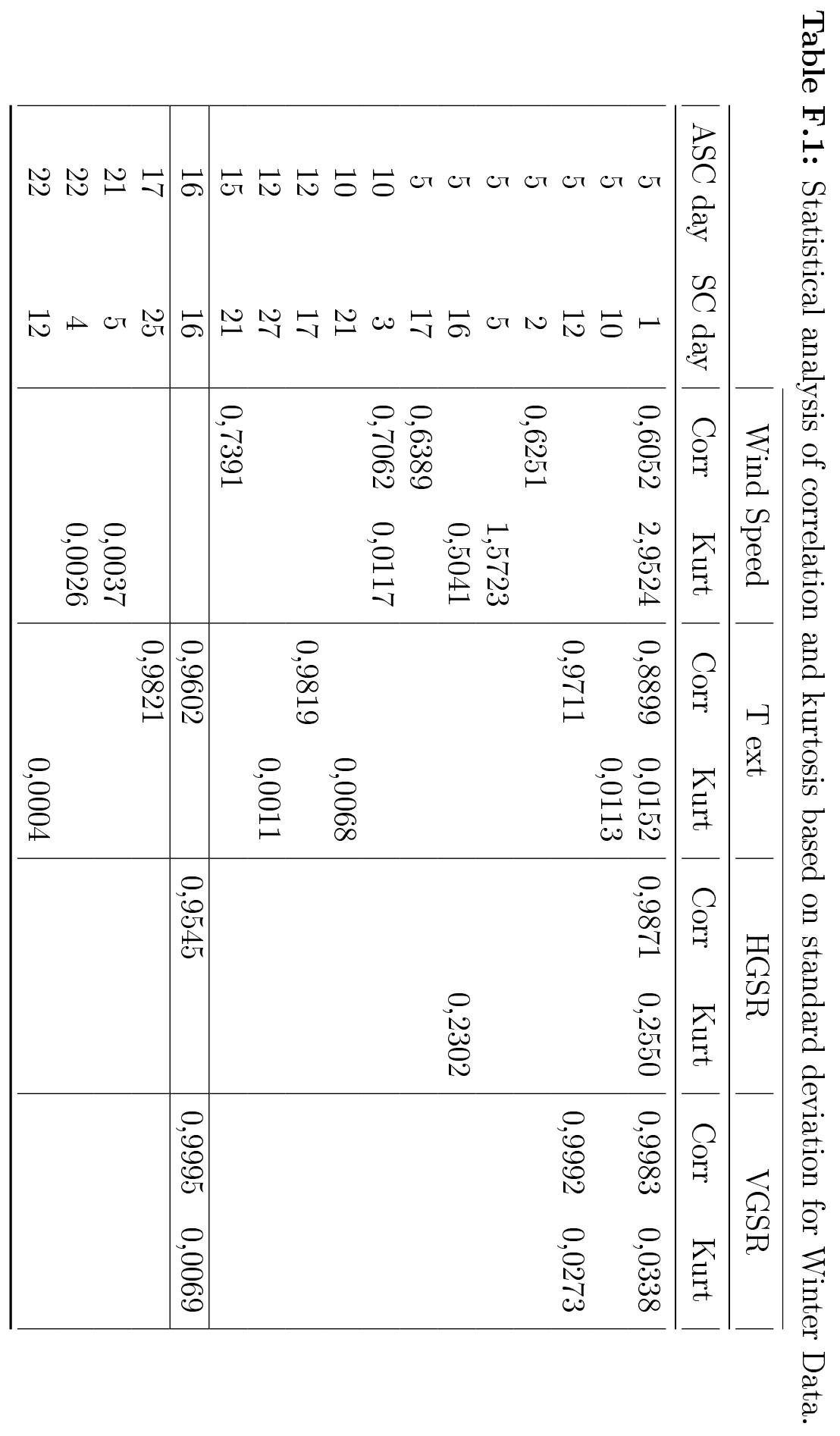




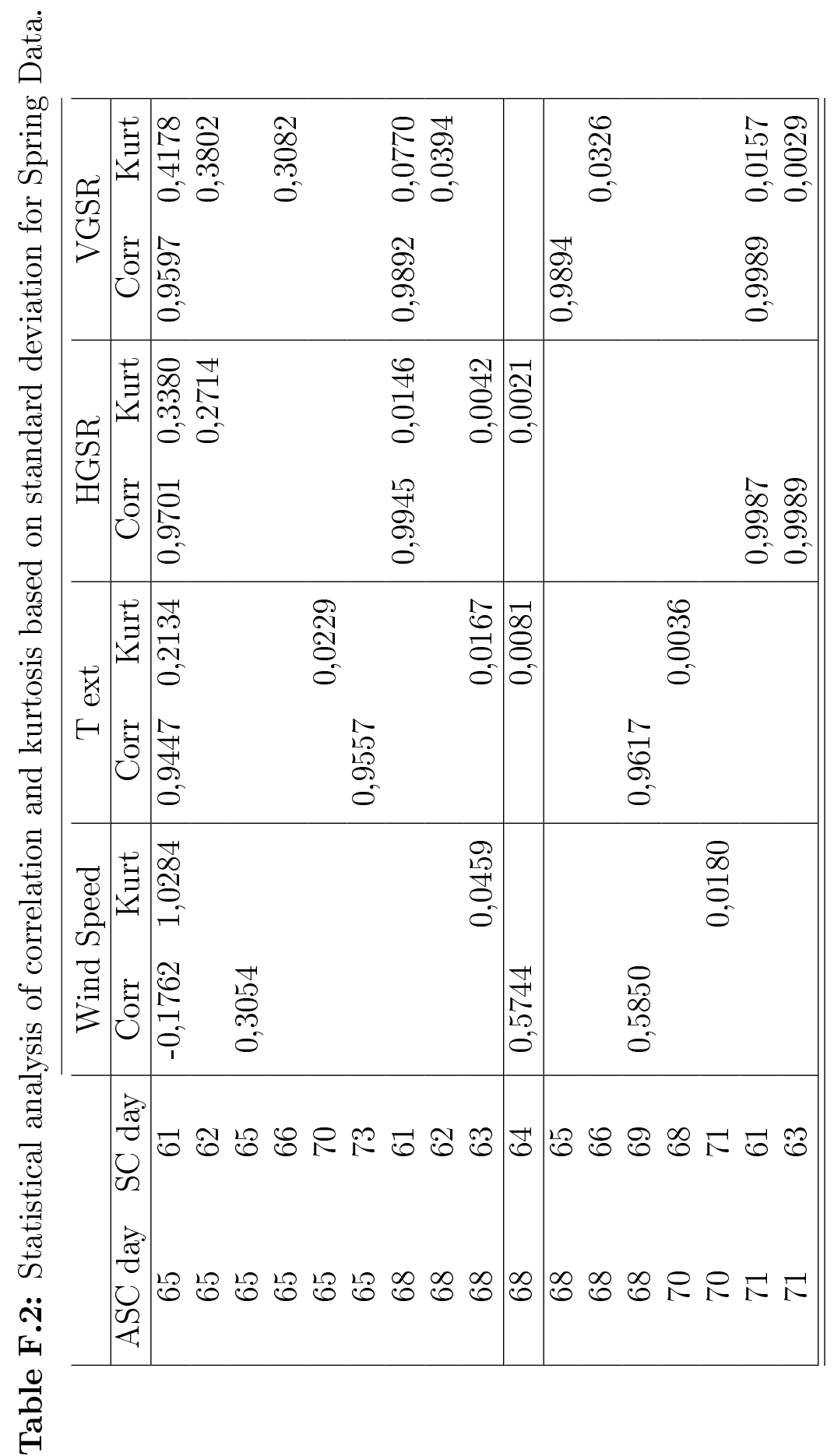




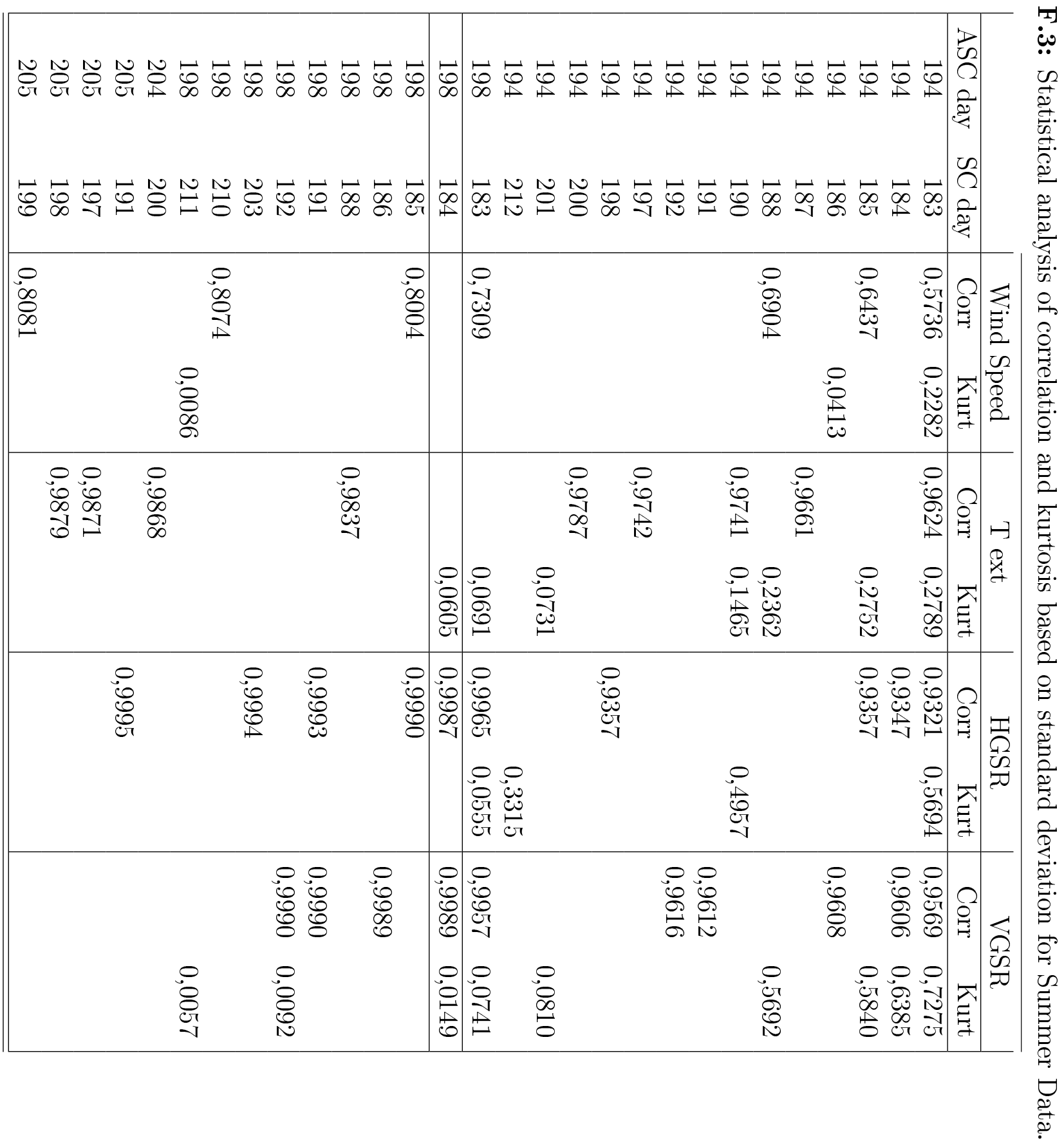




\section{Bibliography}

Abedin, A. and Rosen, M. (2011), 'A Critical Review of Thermochemical Energy Storage Systems.', Open Renewable Energy Journal 4, 42-46.

AboulNaga, M. M. and Abdrabboh, S. N. (2000), 'Improving night ventilation into low-rise buildings in hot-arid climates exploring a combined wall-roof solar chimney', Renewable Energy 19(1-2), 47-54.

Al-Kayiem, H. H., K.V., S. and Gilani, S. I. U. H. (2014), 'Mathematical analysis of the influence of the chimney height and collector area on the performance of a roof top solar chimney', Energy and Buildings 68(PARTA), 305-311.

Alva, G., Liu, L., Huang, X. and Fang, G. (2017), 'Thermal energy storage materials and systems for solar energy applications', Renewable and Sustainable Energy Reviews 68(February 2016), 693-706.

URL: http://dx.doi.org/10.1016/j.rser.2016.10.021

Amori, K. E. and Mohammed, S. W. (2012), 'Experimental and numerical studies of solar chimney for natural ventilation in Iraq', Energy and Buildings 47, 450-457.

Arce, J., Jiménez, M. J., Enríquez, R., Castillo, L., Álvarez, G. and Heras, M. R. (2015), 'Thermal performance analysis of a solar chimney, based on the experimental study of the main driving variables in a physical prototype', Paper conference (October), 385-395.

Arce, J., Jiménez, M. J., Guzmán, J. D., Heras, M. R., Alvarez, G. and Xamán, J. (2009), 'Experimental study for natural ventilation on a solar chimney', Renewable Energy 34(12), 2928-2934. 
Arce, J., Xamán, J. and Álvarez, G. (2011), 'Numerical study of mixed convection and conduction in a 2-D square ventilated cavity with an inlet at the vertical glazing wall and outlet at the top surface', Heat and Mass Transfer/Waerme- und Stoffuebertragung 47(2), 223-236.

Arce, J., Xaman, J., Alvarez, G., Jiménez, M. and Heras, M. (2009), 'A parametric study of conjugate heat transfer of solar chimney', Proceedings of the ASME 3rd International Conference on Energy Sustainability 2009, ES2009 1, 605-612.

Arce, J., Xaman, J. P., Alvarez, G., Jimenez, M. J., Enriquez, R. and Heras, M. R. (2013), 'A Simulation of the Thermal Performance of a Small Solar Chimney Already Installed in a Building', Journal of Solar Energy EngineeringTransactions of the Asme 135(1).

Asadi, S., Fakhari, M., Fayaz, R. and Mahdaviparsa, A. (2016), 'The effect of solar chimney layout on ventilation rate in buildings', Energy and Buildings 123, 71-78.

ASHRAE (2010), 'Standard 62.1 - Ventilation for acceptable indoor air quality', ASHRAE Standard 2007(STANDARD 62.1), 1-70.

Baetens, R., Jelle, B. P. and Gustavsen, A. (2010), 'Phase change materials for building applications: A state-of-the-art review', Energy and Buildings 42(9), 1361-1368.

Bahrar, M., Djamai, Z. I., EL Mankibi, M., Si Larbi, A. and Salvia, M. (2018), 'Numerical and experimental study on the use of microencapsulated phase change materials (PCMs) in textile reinforced concrete panels for energy storage', Sustainable Cities and Society 41(July 2017), 455-468.

URL: https://doi.org/10.1016/j.scs.2018.06.014

Bansal, N. K., Mathur, R. and Bhandari, M. S. (1993), 'Solar chimney for enhanced stack ventilation', Building and Environment 28(3), 373-377.

Bassiouny, R. and Koura, N. S. A. (2008), 'An analytical and numerical study of solar chimney use for room natural ventilation', Energy and buildings 40(5), 865-873. 
Borderon, J., Borderon, J. and Phase, C. D. (2017), 'Intégration des Matériaux à Changement de Phase comme système de régulation dynamique en rénovation thermique To cite this version : HAL Id : tel-01614879'.

Cabeza, L. F., Castell, A., Barreneche, C., De Gracia, A. and Fernández, A. I. (2011), 'Materials used as PCM in thermal energy storage in buildings: A review', Renewable and Sustainable Energy Reviews 15(3), 1675-1695.

Cabeza, L. F. and Mehling, H. (2007), Phase Change Materials And Their Basic Properties, in H. Paksoy, ed., 'Thermal Energy Storage for Sustainable Energy Consumption', Springer Netherlands, pp. $257-277$.

Cai, Y., Hu, Y., Song, L., Kong, Q., Yang, R., Zhang, Y., Chen, Z. and Fan, W. (2007), 'Preparation and flammability of high density polyethylene/paraffin/organophilic montmorillonite hybrids as a form stable phase change material', Energy Conversion and Management 48(2), 462-469.

Cai, Y., Hu, Y., Song, L., Tang, Y., Yang, R., Zhang, Y., Chen, Z. and Fan, W. C. (2006), 'Flammability and thermal properties of high density polyethylene/paraffin hybrid as a form-stable phase change material', Journal of Applied Polymer Science 99(4), 1320-1327.

Chan, H. Y., Riffat, S. B. and Zhu, J. (2010), 'Review of passive solar heating and cooling technologies', Renewable and Sustainable Energy Reviews 14(2), 781-789.

Chen, W. and Qu, M. (2014), 'Analysis of the heat transfer and airflow in solar chimney drying system with porous absorber', Renewable Energy 63, 511-518.

Chen, Z. D., Bandopadhayay, P., Halldorsson, J., Byrjalsen, C., Heiselberg, P. and Li, Y. (2003), 'An experimental investigation of a solar chimney model with uniform wall heat flux', Building and Environment 38(7), 893-906.

Chungloo, S. and Limmeechokchai, B. (2009), 'Utilization of cool ceiling with roof solar chimney in Thailand: The experimental and numerical analysis', Renewable Energy 34(3), 623-633.

Ciampi, M., Leccese, F. and Tuoni, G. (2003), 'Ventilated facades energy performance in summer cooling of buildings', Solar Energy 75(6), 491-502. 
Coley, D. A. (1999), 'An Introduction to Genetic Algorithms for Scientists and Engineers'.

URL: http://www.worldscientific.com/worldscibooks/10.1142/3904

Deb, K., Pratap, A., Agarwal, S. and Meyarivan, T. (2002), 'A fast and elitist multiobjective genetic algorithm: NSGA-II', IEEE Transactions on Evolutionary Computation 6(2), 182-197.

Dehghani-Sanij, A. R., Soltani, M. and Raahemifar, K. (2015), 'A new design of wind tower for passive ventilation in buildings to reduce energy consumption in windy regions', Renewable and Sustainable Energy Reviews 42, 182-195.

URL: http://dx.doi.org/10.1016/j.rser.2014.10.018

Duan, S., Jing, C. and Long, E. (2015), 'Transient flows in displacement ventilation enhanced by solar chimney and fan', Energy and Buildings 103, 124-130.

El Mankibi, M. (2003), 'Developpement et evaluation numerique et experimentale de strategies de regulation de la ventilation hybride', p. 390.

El Mankibi, M., Cron, F., Michel, P. and Inard, C. (2006), 'Prediction of hybrid ventilation performance using two simulation tools', Solar Energy 80(8), 908-926.

El Mankibi, M., Zhai, Z., Al-Saadi, S. N. and Zoubir, A. (2015), 'Numerical modeling of thermal behaviors of active multi-layer living wall', Energy and Buildings 106, $96-110$.

Farid, M. M., Khudhair, A. M., Razack, S. A. K. and Al-Hallaj, S. (2004), 'A review on phase change energy storage: Materials and applications', Energy Conversion and Management 45(9-10), 1597-1615.

Gan, G. (1998), 'A parametric study of Trombe walls for passive cooling of buildings', Energy and Buildings 27(1), 37-43.

URL: http://linkinghub.elsevier.com/retrieve/pii/S0378778897000248

Hadjieva, M., Kanev, S. and Argirov, J. (1992), 'Thermophysical properties of some paraffins applicable to thermal energy storage', Solar Energy Materials and Solar Cells 27(2), 181-187. 
Haghighat, F., Yu, Z., Inard, C., Michaux, G., Kuznik, F., Johannes, K., Virgone, J., Barzin, R., Farid, M., Bastani, A., Stathopoulos, N., Mankibi, M. E., Nkwetta, D. N., Moreau, A., Vouillamoz, P.-E., Castell, A. and Adl-Zarrabi, B. (2013), Annex 23: Energy storage in buildings of the future - Applying Energy Storage in Ultra-low Energy Buildings, Technical report, IEA.

Harris, D. J. and Helwig, N. (2007), 'Solar chimney and building ventilation', Applied Energy 84(2), 135-146.

Hassan Abdallah, A. S. (2017), 'Occupant Comfort and Indoor Temperature Reduction by Using Passive Air Conditioning System with Solar Chimney Concept in Hot Arid Climate', Procedia Engineering 205, 1100-1107.

URL: https://doi.org/10.1016/j.proeng.2017.10.178

Hosien, M. and Selim, S. (2017), 'Effects of the geometrical and operational parameters and alternative outer cover materials on the performance of solar chimney used for natural ventilation', Energy and Buildings 138, 355-367.

Hughes, B. R., Chaudhry, H. N. and Ghani, S. A. (2011), 'A review of sustainable cooling technologies in buildings', Renewable and Sustainable Energy Reviews 15(6), 3112-3120.

URL: http://dx.doi.org/10.1016/j.rser.2011.03.032

Ibañez-Puy, M., Vidaurre-Arbizu, M., Sacristán-Fernández, J. A. and Martín-Gómez, C. (2017), 'Opaque Ventilated Façades: Thermal and energy performance review', Renewable and Sustainable Energy Reviews 79(February), 180-191.

URL: http://dx.doi.org/10.1016/j.rser.2017.05.059

Imran, A. A., Jalil, J. M. and Ahmed, S. T. (2015), 'Induced flow for ventilation and cooling by a solar chimney', Renewable Energy 78, 236-244.

International Energy Agency (IEA) (2015), 'Spain 2015 Review', Energy Policies of IEA Countries p. 178.

International Energy Agency (IEA) (2017a), France 2016 Review, Technical report. 
URL: $\quad$ https://webstore.iea.org/energy-policies-of-iea-countries-france-2016review

International Energy Agency (IEA) (2017b), 'Mexico 2017 Review', Energy Policies Beyond IEA Countries pp. 9-213.

URL: https://www.iea.org/publications/freepublications/publication/EnergyPoliciesBeyondIEAC Mexico/EnergyPoliciesBeyondIEACountriesMexico201\%.pdf\#search=position

International Energy Agency (IEA) (2017c), World Energy Balances: Overview, Technical report.

URL: $h t t p: / / w w w . i e a . o r g / t \& c /$

International Renewable Energy Agency (IRENA) (2015), Renewable Energy Prospects: Mexico, Technical Report May.

URL: http://www.irena.org/DocumentDownloads/Publications/IRENA_REmap_Mexico_repor

International Renewable Energy Agency (IRENA) (2018), Renewable Energy Prospects for the European Union, Technical Report February.

Jianliu, X. and Weihua, L. (2013), 'Study on solar chimney used for room natural ventilation in Nanjing', Energy and Buildings 66, 467-469.

Jiménez, M. J., Heras, M. R. and Arce, J. (2007), 'Estimation of the main thermal parameters of a real size solar chimney from out- door dynamic tests', (September), 455-459.

Kasaeian, A., Ghalamchi, M. and Ghalamchi, M. (2014), 'Simulation and optimization of geometric parameters of a solar chimney in Tehran', Energy Conversion and Management 83, 28-34.

Kenisarin, M. and Mahkamov, K. (2007), 'Solar energy storage using phase change materials', Renewable and Sustainable Energy Reviews 11(9), 1913-1965.

Khanal, R. and Lei, C. (2011), 'Solar chimney-A passive strategy for natural ventilation', Energy and Buildings 43(8), 1811-1819.

Khanal, R. and Lei, C. (2014a), 'A scaling investigation of the laminar convective flow in a solar chimney for natural ventilation', International Journal of Heat and Fluid Flow 45(1), 98-108. 
Khanal, R. and Lei, C. (2014b), 'An experimental investigation of an inclined passive wall solar chimney for natural ventilation', Solar Energy 107, 461-474.

Khanal, R. and Lei, C. (2015), 'A numerical investigation of buoyancy induced turbulent air flow in an inclined passive wall solar chimney for natural ventilation', Energy and Buildings 93, 217-226.

Khedari, J., Boonsri, B. and Hirunlabh, J. (2000), 'Ventilation impact of a solar chimney on indoor temperature fluctuation and air change rate in school building. Energy and Buildings', pp. 89-93.

Khedari, J., Rachapradit, N. and Hirunlabh, J. (2003), 'Field study of performance of solar chimney with air-conditioned building', Energy 28(11), 1099-1114.

Kheradmand, M., Azenha, M., de Aguiar, J. L. B. and Castro-Gomes, J. (2016), 'Experimental and numerical studies of hybrid PCM embedded in plastering mortar for enhanced thermal behaviour of buildings', Energy 94, 250-261.

Knowles, J. and Corne, D. (1999), 'The Pareto archived evolution strategy: A new baseline algorithm for Pareto multiobjective optimisation', Proceedings of the 1999 Congress on Evolutionary Computation, CEC 1999 1(January), 98-105.

Kuwabara, B., Auer, T., Akerstream, T., Klym, G., Pauls, M., Opie, K. and Peterson, J. (2011), 'Harnessing Climate: Manitoba Hydro Place', 6.

Kuwabara, B., Auer, T., Gouldsborough, T., Akerstream, T. and Klym, G. (2009), 'Manitoba Hydro Place. Integrated Design Process Exemplar', Conference on Passive and Low Nergy Architecture (PLEA) (June), 22-24.

Kuznik, F., David, D., Johannes, K. and Roux, J. J. (2011), 'A review on phase change materials integrated in building walls', Renewable and Sustainable Energy Reviews 15(1), 379-391.

URL: http://linkinghub.elsevier.com/retrieve/pii/S1364032110002716

Lee, K. H. and Strand, R. K. (2009), 'Enhancement of natural ventilation in buildings using a thermal chimney', Energy and Buildings 41(6), 615-621. 
Li, Y. and Liu, S. (2014a), 'Experimental study on thermal performance of a solar chimney combined with PCM', Applied Energy 114, 172-178.

Li, Y. and Liu, S. (2014b), 'Numerical study on thermal behaviors of a solar chimney incorporated with PCM', Energy and Buildings 80, 406-414.

Li, Y., Liu, S. and Shukla, A. (2016), 'Experimental analysis on use of thermal conductivity enhancers (TCEs) for solar chimney applications with energy storage layer', Energy and Buildings 116, 35-44.

Lin, S. (2011), 'NGPM - A NSGA-II Program in Matlab', p. 18.

Liu, S. and Li, Y. (2015a), 'An experimental study on the thermal performance of a solar chimney without and with PCM', Renewable Energy 81, 338-346.

Liu, S. and Li, Y. (2015b), 'Heating performance of a solar chimney combined PCM: A numerical case study', Energy and Buildings 99, 117-130.

Mankibi, M. E., Stathopoulos, N., Rezaï, N. and Zoubir, A. (2015), 'Optimization of an Air-PCM heat exchanger and elaboration of peak power reduction strategies', Energy and Buildings 106, 74-86.

Martí-Herrero, J. and Heras-Celemin, M. R. (2007), 'Dynamic physical model for a solar chimney', Solar Energy 81(5), 614-622.

Mathur, J., Bansal, N. K., Mathur, S., Jain, M. and Anupma (2006), 'Experimental investigations on solar chimney for room ventilation', Solar Energy 80(8), 927-935.

Matsumoto, Y., Valdés, M., Urbano, J. A., Kobayashi, T., López, G. and Peña, R. (2014), 'Global solar irradiation in north Mexico city and some comparisons with the south', Energy Procedia 57, 1179-1188.

URL: http://dx.doi.org/10.1016/j.egypro.2014.10.105

Michalewicz, Z. (1996), 'Genetic Algorithms + Data Structures = Evolution Programs'.

Mirzaei, P. A., Haghighat, F., Nakhaie, A. A., Yagouti, A., Giguère, M., Keusseyan, R. and Coman, A. (2012), 'Indoor thermal condition in urban heat Island Development of a predictive tool', Building and Environment 57, 7-17. 
Miyazaki, T., Akisawa, A. and Kashiwagi, T. (2006), 'The effects of solar chimneys on thermal load mitigation of office buildings under the Japanese climate', Renewable Energy 31(7), 987-1010.

Mukhopadhyay, D. M., Balitanas, M. O., A, A. F., Jeon, S.-h. and Bhattacharyya, D. (2009), 'Genetic Algorithm : A Tutorial Review', 2(3), 25-32.

Naraghi, M. H. and Blanchard, S. (2015), 'Twenty-four hour simulation of solar chimneys', Energy and Buildings 94, 219-226.

Onbasioglu, H. and Egrican, A. (2002), 'Experimental approach to the thermal response of passive systems', Energy Conversion and Management 43(15), 2053-2065.

URL: http://www.sciencedirect.com/science/article/pii/S0196890401001388

Paksoy, H. (2007), Thermal Energy Storage for Sustainable Energy Consumption, Fundamentals, Case Studies and Design, Springer.

URL: https://link.springer.com/content/pdf/10.1007/978-1-4020-5290-3.pdf

Rabani, M., Kalantar, V., Dehghan, A. A. and Faghih, A. K. (2015), 'Empirical investigation of the cooling performance of a new designed Trombe wall in combination with solar chimney and water spraying system', Energy and Buildings $102,45-57$.

Ravanfar, A. (2013), 'Simulation study of solar chimney assisted solarium', p. 81.

Roccamena, L., El Mankibi, M. and Stathopoulos, N. (2018), 'Experimental test bed design and development for PCM-water exchangers characterization', Sustainable Cities and Society 37(August 2017), 241-249.

URL: https://doi.org/10.1016/j.scs.2017.11.018

Sadineni, S. B., Madala, S. and Boehm, R. F. (2011), 'Passive building energy savings: A review of building envelope components', Renewable and Sustainable Energy Reviews 15(8), 3617-3631.

URL: http://dx.doi.org/10.1016/j.rser.2011.07.014

Saifi, N., Settou, N., Dokkar, B., Negrou, B. and Chennouf, N. (2012), 'Experimental study and simulation of airflow in solar chimneys', Energy Procedia 18, 1289-1298. 
Saleem, A. A., Bady, M., Ookawara, S. and Abdel-Rahman, A. K. (2016), 'Achieving standard natural ventilation rate of dwellings in a hot-arid climate using solar chimney', Energy and Buildings 133, 360-370.

Schwan, L., Rütschlin, H., Madjidi, M. and Auer, T. (2017), 'Increase of the Ventilation Effectiveness of Solar Chimneys with Consideration of Wind-Effects applying CFD Simulations and Measurements', Solar World Congress 2017.

Shahreza, A. R. and Imani, H. (2015), 'Experimental and numerical investigation on an innovative solar chimney', Energy Conversion and Management 95, 446-452.

Shen, J., Lassue, S., Zalewski, L. and Huang, D. (2007), 'Numerical study on thermal behavior of classical or composite Trombe solar walls', Energy and Buildings 39(8), 962-974.

Shi, L. and Zhang, G. (2016), 'An empirical model to predict the performance of typical solar chimneys considering both room and cavity configurations', Building and Environment 103, 250-261.

Stathopoulos, N., El Mankibi, M. and Santamouris, M. (2017), 'Numerical calibration and experimental validation of a PCM-Air heat exchanger model', Applied Thermal Engineering 114, 1064-1072.

URL: http://dx.doi.org/10.1016/j.applthermaleng.2016.12.045

Suárez-López, M. J., Blanco-Marigorta, A. M., Gutiérrez-Trashorras, A. J., Pistono-Favero, J. and Blanco-Marigorta, E. (2015), 'Numerical simulation and exergetic analysis of building ventilation solar chimneys', Energy Conversion and Management 96, 1-11.

Tan, A. Y. K. and Wong, N. H. (2014), 'Influences of ambient air speed and internal heat load on the performance of solar chimney in the tropics', Solar Energy 102, 116-125.

Tlatelpa, A., Arce, J., Xamán, J. P., Jiménez, M. J., Enríquez, R. and Heras, M. R. (2012), 'Theoretical Study of a Solar Chimney with two air flow channels', ASME2012 International Mechanic Engineering Congress \& Exposition . 
UNFCCC (2015), 'Adoption Of The Paris Agreement', Adoption of the Paris Agreement. Proposal by the President. 21932(December), 32.

URL: http://unfccc.int/resource/docs/2015/cop21/eng/l09r01.pdf

Veerakumar, C. and Sreekumar, A. (2016), 'Phase change material based cold thermal energy storage: Materials, techniques and applications - A review', International Journal of Refrigeration 67, 271-289.

URL: http://dx.doi.org/10.1016/j.ijrefrig.2015.12.005

Yan, T., Wang, R. Z., Li, T. X., Wang, L. W. and Fred, I. T. (2015), 'A review of promising candidate reactions for chemical heat storage', Renewable and Sustainable Energy Reviews 43, 13-31.

Zhou, D., Zhao, C. Y. and Tian, Y. (2012), 'Review on thermal energy storage with phase change materials (PCMs) in building applications', Applied Energy 92, 593-605.

URL: http://linkinghub.elsevier.com/retrieve/pii/S0306261911005216

Zitzler, E. (1999), 'Evolutionary Algorithms for Multiobjective Optimization : Methods and Applications', (30), 120. 